\title{
MODELAGEM FÍSICA DE CONDUTOS ENTERRADOS SUJEITOS A PERDA DE APOIO OU ELEVAÇÃO LOCALIZADA
}

Yuri Daniel Jatobá Costa

Tese apresentada à Escola de Engenharia de São Carlos, da Universidade de São Paulo, como parte dos requisitos para obtenção do título de Doutor em Geotecnia.

ORIENTADOR: Prof. Dr. Benedito de Souza Bueno EESC, Universidade de São Paulo CO-ORIENTADOR: Prof. Dr. Jorge Gabriel Zornberg Universidade do Texas em Austin, EUA

São Carlos

2005 
Ficha catalográfica preparada pela Seção de Tratamento da Informação do Serviço de Biblioteca - EESC/USP

Costa, Yuri Daniel Jatobá

Modelagem física de condutos enterrados sujeitos a perda de apoio ou elevação localizada / Yuri Daniel Jatobá Costa. -- São Carlos, 2005.

Tese (Doutorado) -- Escola de Engenharia de São Carlos-Universidade de São Paulo, 2005.

Área: Geotecnia.

Orientador: Prof. Dr. Benedito de Souza Bueno.

Co-orientador: Prof. Dr. Jorge Gabriel Zornberg

1. Duto enterrado. 2. Arqueamento. 3. Alçapão. 4. Elevação. 5. Perda de apoio. 6. Localização de deformação. I. Título. 
FOLHA DE JULGAMENTO

Candidato: Engenheiro YURI DANIEL JATOBÁ COSTA

Dissertação defendida e julgada em 24-05-2005 perante a Comissão Julgadora:

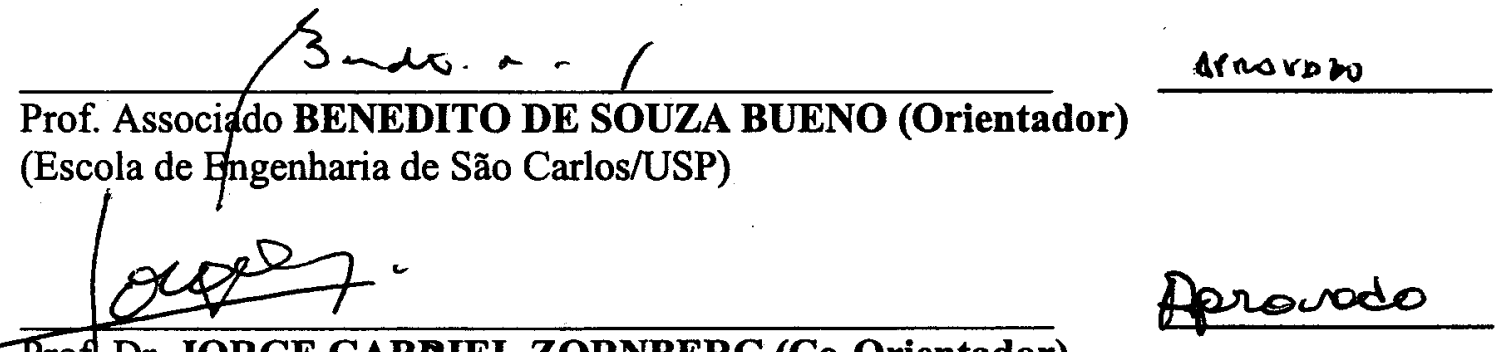

Prof Dr. JORGE GABRIEL ZORNBERG (Co-Orientador)

(Universidade de Austir/texas)

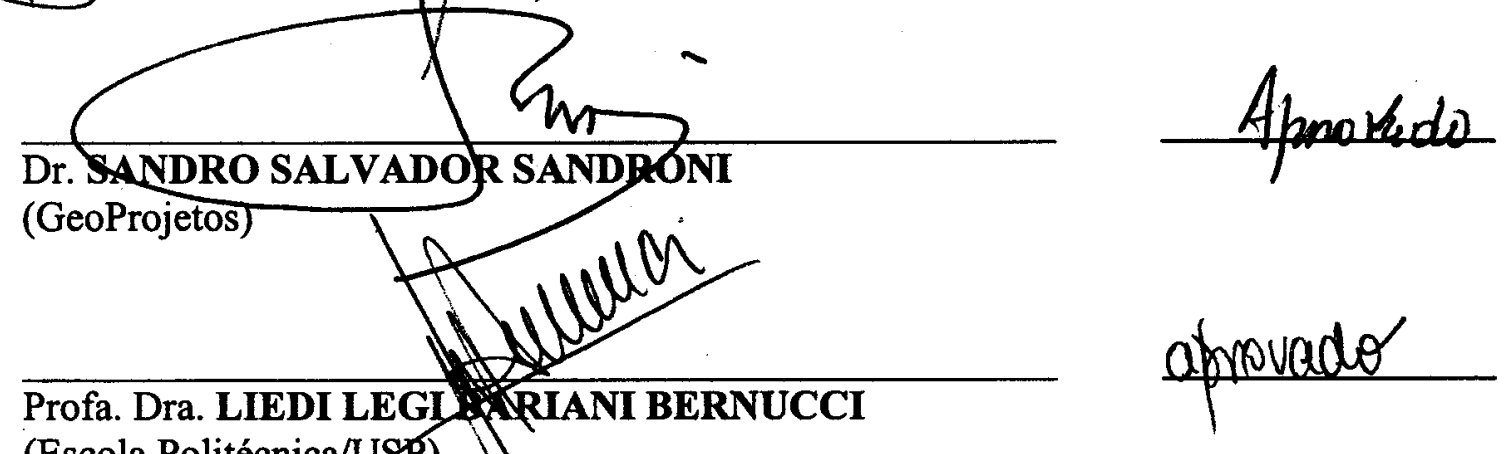

Profa Dra LIeDI LEGL

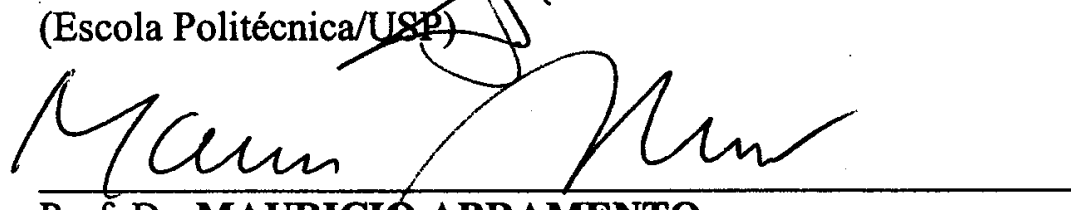

Prof. Dr. MAURICIO ABRAMENTO

(FAAP)

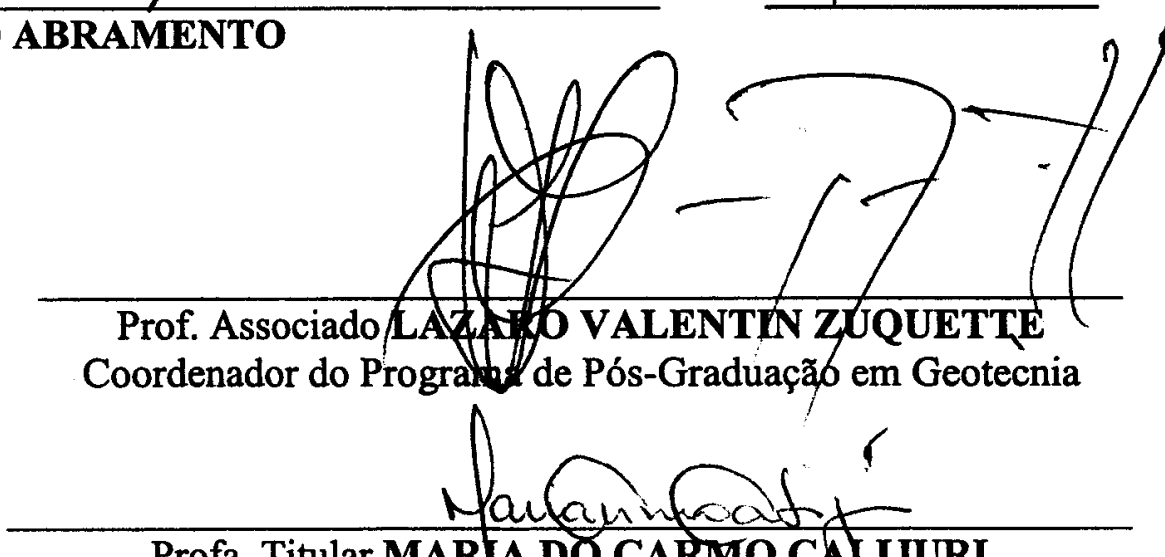

Profa. Titular MAR AA DO CARMMO CALIJURI

Presidente da Comissão de Pós-Graduação 


\section{AGRADECIMENTOS}

Ao Prof. Benedito Bueno, pela orientação, amizade e incentivo em todos os passos do trabalho.

A Carina Costa pela ajuda prestada ao longo de todas as etapas do trabalho.

Ao Prof. Eduardo Dell'Avanzi pelo inestimável apoio na fase da pesquisa conduzida na Universidade do Colorado.

Ao Prof. Jorge Zornberg pela co-orientação do trabalho.

A Érika Sá e Paulo Márcio Viana pela ajuda prestada na etapa de execução dos ensaios na EESC/USP.

Aos laboratoristas Clever Valentin, Silvio Wick, José Luiz Guerra, Antônio Garcia e Marcos pela constante ajuda prestada.

Aos Professores Orêncio Monje Vilar e Alexandre Parreira pelas importantes sugestões fornecidas no exame de qualificação.

A Fundação de Amparo à Pesquisa do Estado de São Paulo - FAPESP, pelo auxílio financeiro e pela concessão da bolsa de estudos.

A todos os colegas, professores e funcionários do Departamento de Geotecnia da USP/São Carlos e da Universidade do Colorado pela cooperação. 


\section{SUMÁRIO}

LISTA DE FIGURAS

LISTA DE TABELAS Xii

RESUMO Xiv

ABSTRACT X Xv

1 INTRODUÇÃO

1.1 Considerações iniciais 1

$\begin{array}{ll}\text { 1.2 Escopo e organização do trabalho } & 6\end{array}$

1.3 Organização do texto 9

$\begin{array}{lr}1.4 \text { Terminologia } & 10\end{array}$

2 REVISÃO BIBLIOGRÁFICA

$\begin{array}{ll}2.1 \text { Redistribuição de tensões no solo } & 12\end{array}$

2.1.1 Considerações iniciais 12

2.1.2 Mobilização dos estados ativo e passivo 13

2.1.3 Influência da geometria da estrutura 16

2.1.4 Redistribuição de tensões no exterior da estrutura 18

2.1.5 Efeito de sobrecargas superficiais concentradas 19

2.1.6 Influência da direção e da velocidade da movimentação da
estrutura na resistência passiva

2.2 Mecanismos de ruptura envolvendo estruturas enterradas 23

2.2.1 Condição ativa 24

2.2.2 Condição passiva 26

2.2.2.1 Movimento vertical ascendente 26

2.2.2.2 Movimento horizontal 28

2.3 Determinação da carga que atinge a estrutura 31

2.3.1 Condição ativa 31 
2.4 Avaliação da interação longitudinal de condutos submetidos a movimentação vertical do solo

2.4.1 Condutos submetidos a recalque localizado

2.4.2 Condutos submetidos a elevação localizada 55

2.4.3 Determinação do perfil de deslocamentos do conduto

2.5 Avaliação da interação longitudinal de condutos submetidos a movimentação longitudinal do solo

\section{MATERIAIS E MÉTODOS DO PROGRAMA DE ENSAIOS DA}

UNIVERSIDADE DO COLORADO

$\begin{array}{ll}\text { 3.1 Considerações iniciais } & 78\end{array}$

3.2 Equipamentos utilizados $\quad 82$

3.2.1 Caixa de testes $\quad 82$

$\begin{array}{ll}3.2 .2 \text { Sistema de alçapão } & 83\end{array}$

3.2.3 Centrífuga utilizada $\quad 84$

3.2.4 Sistema de obtenção de imagens $\quad 84$

$\begin{array}{ll}\text { 3.3 Propriedades do solo utilizado } & 86\end{array}$

$\begin{array}{ll}3.4 \text { Procedimentos de ensaio } & 88\end{array}$

3.4.1 Construção dos modelos $\quad 88$

$\begin{array}{ll}3.4 .2 \text { Execução dos ensaios } & 91\end{array}$

3.5 Análise digital de imagens 94

3.5.1 Considerações iniciais 94

3.5.2 Cálculo de deformações na massa de solo 95

$\begin{array}{ll}\text { 3.6 Programa de ensaios } & 96\end{array}$

4 MATERIAIS E MÉTODOS DO PROGRAMA DE ENSAIOS DA

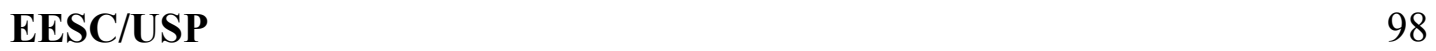

4.1 Considerações iniciais 98

4.2 Projeto da caixa de testes 98

$\begin{array}{ll}\text { 4.3 Sistema de alçapão } & 103\end{array}$

4.4 Instrumentação para medidas de deflexão do tubo 105 
4.4.1 Transdutor de deslocamentos

4.4.2 Sistema de movimentação do transdutor

4.4.3 Calibração e repetibilidade do transdutor

4.5 Medidas de tensão no solo

4.5.1 Células de tensão total

4.5.2 Configuração dos ensaios realizados com tubo

4.5.3 Configuração dos ensaios realizados sem tubo

4.6 Medidas de deformação no tubo

4.7 Materiais ensaiados

4.7.1 Propriedades do solo utilizado

4.7.2 Propriedades dos tubos utilizados

4.8 Procedimentos de ensaio

4.8.1 Preparação do solo nos modelos

4.8.2 Confecção dos modelos e execução dos ensaios

4.9 Programa de ensaios

5 SISTEMA SOLO-ALÇAPÃO: MECANISMOS DE RUPTURA NO ARQUEAMENTO ATIVO

5.1 Considerações iniciais

5.2 Mecanismos de ruptura na seção longitudinal

5.2.1 Propagação e padrão das localizações de deformação

5.2.2 Comportamento do solo sobre o alçapão

5.3 Mecanismos de ruptura nas seções transversais

5.3.1 Propagação e padrão das localizações na seção S1

5.3.2 Padrões das localizações de deformação nas demais seções

5.4 Discussão dos resultados

5.4.1 Tridimensionalidade do problema

5.4.2 Considerações sobre o cisalhamento do solo no interior da localização

5.4.3 O papel da dilatação do solo na formação das localizações na seção longitudinal 
5.4.5 Estimativa da inclinação das localização externa através da bacia de recalques superficiais

5.4.6 Considerações sobre o mecanismo de ruptura em profundidade

\section{SISTEMA SOLO-ALÇAPÃO: REDISTRIBUIÇÃO DE TENSÕES VERTICAIS NOS ARQUEAMENTOS ATIVO E PASSIVO}

6.1 Considerações iniciais

6.2 Avaliações preliminares

6.2.1 Atrito lateral

6.2.2 Repetibilidade dos resultados

6.3 Arqueamento ativo

6.3.1 Redistribuição de tensões no interior do alçapão

6.3.2 Perfil de tensões sobre o alçapão

6.3.3 Redistribuição de tensões no exterior do alçapão

6.3.4 Zona cisalhante e localizações de deformação

6.3.5 Distribuição espacial das tensões verticais no modelo

6.3.6 Influência da densidade do solo

6.3.7 Influência da sobrecarga aplicada

6.3.8 Influência da geometria do alçapão

6.3.9 Previsão das curvas de arqueamento com o método de Gill (1967)

6.3.10 Previsão da tensão sobre o alçapão

6.4.1 Redistribuição de tensões no interior do alçapão

6.4.2 Redistribuição de tensões no exterior do alçapão

6.4.3 Distribuição espacial das tensões verticais no modelo 184

6.4.4 Influência da geometria do alçapão 186

6.4.5 Previsão da tensão sobre o alçapão 190 


\section{SISTEMA SOLO-DUTO-ALÇAPÃO: MECANISMOS DE RUPTURA NA PERDA DE APOIO LOCALIZADA}

7.1 Considerações iniciais

7.2 Avaliação dos mecanismos de ruptura no maciço de solo

7.2.1.1 Características gerais dos padrões de ruptura observados

7.2.1.2 Efeitos da densidade do solo e rigidez do tubo e comparações com os ensaios-base

7.2.1.3 Padrões das localizações nas demais seções e tridimensionalidade do problema

7.2.2 Seção longitudinal

7.3 Desempenho dos dutos flexíveis

7.3.1 Avaliação da deformação preliminar do duto

\section{SISTEMA SOLO-DUTO-ALÇAPÃO: DEFLEXÕES E} DEFORMAÇÕES DO CONDUTO E TENSÕES NO MACIÇO, NA PERDA DE APOIO OU ELEVAÇÃO LOCALIZADA

8.1 Considerações iniciais

8.2 Análises preliminares

8.2.1 Avaliação das deflexões do duto e comparações com métodos teóricos

8.2.2 Avaliação das tensões no solo circundante e determinação do módulo de reação do solo a partir dos experimentos

8.3 Duto submetido a perda de apoio localizada

8.3.1 Avaliação das deflexões do duto e da deformada da seção central

8.3.2 Influência da densidade do solo e da sobrecarga aplicada

8.3.3 Previsões dos deslocamentos do duto

8.3.4 Avaliação das tensões no solo ao redor do duto

8.3.5 Avaliação das deformações na parede do duto

8.4.1 Avaliação das deflexões do duto e da deformada da seção central 
9.1 Considerações iniciais

9.2 Sistema solo-alçapão

9.3 Sistema solo-duto-alçapão 


\section{LISTA DE FIGURAS}

FIGURA 1.1 - Causas da interação longitudinal de condutos enterrados. 5

FIGURA 1.2 - Esquemas dos tipos de modelos construídos. a) Modelos 7 ensaiados na EESC/USP; b) modelos ensaiados na Universidade do Colorado.

FIGURA 1.3 - Faixas de rigidez relativa dos sistemas ensaiados. 8

FIGURA 1.4 - Terminologia adotada para a identificação dos locais da 11 seção transversal do tubo.

FIGURA 2.1 - Resultado de experimento de Terzaghi (1936) mostrando a variação da tensão vertical com a distância do alçapão em arqueamento ativo.

FIGURA 2.2 - Variação da tensão vertical com o deslocamento do alçapão (McNulty 1965).

FIGURA 2.3 - Variação da resistência passiva última com H/D em areia com diferentes densidades (após Trautmann et al. 1985, Trautmann e O'Rourke 1985).

FIGURA 2.4 - Variação de (H/D) cr com o ângulo de atrito do solo (Yimsiri et al. 2004).

FIGURA 2.5 - Variação de $\mathrm{N}_{\mathrm{p}}$ com $\mathrm{H} / \mathrm{B}$ em arqueamento passivo para condições axissimétrica e no estado plano (Koutsabeloulis e Griffiths 1989).

FIGURA 2.6 - Distribuição da tensão vertical no exterior do alçapão em arqueamento ativo através da solução de Finn (1963) e de dados experimentais de McNulty (1965).

FIGURA 2.7 - Ensaios de arqueamento ativo com sobrecarga concentrada na superfície do maciço (Santichaianant 2002).

FIGURA 2.8 - Variação do fator de inclinação i com H/B 22

FIGURA 2.9 - Efeito da velocidade no deslocamento de um conduto em 23 uma argila normalmente adensada (Paulin et al. 1995).

FIGURA 2.10 - Mecanismo de ruptura envolvendo a translação de um 25 alçapão em arqueamento ativo.

FIGURA 2.11 - Inclinação de localizações externas em túneis abertos em diversos tipos de solo (Hunt 1986).

FIGURA 2.12 - Desenvolvimento de localizações com um alçapão provocando arqueamento passivo (Walters e Thomas 1982). 
FIGURA 2.13 - Mecanismos de ruptura de condutos em deslocamento horizontal; a) H/D = 3 e b) $\mathrm{H} / \mathrm{D}=12$ (Audibert e Nyman 1977).

FIGURA 2.14 - Mecanismos de ruptura de conduto em argila normalmente adensada; a) ensaio não drenado, b) ensaio drenado (Paulin et al. 1995).

FIGURA 2.15 - Modelo de Janssen (1895).

FIGURA 2.16 - Método de Engesser (1882) (após Iglesia et al. 1999).

FIGURA 2.17 - Razão h/B em função de H/B (Villard et al. 2000).

FIGURA 2.18 - Fases do arqueamento ativo (Iglesia et al. 1999).

FIGURA 2.19 - Determinação da carga em estruturas na condição passiva. a) estrutura rasa e b) estrutura profunda (solução de Meyerhof e Adams 1968).

FIGURA 2.20 - Modelo proposto por Murray e Geddes (1987).

FIGURA 2.21 - a) Representação esquemática de uma tubulação cruzando um vazio no solo; b) distribuição do momento fletor ao longo tubo (Benmansour et al. 1997).

FIGURA 2.22 - Variação dos esforços internos em depósitos de diferentes prorpiedades, em função da razão $\mathrm{E}_{\mathrm{s} 2} / \mathrm{E}_{\mathrm{s} 1}$. a) Esforço cortante; b) momento fletor (Benmansour et al. 1997).

FIGURA 2.23 - Distribuição de momentos fletores ao longo de condutos de ferro fundido e PVC submetidos a recalque diferencial (Selvadurai e Pang 1988).

FIGURA 2.24 - Variação da tensão e do recalque de um tubo submetido a recalque diferencial com $\mathrm{D}_{\mathrm{r}}=68 \%$ (Hachiya et al. 2002).

FIGURA 2.25 - Deformações longitudinais e transversais em um conduto submetido a carregamento superficial concentrado (O’Rourke e Ahmed 1985).

FIGURA 2.26 - Aterro de dimensões finitas no comportamento de condutos enterrados (Small e Ngu 1991).

FIGURA 2.27 - Variação de momentos transversais ao longo da 55 tubulação (Fernando e Carter 1998).

FIGURA 2.28 - Esforços ao longo de tubulação assente em solo 57 expansivo (Kassiff e Zeitlen 1962).

FIGURA 2.29 - Deslocamentos e momentos fletores em um conduto instalado em solo expansivo, considerando $\mathrm{L} / \mathrm{D}=25$, $\mathrm{H} / \mathrm{D}=3, v_{\mathrm{s}}=0,3$ (Poulos 1974). 
FIGURA 2.30 - Perfil de recalques em condutos a partir de distribuição normal.

FIGURA 2.31 - Situações de apoio adotadas para condutos enterrados e respectivos momentos fletores (Moser 2001).

FIGURA 2.32 - Recalque, rotação e esforços internos no conduto considerando uma carga concentrada e carregamento distribuído (Hetényi 1946).

FIGURA 2.33 - a) Tubulação atravessando um depósito compressível; b) tubulação atravessando um vazio.

FIGURA 2.34 - Determinação do deslocamento do tubo com o método de Levinton (1947).

FIGURA 2.35 - Modelo de Rajani e Morgenstern (1993).

FIGURA 2.36 - Curvas adimensionais carga-deslocamento para um conduto em um meio elasto-plástico e comparação com análise numérica (Rajani e Morgenstern 1993).

FIGURA 2.37 - Determinação da força axial no conduto (Rajani et al. 1995).

FIGURA 2.38 - Deslocamentos do conduto e da massa de solo instável: a) caso I e b) caso II (O’Rourke et al. 1995).

FIGURA 2.39 - Deformação máxima versus comprimento da massa de solo instável (O’Rourke et al. 1995).

FIGURA 3.1 - Caixa de testes utilizada nos ensaios na Universidade do Colorado, com sistema de alçapão; dimensões em mm.

FIGURA 3.2 - Vista inferior do sistema de alçapão; dimensões em mm. 84

FIGURA 3.3 - Centrífuga de 15 g-ton da Universidade do Colorado em 85 Boulder (modificado de Ko 1988).

FIGURA 3.4 - Vista do modelo posicionado no cesto em balanço da 86 centrífuga.

FIGURA 3.5 - $\begin{array}{lll}\text { Curva granulométrica da areia utilizada (Ottawa F-75). } & 87\end{array}$

FIGURA 3.6 - Aparato para pluviação da areia Ottawa para obter $\mathrm{D}_{\mathrm{r}}=$ 85\%. Dimensões em mm.

FIGURA 3.7 - Modelo em fase de construção. 90

FIGURA 3.8 - a) Esquema da configuração dos modelos; b) vista em 92 planta do modelo mostrando a posição das seções transversais. Dimensões em mm.

FIGURA 3.9 - Modelo dissecado para obtenção de imagens das seções transversais. 
FIGURA 3.10 - a) Disposição dos centróides dos marcos no modelo; b) elemento triangular de solo antes e depois de ser deformado.

FIGURA 4.1 - Caixa de testes confeccionada para os modelos realizados na EESC/USP; a) vista lateral; b) vista frontal.

FIGURA 4.2 - a) Vista superior do sistema de alçapão; b) corte A-A. Dimensões em mm.

FIGURA 4.3 - Esquema do transdutor de deslocamentos (dimensões em

105 $\mathrm{mm})$.

FIGURA 4.4 - Transdutor de deslocamentos confeccionado.

106

FIGURA 4.5 - a) Sistema de movimentação do transdutor; b) detalhe dos suportes e do motor-de-passo.

FIGURA 4.6 - Curva de calibração da perna 1 do transdutor de deslocamentos.

FIGURA 4.7 - Repetibilidade do sistema de medição de deflexões no tubo.

FIGURA 4.8 - Esquema das células de tensão total (dimensões em mm).

FIGURA 4.9 - Disposição das células de interface na base da caixa de testes. Dimensões em mm.

FIGURA 4.10 - Disposição das células de inclusão nos ensaios com tubo.

FIGURA 4.11 - a) Tubo instrumentado com strain gages; b) disposição dos strain gages na seção S1 (dimensão em mm).

FIGURA 4.12 - Detalhe dos strain gages instalados no tubo.

FIGURA 4.13 - Curva granulométrica da areia utilizada.

FIGURA 4.14 - Curvas carga-deflexão dos corpos de prova de PVC. 118

FIGURA 4.15 - Vista geral do equipamento de chuva-de-areia. 119

FIGURA 4.16 - Esquema do difusor; (a) vista superior (b) corte A-A. Dimensões em mm.

FIGURA 4.17 - Curva de calibração da areia Itaporã: densidade relativa versus diâmetro do orifício.

FIGURA 4.18 - Tubo posicionado na caixa de testes com células afixadas.

FIGURA 5.1 - Desenvolvimento de localizações de deformação na seção longitudinal do modelo (plano yz) no maciço compacto $\left(\mathrm{D}_{\mathrm{r}}=85 \%\right)$. a) Modelos ensaiados a 45 g. $\theta_{\mathrm{i}}=$ $9^{0}$ para $\delta / \mathrm{B}=14,3 \%, 7^{0}$ para $\delta / \mathrm{B}=28,6 \%$ e $7^{0}$ para $\delta / \mathrm{B}=$ $57,1 \%$; b) modelos ensaiados a 1 g. $\theta_{\mathrm{i}}=13^{0}$ para $\delta / \mathrm{B}=$ $14,3 \%, 7^{0}$ para $\delta / \mathrm{B}=28,6 \%$ e $4^{0}$ para $\delta / \mathrm{B}=57,1 \%$. 
FIGURA 5.2 - Contornos de deformação cisalhante máxima $\left(\gamma_{\max }\right)$ no maciço compacto $\left(D_{\mathrm{r}}=85 \%\right)$. a) Modelos ensaiados a $45 \mathrm{~g}$; b) modelos ensaiados a $1 \mathrm{~g}$.

FIGURA 5.3 - Localizações de deformação na seção longitudinal do modelo (plano yz) no maciço fofo $\left(\mathrm{D}_{\mathrm{r}}=42 \%\right), \delta / \mathrm{B}=$ $57,1 \%$. a) Modelo ensaiado a $45 \mathrm{~g}, \theta_{\mathrm{i}}=4^{0}$; b) modelo ensaiado a $1 \mathrm{~g}, \theta_{\mathrm{i}}=4^{0}$.

FIGURA 5.4 - Contornos de deformação vertical $\left(\varepsilon_{\mathrm{z}}\right)$ no maciço compacto $\left(\mathrm{D}_{\mathrm{r}}=85 \%\right)$. a) Modelos ensaiados a $45 \mathrm{~g}$; b) modelos ensaiados a $1 \mathrm{~g}$.

FIGURA 5.5 - Desenvolvimento de localizações na seção transversal S1 do maciço compacto $\left(\mathrm{D}_{\mathrm{r}}=85 \%\right)$; a) modelos ensaiados a $45 \mathrm{~g}$; b) modelos ensaiados a $1 \mathrm{~g}$.

FIGURA 5.6 - Padrões de localização em seções transversais do maciço compacto $\left(\mathrm{D}_{\mathrm{r}}=85 \%\right)$ para $\delta / \mathrm{B}=57,1 \%$. a) Modelos ensaiados a $45 \mathrm{~g}$; b) modelos ensaiados a $1 \mathrm{~g}$.

FIGURA 5.7 - Regiões R1 e R2 no maciço. a) vista superior; b) vista em corte longitudinal.

FIGURA 5.8 - Representação do cisalhamento dentro de uma localização de deformação nos modelos ensaiados.

FIGURA 5.9 - Razão de dilatação em ensaios de compressão triaxial (após Batiste 1998).

FIGURA 5.10 - Propagação de localizações internas e externas na massa de solo.

FIGURA 5.11 - a) Padrão associado à ruptura do solo contido por um muro de parede rugosa; b) mesma situação de a), com o muro forçado para baixo. $\mathrm{P}_{\mathrm{A}}$ representa o empuxo no muro e $\delta$, sua inclinação (Terzaghi et al. 1996).

FIGURA 5.12 - Relação entre $\theta_{\mathrm{e}} \mathrm{e} \psi$.

FIGURA 6.1 - Variação da tensão vertical na base da caixa de testes com o ângulo de atrito de interface através da equação (6.1).

FIGURA 6.2 - Repetibilidade da tensão vertical medida no centro do alçapão (posição I1) durante a fase de carregamento. Ensaios realizados com $\mathrm{D}_{\mathrm{r}}=100 \%$ e $\mathrm{q}=100 \mathrm{kPa}$.

FIGURA 6.3 - Repetibilidade da tensão vertical medida no exterior do alçapão (posição I4) durante a fase de carregamento. Ensaios realizados com $\mathrm{D}_{\mathrm{r}}=100 \%$ e $\mathrm{q}=100 \mathrm{kPa}$.

FIGURA 6.4 - Repetibilidade da tensão medida na posição I1 durante a fase de movimentação do alçapão. Ensaios realizados com $D_{r}=100 \%$ e q $=100 \mathrm{kPa}$. 
FIGURA 6.5 - Variação típica da tensão vertical na superfície do alçapão em arqueamento ativo.

FIGURA 6.6 - Variação da tensão vertical em um perfil vertical no centro do alçapão retangular em arqueamento ativo.

FIGURA 6.7 - Perfil de tensões sobre o alçapão retangular em arqueamento ativo para diversos níveis de deslocamento.

FIGURA 6.8 - Equilíbrio estático do arco.

FIGURA 6.9 - Variação de tensões no exterior do alçapão retangular em arqueamento ativo (direção $\mathrm{x}$ ).

FIGURA 6.10 - Variação de tensões no exterior do alçapão retangular em arqueamento ativo (direção y).

FIGURA 6.11 - Explicação sobre a variação da tensão vertical no solo no exterior do alçapão.

FIGURA 6.12 - Distribuição das tensões verticais na base do modelo $\left(\mathrm{H}_{\mathrm{e}} / \mathrm{B}=0\right)$ em arqueamento ativo, utilizando o alçapão com $\mathrm{L}_{\mathrm{v}} / \mathrm{B}=3$ e maciço com $\mathrm{D}_{\mathrm{r}}=50 \%$ e sobrecarga de $100 \mathrm{kPa}$. a) Direção x (transversal); b) direção $\mathrm{y}$ (longitudinal).

FIGURA 6.13 - Distribuição da tensão vertical no exterior do alçapão e comparação com a solução de Finn (1963).

FIGURA 6.14 - Variação da tensão vertical no centro do alçapão para $\mathrm{D}_{\mathrm{r}}$ $=50$ e $100 \%$ em arqueamento ativo.

FIGURA 6.15 - Influência da densidade relativa do solo na tensão 169 vertical adjacente ao maior lado do alçapão com $\mathrm{L}_{\mathrm{v}} / \mathrm{B}=$ $3 ; \mathrm{H}_{\mathrm{e}} / \mathrm{B}=0 ; \mathrm{q}=100 \mathrm{kPa}$.

FIGURA 6.16 - Influência da densidade relativa do solo na tensão vertical adjacente ao menor lado do alçapão com $\mathrm{L}_{\mathrm{v}} / \mathrm{B}=$ $3 ; \mathrm{H}_{\mathrm{e}} / \mathrm{B}=0 ; \mathrm{q}=100 \mathrm{kPa}$.

FIGURA 6.17 - Influência do confinamento no comportamento da tensão vertical sobre o alçapão retangular em arqueamento ativo; $\mathrm{D}_{\mathrm{r}}=100 \%$.

FIGURA 6.18 - Influência da sobrecarga aplicada no comportamento da tensão vertical no exterior do alçapão retangular, na direção $\mathrm{x} ; \mathrm{D}_{\mathrm{r}}=100 \%$.

FIGURA 6.19 - Influência do confinamento do solo no comportamento da tensão vertical no exterior do alçapão, na direção y; $\mathrm{D}_{\mathrm{r}}$ $=100 \%$.

FIGURA 6.20 - Comparação do comportamento da tensão vertical no interior de alçapões com a mesma largura e comprimentos diferentes. $\mathrm{H}_{\mathrm{e}} / \mathrm{B}=0$. 
FIGURA 6.21 - Comparação do comportamento da tensão vertical no interior de alçapões com a mesma largura e comprimentos diferentes. $\mathrm{H}_{\mathrm{e}} / \mathrm{B}=0,3$.

FIGURA 6.22 - Comparação do comportamento da tensão vertical no exterior do alçapão retangular e do quadrado, na região do maior lado.

FIGURA 6.23 - Calibração do modelo para obtenção dos parâmetros $\mathrm{A}_{0} \mathrm{e}$ n.

FIGURA 6.24 - Previsão da curva de arqueamento correspondente à posição $\mathrm{I} 1 . \mathrm{H}_{\mathrm{e}} / \mathrm{B}=0 ; \mathrm{L}_{\mathrm{v}} / \mathrm{B}=3 ; \mathrm{D}_{\mathrm{r}}=100 \% ; \mathrm{q}=100 \mathrm{kPa}$.

FIGURA 6.25 - Previsão da curva de arqueamento correspondente à posição $\mathrm{I} 1 . \mathrm{H}_{\mathrm{e}} / \mathrm{B}=0 ; \mathrm{L}_{\mathrm{v}} / \mathrm{B}=3 ; \mathrm{D}_{\mathrm{r}}=50 \% ; \mathrm{q}=100 \mathrm{kPa}$.

FIGURA 6.26 - Previsão da curva de arqueamento correspondente à posição $\mathrm{I} 1 . \mathrm{H}_{\mathrm{e}} / \mathrm{B}=0 ; \mathrm{L}_{\mathrm{v}} / \mathrm{B}=3 ; \mathrm{D}_{\mathrm{r}}=100 \% ; \mathrm{q}=50 \mathrm{kPa}$.

FIGURA 6.27 - Previsão da curva de arqueamento correspondente à posição $\mathrm{I} 1 . \mathrm{H}_{\mathrm{e}} / \mathrm{B}=0, \mathrm{~L}_{\mathrm{v}} / \mathrm{B}=1 ; \mathrm{D}_{\mathrm{r}}=100 \% ; \mathrm{q}=100 \mathrm{kPa}$.

FIGURA 6.28 - Variação da tensão vertical na superfície do alçapão retangular em arqueamento passivo; $\mathrm{D}_{\mathrm{r}}=100 \% ; \mathrm{q}=100$ $\mathrm{kPa}$.

FIGURA 6.29 - Variação da tensão vertical em um perfil vertical no centro do alçapão retangular em arqueamento passivo; $\mathrm{D}_{\mathrm{r}}$ $=100 \% ; \mathrm{q}=100 \mathrm{kPa}$.

FIGURA 6.30 - Variação de tensões no exterior do alçapão retangular em arqueamento passivo (região do maior lado); $\mathrm{D}_{\mathrm{r}}=100 \%$; $\mathrm{q}=100 \mathrm{kPa}$.

FIGURA 6.31 - Variação de tensões no exterior do alçapão retangular em arqueamento passivo (região do menor lado); $\mathrm{D}_{\mathrm{r}}=100 \%$; $\mathrm{q}=100 \mathrm{kPa}$.

FIGURA 6.32 - Distribuição das tensões verticais na base do modelo $\left(\mathrm{H}_{\mathrm{e}} / \mathrm{B}=0\right)$ em arqueamento passivo, utilizando o alçapão com $\mathrm{L}_{\mathrm{v}} / \mathrm{B}=3$ e maciço com $\mathrm{D}_{\mathrm{r}}=100 \%$ e sobrecarga de $100 \mathrm{kPa}$. a) Direção $\mathrm{x}$ (transversal); b) direção $\mathrm{y}$ (longitudinal).

FIGURA 6.33 - Comportamento da tensão no interior do alçapão retangular e do quadrado, em arqueamento passivo; $\mathrm{D}_{\mathrm{r}}=$ $100 \%$ e q $=100 \mathrm{kPa}$.

FIGURA 6.34 - Análise da influência da forma da estrutura no caso passivo.

FIGURA 6.35 - Efeito da geometria da ancoragem no comportamento
carga-deslocamento em areia fofa e compacta com $\mathrm{H} / \mathrm{B}=$ 3 (Dickin 1988). 
FIGURA 6.36 - Comportamento da tensão no exterior do alçapão retangular e do quadrado, na transversal, em arqueamento passivo. $\mathrm{D}_{\mathrm{r}}=100 \% ; \mathrm{q}=100 \mathrm{kPa}$.

FIGURA 6.37 - Comportamento da tensão no exterior do alçapão retangular e do quadrado, na longitudinal, em arqueamento passivo. $\mathrm{D}_{\mathrm{r}}=100 \% ; \mathrm{q}=100 \mathrm{kPa}$.

FIGURA 6.38 - Previsões da tensão máxima sobre o alçapão em arqueamento passivo e comparação com os resultados experimentais.

FIGURA 6.39 - Variação da tensão vertical no interior do alçapão (posição I1) com o deslocamento em arqueamento ativo e passivo. $\mathrm{D}_{\mathrm{r}}=100 \% ; \mathrm{q}=100 \mathrm{kPa}$.

FIGURA 6.40 - Variação da tensão vertical no exterior do alçapão (posição I4) com o deslocamento em arqueamento ativo e passivo. $D_{\mathrm{r}}=100 \% ; \mathrm{q}=100 \mathrm{kPa}$.

FIGURA 6.41 - Comportamento de $\delta_{\mathrm{u}}$ com a profundidade e com a densidade relativa do meio nos estados ativo e passivo.

FIGURA 7.1 - Mecanismo de ruptura nas seções transversais do modelo B1. Tubo flexível em maciço fofo.

FIGURA 7.2 - Mecanismo de ruptura nas seções transversais do modelo B2. Tubo flexível em maciço compacto.

FIGURA 7.3 - Mecanismo de ruptura nas seções transversais do modelo B3. Tubo rígido em maciço fofo.

FIGURA 7.4 - Mecanismo de ruptura nas seções transversais do modelo B4. Tubo rígido em maciço compacto.

FIGURA 7.5 - Variação de $\theta_{\mathrm{e}}$ e $\mathrm{x}_{\mathrm{i}}$ com a densidade relativa do solo nos ensaios sem dutos com dutos rígidos e flexíveis.

FIGURA 7.6 - Padrão de ruptura na seção longitudinal do modelo B1 (tubo flexível em maciço fofo).

FIGURA 7.7 - Padrão de ruptura na seção longitudinal do modelo B2 (tubo flexível em maciço compacto).

FIGURA 7.8 - Dano sofrido pelo tubo flexível no maciço fofo.

FIGURA 7.9 - Detalhe do dano apresentado pelo tubo flexível após perda de apoio no maciço fofo.

FIGURA 8.1 - Perfis de deflexão $d^{*}$ ao longo do conduto após sobrecarga de $100 \mathrm{kPa}$. Ensaio D7.

FIGURA 8.2 - Deformada da seção central S1 após aplicação de sobrecarga superficial de $100 \mathrm{kPa}$ no a) maciço fofo $\left(\mathrm{D}_{\mathrm{r}}\right.$ $=50 \%) ; \mathrm{b})$ maciço compacto $\left(\mathrm{D}_{\mathrm{r}}=100 \%\right)$. 
FIGURA 8.3 - Variação da deflexão total horizontal do duto com a sobrecarga aplicada e previsões teóricas.

FIGURA 8.4 - Variação das tensões no solo circundante com a aplicação da sobrecarga; a) maciço fofo, b) maciço compacto.

FIGURA 8.5 - Variação do módulo E' com a densidade do solo e com a sobrecarga.

FIGURA 8.6 - a) Perfil de deflexões ao longo do conduto e b) deformada da seção transversal S1 em $\delta / \mathrm{B}=1 \%$ (ensaio D7).

FIGURA 8.7 - a) Perfil de deflexões ao longo do conduto e b) deformada da seção transversal S1 em $\delta / \mathrm{B}=15 \%$ (ensaio D7).

FIGURA 8.8 - a) Perfil de deflexões ao longo do conduto e b) deformada da seção transversal S1 em $\delta / \mathrm{B}=50 \%$ (ensaio D7).

FIGURA 8.9 - Variação da deflexão do duto com o deslocamento do alçapão na seção $\mathrm{S} 1$, com $\mathrm{D}_{\mathrm{r}}=50 \%$ e q $=100 \mathrm{kPa}$ (ensaio D7).

FIGURA 8.10 - Deflexões na seção $\mathrm{S} 1$ com $\mathrm{D}_{\mathrm{r}}=50,75$ e $100 \%$ e sobrecarga de $100 \mathrm{kPa}$ para deslocamentos relativos selecionados.

FIGURA 8.11 - Perfis de deflexão em $\delta / B=15 \%$ para $D_{r}=50$ e $100 \%$ (q $=100 \mathrm{kPa}$ ).

FIGURA 8.12 - Coeficiente de deflexão global em função da sobrecarga e da densidade relativa do material na seção S1.

FIGURA 8.13 - Previsões do deslocamento do conduto em maciço fofo.

FIGURA 8.14 - Previsões do deslocamento do conduto em maciço compacto.

FIGURA 8.15 - Variação da tensão no solo em torno da seção S1 no ensaio D7.

FIGURA 8.16 - a) Variação da tensão e b) variação da deflexão alçapão em ensaio realizado com $\mathrm{D}_{\mathrm{r}}=100 \%$ e q $=100 \mathrm{kPa}$.

FIGURA 8.17 - Variação da tensão no solo em torno da seção S3 no ensaio D7.

FIGURA 8.18 - Variação da mínima tensão sobre o topo do duto após a perda de apoio.

FIGURA 8.19 - Variação da tensão vertical em $\mathrm{H}_{\mathrm{e}} / \mathrm{B}=0$ para tubos sofrendo perda de apoio em maciços com densidades relativas de 50,75 e $100 \%$ e sobrecarga de $100 \mathrm{kPa}$. 
FIGURA 8.20 - Variação da deformação da parede do conduto com o deslocamento do alçapão (topo), com $100 \mathrm{kPa}$ de sobrecarga. a) deformação transversal; b) deformação longitudinal.

FIGURA 8.21 - Variação da deformação da parede do conduto com o deslocamento do alçapão (base), com $100 \mathrm{kPa}$ de sobrecarga. a) deformação transversal; b) deformação longitudinal.

FIGURA 8.22 - Variação da deformação da parede do conduto com o deslocamento do alçapão (linha d'água), com $100 \mathrm{kPa}$ de sobrecarga. a) deformação transversal; b) deformação longitudinal.

FIGURA 8.23 - a) Perfil de deflexões ao longo do conduto e b) deformada da seção transversal $\mathrm{S} 1 \mathrm{em} \delta / \mathrm{B}=2 \%$ (ensaio E6). $\mathrm{D}_{\mathrm{r}}=50 \%$; $\mathrm{q}=100 \mathrm{kPa}$.

FIGURA 8.24 - a) Perfil de deflexões ao longo do conduto e b) deformada da seção transversal $\mathrm{S} 1 \mathrm{em} \delta / \mathrm{B}=4 \%$ (ensaio E6). $\mathrm{D}_{\mathrm{r}}=50 \% ; \mathrm{q}=100 \mathrm{kPa}$.

FIGURA 8.25 - Variação da deflexão do duto com o deslocamento do alçapão, com $\mathrm{D}_{\mathrm{r}}=50 \%$ e q $=100 \mathrm{kPa}$ (ensaio E6).

FIGURA 8.26 - Deflexões do duto na elevação localizada, na seção S1, com $\mathrm{D}_{\mathrm{r}}=50$ e $100 \%$ e $\mathrm{q}=50 \mathrm{kPa}$ para deslocamentos relativos selecionados.

FIGURA 8.27 - Variação da deflexão com a sobrecarga aplicada, a) para solo compacto e b) para solo fofo.

FIGURA 8.28 - Esquema do conduto sofrendo elevação localizada.

FIGURA 8.29 - Curvas tensão versus deslocamento do alçapão em M6, utilizadas para a obtenção de $\mathrm{N}_{\mathrm{p}}$.

FIGURA 8.30 - Previsão da deflexão do duto submetido a elevação através do modelo de Rajani e Morgenstern (1993) e comparação com resultados experimentais.

FIGURA 8.31 - Variação da tensão no solo em torno da seção S1 no ensaio E6.

FIGURA 8.32 - Variação da tensão no solo em torno da seção S3 no ensaio E6.

FIGURA 8.33 - Efeito da sobrecarga e da densidade do solo na tensão no solo na linha d'água do conduto em $\delta / B=4 \%$.

FIGURA 8.34 - Variação da tensão vertical em $\mathrm{H}_{\mathrm{e}} / \mathrm{B}=0$ para tubo sofrendo elevação em maciços com densidades relativas de 50 e $100 \%$ e sobrecarga de $50 \mathrm{kPa}$. 
FIGURA 8.35 - Variação da deformação da parede do conduto com o deslocamento do alçapão (topo), com $50 \mathrm{kPa}$ de sobrecarga. a) deformação transversal; b) deformação longitudinal.

FIGURA 8.36 - Variação da deformação da parede do conduto com o deslocamento do alçapão (base), com $50 \mathrm{kPa}$ de sobrecarga. a) deformação transversal; b) deformação longitudinal.

FIGURA 8.37 - Variação da deformação da parede do conduto com o deslocamento do alçapão (linha d'água), com $50 \mathrm{kPa}$ de sobrecarga. a) deformação transversal; b) deformação longitudinal. 


\section{LISTA DE TABELAS}

TABELA 1.1 - Extensão das ocorrências ao longo da dutovia PaulíneaBrasília no trecho entre Porto Ferreira e Ribeirão Preto.

TABELA 2.1 - Inclinação observada da superfície de ruptura com a 44 vertical e comparações com hipóteses teóricas.

TABELA 3.1 - Fatores de escala utilizados em modelagem em 80 centrífuga.

TABELA 3.2 - Fatores de escala para condutos enterrados. 80

TABELA 3.3 - Parâmetros da areia Ottawa F-75. 88

TABELA 3.4 - Série A: ensaios de arqueamento. 97

TABELA 3.5 - Série B: ensaios com tubo. 97

TABELA 4.1 - Valores de e/D adotados em ensaios laboratoriais e 100 análises numéricas.

TABELA 4.2 - Repetibilidade do transdutor de deslocamentos para 109 $\mathrm{d}=5 \mathrm{~mm}$.

TABELA 4.3 - Localização das células de inclusão nos ensaios sem tubo 114

$\begin{array}{lll}\text { TABELA } 4.4 \text { - Parâmetros da areia Itaporã. } & 117\end{array}$

$\begin{array}{lll}\text { TABELA } 4.5 & \text { - Série C: ensaios de arqueamento. } & 124\end{array}$

TABELA 4.6 - Série D: ensaios com tubo submetido a perda de apoio 125 localizada.

TABELA 4.7 - Série E: ensaios com tubo submetido a elevação. 125

TABELA 4.8 - Série F: ensaios com tubo instrumentado. 125

TABELA 5.1 - Características das localizações longitudinais formadas. 131

TABELA 5.2 - Características das localizações externas no 135 deslocamento final do alçapão.

TABELA 5.3 - Área do alçapão que satisfaz a condição de deformação 138 plana.

TABELA 5.4 - Comparação entre os mecanismos em condição profunda 148 e rasa.

TABELA 6.1 - Tensões medidas nos ensaios e tensões esperadas. 152

TABELA 6.2 - Comparação entre as soluções analíticas e os resultados 181 experimentais.

TABELA 7.1 - Características dos padrões de ruptura na seção S1. 200 
TABELA 7.2 - Formatos típicos adquiridos por tubos flexíveis após 207 carregamento.

TABELA 8.1 - Deslocamentos do conduto na seção S3 para $\delta / B=4 \% . \quad 249$

TABELA 8.2 - Tensões ao redor do duto em elevação. 


\section{RESUMO}

Costa, Y. D. J. (2005). Modelagem física de condutos enterrados sujeitos a perda de apoio ou elevação localizada. Tese (Doutorado) - Escola de Engenharia de São Carlos, Universidade de São Paulo, São Carlos, 2005.

Este trabalho apresenta um estudo experimental sobre o comportamento de dutos enterrados sofrendo perda de apoio ou elevação em uma determinada região ao longo do comprimento. Foram realizados ensaios com modelos físicos compostos por um maciço de areia pura contendo um tubo repousando sobre um alçapão localizado no centro do vão. A pesquisa envolveu dois programas experimentais distintos. $\mathrm{O}$ primeiro foi desenvolvido na Escola de Engenharia de São Carlos/USP e contou com o desenvolvimento e a construção de um equipamento de ensaios possuindo um sistema de alçapão. Os modelos eram dotados de instrumental capaz de medir as deflexões e as deformações específicas ao longo do duto, além das tensões totais no maciço de solo circundante e na base do equipamento. O segundo programa experimental foi conduzido na Universidade do Colorado em Boulder, EUA, e envolveu ensaios em centrífuga. Essa fase da pesquisa teve por finalidade realizar uma investigação visual dos mecanismos de ruptura do sistema composto pelo solo e pelo duto sujeito à perda de apoio. Ambas as etapas do trabalho contaram com a execução de testes com modelos sem tubo. Os ensaios realizados revelaram aspectos importantes do problema investigado. A movimentação ativa ou passiva do alçapão exerceu uma forte influência na redistribuição das tensões no maciço de solo exterior à estrutura, a qual abrangeu distâncias horizontais superiores a 5 B e verticais superiores a 4 B. Após a perda de apoio ou a elevação, o topo, a base e as demais partes do conduto assumiram perfis de deflexão distintos ao longo do comprimento, os quais foram consideravelmente influenciados pela densidade relativa do solo e pela sobrecarga aplicada. A movimentação ativa do alçapão revelou ainda padrões de ruptura incluindo localizações de deformação propagando-se para a região do maciço de solo fora do alçapão.

Palavras-chave: duto enterrado; arqueamento; alçapão; elevação; perda de apoio; localização de deformação. 


\section{Abstract}

COSTA, Y. D. J. (2005). Physical modeling of buried pipes subjected to localized loss of support or elevation. Thesis - School of Engineering of Sao Carlos, University of Sao Paulo, Sao Carlos, 2005.

This thesis presents an experimental study on the behavior of buried pipes undergoing a loss of support or elevation in a localized region along its length. Tests with physical models comprising a pure dry sand and a tube resting on a rigid trapdoor base located at the center of its length were performed. The research included two distinct testing programs. The first testing program was carried out at the School of Engineering of Sao Carlos/USP, and included the construction of a laboratory facility containing a trapdoor system. The models were equipped with devices for measuring deflections and strains in the pipe, and total stresses in the soil mass and in the lower boundary of the model. The second phase of this investigation was conducted at the University of Colorado at Boulder, USA, and involved centrifuge testing. The main goal of this part of the research was to assess the failure mechanisms that take place when the pipe experiences loss of support. Models without the pipe were also tested in both phases. Important aspects of the soilstructure interaction were verified with the testing programs carried out in this study. A strong influence on the stress redistribution within the soil mass in the vicinity of the structure was achieved after the active and passive conditions were established, encompassing horizontal distances greater than $5 \mathrm{~B}$ and vertical distances greater than $4 \mathrm{~B}$. After the loss of support or elevation, the crown, the base, and the other parts of the pipe assumed distinct deflection profiles, which were greatly influenced by the relative density of the surrounding soil and by the surficial applied surcharge. The imposed downward boundary movement included the formation of shear bands initiating at the edge of the void and propagating towards the soil mass in the vicinity of the trapdoor.

Keywords: buried pipe; arching; trapdoor; elevation; loss of support; shear bands. 


\section{Introdução}

\subsection{CONSIDERAÇÕES INICIAIS}

O comportamento de condutos enterrados foi, ao longo deste último século, objeto de intensos estudos, iniciados nos anos de 1920 a partir do trabalho pioneiro de Marston e seus colaboradores sobre a determinação do carregamento imposto pelo aterro em tubulações rígidas. Duas décadas mais tarde, Spangler (1941) desenvolveu uma formulação baseada em evidências experimentais para a determinação da deflexão horizontal de condutos flexíveis. Este trabalho representou o marco inicial dos estudos sobre tubulações desta natureza.

Bueno (1987) considera o final da década de 50 como um divisor de águas entre o período clássico e o moderno da investigação de condutos flexíveis. No período clássico, a deformação excessiva do tubo manteve-se como o principal objeto de análise, ao passo que o período moderno é marcado por trabalhos, sobretudo, relacionados a tubos muito flexíveis em aterros bem compactados. A partir de então, observou-se que a ruptura de condutos flexíveis também poderia ocorrer de outras formas que não a deformação excessiva, como a compressão (White e Layer 1960) e a flambagem das paredes (Forrestal e Herrmann 1965, Luscher 1966, Chelapatti e Allgood 1972, Moore 1989).

Desde a modificação da fórmula de Iowa por Watkins e Spangler (1958) um grande número de pesquisas também foi dirigido à determinação do módulo de reação horizontal do solo e às suas variáveis de maior influência, podendo-se destacar os trabalhos realizados por Howard (1977) e Hartley e Duncan (1987). 
As décadas de 1980 e 1990 foram marcadas por um grande volume de trabalhos envolvendo tubos plásticos. Fabricados com diâmetros cada vez maiores, os condutos plásticos têm obtido grande aceitação de mercado e apresentam como principais vantagens leveza, imunidade à corrosão, baixo coeficiente de rugosidade interna e menor número necessário de uniões por unidade de comprimento (Bueno 2005). Muitos trabalhos experimentais e numéricos têm sido conduzidos com o objetivo de averiguar o comportamento desses condutos mediante diversos fatores, como, por exemplo, altura de cobertura (Katona 1988, Phares et al. 1998), tipo de solo (Rogers 1988) e grau de compactação (Rogers 1987, Conrad et al. 1998).

A elevada extensão de uma tubulação pode conduzir a inúmeras situações particulares de interação com o solo em localidades específicas, caracterizando um problema tridimensional. A despeito do grande progresso alcançado ao longo do último século sobre os mais diversos aspectos na área de condutos enterrados, como acima relatado, pouquíssima atenção tem sido dispensada ao comportamento longitudinal dessas estruturas, como vem sendo alertado ao longo das últimas décadas (Poulos 1974, Prevost e Kienow 1994). Isso é refletido nos livros, normas vigentes e manuais técnicos sobre o assunto, os quais geralmente fazem apenas uma breve alusão sobre o tópico, quando não o olvida totalmente.

A importância do tema pode ser exemplificada através do estudo realizado por Benmansour et al. (1997) na rede de saneamento da Cidade de Nice, França. Foram catalogados todos os problemas averiguados ao longo de 90 dos $850 \mathrm{~km}$ totais da rede da cidade, composta por manilhas de concreto armado, sendo classificados em estruturais (referentes ao comportamento mecânico da tubulação) e de serviço (que afetam o funcionamento da rede). Dentro do primeiro grupo, trincas e fissuras decorrentes de interações longitudinais representaram a maior ocorrência, 15,7\%, ao passo que as conseqüentes de interações transversais somaram-se apenas $8,5 \%$ do total. Outros dados levantados por Rajani et al. (1996) sobre investigações semelhantes em diversas cidades canadenses revelam índices ainda maiores. Foi verificado que $70 \%$ do total dos problemas constatados em redes de distribuição de água eram decorrentes de interações longitudinais.

Os fatores que deflagram interações longitudinais são relacionados ao comportamento intrínseco do solo e do material constituinte da tubulação, bem como à presença de sobrecargas superficiais. Os mecanismos provenientes do 
comportamento do solo envolvem variações de volume e movimentação de massa, promovendo recalque, elevação, deslocamentos laterais ou longitudinais. Cargas atuando na superfície do maciço, oriundas do peso de veículos, de aterros e de construções em geral acarretam o recalque do duto. Variações de temperatura e pressão interna causam dilatação ou contração da tubulação e podem ser acompanhadas por deslocamentos axiais. Em estágios mais críticos, o aumento da dilatação do tubo pode causar elevação por flambagem, por conta de restrições à expansão.

A Figura 1.1 lista os principais fatores causadores do comportamento longitudinal, classificando-os segundo a origem mencionada. Os fatores envolvendo recalque ou elevação localizada de tubulações são de grande interesse prático, pois abrangem uma vasta gama de situações, desde problemas causados por subpressão ou carreamento do material de apoio, comuns em redes de água e esgoto nos centros urbanos, até problemas envolvendo o comportamento de solos típicos de regiões tropicais e subtropicais. Cita-se como exemplo o traçado do Poliduto PaulíneaBrasília, o qual intercepta formações geológicas as mais diversas. A Tabela 1.1 exibe a área das principais ocorrências em relação à zona total de influência da dutovia no trecho entre os Municípios de Porto Ferreira e Ribeirão Preto, no interior do Estado de São Paulo, estimada em $790 \mathrm{~km}^{2}$. As extensões das ocorrências são consideráveis, com destaque para os solos colapsíveis.

Tabela 1.1. Extensão das ocorrências ao longo da dutovia Paulínea-Brasília no trecho entre Porto Ferreira e Ribeirão Preto

\begin{tabular}{cc}
\hline Ocorrência & Percentagem da área total \\
\hline Solo colapsível & 66 \\
Afloramento de rocha & 22 \\
Solo mole & 10 \\
Solo expansivo & 9 \\
\hline
\end{tabular}

O cenário instalado após a elevação ou o recalque localizado é caracterizado por uma complexa interação tridimensional, com uma completa redistribuição das tensões no tubo e no maciço circundante. O duto pode experimentar esforços 
longitudinais e circunferenciais de elevada magnitude na região de interesse, inclusive podendo, eventualmente, sofrer ruptura.

A adequada avaliação dessa nova condição deve contemplar análises das deflexões e dos esforços internos ao longo do eixo do duto e, principalmente, da redistribuição das tensões na massa de solo, fenômeno tipicamente denominado de arqueamento. O arqueamento é apontado por Terzaghi (1943) como um dos fenômenos mais universais da mecânica dos solos, tanto no campo quanto no laboratório, e sua compreensão é essencial para o projeto de condutos e tanques enterrados, túneis e escavações de minas, ancoragens, dentre outros. Uma análise apropriada do comportamento do sistema torna-se impossível sem a compreensão do fenômeno (Allgood 1964). A avaliação visual dos mecanismos de ruptura envolvidos no processo também é importante para dar suporte à correta interpretação da interação solo-estrutura.

As pesquisas disponíveis até o presente sobre o comportamento de condutos submetidos a recalque ou elevação localizada são escassas e muitos aspectos da interação necessitam de maiores esclarecimentos. Por exemplo, a maioria dos trabalhos é baseada em análises numéricas e é limitada a investigações da distribuição dos esforços no conduto. As análises experimentais sobre a redistribuição das tensões no solo circundante e as deflexões ao longo do eixo do tubo após a ocorrência são bastante incompletas. Os dados disponíveis tornam-se ainda mais escassos quando se restringe apenas aos tubos flexíveis.

Grande parte dos métodos analíticos desenvolvidos para o problema é limitada à determinação do perfil de deslocamentos longitudinais do tubo, calculado assumindo-se um determinado carregamento, uma dada condição de apoio para o trecho em questão e utilizando a equação diferencial da linha elástica. Outro enfoque consiste em considerar o tubo sobre apoios elásticos discretos que obedecem à hipótese de Winkler. Após os deslocamentos, os esforços internos podem ser determinados. Todos os métodos assumem o conduto como um elemento unidimensional, desconsiderando, portanto, a interação transversal da tubulação. Não há evidência experimental suficiente para validar esses métodos ou dar suporte ao desenvolvimento de novas teorias. 

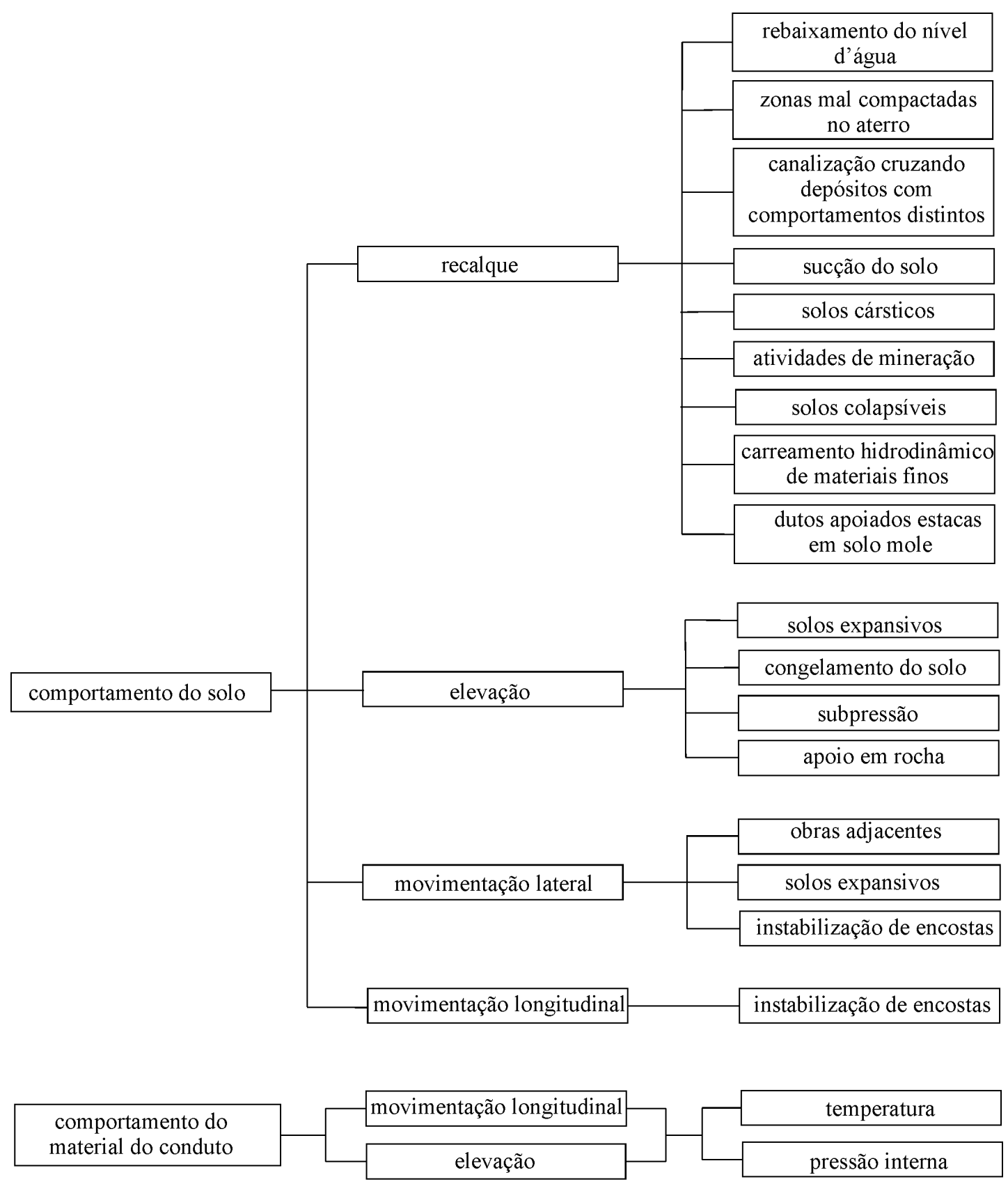

\begin{tabular}{|l|l|}
\hline sobrecargas concentradas & recalque \\
\hline
\end{tabular}

Figura 1.1. Causas da interação longitudinal de condutos enterrados. 


\subsection{ESCOPO E ORGANIZAÇÃO DO TRABALHO}

O presente trabalho tem por objetivo geral realizar um estudo experimental do comportamento de condutos enterrados submetidos a perda de apoio ou elevação localizada e de seus principais parâmetros de influência. Para tanto, foram realizados ensaios com modelos físicos compostos por um maciço de solo contendo um tubo repousando sobre um alçapão retangular ou quadrado localizado no centro do vão (Figura 1.2).

A pesquisa foi desenvolvida com base em dois programas de ensaios distintos. O primeiro programa contou com ensaios com modelos dotados de instrumental capaz de medir as deflexões e as deformações ao longo do tubo e variações de tensões no maciço de solo circundante. Essa fase da pesquisa foi desenvolvida nas dependências do Laboratório de Geossintéticos da EESC/USP e envolveu a construção de uma caixa de testes com dimensões de 1,4 x 0,6 x 0,6 m, possuindo um mecanismo de alçapão. Após a montagem do modelo, uma sobrecarga (q) era aplicada à superfície do maciço através de uma bolsa de ar comprimido e em seguida o alçapão era movimentado verticalmente em sentido descendente ou ascendente. Um esquema desse tipo de teste é exibido na Figura 1.2a.

O segundo grupo de testes foi conduzido na Universidade do Colorado em Boulder, EUA, e teve como objetivo avaliar visualmente os mecanismos de ruptura decorrentes da interação solo-tubo quando este último sofre recalque localizado. As análises dos resultados desses modelos exerceram um papel fundamental nas análises dos modelos construídos na EESC/USP. Confeccionados aproveitando-se a simetria longitudinal do problema, os modelos consistiam basicamente de um maciço de areia pura contido em uma caixa metálica com um alçapão retangular em sua base e com uma das faces transparente para possibilitar a visualização dos padrões de ruptura (Figura 1.2b).

Os dois tipos de modelo foram idealizados com geometrias aproximadamente proporcionais, porém possuíam distribuições distintas das tensões iniciais. Perfis esquemáticos da distribuição das tensões verticais $\left(\sigma_{\mathrm{v}}\right)$ no maciço, antes da movimentação do alçapão, em uma localidade afastada do tubo, são ilustrados na Figura 1.2. Os modelos da EESC/USP (Figura 1.2a) apresentavam um perfil de tensões quase constante com a profundidade por causa da sobrecarga superficial. Já 
os modelos da Universidade do Colorado (Figura 1.2b) possuíam uma distribuição linear e crescente com a profundidade, nula na superfície e máxima na base da caixa de testes, cuja magnitude era definida através da aceleração gravitacional imposta $(\mathrm{N} \cdot \mathrm{g})$. A distribuição da Figura 1.2b é a mais condizente com a realidade, porém a utilização de uma bolsa de ar para aplicar um determinado nível de tensão ao modelo é um artifício comumente empregado em estudos envolvendo modelagem física (McNulty 1965, Brachman et al. 2000, Viana 2003). De forma a reduzir a diferença entre ambas as distribuições nas proximidades do tubo e do alçapão, os modelos foram construídos com altura de cobertura de solo elevada, entre 5 e 6 vezes o diâmetro (D) do duto. Instalações com altura de cobertura de solo acima de 3 ou 4D são tipicamente classificadas como profundas (McNulty 1965, Ladanyi e Hoyaux 1969, Rowe e Davis 1982b, Koutsabeloulis e Griffiths 1989, Iglesia 1991).

A utilização de alturas de cobertura elevadas nessa investigação experimental também encontra respaldo na necessidade de estudos do comportamento soloconduto nessas condições, visto que a complexidade da infraestrutura dos grandes centros urbanos tem exigido a instalação de tubulações em profundidades cada vez maiores. Por exemplo, aterros sanitários são obras que necessitam de sistemas de tubulações para coleta de chorume, o que requer a implantação de condutos em grande profundidade. Um projeto de um aterro próximo às margens de um rio nos arredores de Tóquio, Japão, necessitou da construção de dutos enterrados em profundidades tão elevadas quanto 80D (Yimsiri et al., 2004).

a)

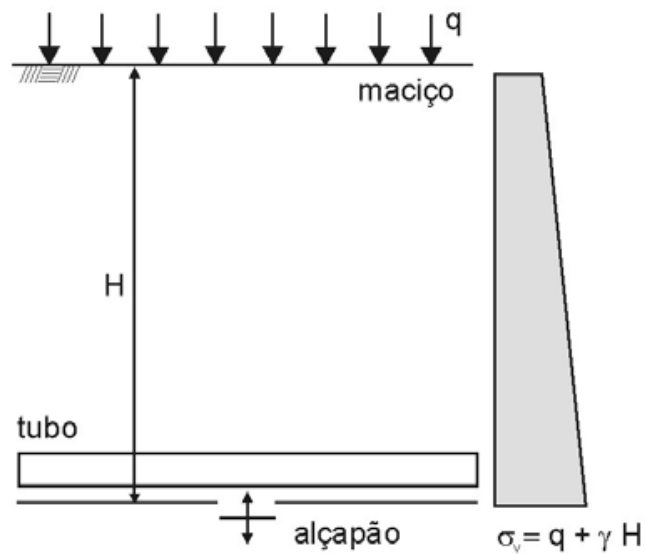

b)

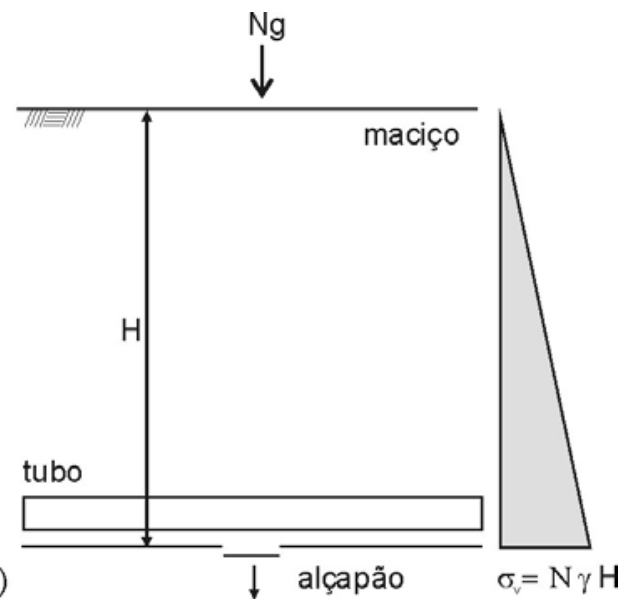

Figura 1.2. Esquemas dos tipos de modelos construídos. a) Modelos ensaiados na EESC/USP; b) modelos ensaiados na Universidade do Colorado. 
O programa conduzido na Universidade do Colorado (P2) contou com a utilização de dois tipos de dutos, diferindo na espessura da parede $(\mathrm{t})$, ao passo que nos modelos do programa da EESC/USP (P1) apenas um tipo de duto foi utilizado. As rigidezes relativas (RR) solo-duto obtidas com os modelos da Universidade do Colorado englobam as obtidas com os modelos da EESC/USP. Na Figura 1.3 as faixas de RR utilizadas, quantificadas através da expressão (1.1), são comparadas à escala de Gumbel et al. (1982).

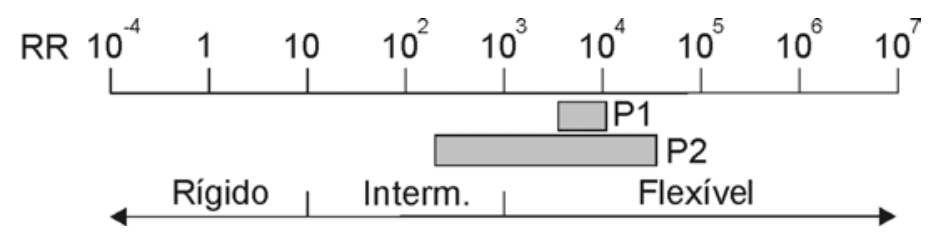

Figura 1.3. Faixas de rigidez relativa dos sistemas ensaiados.

$$
R R=\frac{12 E_{s} \cdot D^{3}}{\left(1-v_{s}^{2}\right) \cdot E \cdot t^{3}}
$$

onde: $\mathrm{E}_{\mathrm{s}}=$ módulo de deformabilidade do solo; $\mathrm{v}_{\mathrm{s}}=$ coeficiente de Poisson do solo; $\mathrm{E}$ $=$ módulo de elasticidade do material do tubo.

Para dar suporte às análises dos resultados dos modelos acima descritos, a pesquisa também contou com testes com modelos sem tubo, nos quais era medida a variação das tensões verticais dentro do alçapão e em suas adjacências. Os ensaios de arqueamento, como são denominados ao longo do texto, correspondem a aproximadamente $40 \%$ do total de testes e figuram tanto na parte executada no exterior, quanto na etapa da pesquisa realizada no Brasil. A utilização de uma base rígida horizontal, ou "alçapão", deslocando-se sob uma camada de solo geralmente granular tem fornecido subsídios de extrema relevância para a compreensão do arqueamento do solo. Contudo, muitas questões sobre o fenômeno ainda carecem de maiores estudos, de modo que a execução desses ensaios também encontra justificativa nos seguintes aspectos: 
a) a ausência de investigações abordando o arqueamento tridimensionalmente, uma vez que basicamente constam na literatura estudos do gênero baseados no estado plano de deformação e no axissimétrico;

b) a lacuna existente sobre trabalhos abordando os mecanismos de ruptura desenvolvidos em instalações profundas;

c) a falta quase que total de análises sobre a redistribuição da tensão nas adjacências do alçapão, cujo conhecimento é essencial para a completa compreensão do fenômeno. McNulty (1965) e Viana (2003) são os únicos trabalho experimentais identificados, nos quais a distribuição externa de tensões na massa de solo é abordada, porém de forma bastante preliminar.

\subsection{ORGANIZAÇÃO DO TEXTO}

Além deste capítulo introdutório, a tese é dividida em mais oito capítulos. O Capítulo 2 apresenta uma revisão bibliográfica que trata inicialmente de aspectos do fenômeno do arqueamento de solo e fatores de influência, dos mecanismos de ruptura envolvendo estruturas enterradas e de soluções analíticas para a determinação da carga que atinge a estrutura. Em seguida, são abordados tópicos sobre a interação longitudinal de condutos enterrados submetidos à movimentação transversal (recalque ou elevação) e à movimentação longitudinal. Esses itens trazem discussões sobre trabalhos nos quais a distribuição de esforços e deflexões ao longo do conduto é avaliada e apresentam métodos analíticos para a determinação do perfil de deslocamentos do conduto.

No capítulo 3, é feita uma descrição detalhada sobre os equipamentos construídos, os materiais e instrumentação utilizados, os procedimentos adotados e o programa de testes referentes aos modelos ensaiados na Universidade do Colorado. O mesmo com relação aos modelos executados na EESC/USP é apresentado no Capítulo 4.

As análises e discussões dos resultados são divididas em duas partes distintas. A primeira parte engloba os resultados dos ensaios de arqueamento (sistema soloalçapão) e abrange os Capítulos 5 e 6 . O Capítulo 5 versa sobre os resultados dos modelos construídos na Universidade do Colorado para visualização de mecanismos 
de ruptura, ao passo que no Capítulo 6 são discorridas as análises sobre a redistribuição das tensões verticais no solo após a movimentação do alçapão dos modelos da EESC/USP. Os Capítulos 7 e 8 formam a segunda parte das análises da presente Tese, e são referentes aos modelos ensaiados com tubo (sistema soloconduto-alçapão). No Capítulo 7, são analisados e discutidos os resultados dos modelos confeccionados na Universidade do Colorado para a visualização dos mecanismos de ruptura de tubos enterrados submetidos à perda de apoio localizada. Já o Capítulo 8 apresenta resultados e discussões alusivos aos modelos realizados na EESC/USP, com os quais foram medidas deflexões e deformações do duto e as variações de tensões na massa de solo. O Capítulo 9 traz as principais conclusões obtidas com o trabalho e apresenta sugestões para pesquisas futuras. Em anexo encontram-se as rotinas computacionais desenvolvidas para o cálculo das deformações do solo nos modelos desenvolvidos na Universidade do Colorado (Anexo A), os esquemas do projeto da caixa de testes da fase da pesquisa conduzida na EESC/USP (Anexo B) e os gráficos de variação de tensão total correspondentes aos ensaios dessa etapa (Anexo C).

\subsection{TERMINOLOGIA}

Ao longo do texto são apresentados alguns termos cujos significados são esclarecidos abaixo.

\section{Partes do conduto}

Uma vez que na língua portuguesa não há uma padronização da nomenclatura usada na identificação das partes da seção transversal de condutos enterrados, a identificação no presente trabalho é feita seguindo a terminologia apresentada na Figura 1.4. Alguns termos são traduções livres daqueles utilizados na língua inglesa.

\section{Alçapão}

Originalmente, alçapão significa uma escotilha horizontal interligando dois pavimentos, que se abre subitamente ao ser acionada. Em Geotecnia, o termo tem sido utilizado para designar um mecanismo com superfície plana, horizontal e de formato variado que se movimenta verticalmente. $O$ termo é empregado 
indistintamente com respeito ao sentido e à velocidade da translação. Essa última denominação também é adotada no presente trabalho.

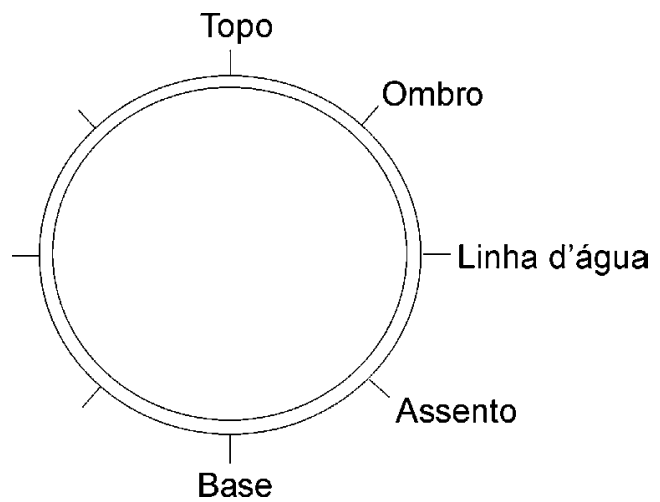

Figura 1.4. Terminologia adotada para a identificação dos locais da seção transversal do tubo.

\section{Deflexão}

Entende-se por deflexão ( $\left.\mathrm{d}^{*}\right)$, no texto, o deslocamento radial (u) de qualquer ponto da seção transversal do tubo, dado em relação ao diâmetro médio da tubulação (D). $\mathrm{O}$ diâmetro médio corresponde à média dos diâmetros interno e externo. A deflexão é convencionada como positiva quando o ponto em questão se aproxima do centro do tubo.

\section{Deflexão total}

Entende-se por deflexão total (d), no texto, a soma dos valores de deflexão de quaisquer dois pontos diametralmente opostos da seção transversal do tubo. 


\section{Revisão Bibliográfica}

\subsection{REDISTRIBUIÇÃO DE TENSÕES NO SOLO}

\subsubsection{Considerações Iniciais}

A interação entre uma estrutura enterrada e o maciço circundante provoca uma redistribuição das tensões no solo, fenômeno comumente conhecido por arqueamento. A transferência das tensões no maciço é basicamente governada pelas características reológicas do solo e da estrutura, pela geometria da estrutura, pelo tipo de movimentação da inclusão (ou de parte dela) e pela presença de carregamentos externos.

$\mathrm{O}$ arqueamento pode ser dividido em duas categorias distintas. É classificado como ativo (ou positivo) quando a tensão em uma determinada zona do maciço próxima à inclusão sofre redução. Até o equilíbrio ser restabelecido, a tensão na região de interesse é transferida para outras localidades do solo. O caso oposto, ou seja, quando há aumento de tensão, é denominado arqueamento passivo (ou negativo). $\mathrm{O}$ arqueamento ativo é comum em túneis, valas escoradas, instalações com condutos flexíveis, estruturas de contenção, dentre outras obras geotécnicas. Ancoragens terrestres e submarinas e condutos rígidos são exemplos típicos de estruturas associadas ao arqueamento passivo.

A redistribuição da tensão vertical $\left(\sigma_{v}\right)$ em um maciço, causada pela movimentação de um alçapão horizontal, deslocado de modo a provocar o 
arqueamento ativo, é ilustrada na Figura 2.1, proveniente de investigações experimentais realizadas por Terzaghi (1936). Nos testes foi utilizada uma caixa preenchida com areia pura, cuja base possuía um alçapão de comprimento muito maior do que a largura, caracterizando o estado plano de deformação. Na Figura 2.1, a tensão vertical medida encontra-se normalizada pela tensão vertical inicial devida ao peso próprio do solo $\left(\sigma_{\mathrm{vi}}\right)$ e a altura do ponto de medida a partir da base, $\mathrm{H}_{\mathrm{e}}$, pela largura do alçapão (B). Verifica-se que menos de $10 \%$ de $\sigma_{\mathrm{vi}}$ chega ao alçapão e que o estado de tensão no solo não mais se altera a partir de $\mathrm{H}_{\mathrm{e}} / \mathrm{B}$ entre 2 e 3 .

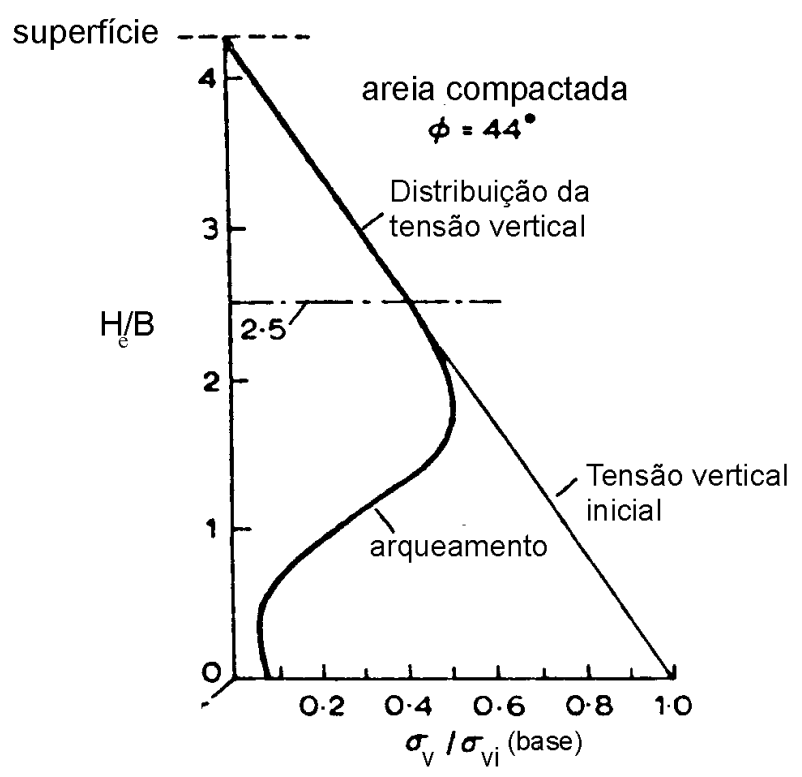

Figura 2.1. Resultado do experimento de Terzaghi (1936) mostrando a variação da tensão vertical com a distância do alçapão em arqueamento ativo.

\subsubsection{Mobilização dos Estados Ativo e Passivo}

Resultados típicos do comportamento de $\sigma_{\mathrm{v}}$ com o deslocamento $(\delta)$ de um alçapão circular são ilustrados através da Figura 2.2 (McNulty 1965). Os resultados são também apresentados em função da razão geométrica $H / B$, onde $H$ é a altura de cobertura de solo sobre a estrutura. $\sigma_{\mathrm{v}}$ converge rapidamente para um valor mínimo à medida que o alçapão se afasta da massa de solo (caso ativo). A redução da carga torna-se mais acentuada com o aumento de $\mathrm{H} / \mathrm{B}$, principalmente para deslocamentos relativos ( $\delta / \mathrm{B})$ maiores. O estado passivo necessita de deslocamentos 
comparativamente maiores para ser mobilizado, sendo esta tendência crescente com o aumento de $\mathrm{H} / \mathrm{B}$.

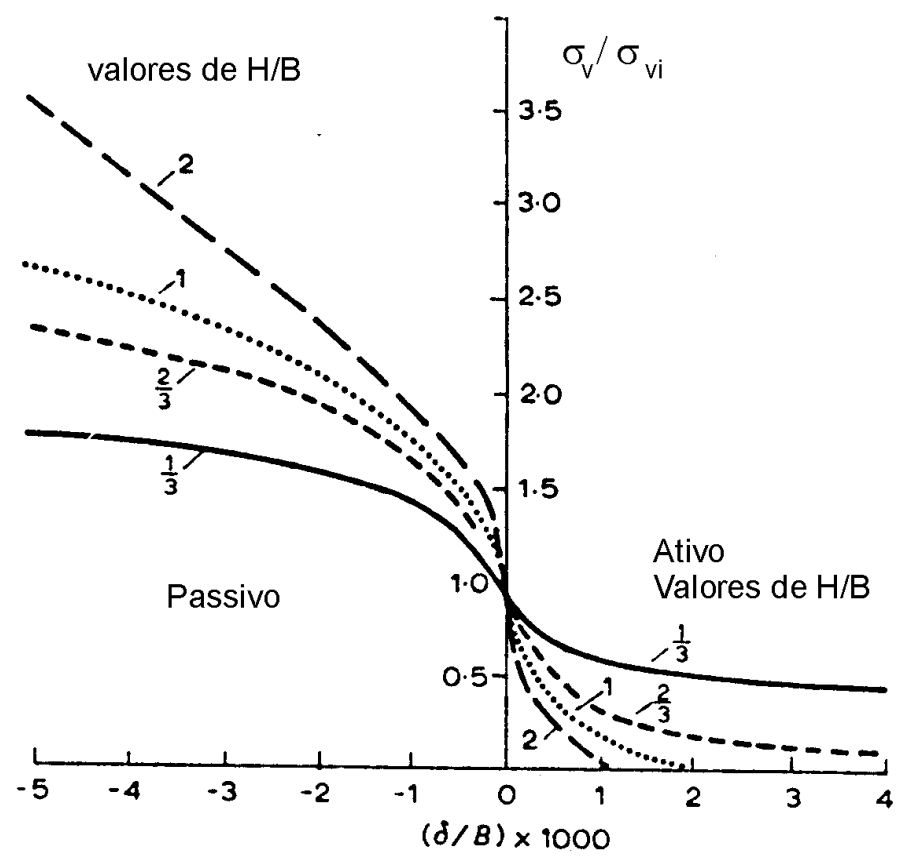

Figura 2.2. Variação da tensão vertical com o deslocamento do alçapão (McNulty 1965).

A Figura 2.3 exibe o fator passivo máximo $\left(\mathrm{N}_{\mathrm{p}}\right)$, mobilizado com tubos rígidos em solo não-coesivo, submetidos à movimentação vertical ascendente e horizontal (Trautmann et al. 1985, Trautmann e O'Rourke 1985). Os resultados são apresentados em função da razão geométrica $\mathrm{H} / \mathrm{D}$, onde $\mathrm{D}$ é o diâmetro do tubo. $\mathrm{N}_{\mathrm{p}}$ é dado por:

$\mathrm{N}_{\mathrm{p}}=\mathrm{F}_{\mathrm{p}} / \gamma \mathrm{HDL}$

onde: $\mathrm{F}_{\mathrm{p}}=$ força passiva máxima medida; $\gamma=$ peso específico do solo; $\mathrm{L}=$ comprimento do tubo.

Nos ensaios de deslocamento vertical, $\mathrm{N}_{\mathrm{p}}$ aumenta praticamente de forma linear com a profundidade, comportamento que se revela tanto mais acentuado quanto maior a densidade da areia. Os valores de $\mathrm{N}_{\mathrm{p}}$ para os ensaios com a areia fofa $\left(\gamma=14,8 \mathrm{kN} / \mathrm{m}^{3}\right)$ variam muito pouco com H/D. Comportamento semelhante foi observado por Dickin (1994). O desempenho do tubo transladado horizontalmente 
também revelou valores de $\mathrm{N}_{\mathrm{p}}$ comparativamente maiores com a areia no estado mais compacto. Esta tendência acentua-se com o aumento da profundidade de instalação.

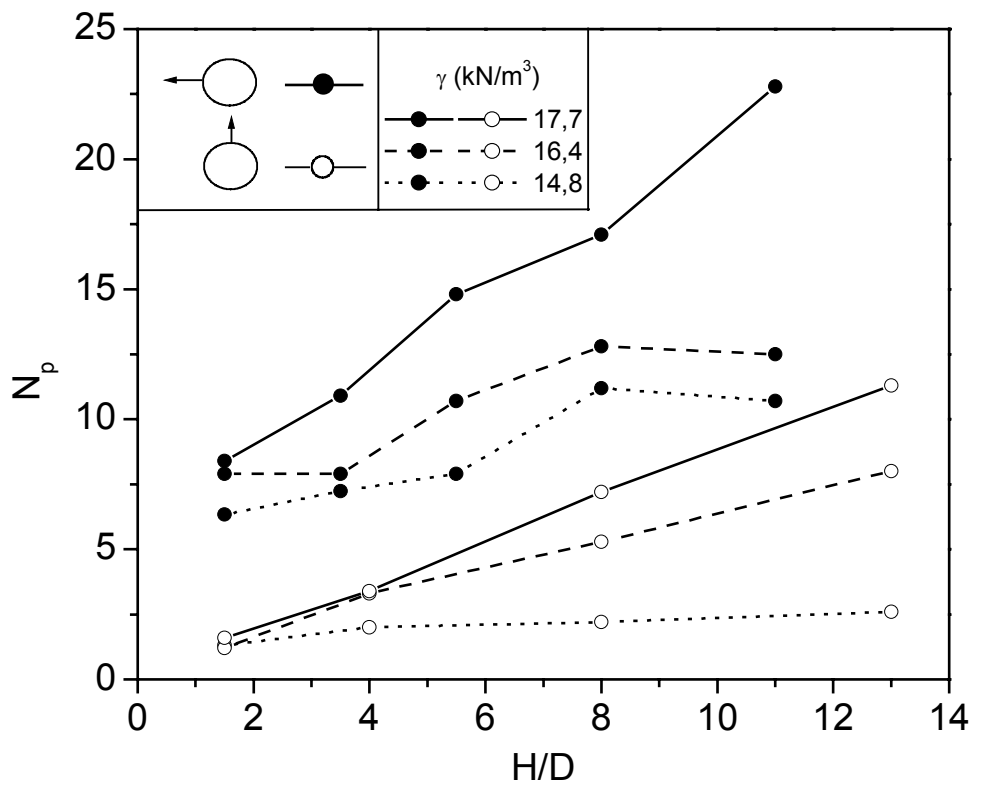

Figura 2.3. Variação da resistência passiva última com H/D em areia com diferentes densidades (após Trautmann et al. 1985, Trautmann e O'Rourke 1985).

Tipicamente, a estabilização da resistência passiva tende a ocorrer em profundidades comparativamente pequenas em maciços de menor densidade. $\mathrm{O}$ oposto é verdade em maciços mais compactos. A razão para a qual a resistência não mais aumenta é denominada razão crítica $(\mathrm{H} / \mathrm{B})_{\mathrm{cr}}$ ou $(\mathrm{H} / \mathrm{D})_{\mathrm{cr}}$, em se tratando de dutos. Baseada em análises com o método dos elementos finitos (MEF) utilizando o modelo constitutivo de Mohr-Coulomb, a Figura 2.4 permite averiguar o comportamento de $(\mathrm{H} / \mathrm{D})_{\text {cr }}$ para valores selecionados de ângulo de atrito do solo $(\phi)$. Nota-se que $(\mathrm{H} / \mathrm{D})_{\mathrm{cr}}$ ocorre para profundidades comparativamente elevadas, aumentando com o aumento de $\phi$.

Em solo puramente coesivo, Rowe e Davis (1982b) verificaram que o aumento de H/B além de 3 ou 4 não exerce efeito significativo na capacidade de carga ao arrancamento de ancoragens. A influência da profundidade sobre a resistência última em argila de baixa consistência foi pesquisada por Paulin et al. (1995), através da movimentação horizontal de um conduto rígido disposto em uma 
trincheira. No modelo, o solo natural era composto por uma argila com $\mathrm{s}_{\mathrm{u}}$ de $33 \mathrm{kPa}$ e o solo de aterro, por uma argila com $\mathrm{s}_{\mathrm{u}}$ de $2,5 \mathrm{kPa}$. Os testes foram conduzidos com H/D variando entre 0 e 3,4. Observou-se um crescimento da resistência última com a profundidade até aproximadamente $\mathrm{H} / \mathrm{D}=0,84$ e acima deste valor a resistência tornou-se aparentemente constante.

No estado ativo, evidências experimentais mostram que o fator ativo mínimo $\left(\mathrm{N}_{\mathrm{a}}\right)$ em material não-coesivo decresce com o aumento da profundidade e tende à estabilização a partir de H/B entre 2 e 3 (Ladanyi e Hoyaux 1969, Iglesia 1991, Koutsabeloulis e Griffiths 1989). Essa faixa independe da forma da estrutura e da densidade relativa do solo.

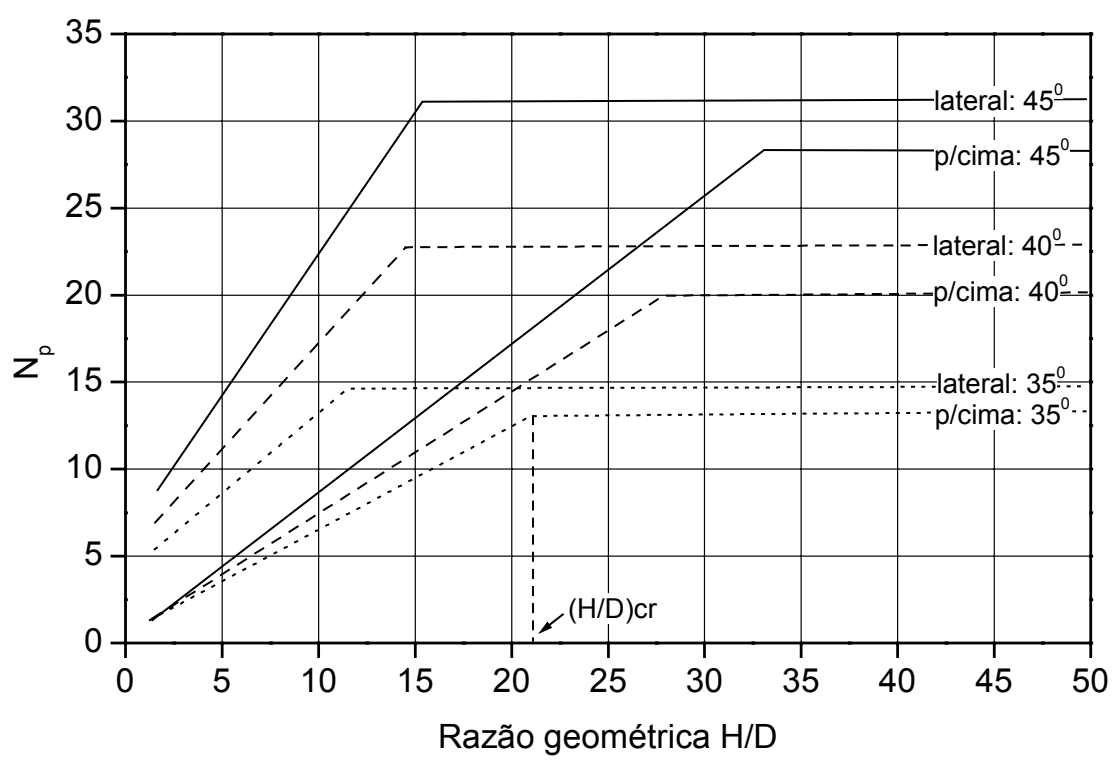

Figura 2.4. Variação de (H/D) cr com o ângulo de atrito do solo (Yimsiri et al. 2004).

\subsubsection{Influência da Geometria da Estrutura}

Evidências experimentais mostram que a resistência passiva ao deslocamento em estruturas retangulares diminui com o aumento da razão $\mathrm{L}_{\mathrm{v}} / \mathrm{B}$, onde $\mathrm{L}_{\mathrm{v}}$ é $\mathrm{o}$ comprimento da estrutura (Audibert e Nyman 1977, Meyerhof e Adams 1968, Murray e Geddes 1987, Frydman e Sharam 1989). Através de análises numéricas com o MEF, Koutsabeloulis e Griffiths (1989) verificaram que $\mathrm{N}_{\mathrm{p}}$ em estruturas 
circulares era maior do que em inclusões retangulares com largura $\mathrm{B}$ igual ao diâmetro da primeira e comprimento muito longo (estado plano). A Figura 2.5 compara os resultados para ambas as condições, assumindo-se $\phi=30^{\circ}$. A diferença na resistência de ambos os sistemas cresce significativamente com o aumento de $\mathrm{H} / \mathrm{B}$. Por exemplo, para $\mathrm{H} / \mathrm{B}=4, \mathrm{~N}_{\mathrm{p}}$ é mais de três vezes superior ao valor obtido com a instalação no estado plano. $\mathrm{O}$ formato exponencial das curvas do caso axissimétrico chama atenção pela divergência que guarda da forma comumente reportada na literatura para casos envolvendo estruturas retangulares. Investigações experimentais mostram que a razão crítica aumenta com $\mathrm{L}_{\mathrm{v}} / \mathrm{B}$. Meyerhof (1973) indica que $(\mathrm{H} / \mathrm{B})_{\text {cr }}$ é aproximadamente uma vez e meia maior com estruturas contínuas, em comparação a estruturas retangulares.

No caso ativo, é relatado que o arqueamento no interior de um alçapão plano não depende do seu formato (Vardoulakis et al. 1981, Koutsabeloulis e Griffiths 1989).

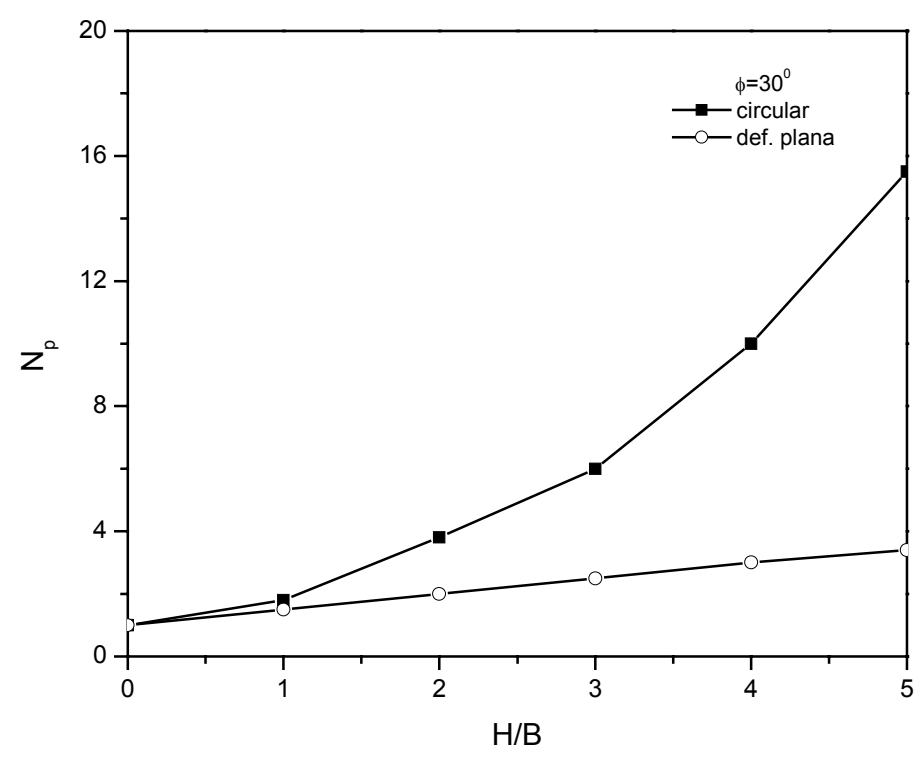

Figura 2.5. Variação de $\mathrm{N}_{\mathrm{p}}$ com $\mathrm{H} / \mathrm{B}$ em arqueamento passivo para condições axissimétrica e no estado plano (Koutsabeloulis e Griffiths 1989).

Com inclusões de mesmas dimensões no plano, mas com seções transversais de geometrias variadas (tais como retangular, triangular, circular e eliptica) Getzler et al. (1968) constataram que os maiores valores de arqueamento ativo ocorrem com o formato circular, seguido do elíptico. Por outro lado, comparando tubos rígidos e 
ancoragens planas de mesmas dimensões no plano, Dickin (1994) mediu capacidades de carga maiores com as ancoragens a partir de $\mathrm{H} / \mathrm{B}=5,5$, sendo aproximadamente iguais até esse valor.

\subsubsection{Redistribuição de Tensões no Exterior da Estrutura}

McNulty (1965) mediu a tensão vertical em pontos fora de um alçapão circular em arqueamento ativo e verificou que, para razões $\mathrm{H} / \mathrm{B}$ acima de 4 , a tensão a $0,4 \mathrm{~B}$ de distância horizontal da borda do alçapão sofreu um aumento em torno de $8 \%$ imediatamente após a translação. Variações de tensões em posições mais remotas não foram verificadas. Quando o alçapão atingiu $\delta / B=1,6 \%$, uma redução de até $10 \%$ da tensão medida em relação à tensão inicial foi medida na mesma distância. Nesse mesmo deslocamento relativo, um ligeiro aumento de $\sigma_{\mathrm{v}}$, não superior a $5 \%$, foi registrado a $1,1 \mathrm{~B}$ de distância.

No caso passivo também foi registrada diminuição de carga a $0,4 \mathrm{~B}$ de distância desde o início da translação, chegando a $11 \%$ em $\delta / B=1,6 \%$. As demais posições não apresentaram variações significativas. A Figura 2.6 apresenta os resultados experimentais de McNulty (1964) na condição ativa, juntamente com a solução teórica de Finn (1963) (vide item 2.3.1), calibrada para as mesmas condições do experimento. O gráfico não tem por finalidade comparar diretamente os resultados, visto que a formulação de Finn (1963) é designada para o estado plano, mas apenas fornecer uma noção da distribuição de $\sigma_{\mathrm{v}}$ no maciço exterior nos dois casos. O resultado teórico indica que a tensão aumenta exponencialmente com a proximidade da estrutura. $\mathrm{O}$ aumento em relação ao valor inicial é de aproximadamente $100 \%$ a 0,4 B de distância. Entretanto, os dados experimentais revelaram um comportamento oposto, ou seja, a ocorrência de alívio de tensão nesta mesma distância. Os resultados convergem para $\sigma_{\mathrm{v}} / \sigma_{\mathrm{vi}}=1$ à medida que a distância do alçapão aumenta. 


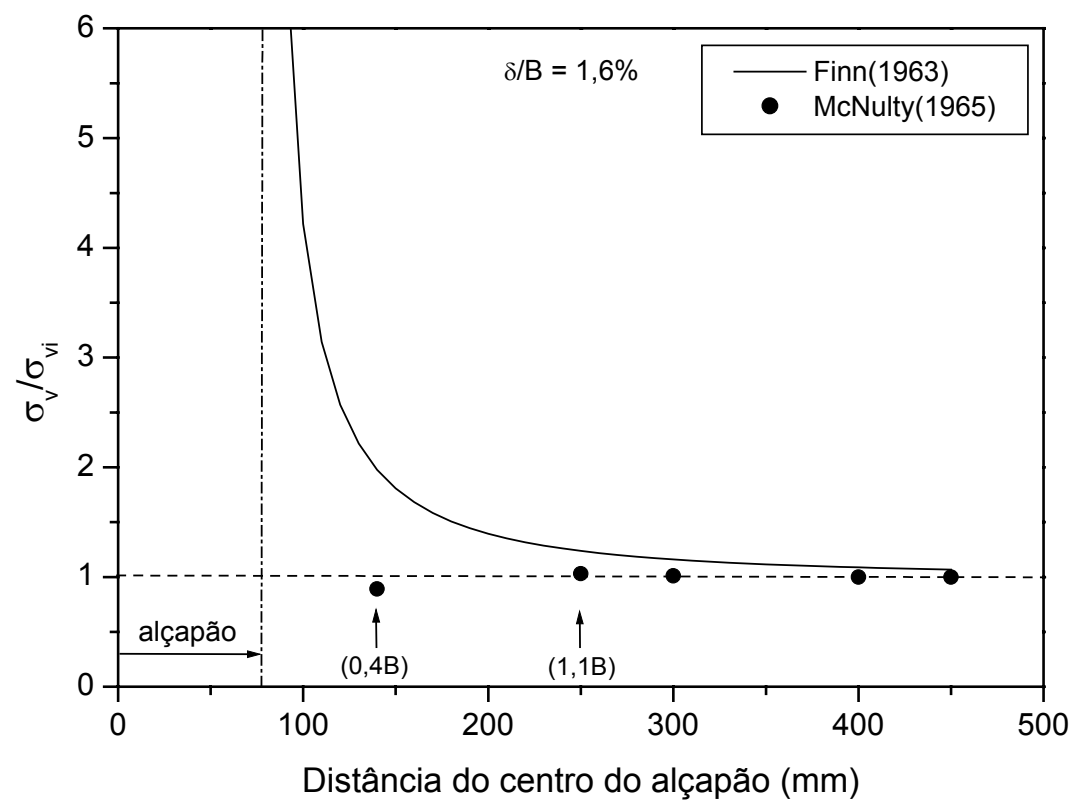

Figura 2.6. Distribuição da tensão vertical no exterior do alçapão em arqueamento ativo através da solução de Finn (1963) e de dados experimentais de McNulty (1965).

\subsubsection{Efeito de Sobrecargas Superficiais Concentradas}

Santichaianant (2002) analisou o efeito de uma sobrecarga concentrada no arqueamento ativo. Uma sapata circular foi disposta na superfície de um maciço construído com uma areia pura, imediatamente sobre um alçapão também circular. $\mathrm{O}$ modelo possuía $\mathrm{H} / \mathrm{B}=2$ e foi ensaiado em centrífuga com aceleração de $75 \mathrm{~g}$. A Figura 2.7 mostra a carga no alçapão em função do deslocamento, onde W representa o peso da sapata. Todas as curvas seguiram um mesmo aspecto, exceto as correspondentes a $\mathrm{W}=713$ e $1026 \mathrm{~N}$. As sobrecargas aplicadas nos dois últimos testes foram capazes de eliminar grande parte do efeito do arqueamento do solo. Como se pode constatar na Figura 2.7, a carga medida nos ensaios sofre um aumento significativo após aproximadamente $3 \mathrm{~mm}$ de deslocamento. 


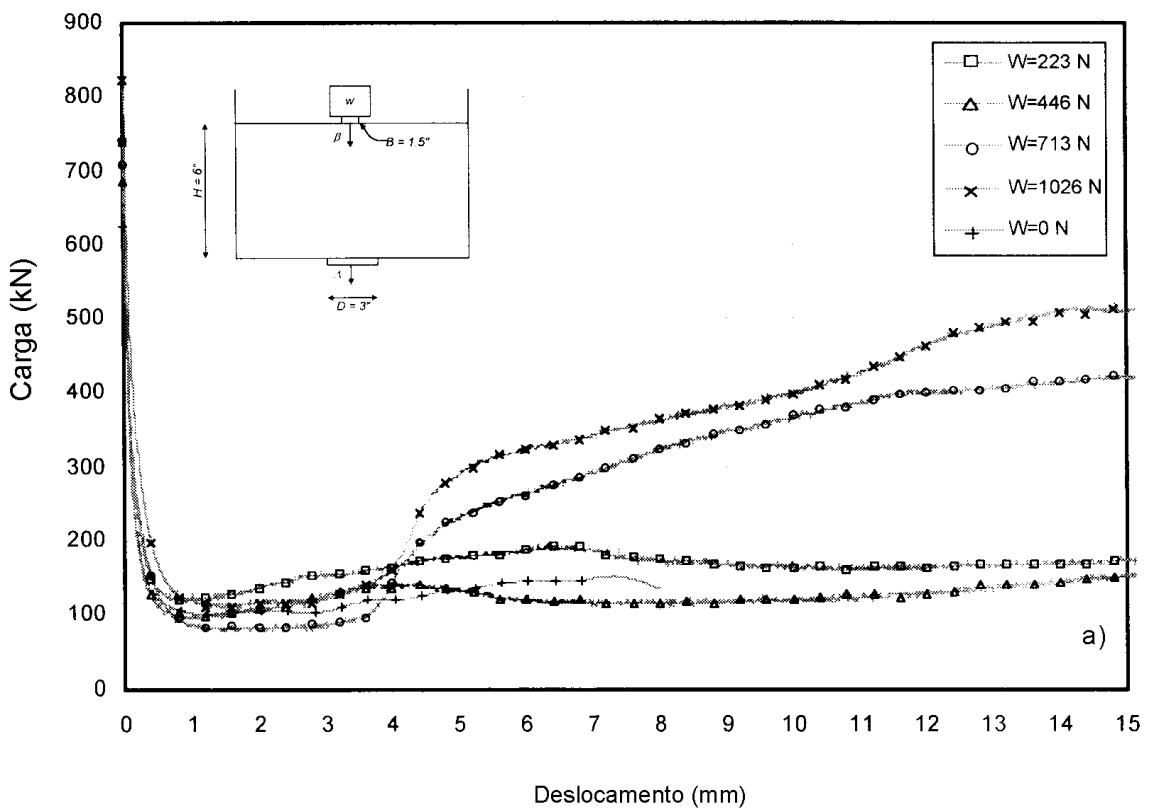

Figura 2.7. Ensaios de arqueamento ativo com sobrecarga concentrada na superfície do maciço (Santichaianant 2002).

\subsubsection{Influência da Direção e da Velocidade da Movimentação da Estrutura na Resistência Passiva}

Em uma determinada profundidade, a maior resistência passiva é geralmente observada quando a estrutura sofre movimentação horizontal, uma vez que na vertical se conta com a mobilização de um volume mais limitado de solo. Os resultados da Figura 2.3, por exemplo, indicam que a resistência mobilizada na horizontal é em média duas a três vezes superior à mobilizada na vertical, para valores constantes de $\mathrm{H} / \mathrm{D}$ e $\gamma$.

Um estudo abrangente sobre a influência da direção do deslocamento de condutos enterrados foi conduzido por Hsu (1996). A pesquisa contou com tubos rígidos instalados em profundidades iguais a 1 e 3 D. Os testes foram executados impondo-se ao conduto deslocamentos transversais segundo uma inclinação com a vertical variando de 0 a $90^{\circ}$, em incrementos de $10^{\circ}$. As seguintes conclusões foram obtidas: a) a resistência aumenta à medida que $\alpha$ aumenta em direção a $90^{\circ}$ (horizontal); b) as maiores variações na resistência ocorrem a partir de $\alpha=45^{\circ}$ e c) a resistência horizontal era aproximadamente quatro vezes superior à vertical. Estes 
resultados corroboram os obtidos por Murray e Geddes (1989) com ancoragens em placa, através dos quais pôde-se observar que mais de $80 \%$ do aumento ocorrido da resistência passiva ocorre dentro do intervalo entre 45 e $90^{\circ}$.

Hsu et al. (2001) realizaram uma investigação sobre a movimentação horizontal do conduto variando o ângulo de inclinação $(\alpha)$ no plano horizontal desde 0 , para movimentação puramente longitudinal, até $90^{\circ}$, para deslocamento exclusivamente transversal. O estudo possibilitou avaliar a parcela de resistência passiva devida ao atrito longitudinal entre o solo e o conduto. Verificou-se que a resistência ao deslocamento puramente longitudinal $\left(\alpha=0^{0}\right)$ é $70 \%$ inferior à resistência ao movimento puramente transversal do conduto $\left(\alpha=90^{\circ}\right)$.

Uma avaliação mais completa da influência da direção da movimentação da na resistência passiva pode ser obtida através do fator de inclinação i, definido como a razão entre o fator passivo máximo inclinado $\left(\mathrm{N}_{\mathrm{pi}}\right)$ e o fator passivo máximo vertical $\left(\mathrm{N}_{\mathrm{pv}}\right)$ (Meyerhof 1973). A Figura 2.8 compara valores de i em função de $\mathrm{H} / \mathrm{B}$, provenientes de dados de testes disponíveis na literatura, envolvendo condutos e ancoragens contínuas, circulares e retangulares em solo granular. Os resultados sugerem que a influência da direção do movimento tende a diminuir com o aumento da profundidade. Com efeito, estando em profundidade elevada o conduto passa a experimentar distribuições de tensão mais uniformes ao seu redor. Observa-se ainda que a variação de i diminui sensivelmente a partir de H/B igual a aproximadamente 4. O fator i poderia ser utilizado como um critério para a classificação da instalação quanto à profundidade. Estruturas profundas seriam aquelas com H/B > 4 .

Em determinadas circunstâncias, a velocidade do movimento da estrutura representa um fator relevante para a resistência do sistema. Em solo coesivo saturado, caso o deslocamento seja suficientemente rápido para não permitir a dissipação instantânea das pressões neutras, uma condição não drenada será instalada, o que implica aumento ou diminuição da resistência em comparação com a resistência drenada, a depender do OCR do solo. Em solos argilosos normalmente consolidados e levemente sobre-adensados, a resistência não drenada na região que sofre solicitação passiva é inferior à resistência drenada devido ao desenvolvimento de pressões neutras positivas. Paulin et al. (1995) realizaram ensaios com modelos em centrífuga variando a velocidade de movimentação de um tubo rígido entre 
$9,5 \times 10^{-4}$ e $1,11 \mathrm{~mm} / \mathrm{min}$ em uma argila normalmente adensada com coesão nãodrenada de $33 \mathrm{kPa}$. Os ensaios foram realizados deslocando-se lateralmente o conduto em uma trincheira. Como solo de aterro foi utilizada uma argila de baixa consistência $\left(\mathrm{c}_{\mathrm{u}}=2,5 \mathrm{kPa}\right)$. A Figura 2.9 exibe as curvas do fator $\mathrm{N}$ versus deslocamento dos ensaios realizados. Nesse caso, $\mathrm{N}$ é dado como a razão entre a força medida $\mathrm{F}$ e o produto $\mathrm{c}_{\mathrm{u}} \mathrm{D}$. A forma das curvas mostra nitidamente a existência de uma fase inicial, estendendo-se até aproximadamente $\delta / D=0,6$, na qual apenas o solo do aterro é mobilizado. O aumento posterior da resistência é conseqüência da contribuição do solo natural. Para um determinado deslocamento, quanto menor a velocidade, maior é a resistência registrada.

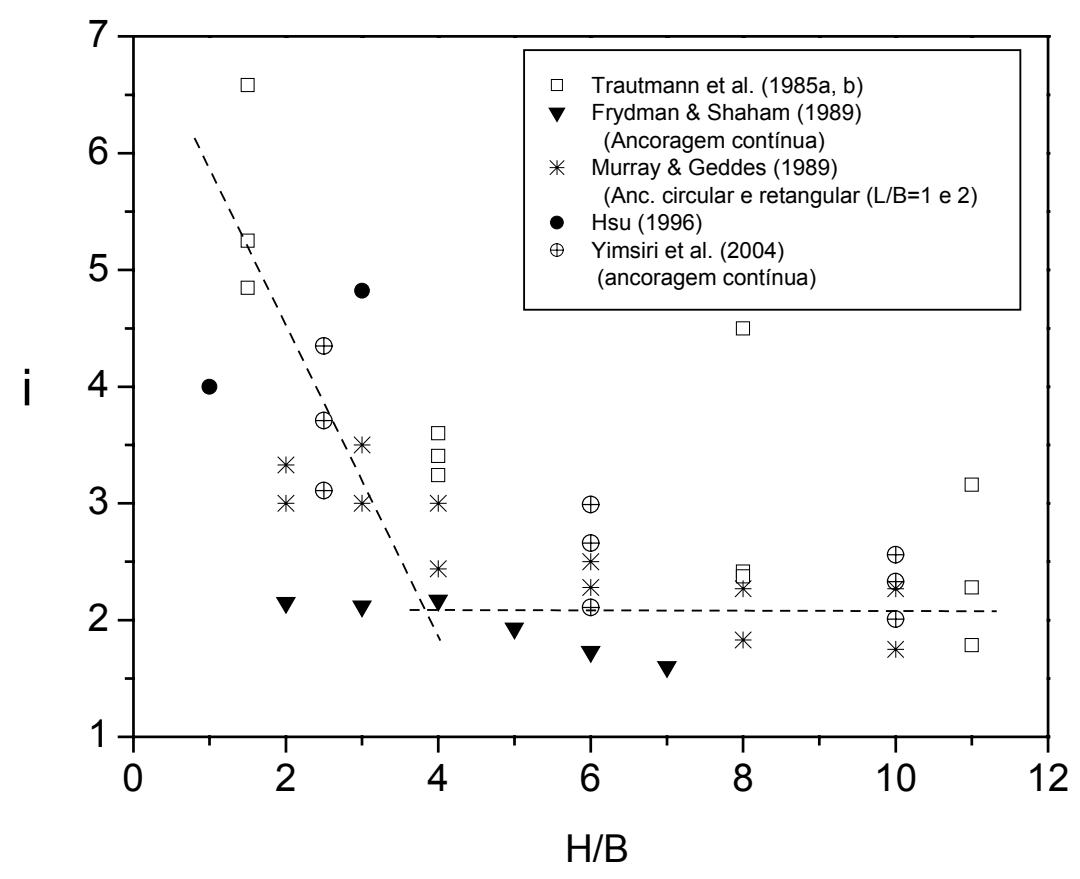

Figura 2.8. Variação do fator de inclinação i com H/B.

Por outro lado, solos altamente pré-adensados desenvolvem pressões neutras negativas durante o cisalhamento, levando a resistências superiores à da condição drenada. Este caso foi averiguado por Altaee et al. (1996) através de análises numéricas em deformação plana de uma tubulação movimentada horizontalmente. Considerou-se um conduto rígido disposto a $0,9 \mathrm{~m}$ de profundidade em uma vala. A Condição drenada foi simulada impondo-se taxas de deslocamento menores ou iguais a $1 \mathrm{~mm} /$ dia. Velocidades acima de $1000 \mathrm{~mm} /$ dia foram empregadas para gerar 
situações não drenadas. A geometria do problema em questão é a mesma descrita nos experimentos de Paulin et al. (1995). O solo natural era representado por uma argila glacial pré-adensada, enquanto que o solo de aterro era composto por uma argila de baixa consistência. Neste caso, observou-se que quanto mais rápido o deslocamento, maior é a resistência não-drenada. Para $\delta / D=20 \%$ a resistência não-drenada é aproximadamente $50 \%$ superior à drenada.

Em solos granulares a influência da velocidade de deslocamento da estrutura enterrada é desprezível, como observou experimentalmente Hsu (1993, 1996).

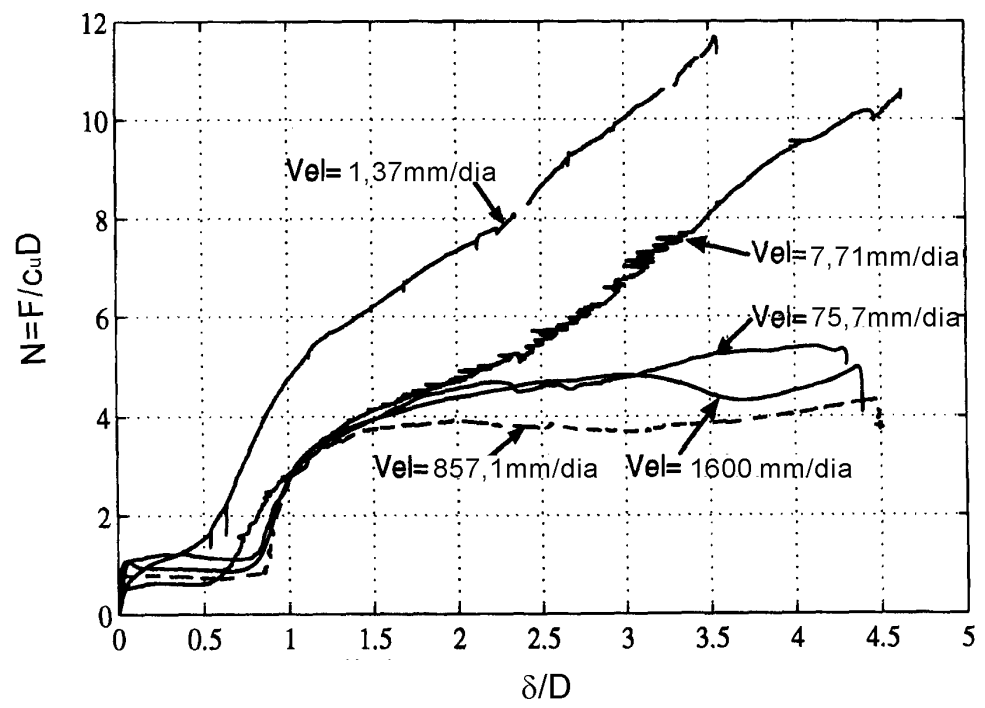

Figura 2.9. Efeito da velocidade no deslocamento de um conduto em uma argila normalmente adensada (Paulin et al. 1995).

\subsection{MECANISMOS DE RUPTURA ENVOLVENDO ESTRUTURAS ENTERRADAS}

A ruptura de diversos sistemas geotécnicos é tipicamente caracterizada pelo desenvolvimento de zonas concentradas de cisalhamento intenso na massa de solo, denominadas localizações de deformação ou superfícies cisalhantes, sendo suficientes deformações cisalhantes de pequena magnitude para sua manifestação (Desrues et al. 1985). A propagação da localização no solo ocorre em virtude do decréscimo da resistência do material na zona cisalhante, o qual direciona o acúmulo 
das deformações iminentes a esta região específica, aumentando gradualmente seu comprimento. Didaticamente, os mecanismos decorrentes da interação solo-estrutura podem ser analisados segundo dois grupos distintos: aqueles provenientes do arqueamento ativo e os associados ao arqueamento passivo.

\subsubsection{Condição Ativa}

Com base em observação experimental, o mecanismo de ruptura causado pela translação de uma base rígida horizontal de modo a provocar uma condição ativa em um meio não-coesivo, caracterizando uma instalação rasa, é esquematicamente ilustrado na Figura 2.10 (Vardoularkis et al. 1981, Stone e Muir Wood 1992, Tanaka e Sakai 1993, Santichaianant 2002). Uma localização inicial OA é formada a partir da aresta do alçapão (ponto $O$ ) e se propaga em direção ao centro do mesmo, dividindo o solo em duas regiões distintas. O caminhamento seguido por OA é governado pela dilatação do solo. O ângulo de inclinação com a vertical de uma tangente a OA em qualquer ponto é igual ao ângulo de dilatação do solo ( $\psi$ ) nas proximidades do ponto de interesse, no momento de formação da localização.

Dessa forma, OA parte do ponto $\mathrm{O}$ com uma inclinação $\theta_{\mathrm{OA}}$ igual ao ângulo de dilatação do solo em $\mathrm{O}$. A localização atinge o ponto A quando o alçapão chega a $\delta_{1}$, com uma inclinação $\theta_{\mathrm{A}}$ igual à dilatação do solo em A. Uma vez que o confinamento em A é menor que em $\mathrm{O}$, a dilatação em A é maior que em $\mathrm{O}$, de modo que $\theta_{\mathrm{A}}>\theta_{\mathrm{OA}}$. Assim, a variação da tensão geostática com a profundidade é responsável pela forma curva da localização. Durante a propagação, o aumento das deformações cisalhantes leva o solo em OA ao estado crítico e, conseqüentemente, $\psi$ decresce do valor associado à formação da localização até zero. Vardoulakis (1981) observou que um deslocamento relativo entre os lados da localização de aproximadamente metade de sua espessura foi suficiente para levar o ângulo de dilatação de uma areia com diâmetro médio $\left(\mathrm{D}_{50}\right)$ de $0,33 \mathrm{~mm}$ do pico a zero. À medida que OA se propaga dentro da massa de solo, sua incompatibilidade com o deslocamento do alçapão aumenta. 
Deslocamentos adicionais da base provocam o surgimento de uma nova localização, $\mathrm{OB}$, orientada segundo um ângulo com a vertical igual a $\theta_{\mathrm{OB}}$. Uma vez que a dilatação na região do ponto $\mathrm{O}$ é comparativamente inferior neste estágio, $\mathrm{OB}$ é propagada com menor inclinação com a vertical (i.e., $\theta_{\mathrm{OB}}<\theta_{\mathrm{OA}}$ ). Quando o alçapão atinge $\delta_{2}$, a localização alcança o ponto B. Uma vez mais, uma nova localização é formada em resposta ao movimento do alçapão. Estudos radiográficos mostram que a mudança do mecanismo de deformação de uma localização para a seguinte é abrupta e que o solo entre ambas permanece praticamente rígido, não interferindo no processo de deformação (Stone e Muir Wood 1992). A rigor, a massa de solo entre as localizações não pode ser exatamente classificada como rígida, uma vez que também sofre deformação.

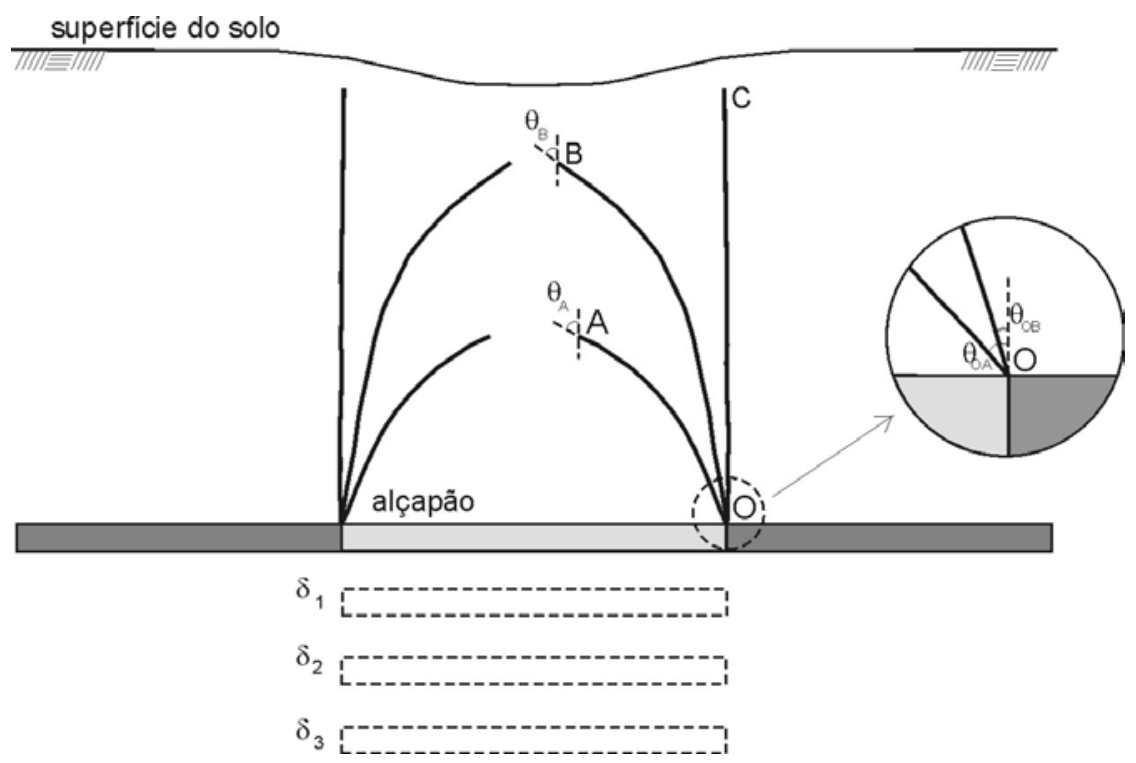

Figura 2.10. Mecanismo de ruptura envolvendo a translação de um alçapão em arqueamento ativo.

A condição final na Figura 2.10 é associada a uma localização aproximadamente vertical, representada pela curva OC, desenvolvendo-se plenamente quando a base atinge $\delta_{3}$. Neste estágio, o solo em $\mathrm{O}$ já atingiu o estado crítico, de forma que a localização se propaga verticalmente. Uma depressão na superfície do maciço é observada acima do alçapão. Se a translação do alçapão for mantida, localizações se propagando para a massa de solo exterior ao alçapão podem 
surgir. A Figura 2.11 exibe dados coletados em obras envolvendo a construção de túneis, com os quais o ângulo externo de inclinação da localização com a vertical $(\beta)$ foi estimado. A figura apresenta a faixa de variação de $\beta$ e da largura da bacia de recalque na superfície do terreno $(\mathrm{w})$ com o tipo de solo e a profundidade.

Na prática, os padrões de localizações no solo em arqueamento ativo podem ser muito mais complexos do que o esquema da Figura 2.10, e dependem da combinação de diversos fatores. Os mais importantes são a densidade e o confinamento, os quais controlam o comportamento volumétrico do solo. Particularmente, o tamanho da partícula do solo também tem se mostrado significante nesse aspecto. Stone e Muir Wood (1992) observaram que para um mesmo deslocamento $\delta$, o número de localizações formadas aumenta com a diminuição de $\mathrm{D}_{50}$. Com base em ensaios de deformação plana, Shibli (1995) reporta que a espessura da localização decresce de forma não-linear com o aumento de $\mathrm{D}_{50}$.

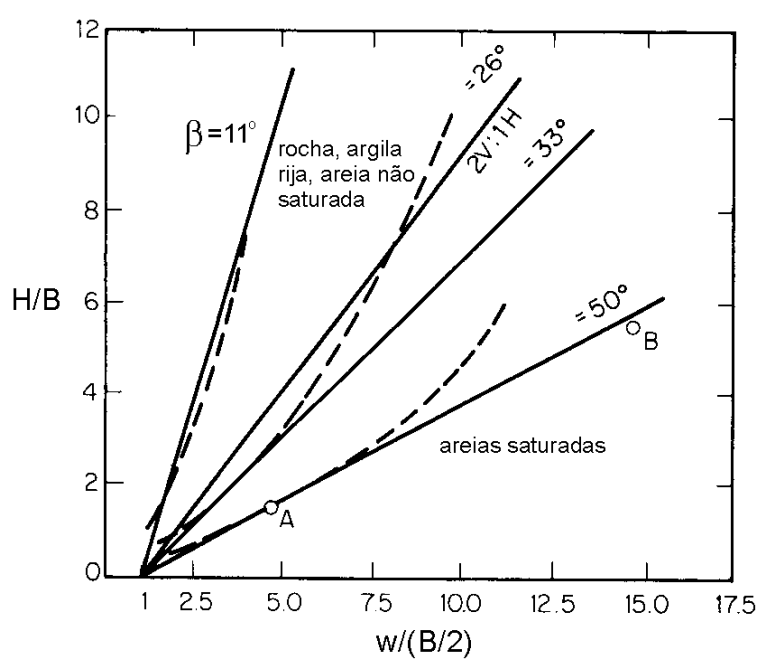

Figura 2.11. Inclinação de localizações externas em túneis abertos em diversos tipos de solo (Hunt 1986).

\subsubsection{Condição Passiva}

\subsubsection{Movimento Vertical Ascendente}

A propagação de localizações em um material não-coesivo, resultante da translação vertical de uma base rígida horizontal, de modo a induzir o arqueamento passivo na 
massa de solo, pode ser idealizada através da Figura 2.12, reproduzida de Walters e Thomas (1982). Quando a base é deslocada verticalmente, em movimento ascendente, a massa de solo situada sobre sua parte superior é solicitada, originando localizações partindo das extremidades da estrutura que se propagam segundo uma determinada inclinação (Figuras 2.12a e b). A depender da distribuição de tensões ao longo da profundidade na massa de solo, a superfície poderá apresentar-se curva. Da mesma forma que no caso ativo, a localização final será aproximadamente vertical, uma vez que o solo se encontrará no estado crítico (Figura 2.12c).
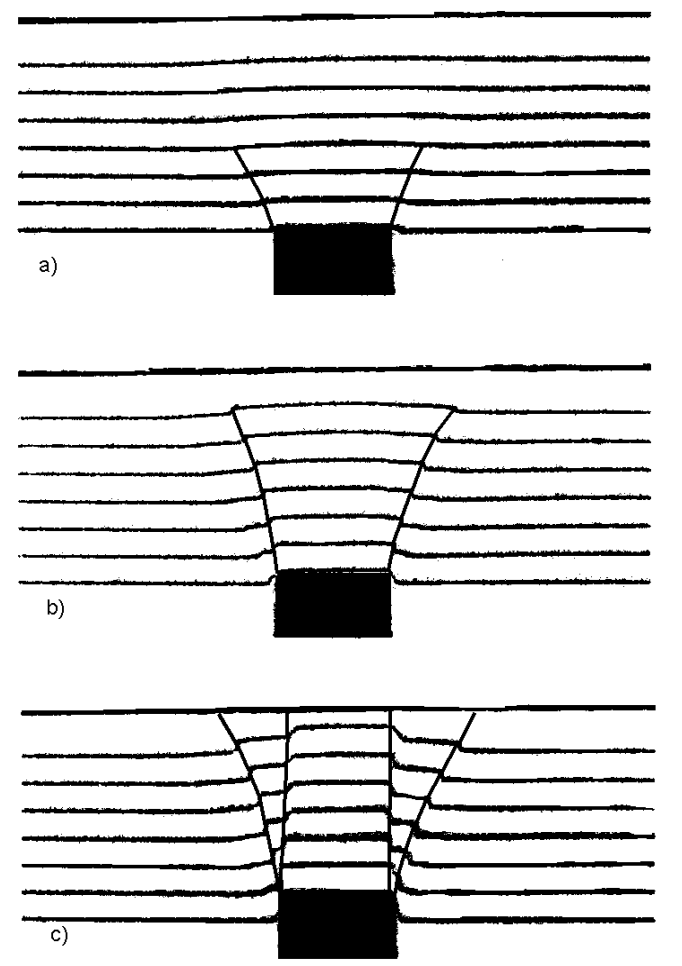

Figura 2.12. Desenvolvimento de localizações com um alçapão provocando arqueamento passivo (Walters e Thomas 1982).

Meyerhof e Adams (1968) relatam o surgimento de superfícies inclinadas com uma discreta curvatura em ensaios com ancoragens em placas circulares submetidas a arrancamento vertical. Em areia compacta e com $\mathrm{H} / \mathrm{B}=2,5$ foram observadas superfícies inclinadas partindo da extremidade da ancoragem e terminando na superfície do terreno. Com $\mathrm{H} / \mathrm{B}=4,5$ foi verificado que, apesar de iniciarem sob determinada inclinação, as superfícies cisalhantes interceptaram 
verticalmente a superfície do solo. Em areia fofa, localizações verticais foram observadas em ambas as profundidades, uma vez que, nesse caso, a areia na região da descontinuidade estava mais próxima do estado crítico. Entretanto, para H/B = 4,5 a superfície cisalhante prolongou-se até uma altura igual a aproximadamente $2 \mathrm{~B}$, ao passo que para $\mathrm{H} / \mathrm{B}=2,5$ a localização interceptou a superfície do terreno. Da mesma forma, Kulhawy et al. (1987) averiguaram que, para $\mathrm{H} / \mathrm{B}<2$ e com solo de aterro com $D_{\mathrm{r}}$ de pelo menos $85 \%$ a ruptura de ancoragens envolve uma zona delimitada por superfícies curvas ou superfícies inicialmente verticais que passam a ser curvas a partir de certo ponto.

Rowe e Davis (1982a) verificaram que a ruptura de uma ancoragem extraída verticalmente em um meio com lei de fluxo associada com $\phi=\psi=30^{\circ}$ envolve uma zona plástica com extensão superior a 5B. A ruptura da mesma ancoragem em um solo no estado crítico $\left(\psi=0^{0}\right.$ e $\left.\phi=30^{\circ}\right)$ mobiliza uma região com extensão de apenas 1,5B. Os autores apontam que o efeito da dilatação do solo torna-se mais evidente a partir de $\mathrm{H} / \mathrm{B}>3$.

O desenvolvimento de localizações de deformações em condutos rígidos enterrados e submetidos a movimentação vertical ascendente ocorre de forma semelhante ao observado em alçapões e ancoragens (Dickin 1994). As localizações partem da linha d'água e adentram a massa de solo segundo uma determinada inclinação com a vertical. Dickin (1994) e Bransby et al. (2002) reportam a formação de um vazio sob a base do tubo. Nessa última referência o deslocamento imposto foi de $\delta / D=1,3$, tendo ocorrido em uma areia fofa e sob uma cobertura de solo de 3D. O mesmo comportamento também foi observado em areia compacta, porém com uma zona de ruptura maior e mais perturbação na superfície do maciço. $\mathrm{O}$ mecanismo de ruptura na areia compacta envolveu localizações de deformação curvas interceptando a superfície do maciço, abrangendo uma região com largura aproximada de 2D. Não foram encontrados registros na literatura sobre padrões com condutos flexíveis.

\subsubsection{Movimento Horizontal}

O mecanismo envolvendo a movimentação horizontal de estruturas enterradas segue um padrão bastante distinto daquele observado no deslocamento vertical. Através de 
ensaios com tubos dispostos em areia densa, Audibert e Nyman (1977) reportam para $H / D=3$ o surgimento de uma cunha de ruptura passiva com formato de uma espiral logarítmica partindo da base do conduto e atingindo a superfície do terreno. Na parte posterior do tubo ocorre a formação de uma cunha ativa praticamente vertical. No topo forma-se uma zona central estendendo-se até a superfície do terreno, separando a região passiva da ativa (Figura 2.13a). Ao passo que a razão H/D aumenta, a cunha passiva é substituída por uma zona de plastificação caracterizando um mecanismo que permanece confinado em torno do tubo. O padrão observado para H/D > 12 é esquematizado na Figura 2.13b. A plastificação do solo nesta profundidade abrangeu uma zona entre dois e três diâmetros com areia fofa e um diâmetro com areia densa.

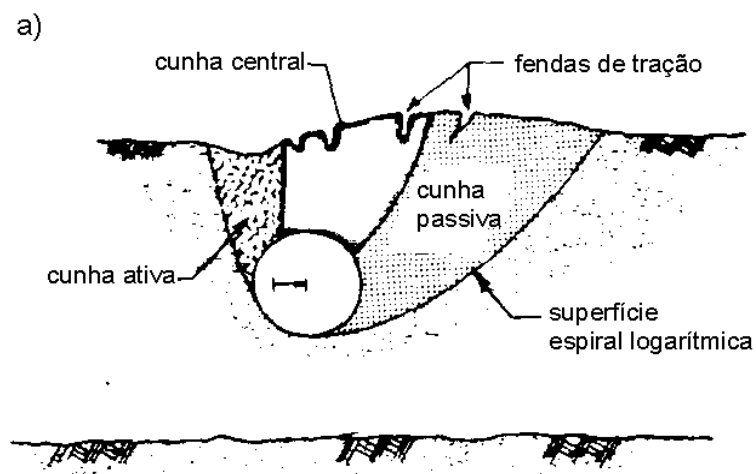

b)

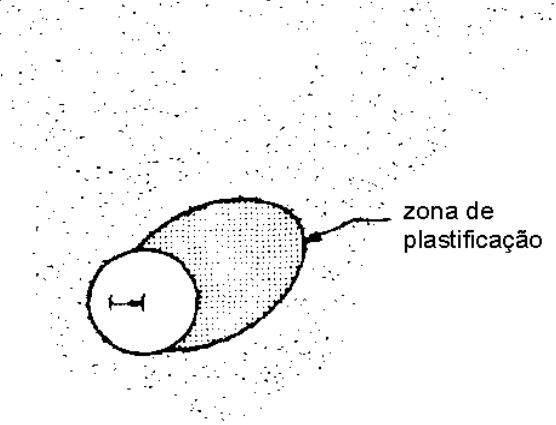

Figura 2.13. Mecanismos de ruptura de condutos em deslocamento horizontal; a) $\mathrm{H} / \mathrm{D}=3$ e b) $\mathrm{H} / \mathrm{D}=12$ (Audibert e Nyman 1977).

Dickin e Leung (1985) observaram padrões muito semelhantes aos de Audibert e Nyman (1977), provocados pela translação de uma ancoragem horizontal em um material granular, com H/B iguais a 3, 5 e 8 . Na menor profundidade, ocorreu a formação de uma zona de ruptura contendo três cunhas distintas chegando à 
superfície do terreno. O mecanismo na profundidade intermediária é mais complexo, envolvendo a formação de um número maior de cunhas, porém abrangendo um volume de solo comparativamente menor. $\mathrm{Em} \mathrm{H} / \mathrm{B}=8$, há a formação de uma zona de ruptura confinada, abrangendo uma massa de solo de largura não superior a 2B.

Paulin et al. (1995) compararam os mecanismos de ruptura que ocorrem com um conduto flexível imerso em um solo argiloso normalmente adensado em condições drenadas e não-drenadas, com $\mathrm{H} / \mathrm{D}=1$. Este foi o único trabalho com conduto flexível localizado nessa revisão da literatura. A Figura 2.14a ilustra o mecanismo de ruptura observado nos ensaios não drenados, em uma seção próxima ao centro do vão do tubo. As linhas abaixo da tubulação indicam uma zona de deformação cisalhante bem definida que se estende até aproximadamente $0,5 \mathrm{D}$ abaixo da base. Não há formação de superfícies de ruptura na região do solo solicitada passivamente. O mecanismo ocorrido nos ensaios drenados difere bastante do verificado para os ensaios não drenados (Figura 2.14b). Neste caso, foi registrado o surgimento de diversos planos de ruptura estendendo-se desde a base do tubo à superfície do solo segundo um ângulo de aproximadamente $50^{\circ}$ com a vertical. Tanto nos ensaios drenados quanto nos não drenados houve uma considerável elevação da superfície do solo nas regiões imediatamente acima e adjacente ao topo do conduto.
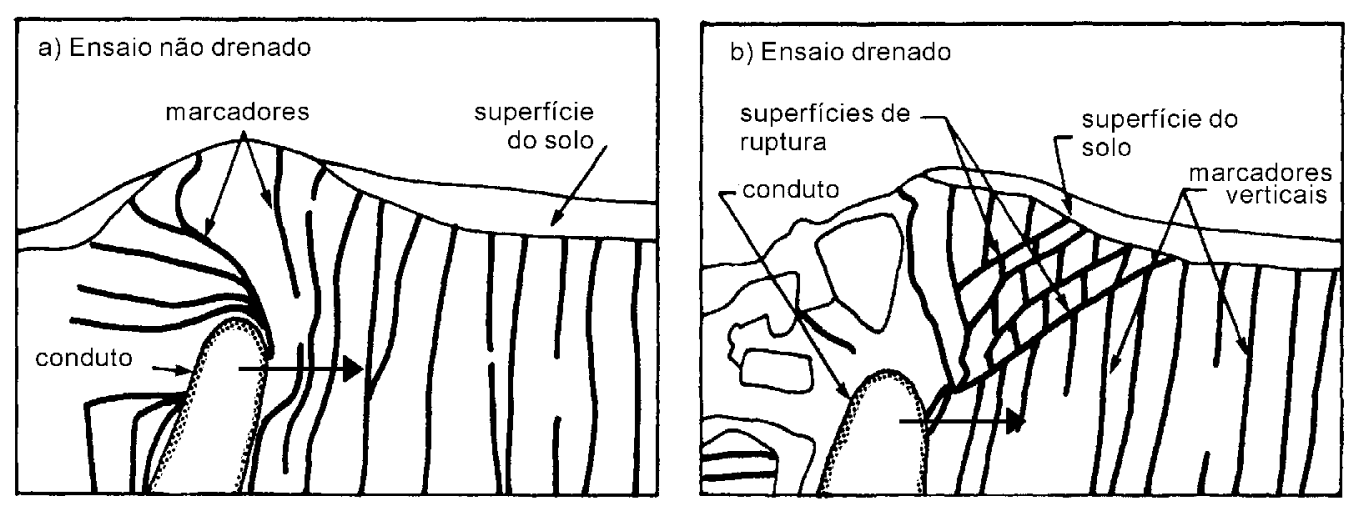

Figura 2.14. Mecanismos de ruptura de conduto em argila normalmente adensada; a) ensaio não drenado, b) ensaio drenado (Paulin et al. 1995). 


\subsection{DETERMINAÇÃO DA CARGA QUE ATINGE A ESTRUTURA}

\subsubsection{Condição Ativa}

As primeiras teorias sobre o arqueamento de solo remontam ao final do século XIX e início do século XX, e foram desenvolvidas para o estado plano de deformação. A mais utilizada tem sido a de Janssen (1895) (após Terzaghi 1943), proposta originalmente para o cálculo de tensões em silos; daí ser também conhecida por Teoria do Silo. Assume-se que a carga vertical em um elemento de solo de espessura dh é igual à diferença entre o peso do solo acima do elemento e o atrito lateral (Figura 2.15), determinado através do critério de Mohr-Coulomb. Resolvendo-se para o equilíbrio vertical do elemento, obtém-se:

$\mathrm{F}_{\mathrm{a}}=\frac{\mathrm{B}^{2} \gamma}{2 \mathrm{ktg} \phi}\left[1-\exp \left(-\operatorname{ktg} \phi \frac{2 \mathrm{z}}{\mathrm{B}}\right)\right]$

onde: $\mathrm{F}_{\mathrm{a}}=$ força ativa mínima por unidade de comprimento.

ou, de forma simplificada:

$\mathrm{F}_{\mathrm{a}}=\mathrm{C} \gamma \mathrm{B}^{2}$

onde: $\mathrm{k}=\mathrm{K}_{\mathrm{a}}=$ coeficiente de empuxo ativo; $\phi=$ ângulo de atrito interno do solo.

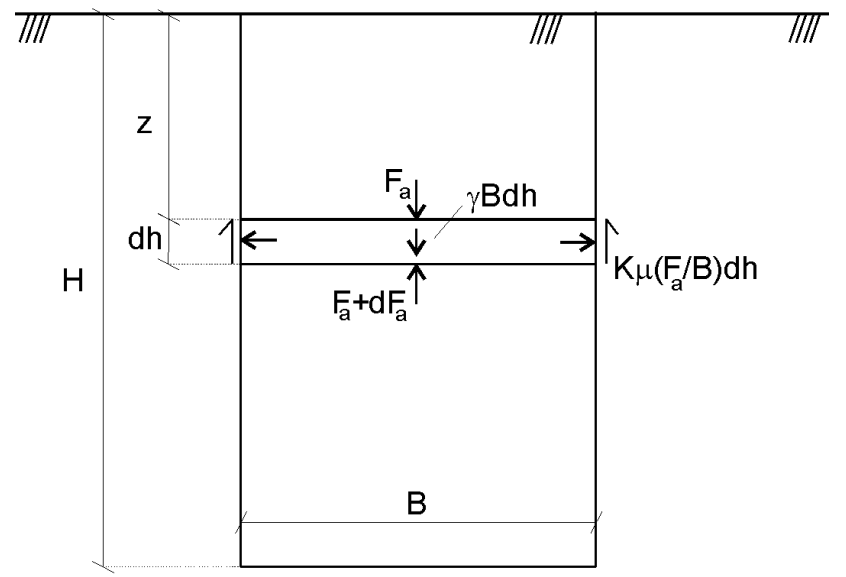

Figura 2.15. Modelo de Janssen (1895). 
Em 1913, Marston e seus associados utilizaram esta solução como base para o desenvolvimento de um método para a determinação da carga vertical em tubulações enterradas (Young e Trott 1984, Moser 2001). Os condutos são classificados em dois grupos principais, de acordo com o tipo de instalação: em trincheira e em aterro. Em instalações em trincheira, a carga que chega ao conduto resulta do peso do prisma de solo sobrejacente subtraído da resistência ao cisalhamento entre as paredes da vala e o solo. Em aterro, quando o tubo é disposto com o topo projetando-se acima do solo natural a instalação é classificada como projeção positiva. Neste caso, as superfícies de cisalhamento partem verticalmente da linha d'água do tubo e atingem a superfície do aterro. A carga vertical será então igual ao peso do prisma central somado ou subtraído da resistência ao cisalhamento ao longo da superfície do solo, dependendo se o solo no topo do tubo recalca menos ou mais que o solo adjacente, respectivamente. A projeção negativa ocorre quando o tubo é disposto em uma trincheira e, em seguida, aterrado, de modo que o topo permanece abaixo da superfície do terreno natural. Este tipo de instalação é vantajoso, pois permite que o prisma central recalque mais que os adjacentes, diminuindo a tensão sobre o topo do conduto em virtude do arqueamento.

O recalque relativo entre o conduto e o solo adjacente é quantificado por um parâmetro denominado razão de recalque $\left(\mathrm{r}_{\mathrm{sd}}\right)$. Valores de $\mathrm{r}_{\mathrm{sd}}$ são relativamente difíceis de serem obtidos experimentalmente, se não impossíveis (Moser 2001) e os poucos valores disponíveis na literatura provêem basicamente do trabalho de Spangler (1950). Utilizando a teoria de Burns e Richards (1964), Nielson e Koo (1968) apresentaram uma proposição para a determinação de $r_{s d}$ em termos da rigidez relativa solo-conduto.

No caso de condutos sob aterro, haverá um plano horizontal no qual as tensões cisalhantes são nulas, denominado de plano de igual recalque (PIR). Acima deste plano, o recalque do prisma central é igual ao dos prismas exteriores. Se o PIR for localizado entre o topo do tubo e a superfície, a condição é denominada projeção incompleta. Quando a altura do aterro não for suficiente para que isto ocorra, as superfícies de cisalhamento interceptarão a superfície do terreno, sendo a instalação classificada como projeção completa. Spangler (1948) desenvolveu um método para o cálculo da altura do PIR $\left(\mathrm{H}_{\mathrm{c}}\right)$ para ambos os casos de projeção positiva e negativa, 
assumindo como premissa básica que os prismas exteriores possuem largura igual a B.

A hipótese de superfícies verticais em instalações em trincheira é aceitável, porém é questionável em instalações em aterro, visto que a verificação dessa condição dependerá do nível de deslocamento imposto (Figura 2.10). Em adição, o coeficiente de empuxo ativo não poderia ser utilizado na fórmula de Janssen (1895), uma vez que $K_{a}=\sigma_{3} / \sigma_{1}$, e $\sigma^{\prime}{ }_{3}$ é uma tensão principal, devendo, por definição, atuar em um plano com tensão cisalhante nula. Em outras palavras, a utilização de $\mathrm{K}_{\mathrm{a}}$ implica obrigatoriamente a inexistência de atrito entre os planos verticais e o elemento de solo em análise (Figura 2.15). Na realidade, o atrito causa a rotação das tensões principais do centro do elemento em direção às superfícies de deslizamento, de modo que $\sigma^{\prime}{ }_{h}$ e $\sigma^{\prime}{ }_{v}$ nestes locais serão diferentes de $\sigma^{\prime}{ }_{3}$ e $\sigma_{1}{ }_{1}$, respectivamente. Maiores críticas sobre as limitações do método de Marston-Spangler podem ser obtidas em Krizek et al. (1971). De uma forma geral, o método merece destaque pela simplicidade e facilidade de utilização.

Com o auxílio do círculo de Mohr, Krynine (1945) chegou à expressão (2.4) para o valor de k na superfície de uma parede rugosa, de maior magnitude em comparação ao fornecido pela teoria de Rankine. $\mathrm{O}$ uso de $\mathrm{K}_{\mathrm{a}}$ subestima o atrito lateral nos planos de cisalhamento, fazendo com que a tensão atuante no alçapão seja superestimada.

$\mathrm{k}_{\mathrm{kr}}=\frac{\sigma_{\mathrm{h}}}{\sigma_{\mathrm{v}}}=\frac{1-\operatorname{sen}^{2} \phi}{1+\operatorname{sen}^{2} \phi}$

Supondo-se que a lamela de solo possui a forma de um arco, definido pela trajetória das tensões principais menores ao longo da largura B do prisma, Handy (1985) desenvolveu uma expressão para k baseada em equilíbrio limite (expressão 2.5). Para paredes lisas (onde $\theta=90^{\circ}$ ), (2.5) torna-se igual à equação de Rankine; no caso de paredes rugosas (onde $\theta=45^{0}+\phi / 2$ ), torna-se igual à proposição de Krynine (1945). 
$\mathrm{k}_{\mathrm{h}}=\frac{\sigma_{\mathrm{h}}}{\sigma_{\mathrm{v}}}=\frac{\cos ^{2} \theta+\mathrm{K}_{\mathrm{a}} \operatorname{sen}^{2} \theta}{\operatorname{sen}^{2} \theta+\mathrm{K}_{\mathrm{a}} \cos ^{2} \theta}$

A hipótese de assumir o solo na condição ativa não tem sido comprovada na prática. Tem-se observado que as tensões verticais são reduzidas consideravelmente com o deslocamento, com $\mathrm{k}$ atingindo valores entre 1 e 1,6 nas proximidades da estrutura (Terzaghi 1936; Krizek et al. 1971). Particularmente, estes valores devem se tornar ainda maiores em instalações rasas em aterros bem compactados, onde a tensão lateral já é inicialmente superior à vertical (Powrie 1997). Nesse caso, um ciclo de carregamento e descarregamento de $\Delta \sigma_{\mathrm{v}}$ devido ao processo de compactação causa o desenvolvimento de uma condição passiva acima de uma profundidade crítica $\left(\mathrm{z}_{\mathrm{c}}\right)$ igual a $\Delta \sigma_{\mathrm{v}} / \gamma\left(\mathrm{K}_{\mathrm{p}}{ }^{2}-1\right)$. Se a profundidade da instalação for pequena, é provável que $\mathrm{z}_{\mathrm{c}}$ seja maior que a altura de cobertura $(\mathrm{H})$ acima da estrutura, fazendo com que o solo esteja na condição passiva. Dessa forma, a adoção de valores entre $\mathrm{K}_{\mathrm{o}}$ e $\mathrm{K}_{\mathrm{p}}$ aparentaria ser mais condizente com a realidade. Evans (1983) constatou experimentalmente através de ensaios de arqueamento ativo que a tensão horizontal no solo sobre o alçapão permanece praticamente constante com o aumento de $\delta$, não acompanhando o decréscimo da tensão vertical. Isto fez com que $\mathrm{k}$ atingisse um valor máximo igual a 1,2 para $\delta / B=1 \%$.

Engesser (1882) (após Iglesia et al. 1999) desenvolveu uma solução analítica considerando a superfície de ruptura como um arco estrutural imaginário de espessura dh e largura $\mathrm{B}$, com forma parabólica e fazendo um ângulo $\theta=\phi$ com a horizontal (Figura 2.16). Quando a estrutura se desloca em relação ao solo adjacente, a redistribuição da carga do topo do arco para as laterais, devida ao carregamento uniformemente distribuído sobrejacente q, causa um aumento da tensão vertical $\left(\sigma_{\mathrm{vr}}\right)$ dentro do arco. A carga vertical, $\mathrm{F}_{\mathrm{a}}$, atuante na estrutura, é então considerada como a soma da tensão resultante do peso de solo abaixo do arco e $\sigma_{\mathrm{vr}}$ (expressão 2.6). A tensão vertical é calculada como $\mathrm{K}_{\mathrm{a}} \sigma_{\mathrm{hr}}$, o que equivale a considerar o solo no estado passivo de Rankine.

$$
\frac{\mathrm{F}_{\mathrm{a}}}{\gamma \mathrm{HB}}=\frac{\mathrm{B}}{\mathrm{H}}\left[\frac{\mathrm{HK}_{\mathrm{a}}}{2 \mathrm{H} \operatorname{tg} \phi+\mathrm{BK}_{\mathrm{a}}}+\frac{\operatorname{tg} \phi}{6}\right]
$$




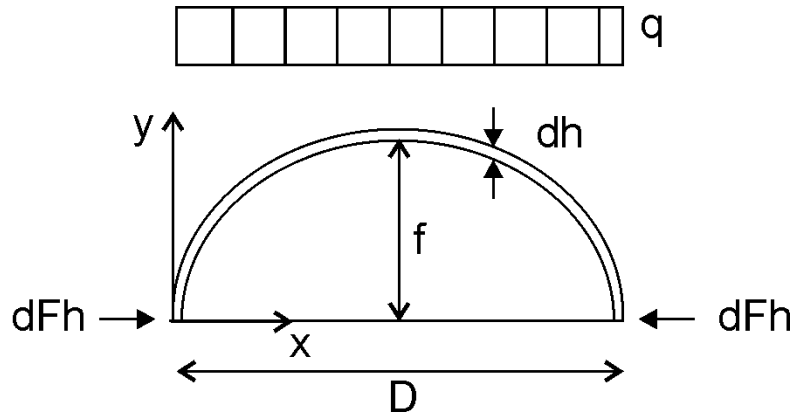

Figura 2.16. Método de Engesser (1882) (após Iglesia et al. 1999).

Villard et al. (2000) analisaram o equilíbrio estático de um domo com seção semi-elíptica. A tensão sobre o domo, $\sigma_{z d}$, foi determinada a partir do equilíbrio de um cilindro de solo, tal como no modelo de Janssen (1895), porém na condição axissimétrica. Assume-se que a tensão normal na parede $\left(\sigma_{\mathrm{r}}\right)$ é igual a $\mathrm{K}_{\mathrm{a}} \cdot \sigma_{\mathrm{z}}$, obtendo-se:

$\sigma_{z d}=\mathrm{k}_{0}+\mathrm{k}_{2} \mathrm{e}^{-\mathrm{k}_{1} \mathrm{~d}}$

onde: $\mathrm{k}_{0}=\frac{\mathrm{B}(\gamma-4 \mathrm{c} / \mathrm{B})}{4} ; \mathrm{k}_{1}=\frac{4 \mathrm{~K}_{\mathrm{a}} \operatorname{tg} \phi \mathrm{z}}{\mathrm{B}} ; \mathrm{k}_{2}=\mathrm{q}-\mathrm{k}_{0} ; \mathrm{q}=$ sobrecarga superficial.

O equilíbrio estático do domo sob as condições de contorno em questão fornece a expressão (2.8), a qual pode ser solucionada para determinar a altura crítica de sustentação (h). O gráfico da Figura 2.17 mostra a relação entre h/B e a razão geométrica $\mathrm{H} / \mathrm{B}$ para $\mathrm{q}=0$ e $\mathrm{K}_{\mathrm{a}}=0,24$. A altura máxima que a cavidade pode atingir antes de entrar em colapso é igual a $0,592 \mathrm{~B}$, ocorrendo com instalações com H/B > 2.

$\mathrm{C}_{1}+\mathrm{C}_{2} \cdot\left(\mathrm{e}^{-\mathrm{k}_{1}(\mathrm{H}-\mathrm{h})}-\mathrm{e}^{-\mathrm{k}_{1} \mathrm{H}}\right)+\frac{\mathrm{R}^{3}}{6}\left(\mathrm{k}_{0}+\mathrm{k}_{2} \mathrm{e}^{-\mathrm{k}_{1}(\mathrm{H}-\mathrm{h})}\right)=0$

onde: $\mathrm{C}_{1}=\frac{\mathrm{K}_{\mathrm{a}} \mathrm{k}_{0} \mathrm{Dh}^{2}}{4}$ e $\mathrm{C}_{2}=\frac{\mathrm{K}_{\mathrm{a}} \mathrm{k}_{2} \mathrm{D}}{2 \mathrm{k}_{1}^{2}}$. 


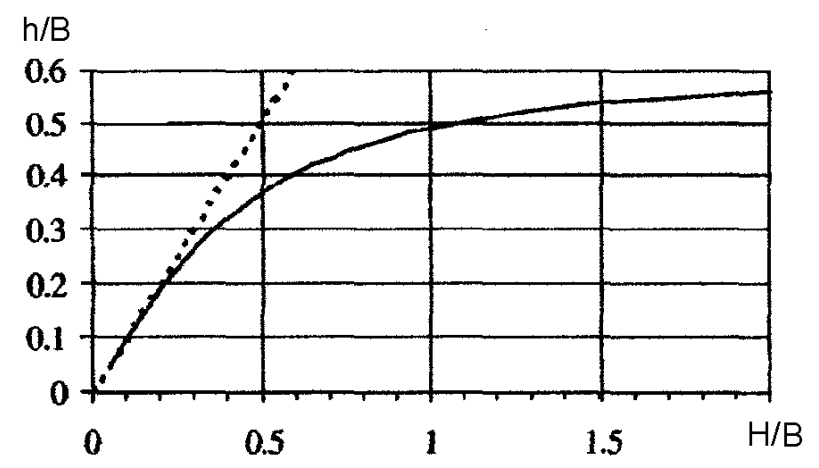

Figura 2.17. Razão h/B em função de H/B (Villard et al. 2000).

Bierbaumer (1913) (após Iglesia et al. 1999) propôs um método para a obtenção da carga sobre a estrutura considerando duas situações limites. A carga mínima $\left(\mathrm{F}_{\mathrm{a}}\right)$ sobre o alçapão é obtida a partir do equilíbrio de um elemento triangular de largura B, cujos lados perfazem um ângulo $\phi$ com a vertical (equação 2.9), e a residual $\left(\mathrm{F}_{\mathrm{ar}}\right)$ é derivada do diagrama de corpo livre de um elemento prismático de largura B, delimitado por planos verticais que interceptam a superfície do terreno, da mesma forma como esquematizado na Figura 2.15 (equação 2.10). O material é considerado no estado ativo de Rankine.

$\mathrm{F}_{\mathrm{a}}=\frac{\gamma \mathrm{B}^{2}}{4 \operatorname{tg} \phi}$

$\mathrm{F}_{\mathrm{a}, \mathrm{r}}=\gamma \mathrm{H}\left(\mathrm{B}-\mathrm{K}_{\mathrm{a}} \operatorname{Htg} \phi\right)$

Iglesia et al. (1999) combinaram as teorias de Janssen, Engesser e Bierbaumer em um único método para a previsão da curva de arqueamento (Figura 2.18). A curva é dividida em quatro estágios distintos. $\mathrm{O}$ primeiro segmento refere-se à fase de arqueamento inicial, na qual deslocamentos de pequena monta são suficientes para causar uma redução abrupta da carga. A inclinação inicial da curva é quantificada pelo módulo de arqueamento $\mathrm{M}_{\mathrm{A}}$, o qual, segundo os autores, possui o valor típico de 125 . Um segundo módulo, $\mathrm{M}_{\mathrm{B}}$, é definido para a parte final do trecho de arqueamento inicial, cujo valor típico, de acordo com os autores, é de 
aproximadamente 63 . O arqueamento máximo é estimado através da proposição de Engesser (1882), assumindo-se $\theta=90$ - $\phi$ ', de acordo com a orientação do plano considerada por Bierbaumer (1913). Nesta etapa em que a carga sobre a estrutura é mínima observa-se o desenvolvimento de uma "cúpula" de solo sobre a estrutura, formada por superfícies cisalhantes que se propagam em direção ao centro do alçapão (vide Figura 2.10). A carga é dada através da equação (2.11), onde $\mathrm{k}_{\mathrm{kr}}$ é o coeficiente de Krynine (1945). O estágio de recuperação de carga é governado pelo índice $\kappa$, dado através da equação empírica (2.12). Por fim, o arqueamento residual é estimado através da proposição de Janssen (1895), em que toda a massa de solo interna se encontra no estado crítico, culminando na formação de superfícies cisalhantes verticais interceptando a superfície do terreno.

$$
\begin{aligned}
& \frac{\mathrm{F}_{\mathrm{a}}}{\gamma \mathrm{HB}}=\frac{\mathrm{B}}{\mathrm{H}}\left(\frac{\mathrm{k}_{\mathrm{kr}}}{2 \cot \phi+\frac{\mathrm{B}}{\mathrm{H}} \mathrm{k}_{\mathrm{kr}}}+\frac{\cot g \phi}{6}\right) \\
& \kappa=2,5+5,7 \log \left(\frac{\mathrm{B}}{10 \mathrm{D}_{50}}\right) \mathrm{e}^{0,65(\mathrm{H} / \mathrm{B})}
\end{aligned}
$$

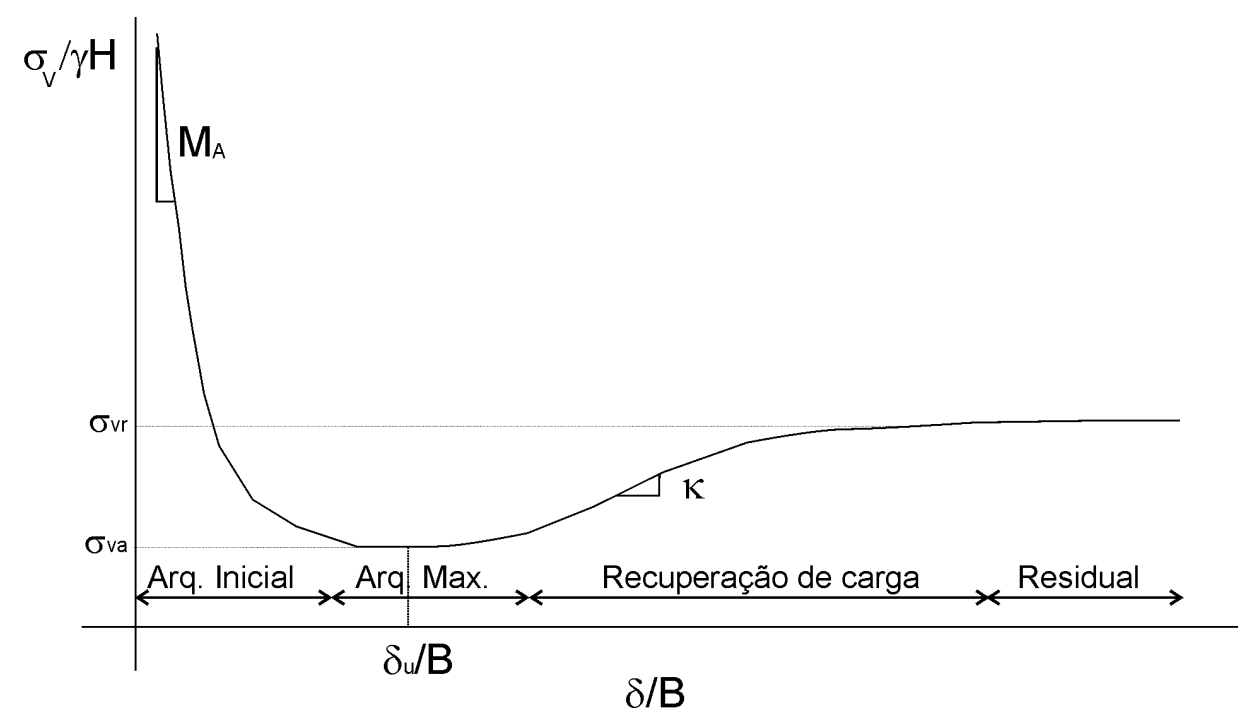

Figura 2.18. Fases do arqueamento ativo (Iglesia et al. 1999). 
Ono e Yamada (1993) derivaram um método para a determinação da distribuição de tensões sobre um alçapão no estado plano, assumindo que o solo se encontra em estado de equilíbrio plástico e que o critério de ruptura de MohrCoulomb é satisfeito. Considera-se que, a partir de uma determinada altura crítica, medida da base do alçapão, as tensões sofrem redistribuição após a plastificação, sendo expressas em qualquer direção por polinômios de segundo grau relacionados à esta altura crítica. A massa de solo sobre a estrutura plastificada assume um formato elíptico.

Com base nos teoremas de colapso plástico, Davis (1968) desenvolveu expressões para a previsão da carga atuante após o deslocamento do alçapão sob um maciço puramente coesivo. O mecanismo admitido para o limite superior é análogo ao adotado por Janssen (1895), com planos verticais partindo das extremidades da estrutura e atingindo a superfície do solo, o que fornece $\sigma_{\mathrm{v}}=\gamma \mathrm{H}-2 \mathrm{Hc} / \mathrm{B}$. Para o limite inferior, três soluções são propostas para mecanismos de ruptura nos quais é assumida a formação de uma cunha triangular sobre a estrutura.

Através de experimentos com placas e cilindros de vidro, em areia, Gill (1967) (após Bulson 1985) propõe uma equação empírica correlacionando o fator de arqueamento do solo $(\mathrm{A})$, definido como $1-\left(\sigma_{\mathrm{v}} / \sigma_{\mathrm{vi}}\right)$, com a rigidez relativa soloestrutura e a geometria da estrutura (expressão 2.13). O termo $\mathrm{A}_{\mathrm{g}} \mathrm{M}_{\mathrm{s}} \delta / \sigma_{\mathrm{vi}}$ relaciona a rigidez da estrutura, representada pela razão $\sigma_{\mathrm{vi}} / \delta$, com a deformabilidade do solo, fornecendo a rigidez relativa do sistema. $\mathrm{O}$ fator geométrico $\mathrm{A}_{\mathrm{g}}$ leva em consideração as características geométricas da estrutura em três dimensões, bem como a profundidade de instalação. Para inclusões cilíndricas e prismáticas, a equação forneceu resultados satisfatórios com $\mathrm{A}_{0}=0,87$ e $\mathrm{n}=0,135$.

$$
\mathrm{A}=\mathrm{A}_{0}\left(1-\exp \left(-\mathrm{n} \cdot \mathrm{A}_{\mathrm{g}} \frac{\mathrm{M}_{\mathrm{s}}}{\sigma_{\mathrm{v}}} \delta\right)\right)
$$

onde: $\mathrm{A}_{0}$ e $\mathrm{n}$ são constantes obtidas experimentalmente; $\mathrm{A}_{\mathrm{g}}=$ fator geométrico $=$ $\left(\mathrm{S} / \mathrm{A}_{\mathrm{s}}\right) \cdot(\mathrm{H} / \mathrm{B}) ; \mathrm{M}_{\mathrm{S}}=$ módulo de compressão confinada do solo; $\mathrm{S}=$ perímetro da estrutura plana. 
Allgood (1971) calcula a altura $\mathrm{H}_{\mathrm{e}}$ do plano de igual recalque (PIR), acima da estrutura, utilizando o valor de A fornecido por Gill (1967). Uma vez conhecida a parcela da carga que chega à estrutura, o PIR é determinado através do equilíbrio de forças do bloco de solo abaixo deste plano, delimitado lateralmente por superfícies verticais partindo das extremidades da inclusão. A resistência ao cisalhamento ao longo das superfícies é levada em conta através do critério de Mohr-Coulomb. A altura do PIR é igual a:

$$
\frac{\mathrm{H}_{\mathrm{e}}}{\mathrm{B}}=\left[\frac{\mathrm{A}}{2\left(\mathrm{c} / \sigma_{\mathrm{vi}}+\mathrm{k} \cdot \operatorname{tg} \phi\right)}\right]
$$

onde: c é a coesão do solo.

Uma solução analítica baseada na teoria da elasticidade para o cálculo da distribuição de tensões dentro e fora de um alçapão em arqueamento ativo foi desenvolvida por Finn (1963), como abordado no item 2.1.4. O problema é representado por uma descontinuidade horizontal rígida, contida em um meio elástico, semi-infinito, homogêneo e isotrópico, à qual são aplicados deslocamentos definidos. No nível do alçapão, a distribuição da tensão vertical com a distância horizontal (x) a partir do centro do alçapão é dada através da expressão (2.15). Os resultados fornecidos pelo método serão tão mais distantes da realidade quanto maior $\delta$.

$$
\sigma_{\mathrm{v}}=\gamma \mathrm{H}+\frac{\delta \mathrm{BE}_{\mathrm{s}}}{2 \pi\left(1-v_{\mathrm{s}}^{2}\right)}\left(\frac{1}{\mathrm{x}^{2}-(\mathrm{B} / 2)^{2}}\right)
$$

onde: $\mathrm{E}_{\mathrm{s}}=$ módulo de deformabilidade do solo; $v_{\mathrm{s}}=$ coeficiente de Poisson do solo.

Chelapati (1964) propôs uma solução semelhante, porém admitindo o maciço com profundidade finita, submetido a um carregamento aplicado na superfície. A tensão inicial transmitida ao alçapão é considerada igual ao peso do solo mais eventuais sobrecargas. Quando o alçapão é movimentado, a redução da tensão sobre o mesmo é equivalente à tensão de tração no solo induzida pelo deslocamento, a qual representa o arqueamento. A tensão de compressão sobre o alçapão é então 
computada como a tensão inicial menos a tensão de tração. Como o solo não pode sofrer tração, Chelapati descarta as tensões de tração que excedem as tensões de compressão. Por não ser fechada, a solução é viável se implementada em rotinas computacionais. Os resultados são apresentados graficamente em termos da sobrecarga aplicada na superfície do maciço (q), de $\delta, H, E_{s}, v_{s}$ e $\sigma_{v}$. Se estes parâmetros forem variados um por vez, é possível estabelecer como a influência de cada variável é tratada no método. Por exemplo, um aumento de $\mathrm{E}_{\mathrm{s}}$ significa maior transferência de carga para um mesmo deslocamento do alçapão; o aumento de H/B faz com que o arqueamento seja menor para um mesmo deslocamento do alçapão. A desvantagem desse método em respeito à solução de Finn (1964) reside no fato de que a tensão é computada somente ao longo do alçapão, não sendo possível conhecer a distribuição externa.

\subsubsection{Condição Passiva (Movimento Vertical Ascendente)}

Diversos modelos analíticos para a estimativa da capacidade de carga do sistema foram propostos para este caso, sobretudo com base na observação dos mecanismos de ruptura envolvendo ancoragens. A grande maioria das soluções foi desenvolvida a partir de análises de equilíbrio limite, sendo uma pequena parcela concebida através dos teoremas de colapso plástico. O peso da estrutura é geralmente desconsiderado no cálculo.

O modelo da superfície de cisalhamento vertical é considerado como a mais simples formulação proposta (Trautmann et al. 1985, Schaminee et al. 1990, Dickin 1994). Como o próprio nome indica, a superfície de ruptura é composta por planos verticais que se estendem desde a borda da estrutura até a superfície do terreno, definindo um prisma central (Figura 2.19a). A resistência passiva do meio é calculada através da expressão (2.16). O primeiro termo do lado direito desta equação é referente ao peso de solo acima do conduto (W) e o segundo, ao empuxo passivo $\left(\mathrm{E}_{\mathrm{p}}\right)$ atuante nas duas superfícies verticais, calculado segundo uma distribuição triangular das tensões horizontais. Em se tratando de um conduto, devese fazer $\mathrm{B}=\mathrm{D}$ e adicionar a parcela $(-\pi \mathrm{D} / 8 \mathrm{H})$ para levar em conta o peso de solo deslocado pela metade superior do tubo. Meyerhof e Adams (1968) introduziram em 
(2.16) a contribuição da força coesiva ao longo das superfícies verticais, igual a $2 \mathrm{cH}$. Para ancoragens profundas, assume-se que a superfície de ruptura não atinge a superfície do terreno, de modo que o solo sobrejacente é considerado como uma sobrecarga (Figura 2.19b). Neste caso, a resistência passiva é dada através da equação (2.17). A simplicidade das equações (2.16) e (2.17) entra em conflito com o valor de k a ser utilizado, não havendo um consenso geral a esse respeito. Alguns autores sugerem valores variando entre $\mathrm{K}_{\mathrm{o}}$ para solo fofo até superiores a 1 para solo compacto (Trautmann et al. 1985). Meyerhof e Adams (1968) recomendam o uso de $\mathrm{k}=0,95$. Das (1999) comparou previsão de Meyerhof e Adams (1968) com experimentos laboratoriais e verificou que o método forneceu estimativas satisfatórias para uma ampla faixa de estruturas de diversas formas geométricas.

$$
\begin{aligned}
& \frac{\mathrm{F}_{\mathrm{p}}}{\gamma \mathrm{HB}}=1+\frac{\mathrm{H}_{\mathrm{B}}}{\mathrm{B}} \mathrm{ktg} \phi \\
& \frac{\mathrm{F}_{\mathrm{p}}}{\gamma \mathrm{HB}}=1+\frac{2 \mathrm{cH}_{\mathrm{e}}}{\gamma \mathrm{HB}}+\left(\frac{2 \mathrm{H}-\mathrm{H}_{\mathrm{e}}}{\mathrm{B}}\right)\left(\frac{\mathrm{H}_{\mathrm{e}}}{\mathrm{H}}\right) \mathrm{ktg} \phi
\end{aligned}
$$

onde: $F_{p}=$ força passiva máxima sobre a estrutura por unidade de comprimento.

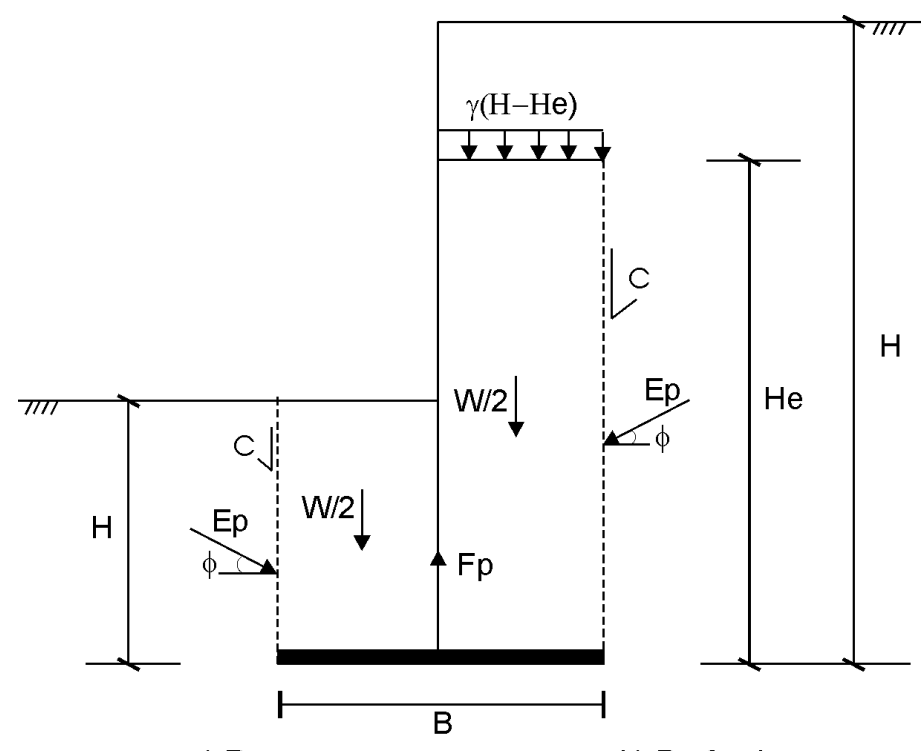

$\begin{array}{ll}\text { a) Rasa } & \text { b) Profunda }\end{array}$

Figura 2.19. Determinação da carga em estruturas na condição passiva. a) estrutura rasa e b) estrutura profunda (solução de Meyerhof e Adams 1968). 
Matyas e Davis (1983) descrevem um método semelhante ao sugerido por Meyerhof e Adams (1968) para ancoragens rasas, todavia admitindo a superfície cisalhante partindo da extremidade da ancoragem segundo uma inclinação com a vertical de $\left(45^{0}-\phi / 2\right)$. Vermeer e Sutjiadi (1985) propõem uma solução que considera o desenvolvimento de superfícies com inclinação com a vertical igual ao ângulo de dilatação do solo $(\psi)$, dada por:

$\frac{\mathrm{F}_{\mathrm{p}}}{\gamma \mathrm{BH}}=1+\frac{\mathrm{H}}{\mathrm{B}} \operatorname{tg} \phi \cdot \cos \phi_{\mathrm{cr}}$

onde: $\phi_{\mathrm{cr}}=$ ângulo de atrito do solo no estado crítico.

Uma abordagem considerando o desenvolvimento de superfícies de ruptura curvas para ancoragem de comprimento infinito é apresentada por Murray e Geddes (1987). A Figura 2.20a esboça o mecanismo de ruptura da solução proposta, com $\phi \geq$ $\alpha \geq \theta \geq 0$. A Figura 2.20 b detalha o equilíbrio de forças na cunha obc. $O$ valor de $F_{p}$ obtido para este caso é fornecido pela equação (2.19). Assumindo-se $\alpha=\theta=\phi$, as equações (2.17), (2.18) e (2.19) possuirão limites inferior e superior comuns, dados por $1 \leq\left[\mathrm{F}_{\mathrm{p}} / \gamma \mathrm{BH}\right] \leq[1+(\mathrm{H} / \mathrm{B}) \operatorname{tg} \phi]$.

$\frac{\mathrm{F}_{\mathrm{p}}}{\gamma \mathrm{BH}}=1+\frac{\mathrm{H}}{\mathrm{B}} \frac{\operatorname{tg} \theta \cdot \operatorname{tg} \delta}{\operatorname{tg} \delta-\operatorname{tg}(\phi-\alpha)}$

Como mencionado no item 2.3.1, Marston e seus colaboradores empregaram a formulação de Janssen para a determinação da carga que chega em um conduto em projeção positiva em uma situação tal que o recalque do topo seja menor do que o recalque dos prismas laterais, resultando em arqueamento passivo. Isso é levado em conta trocando-se o sinal do termo $\mathrm{C}$ da expressão (2.3). A carga na estrutura nesse caso pode ser determinada tanto quando o PIR é localizado no exterior (projeção completa), quanto no interior do maciço (projeção incompleta). 

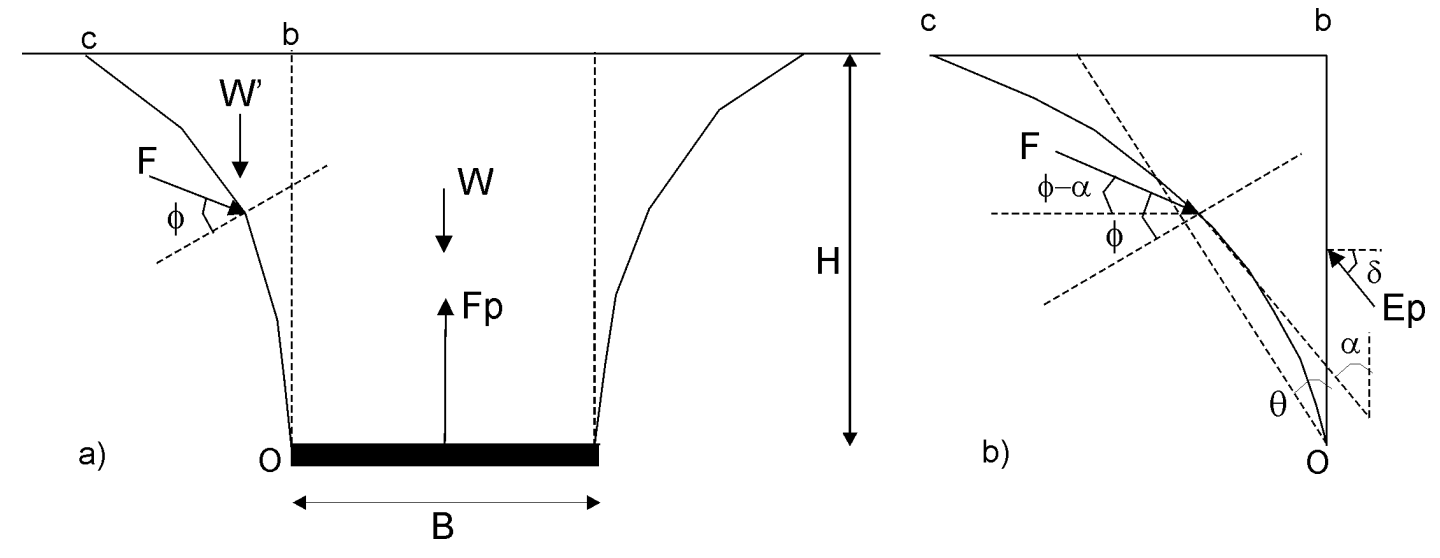

Figura 2.20. Modelo proposto por Murray e Geddes (1987).

A solução de Murray e Geddes (1989) pressupõe superfícies cisalhantes fazendo um ângulo de 0 a $\phi$ com a vertical, sendo o valor médio recomendado. Vermeer e Sutjiadi (1985) assumem um ângulo igual a $\psi$. Já Matias e Davis (1983) utilizam para as superfícies uma inclinação com a vertical igual a $\left(45^{0}-\phi / 2\right)$. De modo a investigar qual das suposições melhor representaria o mecanismo de ruptura real, a Tabela 2.1 traz uma compilação de valores experimentais de ângulos de inclinação $(\theta)$ com a vertical, medidos na base da primeira localização formada. Na mesma tabela é indicado o ângulo de dilatação do material ensaiado, estimado através da relação tensão-dilatação de Rowe (Wood 1990), expressão (2.20). Uma vez que a $\phi_{\mathrm{p}}$ não é citado em Ng e Springman (1994), a dilatação neste caso foi determinada através do método empírico de Bolton (1986), expressões (2.21), utilizando o valor de $D_{r}$ do solo e a tensão confinante média no nível da estrutura (p'). Como se observa, o único caso em que a inclinação coincide com as suposições teóricas é o relatado por Frydman e Shaham (1989). Nos demais, ora $\theta$ é superestimado ora é subestimado, sem tendência definida.

$$
\begin{aligned}
& \operatorname{sen} \psi=\frac{\operatorname{sen} \phi^{\prime}-\operatorname{sen} \phi_{\mathrm{cr}}}{1-\operatorname{sen} \phi^{\prime} \cdot \operatorname{sen} \phi_{\mathrm{cr}}} \\
& \phi^{\prime}-\phi_{\mathrm{cr}}=0,8 \psi=5 \mathrm{I}_{\mathrm{R}} \\
& \mathrm{I}_{\mathrm{R}}=\mathrm{D}_{\mathrm{r}}\left(10-\ln \mathrm{p}^{\prime}\right)
\end{aligned}
$$


Como abordado anteriormente, a translação de uma estrutura enterrada pode envolver a formação de mais de uma localização de deformação, apresentando inclinações variadas. Localizações verticais são observadas somente em estágio avançado da translação, no qual praticamente toda a resistência passiva já foi mobilizada. Por sua vez, localizações inclinadas estão associadas à mobilização de uma parcela menor de resistência. Conseqüentemente, em uma dada situação os métodos que consideram superfícies de deslizamento verticais deveriam, a rigor, fornecer previsões da resistência passiva superiores às das formulações que assumem superfícies inclinadas.

Tabela 2.1. Inclinação observada da superfície de ruptura com a vertical e comparações com hipóteses teóricas

\begin{tabular}{|c|c|c|c|c|c|c|c|c|}
\hline Referência & $\begin{array}{l}\text { Tipo de } \\
\text { estrutura }\end{array}$ & $\mathrm{D}_{\mathrm{r}}(\%)$ & $\phi_{\mathrm{p}}\left(^{0}\right)$ & $\phi_{\mathrm{cr}}\left({ }^{0}\right)$ & $\theta\left(^{0}\right)$ & $\psi\left(\left(^{0}\right)\right.$ & $\phi / 2\left(^{0}\right)$ & $\left(45^{0}-\phi / 2\right)\left({ }^{0}\right)$ \\
\hline $\begin{array}{l}\text { Dickin } \\
\text { (1994) }\end{array}$ & $\begin{array}{l}\text { Conduto } \\
\text { rígido }\end{array}$ & 84 & 42 & - & 10 & 23 & 21 & 24 \\
\hline $\begin{array}{c}\text { Frydman e } \\
\text { Shaham } \\
(1989)\end{array}$ & $\begin{array}{l}\text { Ancoragem } \\
(\mathrm{L} / \mathrm{B} \approx 5)\end{array}$ & 90 & 48 & 30 & 24 & 24 & 24 & 21 \\
\hline $\begin{array}{l}\text { Vardoulakis } \\
\text { et al. (1981) }\end{array}$ & $\begin{array}{c}\text { Alçapão } \\
\text { retangular } \\
(\mathrm{L}>>\mathrm{B})\end{array}$ & - & 45 & 34 & 18 & 14 & 22,5 & 22,5 \\
\hline $\begin{array}{c}\mathrm{Ng} \mathrm{e} \\
\text { Springman } \\
(1994)\end{array}$ & $\begin{array}{l}\text { Conduto } \\
\text { rígido }\end{array}$ & 43 & - & 32 & $\begin{array}{c}21 \mathrm{a} \\
27\end{array}$ & 13 & - & - \\
\hline
\end{tabular}

Rowe e Davis (1982a) desenvolveram uma abordagem baseada em análise numérica através do MEF para computar a resistência de ancoragens imersas em um meio elasto-plástico, cuja formulação é dada através da equação (2.22). $\mathrm{F}_{\gamma}$ é o fator de resistência ao arrancamento para uma ancoragem lisa em um solo que se deforma a volume constante $(\psi=0)$ e que possui $K_{o}=1 . R_{\psi}, R_{R}$ e $R_{k}$ são fatores de correção para a dilatação do solo, rugosidade da ancoragem e o estado de tensão inicial. Os fatores são obtidos através de ábacos. Dentre os parâmetros analisados, a dilatação apresentou influência significativa na capacidade da ancoragem, com $\mathrm{R}_{\psi}$ aumentando 
linearmente com H/B. A rugosidade e o estado de tensão inicial apresentaram uma influência muito reduzida, de modo que $R_{k}$ e $R_{R}$ podem ser considerados igual a 1 .

$\frac{\mathrm{F}_{\mathrm{p}}}{\gamma \mathrm{HB}}=\mathrm{F}_{\gamma} \cdot \mathrm{R}_{\psi} \cdot \mathrm{R}_{\mathrm{R}} \cdot \mathrm{R}_{\mathrm{k}}$

Frydman e Shaham (1989) compilaram dados da literatura contendo resultados de testes com ancoragens de diversas dimensões e descobriram que a resistência ao arrancamento de ancoragens retangulares guarda uma relação crescente e aparentemente linear com a razão $(B / L)$. Os dados sugerem que uma ancoragem retangular pode ser considerada contínua para $\mathrm{L}_{\mathrm{v}} / \mathrm{B}>6,7$. Foi verificado ainda que o efeito do formato da estrutura sobre $\mathrm{F}_{\mathrm{p}}$ aumenta com $\mathrm{H} / \mathrm{B}$. Fatores empíricos para ancoragens retangulares $\left(\mathrm{S}_{\mathrm{r}}\right)$ e quadradas $\left(\mathrm{S}_{\mathrm{q}}\right)$, a serem multiplicados pelo valor obtido de $\mathrm{F}_{\mathrm{p}}$, foram então propostos a partir dos dados analisados, chegando-se às expressões (2.23) e (2.24) para areia densa. Para areia fofa, recomenda-se assumir $\mathrm{S}_{\mathrm{q}}$ $=1$ quando $\mathrm{H} / \mathrm{B}<2$ e $\mathrm{S}_{\mathrm{q}}=1,5$ quando $\mathrm{H} / \mathrm{B} \geq 2$.

$\mathrm{S}_{\mathrm{q}}=1,51+2,35 \log (\mathrm{H} / \mathrm{B})$

$\mathrm{S}_{\mathrm{r}}=1+\frac{(\mathrm{B} / \mathrm{L}-0,15)}{(1-0,15)}\left(\mathrm{S}_{\mathrm{q}}-1\right)$

Meyerhof e Adams (1968) introduziram um fator de forma empírico $s$ na expressão (2.17), igual a $[1+\mathrm{m} \cdot(\mathrm{H} / \mathrm{B})]$, para levar em consideração o formato retangular da inclusão. O parâmetro m é proveniente de observações experimentais e depende de $\phi$. A equação correspondente a esse caso igual a:

$\frac{\mathrm{F}_{\mathrm{p}}}{\gamma \mathrm{HBL}}=1+\frac{2 \mathrm{cH}_{\mathrm{e}}(\mathrm{B}+\mathrm{L})}{\gamma \mathrm{HBL}}+\left(\frac{2 \mathrm{H}-\mathrm{H}_{\mathrm{e}}}{\mathrm{BL}}\right)\left(\frac{\mathrm{H}_{\mathrm{e}}}{\mathrm{H}}\right)(2 \mathrm{sB}+\mathrm{L}-\mathrm{B}) \mathrm{ktg} \phi$

Murray e Geddes (1987) desenvolveram uma solução simples para ancoragem retangular, considerando que a ruptura se dá por superfícies planas 
inclinadas partindo da extremidade da ancoragem segundo um ângulo com a vertical igual a $\phi$ (equação 2.26). Comparações com resultados experimentais revelaram uma previsão conservativa com o método proposto, todavia mais adequada do que a da solução de Meyerhof e Adams (1968).

$$
\frac{\mathrm{F}_{\mathrm{p}}}{\gamma \mathrm{BHL}}=1+\frac{\mathrm{H}}{\mathrm{B}} \operatorname{tg} \phi\left(1+\frac{\mathrm{B}}{\mathrm{L}}+\frac{\pi \mathrm{H}}{3 \mathrm{~L}} \operatorname{tg} \phi\right)
$$

\subsection{AVALIAÇÃO DA INTERAÇÃO LONGITUDINAL DE CONDUTOS SUBMETIDOS A MOVIMENTAÇÃO VERTICAL DO SOLO}

\subsubsection{Condutos Submetidos a Recalque Localizado}

Recalques localizados em tubulações enterradas são causados por redução do volume do solo subjacente, promovida tanto por mecanismos peculiares do comportamento do próprio solo, quanto por sobrecargas concentradas na superfície do terreno, como cargas veiculares e de aterros de dimensões finitas (Figura 1.1). Essas condições promovem uma completa redistribuição das tensões no maciço circundante e dos esforços na parede do conduto, cuja magnitude e padrões são de interesse avaliar.

Admitindo o conduto como um elemento linear sobre apoio elástico (hipótese de Winkler), Benmansour et al. (1997) realizaram análises com base no MEF, com o objetivo de avaliar a situação na qual o conduto perde totalmente o apoio. Para tanto, considerou-se um tubo com comprimento igual a 100D repousando sobre um meio elástico com $\mathrm{E}_{\mathrm{s}}$ igual a $50 \mathrm{MPa}$. Supondo apoio simples nas extremidades, o conduto atravessa um vazio de 3,3D de comprimento situado no centro do vão, como mostra a Figura 2.21a. Foi verificado que os esforços internos da tubulação aumentam significativamente após o surgimento do vazio. O esforço cortante na região sobre a parede do vazio, local onde é máximo, aumenta aproximadamente nove vezes. A Figura 2.21 b compara o diagrama de momentos fletores ao longo do eixo do conduto com e sem a presença do vazio. Nas duas condições o momento fletor é máximo no 
centro do vão, porém muda bruscamente de $+3 \mathrm{kN} \cdot \mathrm{m}$ (compressão) para quase -15 $\mathrm{kN} \cdot \mathrm{m}$ (tração) após a formação do vazio.
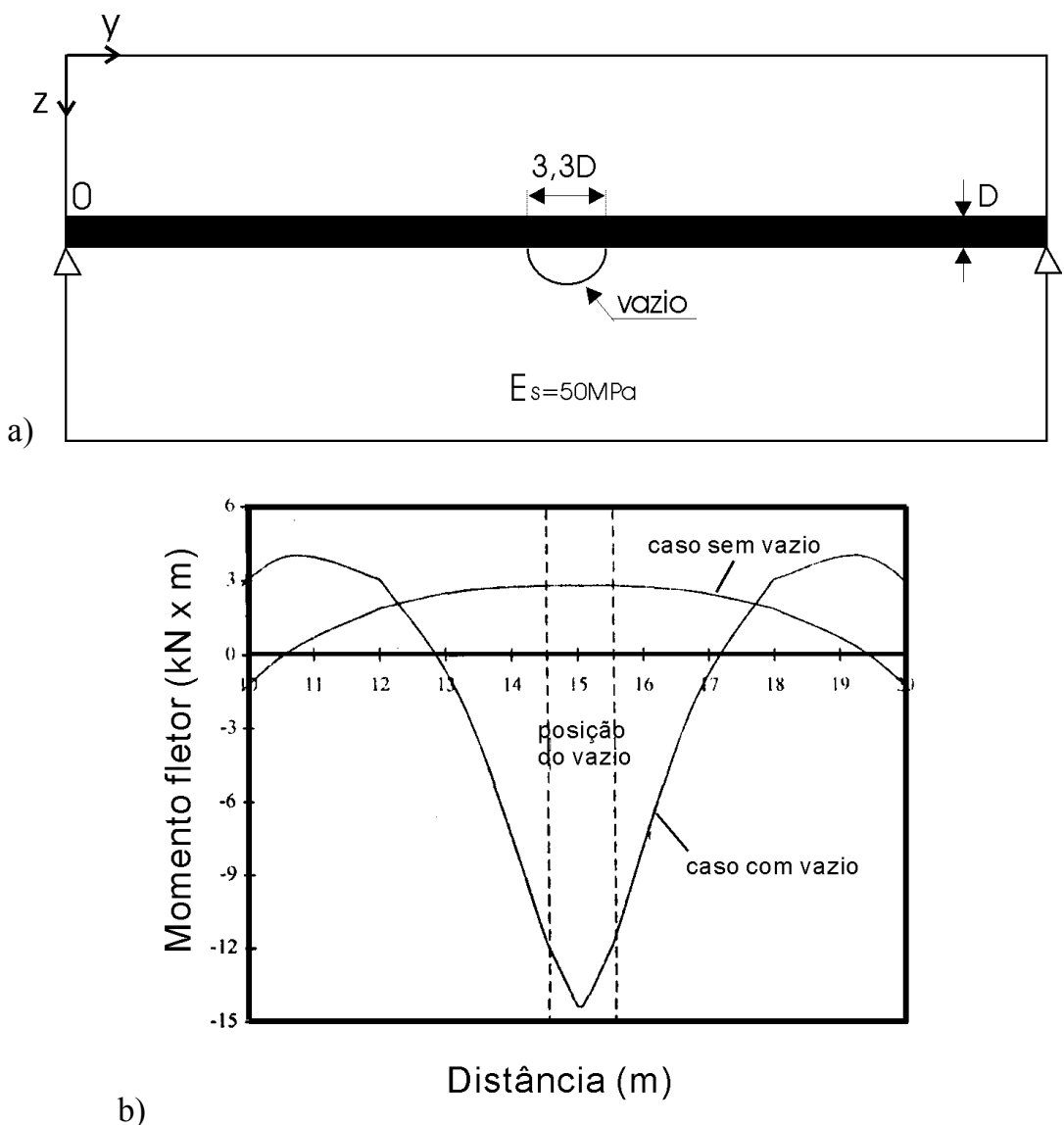

Figura 2.21. a) Representação esquemática de uma tubulação cruzando um vazio no solo; b) distribuição do momento fletor ao longo tubo (Benmansour et al. 1997).

Os autores também analisaram o efeito causado quando a tubulação atravessa materiais de propriedades muito distintas. Considerou-se um tubo cruzando um depósito de $33 \mathrm{D}$ de comprimento situado entre dois depósitos com $\mathrm{E}_{\mathrm{s}}$ igual a 50 $\mathrm{MPa}$. As análises foram conduzidas variando-se o módulo de deformabilidade do depósito central $\left(\mathrm{E}_{\mathrm{s} 2}\right)$ de 10 a $100 \%$ do valor do módulo dos depósitos adjacentes $\left(E_{\mathrm{s} 1}\right)$. As análises também foram realizadas considerando a presença de juntas, modeladas como elementos de viga de $0,15 \mathrm{~m}$ de comprimento e espaçadas de $3 \mathrm{~m}$. O módulo de elasticidade adotado para as juntas foi inferior ao do conduto, não tendo porém sido mencionado. $\mathrm{O}$ momento fletor máximo $\left(\mathrm{M}_{\max }\right)$ ocorreu na seção central do tubo (i.e., na metade do depósito central), enquanto que o máximo esforço 
cortante $\left(\mathrm{Q}_{\max }\right)$ ocorreu na interface entre os materiais. A Figura 2.22 exibe a variação de $Q_{\max }$ e $M_{\max }$ em função da razão $E_{\mathrm{s} 2} / E_{\mathrm{s} 1}$. Os esforços encontram-se normalizados pelos esforços obtidos com o maciço homogêneo $\left(\mathrm{Q}_{\mathrm{hmax}}\right)$ e $\left(\mathrm{M}_{\mathrm{hmax}}\right)$. Os esforços no tubo decrescem à medida que a diferença entre os módulos diminui, atingindo a estabilização a partir de $\mathrm{E}_{\mathrm{s} 2} / \mathrm{E}_{\mathrm{s} 1}$ entre 0,6 e 0,8 . A presença das juntas contribuiu apenas com uma pequena redução nos esforços internos.

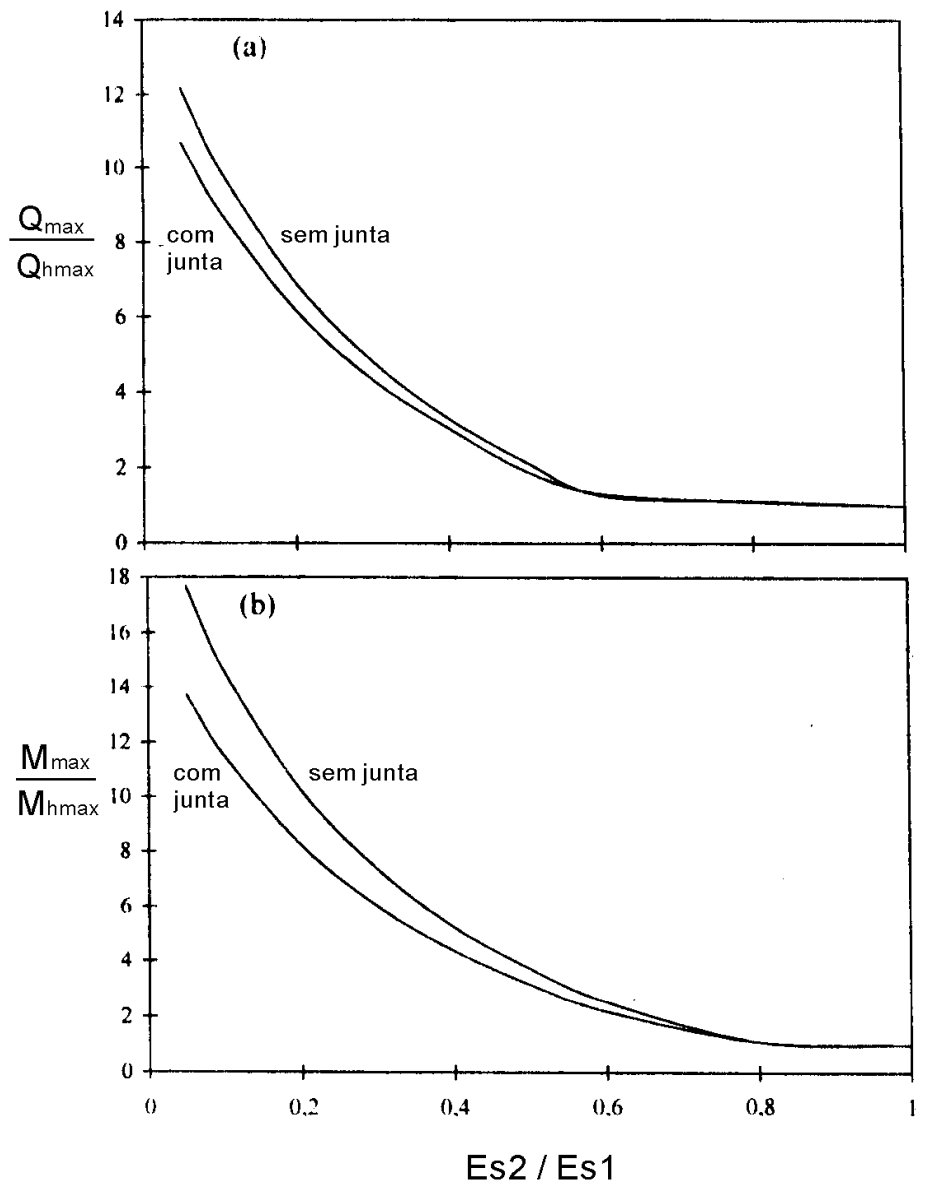

Figura 2.22. Variação dos esforços internos em depósitos de diferentes prorpiedades, em função da razão $E_{\mathrm{s} 2} / E_{\mathrm{s} 1}$. a) Esforço cortante; b) momento fletor (Benmansour et al. 1997).

Selvadurai e Pang (1988) analisaram numericamente a interação de um conduto instalado em um maciço que sofre movimentação por conta da acomodação da camada subjacente. As análises foram realizadas através do método dos elementos finitos, sendo o solo representado pelos modelos elástico-linear e de Drucker-Prager. 
Foram considerados condutos de diferentes rigidezes, representando ferro fundido, concreto e PVC. A Figura 2.23 exibe a variação do momento fletor longitudinal ao longo da tubulação de ferro fundido e PVC, medida a partir da falha no solo. Em ambos os casos, o momento fletor máximo ocorre a uma distância da falha inferior ao diâmetro do tubo. Contudo, a depender do modelo considerado, a resposta obtida muda sensivelmente na região da falha. Quando a coesão do solo é levada em conta através do critério de Drucker-Prager, a rigidez do conduto passa a apresentar uma influência significativa sobre o momento fletor máximo. No conduto de $\mathrm{PVC}, \mathrm{M}_{\max }$ é aproximadamente $60 \%$ inferior ao valor medido no conduto de ferro fundido.
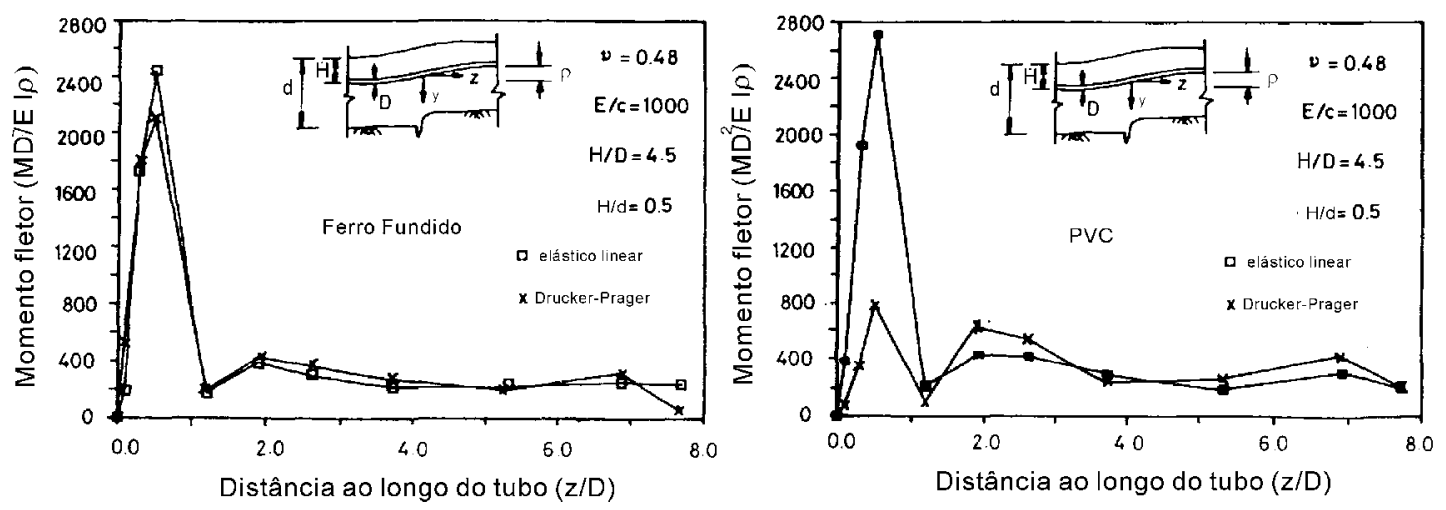

Figura 2.23. Distribuição de momentos fletores ao longo de condutos de ferro fundido e PVC submetidos a recalque diferencial (Selvadurai e Pang 1988).

Uma investigação experimental sobre situação semelhante foi realizada por Hachiya et al. (2002). Os tubos utilizados eram compostos por vigas prismáticas com segmentos de meia seção cilíndrica, dotadas de células para medir a tensão no topo e na base (Figura 2.24a). Foram utilizadas vigas com rigidezes equivalentes às de tubo de PVC e de fibra de vidro, representando elementos flexíveis e rígidos, respectivamente. Uma areia pura com $D_{\mathrm{r}}$ variando de 47 a $90 \%$ foi usada como solo de aterro. O recalque diferencial era simulado por uma base móvel sob o tubo, de largura B igual a 15D e comprimento igual a 5D, compondo uma configuração semelhante à ilustrada na Figura 2.24. Os deslocamentos verticais do tubo eram obtidos por meio de LVDTs instalados na superfície do maciço, ligados à viga central por meio de hastes. As Figuras 2.24a e b mostram um exemplo típico da 
variação da tensão ao longo do topo e da base do tubo para $\delta / D=0$ e 0,9 . O recalque correspondente do tubo (u) é apresentado na Figura 2.24c.
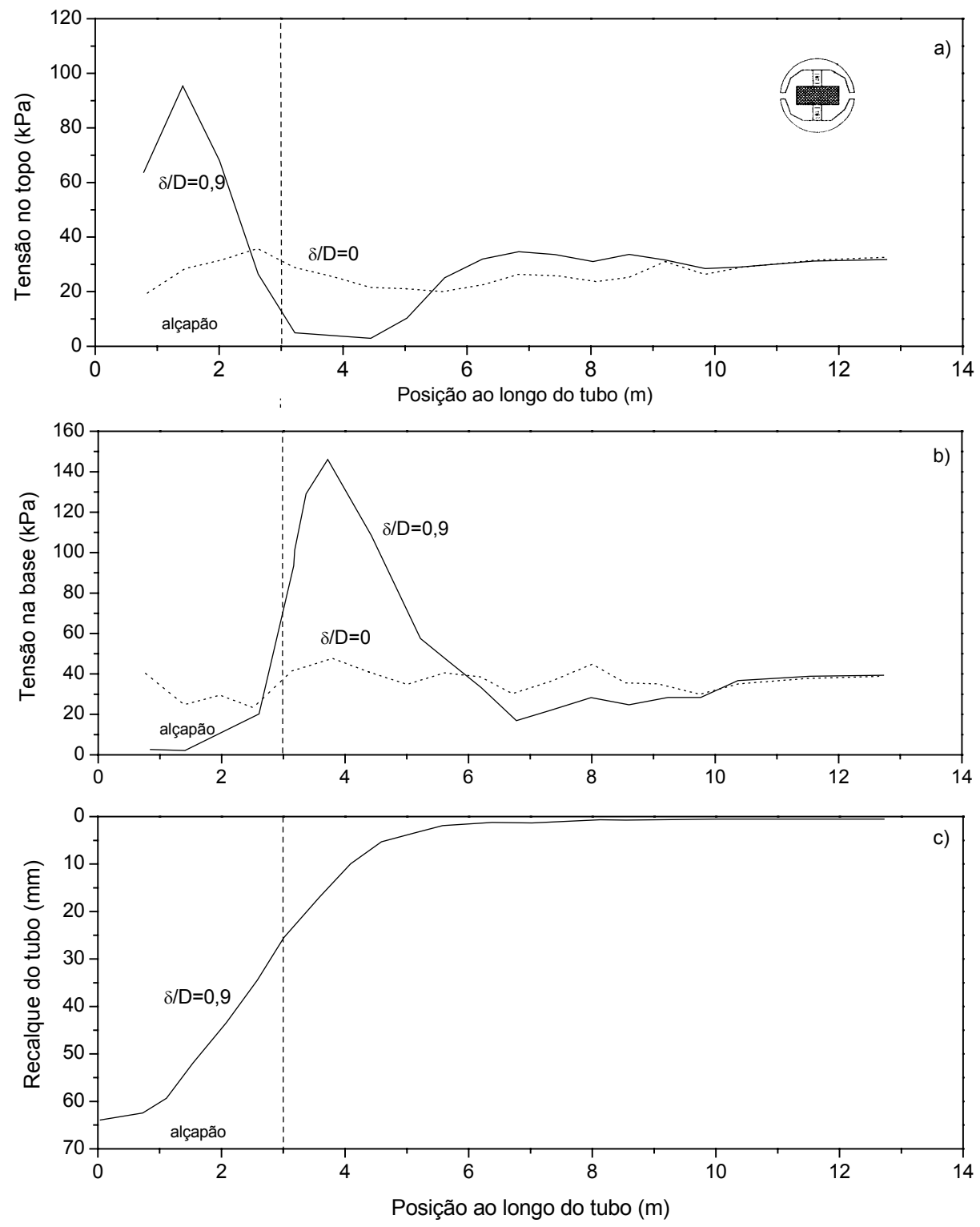

Figura 2.24. Variação da tensão e do recalque de um tubo submetido a recalque diferencial com $\mathrm{D}_{\mathrm{r}}=68 \%$ (Hachiya et al. 2002).

Na região sobre o alçapão a tensão na base do duto torna-se praticamente nula por causa da movimentação descendente do solo, porém a tensão no topo aumenta consideravelmente. Fora do alçapão, a região do conduto entre L/D = 5 e 7,5 (3 e 4,5 $\mathrm{m}$ do marco inicial, respectivamente) experimenta um forte aumento da tensão na 
base e alívio quase total no topo. Em geral, a região onde a tensão medida varia por conta da movimentação do alçapão foi mais abrangente com o tubo flexível imerso no material fofo. Recalques mais acentuados e maiores deformações no maciço foram observados nessa condição. Atenta-se para as diferenças entre a distribuição de tensões nessas duas posições, o que indica que a representação de um tubo por um elemento linear, consideração normalmente assumida em modelos analíticos, pode induzir a erros significativos.

Os resultados desta investigação experimental elucidaram alguns aspectos sobre o comportamento de tubos submetidos a recalque diferencial, porém apresentam diversas limitações. Os testes não contaram com tubos reais, mas com vigas simulando tubos. Por conta disso as deflexões em vários pontos do conduto após a movimentação do alçapão não puderam ser medidas, mas apenas o recalque vertical das vigas. A medida das deflexões do conduto seria essencial para uma caracterização adequada da resposta deste tipo de estrutura nessa situação particular (principalmente em se tratando de tubos flexíveis). Por fim, as tensões foram medidas somente no topo e na base do tubo, permanecendo desconhecidas em regiões de grande interesse, como a linha d'água.

O'Rourke e Ahmed (1985) avaliaram experimentalmente a influência de $\mathrm{E}_{\mathrm{s}}$ sobre os esforços desenvolvidos em um conduto rígido de ferro fundido submetido a uma sobrecarga concentrada na superfície do terreno. Acima do conduto foi aplicada uma carga de forma a simular o eixo traseiro de um caminhão, com $52 \mathrm{kN}$ por roda. O tubo, de $100 \mathrm{~mm}$ de diâmetro, foi disposto com uma razão de altura de cobertura $\mathrm{H} / \mathrm{D}$ igual a 10, distando 9D da borda de uma trincheira adjacente. Para as análises, foram selecionados valores de $\mathrm{E}_{\mathrm{s}}$ iguais a 6,9, 35,5 e $69 \mathrm{MPa}$, representando solo fofo, intermediário e compacto, respectivamente. O coeficiente de Poisson do solo $v_{\mathrm{s}}$ foi mantido constante e igual a 0,495. As Figuras 2.25a e b exibem a variação da deformação longitudinal ao longo da base e da linha d'água no lado do tubo mais próximo da trincheira, respectivamente. A Figura $2.25 \mathrm{c}$ mostra a variação da deformação transversal ao longo da base do conduto. As deformações seguiram um padrão de distribuição semelhante em todos os casos averiguados, sendo a área na qual o carregamento incide, o local onde ocorre a máxima deformação. Como era de se esperar, quanto maior $E_{\mathrm{s}}$ menor é a deformação registrada ao longo do eixo do 
tubo. Comparando-se as Figuras 2.25a e c, nota-se que a influência de $\mathrm{E}_{\mathrm{s}}$ sobre as deformações longitudinais é maior do que sobre as deformações transversais.
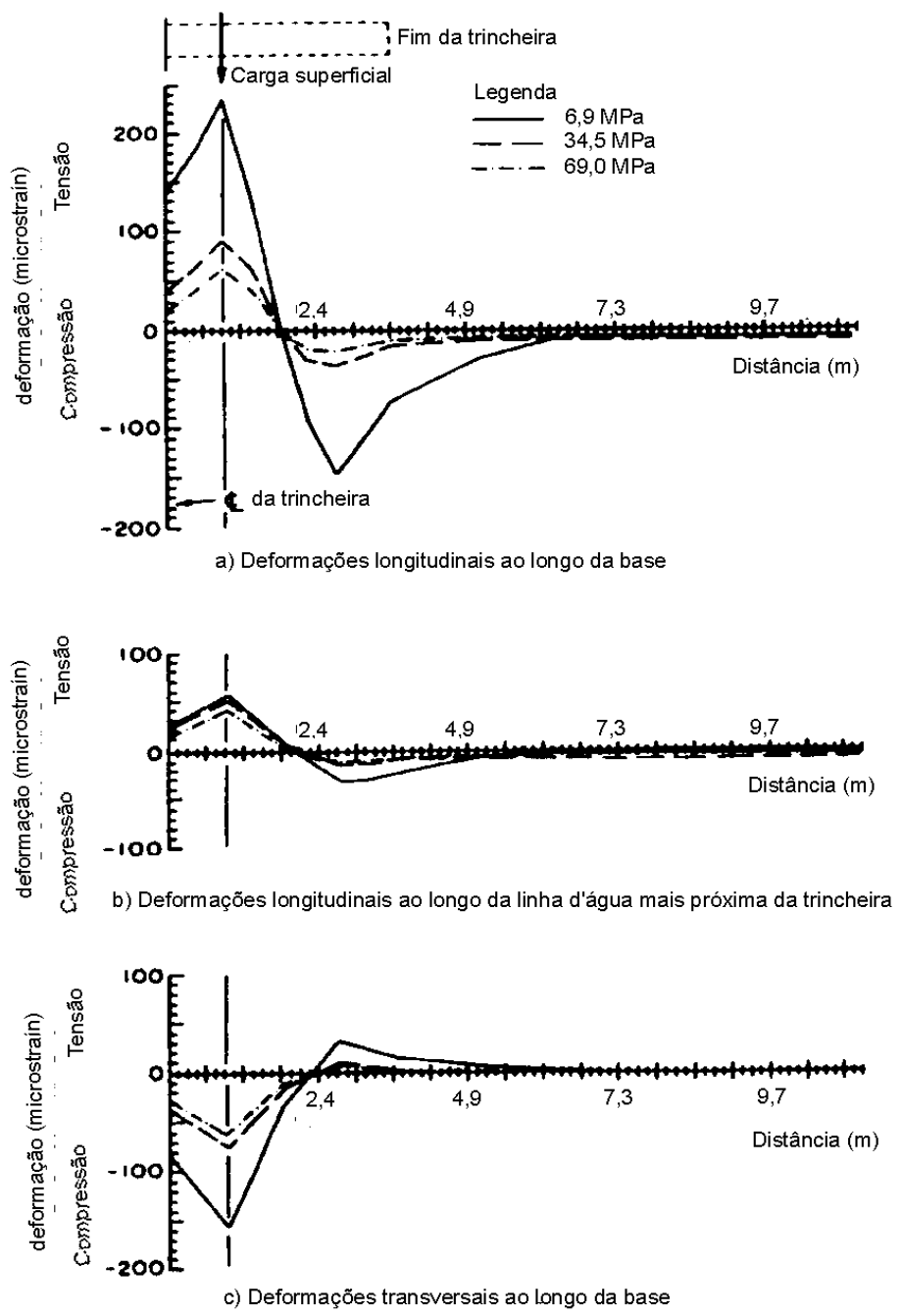

Figura 2.25. Deformações longitudinais e transversais em um conduto submetido a carregamento superficial concentrado (O'Rourke e Ahmed 1985).

Small e Ngu (1991) analisaram a influência da altura de cobertura de solo e da rigidez relativa do sistema sobre o comportamento de um conduto sob um aterro de dimensões finitas. A seção transversal do tubo foi modelada como uma seção sólida de $150 \mathrm{~mm}$ de diâmetro, com área e rigidez à flexão equivalentes à do conduto real. Apesar de modelar corretamente os esforços longitudinais, esta suposição não permite a obtenção correta dos esforços transversais. A geometria do aterro em 
questão é ilustrada na Figura 2.26d. As análises foram realizadas assumindo rigidez relativa (RR) igual a 0,1, 10 e 1000, representando instalação flexível, intermediária e rígida, respectivamente, com $\mathrm{RR}=\mathrm{EI} / \mathrm{E}_{\mathrm{s}} \mathrm{D}^{4}$. Foram adotadas razões $\mathrm{H} / \mathrm{D}$ iguais a 2, 3 e 6, representando instalação rasa, intermediária e profunda, respectivamente. As Figuras 2.26a a c exibem a distribuição dos momentos fletores, determinada a partir das deformações específicas medidas na base do tubo (M positivo significando $\varepsilon$ de tração). O momento máximo positivo ocorreu no centro do aterro $(\mathrm{y} / \mathrm{L}=0)$, ao passo que o momento máximo negativo ocorre para y/L entre 1 e 2 , além da base do talude. $\mathrm{O}$ aumento da rigidez relativa causa um aumento considerável nos momentos despertados na tubulação. Os momentos no centro do aterro aumentam aproximadamente 100 vezes quando RR passa de $10^{-1}$ para 10 . Para um aumento da rigidez de 10 a 100, M aumentou 25 vezes nesta mesma posição. Para um valor fixo de RR, à medida que a profundidade de instalação aumenta, os momentos máximos desenvolvidos no conduto diminuem. Os resultados mostram nitidamente a importância da altura de cobertura de solo na atenuação das tensões que chegam à estrutura.

Fernando e Carter (1998) realizaram análises numéricas com o MEF para averiguar a influência da área do carregamento no comportamento da tubulação. Considerou-se um conduto inserido em um meio elástico-linear e isotrópico com um carregamento central aplicado sobre uma área quadrada no centro do vão. Foram selecionadas três dimensões para a área de aplicação dos carregamentos: $2 \mathrm{a} / \mathrm{D}=0,1$, 0,5 e 1, sendo $a$ a metade do lado do quadrado. A Figura 2.27 mostra a variação típica do momento fletor transversal $\left(\mathrm{M}_{\mathrm{x}}\right)$ ao longo do comprimento da tubulação, medido a partir da seção central do tubo e adimensionalizado pelo máximo momento registrado. Pode-se observar que a dimensão do carregamento influencia consideravelmente a distribuição dos momentos ao longo do conduto. Quando o carregamento é aplicado em uma área menor $(2 \mathrm{a} / \mathrm{D}=0,1)$, os esforços decrescem de maneira mais abrupta com o aumento de y/D e estabilizam-se em seguida. Neste caso, os momentos tornam-se praticamente desprezíveis a uma distância entre um e dois diâmetros do centro do vão do conduto. Concomitantemente, para o carregamento de maior dimensão $(2 \mathrm{a} / \mathrm{D}=1)$, a redução de $\mathrm{M}$ com a distância ocorre de forma mais gradual. Observa-se ainda que o efeito do carregamento é mais 
aparente com o tubo mais rígido $\left(\mathrm{E}_{\mathrm{p}} / \mathrm{E}_{\mathrm{s}}=10^{6}\right)$. A distribuição dos momentos longitudinais segue um padrão bastante semelhante à dos momentos transversais, porém sua magnitude foi ligeiramente inferior à destes últimos.
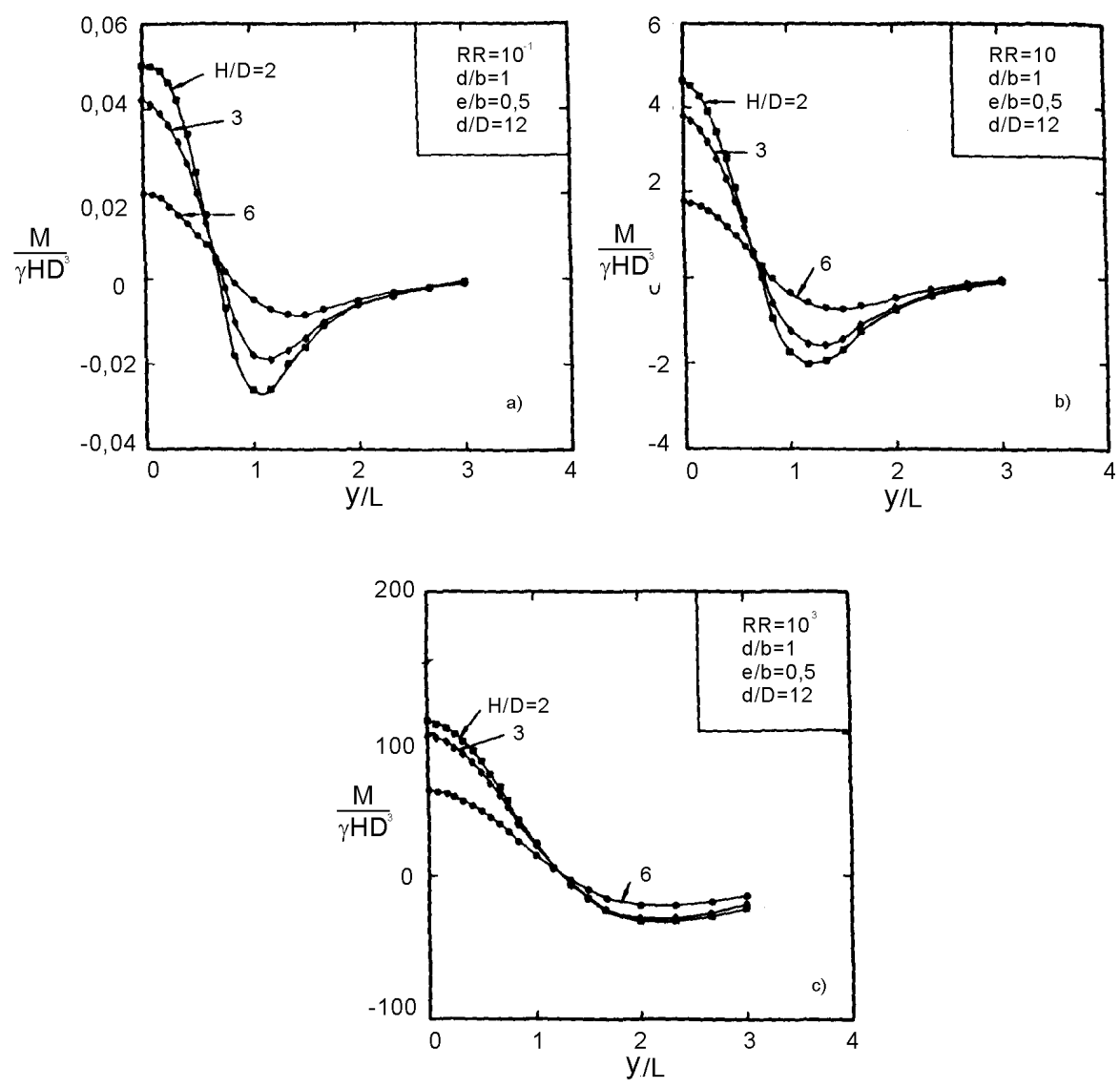

d)

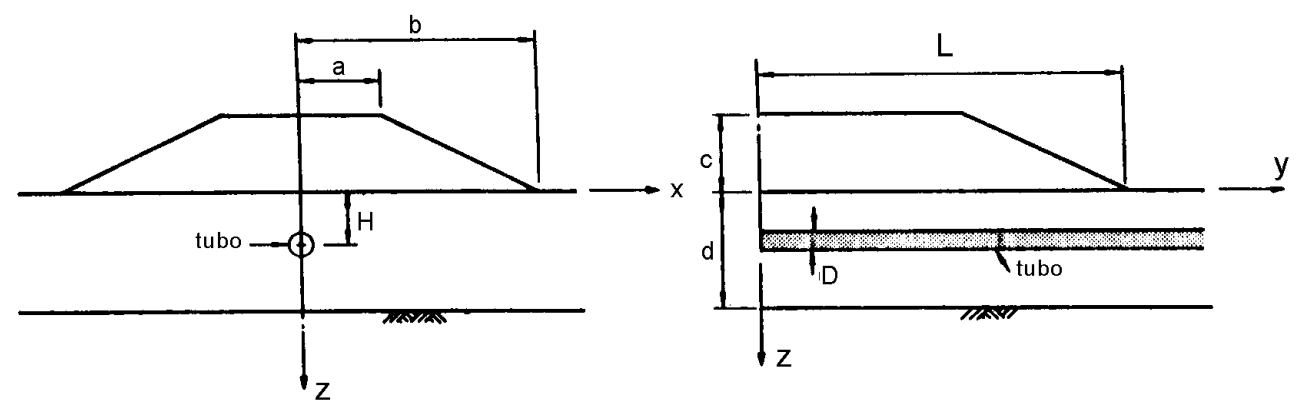

Figura 2.26. Aterro de dimensões finitas no comportamento de condutos enterrados (Small e Ngu 1991).

Ao contrário do que ocorre com os momentos fletores (tanto longitudinais quanto transversais), as tensões axiais na seção central diminuíram com o aumento 
da rigidez do tubo, independentemente da área carregada e da altura de cobertura de solo. Uma possível explicação para isso consiste no fato de que a diminuição da tensão em virtude do aumento da área transversal prevalece sobre o aumento da força axial devido ao aumento da rigidez do conduto. Verificou-se ainda que para razões $\mathrm{t} / \mathrm{D}$ maiores que 0,01 ou menores que 0,0005 , sendo $t$ a espessura do tubo, a influência de $\mathrm{E}_{\mathrm{s}}$ nos resultados tornou-se muito reduzida.

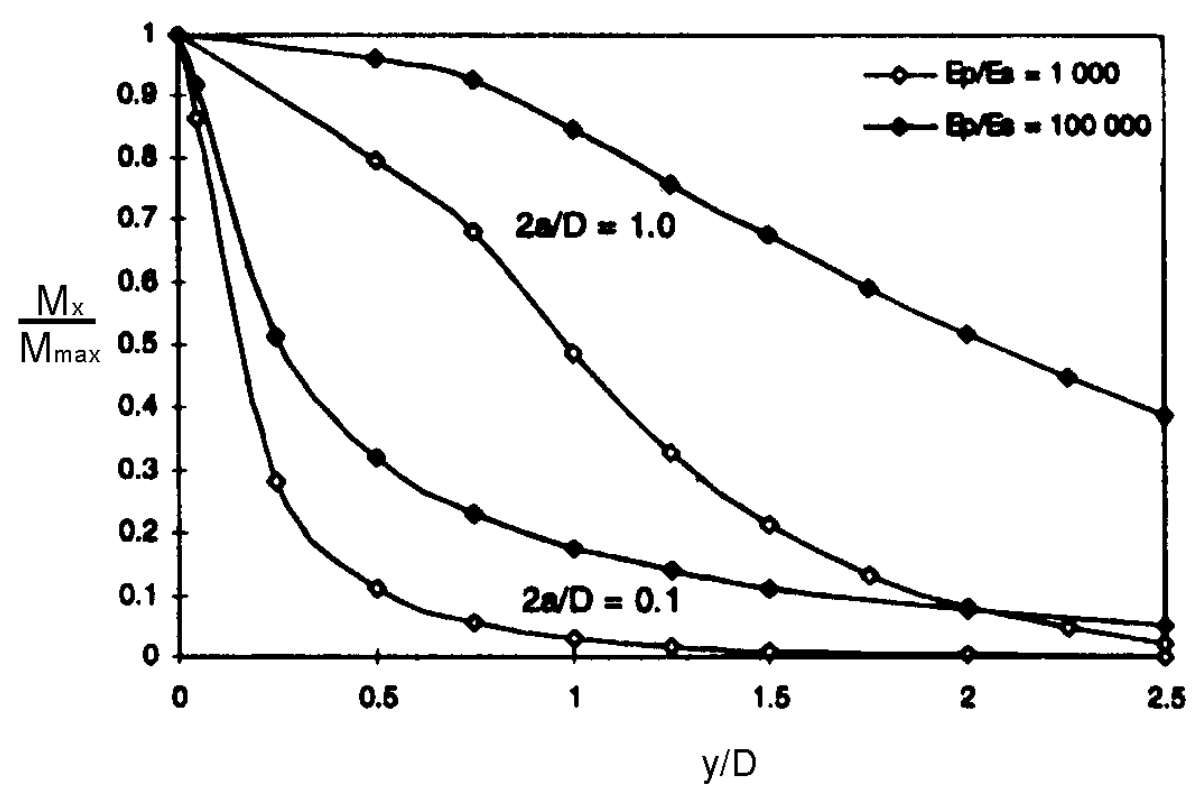

Figura 2.27. Variação de momentos transversais ao longo da tubulação (Fernando e Carter 1998).

\subsubsection{Condutos Submetidos a Elevação Localizada}

As causas mais comuns da elevação de condutos são os solos expansivos e o congelamento. A variação de volume nesses solos pode aumentar drasticamente a tensão vertical na tubulação e eventualmente causar danos de grande magnitude à estrutura. Não é aconselhável que uma tubulação seja disposta diretamente sobre solos dessa natureza. Entretanto, mesmo após a remoção e substituição da camada problemática até certa profundidade, a expansão geralmente continua a afetar o conduto (Moser 2001). 
Os solos expansivos são encontrados em diversas partes do mundo, sendo mais abundantes em regiões semi-áridas. Sua grande variação de volume mediante ciclos de umedecimento e secagem tem sido responsável por danos de amplas proporções, principalmente a pavimentos e construções sobre fundação superficial. A porcentagem de argila, o índice de plasticidade, o limite de contração, a sucção do solo, o teor de umidade inicial, o grau de compactação e o estado de tensão a que o solo é submetido são alguns dos principais fatores que afetam o potencial de expansão (Nelson e Miller 1992).

Dados sobre o comportamento tubulações sofrendo elevação por causa de solos expansivos não são comuns na literatura. Medidas in situ de esforços e deflexões ao longo de dois condutos de $100 \mathrm{~mm}$ de diâmetro instalados em uma argila expansiva foram obtidas por Kassiff e Zeitlen (1962). Fabricados em cimento amianto e dispostos com $\mathrm{H} / \mathrm{D}=9$, os tubos eram compostos por dois trechos centrais de $4 \mathrm{~m}$ de comprimento soldados entre si. Um dos condutos teve a vala inundada antes de ser aterrado, de forma a permitir que o solo atingisse o máximo teor de umidade inicial (conduto 1). O outro conduto teve a vala exposta ao ar por um determinado período previamente ao ensaio, com o desígnio de reduzir ao máximo o teor de umidade (conduto 2). Como conseqüência da expansão da argila, registrou-se uma elevação máxima $(\mathrm{u} / \mathrm{D})$ no topo da ordem de $22 \%$ para o primeiro conduto e de $33 \%$ para o segundo. Concomitantemente, foram obtidos deslocamentos horizontais máximos $\left(\mathrm{u}_{\mathrm{x}}\right)$ de $2 \%$ para o primeiro conduto e $4 \%$ para o segundo. Todos os deslocamentos máximos foram registrados nas proximidades da seção central da tubulação.

A Figura 2.28 exibe a distribuição dos esforços longitudinais no conduto $1 \mathrm{em}$ diferentes períodos, desde antes de receber o aterro até momentos após a inundação do solo. Nota-se que após a inundação os esforços tornam-se muito acentuados, denotando uma grande influência da expansão do solo. A distribuição dos momentos é caracterizada por momentos máximos positivos (tensões de tração) nas extremidades da tubulação e momentos máximos negativos (tensões de compressão) registrados no centro de cada trecho. Esforços axiais de tração desenvolveram-se ao longo de toda a extensão dos trechos instrumentados, atingindo maior magnitude nas proximidades da seção central. 
Em virtude do maior potencial de expansão conferido ao solo, o conduto 2 apresentou esforços comparativamente maiores. Nas proximidades da seção central foram registradas tensões aproximadamente 30\% maiores do que no conduto 1 . As tensões longitudinais medidas foram três a quatro vezes superiores às transversais.

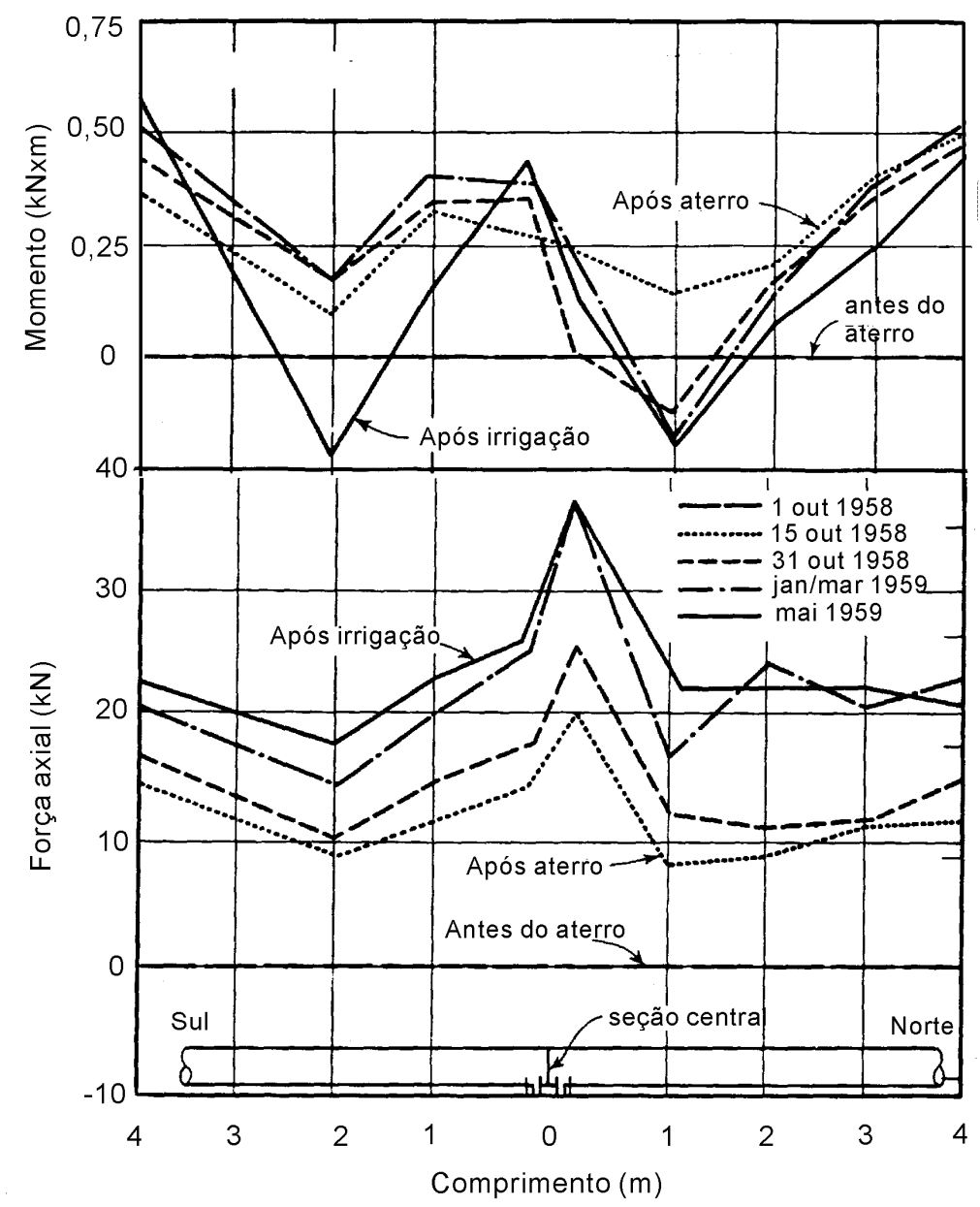

Figura 2.28. Esforços ao longo de tubulação assente em solo expansivo (Kassiff e Zeitlen 1962).

Análises paramétricas para a averiguação da influência da rigidez relativa (RR) em um conduto sofrendo elevação foram executadas por Poulos (1974). Investigou-se o caso de um tubo articulado nas extremidades repousando em um meio elástico-linear e isotrópico com $\mathrm{H} / \mathrm{D}=3$. O comprimento (L) do tubo era igual a 25 D. Assumiu-se uma distribuição triangular para a expansão do solo ( $\delta$ ) ao longo do eixo do tubo, e máxima na seção central. 
A Figura 2.29a exibe o perfil do deslocamento vertical do conduto $(\mathrm{u} / \mathrm{D})$ para $\delta / D=10 \%$. A rigidez relativa $(R R)$ é calculada através da expressão (2.27) (quanto maior o valor de RR, mais rígido será o tubo). Os resultados apresentam um perfil de deslocamento do tubo (u) com crescimento não-linear até a seção central, onde o valor máximo é atingido. Observa-se que $u$ aumenta significativamente com a diminuição da rigidez do tubo. As Figuras $2.29 \mathrm{~b}$ e c mostram a variação do deslocamento $(\mathrm{u})$ e do momento fletor $(\mathrm{M})$ no centro do tubo, respectivamente. $\mathrm{M}$ encontra-se normalizado por $\sigma_{\mathrm{r}} \mathrm{L}^{3}$, onde $\sigma_{\mathrm{r}}$ é a tensão de ruptura do sistema soloconduto. Observa-se que quanto maior a rigidez do conduto, menor é o deslocamento do solo necessário para mobilizar o deslocamento máximo (Figura 2.29b). Para um determinado valor de $\delta / \mathrm{D}, \mathrm{M}$ aumenta consideravelmente à medida que RR aumenta. Considerando $\delta / \mathrm{D}=0,5$, para $\mathrm{RR}=10^{-4}$ o conduto desenvolve esforços aproximadamente cinco vezes inferiores ao registrado para $R R=1$. Observa-se ainda que quanto maior a rigidez do tubo, menor é o deslocamento do solo necessário para a mobilização do momento fletor máximo. Poulos (1974) reporta previsões adequadas dos resultados experimentais de Kassiff e Zeitlen (1962).

$\mathrm{RR}=\frac{\mathrm{EI}}{\mathrm{E}_{\mathrm{s}} \mathrm{L}^{4}}$

onde: $\mathrm{E}=$ módulo de elasticidade do tubo; $\mathrm{I}=$ momento de inércia da seção transversal do tubo.

O congelamento da água é acompanhado por uma expansão volumétrica de cerca de $10 \%$, o que, no solo, pode representar um aumento de volume global entre 2,5 e $5 \%$. A formação de lentes de cristais de gelo é seguramente a maior causa do aumento de volume do solo durante o congelamento. Como o congelamento da água ocorre inicialmente nos poros de maior diâmetro, o decréscimo da temperatura promove o aumento da sucção do solo, a qual, por sua vez, causa a migração de água para estes poros, resultando no aumento do volume das lentes de gelo. Os solos cujas partículas são suficientemente pequenas para permitir a ação da sucção, mas ao mesmo tempo são suficientemente grandes para não restringirem o fluxo de água, são os mais susceptíveis ao congelamento. Os solos que reúnem as melhores condições 
para a manifestação do fenômeno são os que contêm uma alta fração de silte (Craig 1996, Palmer e Williams 2003).
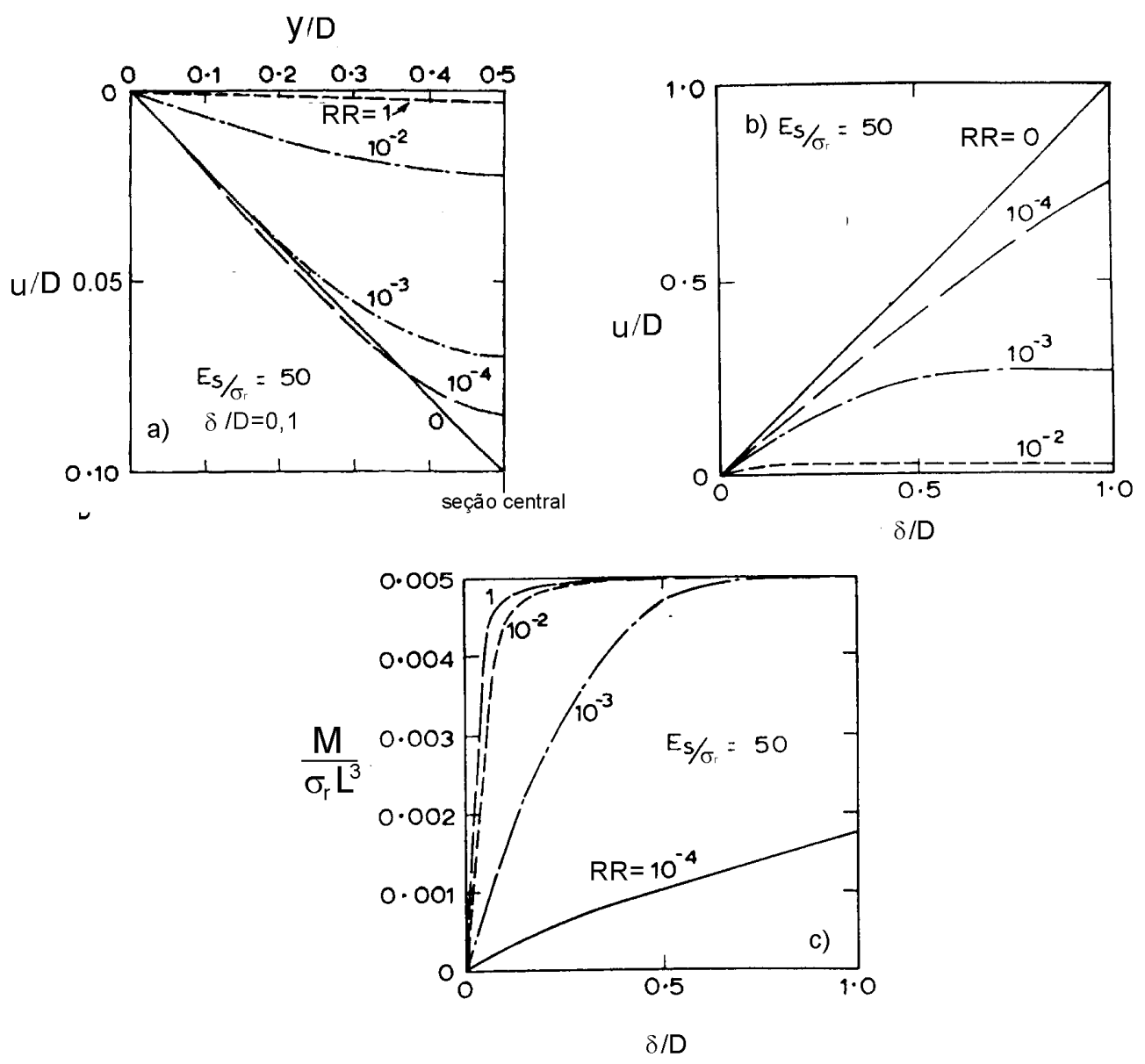

Figura 2.29. Deslocamentos e momentos fletores em um conduto instalado em solo expansivo, considerando $\mathrm{L} / \mathrm{D}=25, \mathrm{H} / \mathrm{D}=3, \mathrm{v}_{\mathrm{s}}=0,3$ (Poulos 1974).

Uma tubulação enterrada que cruza depósitos com diferentes potenciais de congelamento estará sujeita ao desenvolvimento de deformações e momentos causados pelos deslocamentos diferenciais, principalmente nas proximidades das interfaces entre os depósitos (Foriero e Landanyi 1994). Uma avaliação acurada das tensões despertadas na tubulação durante a ação do congelamento torna-se importante para projetos em regiões sujeitas à ocorrência do fenômeno. Razaqpur e Wang (1996) realizaram ensaios laboratoriais em verdadeira grandeza utilizando um conduto de $273 \mathrm{~mm}$ de diâmetro, $5 \mathrm{~mm}$ de espessura e $16 \mathrm{~m}$ de comprimento (L/D = 58,6 ), disposto com H/D = 2,2 em uma câmara refrigerada. Metade do conduto encontrava-se em um silte susceptível ao congelamento e a outra, em uma areia 
insensível ao congelamento. Os deslocamentos verticais do topo do tubo ao longo do silte atingiram um valor máximo igual a $\mathrm{u} / \mathrm{D}=0,22$, ocorrendo na extremidade esquerda dentro da camada de silte $(\mathrm{L} / \mathrm{D}=0)$. Até a metade do vão contido no silte os deslocamentos permaneceram praticamente nesse mesmo patamar, diminuindo em seguida com a proximidade da interface silte-areia. Dentro do depósito arenoso, os deslocamentos do tubo foram mínimos. Tanto no silte quanto na areia os momentos fletores máximos ocorreram a aproximadamente 7D de distância da interface entre os materiais. Momentos de maior magnitude foram desenvolvidos na parte do tubo contida na areia. $\mathrm{Na}$ interface, os momentos foram praticamente nulos. Selvadurai e Shinde (1993) obtiveram distribuição de esforços através de análises numéricas semelhantes às de Foriero e Landanyi (1994).

\subsubsection{Determinação do Perfil de Deslocamentos do Conduto}

Peck (1969) observou que o recalque superficial promovido pela escavação de túneis se assemelha a uma distribuição normal, descrita pela equação (2.28). A mesma distribuição pode ser assumida para um trecho de um conduto longo atravessando um depósito onde ocorre a formação de um vazio por algum dos fatores previamente mencionados, como esquematizado na Figura 2.30. O recalque máximo do duto $\left(\mathrm{u}_{\max }\right)$ é igual a $\mathrm{V}_{\mathrm{s}} / \sqrt{2 \pi}$, onde $\mathrm{V}_{\mathrm{s}}$ é o volume de solo por unidade de comprimento entre o tubo defletido e a linha AA. Na construção de túneis, o volume da bacia de recalque na superfície do terreno em solo coesivo varia entre 1 a $5 \%$ do volume de escavação, ao passo que em solo granular, a faixa usual é de 0,5 a $1 \%$ do volume escavado (Hunt 1986). O deslocamento máximo $\left(\mathrm{u}_{\max }\right)$ experimentado pelo tubo terá como limite inferior o recalque da superfície e como limite superior, o deslocamento que ocorre nas proximidades do vazio. Peng e Luo (1988) reportam valores de $\mathrm{V}_{\mathrm{s}}$ da ordem de $40 \%$ para tubulações cruzando zonas de mineração. O valor de i pode ser obtido através da Figura 2.11.

$\mathrm{u}=\mathrm{u}_{\max }\left[\exp -\mathrm{y}^{2} / 2 \mathrm{i}^{2}\right]$

onde: $\mathrm{u}_{\max }=$ recalque máximo; $\mathrm{i}=$ distância horizontal até o ponto de inflexão $\mathrm{P}$. 


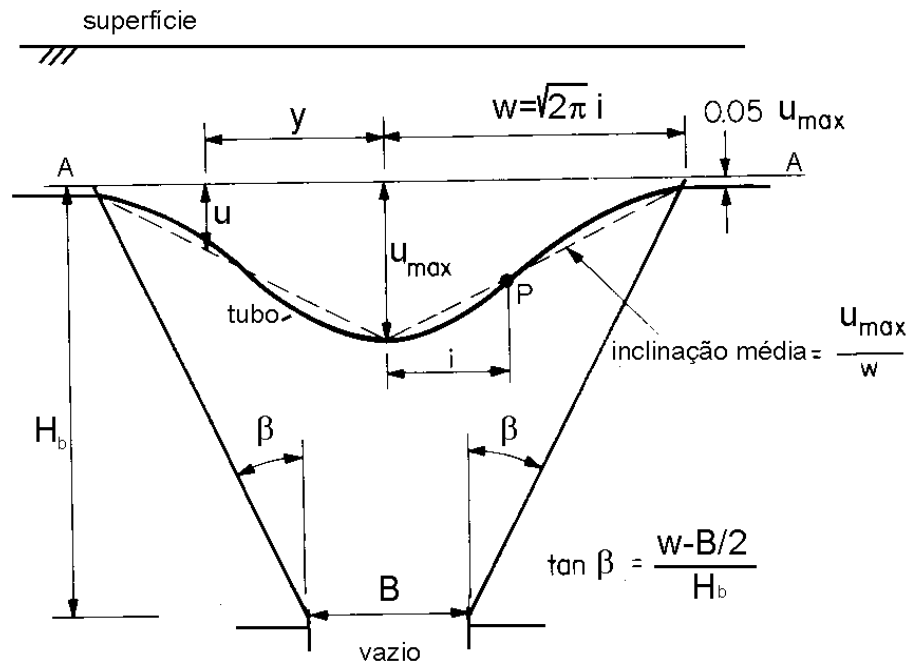

Figura 2.30. Perfil de recalques em condutos a partir de distribuição normal.

Seguindo outra abordagem, o deslocamento do tubo também pode ser calculado assumindo-se um determinado carregamento e condição de apoio para o trecho em questão e utilizando a equação diferencial da linha elástica. A Figura 2.31 ilustra algumas situações de apoio que podem ser consideradas, com os respectivos diagramas de momentos fletores. A Armco (1958) considera o conduto simplesmente apoiado com um carregamento triangular ao longo de todo comprimento, ao passo que a Awwa (1989) recomenda um carregamento uniformemente distribuído. Entretanto, situações envolvendo condutos sobre apoios finitos não são usuais. $\mathrm{Na}$ grande maioria dos casos práticos o conduto encontra-se em contato direto com o solo e experimenta forças de reação distribuídas ao longo do comprimento. Em tubulação com junta do tipo ponta e bolsa, a distribuição da carga sobre o duto não é uniforme, mas será maior na bolsa por causa do maior diâmetro. Assim, tanto a distribuição de tensões sobre o tubo quanto a distribuição da reação pode mudar consideravelmente a depender da acomodação da bolsa no berço. Pearson (1977) enumera três possibilidades distintas: 1) quando o encaixe da bolsa é cuidadosamente escavado no berço; 2) quando o encaixe possui profundidade maior do que a projeção da bolsa e 3) quando a profundidade do encaixe é inferior. Em seguida, o autor derivou expressões para os esforços no tubo nas três situações, as quais podem ser utilizadas para a determinação do deslocamento. 


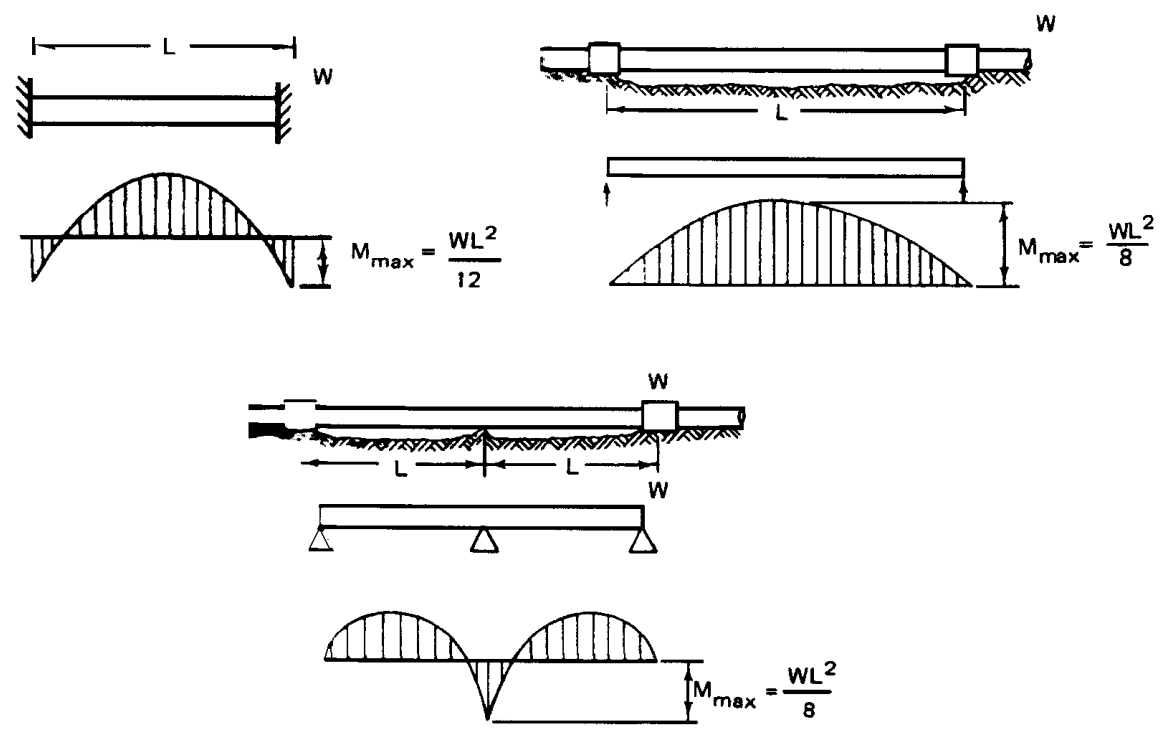

Figura 2.31. Situações de apoio adotadas para condutos enterrados e respectivos momentos fletores (Moser 2001).

Determinar o deslocamento do tubo a partir de um perfil de deslocamentos (ou de reações) pré-concebido é uma solução demasiadamente simplificada para o problema em questão. Quando um determinado carregamento é aplicado a uma tubulação, os deslocamentos e os esforços internos decorrentes não podem ser simplesmente computados procedendo-se ao equilíbrio estático das forças atuantes na estrutura, uma vez que a reação do solo ao longo da tubulação não varia linearmente. Tampouco se pode antecipar um padrão definido para o perfil dos deslocamentos, visto que estes dependerão de diversos fatores, como propriedades do tubo, distribuição e intensidade do carregamento e características do meio em que está inserido.

Um método de análise mais adequado consiste em considerar a tubulação repousando sobre um meio constituído por apoios elásticos discretos, nos quais a tensão de contato por unidade de comprimento (p) é proporcional ao deslocamento vertical (u) (hipótese de Winkler), ou seja:

$\mathrm{p}=\mathrm{Ku}$

onde: $\mathrm{K}=$ módulo de reação do solo, igual a $\mathrm{k}_{\mathrm{v}} \mathrm{D}$, sendo $\mathrm{k}_{\mathrm{v}} \mathrm{o}$ coeficiente de reação do solo. 
Introduzindo-se (2.29) na equação diferencial da linha elástica para uma tubulação infinita sobre apoio distribuído chega-se a:

$\mathrm{EI} \frac{\mathrm{d}^{4} \mathrm{u}}{\mathrm{dy}^{4}}=-\mathrm{Ku}$

onde: y = posição ao longo do eixo da tubulação.

A solução geral de (2.30) é dada por:

$u=e^{\lambda y}\left(C_{1} \cos \lambda y+C_{2} \operatorname{sen} \lambda y\right)+e^{-\lambda y}\left(C_{3} \cos \lambda y+C_{4} \operatorname{sen} \lambda y\right)$

onde: $C_{i}=$ constantes de integração; $\lambda=$ característica do sistema $=\sqrt[4]{\frac{K}{4 E I}}$.

O produto da multiplicação de $\lambda$ pelo comprimento do tubo (L) caracteriza a rigidez relativa longitudinal do sistema e também pode ser utilizado com critério para a classificação do tubo de acordo com o comprimento em três grupos distintos: i) se $\lambda \mathrm{L}<\pi / 4$ a rigidez é elevada e o tubo é dito curto; ii) se $\pi / 4<\lambda \mathrm{L}<\pi$ a rigidez é intermediária e o tubo é classificado como de comprimento médio; iii) se $\lambda \mathrm{L}>\pi$ a rigidez é baixa, e o tubo é considerado longo.

A determinação das constantes $C_{i}$ dependerá das condições de contorno do problema em questão. Hetényi (1946) fornece soluções para (2.31) considerando diversas situações de carregamento, como cargas concentradas, uniformemente distribuídas, triangulares, dentre outras. Para um conduto enterrado sujeito a uma carga concentrada (P) e a um carregamento distribuído (q) representando o peso do solo de aterro, a expressão (2.31) adquire a seguinte forma:

$u=\frac{P \lambda}{2 K}\left[e^{-\lambda y}(\cos \lambda y+\operatorname{sen} \lambda y)\right]+\frac{q}{K}$

Derivando-se sucessivamente (2.32) com respeito a y, obtém-se as equações para rotação $\theta$, momentos fletores $\mathrm{M}$ e esforços cortantes $\mathrm{Q}$ ao longo do conduto, cujas representações gráficas são exibidas na Figura 2.32. 
Selvadurai (1985) aplicou a solução de uma viga infinita sobre apoio elástico para um conduto sujeito a um recalque por conta de uma falha que surge na camada subjacente. Uma grande proporção do duto é abrangida pelo recalque nesse caso. Um deslocamento predefinido foi considerado como condição de contorno do problema em lugar de um carregamento. O modelo assume que o deslocamento sofrido pelo solo $(\delta)$ é conhecido e que não há variação de $\mathrm{K}$ ao longo da tubulação. O eixo de referência é localizado em $z(0)=\delta / 2$. Como condições de contorno tem-se que $u_{e}=$ $\mathrm{u}_{\mathrm{d}}, \mathrm{u}_{\mathrm{e}}=\mathrm{u}_{\mathrm{d}}, \mathrm{u}^{\prime}{ }_{\mathrm{e}}=\mathrm{u}_{\mathrm{d}} \mathrm{e} \mathrm{u}^{\prime \prime}{ }_{\mathrm{e}}=\mathrm{u}{ }^{\prime \prime}{ }_{\mathrm{d}}$ (os subscritos $e$ e $d$ referem-se às regiões do conduto em que $\mathrm{y} \leq 0$ e $\mathrm{y} \geq 0$, respectivamente). O recalque da tubulação é obtido através das expressões (2.33a) e (2.33b).

$$
\begin{array}{ll}
\mathrm{u}_{\mathrm{d}}=\delta\left(1-\frac{\mathrm{e}^{-\lambda \mathrm{y}}}{2} \cos \lambda \mathrm{y}\right) & (\mathrm{y} \geq 0) \\
\mathrm{u}_{\mathrm{e}}=\frac{\delta}{2} \mathrm{e}^{\lambda \mathrm{y}} \cos \lambda \mathrm{y} & (\mathrm{y} \leq 0)
\end{array}
$$

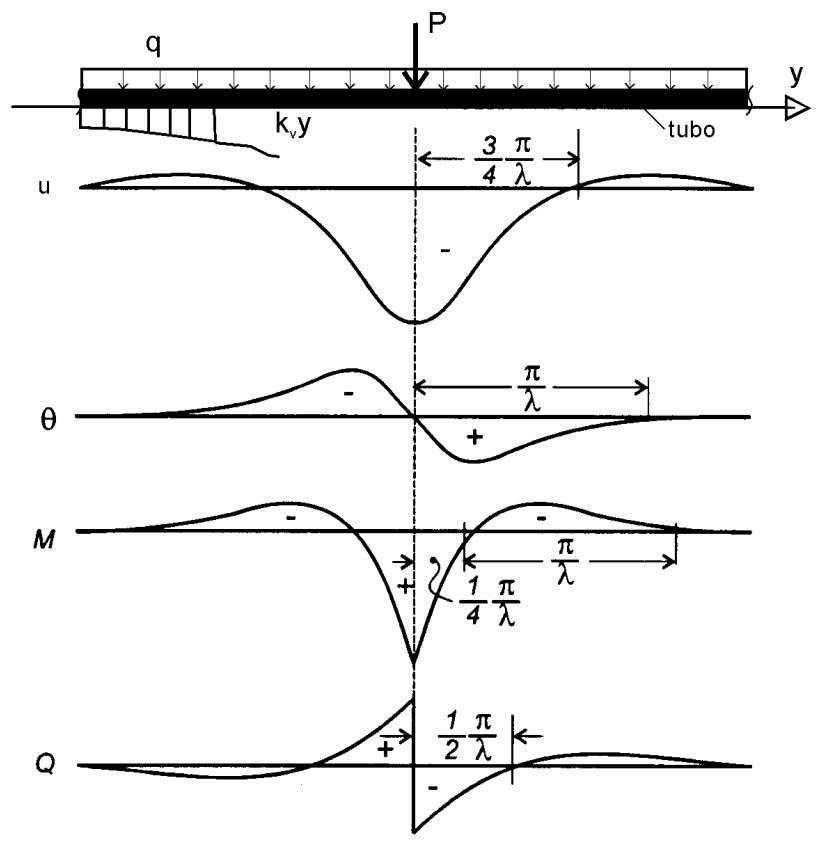

Figura 2.32. Recalque, rotação e esforços internos no conduto considerando uma carga concentrada e carregamento distribuído (Hetényi 1946). 
Em diversas circunstâncias há a necessidade de tratar a tubulação como uma estrutura de comprimento finito. Hetényi (1946) propôs um método de cálculo para vigas de comprimento finito que consiste em empregar a solução desenvolvida para viga infinita e aplicar esforços auxiliares em suas extremidades para anular os esforços calculados naqueles pontos (princípio da superposição). Em outras palavras, supondo-se uma viga com extremidades A e B, deverão ser determinados os esforços $\mathrm{M}_{\mathrm{OA}}, \mathrm{Q}_{\mathrm{OA}}, \mathrm{M}_{\mathrm{OB}}$ e $\mathrm{Q}_{\mathrm{OB}}$ que anularão os esforços $\mathrm{M}_{\mathrm{A}}, \mathrm{Q}_{\mathrm{A}}, \mathrm{M}_{\mathrm{B}}$ e $\mathrm{Q}_{\mathrm{B}}$ previamente obtidos nos pontos A e B supondo-a infinita.

Vesic (1961a, b) ressalta, entretanto, que o método da superposição para vigas de comprimento finito não gera resultados adequados se os esforços auxiliares não forem suficientemente reduzidos em comparação com as cargas atuantes na viga. Com base em avaliações de resultados obtidos com uma viga finita com carga concentrada no meio do vão, o autor recomenda a utilização do método somente para estruturas com $\lambda L>2,25$. Erros próximos a $15 \%$ foram verificados com vigas mais curtas. Por outro lado, soluções baseadas na hipótese de Winkler para vigas de comprimento infinito geram erros desprezíveis quando empregadas para vigas com $\lambda \mathrm{L}>5$.

A solução para viga finita tem aplicação, por exemplo, no caso de um conduto de comprimento L com uma sobrecarga uniformemente distribuída q, atravessando um depósito com compressibilidade superior à dos depósitos adjacentes (Figura 2.33a). O tubo pode ser considerado bi-engastado, sendo o recalque em qualquer ponto entre A e B dado através da expressão (2.34). Outra condição de interesse é a de um conduto com uma sobrecarga q atravessando um vazio de extensão $\mathrm{L}_{\mathrm{v}}$ (Figura 2.33b). $\mathrm{O}$ deslocamento e os esforços em A e $\mathrm{B}$ são determinados através das expressões (2.35) a (2.37), considerando os trechos do duto à esquerda de $\mathrm{A}$ e à direita de $\mathrm{B}$ semi-infinitos. $\mathrm{O}$ deslocamento do tubo no ponto central E é determinado a partir dos esforços calculados em A ou B. A distribuição do momento fletor ao longo do tubo é ilustrada na Figura 2.21b.

$$
\begin{aligned}
u= & \frac{q}{K}\left[1-\frac{1}{\operatorname{senh} \lambda L+\operatorname{sen} \lambda L}\left(\operatorname{senh} \lambda y \cos \lambda y^{\prime}+\operatorname{sen} \lambda y \cosh \lambda y^{\prime}+\operatorname{senh} \lambda y^{\prime} \cos \lambda y+\right.\right. \\
& \left.\left.+\operatorname{sen} \lambda y^{\prime} \cosh \lambda y\right)\right]
\end{aligned}
$$


$\mathrm{u}=\frac{\mathrm{q} \lambda \mathrm{L}_{\mathrm{v}}}{\mathrm{K}}\left[\mathrm{e}^{-\lambda \mathrm{y}} \cos \lambda \mathrm{y}-\alpha\left(\mathrm{e}^{-\lambda \mathrm{y}}(\cos \lambda \mathrm{y}-\operatorname{sen} \lambda \mathrm{y})\right)\right]$

$\mathrm{M}_{\mathrm{A}}=\mathrm{M}_{\mathrm{B}}=(\mathrm{qL} / 2 \lambda) \alpha$

$\mathrm{Q}_{\mathrm{A}}=-\mathrm{Q}_{\mathrm{B}}=\mathrm{qL} / 2$

onde: $\alpha=\frac{6-\lambda^{2} L_{v}^{2}}{6\left(2+\lambda L_{v}\right)} ; M_{A}$ e $M_{B}=$ momento fletor em A e $B$, respectivamente; $Q_{A}$ e $\mathrm{Q}_{\mathrm{B}}=$ esforço cortante em A e B, respectivamente.

a)

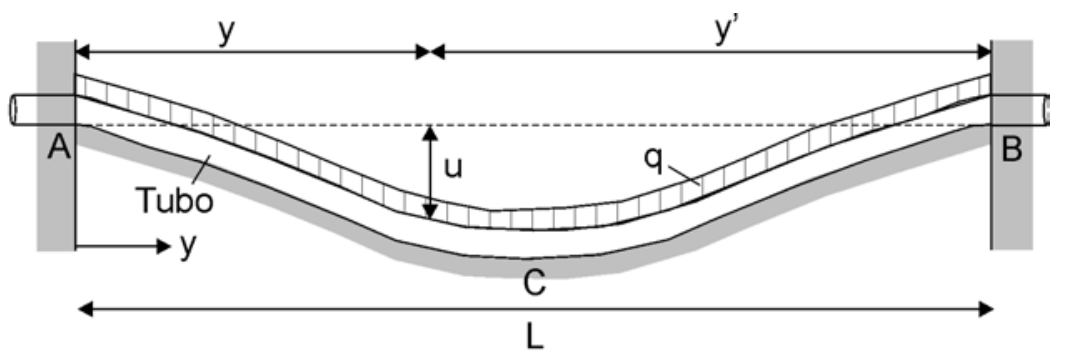

b)

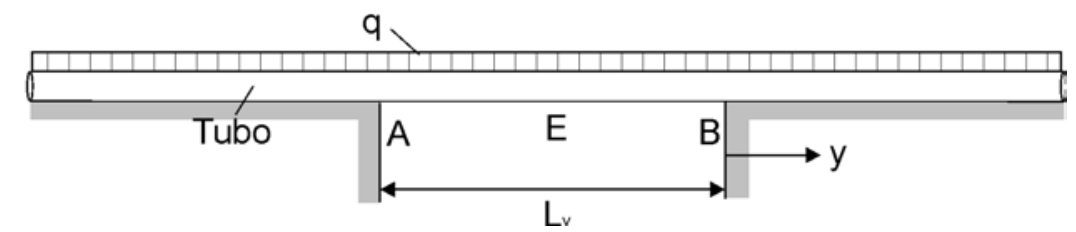

Figura 2.33. a) Tubulação atravessando um depósito compressível; b) tubulação atravessando um vazio.

Levinton (1947) apresentou um método simplificado para a determinação de deslocamentos em um tubo finito sobre apoio elástico. $\mathrm{O}$ diagrama de tensões de contato é determinado por quatro ordenadas, $\mathrm{p}_{1}$ a $\mathrm{p}_{4}$, e é dividido em triângulos, como exibe a Figura 2.34a. Para se determinar as quatro ordenadas são necessárias duas equações de equilíbrio e duas de compatibilidade de deslocamentos. Assumindo-se $\mathrm{p}=\mathrm{Ku}$ (hipótese de Winkler), as equações de equilíbrio são obtidas procedendo-se ao somatório dos momentos nos pontos L e R, chegando-se a:

$$
4 \mathrm{u}_{2}+10 \mathrm{u}_{3}+7 \mathrm{u}_{4}=6 \mathrm{M}_{\mathrm{L}} /\left(\mathrm{a}^{2} \mathrm{~K}\right)
$$


$7 \mathrm{u}_{1}+10 \mathrm{u}_{2}+4 \mathrm{u}_{3}=-6 \mathrm{M}_{\mathrm{R}} /\left(\mathrm{a}^{2} \mathrm{~K}\right)$

onde: $M_{L}$ e $M_{R}$ são os momentos nos pontos $L$ e $R$, respectivamente.

As equações de compatibilidade são obtidas assumindo-se inicialmente que o conduto é rígido e sofre uma deflexão nas extremidades igual a $\mathrm{u}_{1} \mathrm{e} \mathrm{u}_{4}$, como mostra a Figura 2.34b (linha tracejada superior). Nos pontos 2 e 3 essas deflexões são dadas por:

$\mathrm{u}_{\mathrm{f} 2}=\mathrm{u}_{1}+(1 / 3)\left(\mathrm{u}_{4}-\mathrm{u}_{1}\right)$

$\mathrm{u}_{\mathrm{f3}}=\mathrm{u}_{1}+(2 / 3)\left(\mathrm{u}_{4}-\mathrm{u}_{1}\right)$

Em seguida, supõe-se que conduto retoma sua flexibilidade e adquire o comportamento de uma viga flexível bi-apoiada que apresenta deflexões nos pontos 2 e 3 iguais a $u_{b 2}$ e $u_{b 3}$, respectivamente (linha tracejada inferior na Figura 2.34b). Essa parcela do deslocamento pode ser determinada através de fórmulas conhecidas da Resistência dos Materiais. Por fim, aplicam-se as tensões de contato e o conduto recupera parte da deflexão sofrida (linha cheia), de valor igual a $u_{c 2}$ e $u_{c 3}$. Esses deslocamentos representam o efeito das seis cargas triangulares na Figura 2.34a e são obtidos através das seguintes expressões:

$$
\begin{aligned}
& \mathrm{u}_{\mathrm{c} 2}=\frac{\mathrm{a}^{4}}{1080 E I}\left(94 \mathrm{p}_{1}+429 \mathrm{p}_{2}+390 \mathrm{p}_{3}+77 \mathrm{p}_{4}\right) \\
& \mathrm{u}_{\mathrm{c} 3}=\frac{\mathrm{a}^{4}}{1080 E \mathrm{E}}\left(77 \mathrm{p}_{1}+390 \mathrm{p}_{2}+429 \mathrm{p}_{3}+94 \mathrm{p}_{4}\right)
\end{aligned}
$$

Assim, decorre que os deslocamentos totais nos pontos 2 e 3 são estimados através das equações (2.41), as quais são as duas equações de compatibilidade necessárias para a solução do problema juntamente com as equações (2.38).

$$
\begin{aligned}
& \mathrm{u}_{2}=\frac{2}{3} \mathrm{u}_{1}+\frac{1}{3} \mathrm{u}_{4}+\mathrm{u}_{\mathrm{b} 2}-\frac{\mathrm{a}^{2} \mathrm{~K}}{1080 E \mathrm{EI}}\left(94 \mathrm{u}_{1}+429 \mathrm{u}_{2}+390 \mathrm{u}_{3}+77 \mathrm{u}_{4}\right) \\
& \mathrm{u}_{3}=\frac{1}{3} \mathrm{u}_{1}+\frac{2}{3 \mathrm{k}} \mathrm{u}_{4}+\mathrm{u}_{\mathrm{b} 3}-\frac{\mathrm{a}^{2} \mathrm{~K}}{1080 E I}\left(77 \mathrm{u}_{1}+390 \mathrm{u}_{2}+429 \mathrm{u}_{3}+94 \mathrm{u}_{4}\right)
\end{aligned}
$$




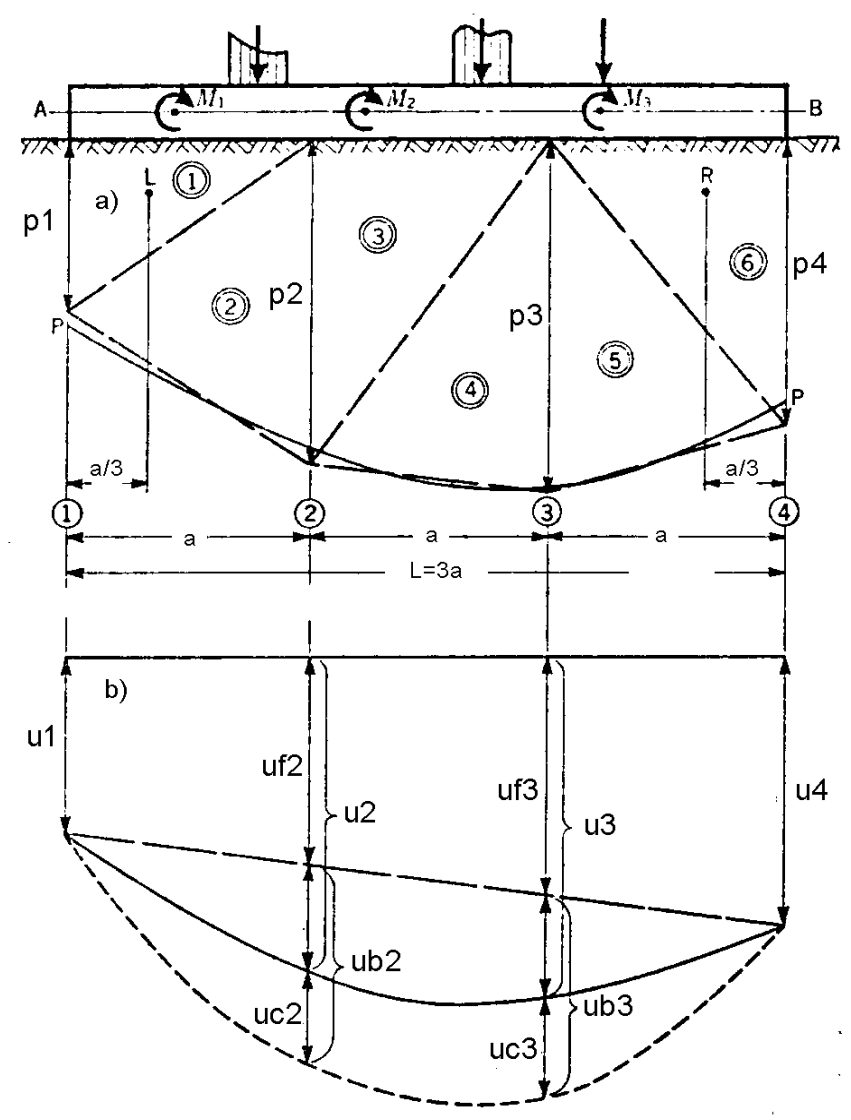

Figura 2.34. Determinação do deslocamento do tubo com o método de Levinton (1947).

A consideração do meio como elástico-linear representa uma suposição distante do comportamento de qualquer tipo de solo. Rajani e Morgenstern (1993) propuseram uma solução analítica para a previsão do comportamento de um conduto enterrado inserido em um meio elasto-plástico. Após ser solicitada por um determinado esforço transversal $\mathrm{F}$, a tubulação exibe uma dupla curvatura, como esquematiza a Figura 2.35. F é aplicado em três incrementos distintos, $F_{1}, F_{2}$ e $F_{3}$, cada qual gerando uma série de eventos em decorrência da interação entre o solo e o conduto. No intervalo $0 \leq \mathrm{F} \leq \mathrm{F}_{1}$, o conduto e o solo comportam-se elasticamente. Nesta fase, a determinação dos esforços e deslocamentos é realizada com o auxílio da hipótese de Winkler, considerando a tubulação infinita. Em $F_{1} \leq F \leq F_{2}$, o eixo $x-x$ divide o meio em duas regiões distintas (Figura 2.35): a região $\mathrm{A}$, onde o solo encontra-se no estado plástico e o conduto no estado elástico, e a região $\mathrm{B}$, onde tanto o tubo quanto o solo ainda se encontram na fase elástica. Inicialmente, o eixo x- 
$\mathrm{x}$ ocupa a posição s-s, sendo paulatinamente transladado à medida que $\mathrm{F}$ aumenta, até atingir uma distância $\bar{y}$. Por fim, quando $F$ ultrapassa $F_{2}$ o tubo passa a apresentar deformações plásticas.

No intervalo $F_{1} \leq F \leq F_{2}$, a equação de equilíbrio para a região A é expressa por:

$\mathrm{EI} \frac{\mathrm{d}^{4} \mathrm{u}}{\mathrm{dy}^{4}}=-\mathrm{F}_{\mathrm{p}}$

onde: $F_{p}=$ resistência passiva do meio (força por unidade de comprimento).

Os autores sugerem que $\mathrm{F}_{\mathrm{p}}$ seja obtido através de uma representação bi-linear das curvas carga $(F)$ versus deslocamento, para diversos valores de $H / D$, propostas por Rowe e Davis (1982a, b) para o arrancamento de ancoragens verticais (item 2.3.2). As condições de contorno admitidas para o problema possibilitam fornecer a seguinte solução para a equação (2.42), no ponto de aplicação da carga $\mathrm{F}$ na região A (em y = $-\bar{y})$ :

$\overline{\mathrm{u}}=\mathrm{N}_{\mathrm{p}}\left(\frac{1}{2}+\frac{2}{3} \frac{\overline{\mathrm{F}}}{\mathrm{N}_{\mathrm{p}}}+\frac{8}{3} \frac{\overline{\mathrm{F}}^{4}}{\mathrm{~N}_{\mathrm{p}}^{4}}\right)$

onde: $\overline{\mathrm{u}}=\mathrm{u} \mathrm{K} / \mathrm{Dc}$ (solo coesivo) ou $\mathrm{uK} / \gamma \mathrm{DH}$ (solo não-coesivo); $\overline{\mathrm{F}}=\mathrm{F} \lambda / \mathrm{Dc}$ (solo coesivo) ou $\mathrm{F} \lambda / \gamma \mathrm{DH}$ (solo não-coesivo); $\mathrm{N}_{\mathrm{p}}=\mathrm{F}_{\mathrm{p}} / \mathrm{Dc}$ (solo coesivo) ou $\mathrm{F}_{\mathrm{p}} / \gamma \mathrm{DH}$ (solo não-coesivo).

O comprimento da região $\mathrm{A}, \overline{\mathrm{y}}$, é obtido através da seguinte expressão:

$\overline{\mathrm{y} \lambda}=\frac{2 \mathrm{~F} \lambda}{\mathrm{F}_{\mathrm{p}}}-1$

A utilização dos ábacos propostos por Rowe e Davis (1982a, b) para a determinação de $F_{p}$, além de considerar o comportamento de resistência do sistema como nãolinear, possibilita também levar em conta a altura de cobertura do solo $(\mathrm{H})$ nas análises. 

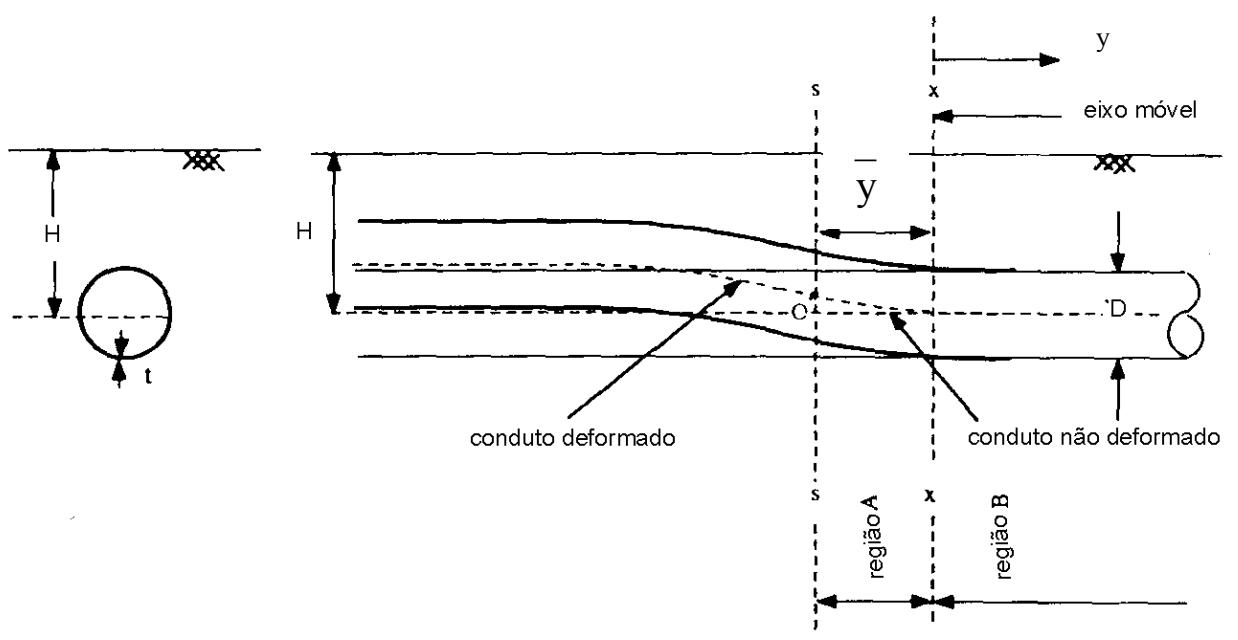

Figura 2.35. Modelo de Rajani e Morgenstern (1993).

A Figura 2.36 expõe a relação entre $\overline{\mathrm{F}}$ e $\overline{\mathrm{u}}$ obtida através da equação (2.43), considerando $\mathrm{N}_{\mathrm{p}}=6,35$, e compara a solução proposta com o resultado de uma análise numérica tridimensional através do método dos elementos finitos, executada para $H / D=1,55$. São ainda exibidas na figura curvas analíticas correspondentes aos limites para H/D. Uma boa concordância entre o modelo analítico proposto e o numérico tridimensional é observada.

A solução de Rajani e Morgenstern (1993) guarda vantagem sobre as demais porque utiliza como dado de entrada a resistência passiva do solo à movimentação do conduto, e não somente uma simples relação elástico-linear entre a tensão de contato e o deslocamento produzido. Assim sendo, a profundidade da instalação está sendo indiretamente considerada no método. Não obstante, apesar do nítido avanço sobre os métodos precedentes, é importante recordar que os dados de Rowe e Davis (1982b), dos quais se derivou $F_{p}$, foram obtidos a partir de análises com ancoragens rígidas, sendo desconsiderada, portanto, a interação transversal que ocorre no caso de condutos flexíveis. A validação do modelo para condutos flexíveis é necessária.

Métodos que consideram o meio como elástico-contínuo, como os de Ohde (1942) (após Velloso e Lopes 1996) e De Beer (1948), juntamente com métodos numéricos (elementos finitos e diferenças finitas, por exemplo), representam soluções alternativas aos modelos que empregam a hipótese de Winkler. 


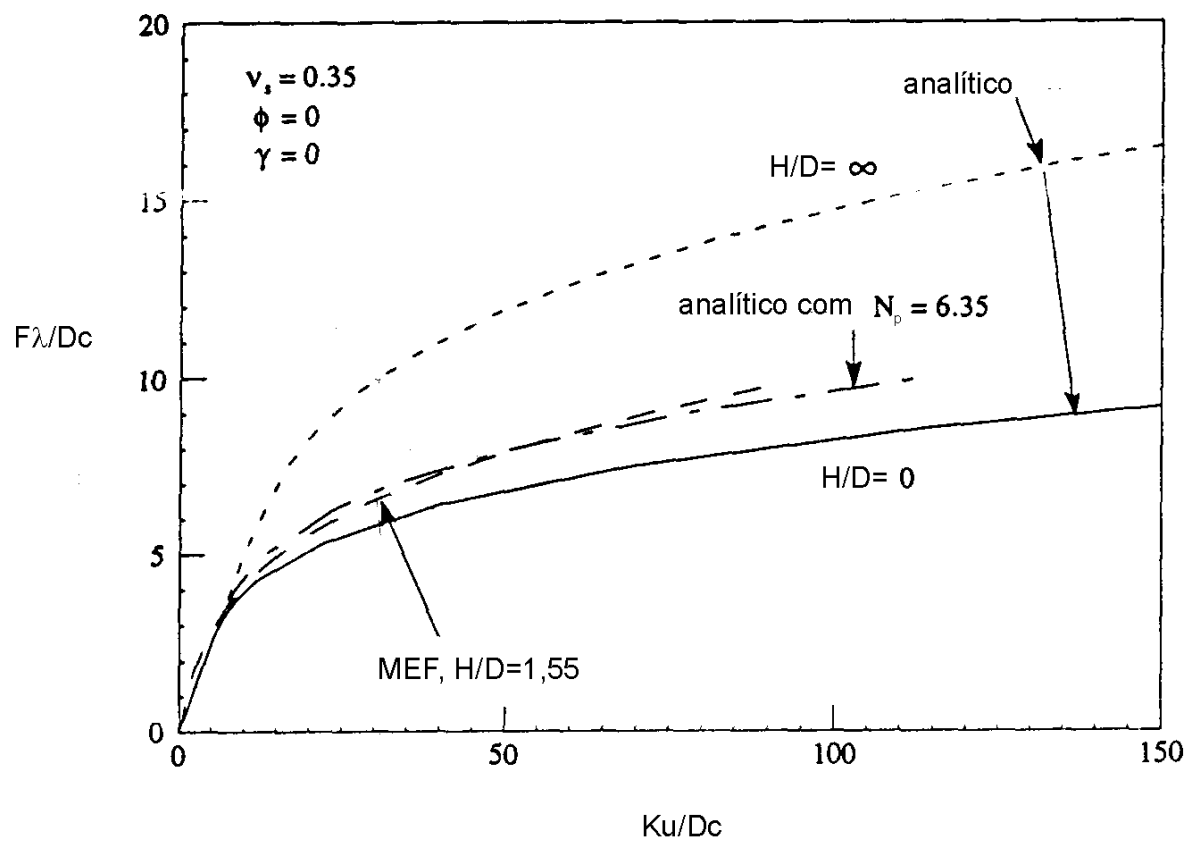

Figura 2.36. Curvas adimensionais carga-deslocamento para um conduto em um meio elasto-plástico e comparação com análise numérica (Rajani e Morgenstern 1993).

\subsection{AVALIAÇÃO DA INTERAÇÃO LONGITUDINAL DE CONDUTOS SUBMETIDOS A MOVIMENTAÇÃO LONGITUDINAL DO SOLO}

Uma vez que se encontra inserido no maciço de solo, qualquer deslocamento relativo entre o solo circundante e o tubo mobilizará atrito, o qual provoca o surgimento de deformações longitudinais. Inclusive, em muitos locais os condutos enterrados necessitam cruzar depósitos propensos a deslizamentos, estando sujeitos a deformações longitudinais provocadas pela movimentação da massa instável ao longo de seu eixo. Considerando um conduto com diâmetro D e espessura t, cuja resposta permaneça dentro do limite elástico, a deformação longitudinal total incluindo efeitos de tensões radiais $\left(\sigma_{\mathrm{r}}\right)$ e circunferenciais $\left(\sigma_{\theta}\right)$ provenientes de pressão interna do fluido $\left(\mathrm{p}_{\mathrm{i}}\right)$ e externa do solo $\left(\mathrm{p}_{\mathrm{e}}\right)$, bem como efeitos de temperatura e atrito, será dada por: 
$\varepsilon_{\mathrm{L}}=\frac{\mathrm{f}_{\mathrm{at}}}{\mathrm{AE}}-v \frac{\mathrm{D}}{2 \mathrm{t}} \frac{\left(\mathrm{p}_{\mathrm{i}}-\mathrm{p}_{\mathrm{e}}\right)}{\mathrm{E}}+v \frac{\left(\mathrm{p}_{\mathrm{i}}+\mathrm{p}_{\mathrm{e}}\right)}{2 \mathrm{E}}+\delta \Delta \mathrm{T}$

onde: $\mathrm{A}=$ área externa do tubo; $\mathrm{E}=$ módulo de elasticidade do material do conduto; $v=$ coeficiente de Poisson do material do conduto; $\mathrm{f}_{\mathrm{at}}=$ força de atrito mobilizada por unidade de comprimento; $\Delta \mathrm{T}=$ variação de temperatura; $\delta=$ coeficiente de expansão térmica.

A força axial por unidade de comprimento $\left(f_{a t}\right)$ despertada pelo atrito na interface depende basicamente do tipo de solo utilizado no aterro e do método de instalação (ou seja, do controle de compactação do aterro) (O’Rourke et al., 1995). Para solo não-coesivo, $\mathrm{f}_{\mathrm{at}}$ depende da tensão normal efetiva na interface solo-tubo, do coeficiente de atrito entre o material do tubo e o solo, assim como do diâmetro do conduto (D). Em solo não-coesivo $\mathrm{f}_{\text {at }}$ pode ser determinada através da expressão (2.46). O’Rourke e El Hmadi (1988) sugerem $\mu=0,9$ tg $\phi$ para condutos de aço. Watkins e Anderson (1999) recomendam para $\mu$ valores entre 0,2 e 0,4.

$\frac{\mathrm{f}_{\mathrm{at}}}{\gamma \mathrm{HD}}=\mu \pi\left(\frac{1+\mathrm{K}_{0}}{2}\right)$

onde: $\mu=$ coeficiente de atrito solo-conduto; $K_{0}=$ coeficiente de empuxo em repouso.

Scott (1981) propõe a seguinte expressão para a determinação de $F_{a t}$ a partir do módulo cisalhante do solo $\left(\mathrm{G}_{\mathrm{s}}\right)$ :

$\mathrm{f}_{\mathrm{at}}=\frac{\pi \mathrm{G}_{\mathrm{s}}}{2\left(1-\mathrm{v}_{\mathrm{s}}\right)} \mathrm{u}_{\mathrm{y}}$

onde: $\mathrm{u}_{\mathrm{y}}=$ deslocamento longitudinal (direção y).

Por outro lado, quando o conduto é instalado em solo puramente coesivo, $\mathrm{f}_{\mathrm{at}}$ depende da resistência não drenada $\left(\mathrm{s}_{\mathrm{u}}\right)$, e é dada através da expressão (2.48). O'Rourke et al. (1995) sugerem assumir $\alpha$ igual a 1 para argilas normalmente adensadas. Apesar da existência de um grande número de dados experimentais que 
corroboram (2.48) para o caso de estacas verticais (Peck 1958, Coyle e Reese 1966), Sladen (1992) adverte que a ruptura que ocorre na interface entre o solo e a estrutura é um fenômeno drenado, de modo que a utilização de tal expressão carece de argumentação teórica.

$f_{a t}=\alpha S_{u} \pi D$

onde $\alpha=$ fator de adesão.

Uma vez determinada $f_{a t}$ e seu comprimento de atuação, torna-se possível avaliar as tensões e deformações longitudinais na tubulação provocadas pelo movimento do solo. Rajani et al. (1995) propuseram duas soluções analíticas para condutos sujeitos à movimentação do solo paralelamente ao tubo. Seguindo abordagens distintas, os métodos visam estimar a resistência axial na região da tubulação localizada na interface entre a massa de solo deslizante e a massa estável. Partindo de uma análise de equilíbrio limite, a primeira abordagem considera o conduto na iminência de ruptura instalado em um talude infinito. Assume-se também que a superfície deslizante é plana e que inexiste movimento entre o solo e o conduto. O critério de ruptura adotado é o de Mohr-Coulomb. Procedendo-se ao equilíbrio das forças atuantes no sistema (Figura 2.37) obtém-se a expressão (2.49) para a força de atrito solo-tubo $\left(f_{a t}\right)$ por unidade de comprimento. A força axial máxima $\left(\mathrm{F}_{\mathrm{y}}\right)$ na tubulação na interface entre a massa estável e a massa instável será então igual ao comprimento total da massa de solo deslizante $\left(L_{s}\right)$ vezes a força de atrito $f_{\text {at }}$.

$f_{a t}=\gamma h_{s} W_{s}\left(\operatorname{sen} \lambda \cos \lambda-\cos ^{2} \lambda \operatorname{tg} \phi^{\prime}\right)-\mathrm{cW}_{\mathrm{s}}$

onde: $\mathrm{W}_{\mathrm{s}}=$ largura da lamela de solo perpendicularmente ao plano da Figura 2.37. Os demais parâmetros encontram-se especificados na figura. 


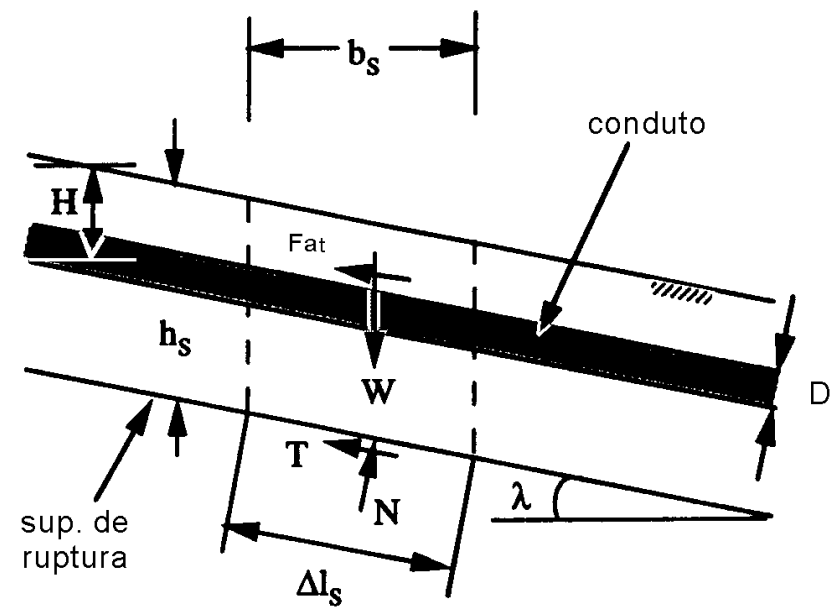

Figura 2.37. Determinação da força axial no conduto (Rajani et al. 1995).

A segunda abordagem segue um desenvolvimento semelhante ao do modelo proposto pelos autores para deslocamento transversal, apresentado no item 2.4.3. O método permite determinar a relação entre o deslocamento longitudinal $\left(\mathrm{u}_{\mathrm{y}}\right)$ e a carga axial na interface $\left(\mathrm{F}_{\mathrm{y}}\right)$ entre as massas instável e estável. A resposta do sistema é avaliada em três estágios distintos. O primeiro utiliza a hipótese de Winkler, ou seja, assume-se o tubo e o solo com comportamento elástico. $\mathrm{Na}$ segunda fase o comportamento do tubo é elástico, porém o solo atinge a plastificação em uma determinada zona ao longo do conduto, sendo a resistência axial por unidade de comprimento do solo obtida através das equações (2.46) ou (2.48), a depender do tipo de solo. Na última etapa, assume-se uma região onde o solo se encontra no estado plástico e o material do tubo passa a apresentar encruamento. A analise dos resultados do método revela que a aplicação das soluções desenvolvidas para as fases 1 e 2 podem resultar em valores de projeto desnecessariamente conservativos. Uma vez que o aço é um material elasto-plástico com comportamento de encruamento, deslocamentos longitudinais de maiores magnitudes podem ser tolerados pelo tubo antes de atingir a deformação axial limite, sendo então a solução fornecida pelo caso 3 mais adequada.

O’Rourke et al. (1995) propõem um modelo para avaliar a deformação máxima do conduto baseado em observações de ocorrências envolvendo deslizamentos por liquefação do solo. Assumindo-se um padrão de deformações longitudinais do solo em forma de bloco, o modelo contempla duas condições 
distintas. Na condição I, supõe-se que o deslocamento da massa de solo possui grande extensão, de modo que as deformações do tubo são controladas pelo comprimento da massa deslizante $\left(\mathrm{L}_{\mathrm{s}}\right)$. Uma vez que o deslocamento máximo do conduto no centro da zona instável é inferior ao movimento do solo, o atrito é mobilizado ao longo de toda extensão da massa de solo em movimento. A Figura 2.38a ilustra o padrão de deslocamentos admitido para o tubo e para o solo nesta situação. As deformações no conduto são máximas nos pontos B (tração) e D (compressão) e nulas em C. A solução obtida para a deformação axial máxima no tubo é indicada em (2.50), onde $\beta_{\mathrm{p}}$ é denominado parâmetro de embutimento, igual a $\mathrm{f}_{\mathrm{at}} / \pi$ Dt. Quanto maior $\beta_{\mathrm{p}}$, maior é a profundidade do tubo. Esta expressão foi derivada considerando-se que a força axial máxima no tubo $\left(\mathrm{F}_{\mathrm{y}}\right)$ é dada por $\mathrm{f}_{\mathrm{at}} \cdot \mathrm{L}_{\mathrm{s}} / 2$, como na Figura 2.38a, e que o comportamento tensão-deformação do aço do conduto segue a proposição de Ramberg e Osgood (1943) (após O’Rourke et al. 1995).

$$
\varepsilon_{\max }=\frac{\beta_{\mathrm{p}} \mathrm{L}_{\mathrm{s}}}{2 \mathrm{E}}\left[1+\left(\frac{\mathrm{n}}{1+\mathrm{r}}\right)\left(\frac{\beta_{\mathrm{p}} \mathrm{L}_{\mathrm{s}}}{2 \sigma_{\mathrm{y}}}\right)^{\mathrm{r}}\right]
$$

onde: $\sigma_{\mathrm{y}}=$ tensão de escoamento do aço; $\mathrm{n}$ e $\mathrm{r}=$ parâmetros de Ramberg-Osgood para a relação tensão-deformação.

No caso II a deformação máxima do conduto $\left(\varepsilon_{\max }\right)$ é obtida a partir do deslocamento do solo. Considera-se que $\mathrm{L}_{\mathrm{s}}$ possui grande dimensão, de modo que o atrito não chega a ser mobilizado na região central da tubulação, de comprimento igual a $\mathrm{L}_{\mathrm{s}}-2 \mathrm{~L}_{\mathrm{e}}$ (Figura 2.38b), uma vez que nesta região o deslocamento do tubo é igual ao do solo. $\varepsilon_{\max }$ ocorrerá nos pontos $\mathrm{B}$ e E e é determinada assumindo-se que a força no segmento $\mathrm{AB}$ é linearmente proporcional à distância ao ponto $\mathrm{A}$, de forma que $\mathrm{F}_{\mathrm{y}}$ em $\mathrm{B}$ é igual a $\mathrm{f}_{\mathrm{at}} \cdot \mathrm{L}_{\mathrm{e}}$. Logo, $\varepsilon_{\max }$ será dado através da expressão (2.51).

$$
\varepsilon_{\max }=\frac{\beta_{\mathrm{p}} \mathrm{L}_{\mathrm{e}}}{\mathrm{E}}\left[1+\left(\frac{\mathrm{n}}{1+\mathrm{r}}\right)\left(\frac{\beta_{\mathrm{p}} \mathrm{L}_{\mathrm{e}}}{2 \sigma_{\mathrm{y}}}\right)^{\mathrm{r}}\right]
$$




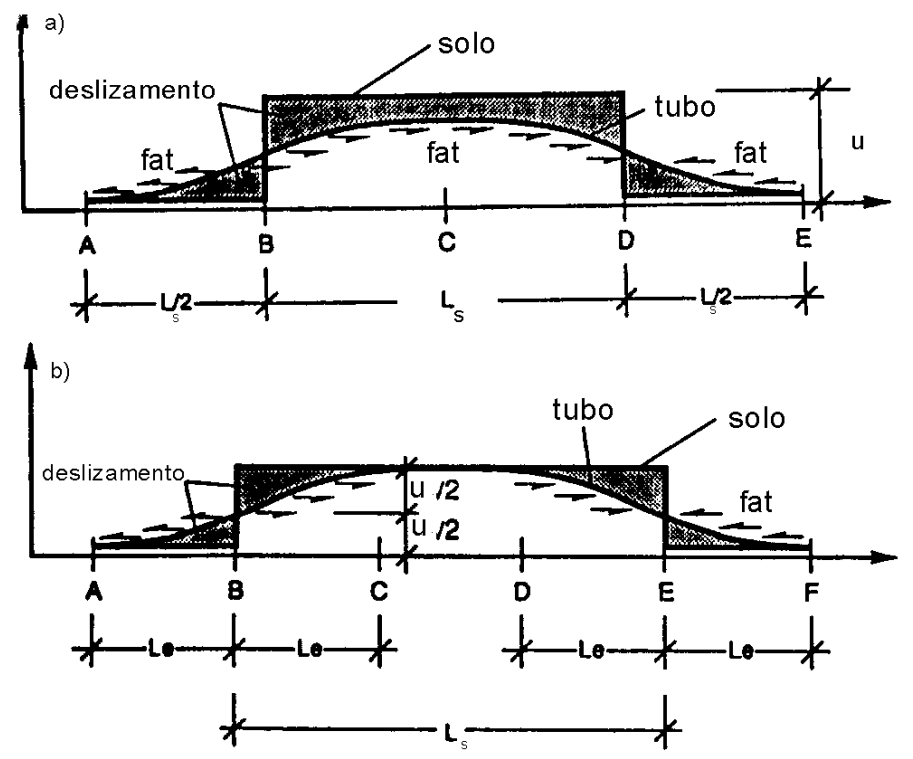

Figura 2.38. Deslocamentos do conduto e da massa de solo instável: a) caso I e b) caso II (O’Rourke et al. 1995).

A Figura 2.39 exibe curvas de $\varepsilon_{\max }$ em função de $\mathrm{L}_{\mathrm{s}}$, correspondentes à condição I para vários valores de $\beta_{\mathrm{p}}$, para um conduto de aço com $\sigma_{\max }=227 \mathrm{MPa}, \mathrm{n}$ $=10$ e $\mathrm{r}=100$. Níveis de $\varepsilon$ relativos ao esmagamento da parede do tubo são exibidos para cinco valores de $\mathrm{R} / \mathrm{t}$, sendo $\mathrm{R}$ o raio do tubo. Observa-se que o comprimento $\mathrm{L}_{\mathrm{s}}$ que provoca o esmagamento é inversamente proporcional à profundidade de instalação do tubo. Por exemplo, um tubo com $\beta_{\mathrm{p}}=41 \mathrm{MN} / \mathrm{m}^{3}$ (parede fina e instalado em profundidade) sofrerá esmagamento para $\mathrm{L}_{\mathrm{s}}=115 \mathrm{~m}$, enquanto que um comprimento seis vezes maior é necessário para causar o esmagamento com $\beta_{\mathrm{p}}=6,8$ $\mathrm{MN} / \mathrm{m}^{3}$ (parede grossa e instalado em pequena profundidade). Observa-se ainda que para esse tipo de aço o comprimento da massa instável que causa o esmagamento é praticamente independente de $\mathrm{R} / \mathrm{t}$. A influência de $\mathrm{R} / \mathrm{t}$ torna-se um pouco mais pronunciada em aços mais resistentes. 


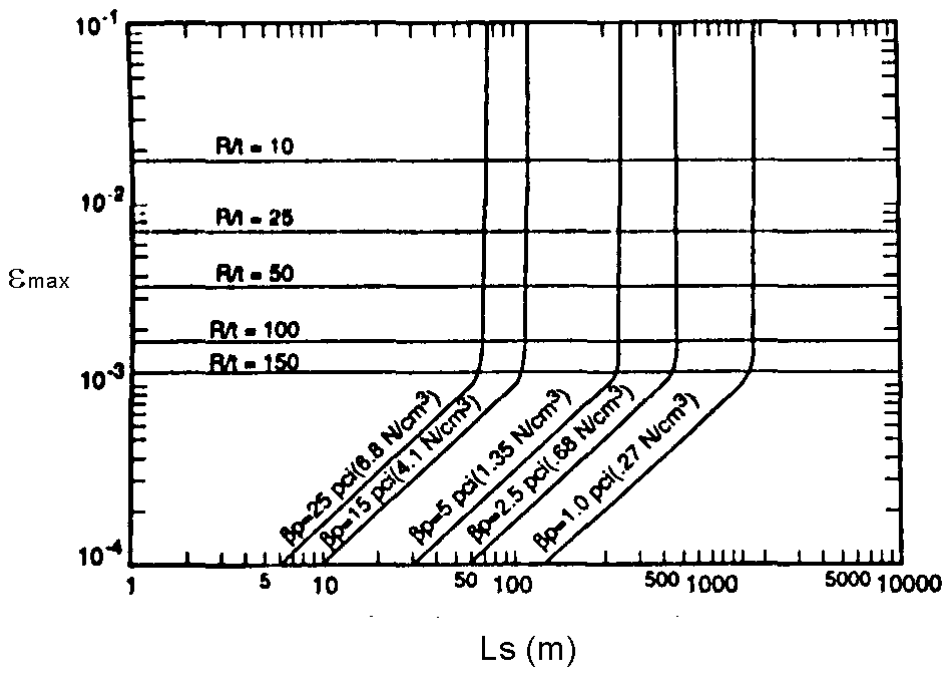

Figura 2.39. Deformação máxima versus comprimento da massa de solo instável (O’Rourke et al. 1995). 


\section{Materiais e Métodos do Programa de Ensaios da Universidade do Colorado}

\subsection{CONSIDERAÇÕES INICIAIS}

Uma grande variedade de problemas geotécnicos pode ser adequadamente investigada através da construção de modelos físicos em centrífuga. Particularmente, estudos utilizando centrífugas geotécnicas têm contribuído significativamente para o entendimento do comportamento de condutos enterrados e do fenômeno do arqueamento do solo (Valsangkar e Britto 1979, Trott et al. 1984, Tohda et al. 1991, Stone e Muir Wood 1992, Santichaianant 2002, Hachiya et al. 2002).

A importância da modelagem em centrífuga deve-se principalmente ao fato do comportamento do solo ser dependente do estado de tensão. Os modelos ensaiados dentro de uma centrífuga são submetidos a uma aceleração radial que simula um campo de aceleração gravitacional muitas vezes superior ao campo gravitacional exercido pela Terra $(1 \mathrm{~g})$, permitindo reproduzir de forma bastante realista a distribuição das tensões no maciço decorrente do peso próprio do solo. Por este motivo é uma ferramenta particularmente apropriada para o estudo de mecanismos de ruptura.

Os modelos em centrífuga apresentam como vantagens sobre os modelos em verdadeira grandeza o baixo custo, a facilidade de repetição, o menor tempo de montagem e a conseqüente possibilidade de realização de um maior número de ensaios. Contudo, apresenta limitações quanto à simulação de alguns aspectos construtivos. Simular etapas de escavação do maciço de solo com o modelo em 
movimento na centrífuga é tarefa de alta complexidade, sendo suprimida na maioria das vezes. Geralmente, os modelos são construídos a $1 \mathrm{~g}$ e só então carregados na centrífuga, impossibilitando a análise das tensões desenvolvidas no protótipo durante a etapa construtiva.

Um outro fator limitante diz respeito ao tamanho relativo das partículas de solo no modelo e no protótipo. A dificuldade de simular o solo faz com que o mesmo solo do protótipo seja utilizado no modelo, o que, a depender da situação, pode resultar em problemas. Por exemplo, no caso de um modelo com dimensões reduzidas utilizando pedregulho e ensaiado a uma aceleração elevada, o tamanho relativo das partículas pode provocar efeitos locais fazendo com que o solo não se comporte mais como um meio contínuo.

Para que um modelo reduzido possa simular adequadamente o comportamento de um determinado protótipo, algumas leis de escala precisam ser observadas. A tensão no modelo $\left(\sigma_{\mathrm{m}}\right)$, por exemplo, deve ser igual à tensão no protótipo $\left(\sigma_{\mathrm{p}}\right)$. Nos modelos, se uma aceleração $\mathrm{N}$ vezes superior à aceleração gravitacional exercida pela Terra atua na centrífuga, a tensão vertical $\left(\sigma_{\mathrm{vm}}\right)$ a uma profundidade $\mathrm{z}_{\mathrm{m}}$ é dada por $\rho \cdot \mathrm{g} \cdot \mathrm{N} \cdot \mathrm{z}_{\mathrm{m}}$, onde $\rho$ é a massa específica do material. Por outro lado, no protótipo, a tensão vertical $\left(\sigma_{\mathrm{p}}\right)$ a uma profundidade $\mathrm{z}_{\mathrm{p}}$ é dada pela expressão $\rho \cdot g \cdot z_{p}$. Assim, para que o comportamento do modelo seja representativo do comportamento do protótipo, as dimensões do modelo precisam ser reduzidas por um fator de escala correspondente a $1 / \mathrm{N}$.

As relações de escala que devem ser observadas em modelos em centrífuga são deduzidas através da análise da equação diferencial que governa o problema ou através de análise dimensional. Alguns fatores de escala, de caráter geral, utilizados em modelos em centrífuga são mostrados na Tabela 3.1. De forma ilustrativa, a Tabela 3.2 apresenta os fatores de escala utilizados na modelagem envolvendo condutos enterrados e que podem ser deduzidos das relações gerais da Tabela 3.1. Nestas tabelas está implícito que o mesmo solo é utilizado no modelo e no protótipo. Maiores detalhes sobre leis de escala e modelagem em centrífuga de uma forma geral podem ser encontrados em Schofield (1980) e Taylor (1995). 
Tabela 3.1. Fatores de escala utilizados em modelagem em centrífuga

\begin{tabular}{cc}
\hline Grandeza & Modelo/protótipo \\
\hline Comprimento & $1 / \mathrm{N}$ \\
Área & $1 / \mathrm{N}^{2}$ \\
Volume & $1 / \mathrm{N}^{3}$ \\
Tensão & 1 \\
Deformação específica & 1 \\
Deslocamento & $1 / \mathrm{N}$ \\
Massa & $1 / \mathrm{N}^{3}$ \\
Massa Específica & 1 \\
Força & $1 / \mathrm{N}^{2}$ \\
Aceleração inercial & $\mathrm{N}$ \\
Tempo & $1 / \mathrm{N}^{2}$ \\
Energia & $1 / \mathrm{N}^{3}$ \\
\hline
\end{tabular}

Tabela 3.2. Fatores de escala para condutos enterrados

\begin{tabular}{lc}
\hline \multicolumn{1}{c}{ Grandeza } & Modelo/protótipo \\
\hline Parâmetros do solo & 1 \\
$\begin{array}{l}\text { Parâmetros de resistência ao cisalhamento } \\
(\mathrm{c}, \phi)\end{array}$ & 1 \\
Módulo de deformabilidade $\left(\mathrm{E}_{\mathrm{s}}\right)$ & 1 \\
Coeficiente de Poisson $\left(v_{\mathrm{s}}\right)$ & \\
Parâmetros do tubo & $1 / \mathrm{N}$ \\
Diâmetro $(\mathrm{D})$ & $1 / \mathrm{N}$ \\
Espessura da parede $(\mathrm{t})$ & 1 \\
Módulo de Elasticidade $\left(\mathrm{E}_{\mathrm{p}}\right)$ & 1 \\
Coeficiente de Poisson $\left(v_{\mathrm{p}}\right)$ & $1 / \mathrm{N}^{3}(*)$ ou $1 / \mathrm{N}^{4}$ \\
Momento de inércia $(\mathrm{I})$ & 1 \\
Rigidez do anel $\left(\mathrm{E}_{\mathrm{p}} \mathrm{I} / \mathrm{D}^{3}\right)$ & 1 \\
Deflexão $\left(\mathrm{d}^{3}\right)$ &
\end{tabular}

"Deformação plana 
Embora tradicionalmente associada a um determinado protótipo, a modelagem em centrífuga não se restringe unicamente a esse objetivo, podendo também ser utilizada com os seguintes propósitos (Ko 1988b):

i) Investigar um determinado fenômeno: os modelos não necessariamente representam um protótipo e são ensaiados para a investigação de um dado fenômeno. Esta investigação fornece informações para a elaboração de novas teorias a fim de justificar as observações experimentais.

ii) Validar métodos numéricos: os modelos são construídos para representar um determinado tipo de protótipo, mas com o objetivo de avaliar ferramentas de análise numérica. O desempenho do método numérico é avaliado através das discrepâncias entre os resultados do modelo e os resultados previstos através do método.

iii) Realizar análises paramétricas: os modelos são usados para gerar sensibilidade a respeito de um determinado parâmetro relevante para projeto.

Os modelos desta fase da pesquisa são enquadrados no item i) e tiveram por objetivo avaliar o mecanismo de ruptura decorrente do deslocamento de um alçapão retangular de modo a provocar o arqueamento ativo na massa de solo e o mecanismo de ruptura envolvendo um conduto submetido a perda de apoio localizada. Não se teve por objetivo relacionar os modelos a determinados protótipos. A centrífuga foi utilizada meramente para se gerar um campo de tensões no maciço distinto do observado em gravidade unitária, de modo a permitir a investigação dessa variável no comportamento do sistema.

Os modelos confeccionados consistiam basicamente de um maciço de areia pura contido em uma caixa metálica dotada de um alçapão retangular em sua base, sobre o qual repousava um tubo (ensaios também foram realizados sem a presença do tubo). Os modelos foram construídos aproveitando-se a simetria longitudinal do problema, sendo uma das faces da caixa transparente para possibilitar a visualização dos padrões de ruptura. Um total de 12 testes foi executado nesta etapa. Avaliou-se a influência da rigidez do tubo, da densidade do solo e do nível de tensão. Uma descrição detalhada sobre os equipamentos construídos, os materiais ensaiados, a 
instrumentação utilizada e procedimentos adotados para estes modelos é feita a seguir. No final do capítulo apresenta-se o programa dos ensaios executados.

\subsection{EQUIPAMENTOS UTILIZADOS}

\subsubsection{Caixa de Testes}

Utilizou-se nos ensaios uma caixa de alumínio com uma das faces laterais em acrílico com 25,4 mm de espessura, de modo a possibilitar a visualização do modelo. A caixa possui dimensões internas de $419 \mathrm{~mm}$ de comprimento, $203 \mathrm{~mm}$ de largura e $300 \mathrm{~mm}$ de altura (Figura 3.1a). De modo a reduzir o atrito lateral, as faces de alumínio foram revestidas com uma película de PTFE, ao passo que a face de acrílico foi revestida com duas camadas de filme transparente de poliéster. O filme em contato com o acrílico possuía uma malha impressa para auxiliar a construção dos modelos e servir de referência para acompanhar suas deformações durante o teste. $\mathrm{O}$ segundo filme evitava arranhões no primeiro e minimizava o atrito lateral.

As seguintes constatações de outros trabalhos empregando a mesma caixa de testes e os mesmos procedimentos para redução do atrito evidenciam a eficiência da utilização destes materiais:

a) Zornberg (1994) realizou ensaios com modelos de muro de reforçado com geotêxtil e verificou que os rasgos transversais dos reforços causados pela ruptura do muro não apresentaram curvatura em direção às bordas;

b) no mesmo trabalho também foi constatada boa concordância entre os deslocamentos observados através da face de acrílico e dentro da massa de solo quando o modelo foi umedecido e dissecado após o término do ensaio;

c) Woodruff (2004) duplicou um dos modelos de muro reforçado ensaiado por Lins Costa (2004), executado com a mesma caixa do presente trabalho. A largura do novo modelo foi aumentada em 2,5 vezes, porém sendo preservadas as demais características e métodos construtivos do modelo original (inclusive o procedimento adotado para redução do atrito de interface). Ambos os muros sofreram ruptura na mesma aceleração centrífuga, sugerindo ser desprezível a influência do atrito lateral no modelo menor. 


\subsubsection{Sistema de Alçapão}

O sistema de alçapão utilizado nesta fase da pesquisa é esquematizado nas Figuras 3.1 e 3.2. Trata-se de um fundo falso de alumínio com as mesmas dimensões internas da caixa. A parte frontal do fundo falso possui um rasgo que permite o deslizamento vertical de um prisma retangular de alumínio com $85 \mathrm{~mm}$ de comprimento e 17,5 $\mathrm{mm}$ de largura. O prisma é posicionado contra a parede de acrílico da caixa, compondo uma configuração representando uma meia-seção longitudinal de um alçapão retangular de $85 \mathrm{~mm}$ de comprimento $\left(\mathrm{L}_{\mathrm{v}}\right)$ e $35 \mathrm{~mm}$ de largura (B). Blocos de aço, parafusados pelo lado inferior do fundo falso, compõem as paredes do alçapão, a fim de confinar a areia que preenche o vazio formado.

Um eletroímã circular posicionado por baixo dos blocos, era responsável pela descida do alçapão. Fabricado pela AEC Magnetics e operando com 12V, o eletroímã possuía diâmetro de $63,5 \mathrm{~mm}$, altura de $19 \mathrm{~mm}$, peso de $680 \mathrm{~g}$ e capacidade de carga máxima de $890 \mathrm{~N}$. Um circuito passando através dos slip rings da centrífuga, com interruptor externo, permitia cessar a alimentação do ímã durante o ensaio, provocando a queda do prisma e a formação de um vazio na massa de solo. A altura de queda do prisma foi variada através de suportes de madeira posicionados no piso da caixa de testes, por baixo do ímã.

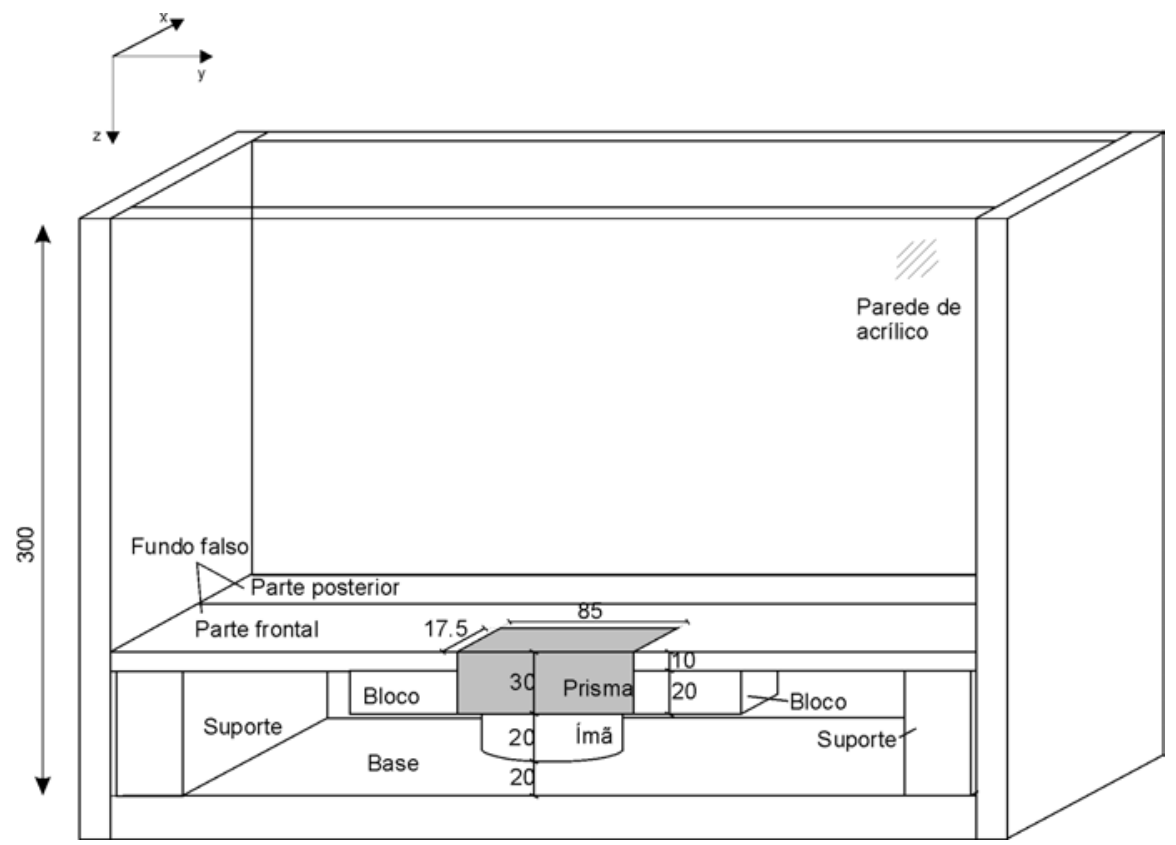

Figura 3.1. Caixa de testes utilizada nos ensaios na Universidade do Colorado, com sistema de alçapão; dimensões em mm. 


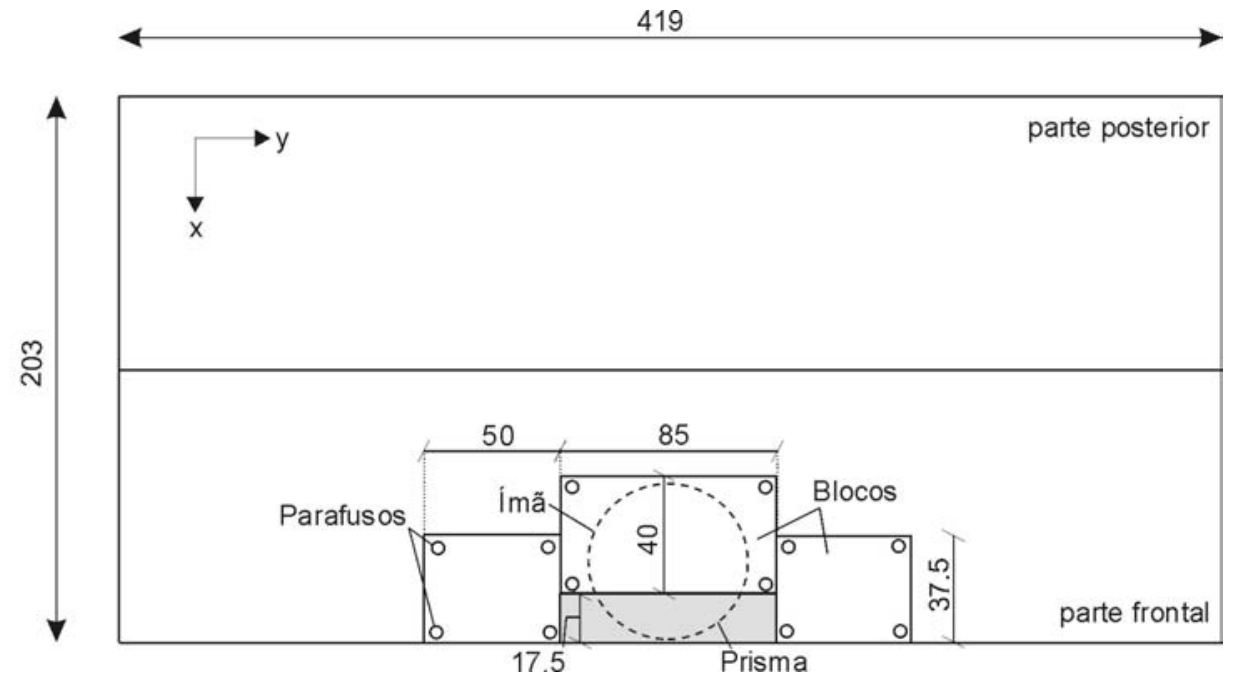

Figura 3.2 Vista inferior do sistema de alçapão; dimensões em mm.

\subsubsection{Centrífuga Utilizada}

Os ensaios foram realizados utilizando-se uma centrífuga Genisco, modelo 1230, com 15g-ton de capacidade, pertencente ao Departamento de Engenharia Civil da Universidade do Colorado. Capaz de acelerar uma carga de $136 \mathrm{~kg}$ a $100 \mathrm{~g}$, esta centrífuga possui raio igual a $1,36 \mathrm{~m}$ e é dotada de braços de rotação simétricos com cestos articulados nas extremidades. O volume máximo comportado pelos cestos é igual a 457 x 457 x $305 \mathrm{~mm}$. A rotação da centrífuga é proporcionada por um motor de $19 \mathrm{~kW}$ de potência, com controle manual. Um esquema da centrífuga utilizada é apresentado na Figura 3.3.

\subsubsection{Sistema de Obtenção de Imagens}

A obtenção de imagens dos modelos ensaiados na centrífuga foi feita através de uma câmera analógica monocromática de alta resolução, posicionada em uma plataforma presa ao cesto. De fabricação da $J A I$, o modelo usado possui resolução de $1300 \mathrm{x}$ 1030 pixels. As imagens eram enviadas através dos slip rings elétricos da centrífuga a um computador externo, equipado com uma placa de vídeo que convertia as imagens analógicas em digitais. $\mathrm{O}$ uso deste sistema permitia a visualização do 
modelo em tempo real e a gravação em intervalos pré-determinados de imagens selecionadas.

O enquadramento do modelo no cesto da centrífuga previamente ao ensaio era feito a partir de uma câmera analógica Mintron, modelo MS-468. Trata-se de um equipamento monocromático de baixa resolução (640 x 420 pixels), cujos sinais eram enviados através dos slip rings para o computador externo. A Figura 3.4 mostra o modelo no cesto da centrífuga juntamente com o equipamento de monitoração digital.

Os ensaios executados fora da centrífuga contaram com a utilização de uma câmera digital em cores com resolução de 1600 x 1200 pixels, de fabricação da Sony, montada sobre um tripé fixo. As imagens eram armazenadas na própria câmera e posteriormente descarregadas em um computador para tratamento.

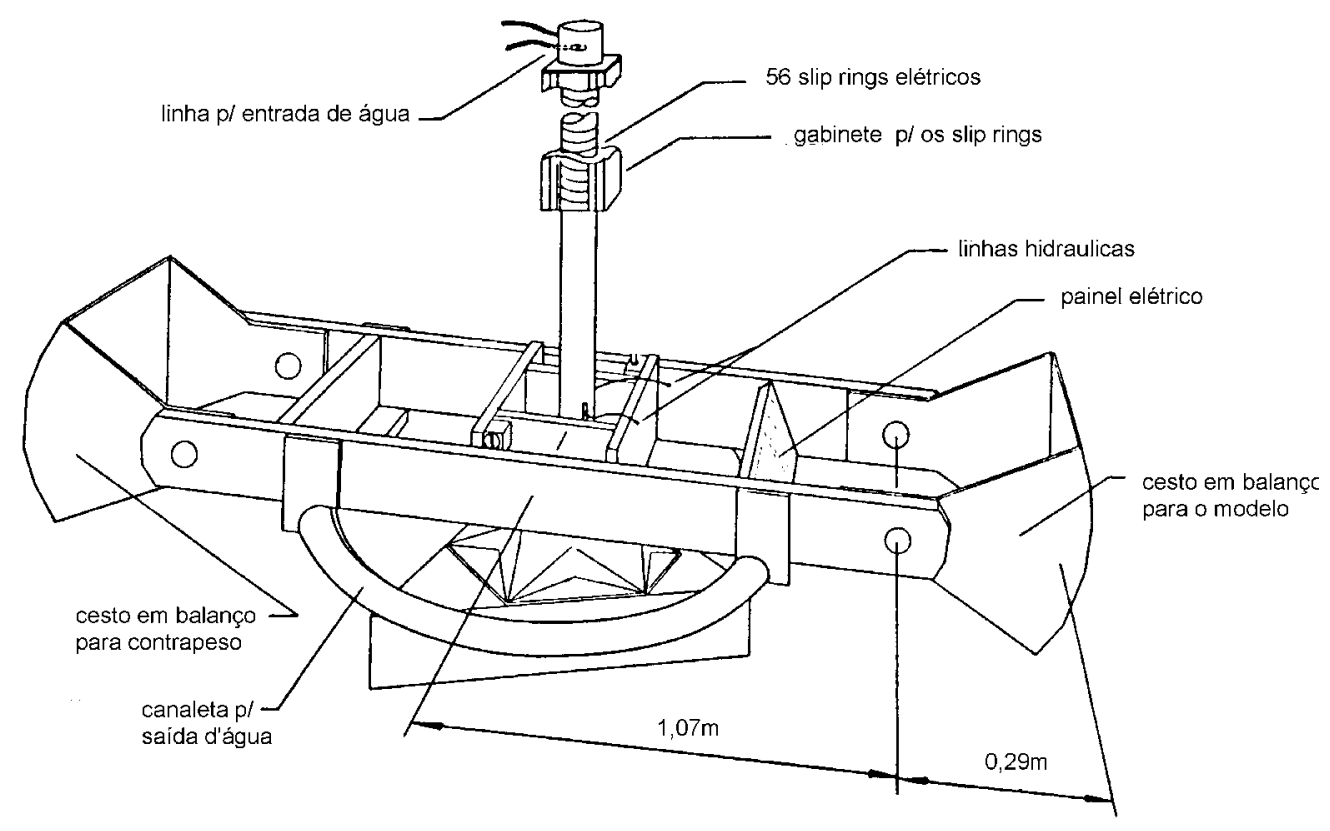

Figura 3.3. Centrífuga de 15 g-ton da Universidade do Colorado em Boulder (modificado de Ko 1988). 


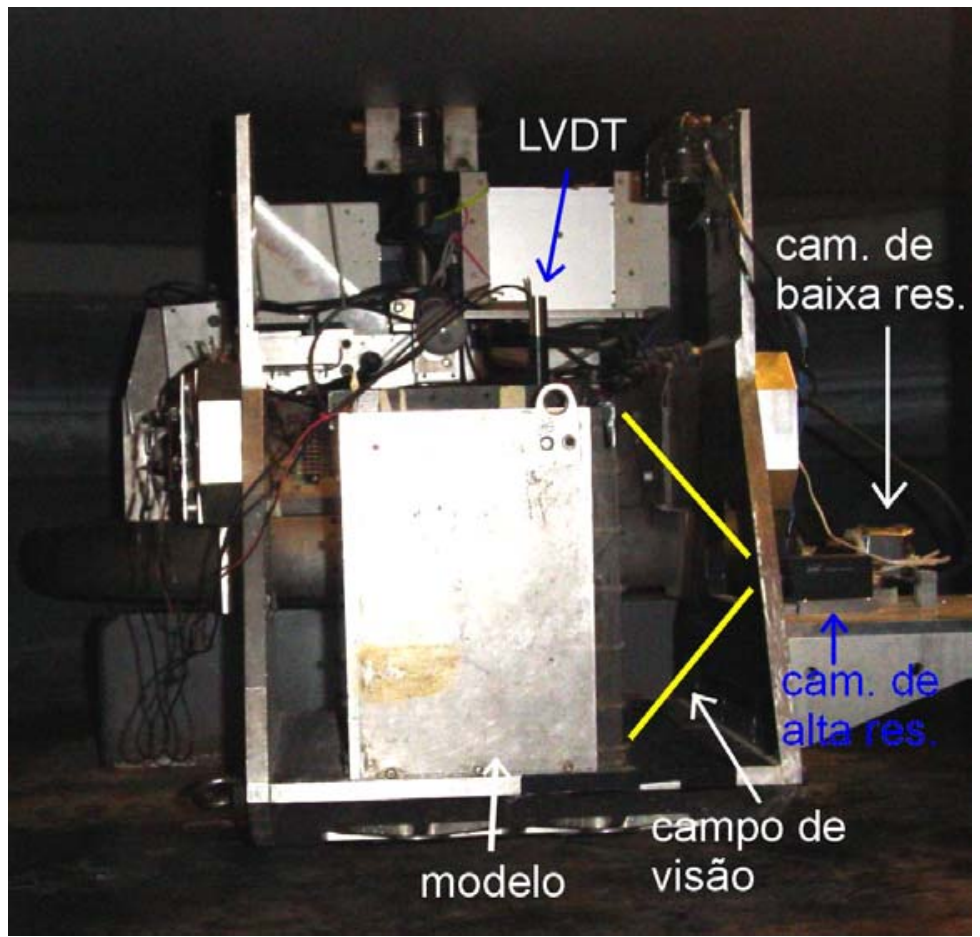

Figura 3.4. Vista do modelo posicionado no cesto em balanço da centrífuga.

\subsection{PROPRIEDADES DO SOLO UTILIZADO}

Os modelos foram preparados utilizando-se areia Ottawa F-75, comercializada pela U.S. Silica Company, EUA. O material é uma areia fina quartzosa, classificada como SP de acordo com o Sistema Unificado de Classificação de Solos. A areia possui tamanho médio das partículas $\left(\mathrm{D}_{50}\right)$ de $0,22 \mathrm{~mm}$, coeficiente de não-uniformidade de 1,28 e coeficiente de curvatura de 1,03. A distribuição granulométrica é mostrada na Figura 3.5. O peso específico dos sólidos é igual a $26,5 \mathrm{kN} / \mathrm{m}^{3}$ e os índices de vazio máximo e mínimo, iguais a 0,805 e 0,486, respectivamente. Os pesos específico mínimo e máximo do material correspondentes às densidades relativas utilizadas para construir os modelos, 42 e $85 \%$, eram iguais a 15,86 e $17,28 \mathrm{kN} / \mathrm{m}^{3}$, respectivamente.

Parâmetros de resistência e variação volumétrica da areia, compilados de diferentes fontes, são apresentados na Tabela 3.3, a qual inclui resultados de ensaios de compressão triaxial e de deformação plana. O ângulo de atrito de pico $\left(\phi^{\prime}{ }_{\mathrm{p}}\right)$ foi 
calculado a partir da máxima razão de tensões principais da curva $\left(\sigma^{\prime}{ }_{1} / \sigma^{\prime}{ }_{3}\right)$ versus deformação axial $\left(\varepsilon_{1}\right)$ e o ângulo de atrito crítico $\left(\phi_{\mathrm{cr}}\right)$, usando a média de três pontos na parte final da curva. Valores de $\phi_{\text {cr }}$ não foram obtidos para os ensaios em deformação plana porque suas curvas não apresentaram estabilização no pós-pico. $O$ ângulo de dilatação $(\psi)$ foi obtido a partir da máxima razão $\left[-\mathrm{d} \varepsilon_{\mathrm{v}} / \mathrm{d} \varepsilon_{1}\right]$ da curva de variação de volume $\left(\varepsilon_{\mathrm{v}}\right)$ versus deformação axial. O módulo de deformabilidade apresentado é o módulo secante correspondente a $50 \%$ do valor da máxima tensão desviadora $\left(\mathrm{E}_{50}\right)$. Os dados de Masad (1996) e Batiste (1998) mostram que o confinamento não exerce efeito significativo sobre o comportamento volumétrico e de resistência ao cisalhamento da areia para uma faixa entre 11 e $350 \mathrm{kPa}$. Entretanto, para uma tensão confinante de $1,3 \mathrm{kPa}, \phi_{\mathrm{p}}^{\prime}$ e $\left[-\mathrm{d} \varepsilon_{\mathrm{v}} / \mathrm{d} \varepsilon_{1}\right]_{\max }$ aumentam consideravelmente.

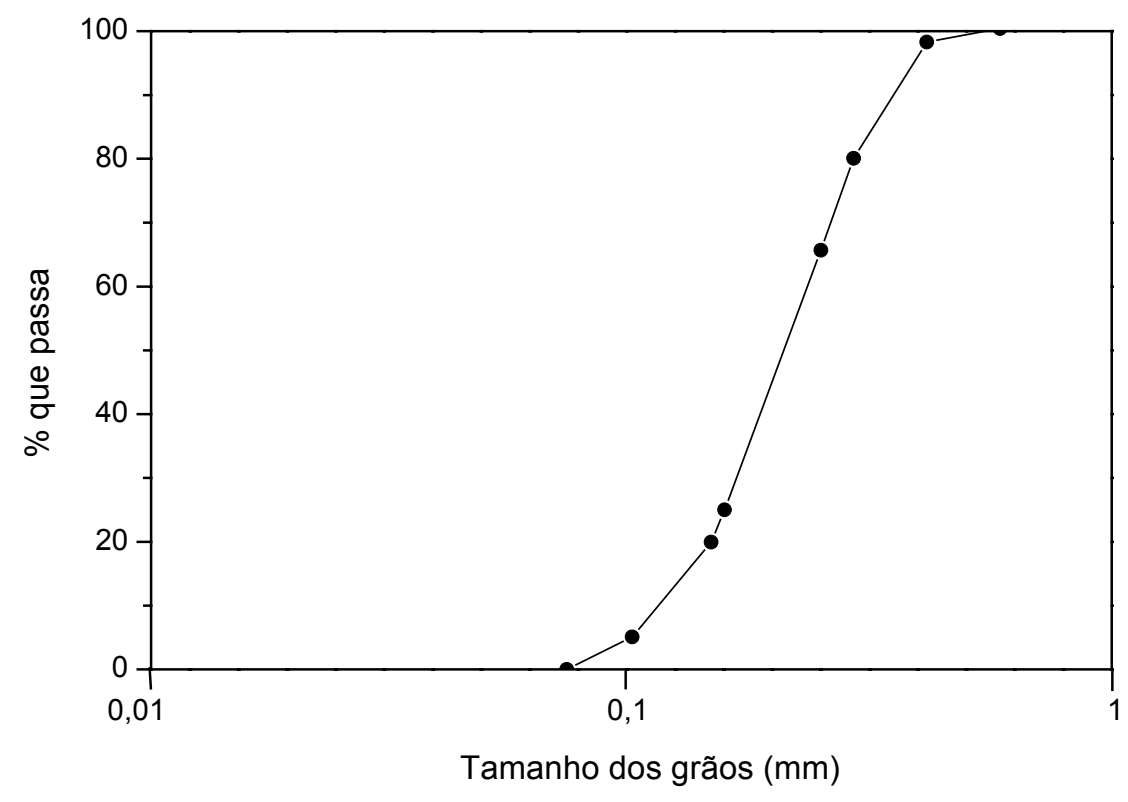

Figura 3.5. Curva granulométrica da areia utilizada (Ottawa F-75).

No estado plano o ângulo de atrito da areia sofre aumento em comparação com o ângulo obtido em ensaios triaxiais convencionais por causa da influência da tensão efetiva intermediária $\left(\sigma^{\prime}{ }_{2}\right)$ (Ladd et al. 1977). Em ensaios realizados em 
condições semelhantes, comparando-se valores do ângulo de atrito triaxial $\left(\phi_{\text {tc }}^{\prime}\right)$ com o obtido em estado plano ( $\phi^{\prime}$ ps $)$, a seguinte relação é obtida para a areia ensaiada:

$\phi^{\prime}{ }_{\mathrm{ps}}=1,16 \phi^{\prime}{ }_{\mathrm{tc}}$

Tabela 3.3. Parâmetros da areia Ottawa F-75

\begin{tabular}{|c|c|c|c|c|c|c|c|c|c|}
\hline Série & $\begin{array}{l}\text { Refe- } \\
\text { rência }\end{array}$ & $\begin{array}{c}\text { Tipo de } \\
\text { teste }\end{array}$ & $\begin{array}{c}D_{r} \\
(\%)\end{array}$ & $\begin{array}{c}\sigma_{3}^{\prime} \\
(\mathrm{kPa}) \\
\end{array}$ & $\begin{array}{l}\phi^{\prime} \mathrm{p} \\
\left({ }^{0}\right)\end{array}$ & $\begin{array}{c}\phi_{\mathrm{cr}} \\
\left({ }^{0}\right)\end{array}$ & $\begin{array}{c}\psi_{\max } \\
\left(^{0}\right)\end{array}$ & {$\left[-\mathrm{d} \varepsilon_{\mathrm{v}} / \mathrm{d} \varepsilon_{1}\right]_{\max }$} & $\begin{array}{c}\mathrm{E}_{50} \\
(\mathrm{MPa})\end{array}$ \\
\hline \multirow{4}{*}{1} & & \multirow{4}{*}{ Triaxial } & 90 & 350 & 41,7 & 34,0 & 17,2 & 0,84 & 64,2 \\
\hline & Masad & & 90 & 300 & 40,6 & 33,3 & 18,2 & 0,91 & 46,7 \\
\hline & et al. & & 90 & 250 & 41,8 & 34,3 & 18,4 & 0,92 & 39,7 \\
\hline & (1996) & & 90 & 150 & 40,0 & 33,5 & 17,0 & 0,83 & 35,9 \\
\hline \multirow{4}{*}{2} & \multirow{4}{*}{$\begin{array}{l}\text { Batiste } \\
\text { (1998) }\end{array}$} & \multirow{4}{*}{ Triaxial } & 87 & 68,9 & 42,4 & 35,5 & 15,4 & 0,73 & 35,6 \\
\hline & & & 87 & 34,5 & 44,8 & 37,0 & 15,4 & 0,73 & 20,6 \\
\hline & & & 88 & 11,2 & 44,6 & 37,9 & 15,2 & 0,71 & 13,0 \\
\hline & & & 84 & 1,3 & 48,0 & 34,3 & 24,6 & 1,43 & 3,7 \\
\hline \multirow{4}{*}{3} & \multirow{4}{*}{$\begin{array}{l}\text { Shibli } \\
\text { (1995) }\end{array}$} & \multirow{4}{*}{$\begin{array}{c}\text { Defor- } \\
\text { mação } \\
\text { plana }\end{array}$} & 86 & 100 & 48,3 & $\ldots$ & 17,8 & 0,88 & 40,3 \\
\hline & & & 44 & 100 & 39,9 & $\ldots$ & 9,4 & 0,39 & 27,5 \\
\hline & & & 97 & 15 & 49,8 & $\ldots$ & 18,5 & 0,93 & 7,7 \\
\hline & & & 55 & 15 & 42,1 & $\ldots$ & 8,5 & 0,34 & 8,7 \\
\hline
\end{tabular}

\subsection{PROCEDIMENTOS DE ENSAIO}

\subsubsection{Construção dos Modelos}

O fundo falso, juntamente com o prisma e o eletroímã já ligado, era posicionado dentro da caixa de testes e todas as frestas eram seladas com fita adesiva para impedir a saída de areia. As frestas em torno do prisma recebiam uma fina camada de graxa de alto vácuo para evitar a migração de grãos de areia e o conseqüente travamento do sistema de alçapão durante o ensaio.

Dentre as técnicas comumente utilizadas na preparação de amostras, como compactação, vibração e chuva-de-areia, esta última possui a vantagem sobre as 
demais de gerar amostras mais homogêneas (Miura e Toki 1982), uma vez que permite um controle preciso da porosidade desejada. Outrossim, o método permite ainda a obtenção de amostras com estruturas mais semelhantes às de depósitos naturais formados por sedimentação. Por estas razões, a técnica de chuva-de-areia foi adotada para a construção dos modelos. A técnica é descrita em maior detalhe no Capítulo 4.

O preenchimento da caixa de testes foi realizado seguindo-se os procedimentos adotados por Batiste (1998). Para se atingir $D_{r}=85 \%$, a areia era pluviada através de um funil com abertura de $10 \mathrm{~mm}$ e um conjunto seis peneiras (duas $\mathrm{n}^{\circ} 4$ e quatro $\mathrm{n}^{\circ} 10$ ) com malhas rotacionadas a $45^{0}$ uma das outras. O conjunto era suportado por um pórtico de madeira, como esquematiza a Figura 3.6. A densidade de $42 \%$ era atingida vertendo-se a areia de uma altura de $330 \mathrm{~mm}$ através de um funil com $19 \mathrm{~mm}$ de diâmetro e uma malha com 6,4 $\mathrm{mm}$ de abertura, posicionada a $25 \mathrm{~mm}$ de sua extremidade.

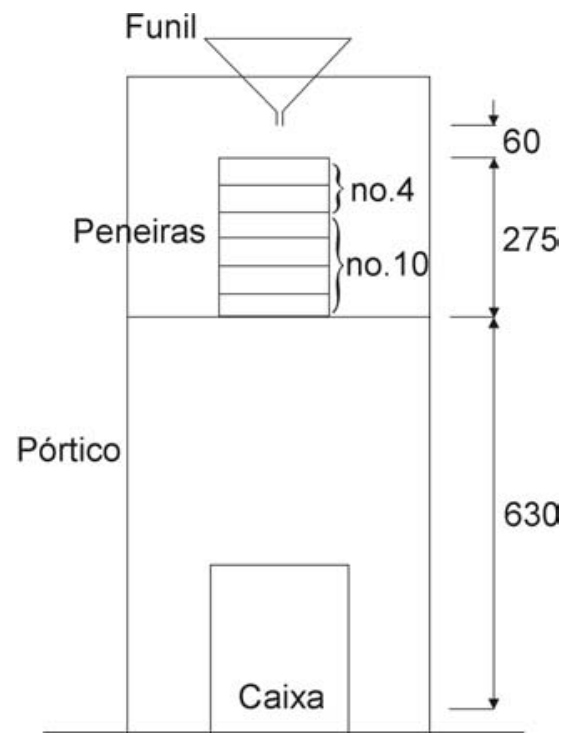

Figura 3.6. Aparato para pluviação da areia Ottawa para obter $\mathrm{D}_{\mathrm{r}}=85 \%$. Dimensões em $\mathrm{mm}$.

De modo a permitir o cálculo das deformações na massa de solo, 12 linhas de areia (10 no caso de modelos com tubo) contendo marcadores coloridos eram dispostas junto à face de acrílico da caixa em intervalos verticais de $12,7 \mathrm{~mm}$ (ver Figura 3.10a). Compostos pela mesma areia utilizada nos ensaios, os marcadores 
possuíam formato trapezoidal e cor preta ou verde. Dentre diversas tonalidade testadas, estas apresentaram melhor contraste com a cor da areia na câmera monocromática da centrífuga. A distância horizontal dos marcos, de centro a centro, era de $9,5 \mathrm{~mm}$.

Previamente à colocação das linhas coloridas, a área da superfície do maciço próxima à parede transparente era devidamente nivelada por intermédio de um tubo de alumínio ligado a um sistema de vácuo e uma régua (Ueno 1998). O excesso de areia colorida era sugado de modo a conferir às linhas uma espessura constante de aproximadamente $3 \mathrm{~mm}$. Doze camadas de areia preta, sem marcos de referência, permitiam a visualização das localizações de deformação no plano xy (transversal). As camadas foram dispostas continuamente às linhas coloridas da face de acrílico, preenchendo uma área de aproximadamente 120 x $120 \mathrm{~mm}$ sobre a região do alçapão (Figura 3.7). A superfície do modelo era nivelada através de uma placa rígida com formato para conferir uma altura uniforme de $159 \mathrm{~mm}$.

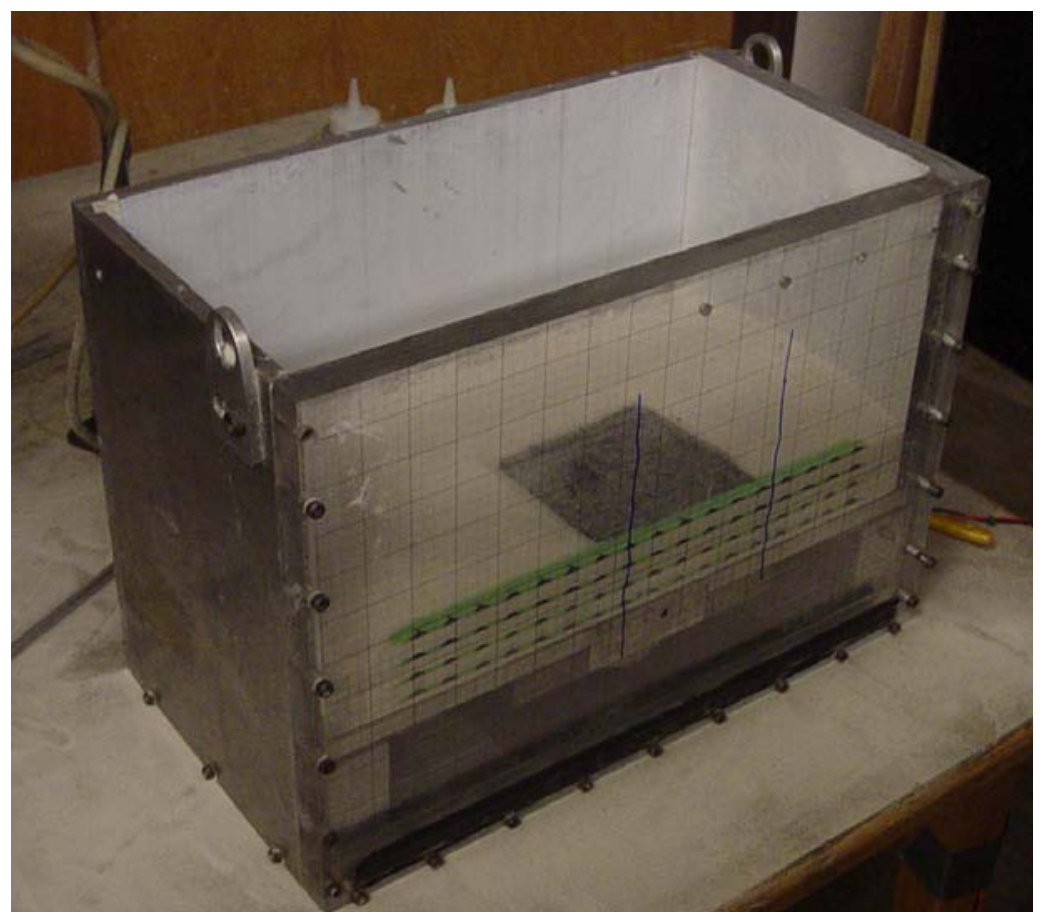

Figura 3.7. Modelo em fase de construção.

A montagem era encerrada com o posicionamento de um LVDT na superfície do maciço. O equipamento era de fabricação da Schaevitz Sensors, modelo DC- 
EC500, com curso de 25,4 mm e resolução de 0,01 mm. O aparelho era posicionado transversalmente na metade do comprimento da caixa (seção S1) através de uma trava parafusada à mesma (ver Figuras 3.4 e 3.8). O centro da haste distava $9 \mathrm{~mm}$ da face de acrílico e sua ponta repousava sobre uma placa metálica quadrada com 15 $\mathrm{mm}$ de lado, posicionada na superfície da areia. O sinal gerado era transmitido através dos slip rings para um sistema de aquisição externo à centrífuga. Alguns ensaios contaram com um segundo LVDT também na seção S1, porém com a haste distando $43 \mathrm{~mm}$ da face.

Os tubos utilizados em alguns dos modelos eram de alumínio, com diâmetro externo de 25,4 mm, comprimento de $400 \mathrm{~mm}$ e espessura da parede (t) de 0,127 ou 0,7 mm. Estas espessuras foram selecionadas para representar tubos flexíveis (F) e rígidos $(\mathrm{R})$, respectivamente. A meia-seção era disposta contra a parede de acrílico sobre uma base de areia com 9,5 $\mathrm{mm}$ de altura, previamente nivelada. Os mesmos procedimentos para preenchimento da caixa com a areia e colocação dos marcos foram seguidos. Para evitar reflexos na fotografia os tubos receberam uma fina camada de tinta branca fosca, sobre a qual foram pintadas listras pretas transversais e longitudinais para facilitar o acompanhamento das deflexões. Figura 3.8a exibe um esquema da configuração dos modelos construídos. As extremidades do meio-tubo não apresentaram rotação após o teste, apesar de nenhum artifício ter sido utilizado para impedi-la.

\subsubsection{Execução dos Ensaios}

Nos ensaios em centrífuga a aceleração era aumentada até $45 \mathrm{~g}$ em incrementos de $10 \mathrm{~g}$ e um incremento final de $5 \mathrm{~g}$. Após a aplicação de cada incremento, a aceleração era mantida constante por 3 min para garantir a estabilização. O controle do tempo era efetuado através de um cronômetro disparado quando o aumento da aceleração era iniciado. Uma imagem do modelo no interior da centrífuga era capturada após cada incremento. As leituras do LVDT eram gravadas em intervalos de 1 segundo, desde o início da aplicação da rotação da centrífuga. Atingido a aceleração final de $45 \mathrm{~g}$, a alimentação do eletroímã era cortada, causando a queda 
do prisma. Imagens do modelo após a translação do prisma eram então obtidas. A duração total dos testes era de aproximadamente $40 \mathrm{~min}$.
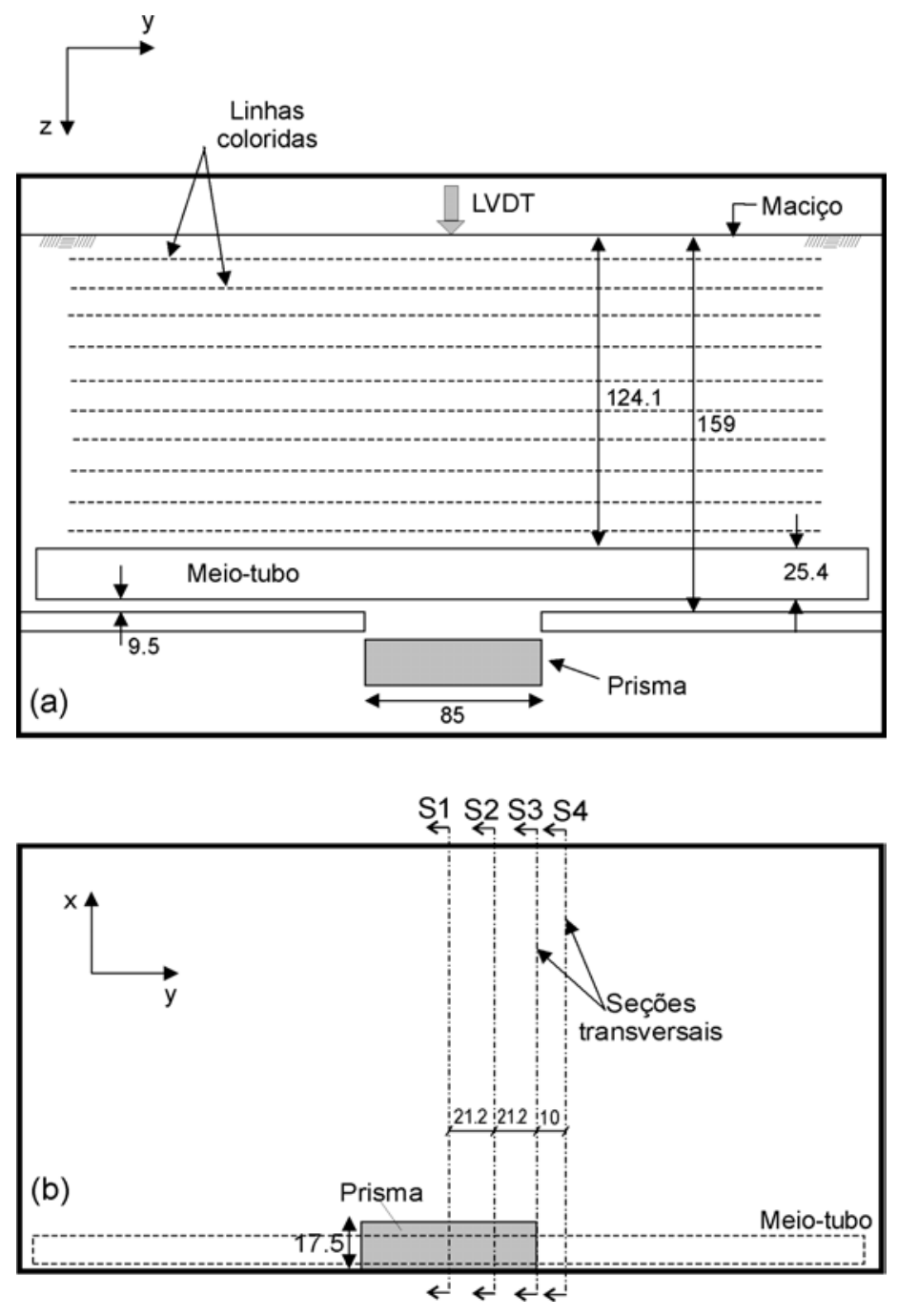

Figura 3.8. a) Esquema da configuração dos modelos; b) vista em planta do modelo mostrando a posição das seções transversais. Dimensões em mm.

Nos ensaios realizados a $1 \mathrm{~g}$ uma ou mais imagens do modelo eram obtidas antes e após o deslocamento do prisma com uma câmera fotográfica digital acoplada a um tripé devidamente posicionado defronte à face de acrílico da caixa de ensaios. As leituras do LVDT eram registradas da mesma forma que nos ensaios a $45 \mathrm{~g}$.

Ao término dos testes a areia era umedecida a partir da superfície até saturar por completo e, em seguida, os modelos eram dissecados a fim de serem obtidos os padrões transversais das localizações de deformação (plano x-z). Os deslocamentos 
das camadas de areia colorida eram obtidos nesta direção em quatro seções verticais distintas. Como ilustra a Figura 3.8b, as três primeiras seções eram localizadas no centro do comprimento do prisma (seção S1), na metade da distância entre o centro e o vértice (seção S2) e no vértice do prisma (seção S3). A quarta seção (S4) era escavada na massa de solo externa, a $10 \mathrm{~mm}$ de distância da borda do alçapão. $\mathrm{O}$ umedecimento era realizado cautelosamente e de forma uniforme para não criar crateras, prejudicando assim a integridade do modelo. A escavação do maciço era realizada com extremo cuidado, de modo a causar a menor perturbação possível na massa intacta. A seção escavada era moldada para se aproximar ao máximo de um plano vertical. Depois de escavada, uma imagem fotográfica da seção era obtida e armazenada para análise posterior. A Figura 3.9 mostra um dos modelos (sem tubo) após ser dissecado.

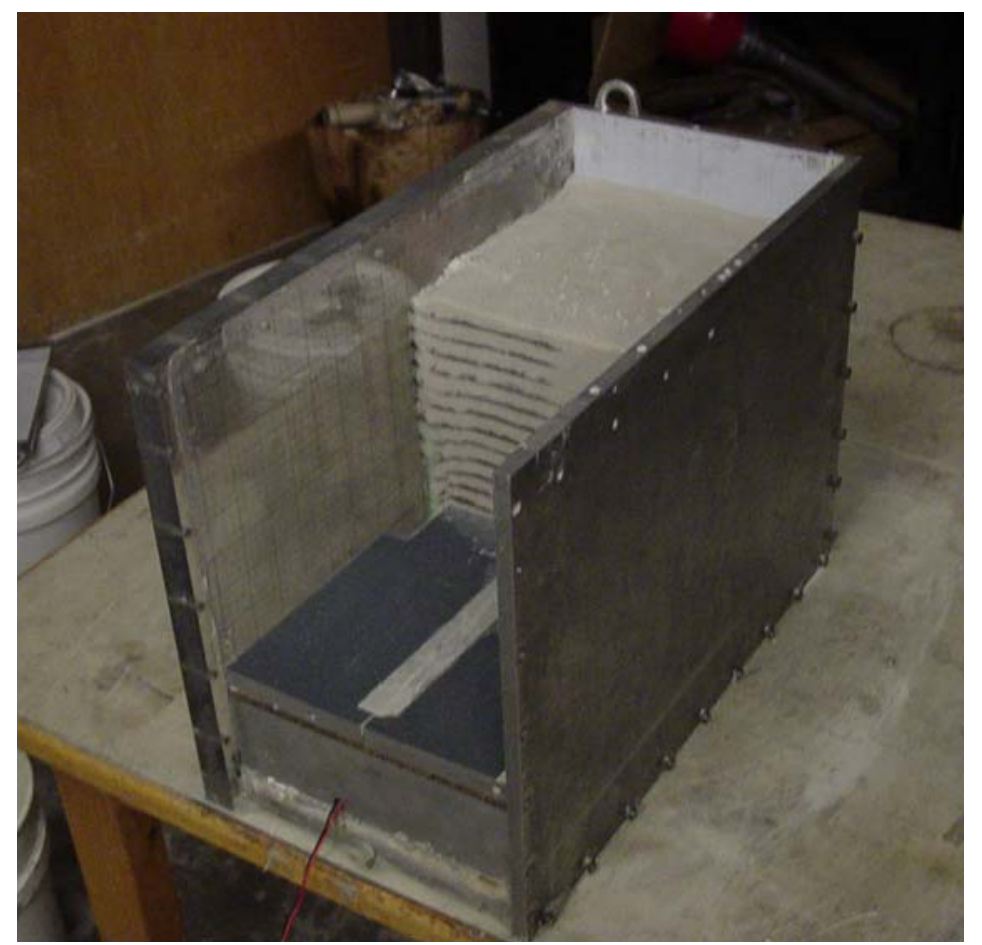

Figura 3.9. Modelo dissecado para obtenção de imagens das seções transversais. 


\subsection{ANÁLISE DIGITAL DE IMAGENS}

\subsubsection{Considerações Iniciais}

A utilização de técnicas fotográficas para o registro do comportamento de amostras de solo, modelos e protótipos geotécnicos data do final da década de 1960, com os trabalhos pioneiros de Buttlerfield et al. (1970) e Roscoe (1970). As técnicas desenvolvidas tinham como princípio básico a captura dos deslocamentos ao longo do tempo de uma malha de pequenos marcos sólidos dispostos na interface de uma superfície transparente com o solo. Após o tratamento das fotografias, as deformações na massa de solo podiam ser calculadas assumindo-se compatibilidade entre os deslocamentos dos marcos e das partículas do solo.

O advento da digitalização de imagens surgido na década de 1990 permitiu uma melhora expressiva da técnica fotográfica, principalmente no que diz respeito ao aumento da velocidade de tratamento e a possibilidade de aplicação de técnicas para aperfeiçoamento da imagem, de modo a facilitar sua análise. Realce de contraste e aplicação de filtros são exemplos típicos dos aperfeiçoamentos possíveis.

No processo de digitalização, a imagem é dividida em elementos denominados pixels, aos quais são atribuídas coordenadas horizontais e verticais individuais. O número de pixels contidos em uma imagem define sua resolução. Uma resolução de 640 x 480 pixels é usual, mas há equipamentos capazes de fornecer, a custo muito elevado, resoluções tão altas quanto 4096 x 4096 pixels. Atualmente, o mercado dispõe de equipamentos capazes de converter uma imagem analógica em formato digital automaticamente, o que é particularmente vantajoso por diminuir significativamente o tamanho do arquivo digital gerado e evitar perdas de qualidade.

Nesta última década, a aplicação de técnicas de análise digital de imagens difundiu-se bastante na área geotécnica. Alguns trabalhos que utilizaram tais técnicas para a determinação de deformações na massa de solo foram Garnier et al. (1991), Shibli (1995), Davies and Jones (1998) e Arriaga (2003). 


\subsubsection{Cálculo de Deformações na Massa de Solo}

O primeiro passo para o cálculo das deformações no solo consistiu em obter o centróide dos marcos de referência através de um programa de tratamento de imagens denominado SigmaScan, disponível comercialmente. O aplicativo gerava arquivos de saída contendo as coordenadas das posições iniciais e finais dos marcos. De posse desses arquivos, as deformações eram calculadas dividindo a massa de solo em uma malha de 704 elementos triangulares cujos nós eram representados pelos marcos. A Figura 3.10a exibe um esquema simplificado da malha, ao passo que a Figura $3.10 \mathrm{~b}$ mostra um elemento triangular de solo antes e depois de sofrer deformação. As deformações no solo foram calculadas através de:

$$
\left\{\begin{array}{c}
\varepsilon_{y} \\
\varepsilon_{z} \\
\gamma_{y z}
\end{array}\right\}=\frac{1}{2 A}\left[\begin{array}{cccccc}
\left(z_{j}-z_{k}\right) & 0 & \left(z_{k}-z_{i}\right) & 0 & \left(z_{i}-z_{j}\right) & 0 \\
0 & \left(y_{k}-y_{j}\right) & 0 & \left(y_{i}-y_{k}\right) & 0 & \left(y_{j}-y_{i}\right) \\
\left(y_{k}-y_{j}\right) & \left(z_{j}-z_{k}\right) & \left(y_{i}-y_{k}\right) & \left(z_{k}-z_{i}\right) & \left(y_{j}-y_{i}\right) & \left(z_{i}-z_{j}\right)
\end{array}\right]\left\{\begin{array}{c}
P_{i} \\
Q_{i} \\
P_{j} \\
Q_{j} \\
P_{k} \\
Q_{k}
\end{array}\right\}
$$

onde: $\varepsilon_{\mathrm{y}}=$ deformação linear específica na direção $\mathrm{y} ; \varepsilon_{\mathrm{z}}=$ deformação linear específica na direção $z ; \gamma_{\mathrm{yz}}=$ deformação cisalhante; $2 \mathrm{~A}=\left(\mathrm{y}_{\mathrm{i}}-\mathrm{y}_{\mathrm{k}}\right)\left(\mathrm{z}_{\mathrm{j}}-\mathrm{z}_{\mathrm{k}}\right)-\left(\mathrm{y}_{\mathrm{k}}-\right.$ $\left.\mathrm{y}_{\mathrm{j}}\right)\left(\mathrm{z}_{\mathrm{k}}-\mathrm{z}_{\mathrm{i}}\right)$. Os demais parâmetros encontram-se indicados na Figura 3.10b.

As deformações principais $\varepsilon_{1}$ e $\varepsilon_{3}$ foram obtidas através da expressão (3.3) e as deformações volumétrica e cisalhante máxima foram calculadas através das expressões (3.4) e (3.5), respectivamente. Rotinas foram programadas na linguagem do aplicativo Matlab para calcular as deformações de cada elemento triangular da malha e gerar os contornos correspondentes no espaço yz (Anexo A).

$$
\begin{aligned}
& \varepsilon_{1}=\frac{\varepsilon_{\mathrm{y}}+\varepsilon_{\mathrm{z}}}{2} \pm\left[\left(\frac{\varepsilon_{\mathrm{y}}-\varepsilon_{\mathrm{z}}}{2}\right)^{2}+\left(\frac{\gamma_{\mathrm{yz}}}{2}\right)^{2}\right]^{0,5} \\
& \varepsilon_{3} \\
& \varepsilon_{\mathrm{v}}=\varepsilon_{1}+\varepsilon_{3} \\
& \gamma_{\max }=\varepsilon_{1}-\varepsilon_{3} .
\end{aligned}
$$


Medidas com os marcadores dispostos nos locais mais afastados do alçapão, onde o solo não sofre deformações, permitiram estimar o erro geral da técnica em torno de $\pm 1 \%$ para as deformações fornecidas.

(a)

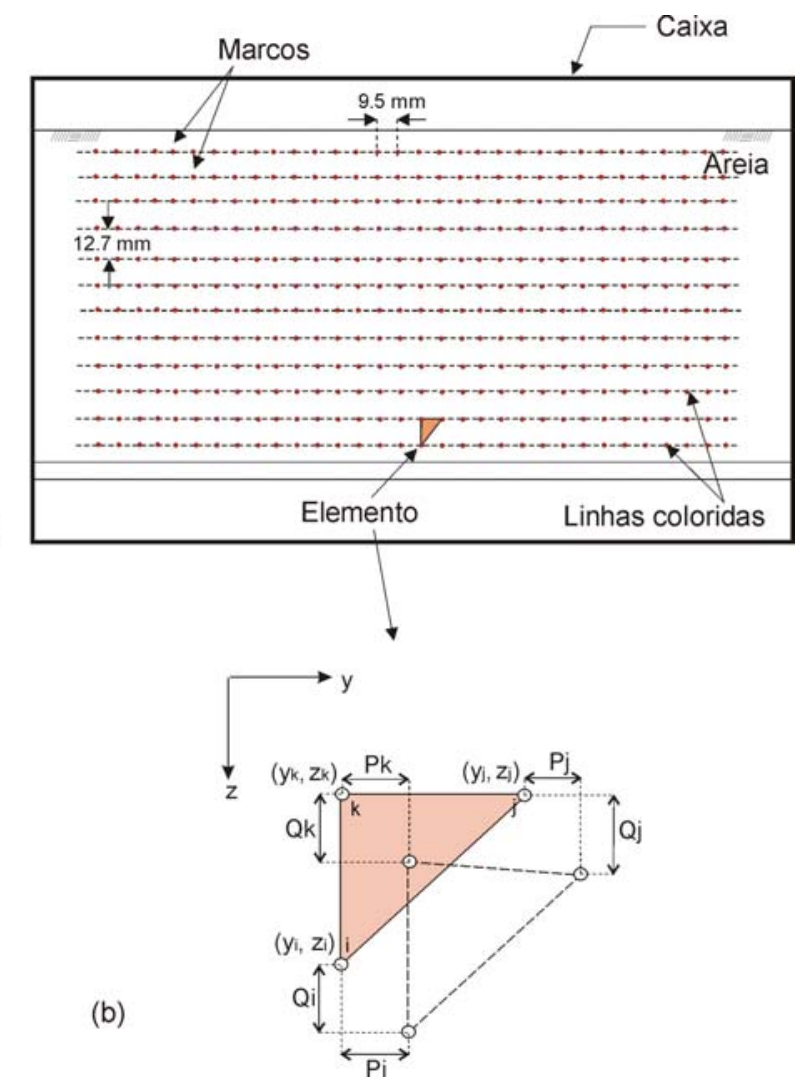

Figura 3.10. a) Disposição dos centróides dos marcos no modelo; b) elemento triangular de solo antes e depois de ser deformado.

\subsection{PROGRAMA DE ENSAIOS}

Esta parte da pesquisa incluiu um total de 12 testes, agrupados em duas séries distintas. Um sumário dos ensaios é apresentado na Tabelas 3.4 e 3.5, as quais indicam a designação e características dos modelos. A aceleração imposta ao modelo (A), a densidade relativa do solo $\left(\mathrm{D}_{\mathrm{r}}\right)$, o deslocamento do alçapão $(\delta)$ e rigidez do tubo foram as variáveis investigadas. Densidades relativas de 42 e $85 \%$ foram selecionadas para representar maciços fofos e compactos, respectivamente. Os modelos foram ensaiados com acelerações centrífugas de 1 e $45 \mathrm{~g}$, o que corresponde 
no maciço compacto a tensões verticais sobre o alçapão de aproximadamente 2,7 e $124 \mathrm{kPa}$, respectivamente. No maciço fofo, a tensão correspondente a $45 \mathrm{~g}$ é de aproximadamente $113 \mathrm{kPa}$ e a $1 \mathrm{~g}, 2,5 \mathrm{kPa}$.

A série A (Tabela 3.4) engloba os ensaios de arqueamento, ou seja, sem tubo. Nesta série o deslocamento relativo máximo do alçapão nos modelos foi $\delta / \mathrm{B}=$ $57,1 \%$, sendo esta magnitude selecionada para permitir a visualização de padrões nítidos de localizações de deformação. De forma a estudar a propagação das localizações, ensaios com $\delta / \mathrm{B}=14,3$ e $28,6 \%$ também foram realizados. Na série $\mathrm{B}$ (Tabela 3.5) foram agrupados os ensaios com tubo, todos efetuados a $45 \mathrm{~g}$ e com $\delta / \mathrm{B}$ $=57,1 \%$. A influência da rigidez do tubo e da densidade da areia na interação soloestrutura foi avaliada nesta seqüência de testes.

Tabela 3.4. Série A: ensaios de arqueamento

\begin{tabular}{cccc}
\hline Ensaio & $\begin{array}{c}\text { Densidade } \\
\text { relativa, } \mathrm{D}_{\mathrm{r}}(\%)\end{array}$ & $\begin{array}{c}\text { Aceleração } \\
\text { centrífuga, A (g) }\end{array}$ & $\begin{array}{c}\text { Deslocamento do } \\
\text { alçapão, } \delta / \mathrm{B}(\%)\end{array}$ \\
\hline A1 & 85 & 45 & 14,3 \\
A2 & 85 & 45 & 28,6 \\
A3 & 85 & 45 & 57,1 \\
\hline A4 & 85 & 1 & 14,3 \\
A5 & 85 & 1 & 28,6 \\
A6 & 85 & 1 & 57,1 \\
\hline A7 & 42 & 45 & 57,1 \\
\hline A8 & 42 & 1 & 57,1
\end{tabular}

Tabela 3.5. Série B: ensaios com tubo

\begin{tabular}{|c|c|c|c|c|c|}
\hline Ensaio & $\begin{array}{c}\text { Densidad } \\
\text { e relativa, } \\
\mathrm{D}_{\mathrm{r}}(\%)\end{array}$ & $\begin{array}{c}\text { Aceleração } \\
\text { centrífuga, } \\
\text { A (g) }\end{array}$ & $\begin{array}{c}\text { Deslocamento } \\
\text { do alçapão, } \\
\delta / \mathrm{B}(\%)\end{array}$ & $\begin{array}{c}\text { Espessura } \\
\text { do tubo, } \mathrm{t} \\
(\mathrm{mm})\end{array}$ & $\begin{array}{l}\text { Tipo de } \\
\text { tubo }\end{array}$ \\
\hline B1 & 42 & 45 & 57,1 & 0,127 & $\mathrm{~F}$ \\
\hline B2 & 85 & 45 & 57,1 & 0,127 & $\mathrm{~F}$ \\
\hline B3 & 42 & 45 & 57,1 & 0,7 & $\mathrm{R}$ \\
\hline B4 & 85 & 45 & 57,1 & 0,7 & $\mathrm{R}$ \\
\hline
\end{tabular}

Obs.: $\mathrm{F}$ = flexível; $\mathrm{R}=$ rígido. 


\section{Materiais e Métodos do Programa de Ensaios da EESC/USP}

\subsection{CONSIDERAÇÕES INICIAIS}

Os modelos construídos e ensaiados na Escola de Engenharia de São Carlos consistiam basicamente de um maciço de areia pura contido em uma caixa metálica dotada de um mecanismo de alçapão em sua base, sobre o qual repousava um tubo. Uma sobrecarga era aplicada à superfície do maciço e em seguida o alçapão era movimentado verticalmente em sentido descendente ou ascendente. Alguns ensaios também foram realizados sem a presença do tubo. A execução destes modelos teve como enfoque principal avaliar a redistribuição das tensões no maciço e as deflexões e deformações do tubo mediante a movimentação do alçapão. Os equipamentos construídos, os materiais ensaiados, a instrumentação utilizada e procedimentos adotados nesta etapa da pesquisa são descritos a seguir.

\subsection{PROJETO DA CAIXA DE TESTES}

O primeiro passo para o dimensionamento da caixa de testes consistiu da definição do diâmetro (D) do tubo a ser utilizado nos modelos, o qual foi fixado em $80 \mathrm{~mm}$. Esta dimensão foi selecionada de forma a facilitar a instrumentação interna do tubo e para que o modelo não adquirisse dimensões inviáveis. O passo seguinte envolveu a identificação das condições de contorno de uma instalação de um tubo no campo. 
Uma instalação típica engloba um conduto imerso em um aterro, sujeito a tensões provenientes do peso próprio do solo e, eventualmente, da superfície. A simulação dessa condição de campo no laboratório deve ser tal que a influência do contorno sob a distribuição das tensões e deformações desenvolvidas na massa de solo seja mínima. Isso significa que a distância das paredes laterais da estrutura que contém o modelo deve, ao mesmo tempo, ser suficientemente grande para minimizar a influência do atrito de interface no sistema solo-conduto e suficientemente pequena para não inviabilizar a construção e utilização da caixa.

Em uma situação ideal em que as paredes da caixa de testes fossem perfeitamente lisas, ou seja, se o ângulo de atrito de interface $\left(\phi_{\mathrm{w}}\right)$ fosse nulo, a tensão vertical no piso, antes do início da movimentação do alçapão, seria igual à soma da sobrecarga aplicada e do peso próprio do solo. Entretanto, mesmo com a utilização de métodos adequados, a eliminação de todo o atrito lateral não é possível, de modo que alguma redução da tensão vertical na base da caixa deve sempre ser esperada.

A Tabela 4.1 enumera alguns valores adotados em trabalhos experimentais e numéricos para a distância da parede do tubo à parede da caixa (e) em relação ao diâmetro do conduto (D). Levando-se em consideração as informações resumidas na Tabela 3.1, adotou-se e/D =3, equivalendo a uma largura interna de $560 \mathrm{~mm}$ para um tubo com diâmetro de $80 \mathrm{~mm}$. Esta dimensão, aliada a um esquema composto por de filmes entre as paredes e a massa de solo, foi suficiente para tornar mínima a interferência do atrito lateral.

O comprimento da caixa foi definido através do comprimento do conduto. Este deveria ser tal que, em conjunto com seu diâmetro e espessura, conferisse flexibilidade suficiente para o estudo da interação longitudinal com o solo. O tubo deveria ainda possuir extensão suficiente para possibilitar a instrumentação de seções transversais de modo a permitir acompanhar o desenvolvimento das tensões e deflexões ao longo de seu eixo axial. Segundo Hetényi (1946), para ser classificada como flexível, uma viga deve possuir comprimento (L) superior a $\pi / \lambda$, sendo $\lambda$ igual a (4.1). Supondo um tubo com $\mathrm{D}=80 \mathrm{~mm}, \mathrm{E}=3,2 \times 10^{6} \mathrm{kPa}$ e $\mathrm{t}=2 \mathrm{~mm}$ e um solo com $E_{\mathrm{s}}=35 \mathrm{MPa}$ e $v=0,4, \mathrm{~L}$ não deve ser inferior a $330 \mathrm{~mm}$ segundo essa classificação. Para os ensaios a serem realizados, adotou-se L $=1400 \mathrm{~mm}$. 
$\lambda=\sqrt[4]{\frac{2 E_{s}}{\pi \mathrm{D}^{3} \mathrm{tE}_{\mathrm{p}}\left(1-\mathrm{v}_{\mathrm{s}}^{2}\right)}}$

onde: $\mathrm{E}_{\mathrm{s}}=$ módulo de deformabilidade do solo; $v_{\mathrm{s}}=$ coeficiente de Poisson do solo; $\mathrm{E}$ $=$ módulo de elasticidade do material do tubo; $\mathrm{t}=$ espessura da parede do tubo.

Tabela 4.1. Valores de e/D adotados em ensaios laboratoriais e análises numéricas

\begin{tabular}{l|c|l}
\hline \multicolumn{1}{c|}{ Referência } & Valor adotado para e/D & \multicolumn{1}{|c}{ Comentários } \\
\hline Allison (1967)* & 0 a 2,25 & $\begin{array}{l}\text { Recomenda e/D > 1,5 } \\
\text { Relata ter havido } \\
\text { Howard (1968)* }\end{array}$ \\
influência do atrito lateral \\
nos ensaios \\
Nath (1977)
\end{tabular}

*Após Bulson (1985); ${ }^{+}$após Bueno (1987).

A altura interna das paredes da caixa de testes foi fixada de modo a permitir a realização de ensaios variando-se a altura de cobertura de solo sobre o conduto $(H)$. Como abordado no Capítulo 2, evidências experimentais mostram que a tensão mínima no estado ativo torna-se praticamente constante para taxas geométricas $\mathrm{H} / \mathrm{B}$ entre 2 e 3 (McNulty 1965, Koutsabeloulis e Griffiths 1989, Iglesia 1991, Santichaianant 2002). Particularmente, Bulson (1985) observou que a variação da 
tensão de colapso de tubos flexíveis de aço e latão diminui consideravelmente a partir de $H / D=3$. Em complementação, no estado passivo a variação da capacidade de carga do sistema com a direção de movimentação tende a diminuir sensivelmente a partir de $\mathrm{H} / \mathrm{B}=4$ (Figura 2.8). Assim, considerou-se uma altura de cobertura máxima igual a 5D suficiente para a construção de modelos representando instalações rasas e profundas. Para um tubo com $80 \mathrm{~mm}$ de diâmetro, H é então igual a $400 \mathrm{~mm}$. Levando-se em consideração as espessuras da camada de solo sobre a qual o tubo repousa e da bolsa de ar comprimido, a altura interna da caixa foi fixada em $560 \mathrm{~mm}$.

Uma vez definidas as dimensões, procedeu-se ao projeto estrutural da caixa de testes, iniciando-se pelas paredes frontais e laterais. Além de atender às dimensões acima selecionadas, o projeto da caixa foi desenvolvido para atender aos seguintes critérios: a) ser versátil o suficiente para permitir o uso da caixa em pesquisas futuras; b) possuir rigidez suficiente de modo a não interferir no comportamento do modelo ensaiado e c) facilitar ao máximo a montagem do ensaio.

As paredes laterais foram confeccionadas com vigas de aço do tipo $\mathrm{U}$, com altura de 101,6 mm, largura da aba de 41,83 mm e espessura da alma de 6,55 $\mathrm{mm}$. Um esquema da parede lateral pode ser visto através da Figura B1 (Anexo B). A disposição das vigas obedeceu a dois critérios distintos: a) fornecer uma rigidez adequada para a peça e b) facilitar a montagem. Por não se encontrar engastada, a parte superior da caixa torna-se o local mais susceptível à ocorrência de deformações durante a fase de deposição do solo. Numa tentativa de reduzir esse problema, optouse por utilizar vigas horizontais superiores para aumentar a rigidez na região.

As paredes frontais foram projetadas também com vigas $U$ de 101,6 x 41,83 x $6,55 \mathrm{~mm}$ e chapa de $6,35 \mathrm{~mm}$ de diâmetro. Foram utilizados quatro perfis verticais de $458 \mathrm{~mm}$ de comprimento e um perfil horizontal com comprimento igual a $560 \mathrm{~mm}$, todos dispostos segundo o esquema da Figura B1 (Anexo B). O vão central da parede é dotado de duas chapas móveis com $150 \mathrm{~mm}$ de comprimento e $166 \mathrm{~mm}$ de largura. A chapa inferior possui um orifício com $100 \mathrm{~mm}$ de diâmetro para possibilitar o acesso da instrumentação ao interior do tubo. Duas vigas móveis, com as mesmas especificações anteriormente descritas, foram dispostas horizontalmente com o 
intuito de diminuir a deflexão da parede na região das chapas móveis. O detalhe das chapas móveis pode ser observado através da Figura B2 (Anexo B).

A base da caixa de testes foi confeccionada com vigas $U$ com dimensões de 152,4 x 51,66 x 7,98 mm. Como se pode observar através da Figura B3 (Anexo B), quatro vigas transversais de $553 \mathrm{~mm}$ de comprimento foram soldadas às vigas principais de $1496 \mathrm{~mm}$ de comprimento. A fim de conferir maior rigidez ao centro da caixa, foram utilizadas nessa região duas vigas duplas transversais com dimensões de $101,6 \times 41,83$ × 6,55 mm. Duas vigas de 152,4 x 51,66 × 7,98 mm, dispostas paralelamente às vigas principais, interligam as vigas duplas entre si. Uma chapa com espessura de $6,35 \mathrm{~mm}$ de diâmetro foi soldada no topo da base, compondo o fundo da caixa. Um orifício retangular de 100 x $300 \mathrm{~mm}$ foi aberto no fundo da caixa para receber o mecanismo com movimentação ascendente e descendente a ser utilizado como alçapão. A base da caixa foi construída com apoios sobre cantoneiras de abas iguais com $550 \mathrm{~mm}$ de altura, $63,5 \mathrm{~mm}$ de largura e $6,35 \mathrm{~mm}$ de espessura. Esta configuração facilita o livre acesso ao fundo da caixa, permitindo a instalação de instrumentação nesta região. A tampa de reação da caixa, com dimensões de 1496 x $656 \mathrm{~mm}$, foi confeccionada a partir de seis perfis do tipo U de 101,6 x 41,83 x 6,55 mm e chapa com 6,35 mm de espessura (Figura B4, Anexo B).

A rigidez foi um dos principais critérios que nortearam o dimensionamento das peças da caixa de testes, uma vez que, assim como o atrito lateral, pode influenciar consideravelmente a distribuição de tensões no modelo. A estrutura deve possuir rigidez suficiente para simular a condição de $\mathrm{K}_{\mathrm{o}}$ no maciço (deformação lateral nula). As paredes e a base foram dimensionadas para suportar com segurança uma pressão aplicada por bolsa de ar de $300 \mathrm{kPa}$. As vigas principais da base da caixa foram dimensionadas como vigas contínuas, simplesmente apoiadas. A flecha medida no vão central da parede lateral com a caixa de testes contendo a areia e sob uma pressão superficial de $150 \mathrm{kPa}$ foi de apenas $0,32 \mathrm{~mm}$. A Figura 4.1 exibe a caixa de testes construída. 


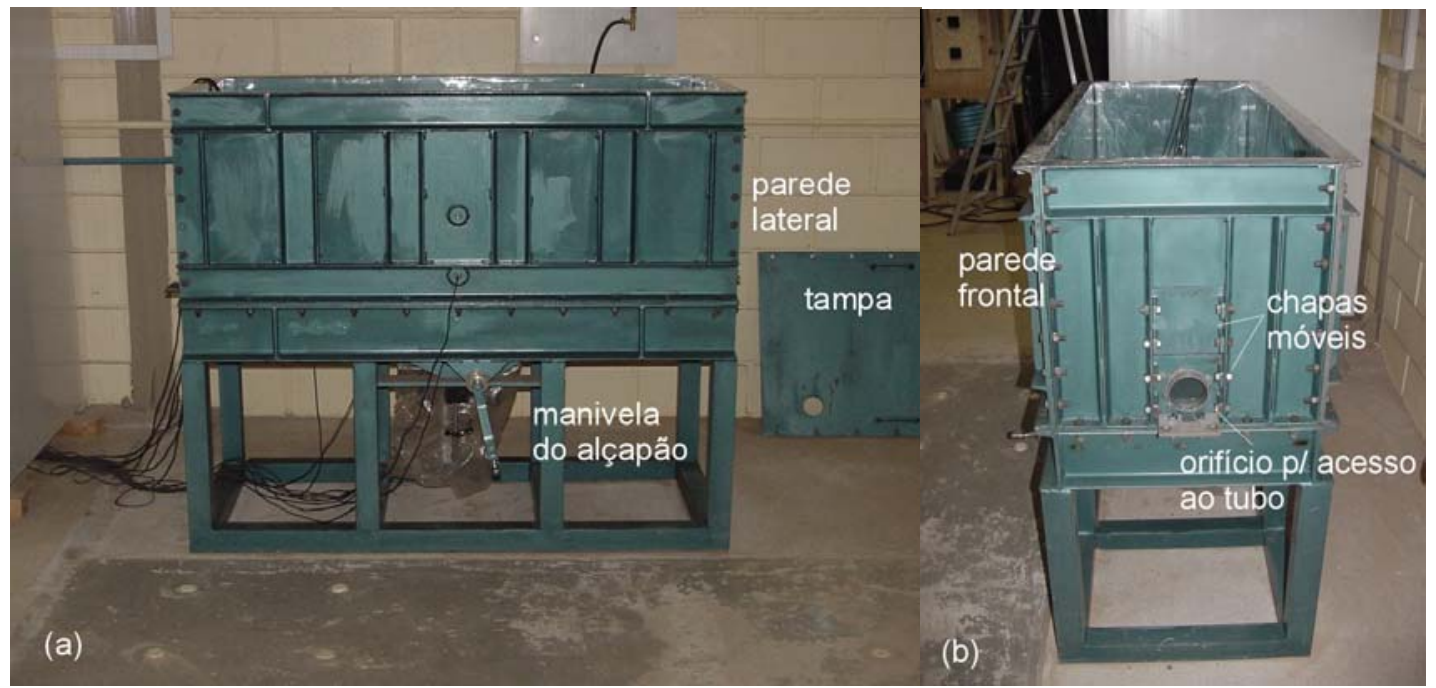

Figura 4.1. Caixa de testes confeccionada para os modelos realizados na EESC/USP; a) vista lateral; b) vista frontal.

\subsection{SISTEMA DE ALÇAPÃO}

Para possibilitar a realização de ensaios com elevação ou recalque do conduto, construiu-se um mecanismo de alçapão cuja configuração é esquematizada através da Figura 4.2. O alçapão é composto por três prismas móveis, localizados no centro da base da caixa de testes, com base quadrada de $100 \mathrm{~mm}$ de lado e $120 \mathrm{~mm}$ de altura. Em determinados locais da face superior dos prismas há ranhuras para o embutimento de células de tensão. Cada prisma repousa diretamente sobre um eixo rosqueado que lhe confere movimentação vertical ascendente ou descendente. Os eixos são movimentados através de engrenagens, acionadas por uma manivela externa (Figura 4.1) e fixas a uma chapa de reação com $52 \mathrm{~mm}$ de espessura.

O sistema confeccionado permite a realização de ensaios com alçapões de duas dimensões distintas. O menor alçapão, composto pelo prisma central, possui $100 \mathrm{~mm}$ de comprimento e $100 \mathrm{~mm}$ de largura, enquanto o alçapão maior possui 300 $\mathrm{mm}$ de comprimento e $100 \mathrm{~mm}$ de largura. A remoção da engrenagem central (Figura 4.2b) torna o prisma central independente dos adjacentes, que permanecem estacionários. Essa configuração compõe o alçapão menor. Quando a engrenagem 
central se encontra posicionada em seu devido local os três prismas deslocam-se juntos, formando o alçapão maior.

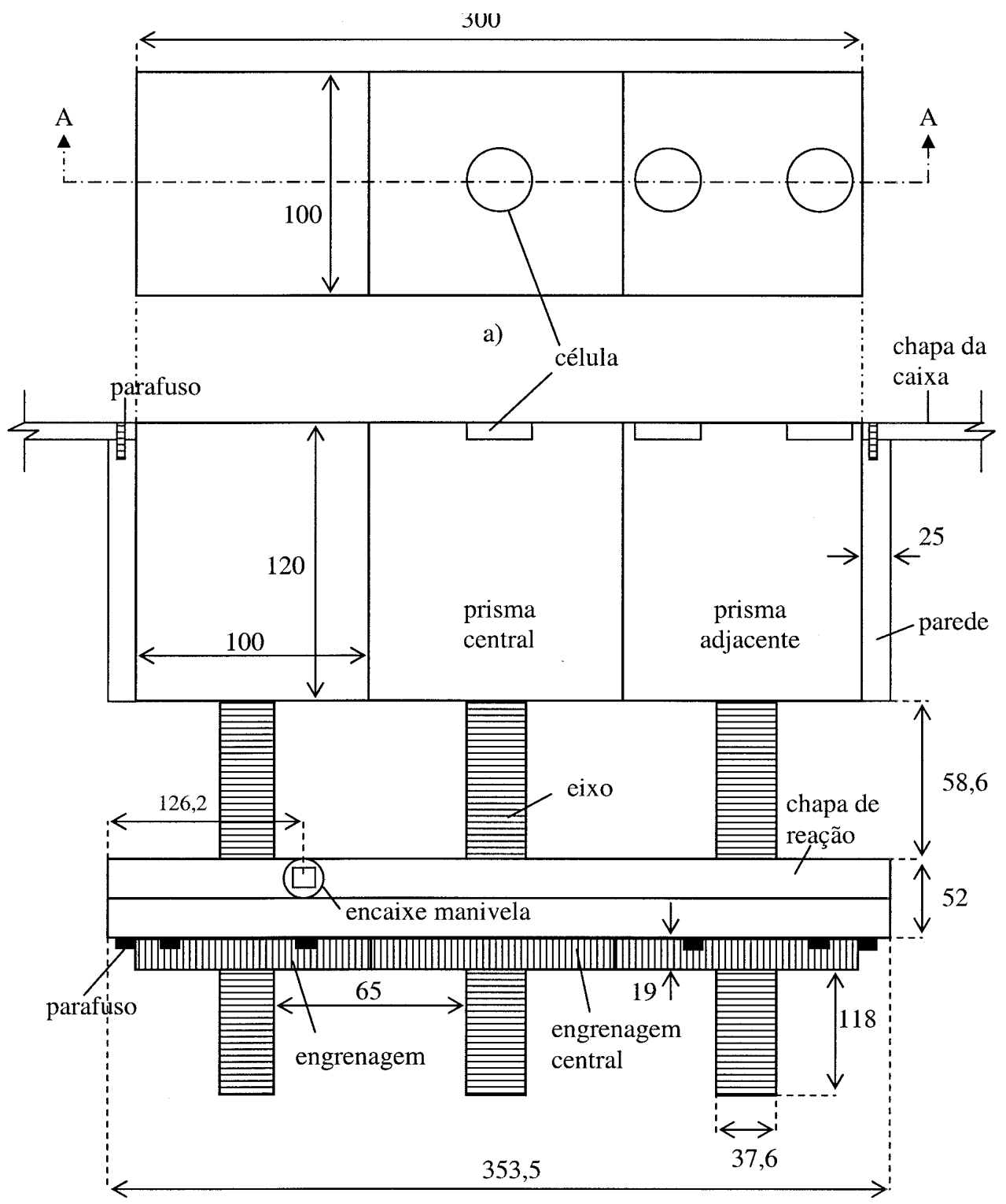

b)

Figura 4.2. a) Vista superior do sistema de alçapão; b) corte A-A. Dimensões em mm. 


\subsection{INSTRUMENTAÇÃO PARA MEDIDAS DE DEFLEXÃO DO TUBO}

\subsubsection{Transdutor de Deslocamentos}

Para a obtenção dos deslocamentos do conduto durante os ensaios, confeccionou-se um transdutor de deslocamentos a base de strain-gages composto por oito tiras de aço-mola de $6 \mathrm{~mm}$ de largura e $0,2 \mathrm{~mm}$ de espessura (pernas), fixadas a uma base cilíndrica de alumínio de $35 \mathrm{~mm}$ de diâmetro e $40 \mathrm{~mm}$ de comprimento, como ilustrado na Figura 4.3. Baseado nos trabalhos de Trott et al. (1984) e Bueno (1987), o instrumento permitia a obtenção de medidas simultâneas de deslocamentos radiais em oito pontos distintos a cada $45^{\circ}$ em torno da seção transversal do tubo.

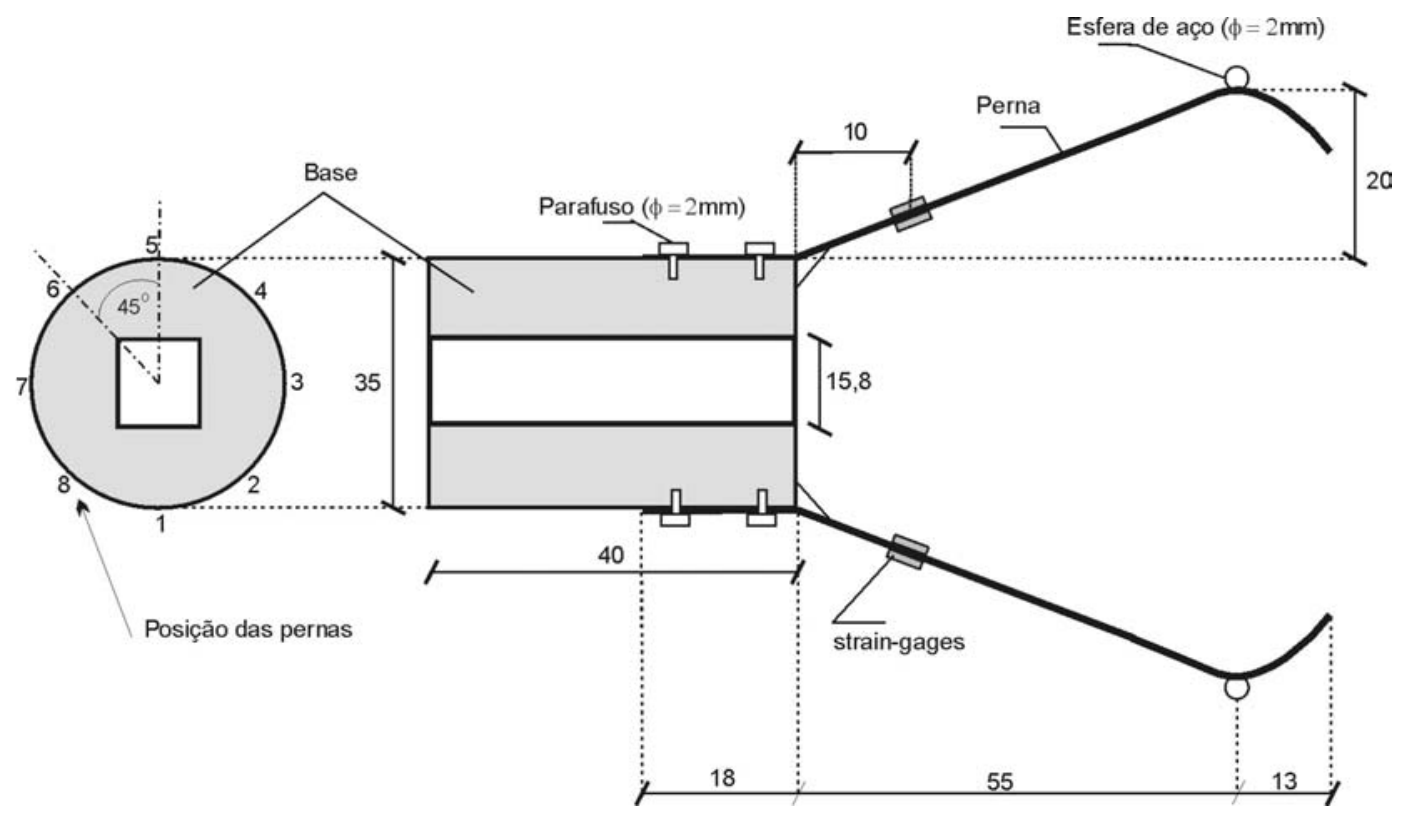

Figura 4.3. Esquema do transdutor de deslocamentos (dimensões em mm).

As pernas do transdutor foram projetadas como vigas engastadas sujeitas a uma força concentrada aplicada no ponto de contato com a parede do tubo. As dimensões da viga foram selecionadas para produzir um nível de deformação no local de instalação, nas proximidades do engaste, sem despertar uma reação excessiva no contato com o tubo. Considerando uma seção transversal de $6,0 \times 0,4$ $\mathrm{mm}$, verificou-se que a reação na parede do tubo produzida pela viga para um 
deslocamento de $5 \mathrm{~mm}$ era igual a aproximadamente $1 \mathrm{~N}$. A deformação teórica $(\varepsilon)$ fornecida pelos strain-gages foi calculada de acordo com a equação (4.2). Devido ao tipo de circuito adotado e ao posicionamento dos extensômetros, o sinal de saída da ponte é dobrado, de modo que a deformação total $\left(\varepsilon_{t}\right)$ calculada é igual a $2 \varepsilon$.

$\varepsilon=3 \mathrm{u}_{\mathrm{i}} \mathrm{h} / 2 \mathrm{~L}^{2}$

onde: $\mathrm{u}_{\mathrm{i}}=$ deslocamento radial da $\mathrm{i}$-ésima perna $(\mathrm{i}=1$ a 8$) ; \mathrm{h}=$ espessura da perna; $\mathrm{L}$ = distância entre o extensômetro e o ponto de aplicação da carga.

Após cortada e forjada para adquirir o formato desejado, cada perna recebeu dois extensômetros elétricos de fabricação da Excel Engenharia e Sensores Ltda., com resistência de $120 \Omega, 3,81 \mathrm{~mm}$ de comprimento e $1,57 \mathrm{~mm}$ de largura, compondo um circuito de $1 / 2$ ponte. Os strain-gages foram instalados sobre o eixo central longitudinal da perna, sendo um deles posicionado na face superior e o outro na face inferior, e ambos distando $10 \mathrm{~mm}$ da base do transdutor. Quando a perna é fletida, o extensômetro superior é tracionado e o inferior, comprimido, de modo que a deformação sofrida por ambos será de igual magnitude e sinal oposto. Uma vez que o material constituinte da viga é homogêneo e isotrópico, o sinal de saída produzido será dobrado e a variação de resistência por temperatura, anulada. As pernas foram fixadas à base através de parafusos de $2 \mathrm{~mm}$ de diâmetro e cola a base de epóxi para garantir um engaste o mais perfeito possível. A Figura 4.4 apresenta o transdutor construído.

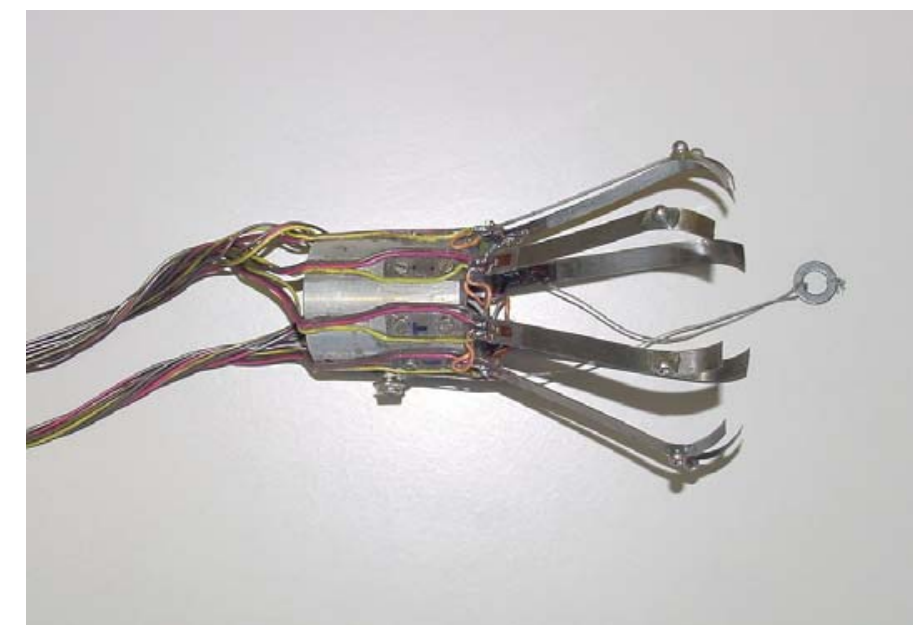

Figura 4.4. Transdutor de deslocamentos confeccionado. 


\subsubsection{Sistema de Movimentação do Transdutor}

Dentro do tubo, o transdutor era movimentado através de uma barra de alumínio de 1,75 m de comprimento e seção transversal quadrada de $15,8 \mathrm{~mm}$ de lado que servia de guia para a movimentação do transdutor dentro do tubo, ao longo de seu eixo longitudinal (Figura 4.5). A fixação da barra era realizada através de dois suportes localizados no exterior da caixa, dotados de fusos rosqueados de $12,7 \mathrm{~mm}$ de diâmetro que permitiam seu correto posicionamento vertical em relação ao eixo central do conduto. $\mathrm{O}$ ajuste horizontal era realizado através de um rasgo no próprio suporte inferior.

Um motor de passo com torque de $1,1 \mathrm{kN} . \mathrm{m}$, instalado no exterior da caixa, em um dos suportes, era responsável pela movimentação do transdutor dentro do tubo a uma velocidade constante, correspondendo a um tempo total de percurso de aproximadamente $30 \mathrm{~s}$. O transdutor percorria uma distância no interior do tubo de $1380 \mathrm{~mm}$, delimitada por dois dispositivos fixados à barra-guia. O início-de-curso do trandutor era composto por um batente parafusado à barra-guia na extremidade inicial. $\mathrm{Na}$ extremidade oposta, o fim-de-curso era delimitado por meio de um interruptor que cortava a alimentação do motor quando tocado pela base do transdutor. De forma a reduzir ao máximo o atrito durante a movimentação, esferas de aço de $2 \mathrm{~mm}$ de diâmetro foram fixadas em cada perna no ponto de contato com a parede do tubo. Além disso, pó de grafite era utilizado para a lubrificação do contato entre a guia de alumínio e a base do transdutor.

\subsubsection{Calibração e Repetibilidade do Transdutor}

A calibração de cada perna foi realizada com o auxílio de um micrômetro com resolução de $0,01 \mathrm{~mm}$ e curso máximo de $25 \mathrm{~mm}$, através do qual os deslocamentos eram impostos em incrementos de $1 \mathrm{~mm}$ até se atingir um total de $15 \mathrm{~mm}$. Simultaneamente, a resposta do transdutor era gravada em um sistema de aquisição de dados. A Figura 4.6 exibe a curva de calibração obtida para uma das pernas. A discrepância dos valores experimentais de $\varepsilon$ em comparação com o valor de projeto 
era esperada e deve-se basicamente às limitações inerentes ao modelo teórico utilizado, as quais são amplamente discutidas em Hearn (1985).

Para a verificação da repetibilidade das medidas geradas pelo equipamento construído, quatro ciclos de carregamento e descarregamento foram realizados em cada perna. A Tabela 4.2 mostra o desvio padrão e o coeficiente de variação das leituras fornecidas para um deslocamento de $5 \mathrm{~mm}$. Os resultados indicaram uma repetibilidade média de $\pm 0,4 \%$ para a sonda construída. As pequenas diferenças observadas de perna para perna decorrem de fatores inerentes à confecção, como, por exemplo, dimensão e curvatura das tiras de aço-mola, bem como posicionamento e colagem dos strain-gages.

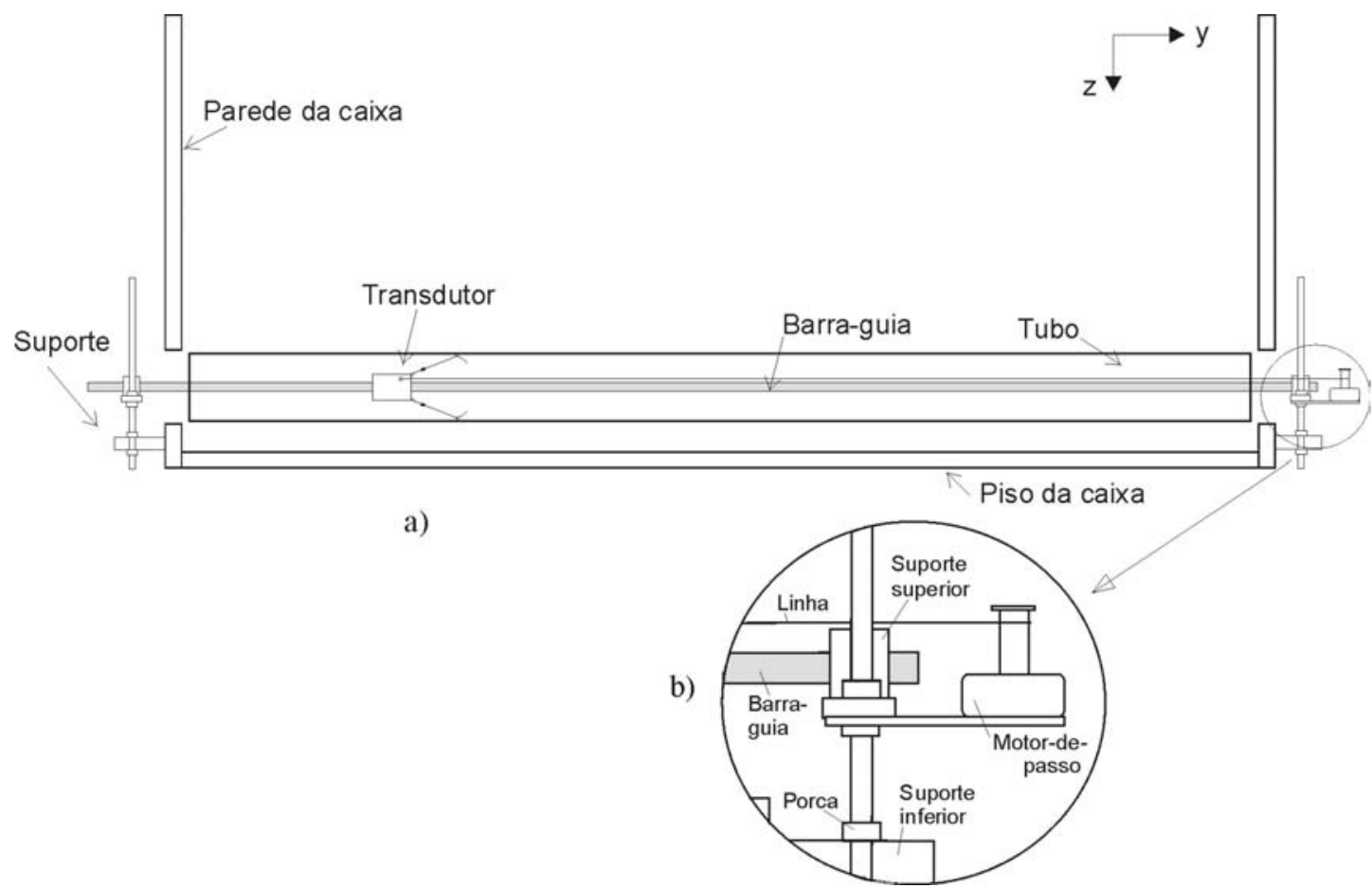

Figura 4.5. a) Sistema de movimentação do transdutor; b) detalhe dos suportes e do motor-de-passo. 


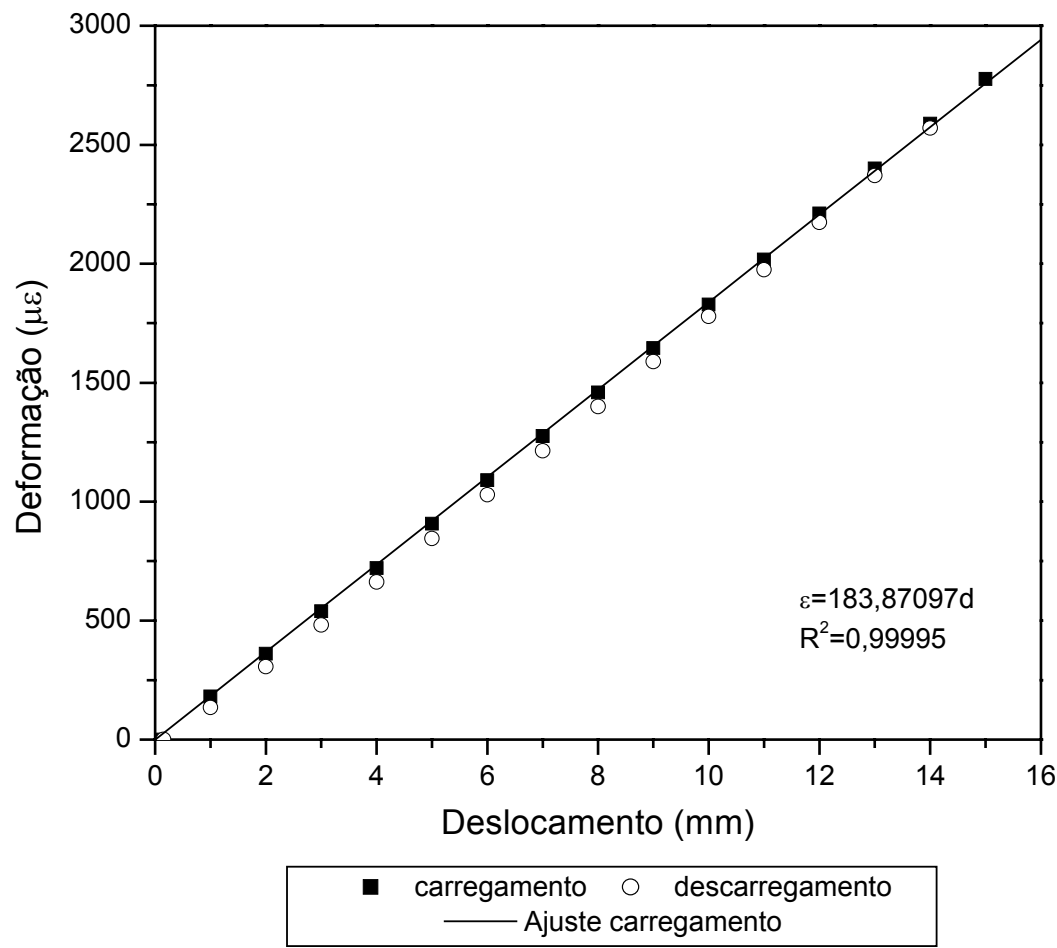

Figura 4.6. Curva de calibração da perna 1 do transdutor de deslocamentos.

Tabela 4.2. Repetibilidade do transdutor de deslocamentos para $\mathrm{d}=5 \mathrm{~mm}$

\begin{tabular}{ccc}
\hline Perna & Desvio padrão $(\mathrm{mm})$ & Coef. de variação $(\%)$ \\
\hline 1 & 0,0112 & 0,23 \\
2 & 0,0099 & 0,20 \\
3 & 0,0203 & 0,41 \\
4 & 0,0206 & 0,42 \\
5 & 0,0326 & 0,68 \\
6 & 0,0083 & 0,17 \\
7 & 0,0163 & 0,34 \\
8 & 0,0292 & 0,60 \\
\hline
\end{tabular}

Os sinais enviados pelo transdutor eram lidos por um sistema de aquisição de dados de fabricação da Measurements Group Inc., modelo WIN5000, e gravado em um micro-computador. As leituras do sinal eram realizadas automaticamente em 
intervalos de $0,5 \mathrm{~s}$, de modo que os deslocamentos em cada perna eram medidos em 60 posições distintas na longitudinal do tubo.

No ensaio, a varredura inicial (subtende-se como varredura o conjunto de leituras fornecidas pelo transdutor em um percurso completo ao longo do tubo) era efetuada após a caixa ser preenchida com areia o suficiente para encobrir o tubo. A segunda varredura ocorria após o total preenchimento da caixa e a terceira, posteriormente à aplicação da pressão desejada com a bolsa de ar. Em seguida, eram realizadas varreduras quando o prisma atingia deslocamentos de 0,25, 0,5, 1, 2, 4, 8, $15,30,50 \mathrm{~mm}$ e posteriormente ao descarregamento. Quatro varreduras eram realizadas em cada um dos estágios citados acima, sendo a média utilizada nas análises dos dados. A Figura 4.7 exibe resultados de oito varreduras consecutivas realizadas sob as mesmas condições, posteriormente à cobertura do tubo. Os testes indicaram uma repetibilidade para o sistema montado de $\pm 1 \%$.

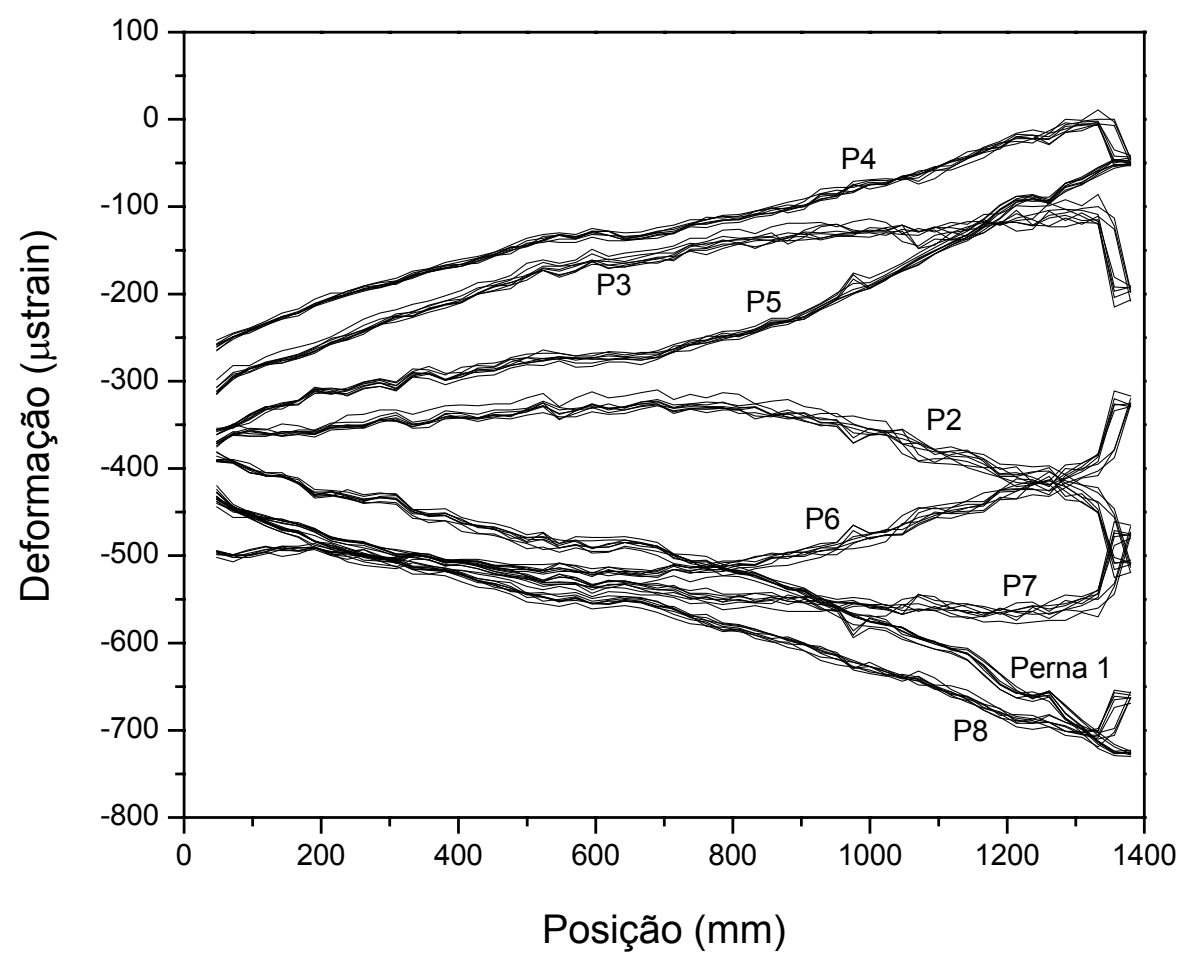

Figura 4.7. Repetibilidade do sistema de medição de deflexões no tubo. 


\subsection{MEDIDAS DE TENSÃO NO SOLO}

\subsubsection{Células de Tensão Total}

As tensões totais no maciço foram obtidas através de células de tensão de interface e de inclusão na massa de solo, perfazendo um total de 16 unidades por ensaio. Foram utilizadas células de fabricação da Kyowa Electronic Instruments Co., Ltd., modelos $\mathrm{BE}-2 \mathrm{KC}$ e BE-2KD (inclusão e interface, respectivamente). Um esquema dos modelos utilizados é apresentado na Figura 4.8.

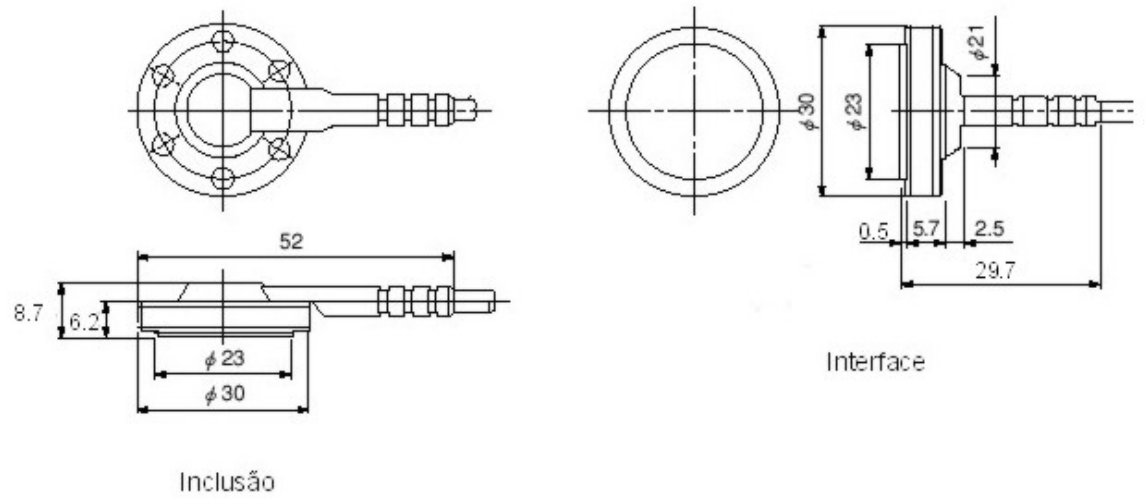

Figura 4.8. Esquema das células de tensão total (dimensões em mm).

As células de interface (identificadas pela letra I) foram posicionadas no piso da caixa de forma a atender a ambas as configurações de alçapão. A Figura 4.9 mostra a disposição destas células na base da caixa. Quando o alçapão maior (300 x $100 \mathrm{~mm}$ ) é acionado, as células I1, I2 e I3 medem as tensões desenvolvidas no interior do mesmo. O par I4 e I6 medem as tensões despertadas a $20 \mathrm{~mm}$ das faces deste alçapão e as demais células medem as tensões externas de interface, desenvolvidas em pontos mais afastados. Da mesma forma, quando o alçapão menor (100 x $100 \mathrm{~mm})$ é movimentado, a célula I1 mede a tensão interna na superfície deste. As células I2 e I4 são utilizadas para obter a as tensões externas a $20 \mathrm{~mm}$ das faces do alçapão, enquanto que as outras unidades registram as tensões externas em posições mais distantes. 


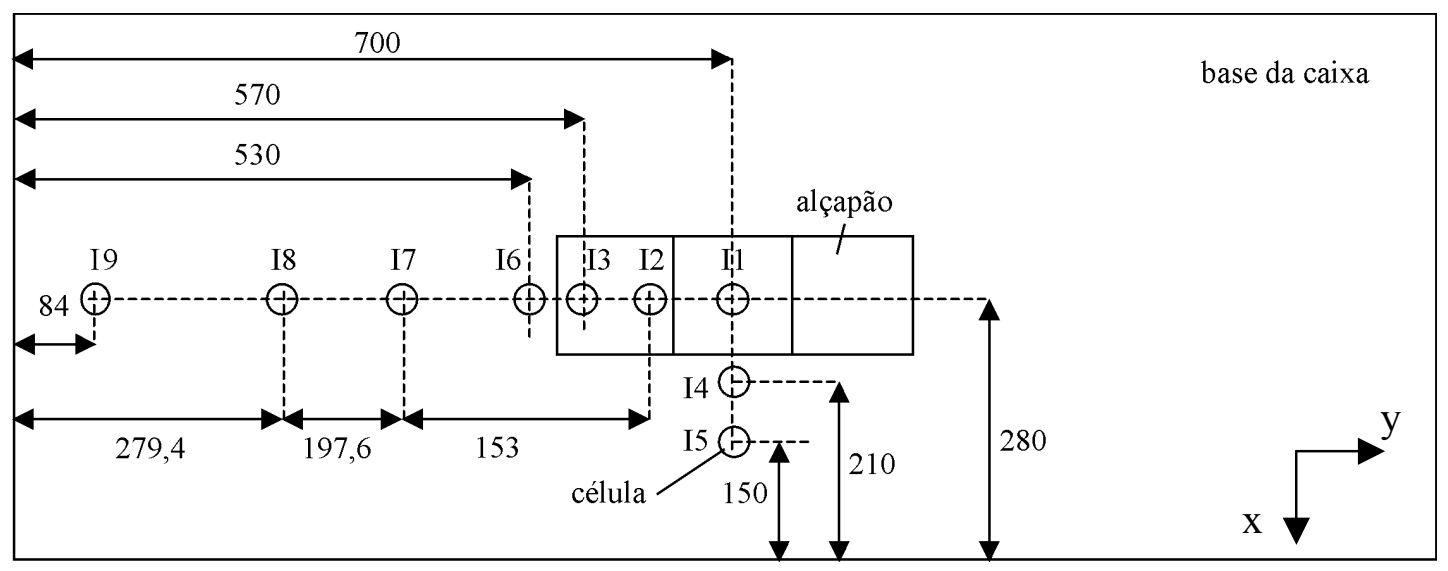

Figura 4.9. Disposição das células de interface na base da caixa de testes. Dimensões em $\mathrm{mm}$.

Mesmo possuindo constante de calibração de fábrica, todas as células foram devidamente re-calibradas antes das seqüências de ensaios serem iniciadas. As células de interface foram calibradas in loco com o auxílio de um aparato constituído de um cilindro de PVC vedado nas extremidades com membranas de borracha. Após dispor a membrana em contato com a face ativa da célula, ar comprimido era injetado no cilindro e a calibração era iniciada aplicando-se incrementos de $10 \mathrm{kPa}$ até atingir $100 \mathrm{kPa}$ (limite de segurança do aparato). A pressão aplicada era lida através de um manômetro devidamente aferido e, em seguida, comparada com a resposta do instrumento. As células de inclusão no solo (identificadas neste trabalho pela letra $\mathrm{M}$ ) foram calibradas através de um equipamento composto por uma bolsa de ar entre duas chapas metálicas. A célula era acomodada entre uma das chapas e a câmara, com a face ativa totalmente em contato com esta última. O procedimento de calibração era idêntico ao das células de interface. As calibrações realizadas forneceram constantes bastante próximas das fornecidas pelo fabricante.

\subsubsection{Configuração dos Ensaios Realizados com Tubo}

Os ensaios com a presença do tubo contaram com células de interface em todas as posições descritas no esquema da Figura 4.9, com exceção de I9. As células de inclusão foram posicionadas em duas seções distintas no conduto, como mostra a Figura 4.10. A seção S1, no centro do vão do tubo, recebeu duas células na linha 
d'água (M1 e M3) e uma no topo (M2). Uma célula adicional, M4, foi alocada a 110 $\mathrm{mm}$ acima de M2. A seção S3, a $150 \mathrm{~mm}$ da primeira seção, recebeu duas células na linha d'água (M5 e M7) e uma no topo (M6).
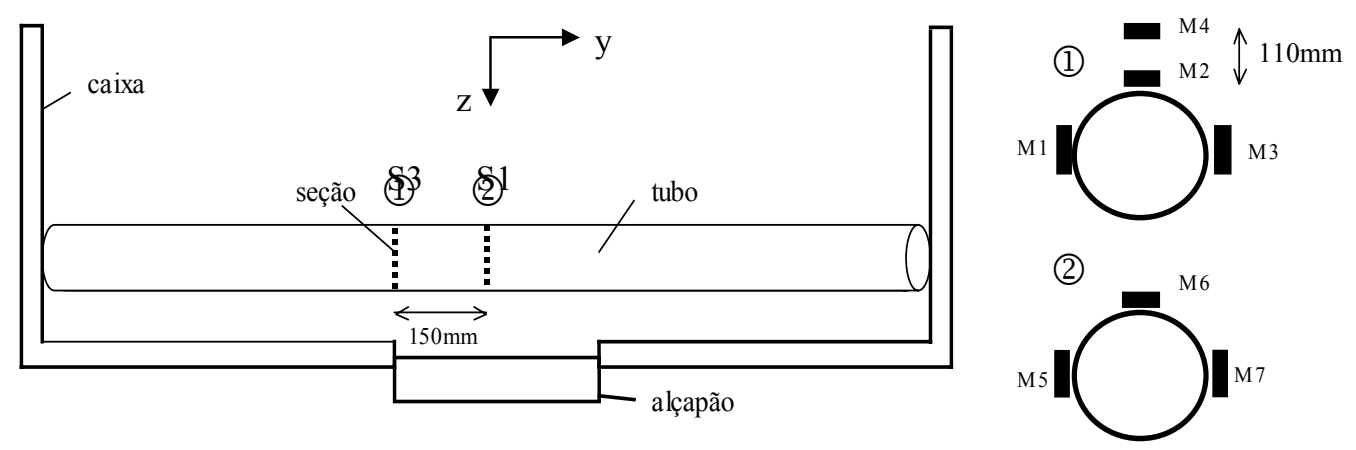

Figura 4.10. Disposição das células de inclusão nos ensaios com tubo.

\subsubsection{Configuração dos Ensaios Realizados sem Tubo}

As células de interface foram dispostas nos ensaios de arqueamento da mesma maneira que nos ensaios realizados com a presença do tubo, mais a célula I9. As células de inclusão eram sempre posicionadas imediatamente acima de células de interface, a uma determinada altura da base da caixa. Diversas configurações foram adotadas para a organização das células do tipo $\mathrm{M}$ em cada ensaio. A Tabela 4.3 fornece a localização das células dentro da caixa: para cada teste é informada a altura da célula em relação à base da caixa e a correspondente célula de interface imediatamente abaixo.

\subsubsection{Procedimentos de Obtenção dos Sinais de Medida}

As leituras das células de tensão eram realizadas desde a fase de preenchimento da caixa até a fase de movimentação do alçapão, sendo gravadas no mesmo sistema de aquisição de dados descrito anteriormente. Durante o preenchimento a resposta das células era obtida após o término da camada onde o tubo era apoiado, após a cobertura do tubo e em intervalos regulares até o preenchimento total da caixa. $\mathrm{Na}$ etapa de carregamento uma leitura era realizada para a cada incremento de pressão 
aplicada pela bolsa de ar. $\mathrm{Na}$ fase de movimentação do alçapão, as leituras eram tomadas para os seguintes deslocamentos: $0,02,0,04,0,06,0,08,0,1,0,15,0,2,0,25$, $0,3,0,4,0,5,0,6,0,8,1,1,5,2,0,2,5,3,4,8,12,15,20,25,30$ e $50 \mathrm{~mm}$.

Tabela 4.3. Localização das células de inclusão nos ensaios sem tubo

\begin{tabular}{cccccccc} 
& \multicolumn{7}{c}{ Célula de inclusão } \\
\cline { 2 - 7 } Ensaio & M1 & M2 & M3 & M4 & M5 & M6 & M7 \\
\hline C1 e & $30 \mathrm{~mm}$ & $30 \mathrm{~mm}$ & $30 \mathrm{~mm}$ & $110 \mathrm{~mm}$ & $30 \mathrm{~mm}$ & $30 \mathrm{~mm}$ & $110 \mathrm{~mm}$ \\
C2 & I4 & I5 & I1 & I7 & I7 & I3 & I4 \\
C3 & $70 \mathrm{~mm}$ & $140 \mathrm{~mm}$ & $220 \mathrm{~mm}$ & $290 \mathrm{~mm}$ & $370 \mathrm{~mm}$ & $30 \mathrm{~mm}$ & $30 \mathrm{~mm}$ \\
& I1 & I1 & I1 & I1 & I1 & I4 & I6 \\
C4 & $30 \mathrm{~mm}$ & $30 \mathrm{~mm}$ & $30 \mathrm{~mm}$ & $140 \mathrm{~mm}$ & $260 \mathrm{~mm}$ & $30 \mathrm{~mm}$ & $30 \mathrm{~mm}$ \\
& I1 & opostoI4 & opostoI6 & I1 & I1 & I4 & I6 \\
C5 & $30 \mathrm{~mm}$ & $140 \mathrm{~mm}$ & $200 \mathrm{~mm}$ & $300 \mathrm{~mm}$ & $390 \mathrm{~mm}$ & $30 \mathrm{~mm}$ & $30 \mathrm{~mm}$ \\
& I1 & I1 & I1 & I1 & I1 & I4 & I6 \\
C6 e & $30 \mathrm{~mm}$ & $140 \mathrm{~mm}$ & $200 \mathrm{~mm}$ & $300 \mathrm{~mm}$ & $30 \mathrm{~mm}$ & $140 \mathrm{~mm}$ & $30 \mathrm{~mm}$ \\
C7 & I1 & I1 & I1 & I1 & I4 & I4 & I2 \\
\hline
\end{tabular}

\subsection{MEDIDAS DE DEFORMAÇÃO NO TUBO}

Tubos de PVC com as mesmas características dos tubos utilizados anteriormente foram instrumentados com 16 strain gages externos na seção $\mathrm{S} 1$, como mostra o esquema da Figura 4.11, sendo oito instalados no sentido longitudinal e oito no transversal.

Foram utilizados strain gages de fabricação da Micro Measurements Group, modelo EP-40-250-BF (específico para plástico), com resistência de $350 \Omega, 9,53 \mathrm{~mm}$ de comprimento e $3,18 \mathrm{~mm}$ de largura. Todas as unidades foram instaladas compondo circuitos em 1/4 de ponte. A Figura 4.12 exibe um detalhe de um tubo instrumentado. Como proteção os strain gages receberam uma camada de borracha de silicone e, em seguida, uma camada de fita isolante. Durante o ensaio, as leituras 
dos strain gages eram realizadas da mesma forma que para as células de tensão, ou seja, desde a fase de enchimento da caixa até a fase de movimentação do alçapão.

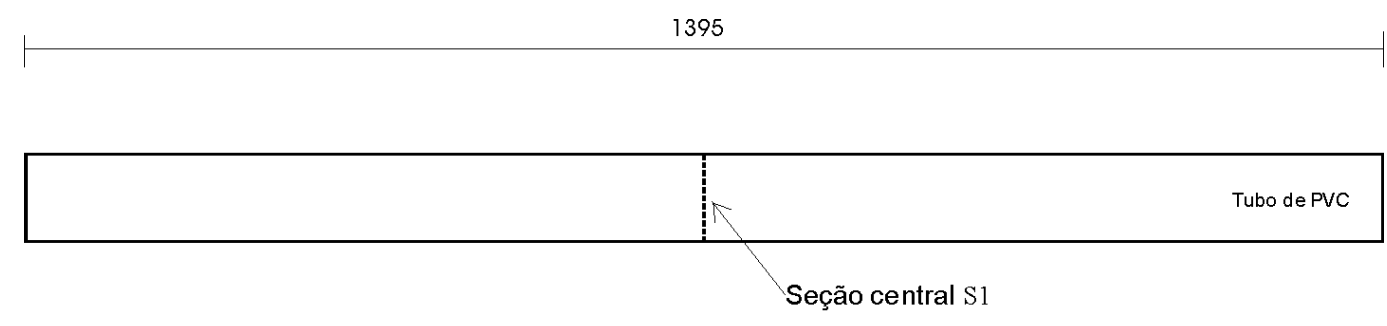

a)

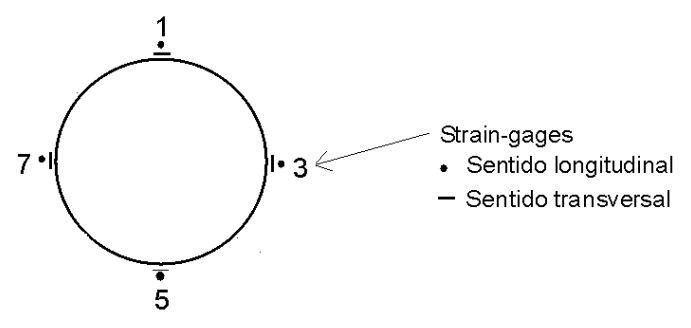

Seção central S1

b)

Figura 4.11. a) Tubo instrumentado com strain gages; b) disposição dos strain gages na seção S1 (dimensão em mm).

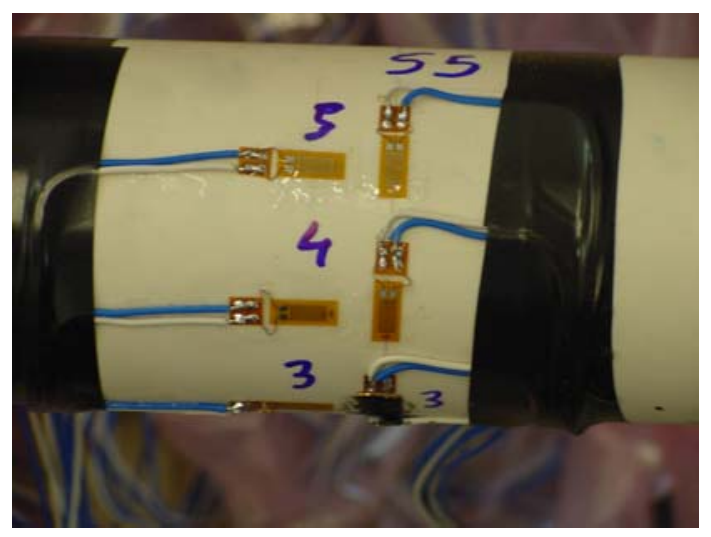

Figura 4.12. Detalhe dos strain gages instalados no tubo. 


\subsection{MATERIAIS ENSAIADOS}

\subsubsection{Propriedades do Solo Utilizado}

Utilizou-se nestes modelos uma areia pura denominada "areia Itaporã", proveniente de uma jazida localizada à Rodovia SP-215 (km 154), próxima à Cidade de São Carlos, e classificada como SP de acordo com o Sistema Unificado de Classificação de Solos. O resultado da análise granulométrica, realizada de acordo com a norma da ABNT NBR-7181/84, é exibido na Figura 4.13. Trata-se de uma areia mal-graduada, com partículas com alto grau de esfericidade e tamanho variando entre 0,07 e $2 \mathrm{~mm}$ (média a fina). O coeficiente de não uniformidade é igual a 2,7 e o diâmetro médio $\left(\mathrm{D}_{50}\right)$ dos grãos é igual a $0,23 \mathrm{~mm}$. O índice de vazios máximo $\left(\mathrm{e}_{\max }\right)$, obtido segundo a norma da ABNT NBR-12004/90, é igual a 0,87, o que corresponde a um peso específico seco mínimo $\left(\gamma_{\mathrm{d}, \min }\right)$ de $14,2 \mathrm{kN} / \mathrm{m}^{3}$. O índice de vazios mínimo $\left(\mathrm{e}_{\min }\right)$, determinado de acordo com a NBR-12051/91 é igual a 0,50, equivalendo a um peso específico seco máximo $\left(\gamma_{\mathrm{d}, \max }\right)$ igual a $17,7 \mathrm{kN} / \mathrm{m}^{3}$. O peso específico dos sólidos é igual a $26,5 \mathrm{kN} / \mathrm{m}^{3}$. Durante a realização dos ensaios o teor de umidade da areia permaneceu inferior a $1 \%$.

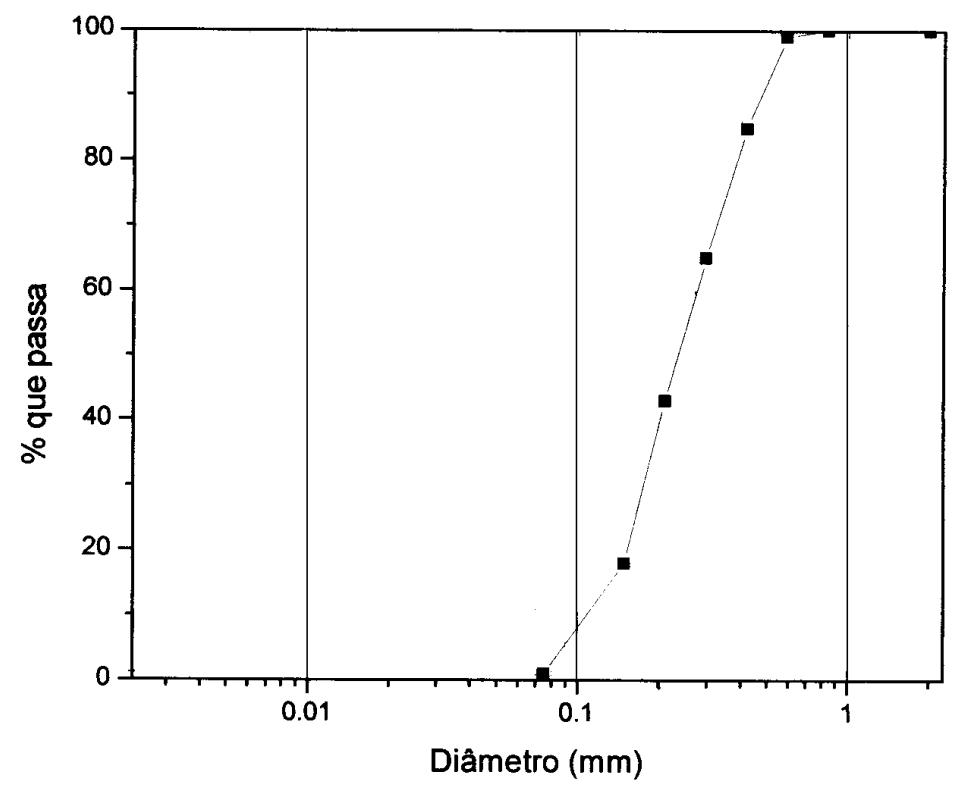

Figura 4.13. Curva granulométrica da areia utilizada. 
Parâmetros de resistência e de variação volumétrica da areia, obtidos a partir de ensaios triaxiais convencionais, são exibidos na Tabela 4.4. Os ensaios foram realizados em duas séries de três corpos-de-prova cada, correspondendo às densidades adotadas para a confecção dos modelos. O ângulo de atrito de pico $(\phi$ p $)$ foi calculado a partir da máxima razão de tensões principais da curva $\left(\sigma^{\prime}{ }_{1} / \sigma^{\prime}{ }_{3}\right)$ versus deformação axial $\left(\varepsilon_{1}\right)$ e o ângulo de atrito crítico $(\phi$ cr), usando a média de três pontos na parte final da curva. O ângulo de dilatação $(\psi)$ foi obtido a partir da máxima razão $\left[-\mathrm{d} \varepsilon_{\mathrm{v}} / \mathrm{d} \varepsilon_{1}\right]$ da curva de variação de volume $\left(\varepsilon_{\mathrm{v}}\right)$ versus deformação axial. O módulo de deformabilidade apresentado é o módulo secante correspondente à $50 \%$ do valor da máxima tensão desviadora $\left(\mathrm{E}_{50}\right)$.

Tabela 4.4. Parâmetros da areia Itaporã

\begin{tabular}{|c|c|c|c|c|c|c|c|c|}
\hline Série & $\mathrm{D}_{\mathrm{r}}(\%)$ & $\sigma_{3}(\mathrm{kPa})$ & $\phi_{p}^{\prime}\left({ }^{0}\right)$ & $\phi_{\text {cr }}\left({ }^{0}\right)$ & $\psi_{\max }\left({ }^{0}\right)$ & $\left(-\mathrm{d} \varepsilon_{\mathrm{v}} / \mathrm{d} \varepsilon_{1}\right)_{\max }$ & $\mathrm{E}_{50}(\mathrm{MPa})$ & $v_{\mathrm{s}}$ \\
\hline & & 50 & 38,0 & $\ldots$ & 11,7 & 0,508 & 27,2 & 0,37 \\
\hline \multirow[t]{3}{*}{1} & 50 & 100 & 36,7 & 33,4 & 8,8 & 0,363 & 35,2 & 0,34 \\
\hline & & 200 & 34,0 & 31,0 & 6,8 & 0,271 & 38,5 & 0,38 \\
\hline & & 50 & 39,9 & 34,6 & 15,5 & 0,731 & 35,9 & 0,44 \\
\hline \multirow[t]{2}{*}{2} & 100 & 100 & 39,2 & 33,1 & 13,4 & 0,604 & 40,6 & 0,41 \\
\hline & & 200 & 38,2 & 31,8 & 8,9 & 0,368 & 49,3 & 0,42 \\
\hline
\end{tabular}

\subsubsection{Propriedades dos Tubos Utilizados}

Os modelos ensaiados contaram com a utilização de tubos comerciais de PVC com $75 \mathrm{~mm}$ de diâmetro externo e $2 \mathrm{~mm}$ de espessura da parede (t). A cada ensaio um novo corpo-de-prova de $1395 \mathrm{~mm}$ de comprimento era utilizado. As propriedades mecânicas do tubo foram obtidas a partir de ensaios de placas paralelas realizados segundo as premissas da norma da ASTM D 2412-02. Três corpos-de-prova com 150 $\mathrm{mm}$ de comprimento foram ensaiados em uma prensa devidamente calibrada de 30 $\mathrm{kN}$ de capacidade, programada para operar a uma taxa de compressão de 12,5 $\mathrm{mm} / \mathrm{min}$. Durante o ensaio, o corpo de prova era comprimido entre duas chapas metálicas rígidas de $200 \mathrm{~mm}$ de largura e $6 \mathrm{~mm}$ de espessura, fixas às garras da 
prensa. A força aplicada era medida através de uma célula de carga acoplada à garra superior, cujo deslocamento era registrado automaticamente.

A Figura 4.14 mostra as curvas carga-deflexão total dos corpos de prova de PVC, através das quais se observa um comportamento de encruamento para o material após $0,24 \mathrm{kN}$, com crescimento praticamente constante da força aplicada com a deflexão sofrida. Para $0,24 \mathrm{kN}$, a rigidez do tubo (RT), razão entre a carga e a variação do diâmetro vertical (Watkins e Anderson 1999), é igual a $178 \mathrm{kN} / \mathrm{m} / \mathrm{m}$. O módulo de elasticidade (E) do material, obtido por retro-análise através da expressão (4.3), é igual a 1,91 GPa.

$$
E=\frac{D^{3} \cdot R T \cdot\left(1-v^{2}\right)}{4,48 \cdot t^{3}}
$$

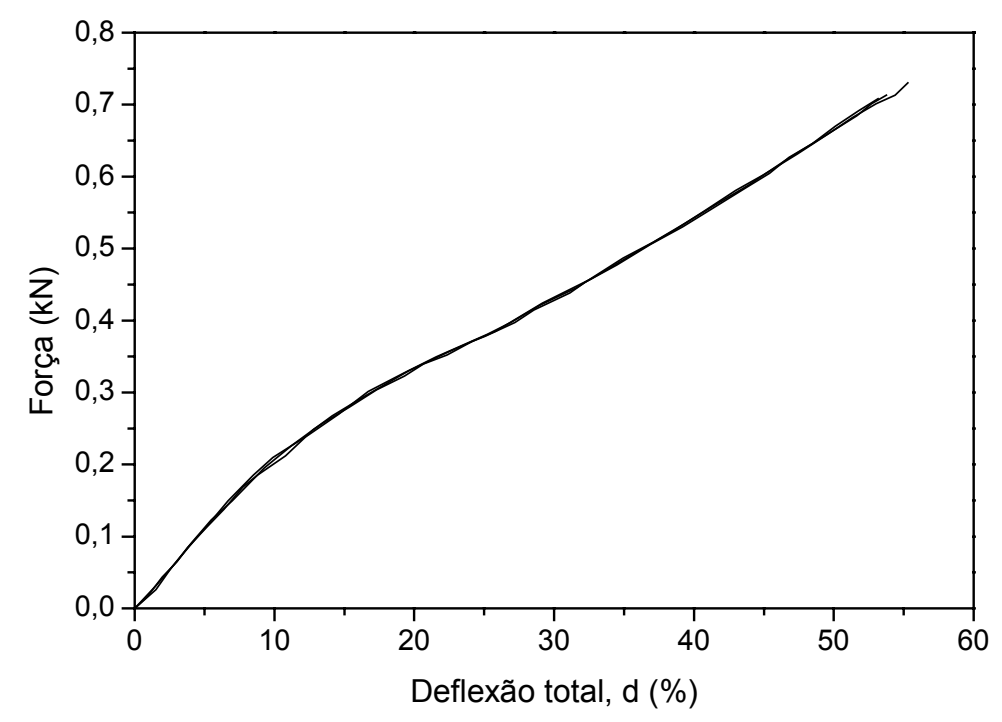

Figura 4.14. Curvas carga-deflexão dos corpos de prova de PVC.

\subsection{PROCEDIMENTOS DE ENSAIO}

\subsubsection{Preparação do Solo nos Modelos}

O preenchimento da caixa de testes foi procedido utilizando-se a técnica de chuvade-areia. Para tanto, o equipamento desenvolvido nesta fase da pesquisa teve por base o trabalho de Rad e Tumay (1987), que realizam um extenso estudo sobre os 
fatores que afetam a densidade de amostras obtidas através do método. Como mostra a Figura 4.15, o equipamento era composto por um pórtico de aço, um reservatório móvel no topo e um conjunto de peneiras localizadas sob este último, denominado difusor. O procedimento consistia em liberar a areia armazenada no reservatório enquanto o mesmo se movimentava a uma velocidade constante sobre a caixa. $\mathrm{O}$ pórtico era composto por perfis de seção transversal de $25 \times 25 \mathrm{~mm}$, possuindo as seguintes dimensões: $2 \mathrm{~m}$ de comprimento, 0,8 $\mathrm{m}$ de largura e 2,04 $\mathrm{m}$ de altura, determinadas de acordo com as dimensões da caixa de teste. O reservatório possuía dimensões de 200 x 400 × $570 \mathrm{~mm}$, sendo dotado de rodas que giravam sobre canaletas em $v$ soldadas no topo da estrutura. $\mathrm{O}$ fundo do reservatório era composto por uma chapa perfurada que dava vazão à areia quando da abertura de uma escotilha. Correias ligadas a um motor eram responsáveis pela movimentação do reservatório a uma velocidade constante. Auxiliado por um conjunto de catracas, um redutor de 1:300 reduzia a rotação do motor, permitindo ao reservatório percorrer a estrutura de uma extremidade a outra em aproximadamente $40 \mathrm{~s}$.

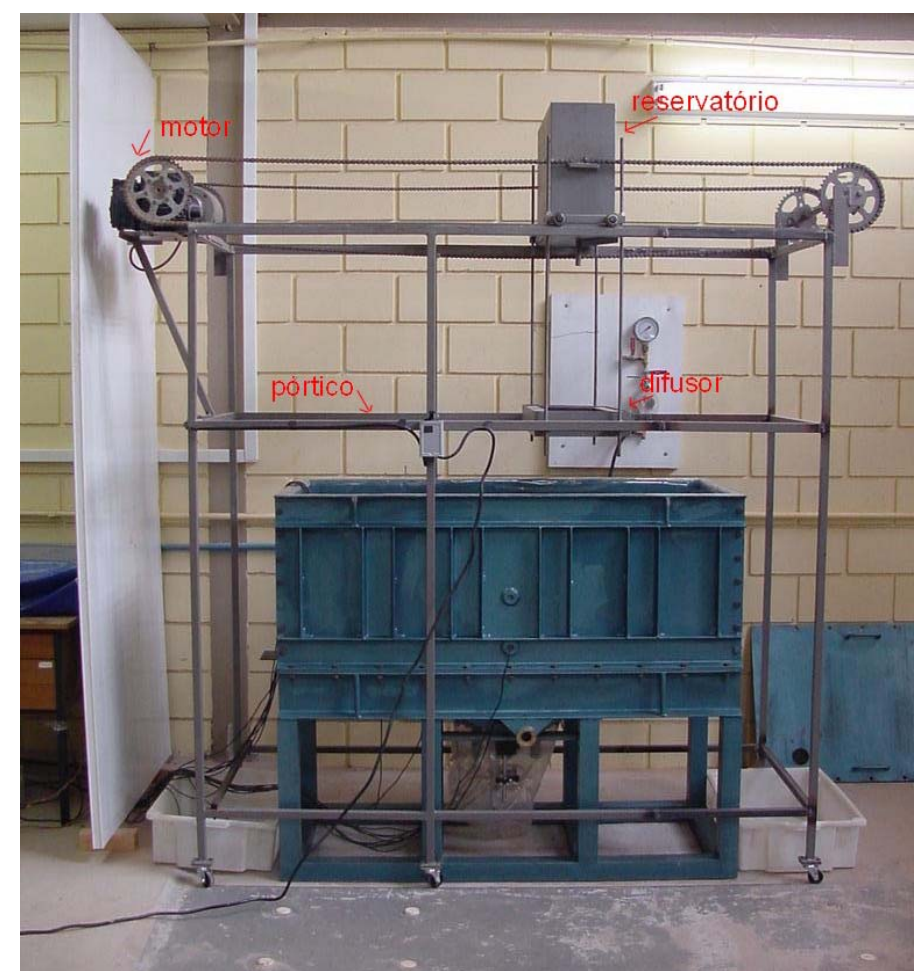

Figura 4.15. Vista geral do equipamento de chuva-de-areia. 
A areia era liberada através da abertura de uma escotilha no fundo do reservatório e atingia a caixa de ensaios após passar pelo difusor, o qual permitia a obtenção de amostras mais homogêneas. Como ilustra a Figura 4.16, o difusor possui dimensões externas de $80 \mathrm{~mm}$ de altura, $305 \mathrm{~mm}$ de comprimento e $665 \mathrm{~mm}$ de largura e era acoplado ao reservatório por quatro barras rosqueadas de $12,7 \mathrm{~mm}$ de diâmetro. O equipamento era formado por duas peneiras com abertura de $6 \mathrm{~mm}$, defasadas de $45^{\circ}$ e distantes $425 \mathrm{~mm}$ entre si. As peneiras possuíam comprimento de $200 \mathrm{~mm}$ e largura de $560 \mathrm{~mm}$.

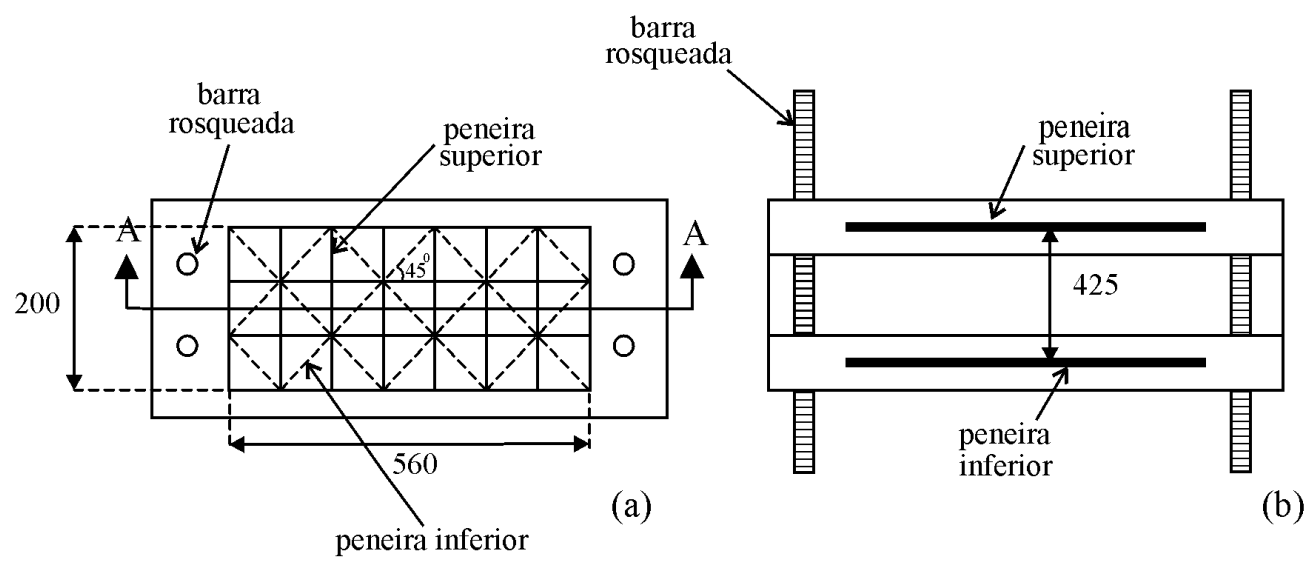

Figura 4.16. Esquema do difusor; (a) vista superior (b) corte A-A. Dimensões em $\mathrm{mm}$.

Maciços com diferentes densidades foram obtidos mantendo a distância entre o difusor e o topo da caixa de testes constante e alterando a descarga do material, tida como o fator de maior influência sobre a densidade final. Altura de queda, distância do reservatório ao difusor, quantidade de peneiras, distância entre peneiras, dentre outros, exercem efeitos secundários (Rad e Tumay 1987). A descarga foi variada através do diâmetro dos orifícios da chapa do fundo do reservatório.

A seleção dos diâmetros da chapa do reservatório e da distância entre o difusor e a caixa de testes foi efetuada através de calibrações. Primeiramente, com a vazão mantida constante, amostras de solo foram preparadas em um recipiente de volume conhecido $(200 \times 200 \times 100 \mathrm{~mm})$ variando-se a altura de queda da areia. Através da determinação do peso da amostra, foi possível avaliar a densidade obtida para cada altura estabelecida. Observou-se que a densidade da areia permanece 
constante já para alturas superiores a $200 \mathrm{~mm}$, de modo que a distância do difusor ao topo da caixa de testes foi fixada em $250 \mathrm{~mm}$.

Em seguida, com a altura entre o difusor e o topo do recipiente mantida constante, variou-se o diâmetro dos furos da chapa inferior do reservatório. A Figura 4.17 mostra a relação obtida entre $\mathrm{D}_{\mathrm{r}}$ e o diâmetro do orifício. Foram confeccionadas chapas com orifícios de 13, 9 e 4 mm de diâmetro, correspondentes a densidades relativas $\left(D_{r}\right)$ de 50,75 e $100 \%$, respectivamente.

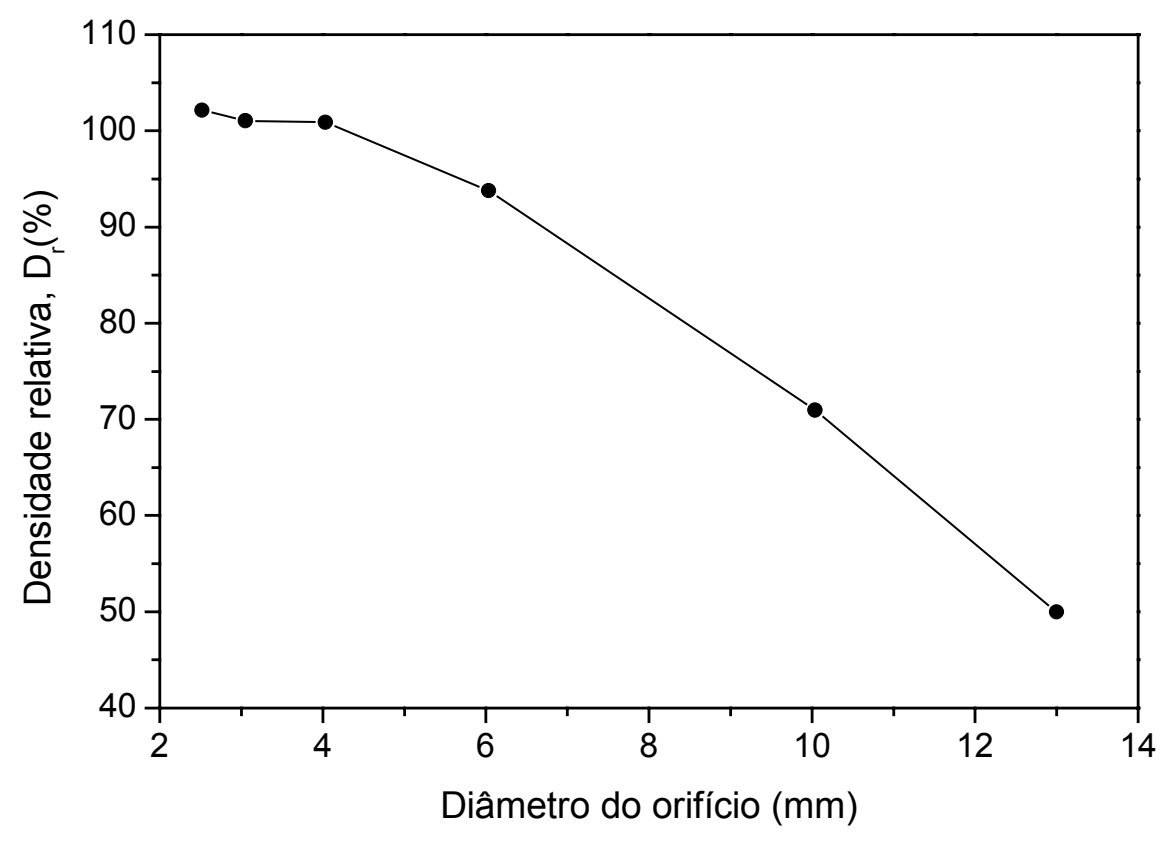

Figura 4.17. Curva de calibração da areia Itaporã: densidade relativa versus diâmetro do orifício.

\subsubsection{Confecção dos Modelos e Execução dos Ensaios}

Antes da realização dos ensaios, as paredes da caixa de testes eram revestidas com duas camadas de filme de poliéster (comercialmente conhecido por Mylar, de Fabricação da DuPont) de 0,075 mm de espessura, sem lubrificação. Considerou-se que o uso de um lubrificante não se justificaria por causa do custo elevado e pelas próprias dimensões da caixa em relação ao tubo, as quais, por si só já reduzem consideravelmente a influência do contorno sobre o comportamento do tubo ensaiado. 
O passo inicial para a realização do ensaio consistia em posicionar o equipamento de chuva-de-areia na caixa de testes, procurando-se alinhar as extremidades das peneiras do dispersor com as paredes. A caixa era então preenchida com areia até compor uma camada de $30 \mathrm{~mm}$ de espessura, onde o tubo repousava. A camada era cuidadosamente nivelada por meio de vácuo (Ueno 1998). Antes do preenchimento da caixa, uma camada de graxa de silicone era aplicada às frestas entre o prisma e a base da caixa para prevenir a entrada de areia no mecanismo do alçapão e o conseqüente travamento do sistema.

O corpo-de-prova era preparado lixando-se suas extremidades, pulverizandose seu interior com pó de grafite e marcando-se o local de instalação das células de tensão total, para em seguida ser posicionado no interior da caixa. Para evitar a saída de areia da caixa, as extremidades do tubo eram vedadas com fita adesiva no interior e tiras de espuma no lado externo. Em seguida, as células de inclusão eram fixadas ao tubo com o auxílio de fita adesiva. As demais células eram dispostas durante o processo de enchimento da caixa. A Figura 4.18 exibe o corpo-de-prova posicionado no interior da caixa com as células de tensão da linha d'água afixadas.

O sistema de medidas das deflexões do tubo era montado iniciando-se pelos suportes externos, seguidos da barra-guia e finalmente do transdutor. A primeira varredura de leituras era realizada após a areia cobrir o teto do tubo. Antes do processo de enchimento da caixa ser retomado, o sistema de medições de deslocamento era protegido com sacos plásticos e fita adesiva para evitar o contato com a areia. Após o preenchimento total da caixa, a superfície da areia era cuidadosamente rasada com uma régua e o exterior da caixa era limpo com o auxílio de um aspirador de pó. Uma bolsa de PVC reforçada com fibras de poliéster, fabricada pela Sansuy S.A., era então colocada sobre a superfície do modelo com o intuito de aplicar pressão no maciço de solo recém-construído. Por fim, a tampa era fixada à caixa através de parafusos. Mais uma varredura com o transdutor de deslocamentos era realizada antes do início da fase de aplicação da pressão.

A pressão era aplicada à bolsa em incrementos de $10 \mathrm{kPa}$ até o nível desejado, sendo registrada através de um manômetro devidamente aferido com resolução de 1 $\mathrm{kPa}$ e capacidade máxima de $200 \mathrm{kPa}$. Quando a pressão final era atingida, uma nova varredura com o transdutor de deslocamentos era efetuada, para então ser iniciada a 
movimentação do alçapão. Novas varreduras eram realizadas em determinados deslocamentos do alçapão, como descrito no item 4.4.3. Os deslocamentos do alçapão eram medidos através de um transdutor de deslocamentos do tipo DTH, de fabricação da Kyowa Electronic Instruments Co., Ltd., com capacidade máxima de $100 \mathrm{~mm}$ e resolução de $0,01 \mathrm{~mm}$. O transdutor era posicionado embaixo da caixa de testes por meio de uma base magnética articulada. Dois DTHs foram utilizados em alguns dos ensaios para confirmação de medidas.

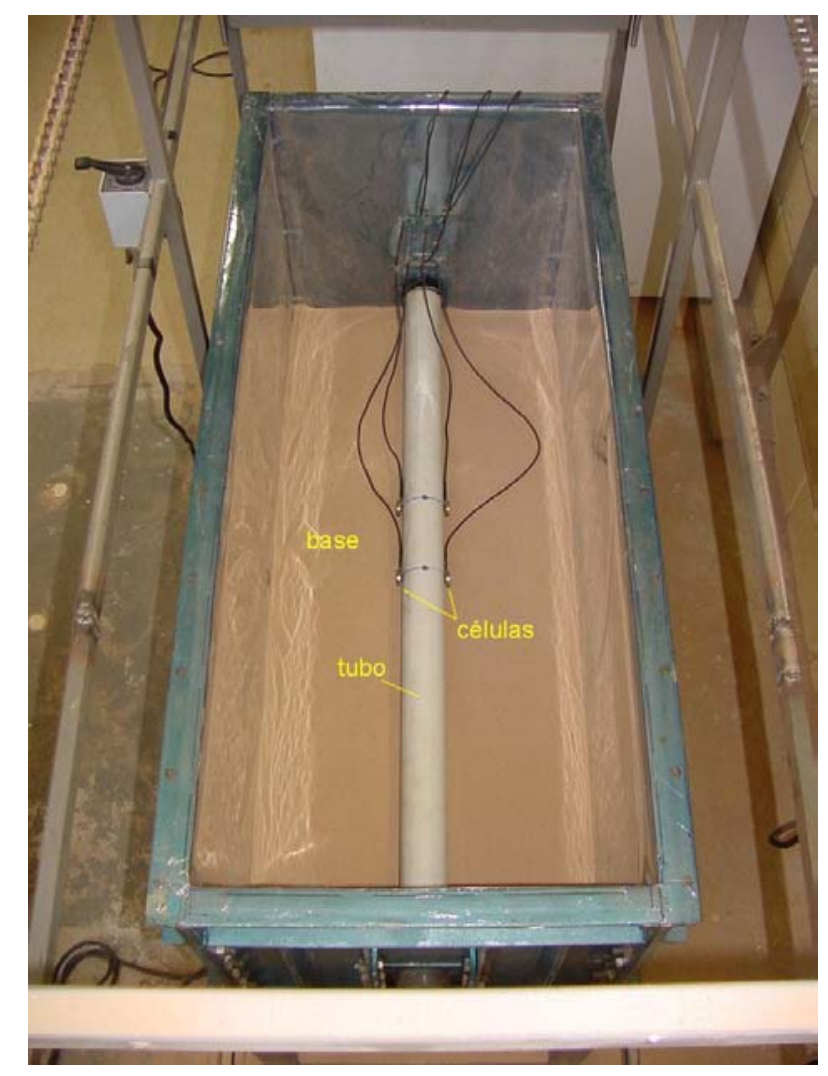

Figura 4.18. Tubo posicionado na caixa de testes com células afixadas.

Como anteriormente mencionado, a resposta dos instrumentos era gravada durante os ensaios através de um sistema de aquisição de fabricação da Measurements Group., Inc, modelo Win5000. Nos ensaios convencionais foram utilizados dois módulos de aquisição, sendo as células de tensão e o DTH ligados em um deles e o transdutor de deslocamentos no outro. Os dados obtidos eram armazenados em um micro-computador para posterior tratamento. Nos ensaios com o tubo instrumentado apenas as leituras dos strain-gages eram obtidas, não sendo medidas as deflexões ao longo do tubo nem tensões na massa de solo. 


\subsection{PROGRAMA DE ENSAIOS}

Um total de 25 ensaios foi realizado nesta fase da pesquisa, dentre testes com e sem a presença do tubo. A seqüência de todos os ensaios é mostrada nas tabelas a seguir, sendo divididas em quatro séries distintas. As variáveis selecionadas para investigação foram a densidade relativa do solo $\left(\mathrm{D}_{\mathrm{r}}\right)$, a sobrecarga (q), o comprimento do alçapão $\left(\mathrm{L}_{\mathrm{v}}\right)$ e o sentido do deslocamento do alçapão. Densidades relativas de 50, 75 e $100 \%$ foram utilizadas para representar maciços fofos, intermediários e compactos, respectivamente. Os modelos foram ensaiados com pressões aplicadas pela bolsa na superfície variando entre 0 e $150 \mathrm{kPa}$.

Continuando a denominação dada aos ensaios em centrífuga, a série C (Tabela 4.5) engloba os ensaios de arqueamento, ou seja, sem tubo, os quais contaram com a utilização de ambas as configurações de alçapão (100 x 100 mm e $300 \times 100 \mathrm{~mm}$ ), deslocando-se em ambos os sentidos. As séries D e E (Tabelas 4.6 e 4.7) envolvem os ensaios com o conduto submetido a perda de apoio e elevação localizada, respectivamente. Todos os modelos dessas séries foram ensaiados com o alçapão de $300 \times 100 \mathrm{~mm}$. A série $\mathrm{F}$ contou com quatro ensaios com o tubo instrumentado, sendo dois com o alçapão subindo e outros dois com o alçapão descendo. A seqüência dos ensaios da série F é mostrada na Tabela 4.8.

Tabela 4.5. Série C: ensaios de arqueamento

\begin{tabular}{ccccc}
\hline Ensaio & $\begin{array}{c}\text { Densidade } \\
\text { relativa, } \mathrm{D}_{\mathrm{r}}(\%)\end{array}$ & $\begin{array}{c}\text { Sobrecarga, } \\
\mathrm{q}(\mathrm{kPa})\end{array}$ & $\begin{array}{c}\text { Compr. do } \\
\text { alçapão, } \mathrm{L}_{\mathrm{v}}\end{array}$ & $\begin{array}{c}\text { Sentido do } \\
\text { alçapão }\end{array}$ \\
\hline $\mathrm{C} 1$ & 100 & 100 & $3 \mathrm{~B}{ }^{*}$ & Desce \\
$\mathrm{C} 2$ & 100 & 100 & $3 \mathrm{~B}$ & Desce \\
$\mathrm{C} 3$ & 50 & 100 & $3 \mathrm{~B}$ & Desce \\
$\mathrm{C} 4$ & 100 & 50 & $3 \mathrm{~B}$ & Desce \\
$\mathrm{C} 5$ & 100 & 100 & $3 \mathrm{~B}$ & Sobe \\
$\mathrm{C} 6$ & 100 & 100 & $\mathrm{~B}^{+}$ & Desce \\
$\mathrm{C} 7$ & 100 & 100 & $\mathrm{~B}$ & Sobe \\
\hline
\end{tabular}

*alçapão de 300 x 100 mm, ${ }^{+}$alçapão de 100 x 100 mm 
Tabela 4.6. Série D: ensaios com tubo submetido a perda de apoio localizada

\begin{tabular}{ccc}
\hline Ensaio & Densidade relativa, $\mathrm{D}_{\mathrm{r}}(\%)$ & Sobrecarga, $\mathrm{q}(\mathrm{kPa})$ \\
\hline D1 & 100 & 50 \\
D2 & 100 & 100 \\
D3 & 100 & 100 \\
D4 & 100 & 150 \\
\hline D5 & 75 & 100 \\
\hline D6 & 50 & 50 \\
D7 & 50 & 100 \\
D8 & 50 & 150 \\
\hline
\end{tabular}

Tabela 4.7. Série E: ensaios com tubo submetido a elevação

\begin{tabular}{ccc}
\hline Ensaio & Densidade relativa, $\mathrm{D}_{\mathrm{r}}(\%)$ & Sobrecarga, $\mathrm{q}(\mathrm{kPa})$ \\
\hline E1 & 100 & 0 \\
E2 & 100 & 25 \\
E3 & 100 & 50 \\
\hline E4 & 50 & 25 \\
E5 & 50 & 50 \\
E6 & 50 & 100 \\
\hline
\end{tabular}

Tabela 4.8. Série F: ensaios com tubo instrumentado

\begin{tabular}{cccc}
\hline Ensaio & $\begin{array}{c}\text { Densidade } \\
\text { relativa, } \mathrm{D}_{\mathrm{r}}(\%)\end{array}$ & $\begin{array}{c}\text { Sobrecarga, } \\
\mathrm{q}(\mathrm{kPa})\end{array}$ & $\begin{array}{c}\text { Sentido do } \\
\text { alçapão }\end{array}$ \\
\hline F1 & 100 & 100 & Desce \\
F2 & 50 & 100 & Desce \\
F3 & 100 & 50 & Sobe \\
F4 & 50 & 50 & Sobe \\
\hline
\end{tabular}




\section{Sistema Solo-Alçapão:}

Mecanismos de Ruptura no Arqueamento Ativo

\subsection{CONSIDERAÇÕES INICIAIS}

A ruptura de diversos sistemas geotécnicos é tipicamente caracterizada pelo desenvolvimento de localizações de deformação, ou seja, zonas concentradas de cisalhamento intenso na massa de solo, sendo suficientes deformações cisalhantes de pequena magnitude para sua manifestação (Desrues et al. 1985). A propagação da localização no solo ocorre em virtude do decréscimo da resistência do material na zona cisalhante, o qual direciona o acúmulo das deformações iminentes a esta região específica, aumentando gradualmente seu comprimento. A orientação e propagação das localizações são extremamente dependentes da dilatação do solo e das condições de contorno impostas.

Este Capítulo tem por objetivo apresentar e discutir os resultados dos ensaios de arqueamento ativo (Série A), cujos procedimentos encontram-se descritos no Capítulo 3. A investigação envolveu ensaios em gravidade unitária e em uma centrífuga geotécnica (45 g), consistindo da análise visual da cinemática do problema e da influência da densidade relativa do solo e do nível de tensão. 


\subsection{MECANISMOS DE RUPTURA NA SEÇÃO LONGITUDINAL}

\subsubsection{Propagação e Padrão das Localizações de Deformação}

A Figura 5.1 exibe a propagação das localizações na seção longitudinal central (plano yz), em contato com a face transparente da caixa de testes, como descrito no Capítulo 3. Os resultados referem-se ao maciço compacto $\left(\mathrm{D}_{\mathrm{r}}=85 \%\right)$ submetido a acelerações (A) de 45 e $1 \mathrm{~g}$ e deslocamentos relativos $\delta / \mathrm{B}$ de 14,3, 28,6 e 57,1\%. A tensão vertical inicial na base do modelo a 45 e $1 \mathrm{~g}$ corresponde a aproximadamente 124 e 2,7 kPa, respectivamente. O contorno da localização no maciço é destacado em cinza e linhas tracejadas passando pelo centro de cada degrau formado pela acomodação da areia colorida após a descida do alçapão delineiam seu eixo longitudinal. A determinação da inclinação, do comprimento e da altura da localização é feita em relação ao eixo longitudinal.

A $45 \mathrm{~g}$ um único par de localizações se propagou em direção ao centro do modelo, com ângulo de inclinação com a vertical $\left(\theta_{\mathrm{i}}\right)$, próximo ao vértice do alçapão, igual a $9^{0}$ (Figura 5.1a). Em virtude da propriedade do solo de se dilatar mais em níveis de tensão mais baixos, o deslocamento inicial do alçapão a $1 \mathrm{~g}$ causou o desenvolvimento de um par de localizações com inclinação $\theta_{\mathrm{i}}$ ligeiramente maior, igual a aproximadamente $13^{0}$ (Figura 5.1b). Localizações secundárias não foram observadas também neste caso. Com a continuidade da translação da base, a inclinação da localização a $1 \mathrm{~g}$ decresceu para $7^{0} \mathrm{em} \delta / \mathrm{B}=28,6 \%$ e $4^{0} \mathrm{em} \delta / \mathrm{B}=$ $57,1 \%$. Já a $45 \mathrm{~g}, \theta_{\mathrm{i}}$ sofreu uma pequena redução para aproximadamente $7^{0} \mathrm{em} \delta / \mathrm{B}=$ $28,6 \%$, permanecendo até o deslocamento final do alçapão. Sabendo-se que a margem de erro de medição é de $\pm 1 \%$, é possível afirmar que a variação de $\theta_{\mathrm{i}}$ é praticamente inexistente.

As Figuras 5.1a e b mostram ainda que as localizações a $1 \mathrm{~g}$ se propagaram com uma determinada curvatura em direção ao centro do modelo, em contraste com as localizações a $45 \mathrm{~g}$. Em complementação, no primeiro estágio de deslocamento analisado $(\delta / \mathrm{B}=14,3 \%)$ os modelos em gravidade unitária exibiram localizações menos desenvolvidas em comparação com os modelos submetidos à aceleração de 45 g. Porém, com o aumento do deslocamento do alçapão, a extensão das localizações 
tende à igualdade em ambos os níveis de aceleração. $\mathrm{Em} \delta / \mathrm{B}=57,1 \%$, as localizações alcançam alturas verticais $\left(\mathrm{h}_{\mathrm{v}}\right)$, medidas a partir da base da caixa de testes, iguais a aproximadamente 2,4 $\mathrm{B}$ em ambas acelerações. Já em $\delta / \mathrm{B}=14,3 \%$, as localizações formadas sob gravidade unitária apresentaram $h_{v}$ igual a 0,4 , aproximadamente 3 vezes menor que a altura atingida a $45 \mathrm{~g}$.
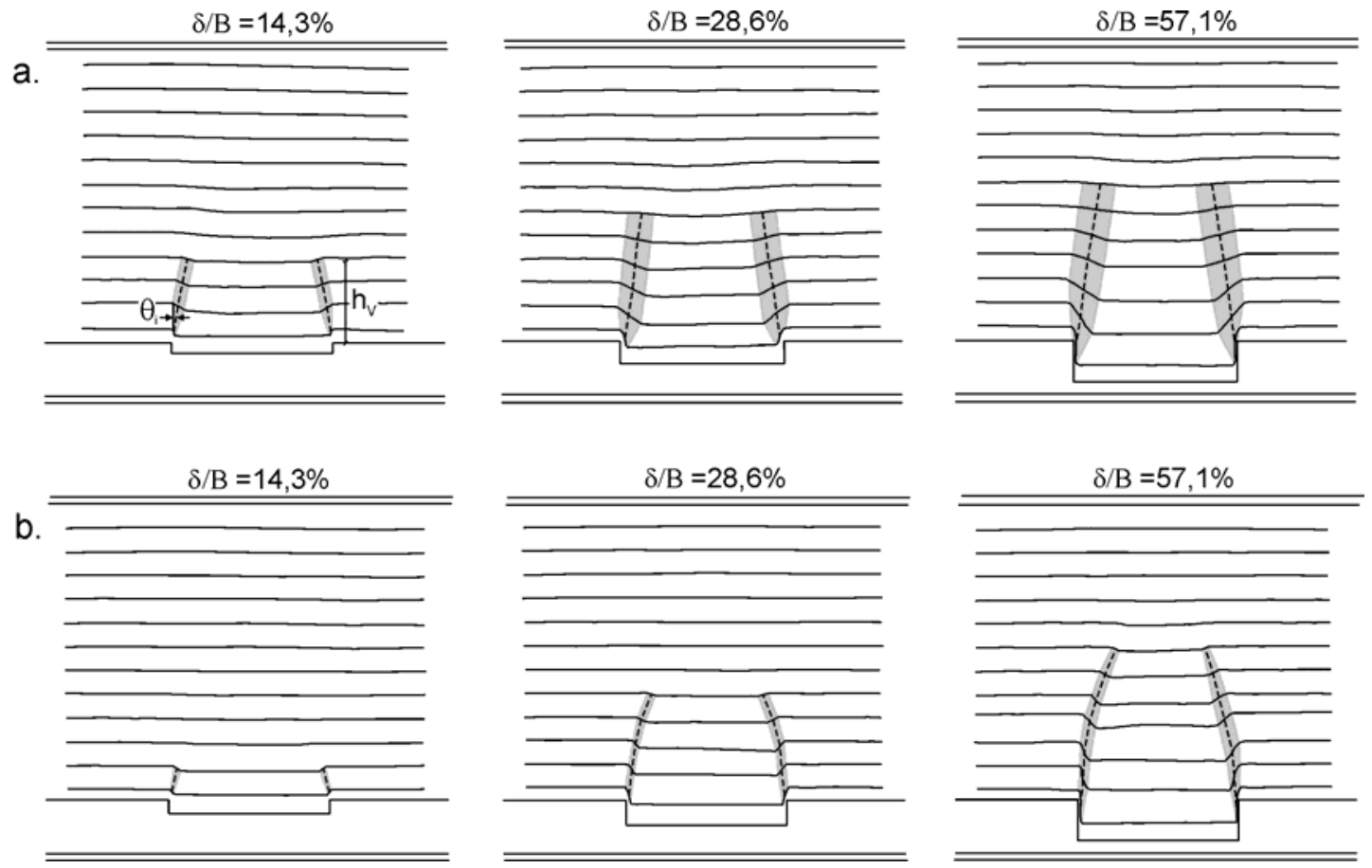

Figura 5.1. Desenvolvimento de localizações de deformação na seção longitudinal do modelo (plano yz) no maciço compacto $\left(\mathrm{D}_{\mathrm{r}}=85 \%\right)$. a) Modelos ensaiados a 45 g. $\theta_{\mathrm{i}}$ $=9^{0}$ para $\delta / \mathrm{B}=14,3 \%, 7^{0}$ para $\delta / \mathrm{B}=28,6 \%$ e $7^{0}$ para $\delta / \mathrm{B}=57,1 \%$; b) modelos ensaiados a 1 g. $\theta_{\mathrm{i}}=13^{0}$ para $\delta / \mathrm{B}=14,3 \%, 7^{0}$ para $\delta / \mathrm{B}=28,6 \%$ e $4^{0}$ para $\delta / \mathrm{B}=$ $57,1 \%$.

O desenvolvimento de localizações de deformação na massa de solo também pode ser analisado através de contornos de deformação cisalhante máxima $\left(\gamma_{\max }\right)$, construídos a partir das posições iniciais e finais dos marcadores de areia dispostos nos modelos contra a face transparente da caixa de testes. Aproveitando-se a simetria do problema, a Figura 5.2 exibe os contornos de $\gamma_{\max }$ para os três estágios de deslocamento total da base móvel. Como esperado, os maiores valores de $\gamma_{\max }$ são verificados a $45 \mathrm{~g}$, sendo essa tendência sensivelmente atenuada com o aumento de $\delta$. Nas proximidades do vértice do alçapão, uma translação de $\delta / \mathrm{B}=14,3 \%$ a $1 \mathrm{~g}$ 
resulta em uma deformação cisalhante aproximadamente duas vezes inferior à observada a $45 \mathrm{~g}$.

a)
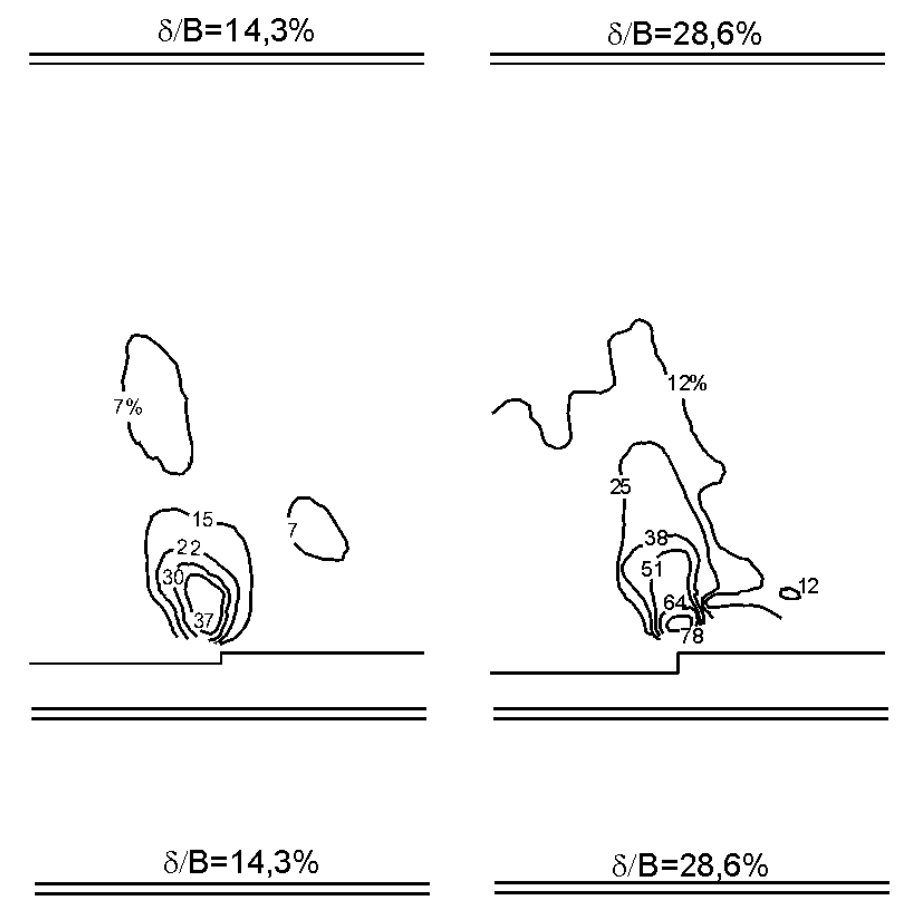

b)

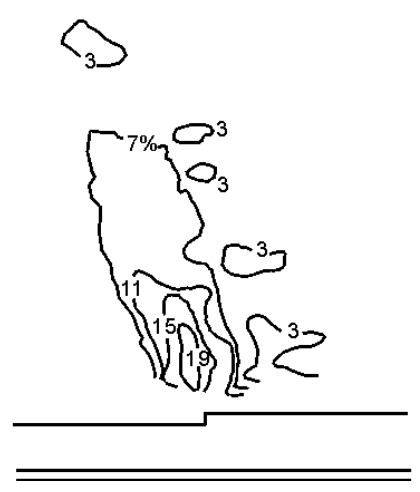

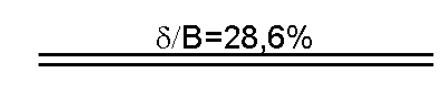

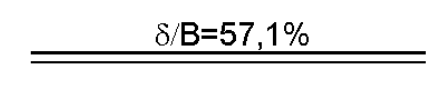

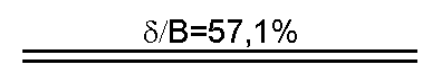
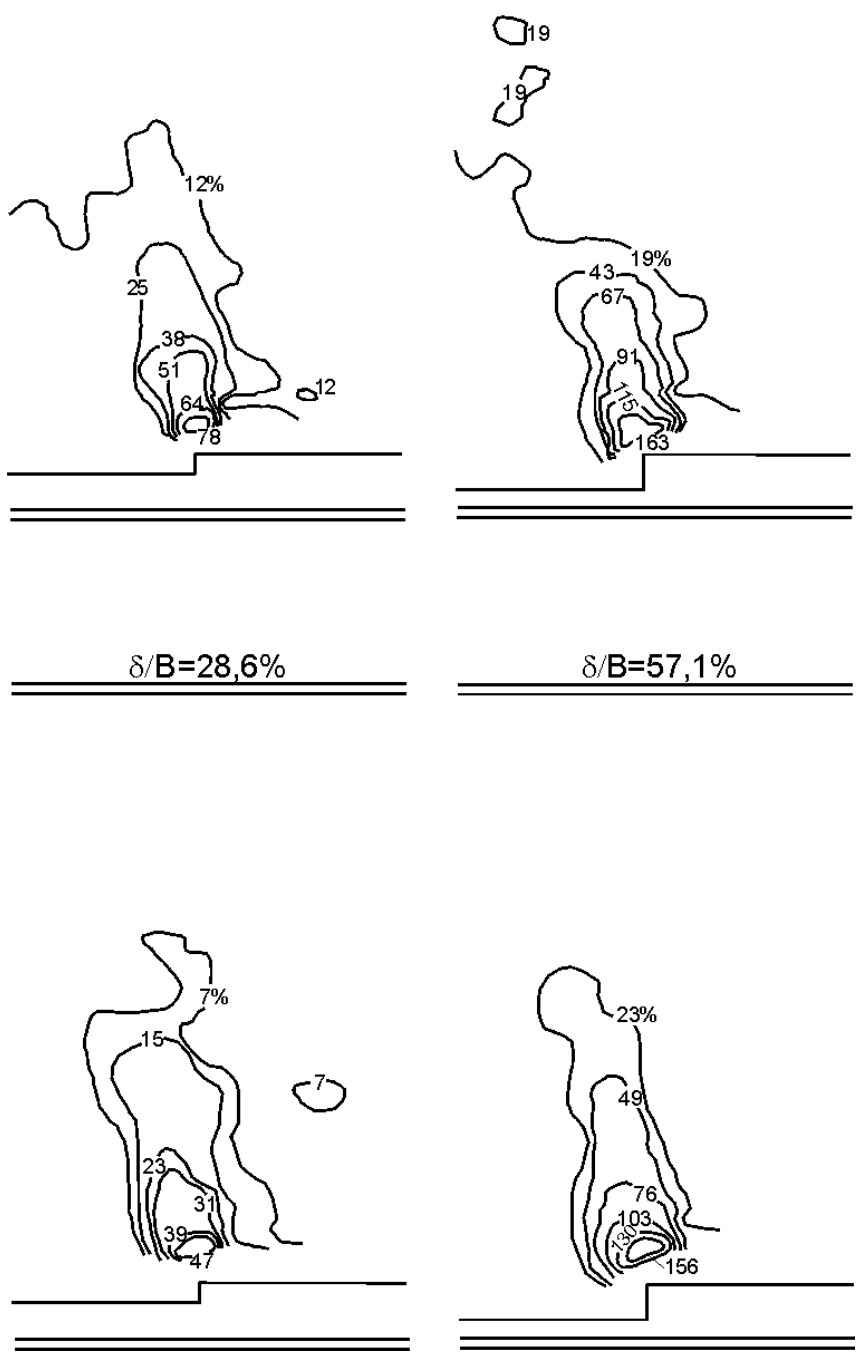

Figura 5.2. Contornos de deformação cisalhante máxima $\left(\gamma_{\max }\right)$ no maciço compacto $\left(D_{\mathrm{r}}=85 \%\right)$. a) Modelos ensaiados a $45 \mathrm{~g}$; b) modelos ensaiados a $1 \mathrm{~g}$.

A Figura 5.3 mostra as localizações desenvolvidas na seção longitudinal do maciço fofo $\left(D_{\mathrm{r}}=42 \%\right)$ para $\delta / B=57,1 \%$. Estando o solo nessa densidade, a tensão vertical estimada na base do modelo antes da movimentação é de aproximadamente 113 e $2,5 \mathrm{kPa}$, para as acelerações de 45 e $1 \mathrm{~g}$, respectivamente. Padrões muito 
semelhantes são obtidos com as duas acelerações, demonstrando ser muito reduzida a influência do nível de tensão com o material no estado fofo. Assim como no maciço compacto, apenas um par de localizações propagando-se em direção ao eixo vertical de simetria do modelo é observado. Em ambos os casos, os eixos centrais das localizações são aproximadamente lineares, possuindo inclinação $\theta_{\mathrm{i}}$ igual a $4^{0}$ e razão $\mathrm{h}_{\mathrm{v}} / \mathrm{B}$ igual a 1,8 .

a.

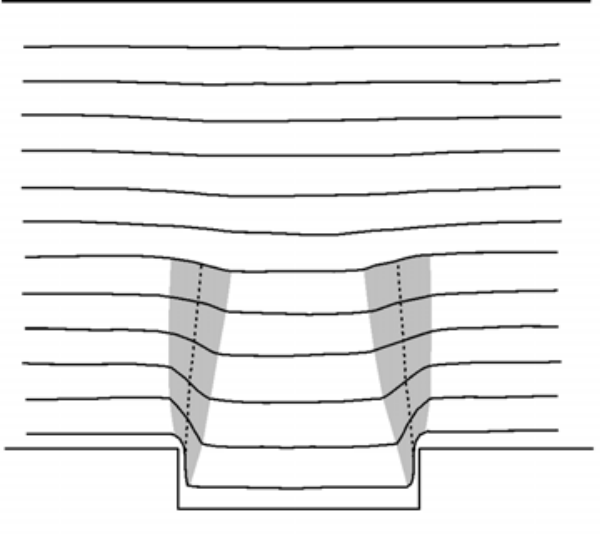

b.

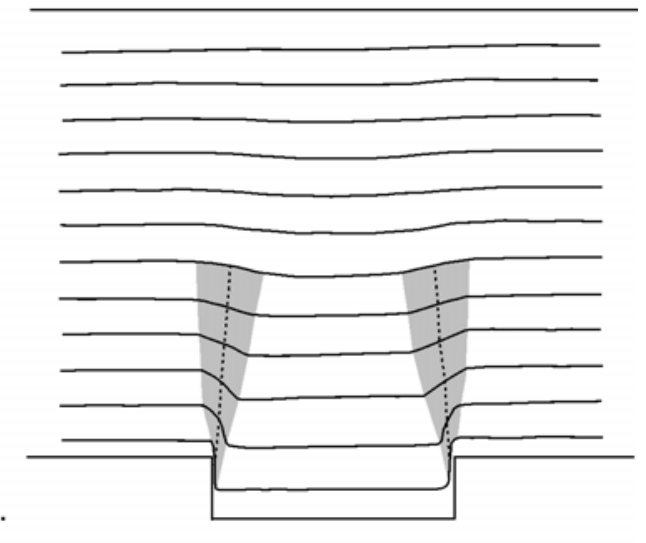

Figura 5.3. Localizações de deformação na seção longitudinal do modelo (plano yz) no maciço fofo $\left(D_{\mathrm{r}}=42 \%\right), \delta / \mathrm{B}=57,1 \%$. a) Modelo ensaiado a $45 \mathrm{~g}, \theta_{\mathrm{i}}=4^{0} ; \mathrm{b}$ ) modelo ensaiado a $1 \mathrm{~g}, \theta_{\mathrm{i}}=4^{0}$.

À espessura das localizações (t) é tipicamente atribuído o valor de 10 vezes o diâmetro médio da partícula do solo $\left(\mathrm{D}_{50}\right)$ (Roscoe 1970, Atkinson 1993). Entretanto, investigações experimentais com ensaios de compressão biaxial mostraram razões t/D $D_{50}$ variando entre 8 e 20 (Vardoulakis 1988, Han 1991, Shibli 1995). Experimentos com alçapão em arqueamento ativo, com H/B entre 0,5 e 2, revelaram valores de $t / D_{50}$ praticamente na mesma faixa, entre 10 e 21 , independentemente da condição ensaiada (estado plano ou axissimétrica) e da densidade do meio.

Como ilustra a Figura 5.1, as localizações propagadas no maciço compacto apresentaram espessura comparativamente constante ao longo de quase toda sua extensão (um afunilamento ocorre próximo à aresta do alçapão). Por outro lado, apesar de possuírem eixo longitudinal aproximadamente linear, as localizações desenvolvidas no solo no estado fofo apresentaram espessura variável ao longo de todo o comprimento, aumentando gradativamente da base ao topo. Como mostra a Figura 5.3, seu formato se aproximava ao de um triângulo. A Tabela 5.1 apresenta 
valores de $\mathrm{t} / \mathrm{D}_{50}$ em cada situação investigada, com $\mathrm{t}$ correspondendo à média de diversas medidas obtidas ao longo da localização (desde a primeira faixa de areia colorida a partir da base). Com exceção dos ensaios A4 a A6, observa-se que as localizações desenvolvidas possuem espessura bastante acima da faixa comumente mencionada.

Os dados dos testes A1 a A3 mostram que a espessura das localizações cresce com o aumento de $\delta / B$. Ainda que significativamente mais discreta, a mesma tendência também se manifestou na seqüência A4 a A6. O crescimento lateral da zona em cisalhamento ocorre tanto em direção ao solo sobre o alçapão, quanto em direção ao material exterior adjacente. Não obstante, o crescimento para o solo externo é maior, o que faz com que o eixo central da localização assuma posições gradualmente mais verticais à medida que $\delta$ aumenta. $\mathrm{O}$ aumento lateral da zona em cisalhamento também pode ser verificado através da Figura 5.2.

Tabela 5.1. Características das localizações longitudinais formadas

\begin{tabular}{ccccc}
\hline Ensaio & $\begin{array}{c}\text { Densidade } \\
\text { relativa, } \mathrm{D}_{\mathrm{r}}(\%)\end{array}$ & $\begin{array}{c}\text { Aceleração } \\
\text { centrífuga, } \mathrm{A}(\mathrm{g})\end{array}$ & $\delta / \mathrm{B}(\%)$ & $\mathrm{t} / \mathrm{D}_{50}$ \\
\hline $\mathrm{A} 1$ & & & 14,3 & 34 \\
$\mathrm{~A} 2$ & 85 & 45 & 28,6 & 62 \\
$\mathrm{~A} 3$ & & & 57,1 & 78 \\
$\mathrm{~A} 4$ & & 1 & 14,3 & 16 \\
$\mathrm{~A} 5$ & 85 & & 28,6 & 22 \\
$\mathrm{~A} 6$ & & 45 & 57,1 & 29 \\
A7 & 42 & 1 & 57,1 & $73^{*}$ \\
A8 & 42 & 57,1 & $67^{+}$ \\
\hline $\mathrm{t} / \mathrm{d}_{50}$ mín. $=47$ e máx. $=100 ;{ }^{+} \mathrm{t} / \mathrm{d}_{50}$ mín. $=27$ e max. $=107$
\end{tabular}

\subsubsection{Comportamento do Solo Sobre o Alçapão}

Tanto no maciço compacto quanto no fofo, observou-se que uma grande região do material sobre o alçapão sofre expansão após o deslocamento. A Figura 5.4 apresenta os contornos de deformação linear vertical $\left(\varepsilon_{\mathrm{z}}\right)$ no maciço compacto, obtidos para as acelerações de 45 e $1 \mathrm{~g}$ e deslocamentos relativos de 14,3, 28,6 e 57,1\%. O sinal negativo antes dos valores indica aumento de volume do solo. Para $\delta / \mathrm{B}=14,3 \%$, a deformação vertical do solo é mais pronunciada a 45 g. Entretanto, com a 
continuidade dos deslocamentos, os valores tornam-se gradualmente mais semelhantes em ambos níveis de aceleração.

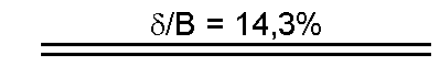

a)
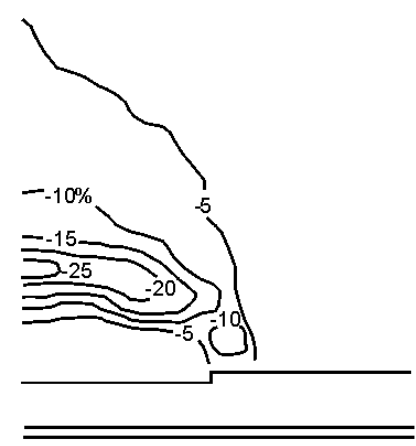

$\delta / B=14,3 \%$

b)

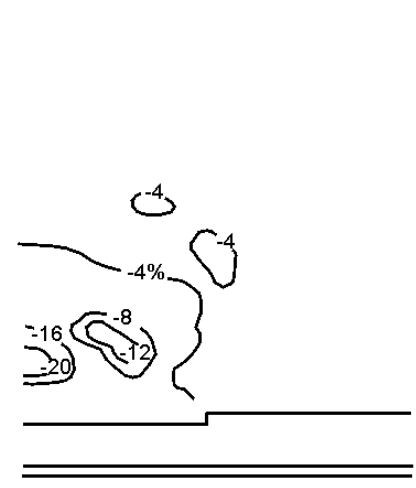

)
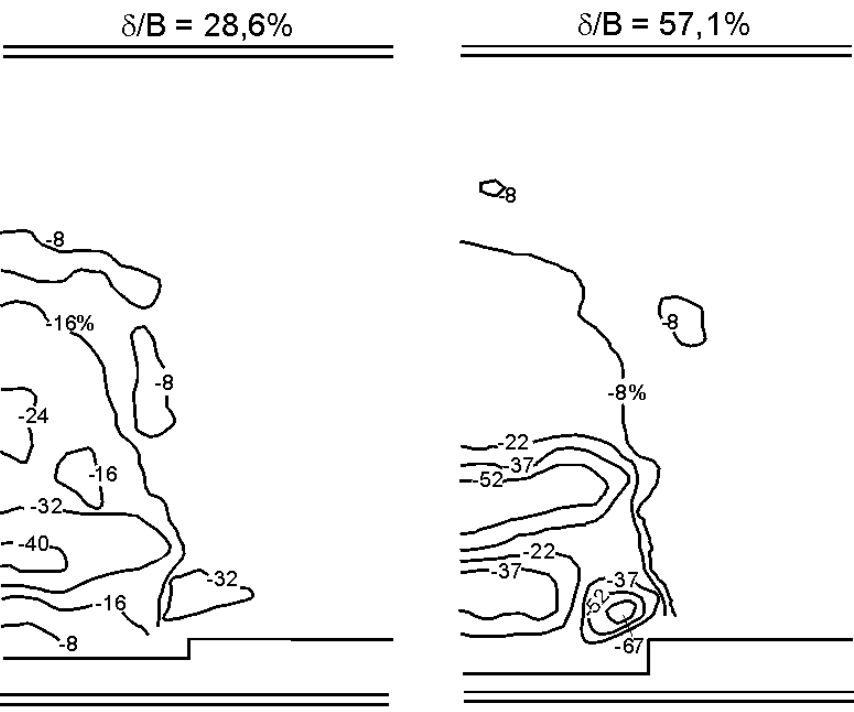

$0_{8}$
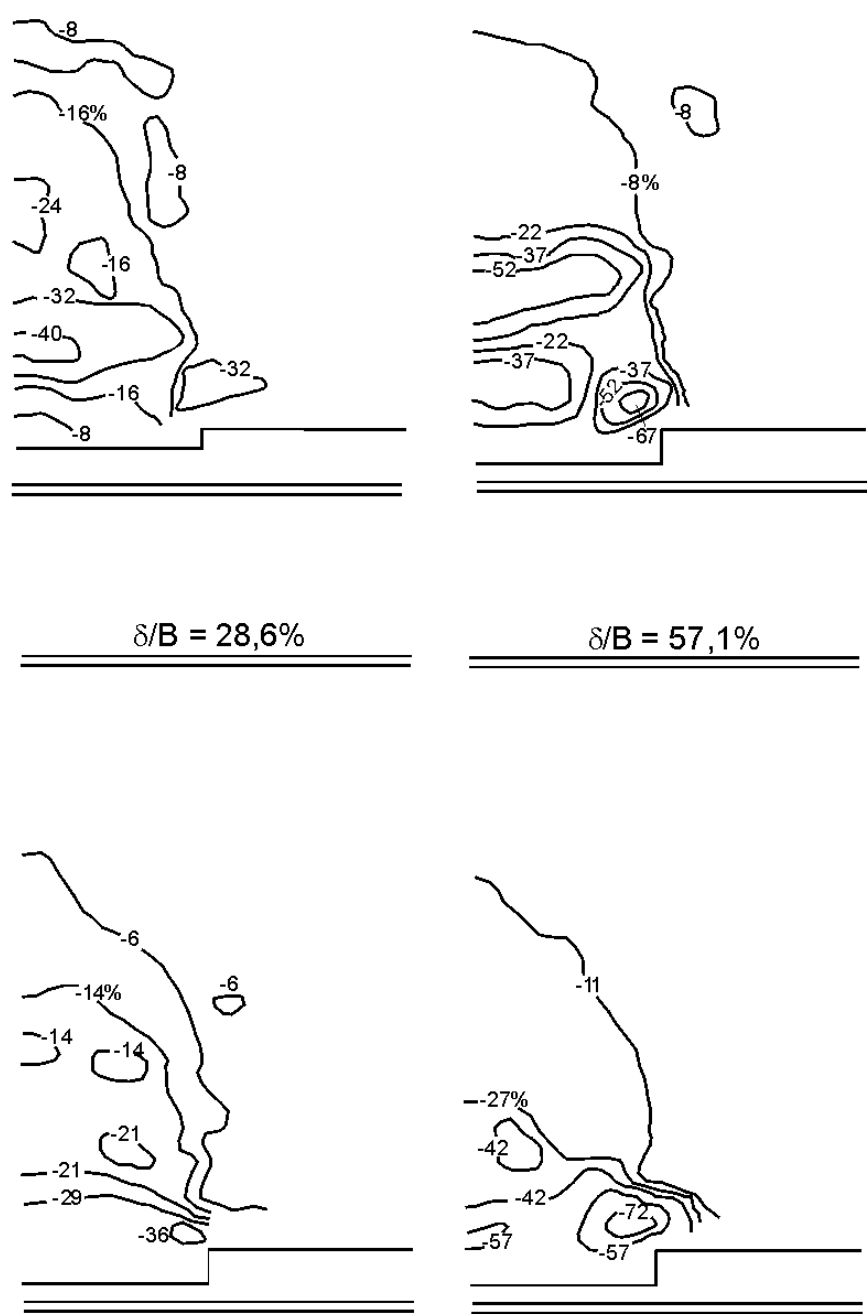

Figura 5.4. Contornos de deformação vertical $\left(\varepsilon_{z}\right)$ no maciço compacto $\left(D_{r}=85 \%\right)$. a) Modelos ensaiados a $45 \mathrm{~g}$; b) modelos ensaiados a $1 \mathrm{~g}$. 


\subsection{MECANISMOS DE RUPTURA NAS SEÇÕES TRANSVERSAIS}

\subsubsection{Propagação e Padrão das Localizações na Seção S1}

A Figura 5.5 apresenta o desenvolvimento das localizações no maciço compacto, na seção transversal S1 (plano $\mathrm{x}-\mathrm{z}$ ). A Figura $3.8 \mathrm{~b}$ indica a posição das seções transversais investigadas em relação ao alçapão. Nos dois níveis de aceleração utilizados os padrões iniciais apresentaram-se similares aos observados na seção longitudinal. Houve a propagação de apenas uma localização sobre o alçapão, com inclinação com a vertical $\left(\theta_{i}\right)$ de mesma magnitude da localização na seção longitudinal na condição correspondente.

No entanto, a continuidade dos deslocamentos da base móvel provocou a manifestação de localizações transversais desenvolvendo-se não mais em direção ao centro do modelo, mas à massa de solo no exterior do alçapão. As localizações externas revelaram padrões distintos com o nível de aceleração utilizado. Como ilustra a Figura 5.5a, a translação do alçapão a $45 \mathrm{~g}$ provocou a formação de duas localizações exteriores, com a mais externa originando-se de uma bifurcação da precedente. Já a $1 \mathrm{~g}$ houve a manifestação de apenas uma única localização (Figura 5.5b). Padrões com localizações mais desenvolvidas a $45 \mathrm{~g}$ foram observados em todos os patamares de deslocamento do alçapão investigados. Em virtude da menor dilatação do solo, as localizações a $45 \mathrm{~g}$ se propagaram com maior inclinação para a horizontal, abrangendo, por conseqüência, uma maior zona do maciço exterior.

Em $\delta / B=28,6 \%$ as localizações externas desenvolvidas no maciço compacto apresentaram inclinações $\left(\theta_{\mathrm{e}}\right)$ na base de aproximadamente 75 e $80^{0} \mathrm{com}$ a horizontal, para 45 e $1 \mathrm{~g}$, respectivamente. As localizações se movimentaram em direção à massa de solo exterior durante a descida do alçapão, com $\theta_{\mathrm{e}}$ sofrendo redução para 63 e $75^{\circ}$, respectivamente, quando o deslocamento relativo de $57,1 \%$ foi atingido. Os modelos com maciço fofo apresentaram valores menores de $\theta_{\mathrm{e}}$ neste nível de deslocamento.

As características das localizações exteriores em cada condição investigada são sumarizadas na Tabela 5.2. $\mathrm{s}_{1}$ e $\mathrm{s}_{2}$ são os recalques superficiais medidos na seção $\mathrm{S} 1$, a 9 e $42 \mathrm{~mm}$ da face transparente da caixa de testes, respectivamente ( $\mathrm{s}_{1}$ não é 
portanto o recalque máximo). Os demais parâmetros são indicados na Figura 5.10. Os dados correspondem ao deslocamento final do alçapão e também incluem os resultados com o maciço fofo $\left(D_{r}=42 \%\right)$.

O alcance horizontal de propagação da localização externa na massa de solo adjacente ao alçapão é quantificado através do comprimento de sua projeção horizontal $\left(\mathrm{x}_{\mathrm{i}}\right)$, medida a partir da aresta do alçapão. Os maiores valores de $\mathrm{x}_{\mathrm{i}}$ foram observados com o maciço fofo, correspondendo a 0,6 B em ambas acelerações. Esse valor é o triplo do obtido no maciço compacto a $1 \mathrm{~g}$.

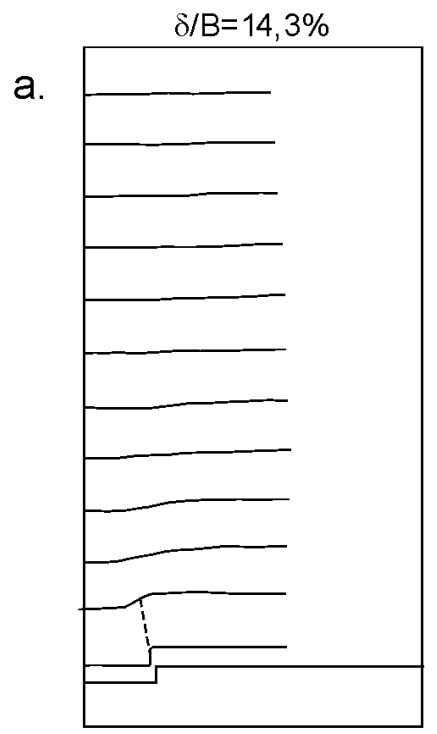

$\delta / \mathrm{B}=14,3 \%$

b.

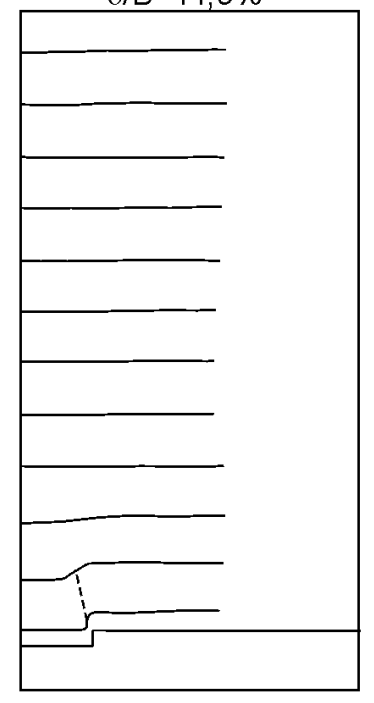

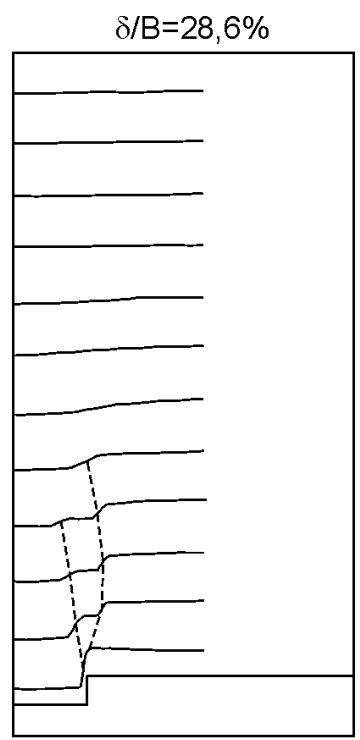

$\delta / B=28,6 \%$

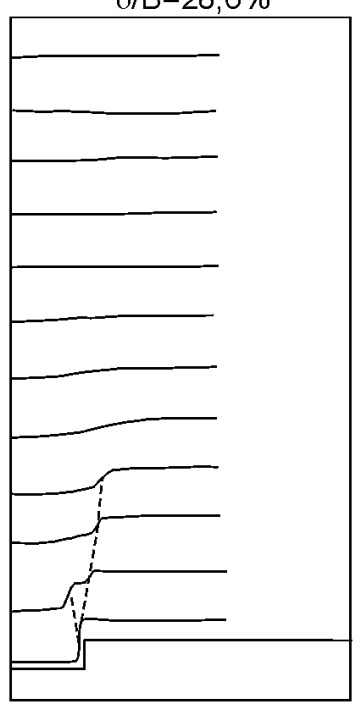

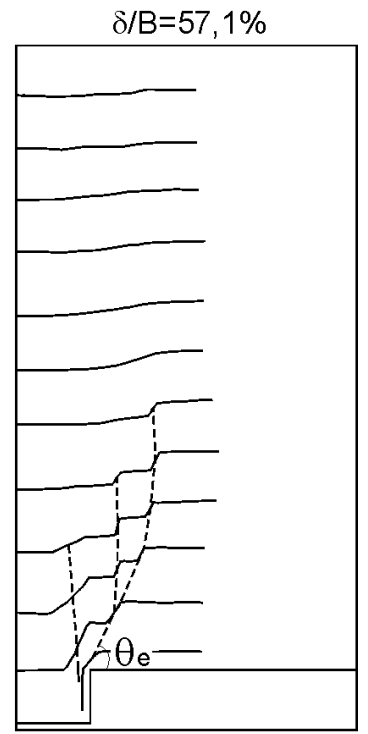

$\delta / B=57,1 \%$

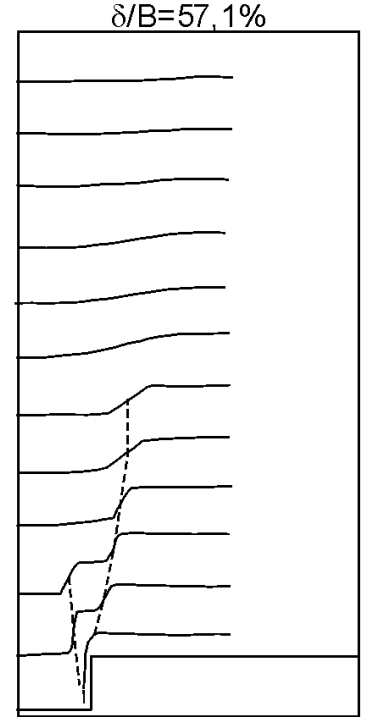

Figura 5.5. Desenvolvimento de localizações na seção transversal S1 do maciço compacto $\left(D_{r}=85 \%\right)$; a) modelos ensaiados a $45 \mathrm{~g}$; b) modelos ensaiados a $1 \mathrm{~g}$. 
A localização atinge uma altura $h_{v}$ de quase duas vezes a largura B com o maciço compacto, independentemente da aceleração centrífuga. Praticamente a mesma altura é atingida com o maciço fofo a $1 \mathrm{~g}$. O solo fofo a $45 \mathrm{~g}$ apresentou as localizações de menor altura. Neste caso, as localizações tornam-se gradualmente mais difusas à medida que se propagam, o que dificulta sua visualização. $\mathrm{O}$ maior recalque superficial é registrado sob essa mesma condição.

Tabela 5.2. Características das localizações externas no deslocamento final do alçapão

\begin{tabular}{cccccccc}
\hline Modelo & $\begin{array}{c}\text { Densidade } \\
\text { relativa, } \\
\mathrm{D}_{\mathrm{r}}(\%)\end{array}$ & $\begin{array}{c}\text { Aceleração } \\
\text { centrífuga, } \\
\mathrm{A}(\mathrm{g})\end{array}$ & $\begin{array}{c}\text { Inclinação com } \\
\text { a horizontal, } \\
\theta_{\mathrm{e}}\left({ }^{0}\right)\end{array}$ & $\mathrm{x}_{\mathrm{i}} / \mathrm{B}$ & $\mathrm{h}_{\mathrm{v}} / \mathrm{B}$ & $\begin{array}{c}\mathrm{s}_{1} / \delta \\
(\%)\end{array}$ & $\begin{array}{c}\mathrm{s}_{2} / \delta \\
(\%)\end{array}$ \\
\hline $\mathrm{A} 3$ & 85 & 45 & 63 & 0,4 & 1,8 & 4,9 & 2,9 \\
$\mathrm{~A} 6$ & 85 & 1 & 75 & 0,2 & 1,8 & 0,0 & 0,0 \\
$\mathrm{~A} 7$ & 42 & 45 & 42 & 0,6 & 1,2 & 13,6 & - \\
$\mathrm{A} 8$ & 42 & 1 & 48 & 0,6 & 1,9 & 6,4 & - \\
\hline
\end{tabular}

\subsubsection{Padrões das Localizações de Deformação nas Demais Seções}

A seção S2 apresentou padrões muito semelhantes aos de S1 em ambos os níveis de A e $D_{r}$. Por outro lado, padrões muito distintos foram verificados na seção S3, localizada no vértice do alçapão. A Figura 5.6 compara as localizações formadas nas seções $\mathrm{S} 1, \mathrm{~S} 2$ e S3 do maciço com $\mathrm{D}_{\mathrm{r}}$ de $85 \%$ para o deslocamento relativo do alçapão de 57,1\%. Observam-se localizações menos desenvolvidas nesta região, com $\mathrm{h}_{\mathrm{v}} 20$ a $40 \%$ menor em comparação com os valores observados na seção central S1. Em nenhuma das condições investigadas foram verificadas localizações na seção transversal S4, localizada na massa de solo externa a 0,28B de distância da aresta do alçapão. A manifestação de localizações menos desenvolvidas na quina do alçapão decorre da influência do atrito entre a massa sobre o mesmo e o material estável adjacente, o qual restringe o movimento das partículas de solo que tendem a seguir seu movimento descendente, retardando o acúmulo de deformações cisalhantes responsáveis pela formação da localização. 
a.

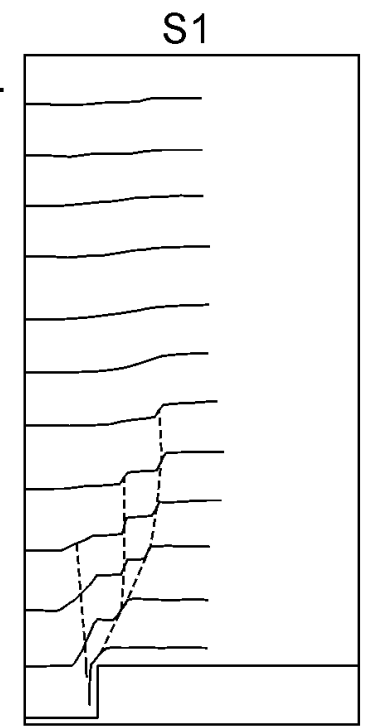

S1

b.

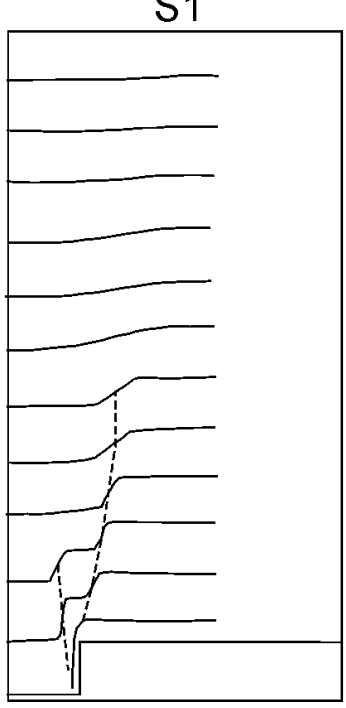

S2

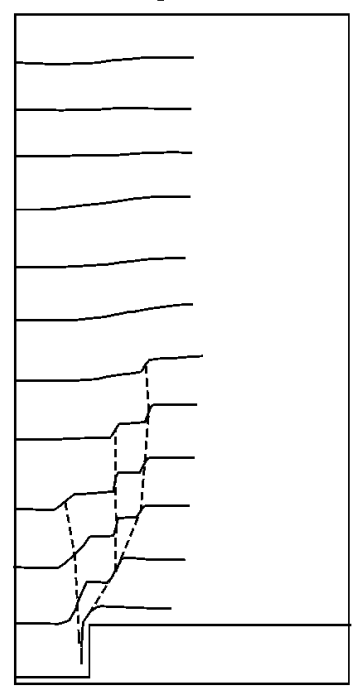

S2

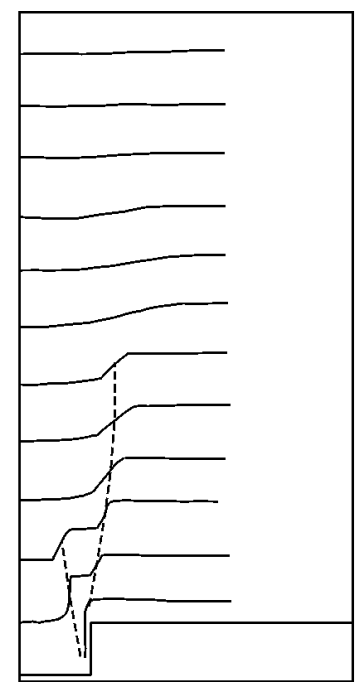

S3

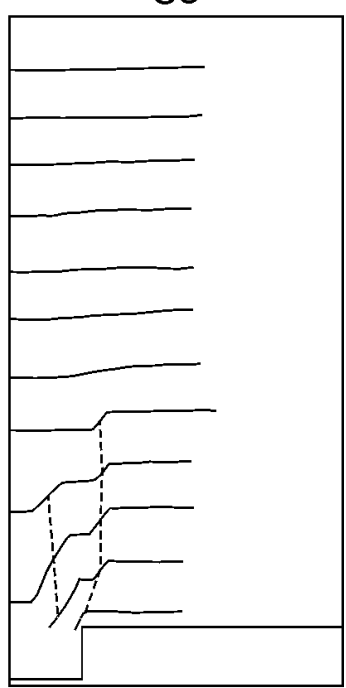

S3

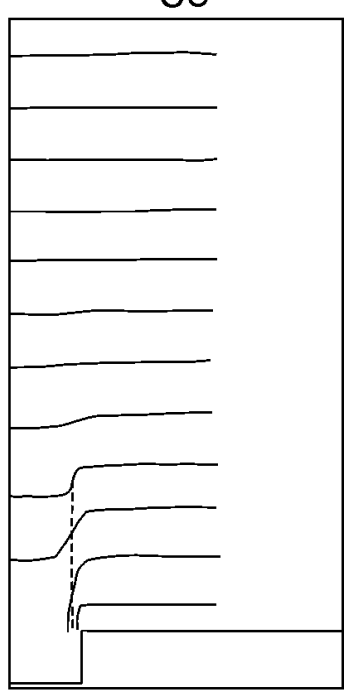

Figura 5.6. Padrões de localização em seções transversais do maciço compacto $\left(D_{\mathrm{r}}=\right.$ $85 \%$ ) para $\delta / \mathrm{B}=57,1 \%$. a) Modelos ensaiados a $45 \mathrm{~g}$; b) modelos ensaiados a $1 \mathrm{~g}$.

\subsection{DISCUSSÃO DOS RESULTADOS}

\subsubsection{Tridimensionalidade do Problema}

A condição de estado plano de deformação em uma estrutura geotécnica requer seções transversais idênticas, com tensões cisalhantes no plano do corte $\left(\tau_{x y}\right.$ e $\left.\tau_{y z}\right)$ e deformações na direção perpendicular $\left(\varepsilon_{y}\right)$ nulas. Uma investigação das seções 
longitudinais correspondentes revelou valores de $\varepsilon_{\mathrm{y}}$ na região do solo sobre o alçapão entre 0 e $-6 \%$ no último estágio do deslocamento, aumentando do centro para as extremidades da estrutura. São valores de magnitude muito pequena, comparados aos resultados de $\varepsilon_{\mathrm{z}}$ obtidos nos níveis de deslocamento investigados (Figura 5.4). Estes resultados, juntamente com os padrões praticamente idênticos das seções S1 e S2 em todos os modelos (Figura 5.6) sugerem que a condição de estado plano de deformação pode ser assumida para uma determinada região do maciço sobre o alçapão.

Por outro lado, pode-se assegurar que o estado plano não pode ser admitido nas zonas no maciço onde as localizações longitudinais se propagam (denominadas de R2), nas quais as condições básicas citadas não são atendidas. A extensão de cada zona dependerá das características da localização longitudinal formada (comprimento, inclinação, largura, etc.), as quais, por sua vez, são comandadas basicamente pela dilatação do solo. A Figura 5.7a, confeccionada segundo o eixo de simetria longitudinal do modelo, apresenta um esquema em planta do alçapão com o contorno que delimita a zona total de abrangência das localizações no maciço, dividindo-a em R1 e R2. A título ilustrativo, a figura também traz indicações das posições das seções $\mathrm{S} 1, \mathrm{~S} 2$ e S3 em relação ao alçapão. A seção longitudinal correspondente é mostrada na Figura 5.7b. O comprimento longitudinal de R1 é denominado $L_{p s}$ e atinge valores entre 53 e $85 \%$ do comprimento total do alçapão, a depender do nível de tensão aplicado, da densidade do solo e da magnitude da translação. A Tabela 5.3 relaciona os valores de $\mathrm{L}_{\mathrm{ps}}$ em cada modelo ensaiado. Os resultados dos testes A1 a A6 mostram que $\mathrm{L}_{\mathrm{ps}}$ diminui com o aumento do deslocamento do alçapão por conta do aumento da região de abrangência das localizações longitudinais à medida que se propagam. Sua variação é maior a $1 \mathrm{~g}$ em virtude da maior inclinação e curvatura assumidas pela localização nesta aceleração (Figura 5.1b). No início da translação, $\mathrm{L}_{\mathrm{ps}}$ é mais abrangente a $1 \mathrm{~g}$ por causa do menor comprimento da localização formada. Com o aumento de $\delta$, a localização adquire comprimento semelhante ao atingido a $45 \mathrm{~g}$, tornando-se, porém, mais inclinadas para o centro do modelo, o que diminui a região em estado plano. No último estágio do deslocamento, $\mathrm{L}_{\mathrm{ps}}$ permanece em torno de $60 \%$ de $\mathrm{L}_{\mathrm{v}}$. 


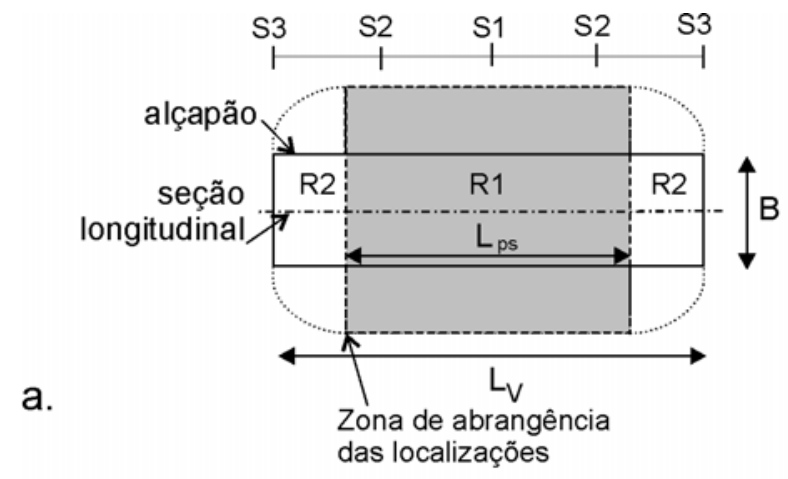

seção longitudinal

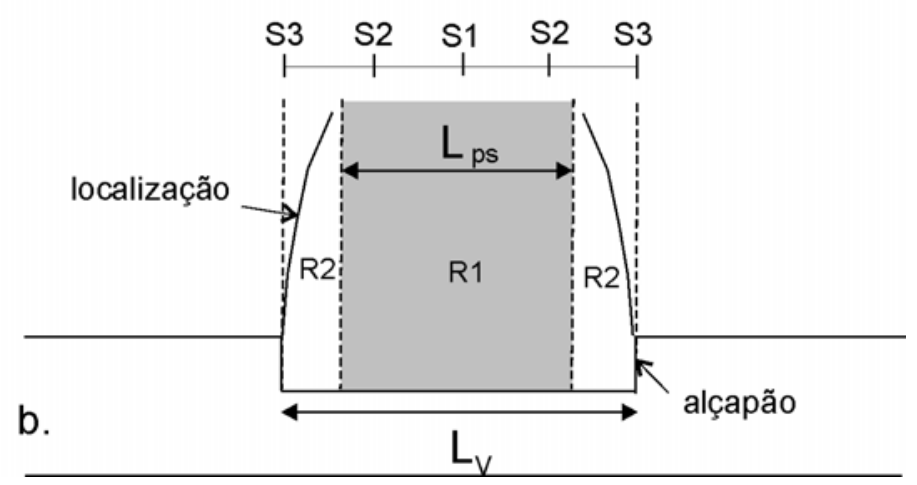

Figura 5.7. Regiões R1 e R2 no maciço. a) vista superior; b) vista em corte longitudinal.

Tabela 5.3. Área do alçapão que satisfaz a condição de deformação plana

\begin{tabular}{ccccc}
\hline Modelo & $\begin{array}{c}\text { Densidade } \\
\text { relativa, } \mathrm{D}_{\mathrm{r}}(\%)\end{array}$ & $\begin{array}{c}\text { Aceleração } \\
\text { centrífuga, A }(\mathrm{g})\end{array}$ & $\begin{array}{c}\delta / \mathrm{B} \\
(\%)\end{array}$ & $\mathrm{L}_{\mathrm{ps}}(\%)$ \\
\hline $\mathrm{A} 1$ & & & 14,3 & 72 \\
$\mathrm{~A} 2$ & 85 & 45 & 28,6 & 60 \\
$\mathrm{~A} 3$ & & & 57,1 & 60 \\
\hline A4 & \multirow{2}{*}{85} & 1 & 14,3 & 85 \\
A5 & & & 28,6 & 63 \\
A6 & & 45 & 57,1 & 53 \\
\hline A7 & 42 & 1 & 57,1 & 60 \\
\hline A8 & 42 & & 57,1 & 65 \\
\hline
\end{tabular}




\subsubsection{Considerações sobre o Cisalhamento do Solo no Interior da Localização}

Em condição rasa, onde se observam localizações desenvolvendo-se entre regiões do solo que permanecem praticamente indeformadas, como será abordado adiante, o cisalhamento do material no interior da localização é comumente relacionado ao de um ensaio de cisalhamento direto (Iglesia 1991, Stone e Muir Wood 1992). As regiões indeformadas são associadas às duas metades da caixa de cisalhamento, forçadas no ensaio a se separarem ao longo de uma zona muito fina de deformações cisalhantes intensas. $\mathrm{Na}$ realidade, este mecanismo não é cinematicamente possível, porquanto a região do solo sobre o alçapão não é capaz de se mover paralelamente em relação à região superior estacionária fora do alçapão.

O cisalhamento do solo dentro da localização de deformação pode ser analisado considerando um elemento retangular abcd, de espessura dm, como exibe a Figura 5.8. A deformação do elemento após a translação do alçapão ocorre devido ao deslocamento vertical relativo entre $a-b$ e c-d. Quanto mais próximo estiver $a-b$ do limite superior da localização, menor será seu deslocamento absoluto. Ao contrário, quanto mais próximo estiver c-d do limite inferior da localização, maior seu deslocamento absoluto.

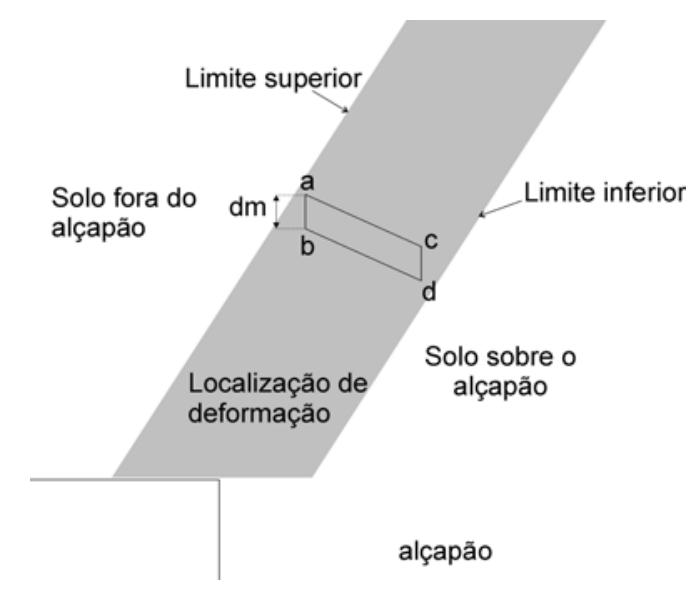

Figura 5.8. Representação do cisalhamento dentro de uma localização de deformação nos modelos ensaiados. 
Grosso modo, o cisalhamento que ocorre no solo dentro de abcd seria semelhante ao sofrido por um corpo-de-prova submetido a um ensaio hipotético de cisalhamento simples rotacionado de $90^{\circ}$. Obviamente, não se pode garantir que o material do elemento não sofra deformação linear paralelamente a a-b e c-d. O mesmo não ocorreria em um ensaio de cisalhamento simples (Roscoe 1970).

\subsubsection{O Papel da Dilatação do Solo na Formação das Localizações na Seção Longitudinal}

A dilatação é a propriedade do solo mais importante no processo de desenvolvimento das localizações de deformação, definindo suas características, como espessura e trajeto seguido. Em instalações rasas com material granular, tem-se observado experimentalmente que a localização de deformação inicia a propagação segundo um ângulo com a vertical $\left(\theta_{\mathrm{i}}\right)$ numericamente igual ao ângulo de dilatação de pico do solo $\left(\psi_{\max }\right)$ Vardoulakis et al. 1981, Stone e Muir Wood 1992, Tanaka e Sakai 1993, Santichaianant 2002), independentemente da condição ensaiada (axissimétrica ou no estado plano). Havendo localizações posteriores, estas possuirão ângulos iniciais de propagação iguais ao ângulo de dilatação correspondente ao estado do solo no momento.

Nos modelos do presente trabalho, a localização se expande lateralmente à medida que se propaga, resultando na sua rotação em direção à vertical (item 5.2.1). De maneira a averiguar a relação que $\theta_{i}$ guarda com $\psi$ neste caso, esse último parâmetro foi determinado através da técnica fotográfica na seção longitudinal do maciço compacto e posteriormente comparado com $\theta_{\mathrm{i}}$ medido (Figura 5.1). Apenas os modelos nos quais foram impostos deslocamentos relativos de $14,3 \%$ participaram desta investigação, visto que a correta determinação de $\psi$ demanda incrementos de deformação os menores possíveis.

Ângulos de dilatação $\psi$ entre $11^{0}$ e $14^{0}$ e entre 15 e $17^{0}$ foram obtidos para acelerações de 45 e 1 g, respectivamente. Esses valores são superiores à inclinação $\theta_{\mathrm{i}}$ das respectivas localizações, iguais a $9^{0}$ a $45 \mathrm{~g}$ e $13^{0}$ a 1 g, respectivamente. Entretanto, é provável que o incremento de deformação utilizado nos cálculos tenha 
gerado valores de $\psi$ superiores aos reais. As Figuras 5.2 e 5.4 fornecem uma noção sobre a magnitude das deformações para $\delta / B=14,3 \%$.

Com base nos resultados dos ensaios triaixiais e de deformação plana com a mesma areia, conduzidos com tensões confinantes e densidades relativas próximas das dos modelos (Tabela 3.3, Capítulo 3), estima-se que o ângulo de dilatação máximo do solo na base do alçapão antes do seu deslocamento (i.e., $\delta / B=0$ ) figure em torno de $17^{0}$ a $45 \mathrm{~g}$ e $25^{\circ}$ a $1 \mathrm{~g}$. É provável que as localizações tenham iniciado a propagação segundo inclinações numericamente iguais a estes valores e acompanhado o decréscimo de $\psi$ em seguida.

$\mathrm{O}$ fato de $\theta_{\mathrm{i}}$ ter variado mais a $1 \mathrm{~g}$ durante a translação, como indica a Figura 5.1, pode ser compreendido analisando-se o comportamento volumétrico do solo registrado nos ensaios triaxiais realizados por Batiste (1998) sob confinantes de 1,3 e $69 \mathrm{kPa}$ (Tabela 3.3). Esses níveis de tensão são bastante próximos à tensão inicial média na base do modelo a 1 e 45 g, respectivamente. A Figura 5.9 exibe o comportamento da razão de dilatação $\left[-\mathrm{d} \varepsilon_{\mathrm{v}} / \mathrm{d} \varepsilon_{\mathrm{a}}\right]$ com a deformação axial $\left(\varepsilon_{\mathrm{a}}\right)$ para ambas confinantes mencionadas. As curvas mostram que a dilatação do solo varia mais com a deformação quando o confinamento é menor. Com o aumento da deformação, a diferença de $\left[-\mathrm{d} \varepsilon_{\mathrm{v}} / \mathrm{d} \varepsilon_{\mathrm{a}}\right]$ nos dois níveis de confinamento diminui até se tornar praticamente nula.

As localizações não assumiram posições verticais mesmo após um deslocamento comparativamente grande do alçapão porque a dilatação não decresce até zero para grandes deformações, mas permanece em um valor residual em torno de 0,2 , equivalendo a $\psi=5^{0}$, como mostra a Figura 5.9. Isso mostra que a areia não atinge o estado crítico. Nota-se que $\psi$ é bastante próximo à inclinação adquirida pelas localizações no deslocamento relativo final de $57,1 \%$, não somente com o maciço compacto (Figura 5.1), mas também com o maciço fofo (Figura 5.3). Esta é uma forte evidência a favor da paridade entre $\psi$ e $\theta_{\mathrm{i}}$ na condição investigada com os modelos. Por se deformar mais para uma mesmo $\delta$, o solo a $45 \mathrm{~g}$ atinge a dilatação residual antes do solo a $1 \mathrm{~g}$. 


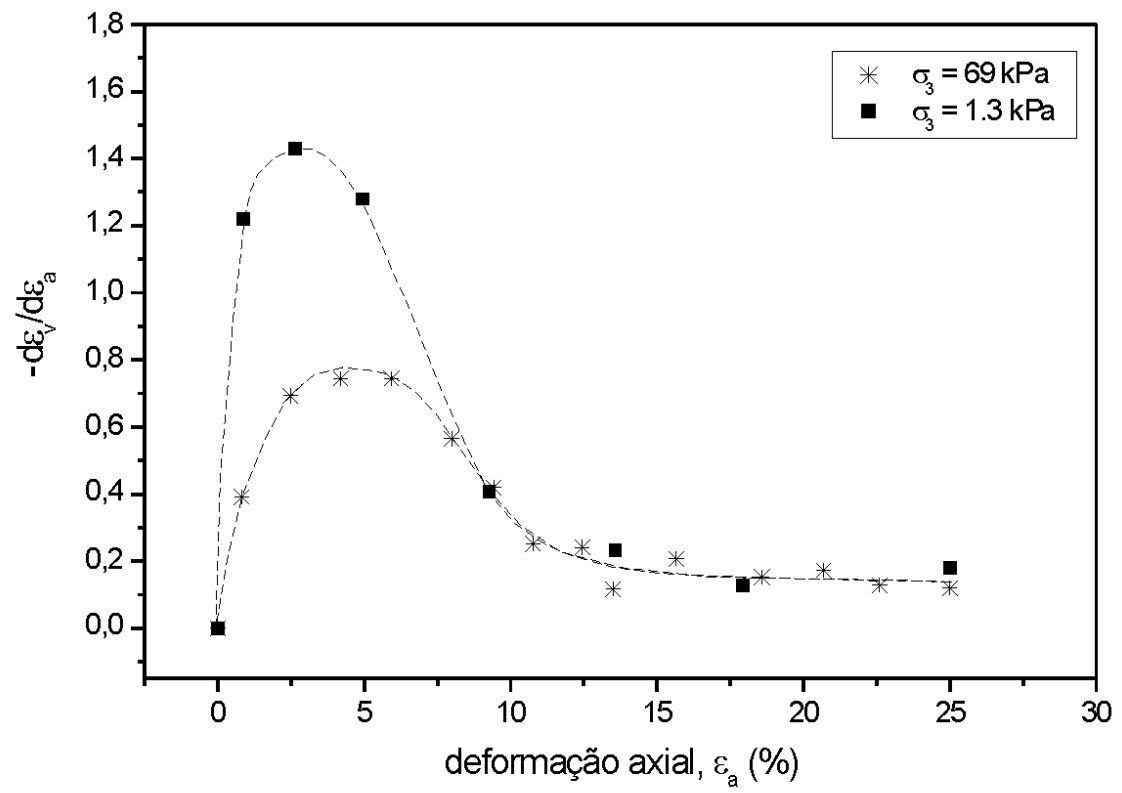

Figura 5.9. Razão de dilatação em ensaios de compressão triaxial (após Batiste 1998).

Os dados de Batiste (1998) revelam ainda que o comportamento volumétrico do solo apresenta variações muito reduzidas entre as confinantes de 11,2 e 68,9 kPa, ao contrário do que ocorre em confinamentos mais baixos. Isto explica porque as localizações se propagam a $1 \mathrm{~g}$ com maior curvatura em direção ao centro do modelo (Figura 5.1b). Apesar do perfil de tensões ser mais variável a $45 \mathrm{~g}$, com $\sigma_{\mathrm{vi}}$ partindo de $0 \mathrm{kPa}$ na superfície até $124 \mathrm{kPa}$ na base do modelo, as localizações se propagaram no maciço dentro de uma faixa de $\sigma_{\mathrm{vi}}$ entre 50 e $124 \mathrm{kPa}$, para a qual a variação da dilatação é pequena. Tem-se como resultado o desenvolvimento de localizações de formato aproximadamente linear.

Os resultados dos modelos apontam também uma relação muito nítida entre a espessura da localização e a dilatação do solo. O maciço compacto sujeito à aceleração unitária representa a condição mais propícia para o solo apresentar maior variação de volume. Nesse caso foram observadas as localizações mais delgadas e bem definidas, com espessura dentro da faixa anteriormente citada para os ensaios de arqueamento em pequena profundidade. $\mathrm{O}$ aumento da aceleração para $45 \mathrm{~g}$ no maciço compacto forneceu localizações com espessuras constantes, mas muito superiores aos valores comumente reportados na literatura. Nesta situação, a 
dilatação é menor por conta do maior nível de tensão. O maciço fofo, condição muito desfavorável para o solo manifestar dilatação, apresentou localizações difusas, muito espessas na parte superior.

Quando no estado fofo, as propriedades volumétricas e de resistência ao cisalhamento do solo variam muito menos com o nível de tensão aplicado. Como se observa através da Figura 5.3, a inclinação, a forma e o comprimento das localizações no deslocamento final do alçapão é muito semelhante tanto a 45 , quanto a $1 \mathrm{~g}$.

\subsubsection{Considerações Sobre a Ocorrência de Localizações Externas}

O mecanismo de ruptura causado pela translação descendente de uma base rígida horizontal instalada em um meio granular pode ser dividido em duas fases distintas: a Fase 1, que engloba a formação das localizações internas e a Fase 2, na qual as localizações externas se propagam. A propagação de localizações externas foi pioneiramente prevista por Terzaghi (1943), ao afirmar que os planos de ruptura que emergem da translação de um alçapão ativo deveriam possuir largura maior do que a da estrutura. Esta hipótese foi posteriormente confirmada experimentalmente através de modelos físicos axissimétricos (Santichaianant 2002) e em deformação plana (Ladanyi e Hoyaux 1969), ambos em situações representando condição rasa. $\mathrm{Na}$ realidade, a manifestação de localizações externas dependerá, sobretudo, do nível de deslocamento imposto ao alçapão em relação à sua dimensão, uma vez que seu comprimento é proporcional a B.

Basicamente, o mecanismo de formação de localizações externas é governado pela instabilidade da massa de solo adjacente ao alçapão, a qual é despertada pela migração contínua do material central para o vazio criado. Como esboçado no esquema da Figura 5.10, após o surgimento de um determinado número de localizações internas, como $o a$ e $o b$, a continuação do deslocamento do alçapão provoca o surgimento de localizações externas, como oc e od. Uma vez que a dilatação do material diminui com o aumento de $\delta$ devido ao intenso cisalhamento do solo na região adjacente ao ponto $o$, od se propaga mais inclinada para a horizontal em comparação a $o c$ (ou seja, $\theta_{\text {ed }}<\theta_{\text {ec }}$ ). 
Com a continuidade do deslocamento do alçapão, teoricamente novas localizações poderiam ser formadas até a linha limite $o e$, a qual possui inclinação $i_{c}$ com a horizontal igual ao ângulo de repouso e ao ângulo de atrito crítico $\left(\phi_{\mathrm{cr}}\right)$ do material. Dessa forma, é possível afirmar que a inclinação de $o c$ nas imediações do ponto $o$ é igual à soma de $\phi_{\mathrm{cr}}$ com um determinado ângulo $\alpha_{\mathrm{c}}$, ou seja,

$\theta_{\mathrm{ec}}=\phi_{\mathrm{cr}}+\alpha_{\mathrm{c}}$

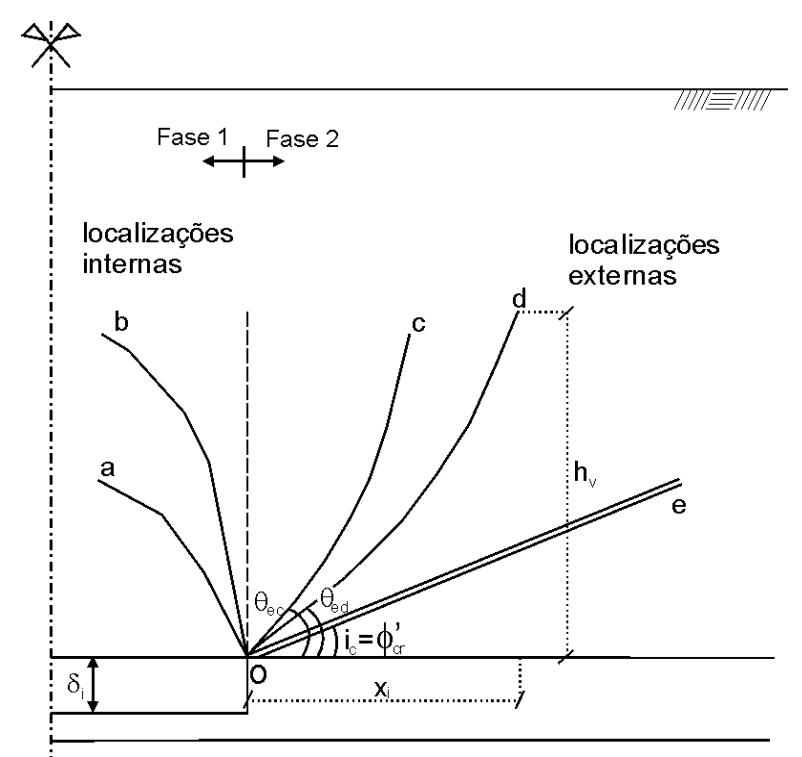

Figura 5.10. Propagação de localizações internas e externas na massa de solo.

O ângulo $\alpha_{c}$ é função da dilatação do solo na região de $o$, mas também depende da interação da massa de solo à esquerda de $o b$, que se opõe à movimentação do solo à direita de $o b$. Entretanto, o deslocamento para baixo da massa de solo sobre o alçapão em relação à massa à direita de $o b$ provoca a rotação das tensões e deformações principais no solo externo adjacente a $o$, aumentando a inclinação de propagação das localizações exteriores. A situação é comparável ao que ocorre quando um muro de contenção é forçado para baixo por algum motivo com referência ao aterro contido. A Figura 5.11 mostra as diferentes superfícies de ruptura formadas quando há atrito na interface muro-aterro (Figura 5.11a) e, quando além do atrito, o muro se desloca para baixo em relação ao aterro (Figura 5.11b). 
Neste último caso, a superfície de ruptura $b d c$ é formada com maior inclinação para a vertical.
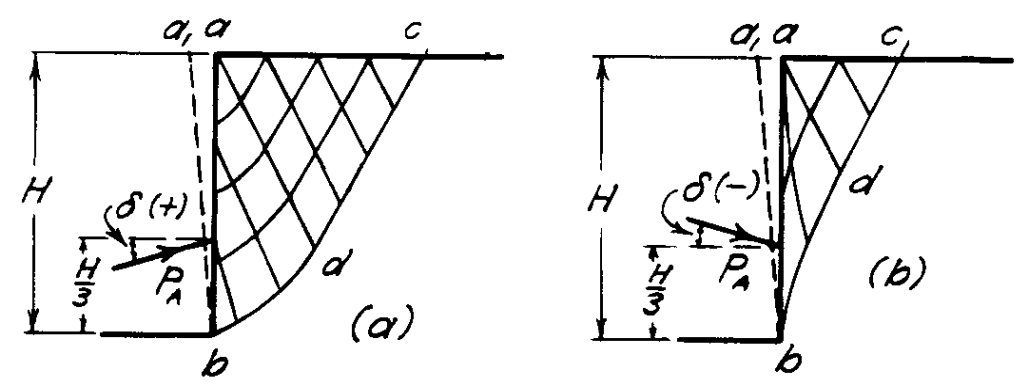

Figura 5.11. a) Padrão associado à ruptura do solo contido por um muro de parede rugosa; b) mesma situação de a), com o muro forçado para baixo. $\mathrm{P}_{\mathrm{A}}$ representa $\mathrm{o}$ empuxo no muro e $\delta$, sua inclinação (Terzaghi et al. 1996).

Assumindo-se uma relação entre $\alpha$ e $\psi$ do tipo $\alpha=\eta \psi$, onde $\eta$ é um número maior do que 1 , a variação de $\theta_{\mathrm{e}} \operatorname{com} \psi$ será descrita por uma reta, como mostra a Figura 5.12. O parâmetro empírico $\eta$ pode ser determinado através da estimativa do ângulo de dilatação do maciço em cada condição ensaiada. Isto pode ser feito com o auxílio dos resultados apresentados na Tabela 3.3. Uma vez que $\theta_{\mathrm{e}}$ varia $\operatorname{com} \delta$, é importante obter inclinações nos modelos as mais próximas possíveis do momento inicial da formação da localização, de forma que haja concordância com os valores de $\psi$ dos ensaios laboratoriais. Nos modelos, a propagação das localizações externas se deu dentro do intervalo de $\delta / \mathrm{B}$ entre 14,3 e $28,6 \%$ (Figura 5.5). Assumindo-se convenientemente que ocorre em $\delta / B=28,6 \%$ e sabendo-se que neste patamar $\theta_{\mathrm{e}}$ no maciço compacto é igual a 75 e $80^{\circ}$ para as acelerações de 45 e 1 g, obtém-se $\eta=2,2$ e 1,6 , respectivamente.

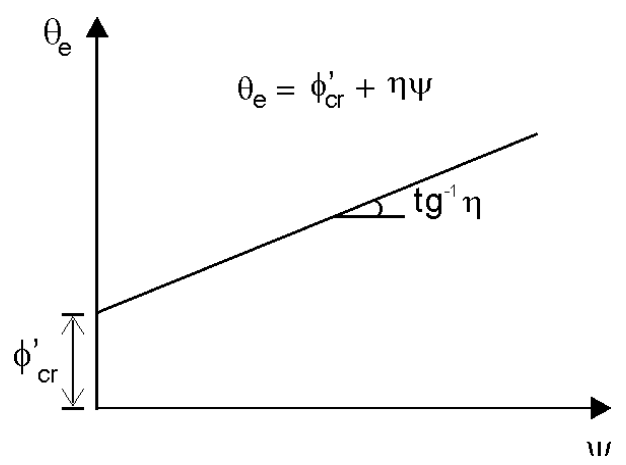

Figura 5.12. Relação entre $\theta_{\mathrm{e}} \mathrm{e} \psi$. 


\subsubsection{Estimativa da Inclinação da Localização Externa Através da Bacia de Recalques Superficiais}

Os dados de recalque superficial no modelo $A 3, s_{1}$ e $s_{2}$, podem ser utilizados para a estimativa da largura da bacia de recalques $(2 \mathrm{w})$ gerada após a descida do alçapão e do recalque máximo $\left(\mathrm{s}_{\max }\right)$. Peck (1969) observou que a depressão superficial causada pela escavação de túneis assemelha-se a uma distribuição normal simétrica com relação ao eixo vertical do túnel, da forma:

$$
\mathrm{s}(\mathrm{x})=\mathrm{s}_{\max } \exp \left[-\frac{1}{2} \frac{\mathrm{x}^{2}}{\mathrm{i}^{2}}\right]
$$

onde i é a distância horizontal ao ponto de inflexão da curva. Assumindo-se uma distribuição desse tipo, obtém-se $\mathrm{s}_{\max } / \delta=5 \%$ e w/(B/2) $=6,1$. Utilizando-se este último valor e sabendo-se que H/B é igual a 4,5 nos modelos, uma estimativa de $\theta_{\mathrm{e}}$ através da Figura 2.11, a qual traz dados de campo provenientes de obras de túneis em diversos tipos de solo, fornece $\beta \approx 26^{0}$, inclinação dentro da faixa de dados para areias secas. Sendo $\beta=90^{\circ}-\theta_{\mathrm{e}}$, chega-se a $\theta_{\mathrm{e}}=64^{\circ}$, a mesma inclinação medida no modelo A3 no deslocamento final.

\subsubsection{Considerações Sobre o Mecanismo de Ruptura em Profundidade}

Na Fase 1, os mecanismos de ruptura correspondentes às situações rasa e profunda guardam diferenças significativas. O item 2.2.1 do Capítulo 2 traz uma detalhada descrição do mecanismo desenvolvido na condição rasa, baseada em observações experimentais (Vardoularkis et al. 1981, Stone e Muir Wood 1992, Tanaka e Sakai 1993, Santichaianant 2002). A Tabela 5.4 apresenta uma comparação sinóptica entre o mecanismo descrito nestes trabalhos e o verificado na presente investigação durante a Fase 1, destacando as principais diferenças.

Como visto anteriormente, a Fase 2 é caracterizada pela propagação de uma ou mais localizações exteriores. O cisalhamento através do deslizamento de blocos rígidos é preferível em detrimento a um processo contínuo de deformação, porquanto 
a energia dissipada nesse processo é menor. Entretanto, como visto anteriormente, as localizações externas também apresentam movimentação com o aumento de $\delta$. Essa constatação revela a atuação simultânea de ambos os mecanismos de cisalhamento nas localizações externas em profundidade. A predominância do mecanismo de blocos rígidos aumenta com a distância do alçapão.

Obviamente, a existência de blocos rígidos é uma simples idealização, pois na realidade o solo entre as localizações também sofre deformação, apesar de muito reduzida.

\subsubsection{O Plano de Igual Recalque a Partir das Localizações de Deformação}

Os valores de $h_{v}$ e do recalque superficial (s) exibidos na Tabela 5.2 podem ser utilizados como limite inferior e superior, respectivamente, para estabelecer a posição do plano para o qual o recalque do solo adjacente se iguala ao recalque do solo sobre o alçapão, ou plano de igual recalque (PIR). No maciço compacto a $45 \mathrm{~g}$ e no maciço fofo em ambas acelerações o PIR situa-se além da superfície, uma vez que foi registrado recalque superficial nestes casos (Tabela 5.2). Em outras palavras, a altura de influência da movimentação do alçapão nestes casos se estende até a altura total do maciço (4,5 B). Tal situação é classificada no método de Marston-Spangler como trincheira completa. $\mathrm{O}$ solo compacto sujeito à gravidade unitária representa a única condição em que o PIR é situado dentro do maciço, no intervalo 1,8 $<\mathrm{H} / \mathrm{B}<$ 4,5, cuja ocorrência recebe a denominação de trincheira incompleta.

Uma previsão da altura $\mathrm{H}_{\mathrm{e}}$ do PIR em $\delta / \mathrm{B}=57,1 \%$, medida a partir da base do modelo, pode ser obtida através do método de Marston-Spangler, que divide a massa de solo abaixo do PIR em um prisma interior sobre o alçapão e dois exteriores adjacentes ao mesmo. A largura efetiva dos prismas externos é considerada igual a B. Um desenvolvimento detalhado do método pode ser obtido em Young e Trott (1984) e Bulson (1985). A seguinte expressão é utilizada para o cálculo de $\mathrm{H}_{\mathrm{e}}$ :

$$
\frac{\exp \left(-2 \mathrm{k}_{\mathrm{kr}} \operatorname{tg}\left(\mathrm{H}_{\mathrm{e}} / \mathrm{B}\right)\right)-1}{2 \mathrm{k}_{\mathrm{kr}} \operatorname{tg} \phi} \cdot\left(-\frac{\mathrm{H}}{\mathrm{B}}+\frac{\mathrm{H}_{\mathrm{e}}}{\mathrm{B}}+\frac{1}{2 \mathrm{k}_{\mathrm{kr}} \operatorname{tg} \phi}\right)+\frac{1}{2}\left(\frac{\mathrm{H}_{\mathrm{e}}}{\mathrm{B}}\right)^{2}+\frac{\mathrm{H}_{\mathrm{e}}}{2 \mathrm{Bk}_{\mathrm{kr}} \operatorname{tg} \phi}-\frac{\mathrm{H} \cdot \mathrm{H}_{\mathrm{e}}}{\mathrm{B}^{2}}=0
$$


Tabela 5.4. Comparação entre os mecanismos em condição profunda e rasa

\begin{tabular}{|c|c|}
\hline Condição rasa & Condiçã \\
\hline $\begin{array}{l}\text { O solo sobre o alçapão permanece } \\
\text { praticamente rígido desde o início da } \\
\text { translação. }\end{array}$ & $\begin{array}{l}\text { O solo sobre o alçapão sofre grandes } \\
\text { deformações na direção vertical (z), } \\
\text { interagindo diretamente no processo de } \\
\text { formação das localizações (Figura 5.4). }\end{array}$ \\
\hline $\begin{array}{l}\text { O deslocamento do alçapão pode } \\
\text { provocar o surgimento gradual de } \\
\text { diversas localizações. Cada localização é } \\
\text { formada com um ângulo de inclinação } \\
\text { inicial com a vertical menor que o da } \\
\text { antecessora. }\end{array}$ & $\begin{array}{l}\text { O deslocamento do alçapão provoca o } \\
\text { surgimento de apenas uma única } \\
\text { localização. }\end{array}$ \\
\hline $\begin{array}{l}\text { O cisalhamento no maciço é transferido } \\
\text { entre as diversas localizações. Sempre } \\
\text { que uma nova localização é formada, a } \\
\text { deformação cisalhante na anterior cessa } \\
\text { imediatamente. A transferência de } \\
\text { deformação entre as localizações é } \\
\text { abrupta. }\end{array}$ & $\begin{array}{l}\text { O cisalhamento no maciço ocorre } \\
\text { através do aumento lateral da } \\
\text { localização concomitantemente à sua } \\
\text { propagação, caracterizando um processo } \\
\text { contínuo de deformação. O aumento se } \\
\text { dá tanto em direção ao solo sobre o } \\
\text { alçapão, quanto ao material adjacente, } \\
\text { fora do alçapão. O crescimento para o } \\
\text { lado do material exterior é maior, } \\
\text { fazendo com que o eixo longitudinal da } \\
\text { localização assuma posições mais } \\
\text { verticais à medida que } \delta \text { aumenta. }\end{array}$ \\
\hline $\begin{array}{l}\text { A zona do solo que sofre cisalhamento é } \\
\text { muito delgada, e sua espessura } \\
\text { permanece constante. }\end{array}$ & $\begin{array}{l}\text { A zona do solo que sofre cisalhamento } \\
\text { pode abranger uma região relativamente } \\
\text { grande. }\end{array}$ \\
\hline $\begin{array}{l}\text { O solo entre as localizações sofre } \\
\text { deformações muito pequenas, } \\
\text { comportando-se como um "bloco rígido" } \\
\text { durante o processo, não exercendo } \\
\text { interferência na sua propagação. }\end{array}$ & $\begin{array}{l}\text { O mecanismo desencadeado exclui a } \\
\text { formação de "blocos rígidos". }\end{array}$ \\
\hline
\end{tabular}


onde: $\mathrm{k}_{\mathrm{kr}}=\frac{1-\operatorname{sen}^{2} \phi}{1+\operatorname{sen}^{2} \phi}($ Krynine 1945).

Os valores de $\phi$ utilizados em (5.3) foram obtidos a partir dos dados apresentados na Tabela 3.1, corrigidos para o estado plano de deformação através da expressão (3.1). A equação (5.3) fornece $\mathrm{H}_{\mathrm{e}} / \mathrm{B}$ em torno de 7,9 para todas as situações investigadas. Sendo $\mathrm{H}_{\mathrm{e}} / \mathrm{B}>\mathrm{H} / \mathrm{B}$, o método prevê o PIR além da superfície do maciço, o que concorda com os resultados experimentais para em todas as situações, exceto com o maciço compacto a $1 \mathrm{~g}$. Neste caso, o método revelou-se bastante conservador ao indicar a ocorrência de recalque superficial em decorrência da movimentação do alçapão. 


\section{Sistema Solo-Alçapão:} Redistribuição de Tensões Verticais nos Arqueamentos Ativo e Passivo

\subsection{CONSIDERAÇÕES INICIAIS}

A interação entre uma estrutura subterrânea e o meio circundante tem como resposta o desenvolvimento do arqueamento do solo. O fenômeno é definido como a capacidade do solo de transferir a tensão atuante em uma determinada região da estrutura a outra em virtude do deslocamento relativo entre ambas, e tem o cisalhamento como o mecanismo pelo qual as cargas são transferidas no maciço. A interação é influenciada basicamente pelas características geométricas e reológicas da estrutura e pelas características reológicas do meio circundante.

O presente capítulo tem por objetivo apresentar e discutir os resultados dos modelos da Série C, confeccionados na EESC/USP. Nestes testes, foi utilizado um alçapão de formato retangular ou quadrado sob um material granular sujeito a uma sobrecarga aplicada na superfície. Essa parte da pesquisa teve por finalidade investigar as tensões totais verticais mobilizadas em diversos locais na massa de solo e na interface inferior do modelo, considerando tanto o estado ativo quanto o passivo. Os procedimentos de construção e execução dos modelos, bem como o programa de ensaios, foram descritos no Capítulo 4. 


\subsection{AVALIAÇÕES PRELIMINARES}

\subsubsection{Atrito Lateral}

Qualquer ensaio laboratorial está sujeito a influências das condições de contorno do equipamento utilizado, as quais devem ser minimizadas sempre que possível. Em uma situação ideal na qual as paredes da caixa de testes utilizadas fossem perfeitamente lisas, ou seja, se o ângulo de atrito de interface $\left(\phi_{\mathrm{w}}\right)$ fosse nulo, a tensão vertical no piso, antes do início da movimentação do alçapão, seria estritamente igual à soma da sobrecarga aplicada e do peso próprio do solo. Entretanto, mesmo com a utilização de métodos adequados, a eliminação de todo o atrito lateral não é possível, de modo que alguma redução da tensão vertical na base da caixa deve sempre ser esperada. Nos modelos confeccionados, duas camadas de poliéster entre a areia e as paredes da caixa foram utilizadas para a redução do atrito lateral (ver item 4.8.2). Como discutido no item 3.2.1, este expediente tem se mostrado muito eficiente na redução do atrito lateral em experimentos laboratoriais.

A Tabela 6.1 compara a tensão vertical média $\left(\sigma_{\mathrm{vm}}\right)$ obtida no piso da caixa de testes, em resposta à aplicação da sobrecarga (q) mais o peso próprio do solo, com o valor teórico esperado $\left(\sigma_{\mathrm{vt}}\right)$. Observa-se que o erro nas leituras da tensão total manteve-se abaixo de $14 \%$ em todos os ensaios, o que indica que a influência do atrito lateral ao longo das paredes da caixa sobre o comportamento do sistema investigado é bastante reduzida. No teste com $q=50 \mathrm{kPa}$, mais de $95 \%$ da tensão esperada atinge a base da caixa, resultado ligeiramente superior ao registrado nos demais ensaios.

Conhecida a tensão que chega à base da caixa de testes, estimativas do ângulo de atrito de interface $\left(\phi_{\mathrm{w}}\right)$ em cada ensaio foram obtidas através da formulação da teoria clássica do arqueamento (item 2.3.1), modificada para atender à condição tridimensional do problema (equação 6.1). Sabendo-se que as dimensões da caixa de testes são $\mathrm{B}=\mathrm{H}=0,56 \mathrm{~m}$ e $\mathrm{L}=1,4 \mathrm{~m}$, o valor de $\phi_{\mathrm{w}}$ obtido através de (6.1) é estimado em aproximadamente $9^{0}$ na situação mais desfavorável. 
Tabela 6.1. Tensões medidas nos ensaios e tensões esperadas

\begin{tabular}{ccccccc}
\hline Ensaio & $\mathrm{D}_{\mathrm{r}}(\%)$ & $\mathrm{q}(\mathrm{kPa})$ & $\sigma_{\mathrm{vm}}(\mathrm{kPa})$ & $\sigma_{\mathrm{vt}}(\mathrm{kPa})$ & $\sigma_{\mathrm{vm}} / \sigma_{\mathrm{vt}}$ & Erro $(\%)$ \\
\hline $\mathrm{C} 1$ & 100 & 100 & 94,7 & 109,9 & 0,86 & 13,9 \\
$\mathrm{C} 2$ & 100 & 100 & 95,4 & 109,9 & 0,87 & 13,2 \\
$\mathrm{C} 3$ & 50 & 100 & 97,4 & 108,8 & 0,90 & 11,7 \\
$\mathrm{C} 4$ & 100 & 50 & 56,2 & 58,8 & 0,96 & 5,7 \\
$\mathrm{C} 5$ & 100 & 100 & 96,9 & 109,9 & 0,88 & 12,1 \\
$\mathrm{C} 6$ & 100 & 100 & 97,0 & 109,9 & 0,88 & 11,7 \\
$\mathrm{C} 7$ & 100 & 100 & 98,9 & 109,9 & 0,90 & 10,6 \\
\hline
\end{tabular}

$\sigma_{v}=\frac{\gamma}{2 K_{0} \operatorname{tg} \phi_{w} \mathrm{w}}\left[1-\mathrm{e}^{-2 \mathrm{~K}_{0} \operatorname{tg} \phi_{\mathrm{w}} w \mathrm{H}}\right]+\mathrm{q} \cdot \mathrm{e}^{-2 \mathrm{~K}_{0} \operatorname{tg} \phi_{\mathrm{w}} w \mathrm{H}}$

onde: $\mathrm{w}=$ fator geométrico igual a $1 / \mathrm{B}+1 / \mathrm{L}$, com $\mathrm{B}$ correspondendo à largura da caixa e $\mathrm{L}$, ao comprimento; $\mathrm{H}=$ altura do maciço; $\mathrm{K}_{0}=1-\operatorname{sen} \phi$, com $\phi$ obtido através da Tabela 4.4; $\gamma=$ peso específico do material, igual a 15,7 e $17,7 \mathrm{kN} / \mathrm{m}^{3}$ para $\mathrm{D}_{\mathrm{r}}=$ 50 e $100 \%$, respectivamente.

A Figura 6.1 mostra o comportamento da tensão vertical na base da caixa de testes, previsto com a equação (6.1), para as combinações de $\mathrm{D}_{\mathrm{r}}$ e q listadas na Tabela 6.1. Nota-se que a partir de $\phi_{\mathrm{w}} \approx 10^{0}$ a variação de $\sigma_{\mathrm{v}}$ com $\mathrm{D}_{\mathrm{r}}$ apresenta-se maior para a menor sobrecarga $\mathrm{q}$.

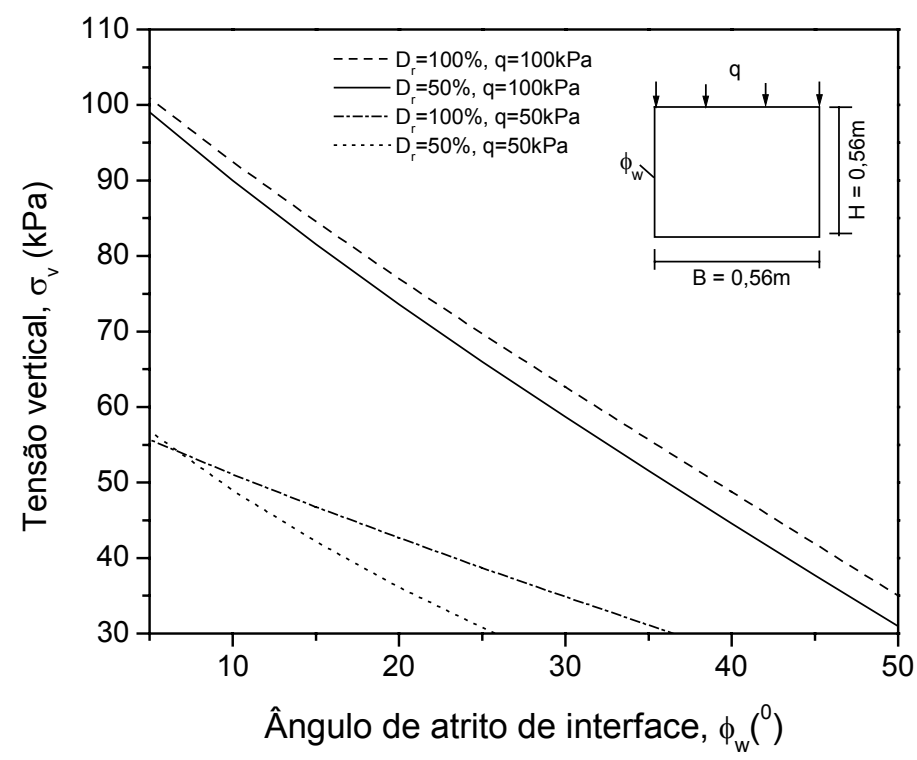

Figura 6.1. Variação da tensão vertical na base da caixa de testes com o ângulo de atrito de interface através da equação (6.1). 


\subsubsection{Repetibilidade dos Resultados}

As leituras de tensão total, obtidas durante a fase de carregamento dos ensaios, revelaram resultados com alta repetibilidade, como mostram as Figuras 6.2 e 6.3, as quais exibem a tensão vertical medida $\left(\sigma_{v}\right)$ no centro da caixa de testes (posição I1) e a $0,7 \mathrm{~B}$ do centro (posição I2), respectivamente, em função da sobrecarga q. Os resultados são referentes a quatro ensaios realizados sob as mesmas condições $\left(\mathrm{D}_{\mathrm{r}}=\right.$ $100 \%$ e q $=100 \mathrm{kPa}$ ). A disposição dos locais de medida de tensão total no piso da caixa de testes encontra-se esquematizada em planta na Figura 4.9. A máxima variação da tensão em torno da média nesses casos foi de $2 \mathrm{kPa}$.

Da mesma forma, para avaliar a resposta do sistema durante o deslocamento do alçapão, a Figura 6.4 compara as tensões registradas na posição I1 em dois ensaios realizados sob condições idênticas e com o alçapão retangular de 300 x 100 $\mathrm{mm}\left(\mathrm{L}_{\mathrm{v}} / \mathrm{B}=3\right)$. As curvas apresentadas demonstram a elevada repetibilidade dos resultados também nesta etapa do teste. Neste gráfico, a tensão vertical $\left(\sigma_{\mathrm{v}}\right)$ encontra-se normalizada pela tensão vertical registrada imediatamente antes do início da movimentação da estrutura $\left(\sigma_{\mathrm{vi}}\right)$. A diferença máxima em $\sigma_{\mathrm{v}}$ registrada entre os testes também foi igual a $2 \mathrm{kPa}$.

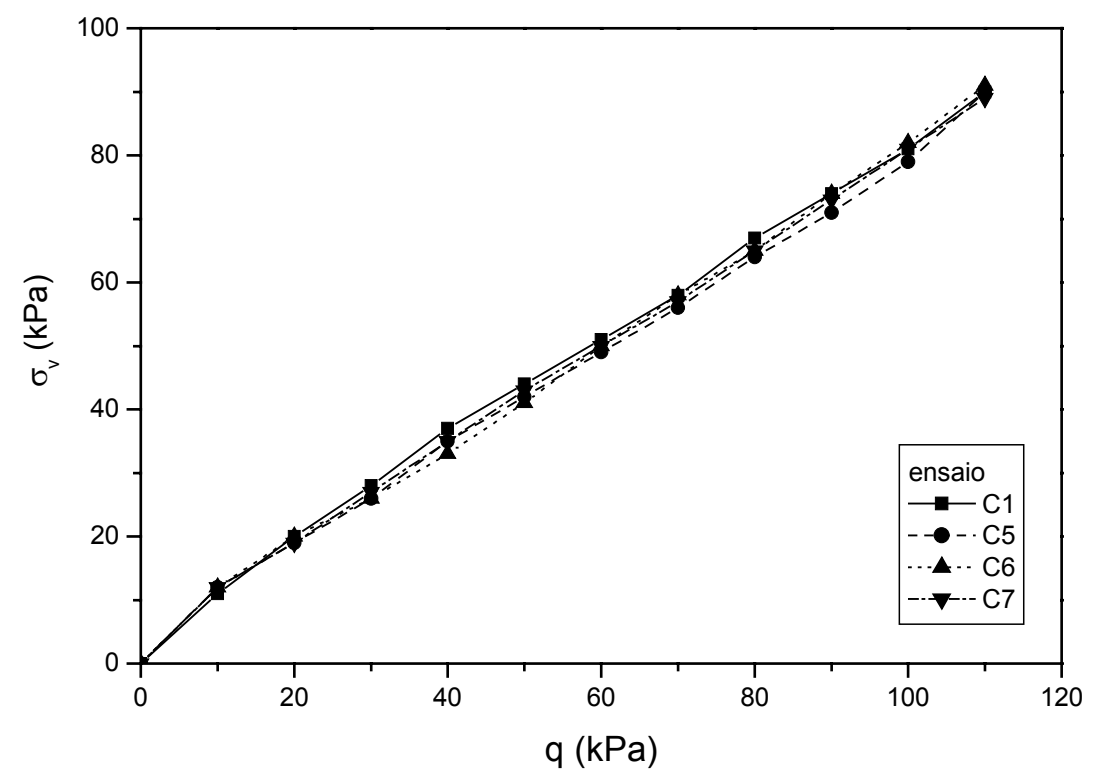

Figura 6.2. Repetibilidade da tensão vertical medida no centro do alçapão (posição I1) durante a fase de carregamento. Ensaios realizados com $D_{r}=100 \%$ e $q=100$ $\mathrm{kPa}$. 


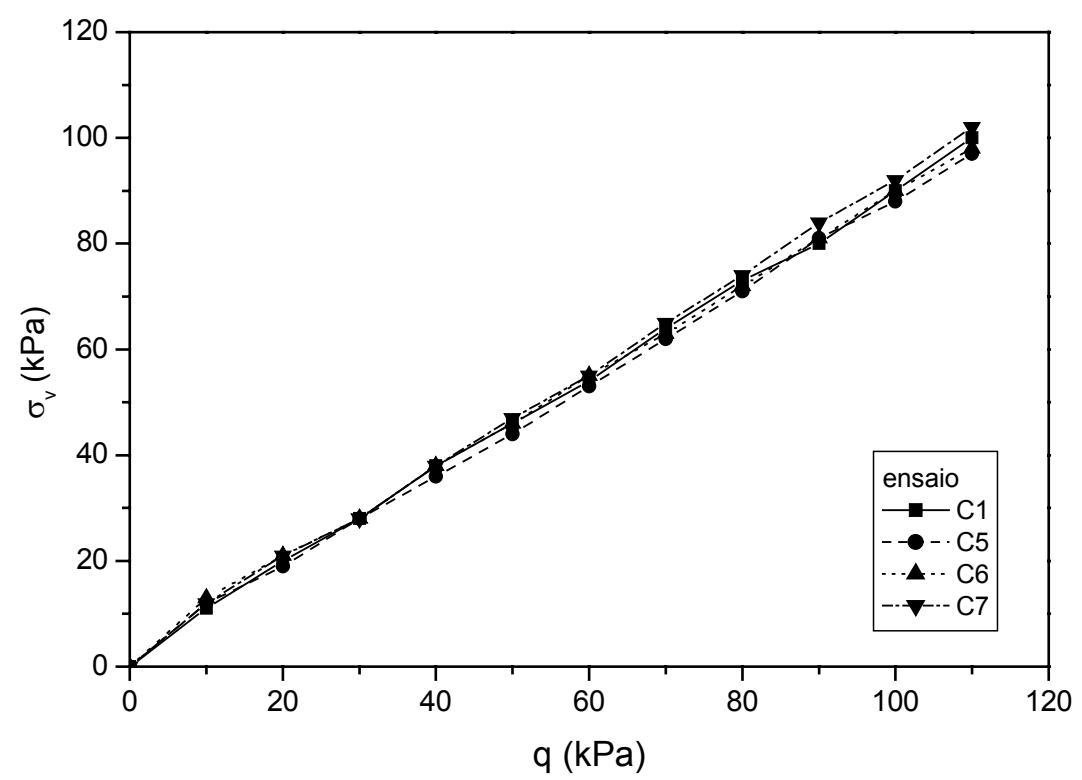

Figura 6.3. Repetibilidade da tensão vertical medida no exterior do alçapão (posição I4) durante a fase de carregamento. Ensaios realizados com $D_{r}=100 \%$ e q $=100$ $\mathrm{kPa}$.

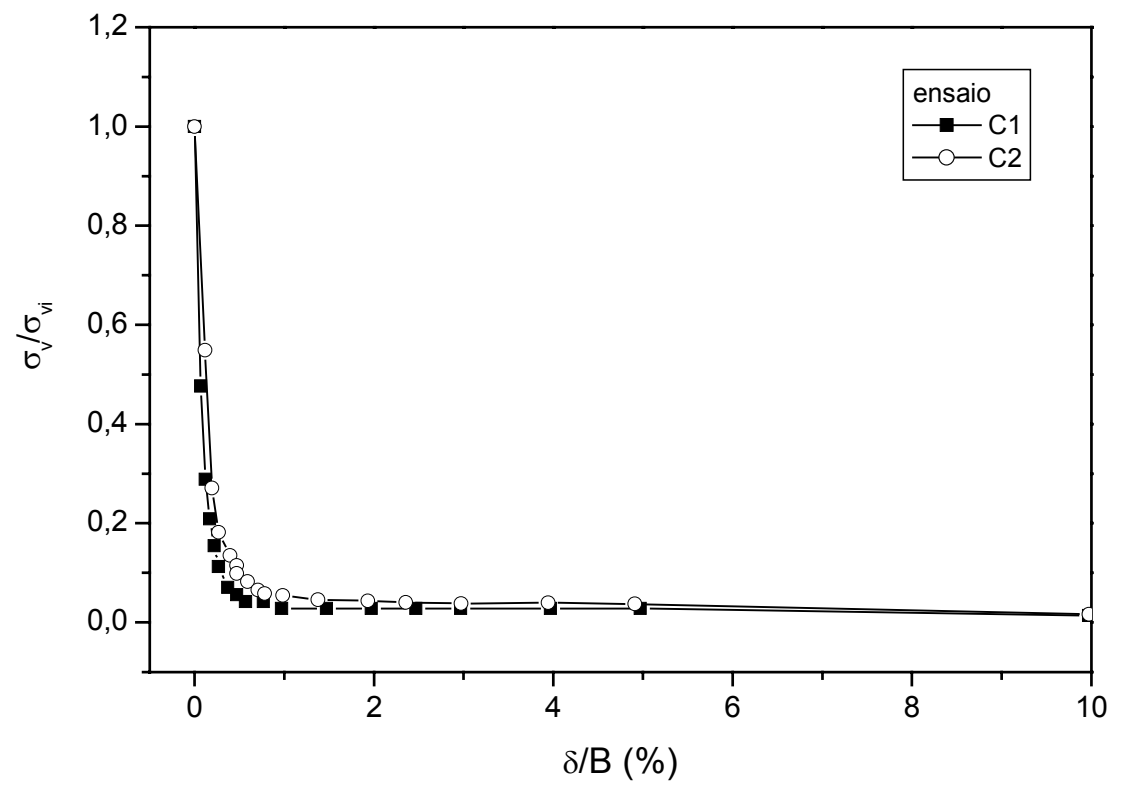

Figura 6.4. Repetibilidade da tensão medida na posição I1 durante a fase de movimentação do alçapão. Ensaios realizados com $D_{r}=100 \%$ e q $=100 \mathrm{kPa}$. 


\subsection{ARQUEAMENTO ATIVO}

\subsubsection{Redistribuição de Tensões no Interior do Alçapão}

A variação típica da tensão vertical na superfície do alçapão é caracterizada por uma redução inicial abrupta seguida de uma rápida estabilização. A mobilização do arqueamento máximo é atingida com deslocamentos relativos $(\delta / \mathrm{B})$ de magnitudes muito reduzidas, inferiores a $1 \%$ para o maciço compacto $\left(D_{r}=100 \%\right)$ e $2,5 \%$ para o fofo $\left(D_{\mathrm{r}}=50 \%\right)$. A Figura 6.5 exibe resultados das tensões medidas sobre a superfície do alçapão na posição central $\mathrm{I} 1$, bem como a 0,7 e a $1,3 \mathrm{~B}$ do centro (posições I2 e I3, respectivamente). Os dados foram obtidos com o maciço fofo sujeito a uma sobrecarga de $100 \mathrm{kPa}$ e com o alçapão com $\mathrm{L}_{\mathrm{v}} / \mathrm{B}=3$ (ensaio $\mathrm{C} 3$ ). De forma a auxiliar a interpretação, um esboço simplificado indicando os pontos de medida da tensão em relação ao alçapão é reproduzido nos gráficos a seguir.

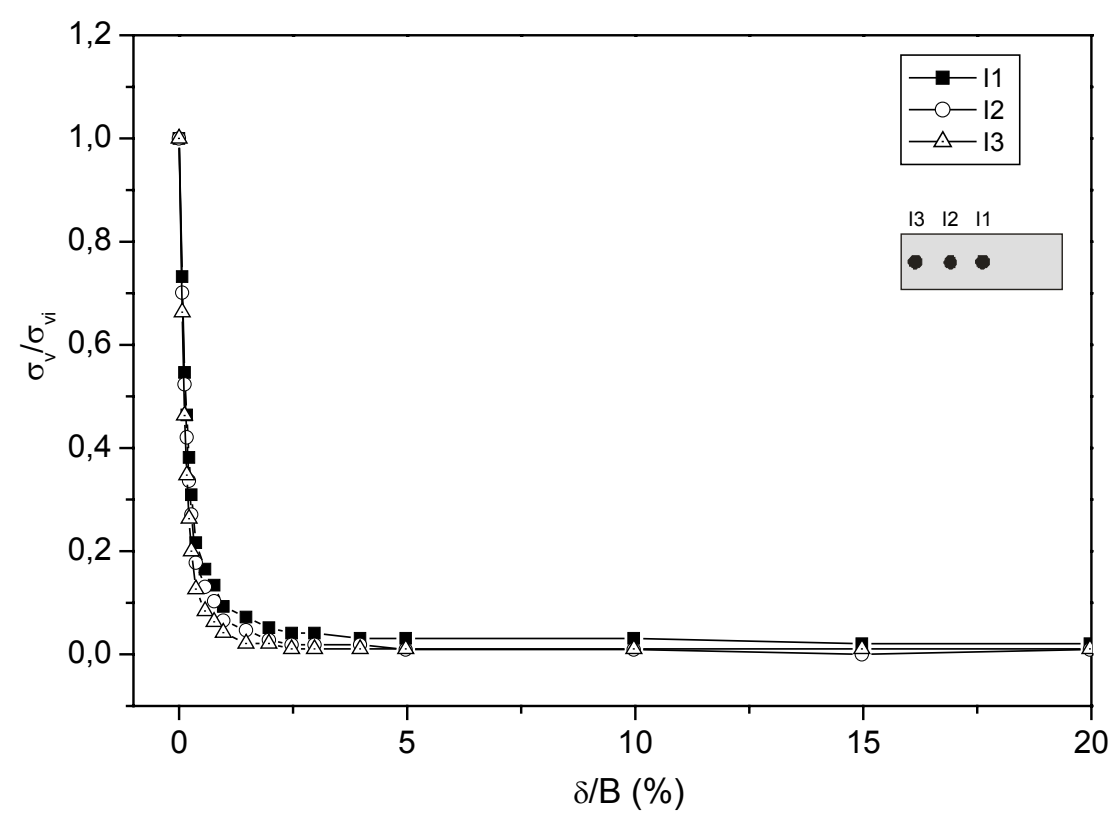

Figura 6.5. Variação típica da tensão vertical na superfície do alçapão em arqueamento ativo. 
As curvas obtidas para I1, I2 e I3 são praticamente idênticas e possuem formato hiperbólico. O primeiro trecho, ou de arqueamento inicial, segundo a nomenclatura sugerida por Iglesia et al. (1999), possui módulo de arqueamento $\left(\mathrm{M}_{\mathrm{A}}\right)$ igual a 257. Isto representa um alívio de aproximadamente $70 \%$ da tensão inicial sobre o alçapão após uma translação de apenas $0,15 \%$ de B. O deslocamento relativo $\left(\delta_{\mathrm{u}} / \mathrm{B}\right)$ associado à mobilização da mínima tensão na estrutura $\left(\sigma_{\mathrm{va}}\right)$ é igual a aproximadamente $2,5 \%$ nas três posições. As curvas não indicaram recuperação de carga, de modo que $\sigma_{\mathrm{va}}$ é praticamente igual à tensão residual $\left(\sigma_{\mathrm{vr}}\right)$ (ver Figura 2.18).

\subsubsection{Perfil de Tensões sobre o Alçapão}

A Figura 6.6 exibe a distribuição de tensões em função do deslocamento em um perfil vertical sobre I1 no ensaio C3. A altura medida a partir da base do modelo $\left(\mathrm{H}_{\mathrm{e}}\right)$ é indicada em função de B. Duas constatações imediatas podem ser derivadas desses resultados: a) o efeito do arqueamento diminui com o aumento de $\mathrm{H}_{\mathrm{e}} / \mathrm{B}$ e b) a forma inicialmente hiperbólica da curva sofre modificação gradual em direção à reta horizontal $\sigma_{\mathrm{v}} / \sigma_{\mathrm{vi}}=1$, correspondendo à altura a partir da qual o deslocamento da estrutura não mais causa alívio da tensão vertical devido ao arqueamento. A alteração no formato das curvas torna-se mais evidente além de $\mathrm{H}_{\mathrm{e}} / \mathrm{B}=1,4$. Após essa altura, o comprimento do trecho inicial diminui de forma mais evidente. $\mathrm{M}_{\mathrm{A}}$ decresce $52 \%$ entre $H_{e} / B=0$ e 1,4 e $85 \%$ entre essa última altura e $H_{e} / B=3,7$. Concomitantemente, a curvatura do segmento intermediário também diminui com o aumento da altura e tende a se confundir com o trecho final. Acima de $\mathrm{H}_{\mathrm{e}} / \mathrm{B}=1,4$ os deslocamentos do alçapão não são suficientes para a estabilização da tensão em um valor mínimo.

O conhecimento do perfil de tensão sobre o alçapão possibilita avaliar experimentalmente a altura do plano ao longo do qual o recalque da massa de solo sobre o alçapão se iguala ao recalque da massa exterior, ou plano de igual recalque (PIR). A Figura 6.7 apresenta a variação da tensão vertical no centro do alçapão em função da profundidade para cinco valores de $\delta / \mathrm{B}$ entre 0,25 e $20 \%$. A partir de $\delta / B$ $=2,5 \%$, a estrutura sofre um alívio de carga muito acentuado, que se estende até aproximadamente 1,5 B sobre o alçapão. Altura da mesma ordem foi observada no 
modelo com $\mathrm{D}_{\mathrm{r}}=100 \%$ e $\mathrm{q}=50 \mathrm{kPa}(\mathrm{C} 4)$. Uma estimativa primária da altura máxima de influência do deslocamento do alçapão pode ser obtida considerando-se que o comportamento de $\sigma_{\mathrm{v}}$ além de $\mathrm{H}_{\mathrm{e}} / \mathrm{B}=3,7$ seja representado pelo prolongamento da reta composta pelos dois últimos pontos de cada curva da Figura 6.7. A interseção dessas com a vertical em $\sigma_{\mathrm{v}} / \sigma_{\mathrm{vi}}=1$ fornece uma altura de influência variando entre 4 e $5 \mathrm{~B}$, de acordo com o deslocamento imposto. Sendo a altura total do modelo em relação à base do alçapão (H/B) igual a 5,6, nota-se que a movimentação do alçapão exerce influência ao longo de praticamente toda a altura do maciço.

Uma previsão do PIR através do método de Marston-Spangler (Young e Trott 1984, Bulson 1985) forneceu valores de $H_{e} / B$ muito superiores a $H / B$, por conta da sobrecarga aplicada. Em contrapartida, o método de Allgood (1971) subestimou a altura do PIR, resultando em valores não superiores $\mathrm{H}_{\mathrm{e}} / \mathrm{B}=1,2$.

Uma estimativa da altura da zona de redução acentuada de $\sigma_{\mathrm{v}}$ (ver Figura 6.7) pode ser realizada tomando como ponto de partida o modelo analítico proposto por Villard et al. (2000) (item 2.3.1). O método pressupõe a formação de um arco sobre o alçapão após sua movimentação, responsável pelo alívio da carga proveniente da superfície e do peso próprio do solo.

A altura $\mathrm{h}$ do arco é determinada através do equilíbrio estático das forças atuantes (Figura 6.8), sendo a tensão sobre o topo do mesmo $\left(\sigma_{\mathrm{zd}}\right)$ obtida através da Teoria do Silo (Figura 2.15). Uma vez que o método original é voltado para o estado axissimétrico, uma solução para o estado plano foi desenvolvida. O emprego de soluções concebidas considerando o estado plano de deformação encontra justificativa no fato da variação da tensão no interior do alçapão independer da geometria do mesmo, como será abordado no item 6.3.8. Para um material sem coesão e sujeito a uma carga superficial q, $\sigma_{z d}$ é dada através de (6.2) e a altura do arco (h) é determinada resolvendo-se as equações (6.3) e (6.4), resultando em (6.5).

Previsões com a equação (6.5) forneceram h/B igual a aproximadamente 1 para condições com $\mathrm{D}_{\mathrm{r}}=100 \%$ e q $=50$ e $100 \mathrm{kPa}$, o que concorda bem com os resultados experimentais dos respectivos modelos executados sob as mesmas condições. Os valores de $\phi$ utilizados nos cálculos foram obtidos da Tabela 4.4 e 
majorados em 10\% para levar em conta o estado plano de deformação (Zornberg et al. 1998).

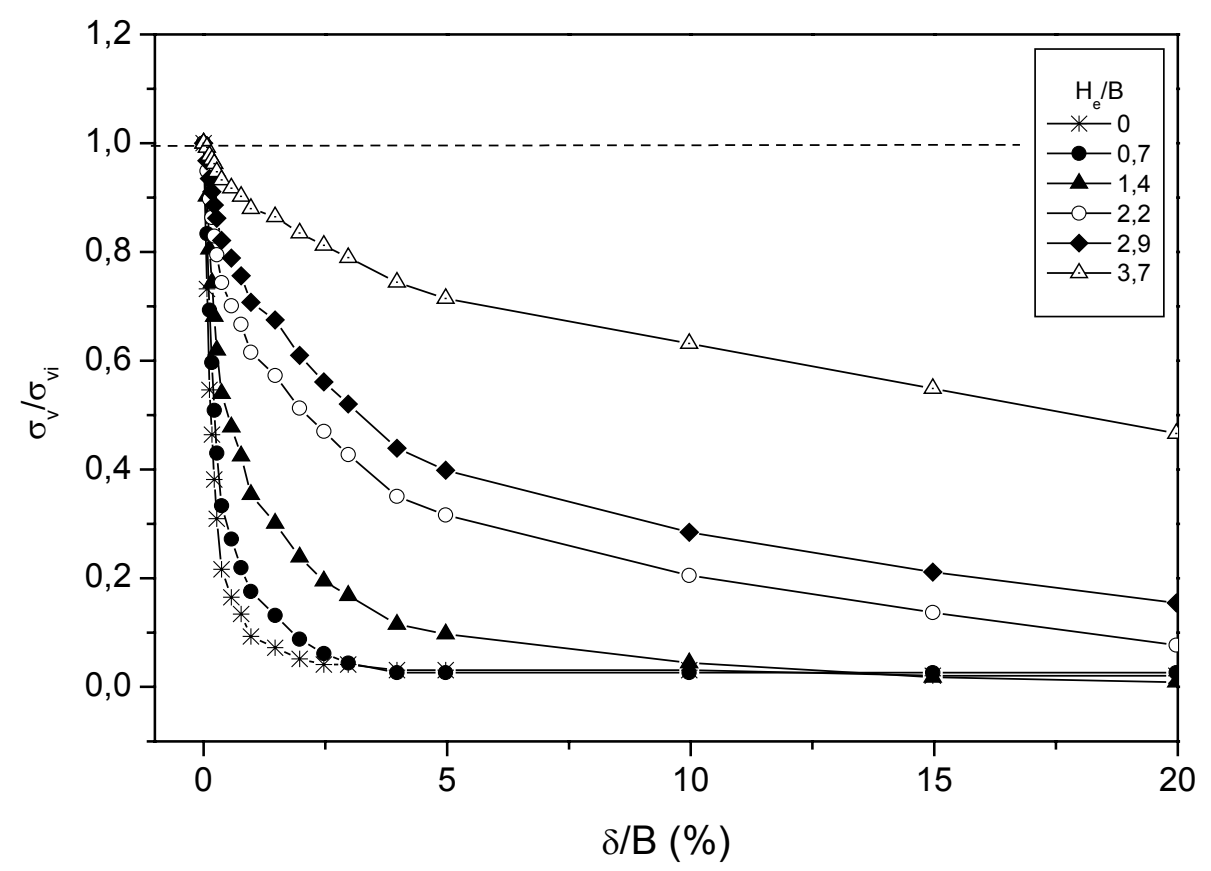

Figura 6.6. Variação da tensão vertical em um perfil vertical no centro do alçapão retangular em arqueamento ativo.

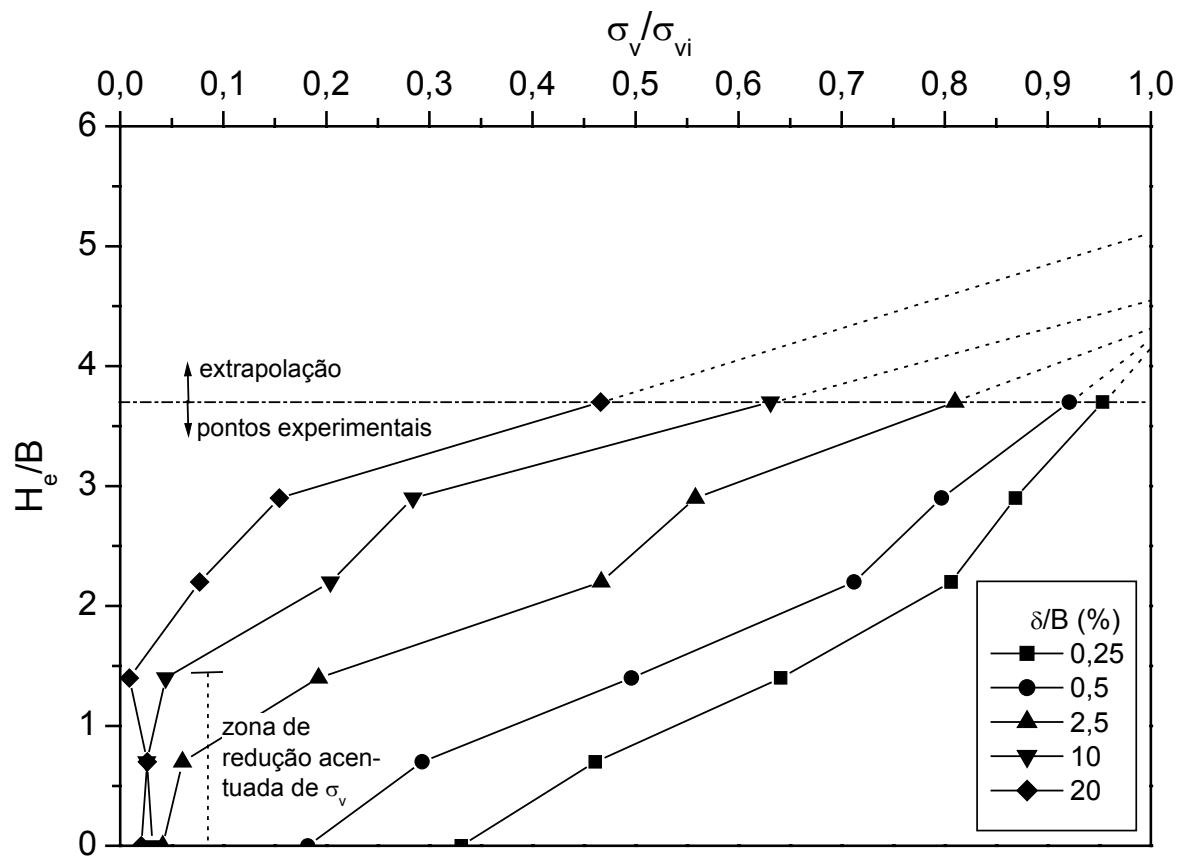

Figura 6.7. Perfil de tensões sobre o alçapão retangular em arqueamento ativo para diversos níveis de deslocamento. 
$\sigma_{z d}=\mathrm{k}_{0}+\mathrm{k}_{2} \mathrm{e}_{1}^{-\mathrm{k}}(\mathrm{H}-\mathrm{h})$

onde: $\mathrm{k}_{0}=\mathrm{B} \gamma /\left(4 \mathrm{k}_{\mathrm{kr}} \mathrm{tg} \phi\right) ; \mathrm{k}_{1}=\left(4 \mathrm{k}_{\mathrm{kr}} \mathrm{tg} \phi\right) / \mathrm{B} ; \mathrm{k}_{2}=\mathrm{q}-\mathrm{k}_{0} ; \mathrm{k}_{\mathrm{kr}}=$ coeficiente de Krynine (expressão 2.4).

$\Sigma \mathrm{R}_{\mathrm{z}}=0 \therefore-\mathrm{dF}_{\mathrm{z}}+\int_{0}^{\mathrm{R}} \sigma_{\mathrm{zd}} \mathrm{dx}=0 \therefore \mathrm{dF}_{\mathrm{z}}=\sigma_{\mathrm{zd}}(\mathrm{B} / 2)$

$\Sigma \mathrm{M}_{\mathrm{A}}=0 \therefore \int_{0}^{\mathrm{R}} \sigma_{\mathrm{zd}} \mathrm{xdx}=0+\int_{\mathrm{H}-\mathrm{h}}^{\mathrm{H}}(\mathrm{z}+\mathrm{h}-\mathrm{H}) \cdot \mathrm{k}_{\mathrm{kr}} \sigma_{\mathrm{zd}} \mathrm{dz}-\mathrm{dF}_{\mathrm{z}} \cdot(\mathrm{B} / 2)=0$

$\mathrm{C}_{1}^{\prime}+\mathrm{C}_{2}^{\prime}\left(\mathrm{e}^{-\mathrm{k}_{1}(\mathrm{H}-\mathrm{h})}-\mathrm{e}^{-\mathrm{k}_{1} \mathrm{H}}\right)-\frac{\mathrm{k}_{\mathrm{kr}} \mathrm{k}_{2} \mathrm{~h}}{\mathrm{k}_{1}} \mathrm{e}^{-\mathrm{k}_{1} \mathrm{H}}-\frac{\mathrm{B}^{2}}{8}\left(\mathrm{k}_{0}+\mathrm{k}_{2} \mathrm{e}^{-\mathrm{k}_{1}(\mathrm{H}-\mathrm{h})}\right)=0$

onde: $\mathrm{C}_{1}^{\prime}=\frac{\mathrm{k}_{\mathrm{kr}} \mathrm{h}^{2} \mathrm{k}_{0}}{2} ; \mathrm{C}_{2}^{\prime}=\frac{\mathrm{k}_{\mathrm{kr}} \mathrm{k}_{2}}{\mathrm{k}_{1} \mathrm{k}_{1}}$

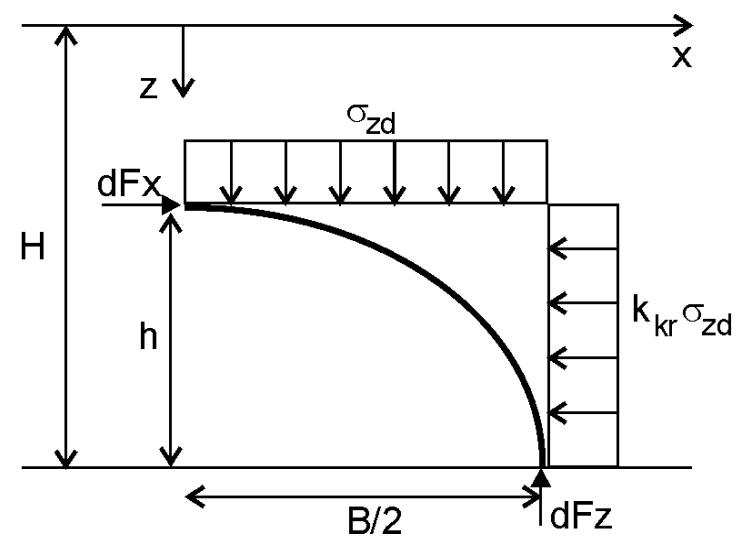

Figura 6.8. Equilíbrio estático do arco.

\subsubsection{Redistribuição de Tensões no Exterior do Alçapão}

A análise dos resultados dos experimentos mostrou que a redistribuição de tensões abrange uma área de grande extensão em torno do alçapão. Em outras palavras, a variação da carga não se restringiu ao interior da estrutura, mas se estendeu a uma parte da massa de solo exterior, até distâncias em planta superiores a 5B. A tendência geral observada na região imediatamente adjacente à estrutura foi de um ligeiro 
aumento de $\sigma_{\mathrm{v}}$ seguido de redução acentuada logo no início da translação. As regiões mais remotas do maciço experimentaram apenas aumento de tensão.

Este comportamento concorda com o relato de McNulty (1965) com um alçapão circular em material granular, com razões H/B variando entre 0,7 e 6 , e de Viana (2003), utilizando um alçapão retangular com $\mathrm{L}_{\mathrm{v}} / \mathrm{B}=6$ e $\mathrm{H} / \mathrm{B}=5,5$. Essas investigações, porém, foram muito limitadas nesse aspecto, não fornecendo uma perspectiva geral sobre o problema.

A Figura 6.9 mostra o comportamento da tensão vertical com o maciço fofo $\left(\mathrm{D}_{\mathrm{r}}=50 \%\right)$ sujeito a uma sobrecarga $\mathrm{q}=100 \mathrm{kPa}$ em $\mathrm{x}_{\mathrm{i}} / \mathrm{B}=0,2$ e 0,8 (posições I4 e I5, respectivamente) e $\mathrm{H}_{\mathrm{e}} / \mathrm{B}=0 . \mathrm{O}$ parâmetro $\mathrm{x}_{\mathrm{i}}$ representa a distância horizontal medida a partir da aresta de maior comprimento do alçapão. A variação de $\sigma_{\mathrm{v}}$ nas coordenadas $\mathrm{H}_{\mathrm{e}} / \mathrm{B}=0,3$ e $\mathrm{x}_{\mathrm{i}} / \mathrm{B}=0,2$ é fornecida na mesma figura. Em $\mathrm{x}_{\mathrm{i}} / \mathrm{B}=0,2, \mathrm{o}$ deslocamento relativo do alçapão provoca um aumento máximo em $\sigma_{\mathrm{v}}$ de $5 \%$, decorrente da transferência da tensão sobre a estrutura para as adjacências. Com o avanço dos deslocamentos, há redução de tensão e, a partir de $\delta / B=0,2 \%, \sigma_{v}$ tornase inferior a $\sigma_{\mathrm{vi}}$.

À medida que o deslocamento do alçapão progride com o movimento descendente, a carga aliviada no solo adjacente é então transferida a distâncias maiores, causando o aumento da tensão nas regiões mais remotas do maciço. Apesar de $\sigma_{\mathrm{v}}$ começar a diminuir em $\mathrm{x}_{\mathrm{i}} / \mathrm{B}=0,2$ a partir de $\delta / \mathrm{B}=0,07 \%$, a tensão continua a aumentar em $\mathrm{x}_{\mathrm{i}} / \mathrm{B}=0,8$, atingindo o pico em $\delta / \mathrm{B}=0,37 \%$. O aumento máximo de $\sigma_{\mathrm{v}}$ foi de $12 \%$. Um deslocamento relativo de $2,5 \%$ foi necessário para que $\sigma_{\mathrm{v}}$ decrescesse aquém de $\sigma_{\mathrm{vi}}$ nessa posição. $\mathrm{O}$ efeito do arqueamento em $\mathrm{x}_{\mathrm{i}} / \mathrm{B}=0,8$ é muito menor que o observado em $\mathrm{x}_{\mathrm{i}} / \mathrm{B}=0,2$. $\mathrm{O}$ comportamento da tensão na altura $\mathrm{H}_{\mathrm{e}} / \mathrm{B}=0,3$ é bastante semelhante ao constatado em $\mathrm{H}_{\mathrm{e}} / \mathrm{B}=0$. Após aproximadamente $\delta / B=3 \%$ o efeito do arqueamento mostrou-se ligeiramente maior $\mathrm{em}_{\mathrm{e}} / \mathrm{B}=0,3$.

O comportamento da tensão vertical em função do deslocamento entre $\mathrm{y}_{\mathrm{i}} / \mathrm{B}=$ 0,2 e 4,7 na direção y (posições I6 a I9) é exibido na Figura 6.10. A mesma figura também traz a variação da tensão na altura $\mathrm{H}_{\mathrm{e}} / \mathrm{B}=0,3$ sobre $\mathrm{I}$. Em $\mathrm{y}_{\mathrm{i}} / \mathbf{B}=0,2, \sigma_{\mathrm{v}}$ decai desde o início da translação do alçapão, o que demonstra que esta região não recebe nenhuma parcela da carga proveniente do alívio que ocorre na massa de solo sobre o alçapão, sendo a mesma transferida diretamente para regiões mais remotas. $\mathrm{O}$ 
mesmo ocorre em $\mathrm{H}_{\mathrm{e}} / \mathrm{B}=0,3$, porém o efeito do arqueamento é relativamente mais pronunciado nessa altura. Nota-se então que essa região do maciço é menos sujeita a influências da movimentação da estrutura em comparação com a região da maior aresta (direção x). Por exemplo, a redução de $\sigma_{\mathrm{v}}$ é três vezes maior em I4 em comparação com I6.

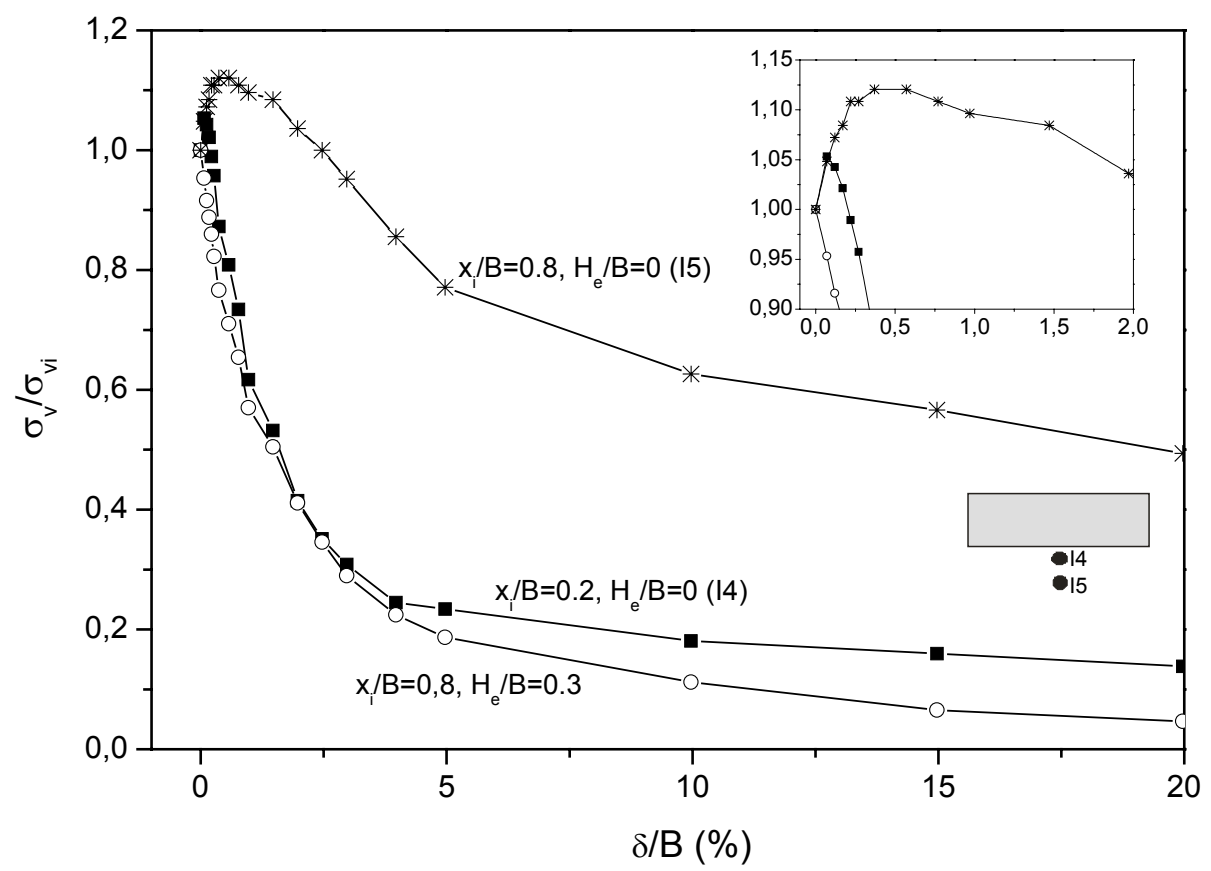

Figura 6.9. Variação de tensões no exterior do alçapão retangular em arqueamento ativo (direção x).

As regiões além de $\mathrm{y}_{\mathrm{i}} / \mathrm{B}=0,2$ sofreram um discreto aumento de tensão. Em $\mathrm{y}_{\mathrm{i}} / \mathrm{B}=0,7$ (I7), o aumento máximo de $\sigma_{\mathrm{v}}$ é de $13 \%$ quando o deslocamento relativo atinge $\approx 2 \%$. Em seguida $\sigma_{\mathrm{v}}$ sofre ligeira redução e alcança a estabilização em $\delta / \mathrm{B}=$ $10 \%$. Em $\mathrm{y}_{\mathrm{i}} / \mathrm{B}=2,7(\mathrm{I} 8)$ a tensão aumenta suavemente ao longo de toda a translação da estrutura, chegando a um aumento máximo de $20 \%$ de $\sigma_{\mathrm{vi}}$. Comportamento semelhante é observado em $\mathrm{y}_{\mathrm{i}} / \mathrm{B}=4,7$ (I9), porém o crescimento da tensão é comparativamente mais tênue. 


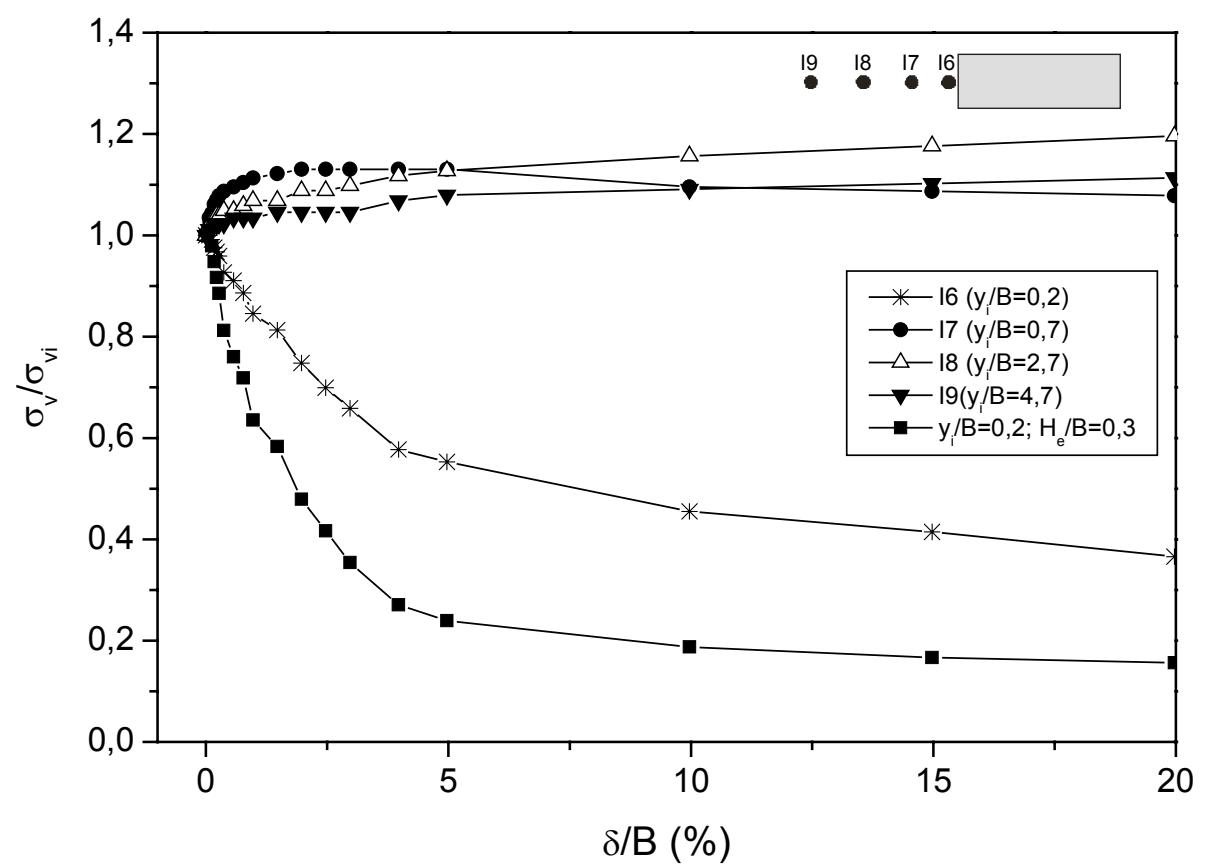

Figura 6.10. Variação de tensões no exterior do alçapão retangular em arqueamento ativo (direção y).

A redução de $\sigma_{\mathrm{v}}$ nas adjacências do alçapão até valores abaixo de $\sigma_{\mathrm{vi}}$ evidencia a propagação de tensões cisalhantes no maciço de solo exterior a partir de deslocamentos muito pequenos da estrutura. Isso pode ser explicado através do esquema da Figura 6.11, o qual divide o maciço em três zonas distintas. Na zona de alívio, como o próprio nome indica, as tensões verticais diminuem com o aumento de $\delta$. Na zona de solicitação, ao contrário, as tensões aumentam. Essas duas zonas são delimitadas pela linha vertical a-a'. A zona onde as tensões cisalhantes se propagam no meio é denominada zona cisalhante, e envolve deformações de magnitude muito reduzida. Na Figura 6.11, a zona cisalhante é delimitada pela linha b-b'. Antes da zona cisalhante interceptar a coluna de solo $\mathrm{ABCD}$, a célula da base registrava aumento de tensão. Após a interceptação, a região AEFD passa a experimentar alívio de carga, diminuindo, por conseguinte, a tensão vertical sobre a célula. A redução de $\sigma_{\mathrm{v}}$ com o aumento de $\delta$, como mostram as Figuras 6.9 e 6.10 , indica que a zona cisalhante cresce paulatinamente em direção ao maciço exterior. $\mathrm{O}$ aumento da zona cisalhante leva ao aumento da zona de alívio. Por sua vez, se a zona de alívio aumenta, também o faz a região AEFD. 
Nos modelos, a zona cisalhante atingiu uma distância igual ou maior que $0,8 \mathrm{~B}$ na direção x e uma distância compreendida entre 0,2 e $0,7 \mathrm{~B}$ na direção y. $\mathrm{O}$ alívio

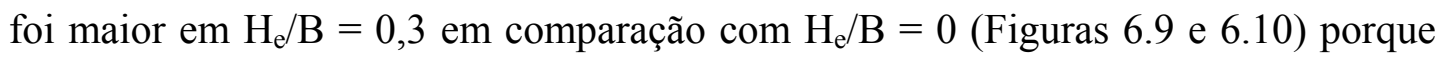
aquela altura na massa de solo está mais próxima da zona cisalhante do que esta. Com efeito, a região EB'C'F é menor que EBCF (Figura 6.11).

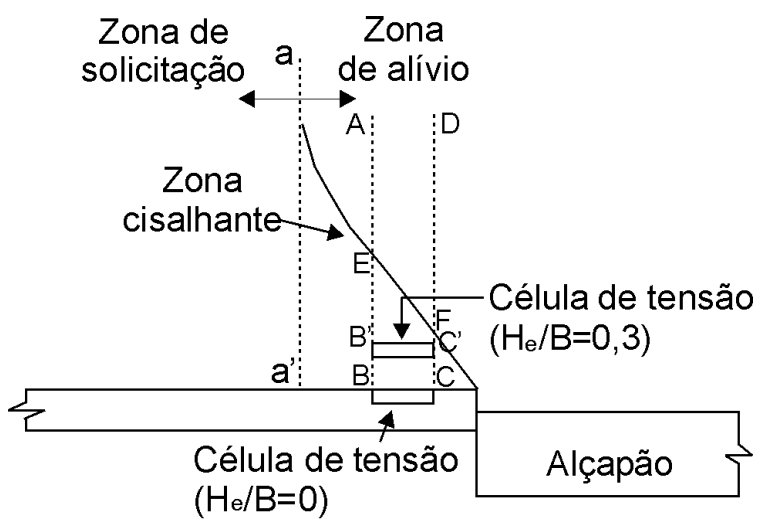

Figura 6.11. Explicação sobre a variação da tensão vertical no solo no exterior do alçapão.

Na Figura 6.5, a máxima redução da tensão sobre o centro do alçapão, em $\delta / B$ $=2,5 \%$, ocorre em virtude da mobilização do ângulo de atrito de pico $\left(\phi_{\mathrm{p}}\right)$ do solo. Por outro lado, na Figura 6.9, o aumento máximo de tensão observado no exterior da estrutura nas posições I4 e I5, em $\delta / B=0,07$ e $0,37 \%$, respectivamente, não significa que $\phi_{\mathrm{p}}$ foi mobilizado, mas apenas que a zona cisalhante iniciou a interceptação da coluna de solo sobre a célula de tensão correspondente. Ora, se $\phi_{\mathrm{p}}$ é mobilizado para $\delta / B=2,5 \%$ no alçapão, certamente não será mobilizado no maciço exterior com deslocamentos relativos iguais ou menores que este, uma vez que o cisalhamento no solo diminui com a distância do alçapão. Já a redução registrada em I7 após $\delta / \mathrm{B}=$ $5 \%$, pode ter ocorrido tanto porque a resistência de pico foi ultrapassada, quanto por conta da interceptação da zona cisalhante. 


\subsubsection{Zona Cisalhante e Localizações de Deformação}

Como se observa nas Figuras 6.9 e 6.10, o alívio de carga no exterior do alçapão ocorre instantaneamente à movimentação inicial da estrutura. Isso significa que a zona cisalhante atinge o maciço exterior a partir de deslocamentos muito pequenos do alçapão. Em contraste, os resultados dos modelos da série A, apresentados no Capítulo 5, mostraram a formação de localizações de deformação externas apenas entre $\delta / \mathrm{B}=14,3$ e $28,6 \%$ (Figura 5.5). Nesses níveis de deslocamento, as tensões medidas se encontram praticamente estabilizadas. Logo, verifica-se que a propagação da zona cisalhante precede o desenvolvimento das localizações de deformação externas. As deformações envolvidas são de magnitude muito pequena (bem inferior às deformações que ocorrem na localização), diminuindo gradualmente com o aumento da distância ao alçapão.

Esse fato aparenta guardar relação com a profundidade da instalação. Nos modelos da série A, classificados como profundos, verificou-se que as deformações no solo devidas à movimentação do alçapão abrangem uma grande área sobre o alçapão e em torno do mesmo (Figuras 5.2 e 5.4). Em contraste, nos ensaios de Stone e Muir Wood (1992) definidos como instalações rasas $(H / B=0,5)$, radiografias permitiram mostrar com nitidez que as deformações se limitaram praticamente às localizações formadas, com o solo entre elas se comportando como "blocos rígidos", como definem os próprios autores. Essa constatação representa um indício de que a referida zona cisalhante não ocorre em condição rasa. Outrossim, uma análise dos resultados dos ensaios reportados por McNulty (1965), realizados com diversas alturas de cobertura, revelou que, para um mesmo deslocamento $\delta$, a perturbação no maciço aumenta com o aumento da altura de cobertura.

Assim, pressupõe-se que as localizações de deformação possuem um papel secundário no comportamento do sistema em profundidade, e não guardam relação com a variação das tensões. O oposto seria verdadeiro em instalação rasa. No entanto, um estudo mais aprofundado é necessário em favor de uma melhor compreensão acerca do problema. A investigação deve envolver medições de tensões no maciço e o acompanhamento concomitante da propagação das localizações formadas em modelos variando-se a altura de cobertura de solo. 
Por fim, é importante esclarecer que localizações de deformação também são zonas cisalhantes, porém os termos foram empregados dessa maneira com o intuito de distinguir os dois mecanismos identificados.

\subsubsection{Distribuição Espacial das Tensões Verticais no Modelo}

As Figuras 6.12a e b reúnem os dados coletados nas posições I4 a I9, permitindo visualizar a distribuição espacial de $\sigma_{\mathrm{v}}$ dentro e fora do alçapão, na base do modelo $\left(\mathrm{H}_{\mathrm{e}} / \mathrm{B}=0\right)$. Deslocamentos relativos $\delta / \mathrm{B}$ iguais a $0,1,1$ e $10 \%$ foram selecionados nesta análise, sendo os resultados reproduzidos segundo o eixo vertical de simetria do modelo. Em ambas as direções, o interior do alçapão experimenta uma forte redução de tensão no intervalo entre $\delta / \mathrm{B}=0,1$ e $1 \%$. Em contraste, a redução é muito pequena na faixa entre $\delta / \mathrm{B}=1 \%$ e $10 \%$.

Observa-se ainda na Figura 6.12 b que o alívio da tensão no interior do alçapão é ligeiramente menor em direção ao centro, possivelmente em decorrência de menores deformações cisalhantes no solo neste local em relação às extremidades. Esse comportamento é atenuado com o aumento de $\delta / B$, com as tensões tendendo ao nivelamento. Resultados semelhantes foram obtidos por Tanaka e Sakai (1993).

A Figura 6.13 compara os resultados exibidos na Figura 6.12a com uma previsão realizada através da solução teórica de Finn (1963). Considera-se, nesta análise, que a condição de estado plano de deformação pode ser assumida para os modelos laboratoriais, conforme discutido no item 6.3.8, tornando a comparação entre o modelo teórico e o experimento possível. A previsão foi realizada para os deslocamentos relativos de $0,1,1$ e $10 \%$. A tensão vertical é obtida no modelo teórico através de:

$$
\sigma_{\mathrm{v}}=\frac{\delta}{2 \pi \beta}\left[\frac{\mathrm{x}+(\mathrm{B} / 2)}{(\mathrm{x}+(\mathrm{B} / 2))^{2}}-\frac{\mathrm{x}-(\mathrm{B} / 2)}{(\mathrm{x}-(\mathrm{B} / 2))^{2}}\right]+\gamma \mathrm{H}
$$

onde: $\beta=\left(1-v_{\mathrm{s}}^{2}\right) / \mathrm{E}_{\mathrm{s}}$. Os valores de $\mathrm{E}_{\mathrm{s}}$ e $v_{\mathrm{s}}$ utilizados são apresentados na Tabela 4.4. 


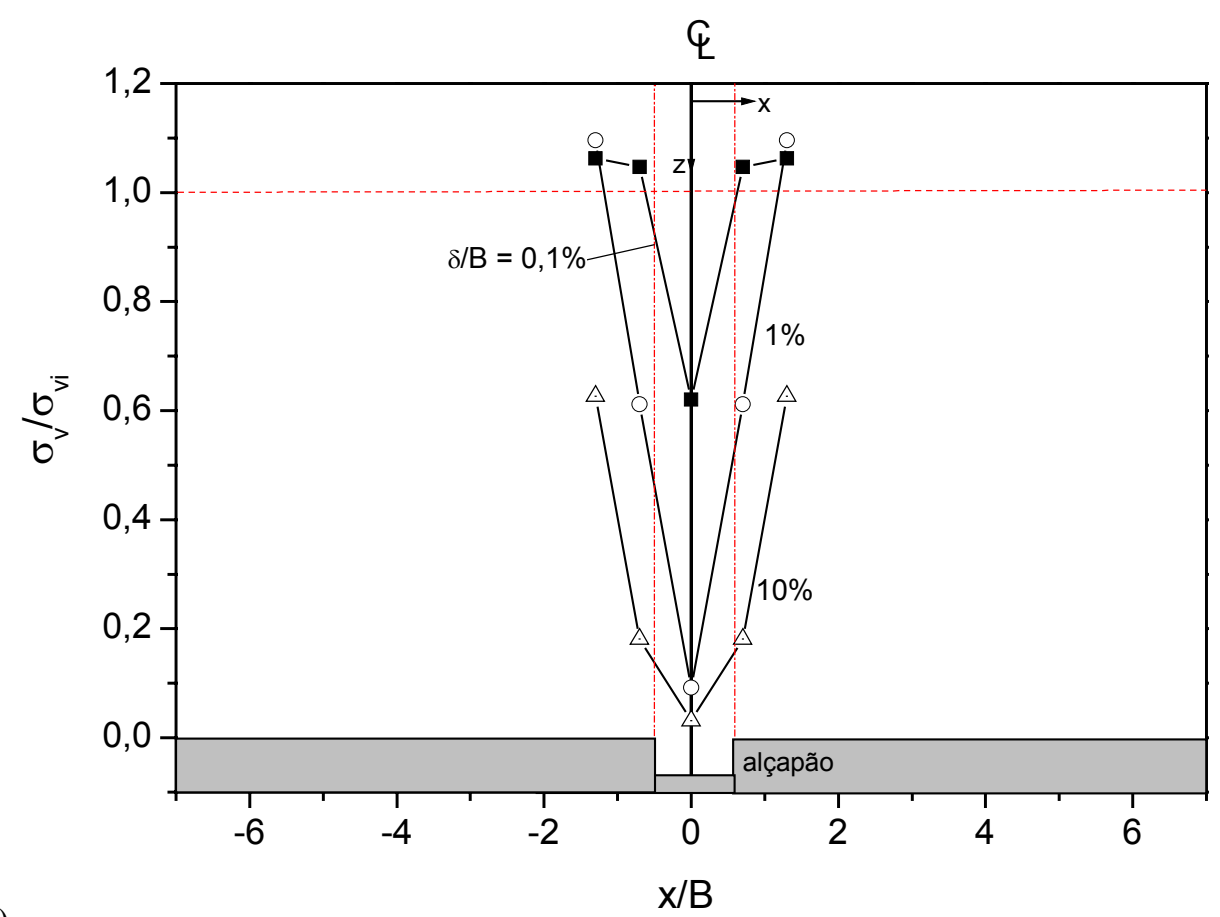

a)

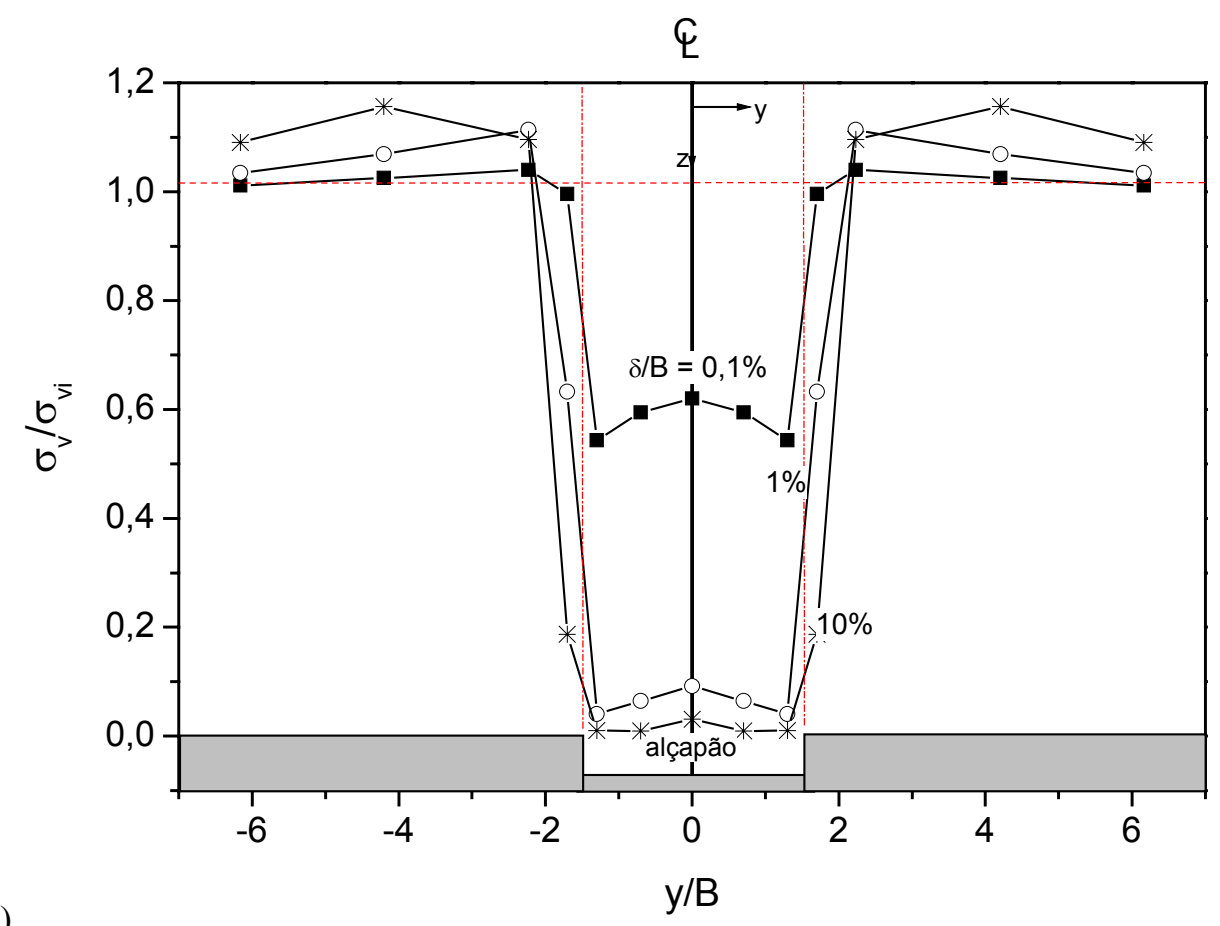

Figura 6.12. Distribuição das tensões verticais na base do modelo $\left(\mathrm{H}_{\mathrm{e}} / \mathrm{B}=0\right) \mathrm{em}$ arqueamento ativo, utilizando o alçapão com $\mathrm{L}_{\mathrm{v}} / \mathrm{B}=3$ e maciço com $\mathrm{D}_{\mathrm{r}}=50 \%$ e sobrecarga de $100 \mathrm{kPa}$. a) Direção x (transversal); b) direção y (longitudinal). 
Observa-se uma grande disparidade entre os resultados experimentais e o teórico. Esse último prevê um aumento acentuado da tensão com a proximidade da borda do alçapão. Para uma determinada distância x, também prevê o crescimento da tensão com o aumento de $\delta / B$. Ao contrário, os resultados laboratoriais mostraram um ligeiro aumento da tensão apenas no início dos deslocamentos, com alívio em seguida.

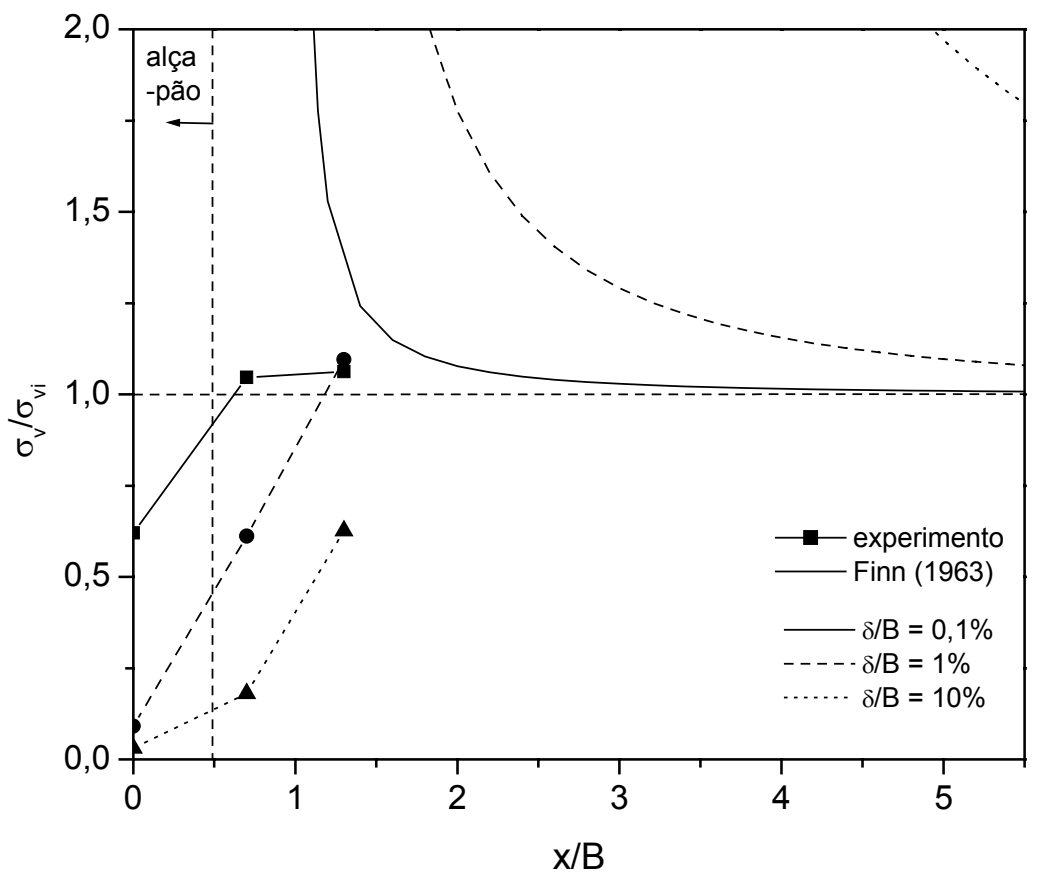

Figura 6.13. Distribuição da tensão vertical no exterior do alçapão e comparação com a solução de Finn (1963).

\subsubsection{Influência da Densidade do Solo}

$\mathrm{O}$ efeito da densidade do material sobre o fenômeno do arqueamento é investigado através da comparação de dois ensaios com $\mathrm{D}_{\mathrm{r}}$ de 50 e 100\%, representando, respectivamente o estado fofo e o compacto. Ambos os modelos foram executados com sobrecarga de $100 \mathrm{kPa}$ e com o alçapão com $\mathrm{L}_{\mathrm{v}} / \mathrm{B}=3$. Como mostra a Figura 6.14, a variação de $\sigma_{\mathrm{v}}$ no centro do alçapão (posição I1) é bastante semelhante nos estados fofo e compacto. A diferença entre os resultados resume-se a uma redução ligeiramente mais acentuada da tensão no trecho intermediário da curva pertencente a $\mathrm{D}_{\mathrm{r}}=100 \%$, uma vez que a resistência ao cisalhamento aumenta com a compacidade, possibilitando um maior alívio de carga sobre a estrutura. A maior diferença entre os 
resultados ocorre em $\delta / \mathrm{B}=1 \%$. A tensão torna a convergir com a continuidade dos deslocamentos.

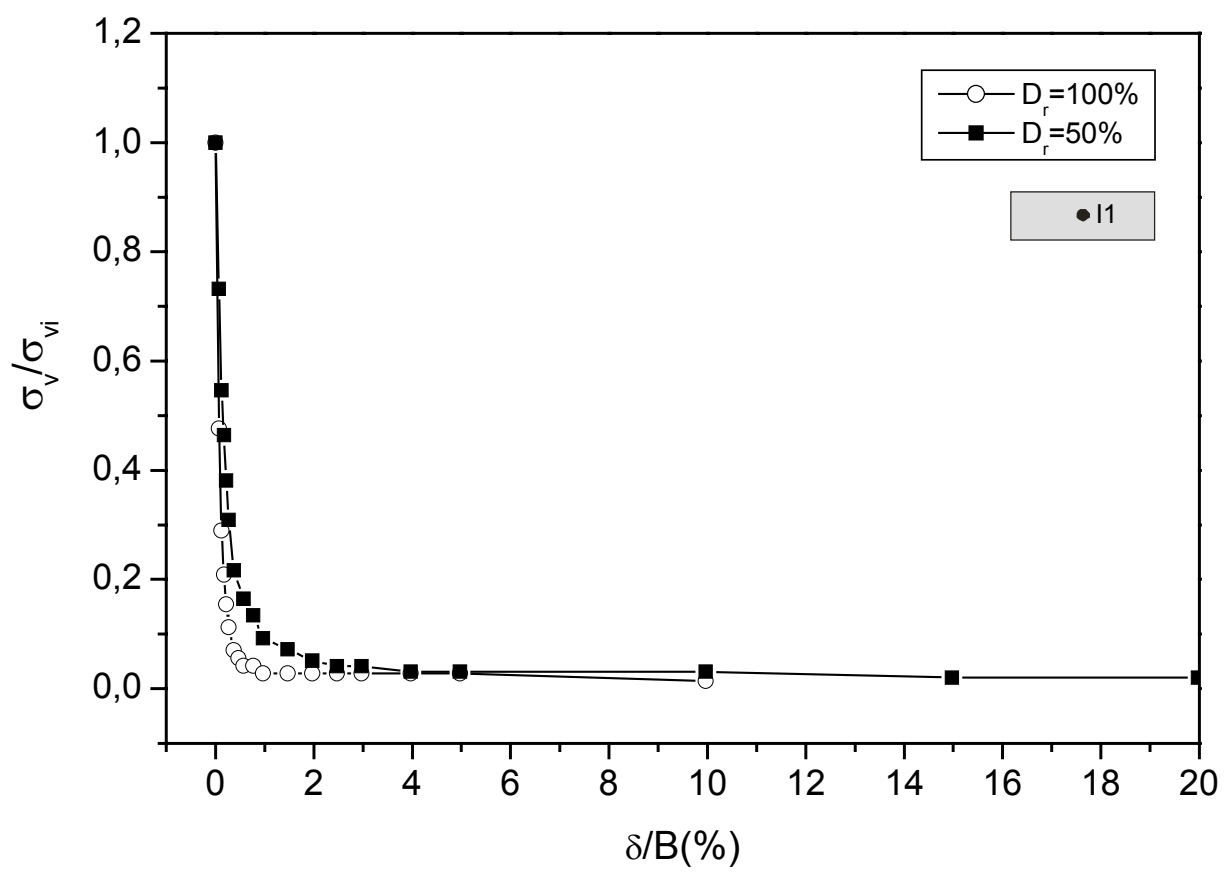

Figura 6.14. Variação da tensão vertical no centro do alçapão para $D_{r}=50$ e $100 \%$ em arqueamento ativo.

A influência da densidade do solo sobre o arqueamento também é relativamente pequena nas proximidades do maior lado do alçapão (posições I4 e I5), como mostra a Figura 6.15. Entretanto, a ampliação do gráfico da Figura 6.15 revela que a tensão de pico em $x_{i} / B=0,2$ é maior com o material compacto. A maior resistência ao cisalhamento do solo nessa condição faz com que a região em questão receba uma parcela maior da carga proveniente do alçapão. Com o aumento de $\delta$, a tensão vertical diminui mais com o material fofo, possivelmente por causa da maior abrangência da zona cisalhante, que se dá em virtude da menor dilatação do solo nesse estado. Em $\mathrm{x}_{\mathrm{i}} / \mathrm{B}=0,8$, o aumento inicial da tensão é praticamente o mesmo para ambas as densidades investigadas. Nessa posição, as tensões correspondentes a $D_{r}=50 \%$ tornam-se inferiores a partir de aproximadamente $\delta / B=4 \%$. 


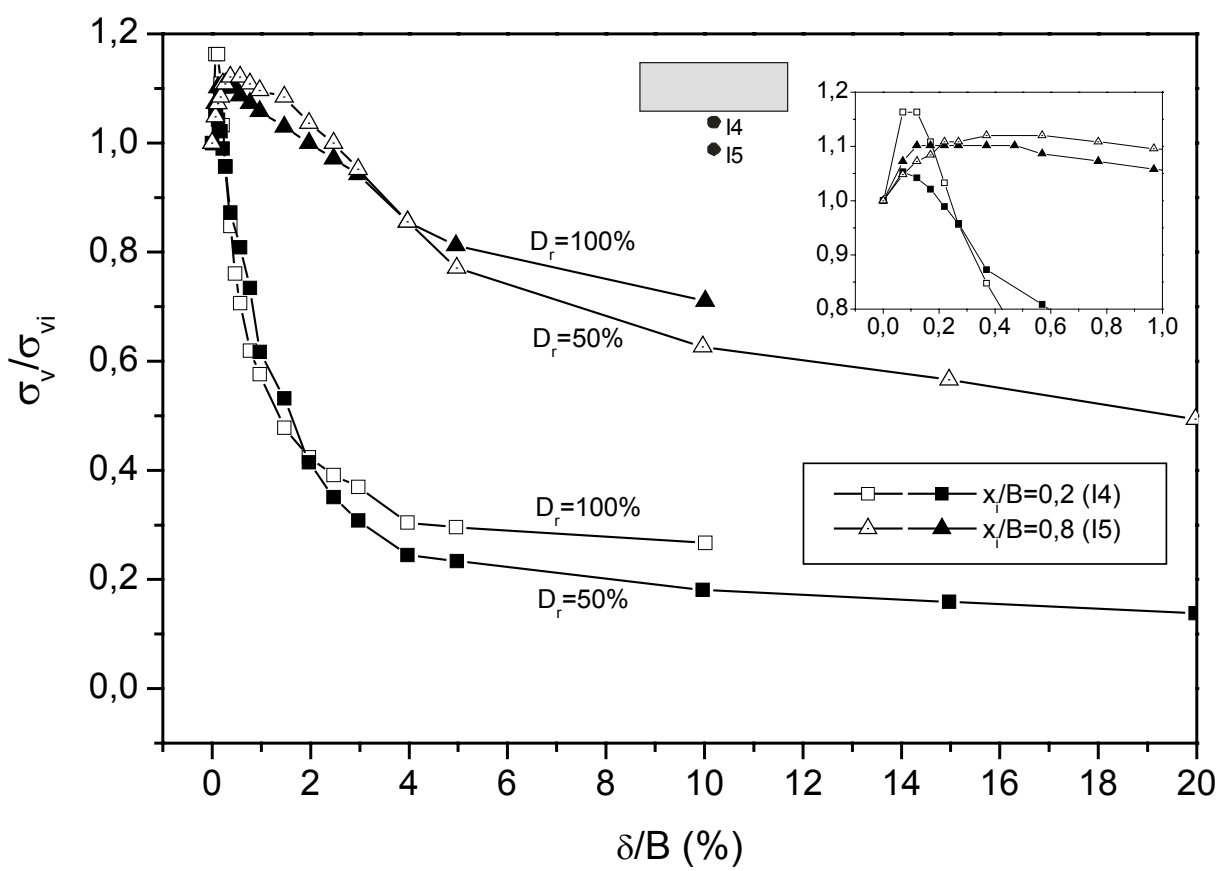

Figura 6.15. Influência da densidade relativa do solo na tensão vertical adjacente ao maior lado do alçapão com $\mathrm{L}_{\mathrm{v}} / \mathrm{B}=3 ; \mathrm{H}_{\mathrm{e}} / \mathrm{B}=0 ; \mathrm{q}=100 \mathrm{kPa}$.

Variações mais contundentes no comportamento da tensão vertical em virtude da densidade do solo foram observadas na região do menor comprimento do alçapão (posições I6 e I7), como mostra a Figura 6.16. No início do deslocamento, a região em $\mathrm{y}_{\mathrm{i}} / \mathrm{B}=0,2$ (I6) do material compacto recebe uma pequena parcela da carga proveniente do solo sobre a instalação, traduzida por um aumento um pouco superior a $10 \%$ da tensão inicial. Já o solo fofo sofre quase que exclusivamente redução de tensão. Com a continuação da translação, o alívio de carga nessa zona torna-se mais acentuado com o solo no estado fofo, indicando haver uma abrangência maior da superfície cisalhante, como citado anteriormente. A menor resistência ao cisalhamento do material fofo reduz o efeito da transferência da tensão proveniente das regiões do maciço mais próximas ao alçapão para a posição em $\mathrm{x}_{\mathrm{i}} / \mathrm{B}=0,8$ (I7). 


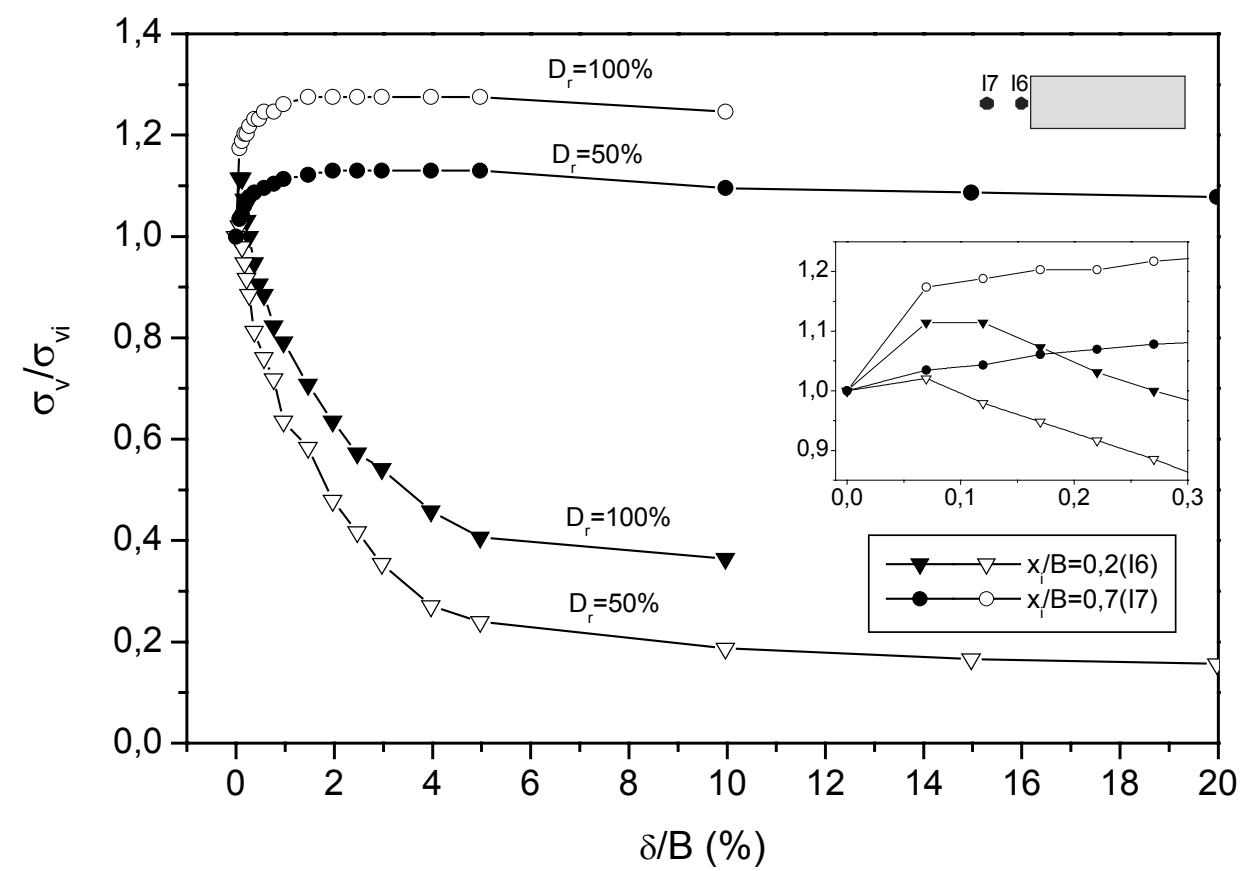

Figura 6.16. Influência da densidade relativa do solo na tensão vertical adjacente ao menor lado do alçapão com $\mathrm{L}_{\mathrm{v}} / \mathrm{B}=3 ; \mathrm{H}_{\mathrm{e}} / \mathrm{B}=0 ; \mathrm{q}=100 \mathrm{kPa}$.

\subsubsection{Influência da Sobrecarga Aplicada}

Com o intuito de investigar a influência do nível de sobrecarga na redistribuição das tensões na condição investigada, resultados de ensaios realizados com sobrecargas de 50 e $100 \mathrm{kPa}$, ambos com o solo com $\mathrm{D}_{\mathrm{r}}=100 \%$, foram confrontados.

De forma geral, tem-se observado que maiores coberturas de solo sobre o alçapão contribuem para uma maior redução das tensões em arqueamento ativo (McNulty 1965, Koutsabeloulis e Griffiths 1989, Iglesia 1991, Santichaianant 2002). No entanto, os níveis de sobrecarga utilizados resultaram uma influência pouco expressiva na redistribuição das tensões após a descida da estrutura, como se observa na Figura 6.17. As curvas apresentam trechos de arqueamento inicial idênticos. A tensão estabilizou-se em um valor ligeiramente superior, para q $=50 \mathrm{kPa}$. A tensão residual medida foi praticamente a mesma em ambos os casos, em torno de $3,5 \mathrm{kPa}$, mas como $\sigma_{\mathrm{vi}}$ é maior para $\mathrm{q}=100 \mathrm{kPa}$, obtém-se uma razão $\sigma_{\mathrm{v}} / \sigma_{\mathrm{vi}}$ menor nessa sobrecarga. McNulty (1965) obteve resultados semelhantes com ensaios com H/B constante e sobrecargas variando entre 280 e $770 \mathrm{kPa}$. O autor atribuiu a pequena 
variação entre as curvas dos ensaios ao fato do ângulo de atrito do solo ser quase independente do confinamento. O mesmo é observado na Tabela 4.4 para os dados correspondentes a $\mathrm{D}_{\mathrm{r}}=100 \%$.

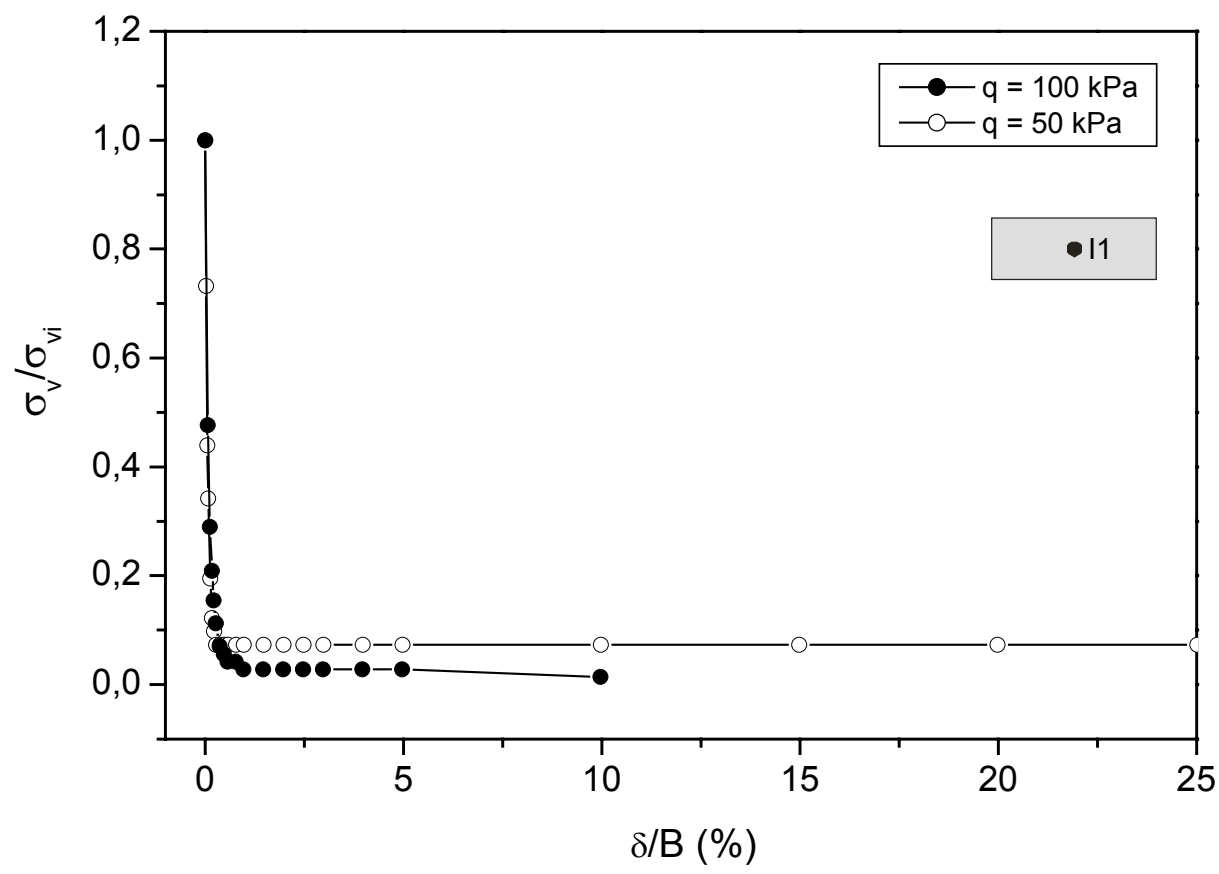

Figura 6.17. Influência do confinamento no comportamento da tensão vertical sobre o alçapão retangular em arqueamento ativo; $\mathrm{D}_{\mathrm{r}}=100 \%$.

A variação da tensão vertical no exterior do alçapão é observada através das Figuras 6.18 e 6.19. Em $\mathrm{x}_{\mathrm{i}} / \mathrm{B}=0,2$ (posição I4), o efeito do arqueamento é muito semelhante para ambas as sobrecargas até $\delta / B=3 \%$, tornando-se em seguida ligeiramente mais pronunciado para $\mathrm{q}=100 \mathrm{kPa}$ (Figura 6.18). Como se observa na Figura 5.4, um maior nível de tensões implica maiores deformações no solo. Assim, é provável que a zona cisalhante no solo submetido à maior sobrecarga tenha abrangido uma região um pouco maior do maciço exterior, mobilizando, por conseguinte, maior alívio de carga. A variação da tensão por conta da sobrecarga não foi significativa em $\mathrm{x}_{\mathrm{i}} / \mathrm{B}=0,8$ (I5). Nessa distância, as deformações em ambos os casos devem decrescer até níveis próximos, resultando em zonas cisalhantes de extensão semelhante. 


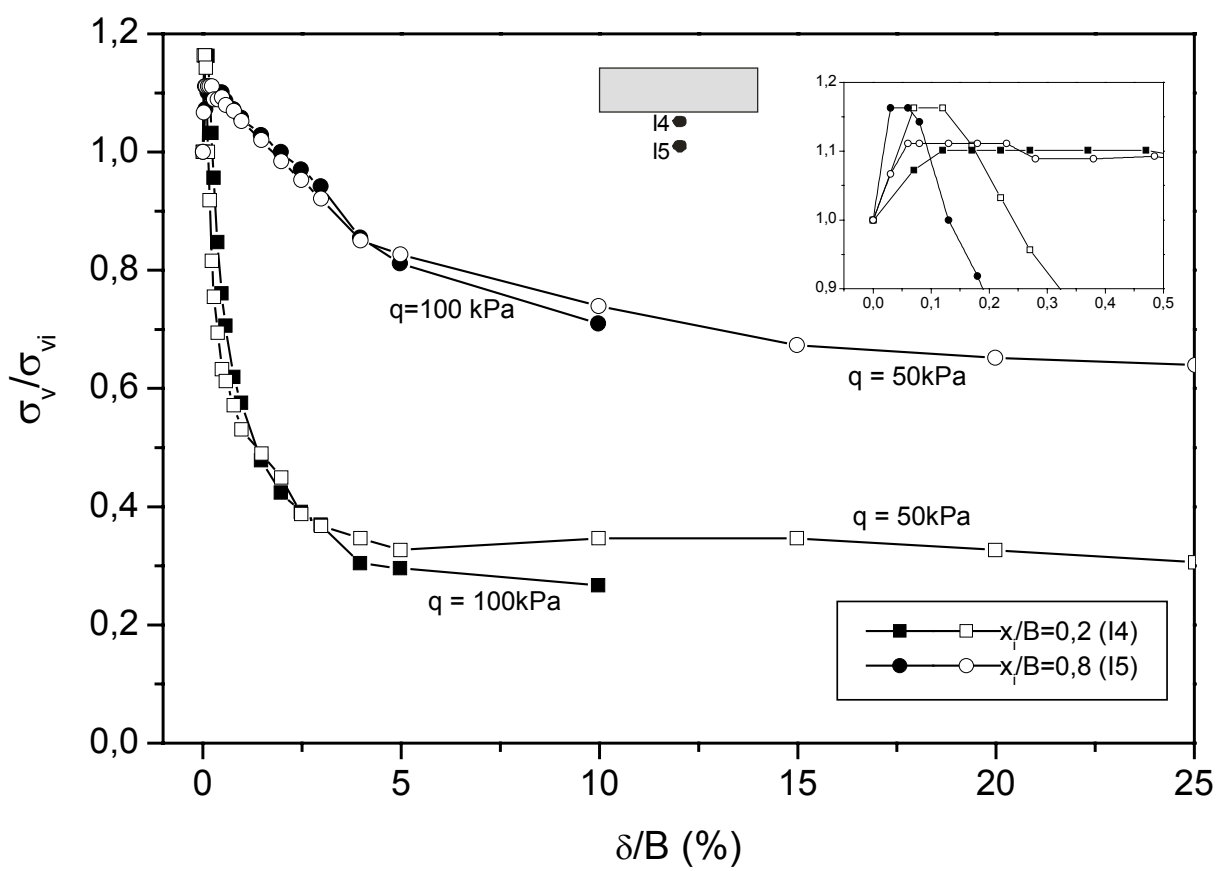

Figura 6.18. Influência da sobrecarga aplicada no comportamento da tensão vertical no exterior do alçapão retangular, na direção x; $\mathrm{D}_{\mathrm{r}}=100 \%$.

Em $\mathrm{y}_{\mathrm{i}} / \mathrm{B}=0,2$ (posição I6) o comportamento da tensão vertical com o deslocamento foi bastante semelhante para ambas as sobrecargas aplicadas, como se observa na Figura 6.19. A tensão vertical apresentou um crescimento inicial de aproximadamente $10 \%$, decrescendo em seguida e atingindo um patamar mínimo ligeiramente superior ao registrado em $\mathrm{x}_{\mathrm{i}} / \mathrm{B}=0,2$. Em $\mathrm{y}_{\mathrm{i}} / \mathrm{B}=0,8$ (posição $\mathrm{I7}$ ), a tensão vertical aumentou com os deslocamentos nas duas sobrecargas. Considerando que a zona cisalhante abrange uma menor região do maciço submetido a q $=100 \mathrm{kPa}$ por causa da menor dilatação do solo, a mesma pode ter atingido uma posição mais próxima de $\mathrm{y}_{\mathrm{i}} / \mathrm{B}=0,8$ em comparação com o ocorrido no maciço com $50 \mathrm{kPa}$ de sobrecarga, transferindo mais a carga proveniente do centro do alçapão para a região em questão. 


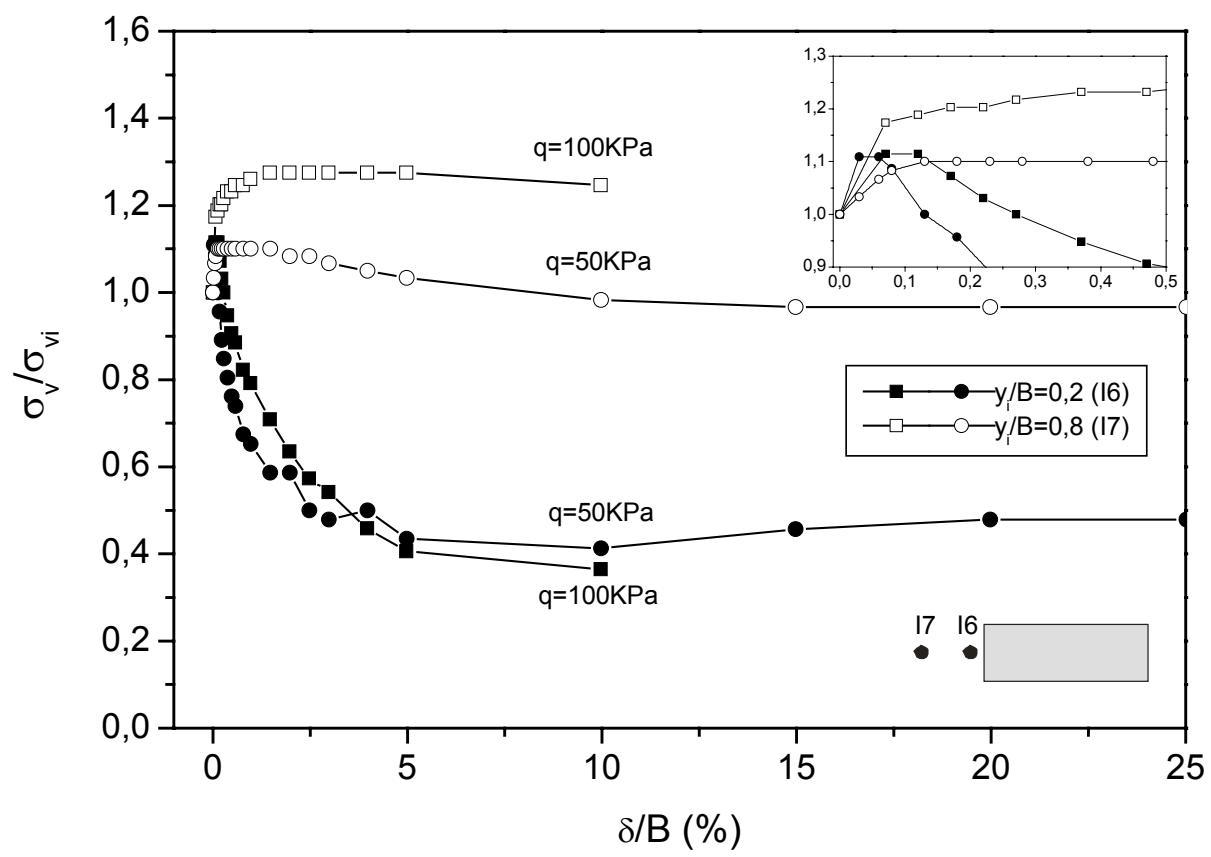

Figura 6.19. Influência do confinamento do solo no comportamento da tensão vertical no exterior do alçapão, na direção y; $D_{r}=100 \%$.

\subsubsection{Influência da Geometria do Alçapão}

A Figura 6.20 compara a curva de arqueamento obtida no centro do alçapão de formato quadrado $\left(\mathrm{L}_{\mathrm{v}} / \mathrm{B}=1\right)$ com a curva obtida no centro do alçapão retangular $\left(\mathrm{L}_{\mathrm{v}} / \mathrm{B}=3\right)$. Os dados são referentes a ensaios executados com $\mathrm{D}_{\mathrm{r}}=100 \% \mathrm{e}$ sobrecarga de $100 \mathrm{kPa}$. As medidas de tensão são referentes $\mathrm{H}_{\mathrm{e}} / \mathrm{B}=0 . \mathrm{O}$ gráfico também traz resultados de um ensaio de arqueamento realizado por Viana (2003), com sobrecarga de $100 \mathrm{kPa}$ e $\mathrm{D}_{\mathrm{r}}=80 \%$. O modelo foi construído com areia pura e $\mathrm{H} / \mathrm{B}=5,5$ (praticamente a mesma razão geométrica utilizada nos ensaios do presente trabalho) e contou com um alçapão com $600 \mathrm{~mm}$ de comprimento e $100 \mathrm{~mm}$ de largura $\left(\mathrm{L}_{\mathrm{v}} / \mathrm{B}=6\right)$. O ensaio foi levado até um deslocamento máximo de $\delta / \mathrm{B}=0,3 \%$. Assume-se que o uso de um material com densidade relativa ligeiramente menor não invalida a comparação com os demais resultados, uma vez que o solo pode ser classificado como compacto em todos os casos. Observa-se que a variação da tensão é praticamente análoga nas três situações. Com efeito, os resultados das tensões medidas nas posições I1, I2 e I3 (Figura 6.5) mostram claramente que o contorno do alçapão não exerce influência significativa na redistribuição da tensão em seu 
interior. O mesmo é sugerido pelos resultados da Figura 6.21, a qual exibe a variação das tensões em $\mathrm{H}_{\mathrm{e}} / \mathrm{B}=0,3$ sobre o centro de alçapões com $\mathrm{L}_{\mathrm{v}} / \mathrm{B}=1$ e 3 , em ensaios com $D_{r}=100 \%$ e q $=100 \mathrm{kPa}$.

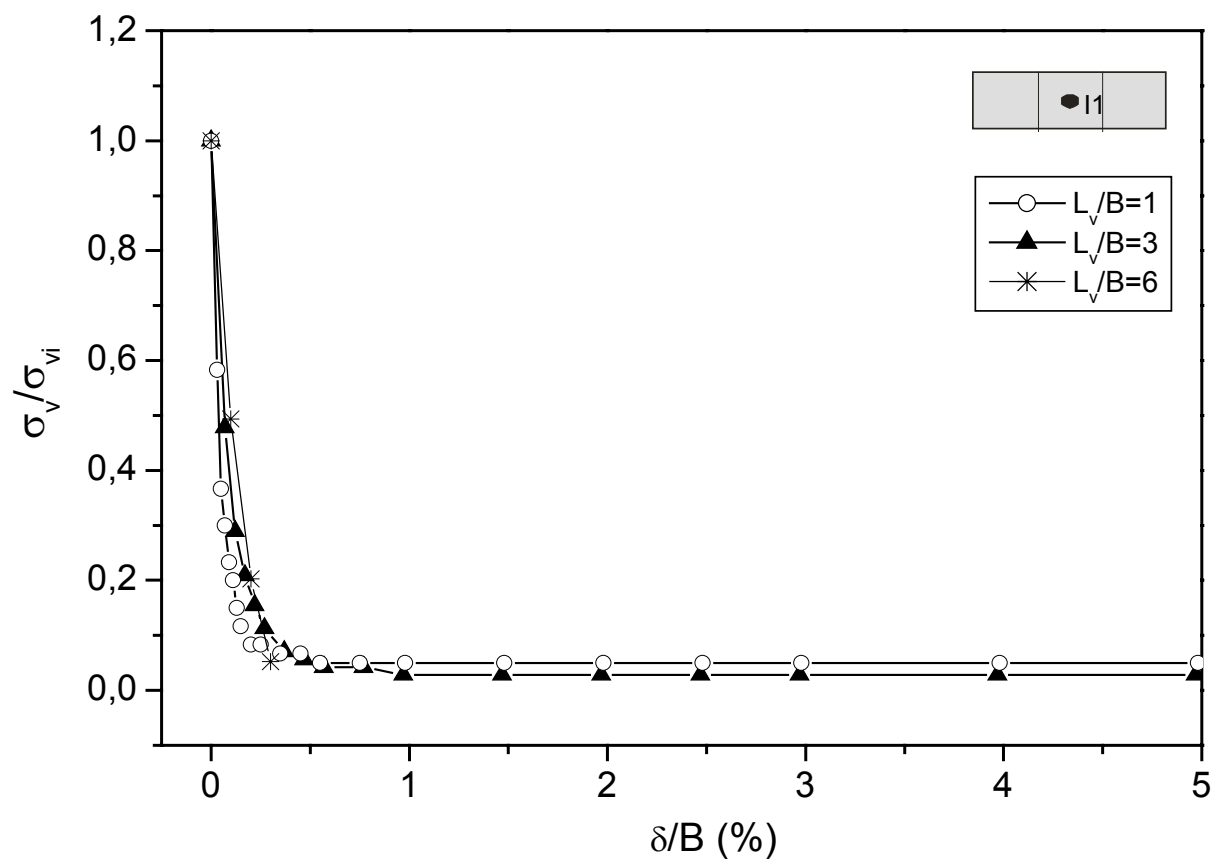

Figura 6.20. Comparação do comportamento da tensão vertical no interior de alçapões com a mesma largura e comprimentos diferentes. $\mathrm{H}_{\mathrm{e}} / \mathrm{B}=0$.

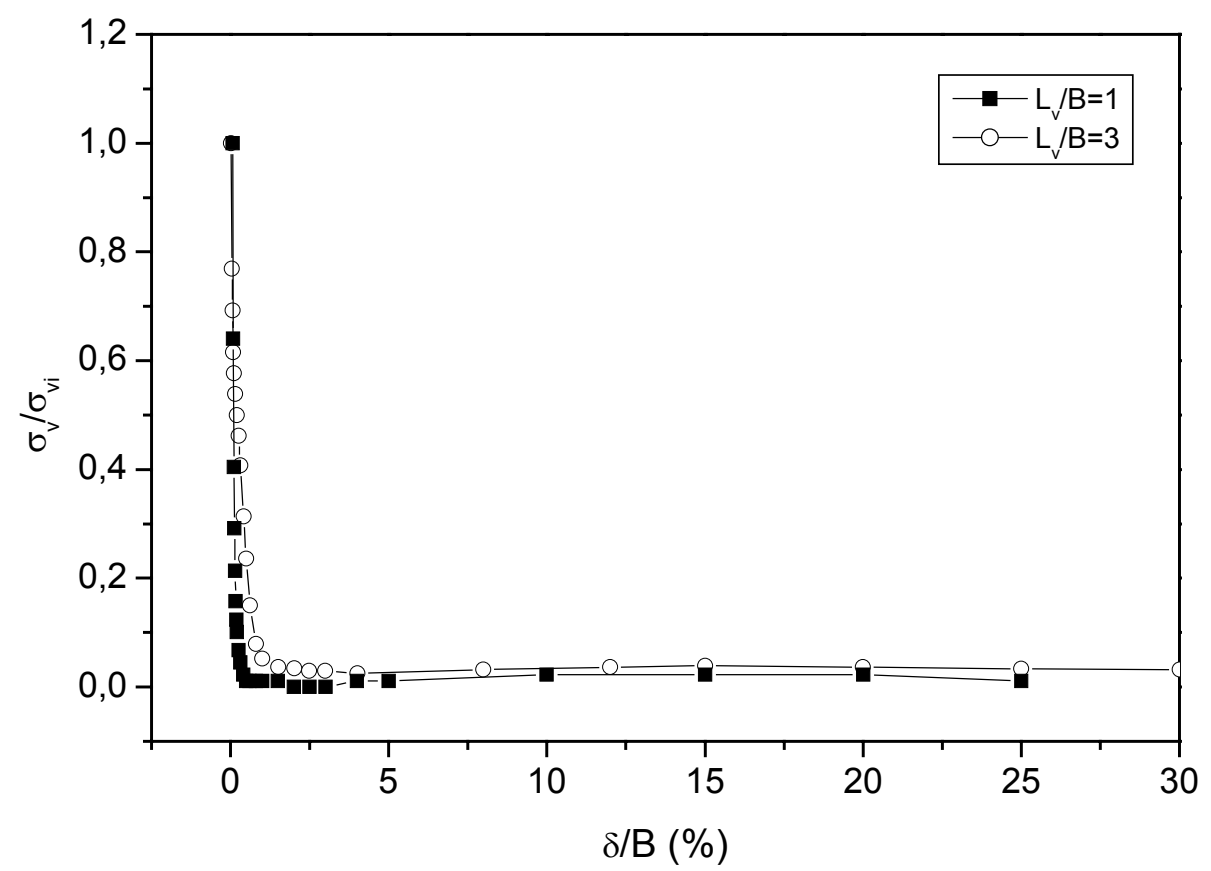

Figura 6.21. Comparação do comportamento da tensão vertical no interior de alçapões com a mesma largura e comprimentos diferentes. $\mathrm{H}_{\mathrm{e}} / \mathrm{B}=0,3$. 
Baseando-se apenas em medições de carga no interior do alçapão, alguns trabalhos disponíveis na literatura afirmam erroneamente que o arqueamento ativo essencialmente independe do formato da estrutura (Vardoulakis et al. 1981, Koutsabeloulis e Griffiths 1989). A Figura 6.22 compara o comportamento da tensão vertical em $\mathrm{x}_{\mathrm{i}} / \mathrm{B}=0,2$ e 0,8 (posições I4 e I5, respectivamente), obtido com os dois alçapões utilizados no presente trabalho. $\mathrm{Em} \mathrm{x}_{\mathrm{i}} / \mathrm{B}=0,2$ (posição I4), a diferença entre ambos os resultados é muito pequena. Porém, em $\mathrm{x}_{\mathrm{i}} / \mathrm{B}=0,8$ (posição I5), a tensão vertical adjacente ao alçapão retangular decresce mais.

Os resultados discutidos no Capítulo 5 indicam que a condição de estado plano de deformação pode ser assumida em uma determinada região do centro de um alçapão retangular com $\mathrm{L}_{\mathrm{v}} / \mathrm{B}=2,4$. Esses resultados permitem inferir que a mesma

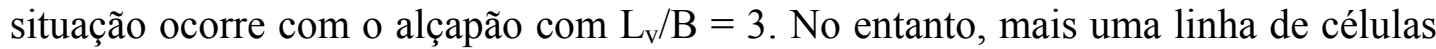
paralelas à I4 e I5 seria necessária para confirmação através da medição das tensões verticais externas. Por outro lado, pode-se assegurar que as dimensões do alçapão com $\mathrm{L}_{\mathrm{v}} / \mathrm{B}=1$ não permitem o desenvolvimento de uma condição de deformação plana sobre o mesmo.

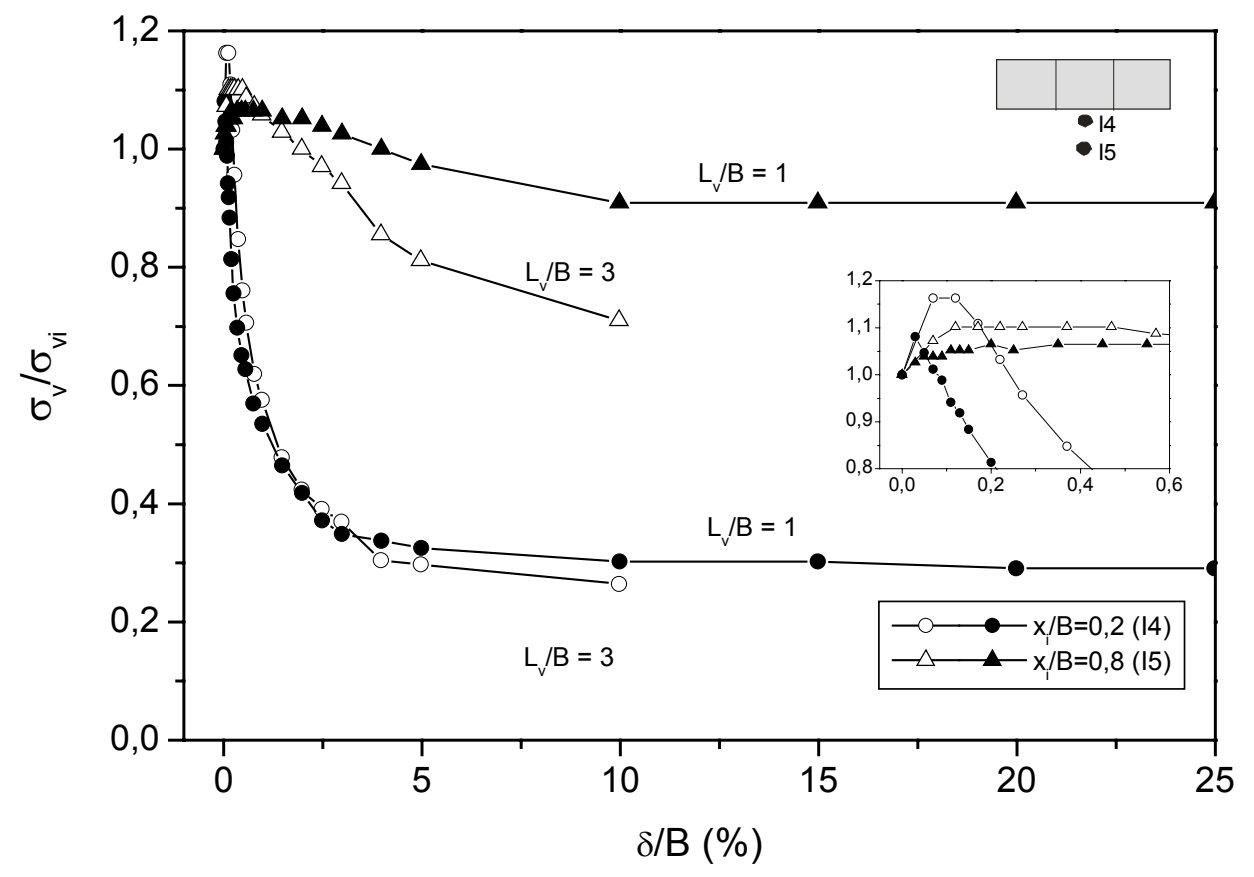

Figura 6.22. Comparação do comportamento da tensão vertical no exterior do alçapão retangular e do quadrado, na região do maior lado. 


\subsubsection{Previsão das Curvas de Arqueamento com o Método de Gill (1967)}

Uma previsão das curvas de arqueamento referentes à posição I1 (centro do alçapão) é realizada nesta seção com o auxílio do método empírico de Gill (1967), descrito no item 2.3.1. De maneira a determinar as constantes empíricas $A_{o}$ e n, a Figura 6.23 exibe a relação entre o fator de arqueamento do solo (A), calculado como (1 - $\left.\sigma_{\mathrm{v}} / \sigma_{\mathrm{vi}}\right)$, e o parâmetro $\mathrm{R}$, dado através da expressão (6.7). R relaciona a rigidez da estrutura, representada pela razão $\sigma_{\mathrm{vi}} / \delta$, com a deformabilidade do solo, dada através do módulo de compressão confinada $\mathrm{M}_{\mathrm{s}}$. $\mathrm{R}$ é proporcional à geometria do alçapão e à altura de cobertura de solo. A calibração inclui os dois tipos de alçapão utilizados. $\mathrm{O}$ ajuste aos pontos experimentais forneceu $\mathrm{A}_{0}=0,955$ e $\mathrm{n}=0,025$.

$\mathrm{R}=\mathrm{A}_{\mathrm{g}}\left(\frac{\mathrm{M}_{\mathrm{s}}}{\sigma_{\mathrm{v}}}\right) \delta$

onde: $A_{g}=$ fator geométrico $=\left(S / A_{s}\right) \cdot(H / B) ; S=2\left(L_{v}+B\right) ; A_{s}=L_{v} B ; M_{s}=$ módulo de compressão confinada do solo.

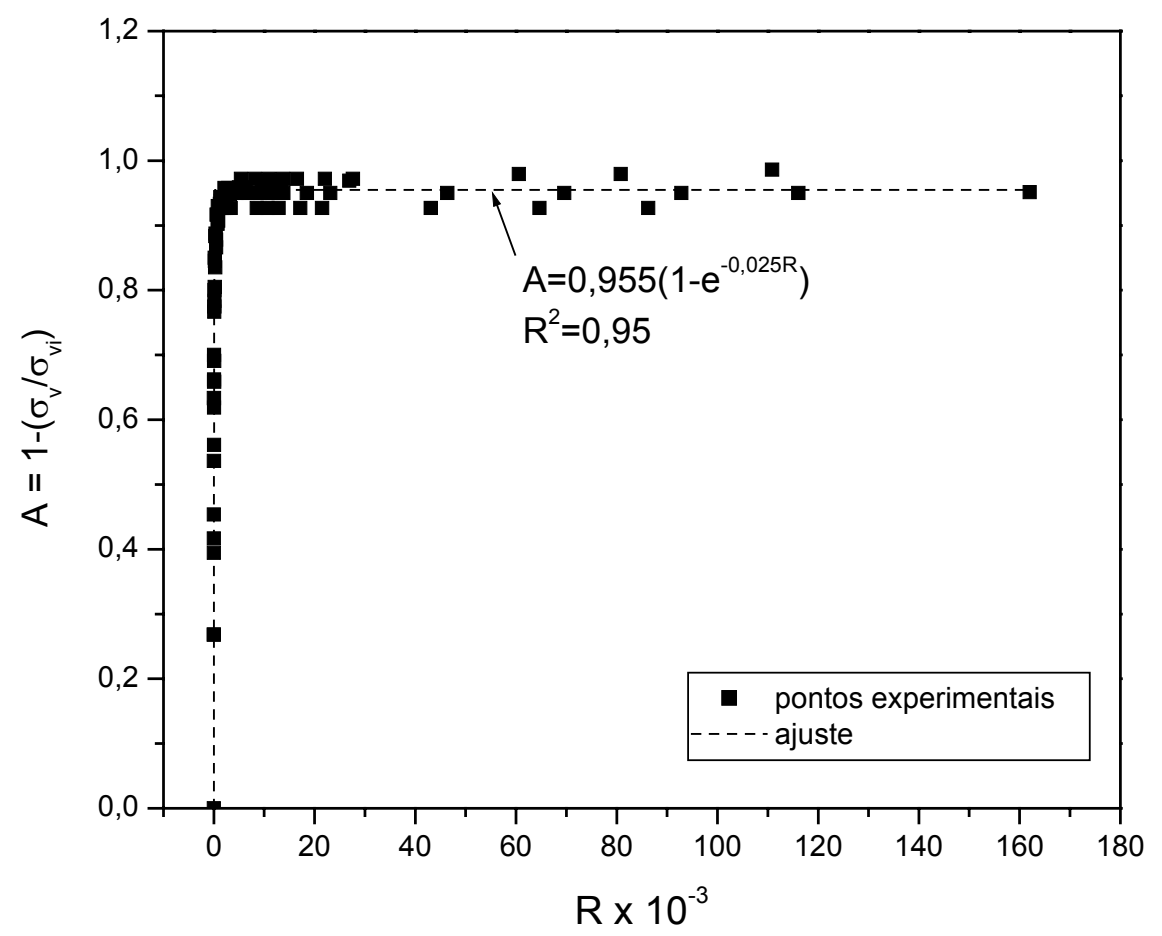

Figura 6.23. Calibração do modelo para obtenção dos parâmetros $\mathrm{A}_{0}$ e n. 
A razão $\sigma_{\mathrm{v}} / \sigma_{\mathrm{vi}}$ foi estimada através da equação (6.8). O módulo de compressão confinada foi calculado a partir dos valores de $E_{50} \mathrm{e} v_{\mathrm{s}}$ listados na Tabela 4.4, utilizando a expressão (6.9). As Figuras 6.24 a 6.27 apresentam as previsões obtidas com o método e as compara com as curvas experimentais correspondentes.

As curvas previstas apresentam trecho inicial menos inclinado, com módulo de arqueamento $\mathrm{M}_{\mathrm{a}}$ aproximadamente duas a quatro vezes menor que o da curva experimental correspondente. $\mathrm{O}$ trecho final previsto, no entanto, é bastante semelhante ao experimental, com destaque à estimativa para o alçapão com $\mathrm{L}_{\mathrm{v}} / \mathrm{B}=1$. Para $\delta / B$ de pequena magnitude, o método fornece estimativas conservadoras da tensão. A solução mostrou-se bastante adequada para a determinação da tensão mínima sobre a estrutura $\left(\sigma_{\mathrm{va}}\right)$.

$$
\begin{aligned}
& \frac{\sigma_{\mathrm{v}}}{\sigma_{\mathrm{vi}}}=1-\mathrm{A}_{0}\left(1-\exp \left(-\mathrm{n} \cdot \mathrm{A}_{\mathrm{g}} \cdot \frac{\mathrm{M}_{\mathrm{s}}}{\mathrm{q}+\gamma \mathrm{H}} \delta\right)\right) \\
& \mathrm{M}_{\mathrm{s}}=\frac{\mathrm{E}_{\mathrm{s}}\left(1-\mathrm{v}_{\mathrm{s}}\right)}{(1+v)(1-2 v)}
\end{aligned}
$$

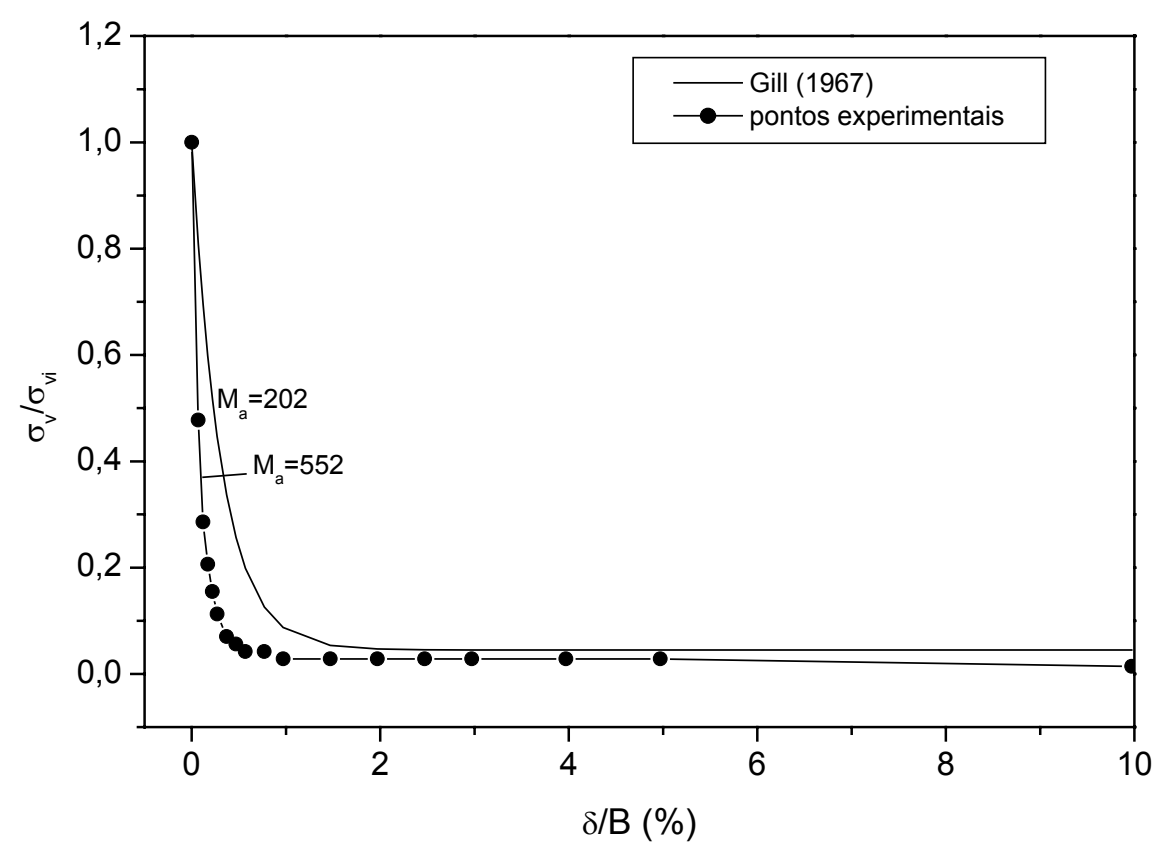

Figura 6.24. Previsão da curva de arqueamento correspondente à posição $\mathrm{I} 1 . \mathrm{H}_{\mathrm{e}} / \mathrm{B}=$ $0 ; \mathrm{L}_{\mathrm{v}} / \mathrm{B}=3 ; \mathrm{D}_{\mathrm{r}}=100 \% ; \mathrm{q}=100 \mathrm{kPa}$. 


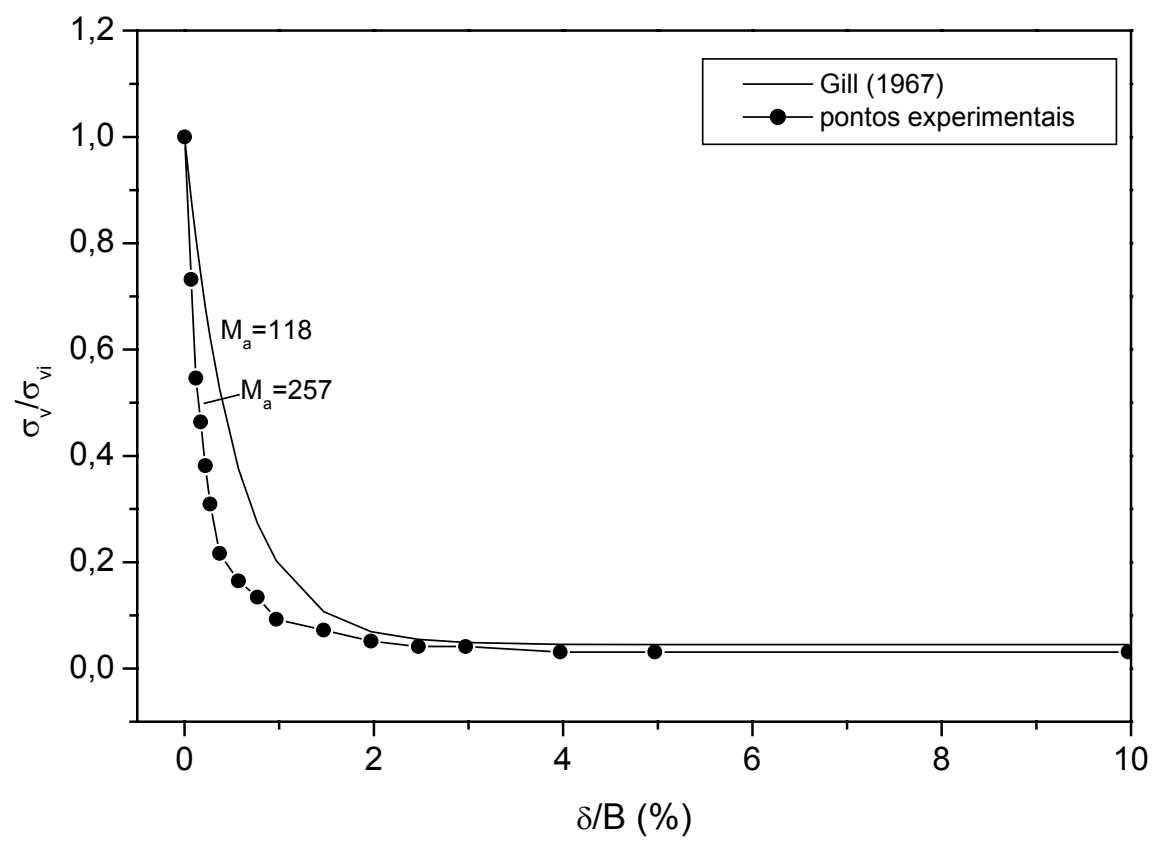

Figura 6.25. Previsão da curva de arqueamento correspondente à posição $\mathrm{I} 1 . \mathrm{H}_{\mathrm{e}} / \mathrm{B}=$ $0 ; \mathrm{L}_{\mathrm{v}} / \mathrm{B}=3 ; \mathrm{D}_{\mathrm{r}}=50 \% ; \mathrm{q}=100 \mathrm{kPa}$.

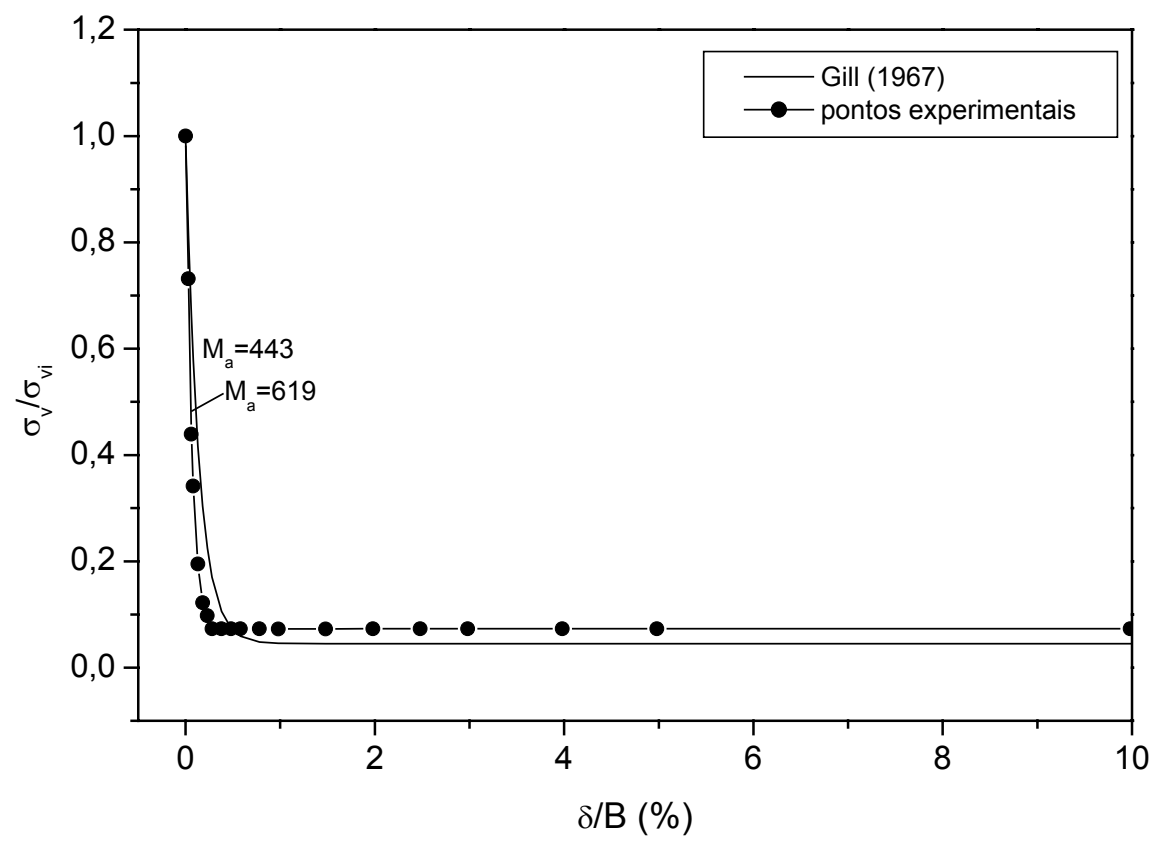

Figura 6.26. Previsão da curva de arqueamento correspondente à posição $\mathrm{I} 1 . \mathrm{H}_{\mathrm{e}} / \mathrm{B}=$ $0 ; \mathrm{L}_{\mathrm{v}} / \mathrm{B}=3 ; \mathrm{D}_{\mathrm{r}}=100 \% ; \mathrm{q}=50 \mathrm{kPa}$. 


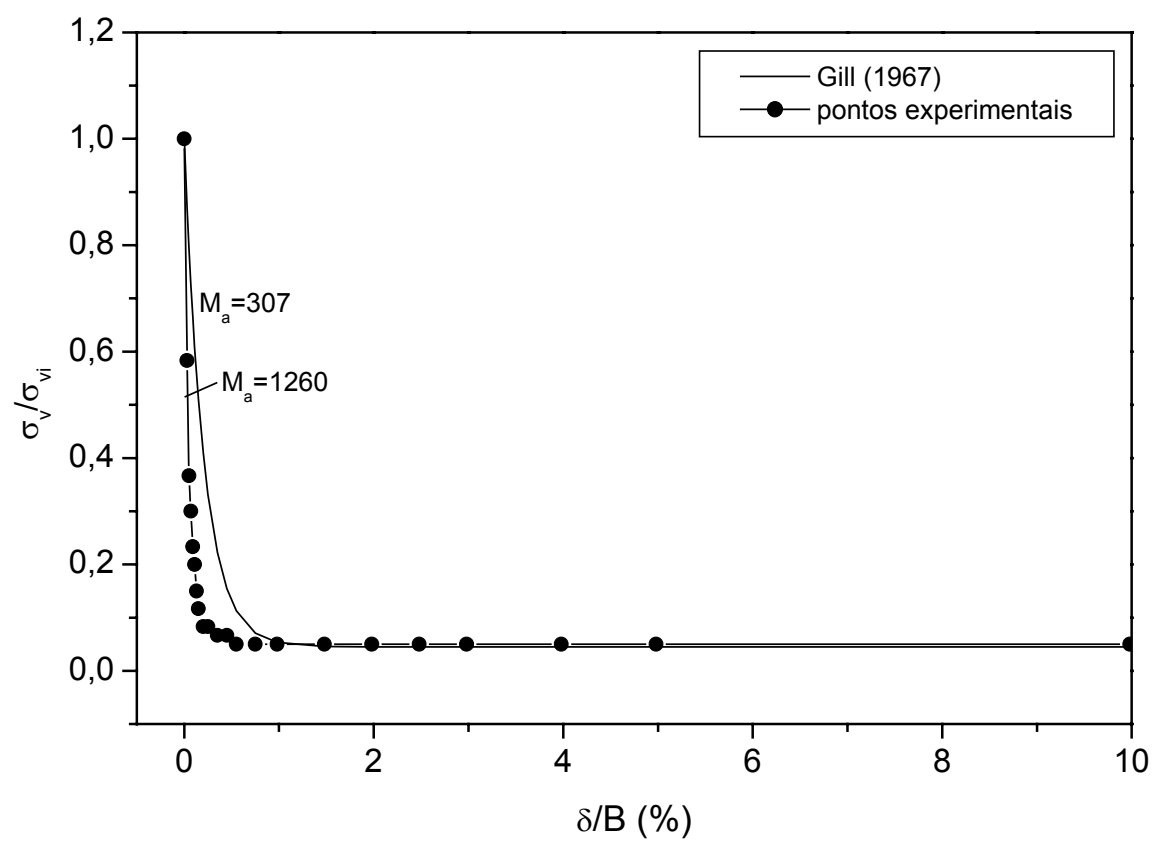

Figura 6.27. Previsão da curva de arqueamento correspondente à posição $\mathrm{I} 1 . \mathrm{H}_{\mathrm{e}} / \mathrm{B}=$ $0, \mathrm{~L}_{\mathrm{v}} / \mathrm{B}=1 ; \mathrm{D}_{\mathrm{r}}=100 \% ; \mathrm{q}=100 \mathrm{kPa}$.

\subsubsection{Previsão da Tensão Sobre o Alçapão}

Os resultados dos modelos analíticos da Teoria do Silo, Bierbaumer (1913), Gill (1967), Iglesia (1991) são comparados com os resultados experimentais nesta seção. Um método simplificado, denominado de método do arco, utilizando a proposição de Villard et al. (2000) modificada (item 6.3.2) também é apresentado.

Uma das principais diferenças entre os métodos analíticos recai sobre o valor de $\mathrm{k}$ a ser adotado. $\mathrm{O}$ coeficiente de empuxo ativo $\mathrm{K}_{\mathrm{a}}$ é comumente utilizado na fórmula da Teoria do Silo (Young e Trott 1984), apesar do alerta que diversos autores fazem sobre o erro que se introduz com o uso desse parâmetro por causa do atrito nas superfícies de ruptura assumidas (Ladanyi e Hoyaux 1969, Handy 1985). Por esse motivo, o coeficiente proposto por Krynine (1945) $\left(\mathrm{k}_{\mathrm{kr}}\right)$ é adotado nas soluções que utilizam o coeficiente de empuxo. Com efeito, Iglesia et al. (1991) recomendam a utilização de $\mathrm{k}_{\mathrm{kr}}$ em seu modelo.

O método de Iglesia et al. (1991) foi modificado para levar em consideração a sobrecarga superficial (q), sendo dado através da expressão (6.10). O método do arco 
determina a tensão que atinge o alçapão como a soma do peso do solo abaixo do arco com a tensão sobre o topo do arco, calculada através da Teoria do Silo. A expressão utilizada nos cálculos é dada em (6.11), considerando o arco como uma semi-elípse. Os respectivos valores de $\phi$ utilizados foram obtidos da Tabela 4.4 e majorados em 10\% para levar em conta o estado plano de deformação (Zornberg et al. 1998).

$\sigma_{\mathrm{va}}=\frac{\mathrm{k}_{\mathrm{kr}} \mathrm{B}(\gamma \mathrm{H}+\mathrm{q})}{2 \cot g \phi \mathrm{H}+\mathrm{k}_{\mathrm{kr}} \mathrm{B}}+\frac{\gamma \mathrm{B} \operatorname{cotg} \phi}{6}$

$\sigma_{\mathrm{va}}=\sigma_{\mathrm{zd}}+\frac{\gamma \pi \mathrm{h}}{4}$

onde: $\sigma_{\mathrm{zd}}=$ tensão vertical sobre o arco (equação 6.2 ); $\mathrm{h}=$ altura do arco (equação $6.5)$.

A Tabela 6.2 sumariza os resultados analíticos obtidos e os compara com os resultados experimentais. As soluções da Teoria do Silo, Gill (1967) e Iglesia (1991) forneceram valores 1,2 a 2 vezes maiores que os experimentais para $\mathrm{q}=100 \mathrm{kPa}$. Para $\mathrm{q}=50 \mathrm{kPa}$, os resultados obtidos com os métodos de Gill (1967) e Iglesia (1991) foram 25 e 40\% inferiores ao experimental, respectivamente. Já o método de Bierbaumer (1913) gerou resultados muito subestimados de $\sigma_{\mathrm{va}}$ em todas as condições investigadas. A concepção desse método é extremamente simplificada, baseando-se apenas na hipótese de que a tensão sobre o alçapão é proveniente do peso de um elemento de solo representado por um triângulo isósceles com ângulo do vértice central igual a $2 \phi$. Não há considerações, por exemplo, sobre o coeficiente de empuxo lateral, profundidade ou presença de eventuais sobrecargas superficiais. De forma geral, a solução que gerou resultados mais próximos dos experimentos foi o método do arco, seguido de Iglesia (1999), cuja concepção também é fundamentada na formação de um arco estrutural sobre o alçapão. 
Tabela 6.2. Comparação entre as soluções analíticas e os resultados experimentais

\begin{tabular}{ccccccccc}
\cline { 3 - 8 } & & \multicolumn{6}{c}{$\sigma_{\mathrm{va}}(\mathrm{kPa})$} \\
\hline $\begin{array}{c}\mathrm{D}_{\mathrm{r}} \\
(\%)\end{array}$ & $\begin{array}{c}\mathrm{q} \\
(\mathrm{kPa})\end{array}$ & $\mathrm{L}_{\mathrm{v}} / \mathrm{B}$ & $\begin{array}{c}\text { Resultado } \\
\text { experi- } \\
\text { mental }\end{array}$ & $\begin{array}{c}\text { Teoria } \\
\text { do silo }\end{array}$ & $\begin{array}{c}\text { Bierbau- } \\
\text { mer } \\
(1913)\end{array}$ & $\begin{array}{c}\text { Gill } \\
(1967)\end{array}$ & $\begin{array}{c}\text { Iglesia } \\
(1991)\end{array}$ & $\begin{array}{c}\text { método } \\
\text { do arco }\end{array}$ \\
\hline 100 & 100 & 3 & 3 & 4,8 & 0,5 & 4,8 & 3,5 & 2,9 \\
50 & 100 & 3 & 2,5 & 4,2 & 0,4 & 5,1 & 3,5 & 2,1 \\
100 & 50 & 3 & 3,5 & 3,6 & 0,5 & 2,6 & 2,1 & 2,9 \\
100 & 100 & 1 & 4 & 4,8 & 0,5 & 4,8 & 3,5 & 2,9 \\
\hline
\end{tabular}

\subsection{ARQUEAMENTO PASSIVO}

\subsubsection{Redistribuição de Tensões no Interior do Alçapão}

A Figura 6.28 apresenta a variação de $\sigma_{\mathrm{v}} \operatorname{com} \delta / \mathrm{B}$, medida na superfície do alçapão na posição central I1, bem como a 0,7 e a 1,3B de distância do centro (posições $\mathrm{I} 2$ e $\mathrm{I} 3$, respectivamente). Os dados foram obtidos com o alçapão de $300 \times 100 \mathrm{~mm}\left(\mathrm{~L}_{\mathrm{v}} / \mathrm{B}\right.$ $=3)$, movimentando-se no maciço compacto $\left(\mathrm{D}_{\mathrm{r}}=100 \%\right)$ sujeito a uma sobrecarga de $100 \mathrm{kPa}$. O deslocamento $\delta$ possui sinal negativo para indicar que a estrutura está sendo movimentada em direção à massa de solo. Ao final da translação, a tensão vertical nas posições I1 e I2 é superior ao triplo da tensão inicial. Já na extremidade do alçapão (posição I3), este crescimento é ainda mais acentuado em comparação com o verificado nas outras duas posições mencionadas, com $\sigma_{\mathrm{v}}$ aumentando quase seis vezes, efeito decorrente da maior proximidade da zona cisalhante formada na massa de solo, que parte das arestas do alçapão.

O efeito da movimentação do alçapão na redistribuição das tensões na massa de solo sobre a estrutura é bastante acentuado. Como se observa na Figura 6.29, a qual apresenta a variação de $\sigma_{\mathrm{v}}$ em um perfil vertical sobre I1, um deslocamento relativo máximo um pouco superior a $0,6 \%$ foi capaz de interferir no estado de tensões até alturas maiores que 2B. Assim como no caso ativo, o efeito do arqueamento diminui com a altura, revelando-se já bastante reduzido em $\mathrm{H}_{\mathrm{e}} / \mathbf{B}=1,4$. A variação é muito pequena em $\mathrm{H}_{\mathrm{e}} / \mathrm{B}=2$, e quase imperceptível a partir de então, 
sugerindo que o PIR está localizado entre $\mathrm{H}_{\mathrm{e}} / \mathrm{B}=2$ e $3 . \mathrm{M}_{\mathrm{A}}$ é igual a $750 \mathrm{em} \mathrm{H}_{\mathrm{e}} / \mathrm{B}=$ 0 .

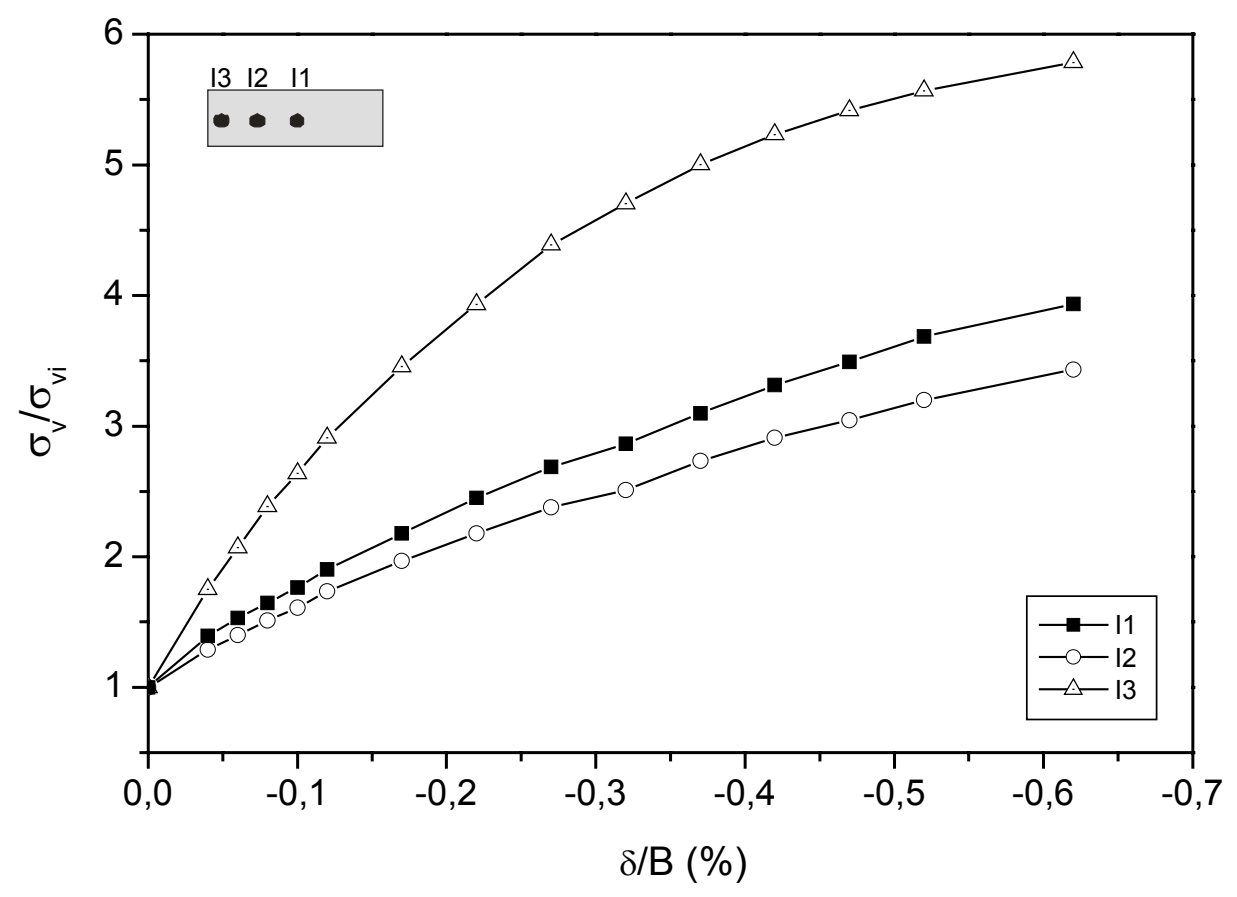

Figura 6.28. Variação da tensão vertical na superfície do alçapão retangular em arqueamento passivo; $\mathrm{D}_{\mathrm{r}}=100 \% ; \mathrm{q}=100 \mathrm{kPa}$.

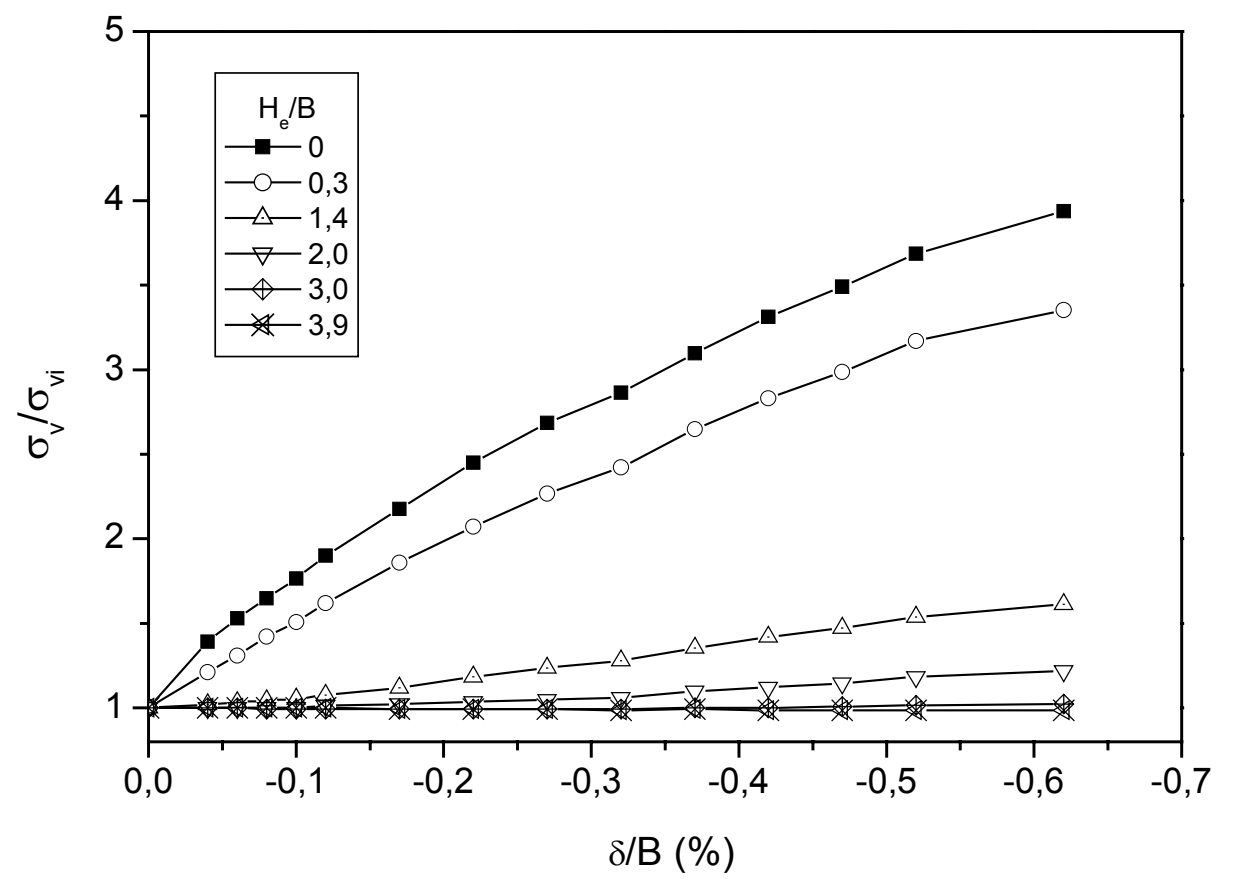

Figura 6.29. Variação da tensão vertical em um perfil vertical no centro do alçapão retangular em arqueamento passivo; $\mathrm{D}_{\mathrm{r}}=100 \% ; \mathrm{q}=100 \mathrm{kPa}$. 


\subsubsection{Redistribuição de Tensões no Exterior do Alçapão}

Os resultados dos ensaios revelaram que a movimentação passiva da estrutura enterrada modifica o campo de tensões de uma grande área do maciço em torno da instalação. A redistribuição das tensões na região adjacente ao maior lado do alçapão é apresentada na Figura 6.30. Em $\mathrm{x}_{\mathrm{i}} / \mathrm{B}=0,2$ e $\mathrm{H}_{\mathrm{e}} / \mathrm{B}=0$ (posição I4), observa-se um alívio marcante da tensão vertical. A tensão também decresce em $\mathrm{H}_{\mathrm{e}} / \mathrm{B}=0,3$, porém muito menos acentuadamente, uma vez que nesta altura o cisalhamento no solo é menor. A influência exercida pela movimentação da estrutura em $\mathrm{x}_{\mathrm{i}} / \mathrm{B}=0,8$ e $\mathrm{H}_{\mathrm{e}} / \mathrm{B}=$ 0 (posição I5) é comparativamente menor que em I4, com a tensão vertical reduzindo a aproximadamente metade de $\sigma_{\mathrm{vi}}$.

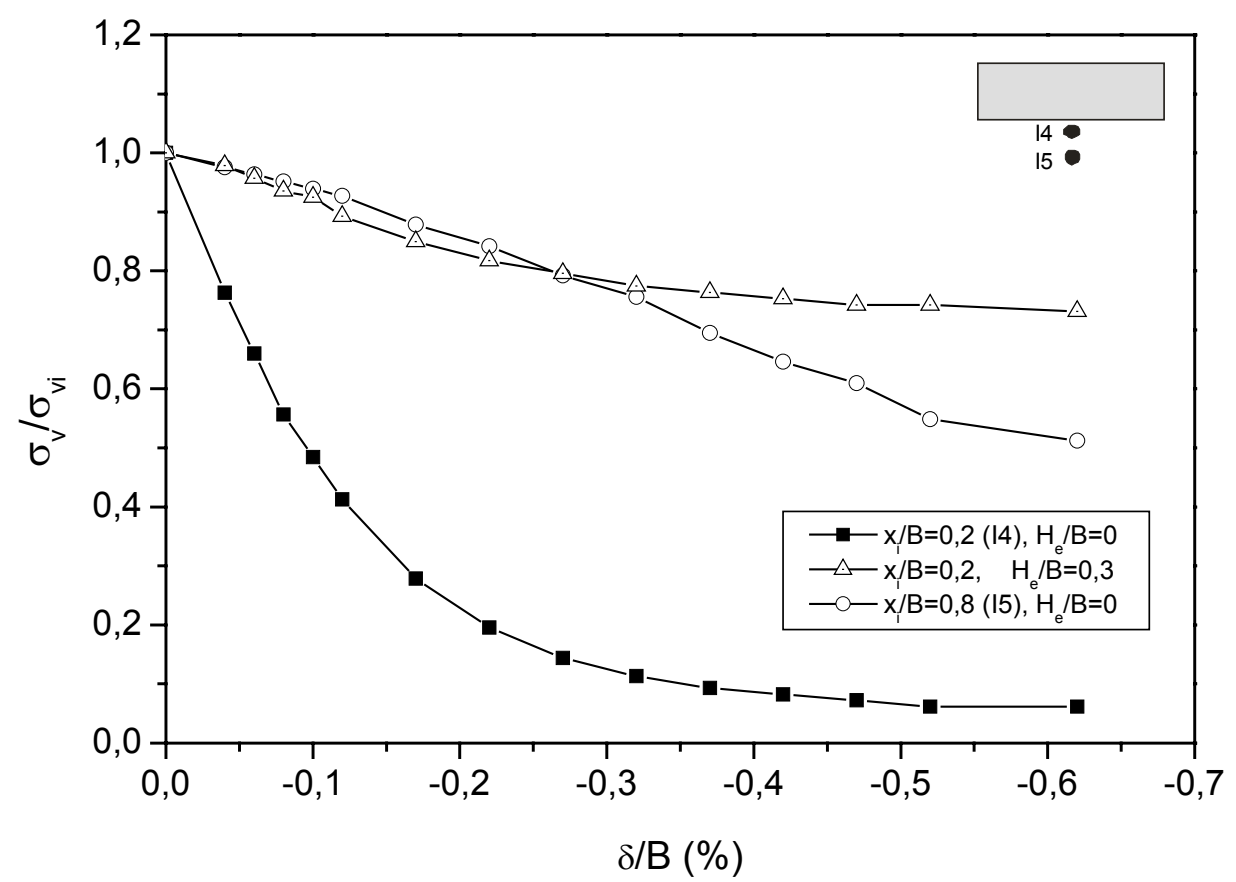

Figura 6.30. Variação de tensões no exterior do alçapão retangular em arqueamento passivo (região do maior lado); $\mathrm{D}_{\mathrm{r}}=100 \% ; \mathrm{q}=100 \mathrm{kPa}$.

$\mathrm{O}$ comportamento da tensão vertical em função do deslocamento entre $\mathrm{y}_{\mathrm{i}} / \mathrm{B}=$ 0,2 e 4,7 (posições I6 a I9) é apresentado na Figura 6.31. A mesma figura também traz a variação da tensão na altura $\mathrm{H}_{\mathrm{e}} / \mathrm{B}=0,3$ sobre I6. Apesar do formato retangular da estrutura, o decréscimo de tensão experimentado em $\mathrm{y}_{\mathrm{i}} / \mathrm{B}=0,2$ assemelha-se 
bastante ao obtido no lado oposto, na posição I4. A influência dos deslocamentos do alçapão é bastante reduzida em $\mathrm{y}_{\mathrm{i}} / \mathrm{B}=0,7$ (I7), não havendo praticamente nenhuma variação em $\mathrm{y}_{\mathrm{i}} / \mathrm{B}=2,7$ (I8).

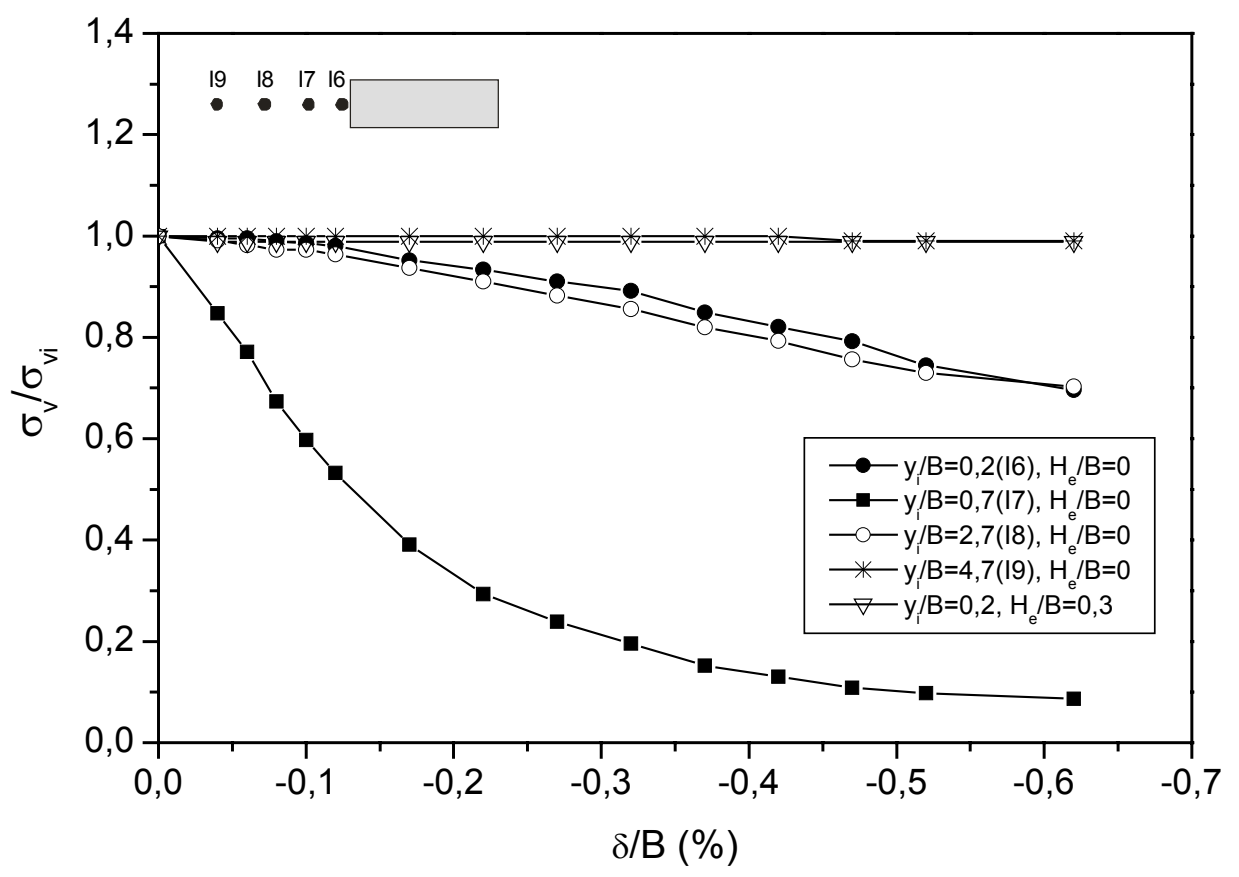

Figura 6.31. Variação de tensões no exterior do alçapão retangular em arqueamento passivo (região do menor lado); $\mathrm{D}_{\mathrm{r}}=100 \% ; \mathrm{q}=100 \mathrm{kPa}$.

\subsubsection{Distribuição Espacial das Tensões Verticais no Modelo}

A distribuição espacial da tensão vertical no alçapão $\operatorname{com} \mathrm{L}_{\mathrm{v}} / \mathrm{B}=3$ e em suas adjacências, obtida através dos dados coletados nas posições I4 a I9 no maciço compacto $\left(D_{r}=100 \%\right)$ sujeito a uma sobrecarga de $100 \mathrm{kPa}$, é apresentada na Figura 6.32. Os resultados referem-se às tensões despertadas $\mathrm{em}_{\mathrm{e}} / \mathrm{B}=0$ e com $\delta / \mathrm{B}=0,06$ e $0,27 \%$, sendo reproduzidos simetricamente segundo o eixo vertical do modelo. No eixo x (Figura 6.32a), as maiores variações de tensão ocorrem no centro e próximo às extremidades do alçapão. Para $\delta / B=0,27 \%, \sigma_{v}$ aumenta quase três vezes no centro e diminui a valores próximos de zero nas adjacências do alçapão. 


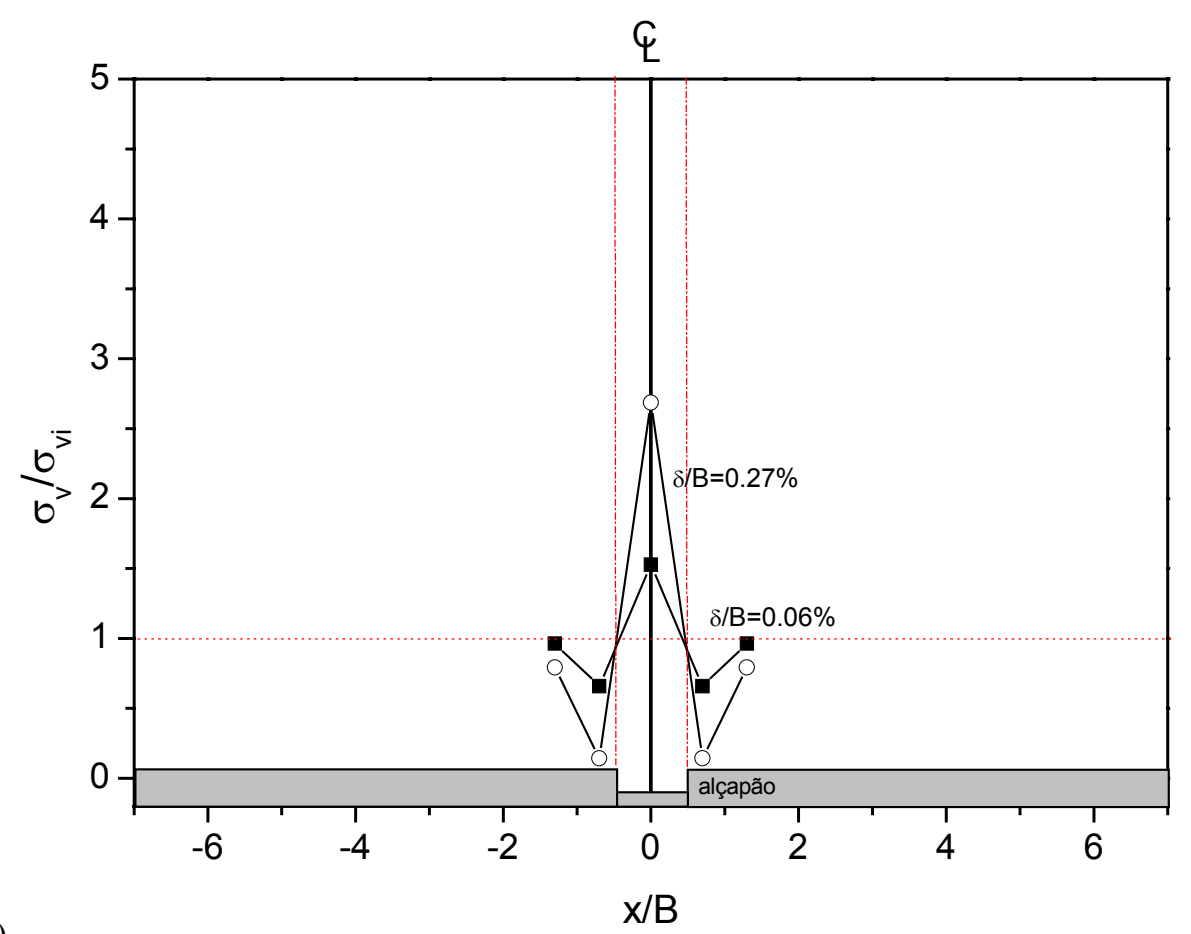

a)

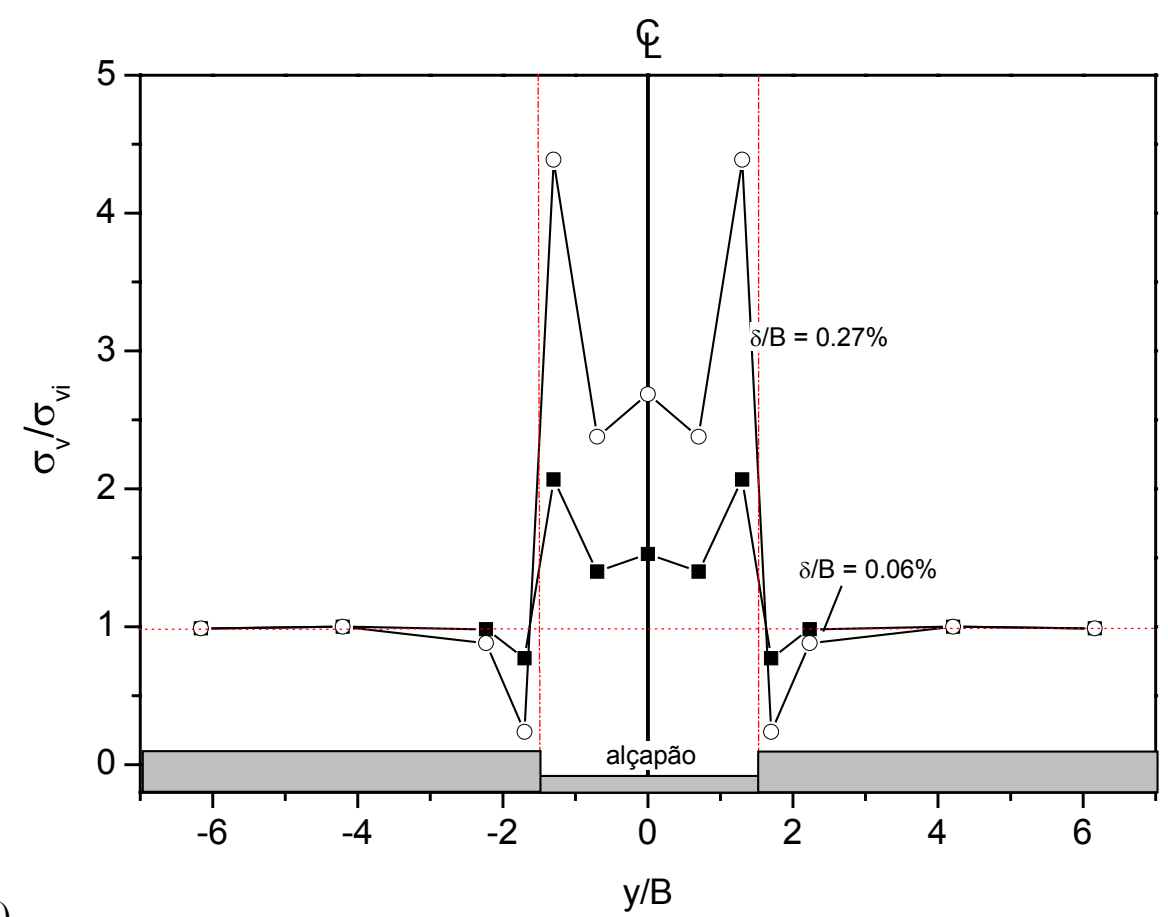

b)

Figura 6.32. Distribuição das tensões verticais na base do modelo $\left(\mathrm{H}_{\mathrm{e}} / \mathrm{B}=0\right) \mathrm{em}$ arqueamento passivo, utilizando o alçapão com $\mathrm{L}_{\mathrm{v}} / \mathrm{B}=3$ e maciço com $\mathrm{D}_{\mathrm{r}}=100 \% \mathrm{e}$ sobrecarga de $100 \mathrm{kPa}$. a) Direção x (transversal); b) direção y (longitudinal). 
Na direção y (Figura 6.32b), as maiores variações da tensão vertical ocorrem nas extremidades internas do alçapão. No lado interno foi registrado um aumento de $\sigma_{\mathrm{v}}$ superior a quatro vezes em $\delta / \mathrm{B}=0,27 \%$, em contraste com uma diminuição de $\sigma_{\mathrm{v}}$ até próximo de zero no exterior imediatamente próximo ao alçapão. Como mencionado anteriormente, isso ocorre porque essas regiões encontram-se mais próximas da zona do solo em processo de cisalhamento, a qual parte da extremidade do alçapão e se dirige à massa de solo externa segundo uma determinada inclinação. Diversos trabalhos experimentais relatam a propagação de superfícies cisalhantes em direção ao maciço de solo exterior com estruturas em arqueamento passivo, como discutido no Capítulo 2 (Meyerhof e Adams 1968, Walters e Thomas 1982, Dickin 1994, Bransby et al. 2002). A variação da tensão no centro do alçapão foi menor do que nas extremidades, apresentando um valor aproximadamente 2,5 vezes superior ao valor inicial. A partir de $\mathrm{y} / \mathrm{B}=4$, a influência da movimentação da estrutura no solo é praticamente inexistente, porém se torna bastante reduzida já em y/B =2,5.

\subsubsection{Influência da Geometria do Alçapão}

A Figura 6.33 compara a variação da tensão vertical medida na posição I1, com o alçapão com $\mathrm{L}_{\mathrm{v}} / \mathrm{B}=1$ (formato quadrado) e 3 (formato retangular). Os dados são referentes a ensaios executados com $D_{r}=100 \%$ e sobrecarga superficial de $100 \mathrm{kPa}$. Observa-se que o alçapão com $\mathrm{L}_{\mathrm{v}} / \mathrm{B}=1$ forneceu tensões um pouco maiores ao longo dos deslocamentos aplicados. Medidas de tensões ao longo de um perfil sobre I1 revelaram que o PIR atingiu uma altura $\mathrm{H}_{\mathrm{e}} / \mathrm{B}$ em torno de 4 com esse alçapão, próxima à obtida com o alçapão retangular.

A influência da geometria de estruturas enterradas pode ser analisada através do fator de forma $\mathrm{S}$, dado como a razão entre a tensão passiva máxima obtida com ancoragem de formato retangular ou quadrado $\left(\sigma_{\mathrm{vp}}\right)_{\mathrm{r}}$ e a tensão passiva máxima com ancoragem muito longa, ou contínua, $\left(\sigma_{\mathrm{vp}}\right)_{\mathrm{c}}$ (Frydman e Shaham 1989). Valores de $\mathrm{S}$ iguais a 1,34 e 1,26 foram obtidos para os alçapões com $L_{v} / B=1$ e 3 , respectivamente. Como os deslocamentos impostos nos ensaios não foram suficientes para que $\sigma_{\mathrm{v}}$ apresentasse estabilização ou um valor de pico, $\left(\sigma_{\mathrm{vp}}\right)_{\mathrm{r}}$ foi assumida igual à máxima tensão registrada. Seguindo a proposição de Murray e 
Gueddes (1987), que classificam uma estrutura submetida a arqueamento passivo como contínua a partir de $\mathrm{L}_{\mathrm{v}} / \mathrm{B}=10$, a extrapolação dos valores de $\left(\sigma_{\mathrm{vp}}\right)_{\mathrm{r}} /\left(\sigma_{\mathrm{vi}}\right)$ para um alçapão contínuo fornece $\left(\sigma_{\mathrm{vp}}\right)_{\mathrm{c}} / \sigma_{\mathrm{vi}}=2,1$.

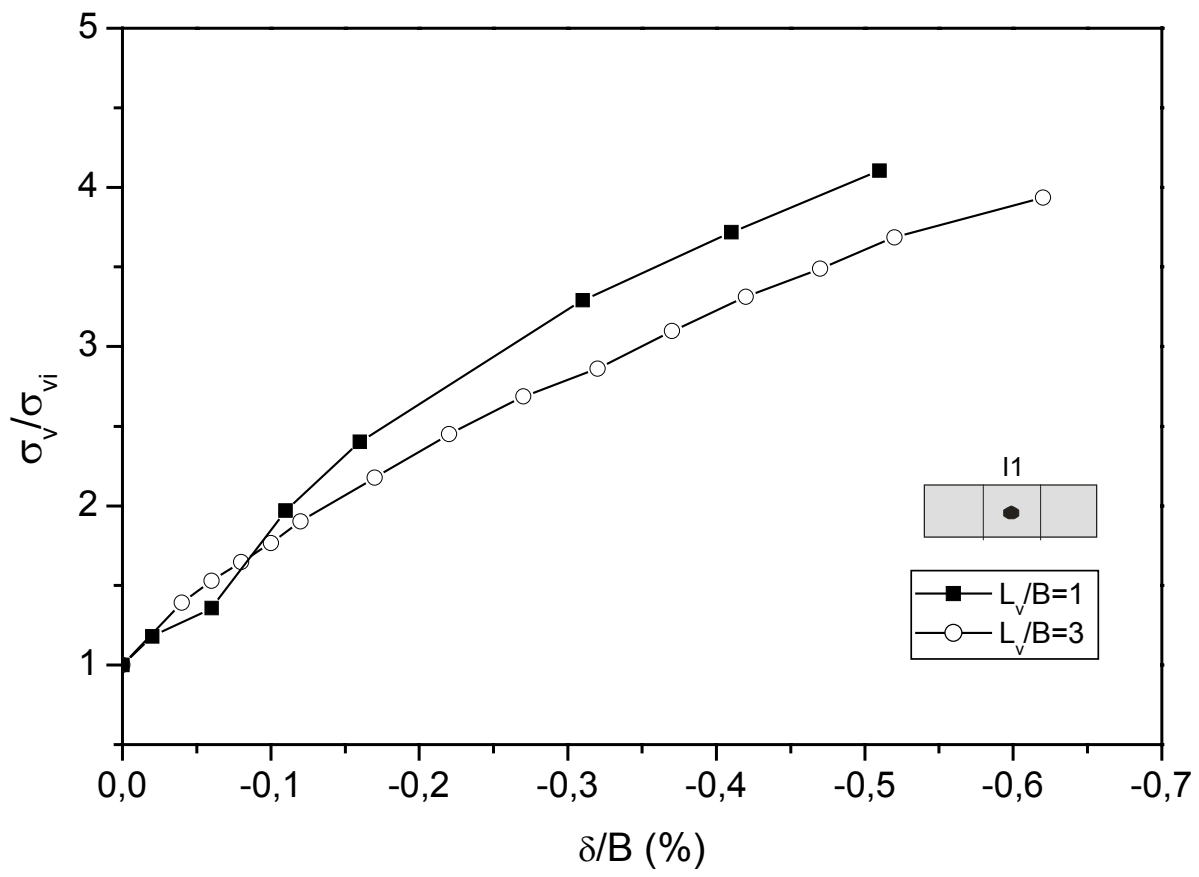

Figura 6.33. Comportamento da tensão no interior do alçapão retangular e do quadrado, em arqueamento passivo; $\mathrm{D}_{\mathrm{r}}=100 \% \mathrm{e} \mathrm{q}=100 \mathrm{kPa}$.

A Figura 6.34 compara os valores de $\mathrm{S}$ obtidos com valores determinados a partir de resultados de ensaios de arrancamento vertical de ancoragens rígidas em areia pura compacta, provenientes de fontes disponíveis na literatura (Murray e Geddes 1987, Dickin 1988). Linhas de tendência ajustadas aos dados também são exibidas na figura. $\mathrm{O}$ tratamento desses dados seguiu o mesmo procedimento adotado com os dados do presente trabalho. Observa-se que $\mathrm{S}$ apresenta uma relação crescente e não-linear com H/B, tornando-se menos variável com o aumento de H/B. $\mathrm{S}$ diminui com o aumento de $\mathrm{L}_{\mathrm{V}} / \mathrm{B}$, sendo máximo para estruturas de formato quadrado $\left(\mathrm{L}_{\mathrm{v}} / \mathrm{B}=1\right)$. Os dados de Murray e Geddes (1987) e Dickin (1988) sugerem que o formato da estrutura praticamente não exerce influência no comportamento do sistema a partir de $\mathrm{L}_{\mathrm{v}} / \mathrm{B}=5$. 
Os resultados obtidos na presente investigação concordam com os resultados provenientes das demais fontes, no sentido de que um maior fator de forma é associado ao alçapão de menor razão $\mathrm{L}_{\mathrm{v}} / \mathrm{B}$. Contudo, a variação de $\mathrm{S}$ com o formato da estrutura foi muito pequena em comparação com os resultados das outras investigações. Valores de $\mathrm{S}$ bastante inferiores aos limites definidos com os dados de Murray e Geddes (1987) e Dickin (1988) foram obtidos, principalmente para $\mathrm{L}_{\mathrm{v}} / \mathrm{B}=$ 1. Isto possivelmente ocorreu por causa do valor de $\left(\sigma_{\mathrm{vp}}\right)_{\mathrm{r}}$ utilizado. Curvas cargadeslocamento dos ensaios dos autores supra citados em material compacto apresentam trechos iniciais de formato semi-retilíneos muito próximos entre si, independentemente de $\mathrm{L}_{\mathrm{v}} / \mathrm{B}$. Em contraste, os trechos subseqüentes, associados a deslocamentos de maior magnitude da estrutura, são bastante distintos, fornecendo tensões maiores para razões $L_{v} / B$ menores. Esse comportamento é exemplificado na Figura 6.35 com os resultados de Dickin (1988) para H/B = 3. A comparação dessas curvas com as da Figura 6.33 sugere que essas últimas podem ser trechos iniciais e, caso $\delta$ fosse levado adiante, valores maiores de $\left(\sigma_{\mathrm{vp}}\right)_{\mathrm{r}}$ poderiam ser obtidos, os quais forneceriam, por conseguinte, valores de $\mathrm{S}$ de maior magnitude, principalmente para $\mathrm{L}_{\mathrm{v}} / \mathrm{B}=1$. A interrupção dos ensaios nos deslocamentos máximos indicados na Figura 6.33 deveu-se a limitações das células de tensão utilizadas.

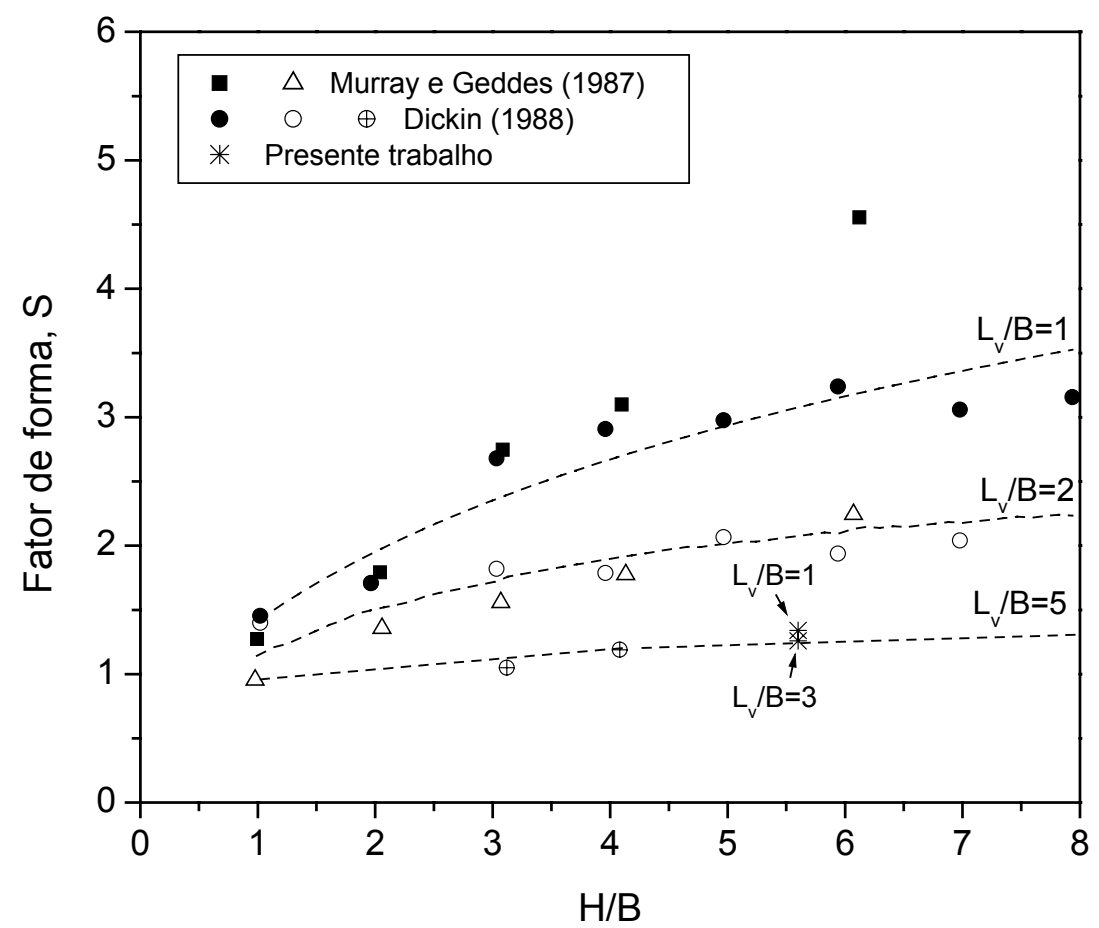

Figura 6.34. Análise da influência da forma da estrutura no caso passivo. 


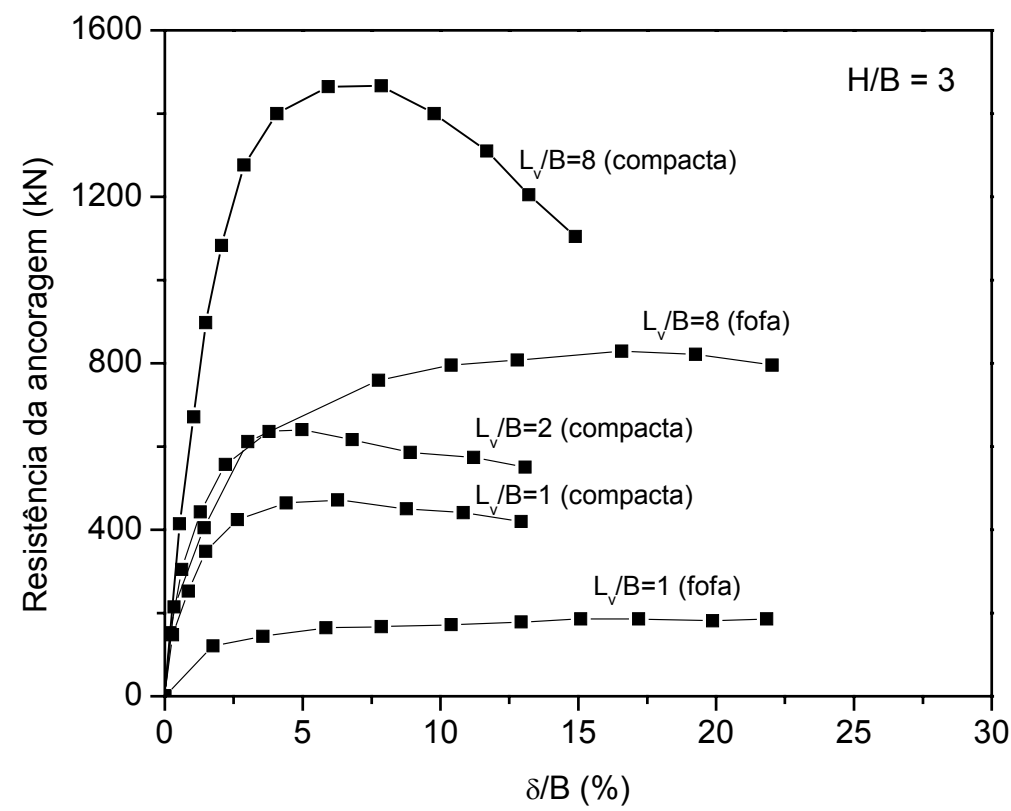

Figura 6.35. Efeito da geometria da ancoragem no comportamento cargadeslocamento em areia fofa e compacta com H/B = 3 (Dickin 1988).

A variação de $\sigma_{\mathrm{v}}$ no exterior do alçapão nas direções x e y revelou-se pouco influenciada pela geometria da estrutura, como mostram as Figuras 6.36 e 6.37 . Apenas na posição $\mathrm{I} 5$, em $\mathrm{x}_{\mathrm{i}} / \mathrm{B}=0,8$, é que a tensão apresentou-se ligeiramente menor com o alçapão retangular (Figura 6.36).

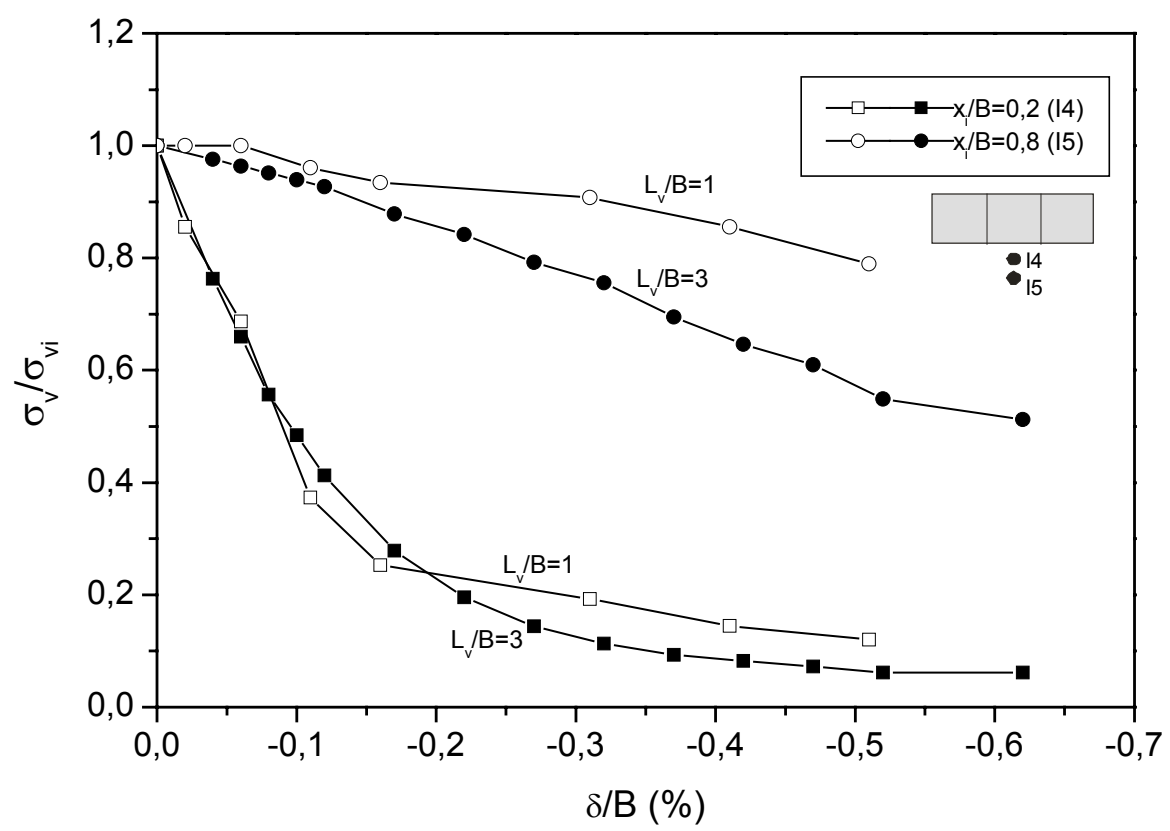

Figura 6.36. Comportamento da tensão no exterior do alçapão retangular e do quadrado, na transversal, em arqueamento passivo. $\mathrm{D}_{\mathrm{r}}=100 \% ; \mathrm{q}=100 \mathrm{kPa}$. 


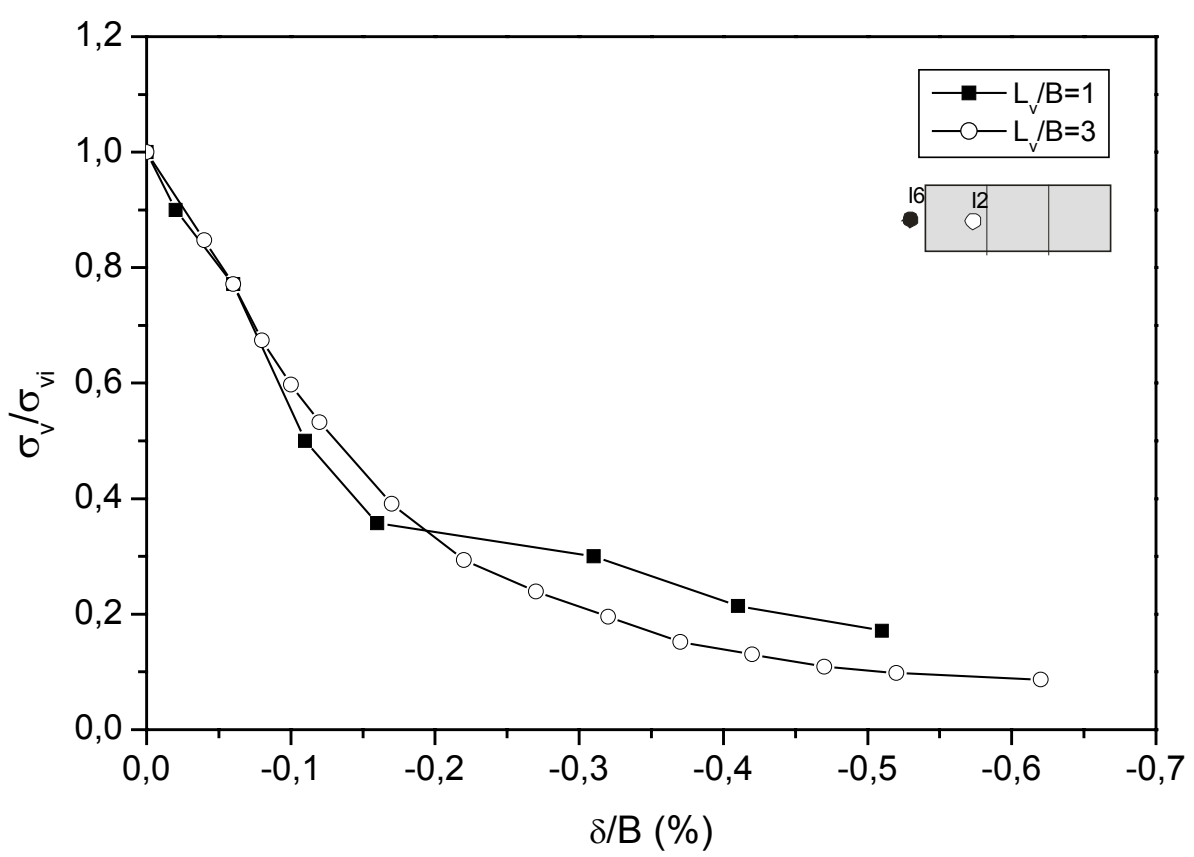

Figura 6.37. Comportamento da tensão no exterior do alçapão retangular e do quadrado, na longitudinal, em arqueamento passivo. $\mathrm{D}_{\mathrm{r}}=100 \% ; \mathrm{q}=100 \mathrm{kPa}$.

\subsubsection{Previsão da Tensão Sobre o Alçapão}

A previsão da tensão passiva máxima $\left(\sigma_{\mathrm{vp}}\right)$ medida no centro dos dois alçapões com $\mathrm{L}_{\mathrm{v}} / \mathrm{B}=1$ e 3 é realizada a seguir utilizando-se quatro soluções analíticas distintas. Os dados experimentais são provenientes de ensaios realizados com sobrecarga de 100 $\mathrm{kPa}$ e areia com densidade relativa de $100 \%$. Os parâmetros adotados para o solo foram: $\gamma=17,7 \mathrm{kN} / \mathrm{m}^{3}, \phi=39,2^{0}$ e $\phi_{\mathrm{cr}}=33,1^{0}$ (Tabela 4.4).

O formato retangular ou quadrado do alçapão foi levado em conta na solução de Meyerhof e Adams (1968), desenvolvida para estruturas em condição profunda (Figura 2.19b), através do fator empírico $s$, proposto pelos autores, igual a $[1+\mathrm{m}$. (H/B)]. O parâmetro $\mathrm{m}$ depende de $\phi$, e foi assumido igual a 0,35. Nos cálculos, considerou-se $\mathrm{H}_{\mathrm{e}} / \mathrm{B}=4$, com base nos modelos físicos, e $\mathrm{k}=0,95$, conforme sugestão dos autores. A solução é dada através da equação (2.25), com c $=0$.

A proposição de Frydman e Shaham (1989) é uma modificação do modelo da superfície de cisalhamento vertical (Figura 2.19a), incorporando os fatores de forma empíricos $\mathrm{S}_{\mathrm{q}}$ e $\mathrm{S}_{\mathrm{r}}$, propostos pelos autores para ancoragens retangulares e quadradas (expressões 2.23 e 2.24), respectivamente. A capacidade de carga do alçapão foi 
então obtida através da equação (6.12), adotando-se $\mathrm{k}$ igual à unidade, segundo sugestão dos autores. A tensão no método de Vermeer e Sutjiadi (1985) foi calculada através da equação (6.13) e no modelo de Murray e Geddes (1987), através da equação (2.26).

$$
\begin{aligned}
& \sigma_{\mathrm{vp}}=\left[\gamma \mathrm{H}+\frac{\gamma \mathrm{H}^{2} \mathrm{k} \cdot \operatorname{tg} \phi}{\mathrm{B}}+\mathrm{q}\right] \cdot\left[1+\frac{\left.\left(\mathrm{B} / \mathrm{L}_{\mathrm{v}}\right)-0,15\right)}{0,85} \cdot(0,5+2,35 \log (\mathrm{H} / \mathrm{B}))\right] \\
& \sigma_{\mathrm{vp}}=\left[1+\left(\frac{\mathrm{H}}{\mathrm{B}}+\frac{\mathrm{H}}{\mathrm{L}}\right) \operatorname{tg} \phi \cdot \cos \phi_{\mathrm{cr}}\right] \gamma \mathrm{H}+\mathrm{q}
\end{aligned}
$$

A Figura 6.38 mostra a variação de $\sigma_{v p} / \sigma_{v i}$ com a razão $L_{v} / B$ fornecida pelos modelos analíticos, comparando-a com os resultados experimentais. Em todos os modelos as maiores variações em $\sigma_{\mathrm{vp}}$ ocorrem com estruturas com $\mathrm{L}_{\mathrm{v}} / \mathrm{B}$ igual até aproximadamente 2. Praticamente não há mais variação da tensão no alçapão por conta de sua geometria a partir de $\mathrm{L}_{\mathrm{v}} / \mathrm{B}$ igual a aproximadamente 6. Logo, segundo os modelos, uma estrutura poderia ser considerada contínua para $\mathrm{L}_{\mathrm{v}} / \mathrm{B} \geq 6$.

A tensão última foi prevista com muito boa aproximação através do método de Frydman e Shaham (1989) para o resultado experimental com $\mathrm{L}_{\mathrm{v}} / \mathrm{B}=1$. Por outro lado, uma estimativa muito conservadora para o resultado experimental com $\mathrm{L}_{\mathrm{v}} / \mathrm{B}=3$ foi obtida. Os demais métodos teóricos forneceram estimativas para o resultado experimental referente ao alçapão com $\mathrm{L}_{\mathrm{v}} / \mathrm{B}=3$ bastante próximas à da solução de Frydman e Shaham (1989).

Os resultados mais incoerentes foram obtidos com a solução de Vermeer e Sutjiadi (1985), a qual se destaca das demais por ter se revelado praticamente insensível à variação da geometria da estrutura. As hipóteses adotadas para o cálculo da contribuição da carga devida ao atrito desenvolvido ao longo das superfícies cisalhantes fazem com que o modelo gere resultados muito conservadores. Frydman e Shaham (1989) também reportam estimativas muito conservadoras com os métodos da superfície de cisalhamento vertical e de Vermeer e Sutjiadi (1985). 


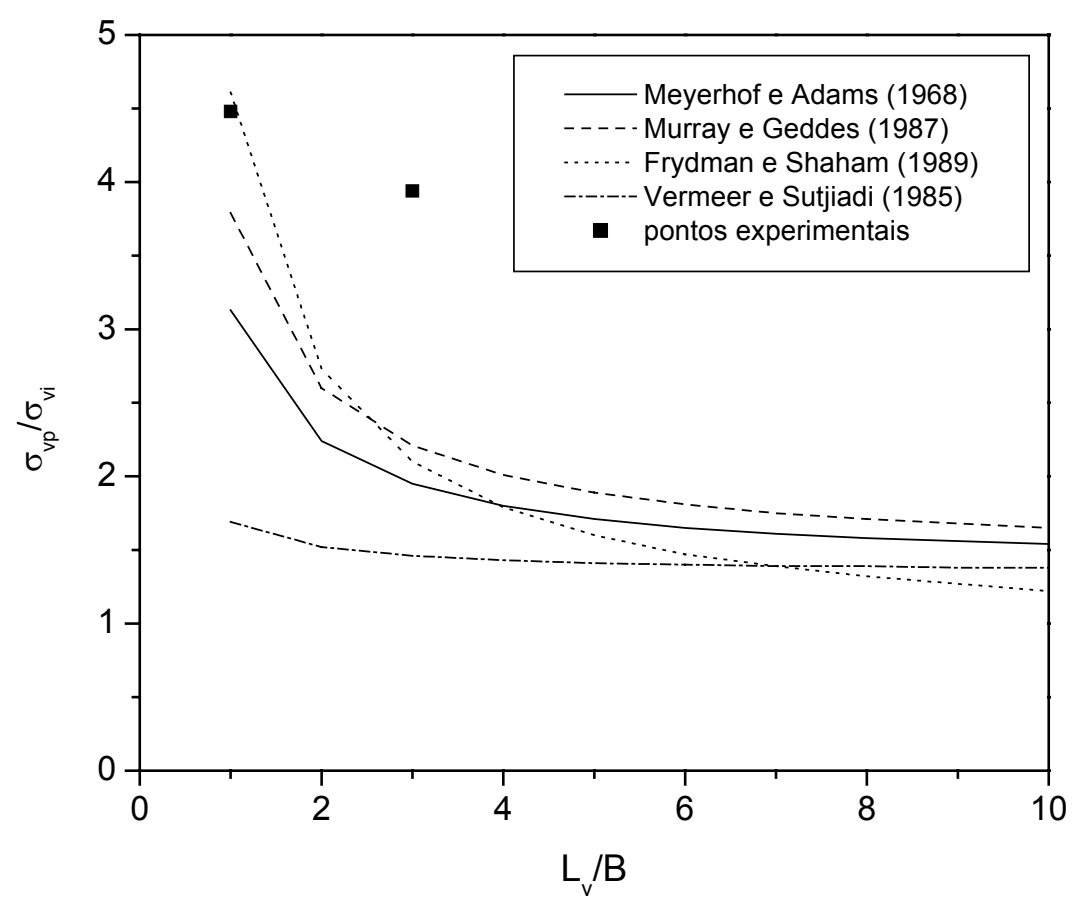

Figura 6.38. Previsões da tensão máxima sobre o alçapão em arqueamento passivo e comparação com os resultados experimentais.

\subsection{ESTADO ATIVO VERSUS ESTADO PASSIVO}

A Figura 6.39 compara o comportamento da tensão vertical no centro do alçapão (posição I1) obtido nos estados ativo e passivo, com ambos os tipos de alçapão investigados. $\sigma_{\mathrm{v}}$ converge rapidamente para um valor mínimo à medida que a estrutura se afasta da massa de solo. Deslocamentos de apenas $0,3 \%$ de B são suficientes para a mobilização quase que total da condição ativa. Em contrapartida, as curvas do estado passivo não mostram estabilização da tensão na mesma faixa de deslocamentos impostos. Deslocamentos muito superiores ao máximo aplicado seriam necessários para a condição passiva ser completamente mobilizada. Esta figura assemelha-se bastante à Figura 2.2, de McNulty (1965). A Figura 6.40 compara a variação de $\sigma_{\mathrm{v}}$ nas condições ativa e passiva na posição I4, adjacente ao alçapão. Nessa localidade, a queda da tensão é muito mais acentuada na situação passiva. A tendência à estabilização da tensão em ambos os casos inicia em níveis de $\delta / \mathrm{B}$ aproximados, em torno de $0,5 \%$. 


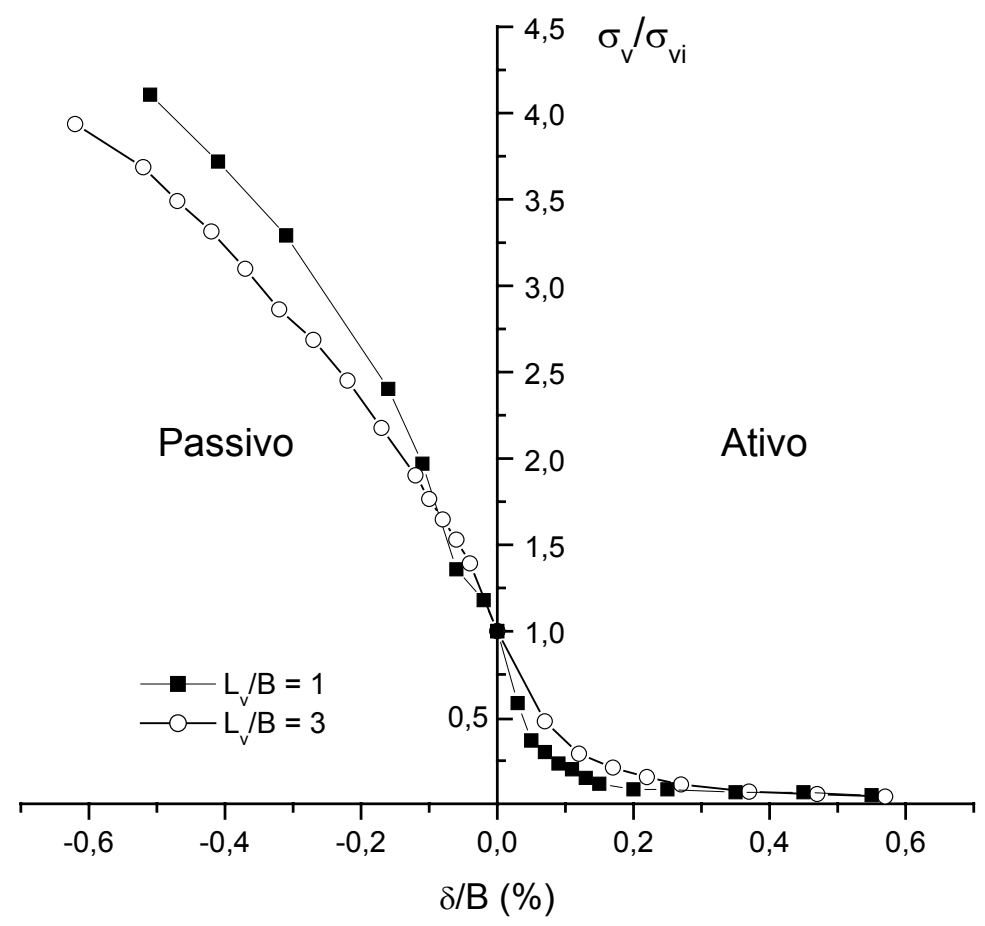

Figura 6.39. Variação da tensão vertical no interior do alçapão (posição I1) com o deslocamento em arqueamento ativo e passivo. $\mathrm{D}_{\mathrm{r}}=100 \% ; \mathrm{q}=100 \mathrm{kPa}$.

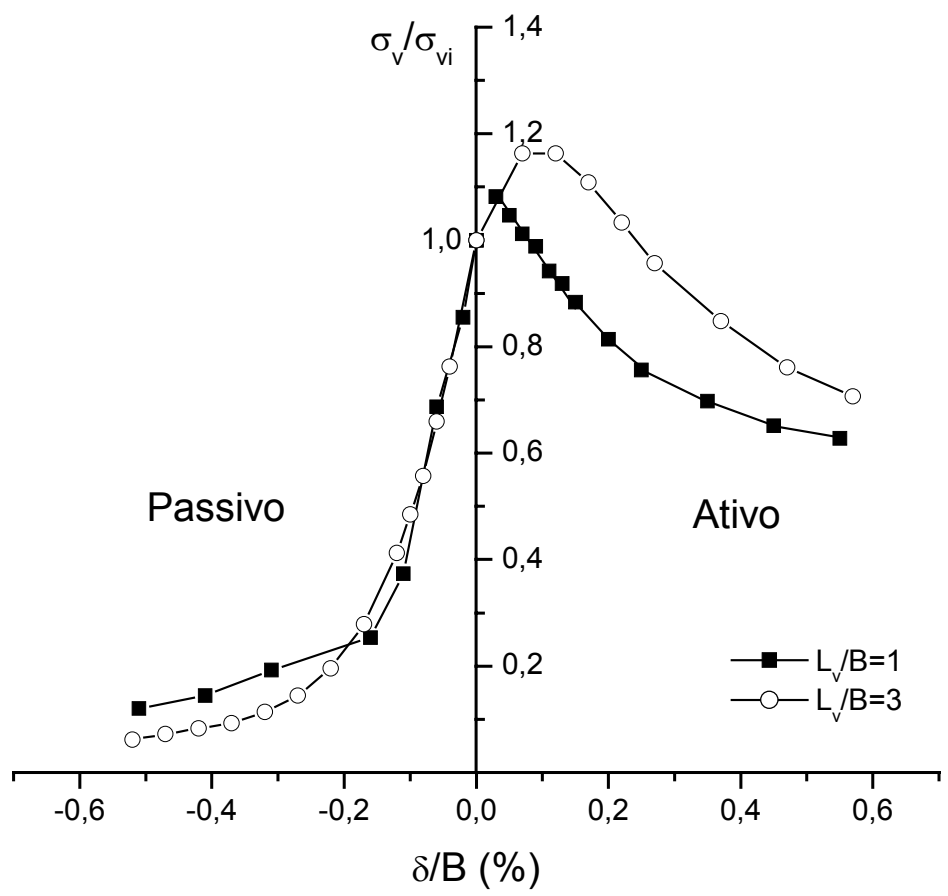

Figura 6.40. Variação da tensão vertical no exterior do alçapão (posição I4) com o deslocamento em arqueamento ativo e passivo. $\mathrm{D}_{\mathrm{r}}=100 \% ; \mathrm{q}=100 \mathrm{kPa}$. 
A Figura 6.41 exibe dados compilados de diversas fontes da literatura sobre 0 deslocamento $\delta_{\mathrm{u}}$ associado à mobilização da tensão mínima do arqueamento ativo $\left(\sigma_{\mathrm{va}}\right)$ ou a tensão máxima do arqueamento passivo $\left(\sigma_{\mathrm{vp}}\right)$, obtido com o movimento vertical de estruturas diversas em material não-coesivo. Os resultados dos modelos da presente pesquisa também se encontram incluídos na figura. Os dados são agrupados de acordo com a densidade relativa da areia e são apresentados em função da razão H/B. No caso passivo, em situações em que não houve estabilização da carga $\delta_{\mathrm{u}}$ foi tomado igual à máxima tensão medida no teste. A Figura 6.41a traz os resultados correspondentes a $D_{r}$ entre 80 e 100\% (areia compacta), e a Figura 6.41b, a $D_{r}$ entre 40 e $55 \%$ (areia fofa). A geometria de cada estrutura é indicada nas legendas dos gráficos. Os resultados mostram que $\delta_{u}$ na condição passiva possui magnitude muito superior à da condição ativa, caso em que não ultrapassa $2,5 \%$ de B. A profundidade exerce uma forte influência sobre $\delta_{u}$ no caso passivo. De modo geral, quanto maior a razão geométrica $\mathrm{H} / \mathrm{B}$, maior é o aumento do deslocamento necessário para a mobilização total da resistência passiva. Já o deslocamento para a mobilização da tensão mínima no estado ativo aparenta guardar relação com a profundidade somente para $\mathrm{H} / \mathrm{B}$ inferior a aproximadamente 2. Comparando as Figuras 6.41a e b, observa-se que, para uma razão H/B fixa, menores deslocamentos da estrutura são necessários com o solo mais compacto para se atingir a resistência passiva. Não obstante, de forma muito menos acentuada, o mesmo aparenta ocorrer na condição ativa. 


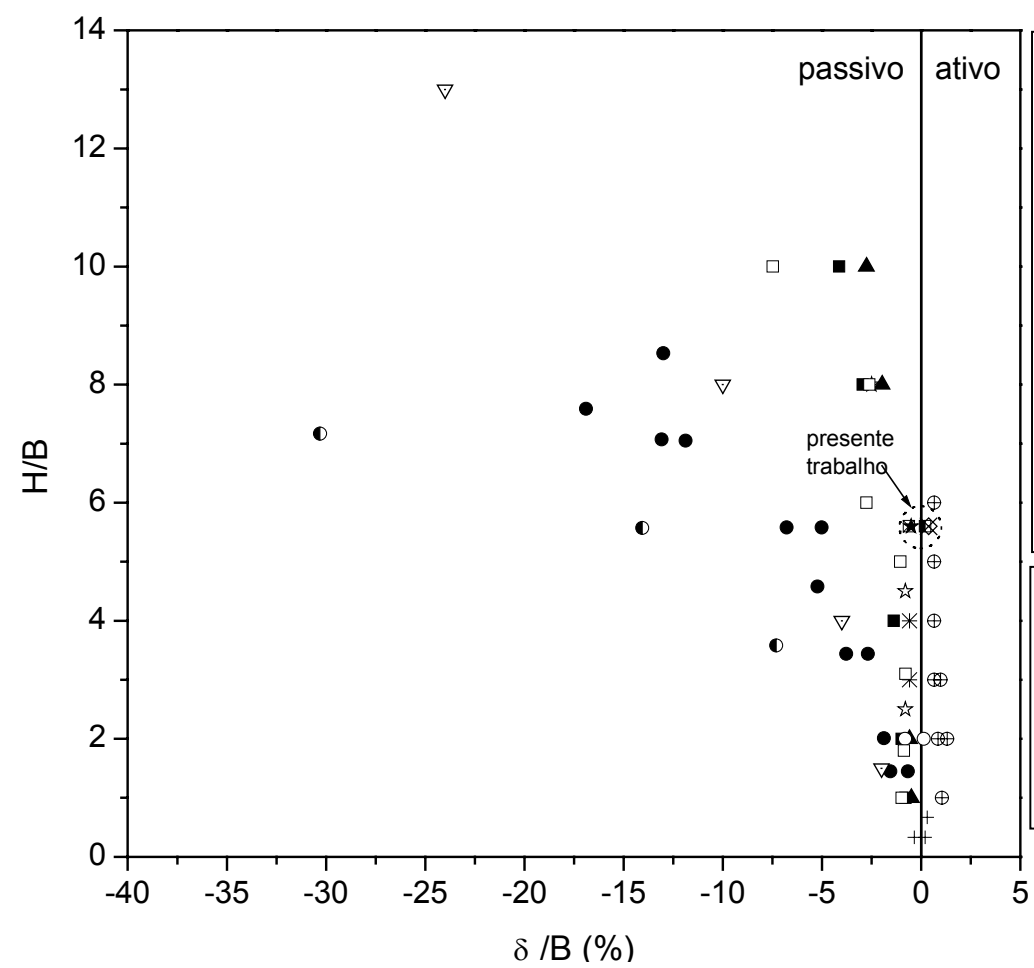

Condição passiva

Retangular

Murray\&Geddes(1987) (L/B=1)

Presente trabalho $(\mathrm{L} / \mathrm{B}=1)$

- Murray\&Geddes(1987) $(\mathrm{L} / \mathrm{B}=2)$

* Presente Trabalho $(\mathrm{L} / \mathrm{B}=3)$

○ Tanaka\&Sakai(1993) $(\mathrm{L} / \mathrm{B}=4)$

t. Frydman\&Shaham(1989) $(\mathrm{L} / \mathrm{B}=4,5)$

- Dickin(1994) $(\mathrm{L} / \mathrm{B}=8,5)$

* Murray\&Geddes(1987) (L/B=10)

Circular

Murray\&Geddes(1987)

+ McNulty(1965)

Tubo

Dickin(1994) $(\mathrm{L} / \mathrm{B}=8,5)$

Trautmann et al.(1985) $(\mathrm{L} / \mathrm{B}=11,7)$

condição ativa

Retangular

Presente trabalho $(\mathrm{L} / \mathrm{B}=1)$

Presente trabalho $(\mathrm{L} / \mathrm{B}=3)$

Tanaka\&Sakai(1993) $(\mathrm{L} / \mathrm{B}=4)$

Circular

McNulty(1965)

$\oplus$ Santichaianant(2002)

a) areia compacta

$\delta / \mathrm{B}(\%)$

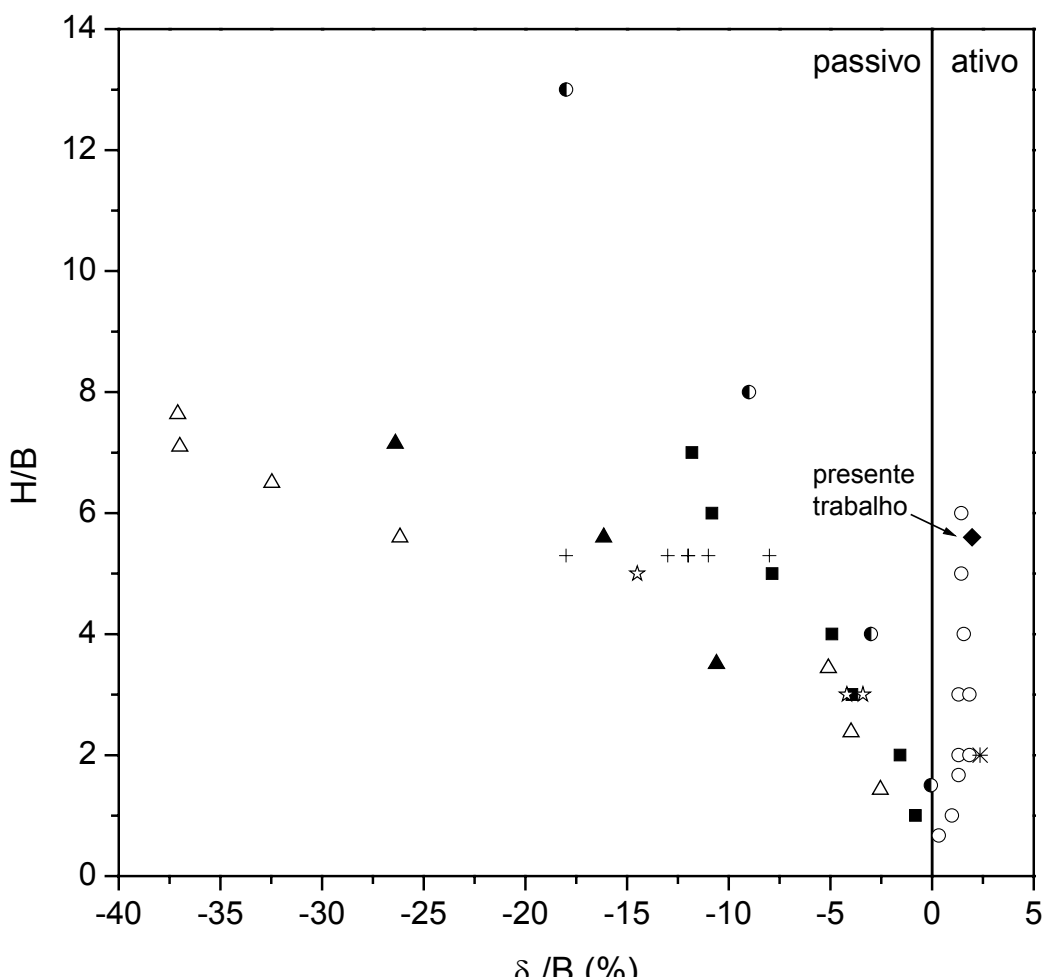

Condição Passiva

Retangular

- Murray\&Geddes(1987)(L/B=5)

- Dickin(1994) $(\mathrm{L} / \mathrm{B}=8,5)$

Rowe\&Davis (1982)(L/B=8,7)

Tubo

$\Delta \overline{\operatorname{Dickin}}(1994)(\mathrm{L} / \mathrm{B}=8,5)$

- Trautmann et al. $(1985)(\mathrm{L} / \mathrm{B}=11,7)$ Ng\&Springman(1994)(L/B=12,9)

Condição Ativa

Circular

- Santichaianant(2002)

Retangular

- Presente trabalho $(\mathrm{L} / \mathrm{B}=3)$

Iglesia(1991) $(\mathrm{L} / \mathrm{B}=15)$

b) areia fofa

Figura 6.41. Comportamento de $\delta_{\mathrm{u}}$ com a profundidade e com a densidade relativa do meio nos estados ativo e passivo. 


\section{Sistema Solo-Duto-Alçapão: Mecanismos de Ruptura na Perda de Apoio Localizada}

\subsection{CONSIDERAÇÕES INICIAIS}

No Capítulo 5, estudou-se o mecanismo de ruptura provocado por uma base rígida movendo-se para longe do maciço, de forma a causar o arqueamento ativo no solo. Este Capítulo trata da análise do mecanismo de ruptura de um sistema formado pelo maciço de solo mais o alçapão e um duto sujeito a perda de apoio localizada. Os mecanismos de ruptura envolvendo tubos, que se conhecem até o presente, foram avaliados visualmente mediante o uso de estruturas rígidas, às quais eram impostos deslocamentos incrementais ascendentes ou laterais (ex.: Audibert e Nyman 1977, Dickin 1988, Bransby et al. 2002). Uma grande lacuna ainda permanece na literatura com respeito a estudos voltados a situações envolvendo o desenvolvimento da condição ativa no solo com o uso de dutos flexíveis.

O programa experimental referente a essa parte do trabalho contou com a execução de quatro ensaios em centrífuga (série B) com modelos com tubos com altura de cobertura $(\mathrm{H})$ igual a aproximadamente $5 \mathrm{D}$, imersos em areia pura e repousando sobre um alçapão em seu centro. Todos os modelos foram ensaiados com aceleração de $45 \mathrm{~g}$. Os padrões de ruptura foram observados em uma seção vertical compreendendo o eixo central do tubo e em determinadas seções transversais selecionadas ao longo do tubo. Os efeitos da densidade do solo e da rigidez do duto 
no comportamento do sistema são avaliados. Os procedimentos de construção e execução dos modelos encontram-se devidamente detalhados no Capítulo 3.

\subsection{AVALIAÇÃO DOS MECANISMOS DE RUPTURA NO MACIÇO DE SOLO}

\subsubsection{Seções Transversais}

\subsubsection{Características Gerais dos Padrões de Ruptura Observados}

As Figuras 7.1 a 7.4 mostram os padrões de ruptura constatados nas seções transversais S1, S2 e S3 (plano x-z) dos modelos. A posição das seções é dada através da Figura 3.8b. As zonas de maior deformação observadas no maciço encontram-se sombreadas e as localizações de deformação, representadas por linhas tracejadas. O conduto é representado nas figuras por uma seção circular indeformada, sendo as deformações sofridas pelo mesmo discutidas separadamente no item 7.4.

Em todas as situações investigadas, ocorrem padrões de ruptura compostos por três localizações de deformação distintas. A mais interna é formada pelo fluxo do material inicialmente sobre o ombro e o topo do duto, que se desloca para preencher o vazio formado após a descida do alçapão. A formação dessa localização é em grande parte influenciada pelo atrito da areia com a parede do tubo, bem como pelas deformações deste último. O mecanismo de formação das outras duas localizações é relacionado à instabilidade da massa adjacente ao alçapão, no exterior do mesmo, despertada pela migração da areia na lateral do conduto. A localização externa inicia a propagação segundo um determinado ângulo, a partir das imediações da aresta do alçapão e torna-se quase que totalmente inclinada para a vertical após certa altura. Sua propagação guarda muita semelhança com a das localizações externas dos modelos sem a presença do conduto.

As características geométricas dos padrões de ruptura na seção S1 são sumarizadas na Tabela 7.1, juntamente com o recalque (s) medido na superfície do modelo, a $9 \mathrm{~mm}$ da face transparente da caixa de testes. As dimensões encontram-se normalizadas tanto pelo diâmetro do tubo, quanto pela largura do alçapão. A nomenclatura adotada para os parâmetros é indicada na Figura 7.1. A Tabela 7.1 
também reproduz os resultados dos modelos A3 e A7, sem a presença do tubo, executados com aceleração de $45 \mathrm{~g}$ e densidades relativas $\left(\mathrm{D}_{\mathrm{r}}\right)$ de 85 e 42\%, respectivamente. Esses modelos serão utilizados como base para comparações nas análises a seguir.

S1

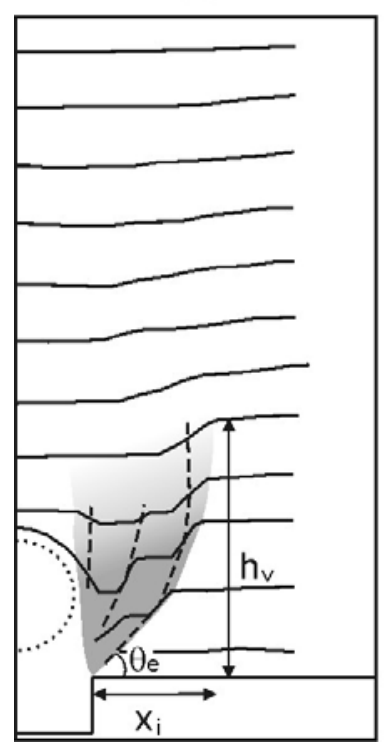

S2

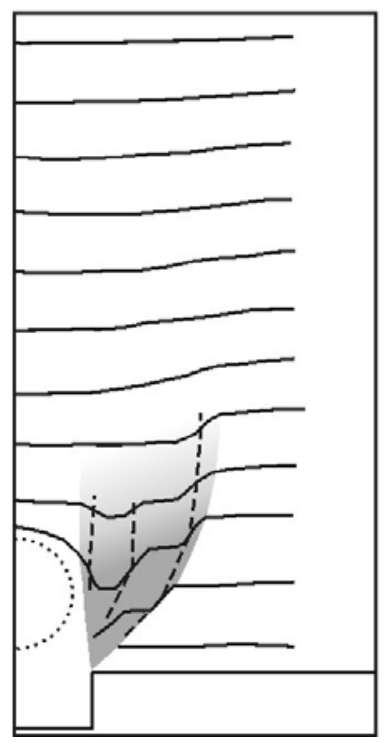

S3

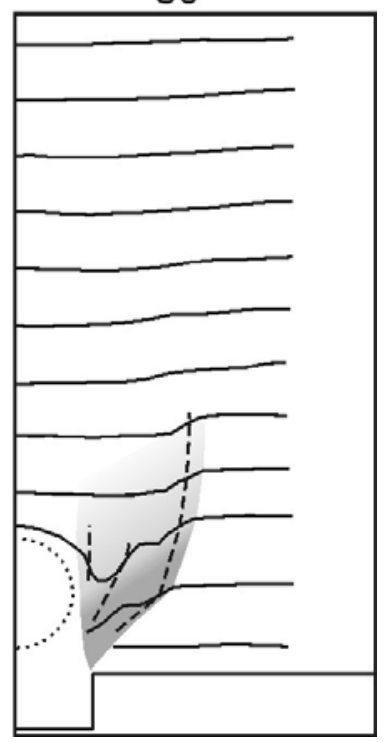

Figura 7.1. Mecanismo de ruptura nas seções transversais do modelo B1. Tubo flexível em maciço fofo.
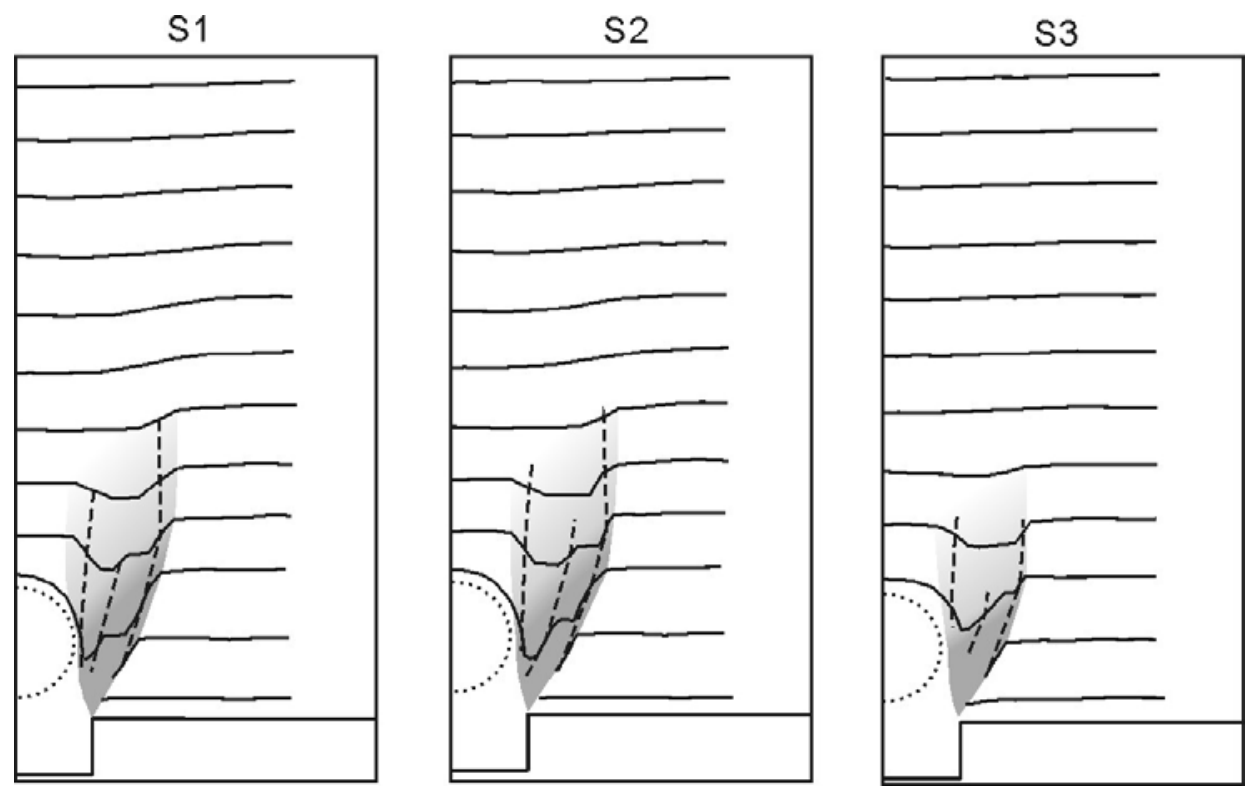

Figura 7.2. Mecanismo de ruptura nas seções transversais do modelo B2. Tubo flexível em maciço compacto. 

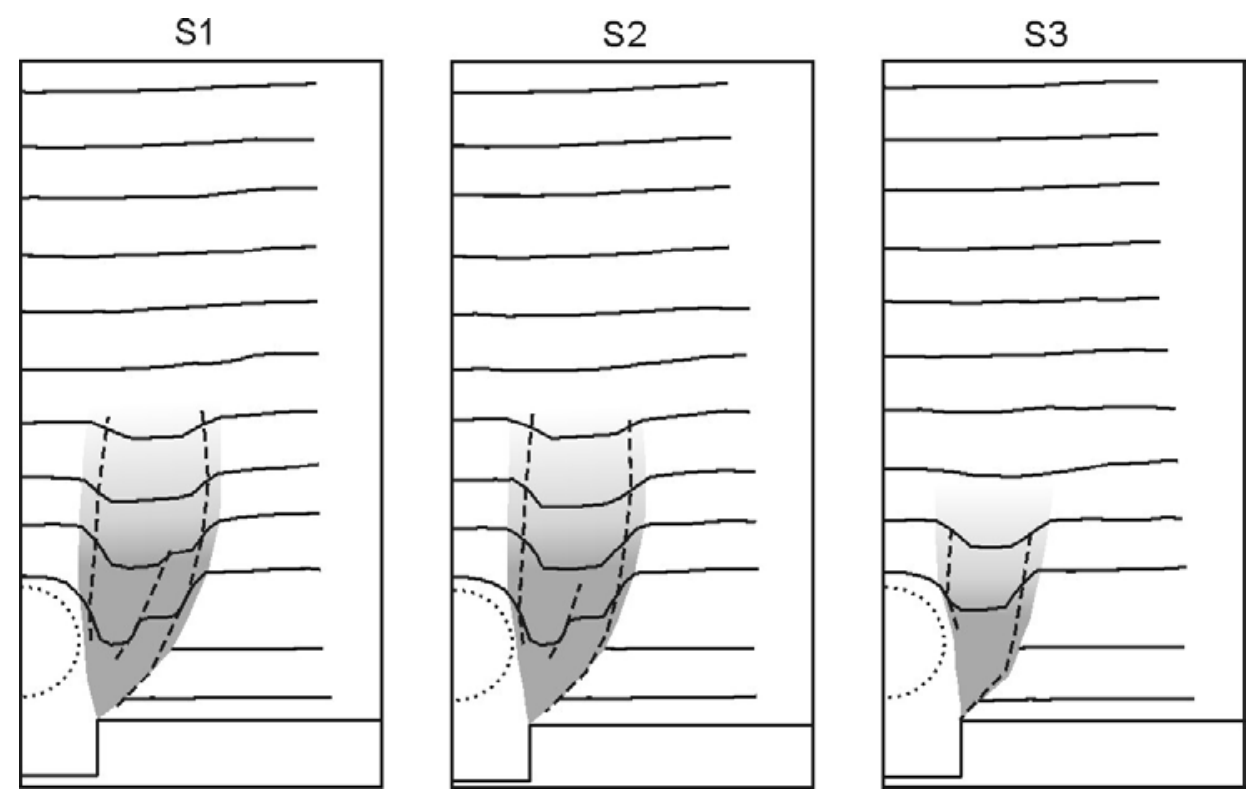

Figura 7.3. Mecanismo de ruptura nas seções transversais do modelo B3. Tubo rígido em maciço fofo.
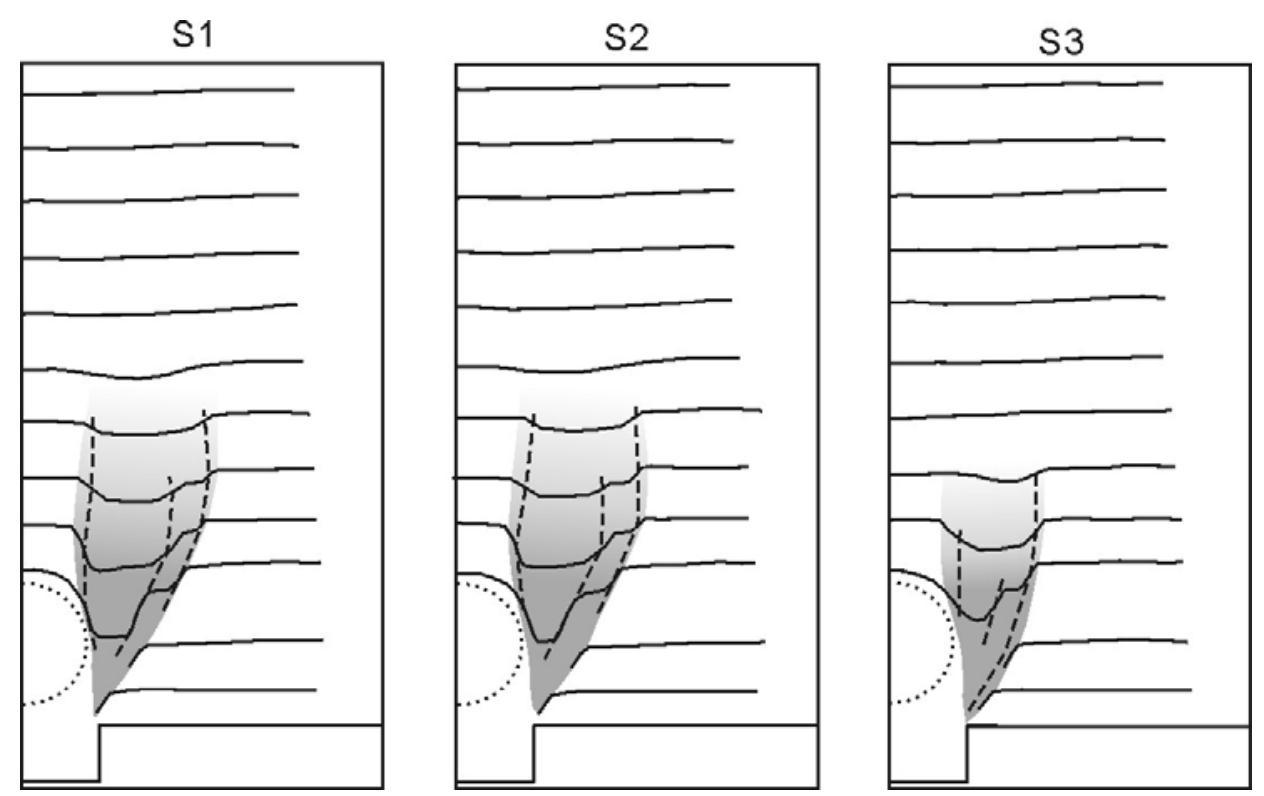

Figura 7.4. Mecanismo de ruptura nas seções transversais do modelo B4. Tubo rígido em maciço compacto. 
Tabela 7.1. Características dos padrões de ruptura na seção S1

\begin{tabular}{ccccccccc}
\hline Ensaio & $\begin{array}{c}\text { Densidade } \\
\text { relativa, } \\
\mathrm{D}_{\mathrm{r}}(\%)\end{array}$ & $\begin{array}{c}\text { Tipo de } \\
\text { tubo }\end{array}$ & $\mathrm{x}_{\mathrm{i}} / \mathrm{D}$ & $\mathrm{x}_{\mathrm{i}} / \mathrm{B}$ & $\mathrm{h}_{\mathrm{v}} / \mathrm{D}$ & $\mathrm{h}_{\mathrm{v}} / \mathrm{B}$ & $\theta_{\mathrm{e}}\left(^{0}\right)$ & $\begin{array}{c}\text { Recalque } \\
\text { superficial, } \\
\mathrm{s} / \delta(\%)\end{array}$ \\
\hline $\mathrm{B} 1$ & 42 & Flexível & 1,1 & 0,8 & 2,3 & 1,6 & 44 & 18,0 \\
$\mathrm{~B} 2$ & 85 & Flexível & 0,8 & 0,6 & 2,9 & 2,0 & 63 & 5,5 \\
$\mathrm{~B} 3$ & 42 & Rígido & 1,1 & 0,8 & 2,8 & 1,9 & 43 & 16,0 \\
$\mathrm{~B} 4$ & 85 & Rígido & 1,1 & 0,8 & 2,9 & 2,0 & 54 & 5,5 \\
\hline $\mathrm{A} 3$ & 85 & - & - & 0,4 & - & 1,8 & 63 & 4,9 \\
$\mathrm{~A} 7$ & 42 & - & - & 0,6 & - & 1,2 & 42 & 13,6 \\
\hline
\end{tabular}

\subsubsection{Efeitos da Densidade do Solo e da Rigidez do Tubo e Comparações com os Ensaios-Base}

Tipicamente, observa-se que inclusões exercem forte influência sobre 0 desenvolvimento de localizações de deformação no solo. Através de ensaios de compressão bi-axial com inclusões cilíndricas maciças dispostas em material granular, Vardoulakis e Graf (1985) constataram que as mesmas sempre condicionam as localizações a se propagarem a partir de seu entorno. Em testes semelhantes, Shibli (1995) verificou que as inclusões causam a formação de localizações mais inclinadas com a horizontal e que a resposta do solo à sua presença é diretamente proporcional à densidade relativa do material.

Influências significativas da inclusão em estudo, ou seja, do conduto, nos padrões de ruptura no solo também foram identificadas no presente trabalho. As Figuras 7.5a e b, confeccionadas a partir dos dados apresentados na Tabela 7.1, exibem a variação de $\theta_{\mathrm{e}}$ e de $\mathrm{x}_{\mathrm{i}} / \mathrm{B}$, respectivamente, com a densidade relativa do solo para os modelos com tubos flexíveis $(\mathrm{F})$, rígidos $(\mathrm{R})$ e sem tubo (ST). No maciço compacto ( $\mathrm{Dr}=85 \%$ ), a presença do conduto provocou um aumento sensível da inclinação inicial da localização para a horizontal $\left(\theta_{\mathrm{e}}\right)$. Por outro lado, a variação de $\theta_{\mathrm{e}}$ no maciço fofo $\left(\mathrm{D}_{\mathrm{r}}=42 \%\right)$ foi pequena, e aparentou não guardar relação com a existência do conduto. Apesar das condições ensaiadas serem completamente distintas, tal comportamento concorda com o relatado por Shibli (1995). O atrito da 
massa de solo que colapsa para o vazio formado e que age contra o tubo mais a coluna de solo que permanece sobre seu topo contribui para aumentar o ângulo de inclinação da propagação da localização exterior. No maciço fofo, a influência em $\theta_{\mathrm{e}}$ é menos pronunciada a) por conta do menor ângulo de atrito interno do material e b) por causa das maiores deformações experimentadas pela coluna de solo sobre o topo do tubo, o que diminui o cisalhamento entre as massas. Essa situação é semelhante à esquematizada na Figura 5.11.

No maciço compacto, a extensão lateral da localização $\left(\mathrm{x}_{\mathrm{i}}\right)$ é menor na ausência do conduto. Na presença do tubo, $x_{i}$ diminui com a redução da sua rigidez (Figura 7.5b). $\mathrm{x}_{\mathrm{i}}$ é o dobro com o tubo rígido (R) e 50\% maior com o tubo flexível (F), em relação ao valor medido no modelo sem tubo (ST). A limitação das deformações na coluna de solo sobre o topo do duto rígido é compensada através do alastramento lateral das deformações do solo adjacente ao alçapão. Na ausência do tubo, o solo não encontra obstáculos e as deformações ficam mais concentradas sobre o alçapão. No maciço fofo, $x_{i}$ também é menor sem o tubo, porém aparenta não depender da rigidez do mesmo.

A rigidez do duto influenciou de forma significativa a propagação da localização mais interna, que atinge maior comprimento com o tubo rígido. Como mencionado, uma vez que a deformação do tubo rígido após a perda de apoio é praticamente nula, a coluna de solo sobre seu topo apresenta deformações comparativamente menores, permitindo a formação de uma localização com maior comprimento. De maneira geral, a altura das localizações no maciço fofo é menor sem o conduto e aumenta com o aumento da sua rigidez. Tendência semelhante foi constatada no maciço compacto, porém a variação de altura é bem menos significativa nessa densidade.

A presença do tubo no maciço aparenta não exercer efeito significativo no recalque superficial. Os resultados da Tabela 7.1 indicam que $s$ guarda relação apenas com a densidade do material. O recalque superficial é aproximadamente três vezes maior no maciço fofo. 


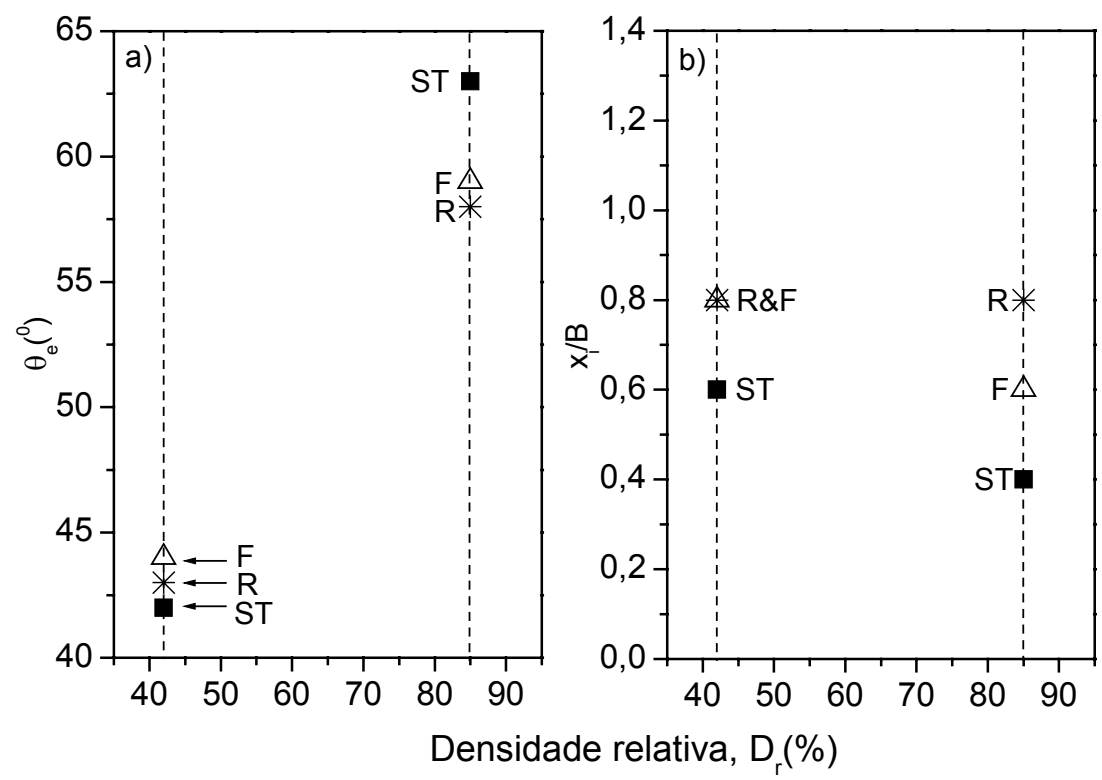

Figura 7.5. Variação de $\theta_{\mathrm{e}}$ e $\mathrm{x}_{\mathrm{i}}$ com a densidade relativa do solo nos ensaios sem dutos com dutos rígidos e flexíveis.

\subsubsection{Padrões das Localizações nas Demais Seções e}

\section{Tridimensionalidade do Problema}

As Figuras 7.1 a 7.4 permitem constatar que as seções S1 e S2 apresentaram padrões muito semelhantes. Por outro lado, padrões muito distintos foram verificados na seção S3, localizada no vértice do alçapão, a qual apresenta zonas de ruptura comparativamente menos desenvolvidas. Esse comportamento é semelhante ao observado nos ensaios de arqueamento puro (Figura 5.6). A altura máxima da localização nessa região é 15 a 30\% menor, em comparação com o constatado nas seções S1 e S2. Exceção se fez ao modelo B1, o qual revelou um padrão em S3 não muito diferente do das demais seções.

Como explicado anteriormente, a manifestação de localizações menos desenvolvidas na quina do alçapão decorre da influência do atrito entre a massa sobre o mesmo e o material estável adjacente, o qual restringe o movimento das partículas de solo que tendem a seguir seu movimento descendente, retardando o acúmulo das deformações responsáveis pela formação da localização. No caso do modelo B1, a menor resistência ao cisalhamento do solo no estado fofo, combinada à baixa rigidez 
do tubo, contribuiu com o desenvolvimento de padrões de localizações mais homogêneos ao longo do seu eixo.

Em nenhuma condição investigada foram observadas localizações na seção transversal S4, localizada na massa de solo externa.

Os resultados dos padrões praticamente idênticos das seções S1 e S2 em todos os modelos sugerem que a condição de estado plano de deformação poderia ser assumida para uma determinada região central R1 do maciço sobre o alçapão, como ilustrado na Figura 5.7. Essa constatação levaria à possibilidade de se considerar o sistema no estado plano de deformação para, no mínimo, a distância entre as duas seções. No entanto, ao menos para a situação envolvendo o tubo flexível no maciço fofo (Figura 7.6), isso não é possível, visto que o conduto não apresentou deformações exatamente iguais entre $\mathrm{S} 1$ e S2, o que viola um dos princípios básicos do estado plano de deformação. Para os demais casos, a hipótese aparenta, ao menos visualmente, ser válida, uma vez que os tubos praticamente não apresentaram deformações, mas deve ser vista com cautela. Medições de tensões nas seções de interesse seriam necessárias para uma averiguação mais precisa sobre essa questão.

\subsubsection{Seção Longitudinal}

Localizações de deformação não foram visualizadas na seção longitudinal dos modelos (plano y-z). Nessas seções, as linhas de areia colorida apenas apontaram a formação de perfis de recalque no solo, ao longo da profundidade, devido à migração do material para o vazio formado sob o tubo. As Figuras 7.6 e 7.7 mostram os padrões longitudinais de ruptura nos modelos B1 e B2, respectivamente, ambos ensaiados com tubos flexíveis.

Como esperado, as maiores deformações no interior do maciço ocorreram com o solo no estado fofo. A região de subsidência no solo atingiu uma extensão lateral $\mathrm{y}_{\mathrm{i}}$, medida a partir da aresta do alçapão, igual a aproximadamente 0,25 e 0,4D, para o conduto rígido e flexível, respectivamente. No maciço compacto, $\mathrm{y}_{\mathrm{i}}$ é praticamente inexistente, independentemente da rigidez do duto. Esses dados, juntamente com os resultados observados nas seções transversais, são indicativos de que a bacia de recalques superficiais no maciço fofo abrange uma área bem maior 
que no maciço compacto. Neste último, as linhas coloridas mostram também que as maiores deformações não ocorrem imediatamente sobre o tubo, mas em uma altura medida a partir do topo igual a aproximadamente 1D.

Os padrões de ruptura em todos os modelos também incluíram o desenvolvimento de pequenas cavidades na camada de solo onde o tubo é apoiado, acima das arestas do alçapão, como indicado nas Figuras 7.6 e 7.7. As cavidades possuem dimensões semelhantes tanto no maciço fofo quanto no compacto.

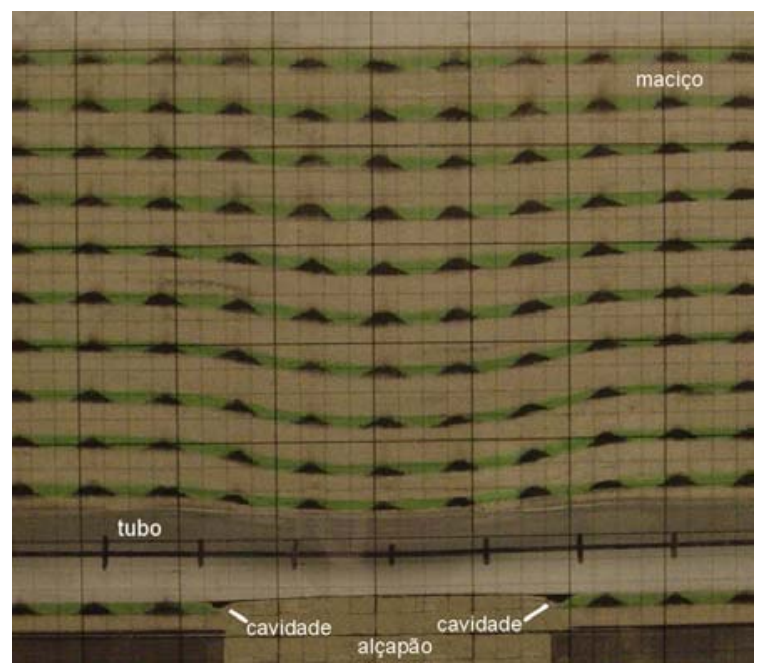

Figura 7.6. Padrão de ruptura na seção longitudinal do modelo B1 (tubo flexível em maciço fofo).

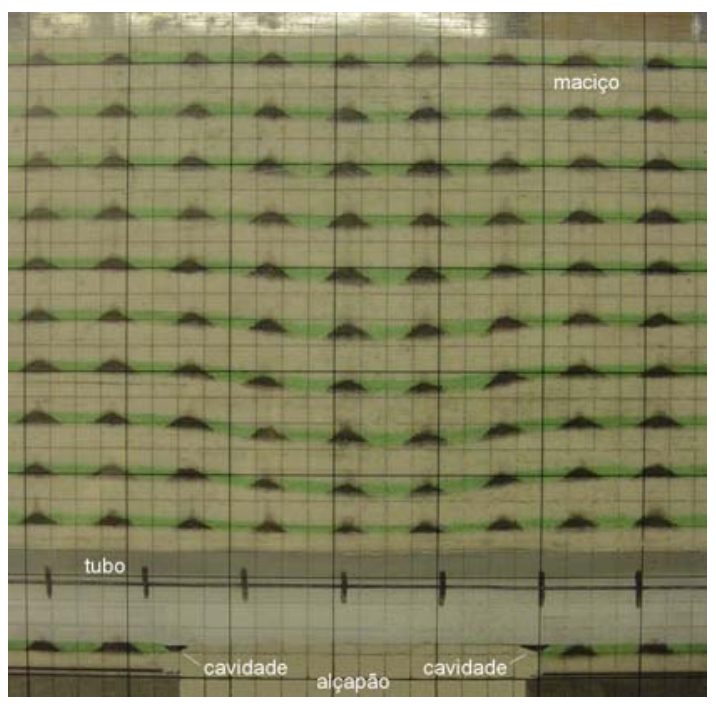

Figura 7.7. Padrão de ruptura na seção longitudinal do modelo B2 (tubo flexível em maciço compacto). 


\subsection{DESEMPENHO DOS DUTOS FLEXÍVEIS}

\subsubsection{Avaliação da Deformação Preliminar do Duto}

A análise da deformada adquirida pela seção transversal imediatamente antes da movimentação do alçapão é muito importante para uma compreensão mais precisa do desempenho dos dutos flexíveis após a perda de apoio. Para tanto, uma avaliação sobre os tipos possíveis de ruptura de tubos flexíveis e sobre as configurações assumidas pela seção em instalações convencionais, cujo carregamento provém somente do peso próprio do solo, é feita a seguir.

Tipicamente, assume-se que a ruptura de condutos flexíveis pode ocorrer por três maneiras distintas: deflexão excessiva, flambagem e compressão excessiva da parede. Por causa da baixa rigidez, a ruptura por deflexão excessiva prevalece sobre os outros modos nesta classe de conduto.

Logo após a publicação da Fórmula de Iowa, convencionou-se que dutos corrugados de aço suportariam um limite máximo de deflexão total igual a $20 \%$ (Spangler 1941). Como resultado, incorporou-se à prática um limite de 5\% para tubos metálicos flexíveis, obtido mediante um coeficiente de segurança igual a quatro. Pesquisas conduzidas na Universidade Estadual de Utah, EUA, mostraram que a integridade estrutural de condutos de PVC permanece até uma deflexão total máxima de 30\% (Unibell 1997). Dessa forma, a prática atual com tubos fabricados com esse material é utilizar em projetos um limite de 7,5\%. Em estágios avançados, é comum observar a deflexão excessiva evoluir para uma reversão de curvatura na metade superior do duto. Nessa fase, considera-se que o duto sofre ruptura, uma vez que o equilíbrio decorrente de uma interação adequada com o meio circundante é perdido. A ruptura por deflexão excessiva geralmente ocorre em aterros mal compactados (Bueno 1987).

Seguindo uma analogia com colunas verticais (Timoshenko e Gere 1961), a reversão da curvatura que ocorre em estágios avançados de deformação excessiva pode ser classificada como uma flambagem de onda única. Se a rigidez do solo for aumentada, as deflexões do duto serão limitadas, possibilitando o desenvolvimento de tensões compressivas maiores em suas paredes. Isso permitirá a ruptura por 
compressão das paredes ou flambagem através de múltiplas ondas. A flambagem pode ser elástica ou plástica, dependendo se ocorre antes ou após a tensão de escoamento do material. As instalações em profundidade em solo bem compactado reúnem as condições mais adequadas para rupturas dessa natureza (Krizek et al. 1972).

Considerar que a seção do tubo após o carregamento assume um formato elíptico representou a hipótese fundamental que norteou o desenvolvimento das formulações básicas para o cálculo das deflexões em condutos flexíveis (Spangler 1941). No entanto, alguns trabalhos experimentais reportam desvios do formato elíptico, em certas circunstâncias.

Alguns autores mencionam formatos aproximadamente retangulares (Howard 1972, Rogers 1988, Prevost e Kienow 1994). Entretanto esse formato parece somente ocorrer com tubos muito flexíveis enterrados em aterros com grau de compactação muito alto. Por exemplo, Howard (1972) cita a ocorrência de formatos retangulares apenas para tubos flexíveis imersos em aterros com grau de compactação (GC) igual a 100\% da energia de Proctor Normal. Moser (2001) descreve resultados de mais de 20 ensaios em verdadeira grandeza com carregamento distribuído no topo de condutos flexíveis metálicos e plásticos, com aterros com GC variando entre $70 \mathrm{e}$ 95\%, através dos quais apenas deflexões elípticas foram observadas, seguidas por flambagens localizadas ocorrendo geralmente na linha d'água. Decerto, os tubos testados não eram flexíveis o suficiente em relação ao aterro para assumirem a forma retangular.

Além da rigidez relativa do sistema, outro fator básico que governa a configuração adquirida pelo duto após o carregamento é a qualidade da compactação do solo ao longo da seção transversal, possibilitando o surgimento de mais dois padrões característicos: os formatos de "coração" e de "coração invertido" (Rogers 1988). A Tabela 7.2 resume os formatos tipicamente identificados, juntamente com as condições ideais para sua formação. Esboços esquemáticos da seção deformada em cada situação também são exibidos. 
Tabela 7.2. Formatos típicos adquiridos por tubos flexíveis após carregamento

\begin{tabular}{|l|l|l|}
\hline $\begin{array}{c}\text { Condição do solo de } \\
\text { aterro }\end{array}$ & Seção deformada & \multicolumn{1}{|c|}{ Observações } \\
\hline $\begin{array}{l}\text { Solo mal compactado } \\
\text { ao longo de toda a } \\
\text { profundidade do tubo. }\end{array}$ & $\begin{array}{l}\text { A baixa restrição lateral fornecida } \\
\text { pelo solo permite maiores } \\
\text { deformações na linha d'água, com } \\
\text { conseqüente afundamento do topo e } \\
\text { ombros. É a configuração mais } \\
\text { freqüentemente identificada. }\end{array}$ \\
\hline $\begin{array}{l}\text { Solo bem compactado } \\
\text { até a metade inferior } \\
\text { do tubo e mal } \\
\text { compactado na metade } \\
\text { superior. }\end{array}$ & $\begin{array}{l}\text { O topo sofre achatamento e os ombros } \\
\text { adquirem maior curvatura. A linha } \\
\text { d'água sofre pouca deformação. }\end{array}$ \\
\hline $\begin{array}{l}\text { Solo mal compactado } \\
\text { até a metade inferior } \\
\text { do tubo e bem } \\
\text { compactado na metade } \\
\text { superior. }\end{array}$ & "Coração" & $\begin{array}{l}\text { Comportamento oposto ao descrito } \\
\text { acima. }\end{array}$ \\
\hline $\begin{array}{l}\text { Solo bem compactado } \\
\text { ao longo de toda a } \\
\text { profundidade do tubo. }\end{array}$ & invertido" & $\begin{array}{l}\text { O topo e a base sofrem achatamento. } \\
\text { Os ombros e os assentos adquirem } \\
\text { maior curvatura. A linha d'água } \\
\text { permanece praticamente indeformada. }\end{array}$ \\
\hline
\end{tabular}

É possível que a configuração adquirida pelo tubo flexível no maciço fofo, imediatamente antes da translação do alçapão, tenha se situado entre a elíptica e a de "coração invertido". A tendência ao formato de "coração invertido" depende do nível de compactação atingido pelo solo na região do assento, e é cogitada por causa da forma de deposição da areia nos modelos. De maneira a se obter um maciço o mais homogêneo possível, é comum, em experimentos envolvendo condutos, que o solo granular seja depositado paralelamente ao eixo longitudinal (Valsangkar e Britto 1979, Bueno 1987). No entanto, esse expediente não foi adotado no presente trabalho por dois motivos distintos: a) pelas dimensões dos modelos da EESC/USP e b) por essa ser uma condição mais distante da condição de campo, visto que o assento é a região mais difícil de ser compactada durante a instalação do duto, onde geralmente não são atingidas as condições especificadas (McGrath et al. 1990).

No maciço compacto, três possibilidades para a configuração preliminar do duto, antes da translação do alçapão, são aventadas: o formato retangular, o elíptico e o "coração invertido". Deve-se recordar que a tendência à forma retangular é tão 
maior quanto menor for a rigidez do tubo em relação à do solo de aterro. Assim, é possível que o tubo tenha assumido um formato entre o retangular e o de "coração invertido", ou entre o elíptico e o de "coração invertido".

A julgar pelos resultados dos modelos da série D (item 8.2.1), uma configuração aproximadamente elíptica é a mais provável de ter ocorrido nos modelos discutidos neste capítulo tanto no maciço fofo quanto no compacto.

\subsubsection{Avaliação da Resposta do Duto à Perda de Apoio Localizada}

O tubo flexível imerso no maciço fofo (modelo B1) apresentou um padrão de deformação caracterizado por uma flambagem acentuada no terço superior, principalmente na região do ombro. A Figura 7.8 apresenta uma fotografia do tubo após o ensaio, tomada a partir de uma de suas extremidades, com o dano indicado através de setas. A Figura 7.9 mostra em detalhe a parte central do tubo deformado, após ter sido desenterrado do modelo. O topo do conduto apresentou deflexão positiva, ou seja, deslocamento em direção ao eixo central. Ao contrário do naturalmente esperado, o mesmo aconteceu com a base, a qual experimentou uma ascensão relativamente acentuada. Como mostra a Figura 7.6, o cenário foi mais crítico na seção central $\mathrm{S} 1$, atenuando-se gradualmente em direção às arestas do alçapão. A deflexão total vertical do tubo após a translação do alçapão alcançou, aproximadamente, $26 \%$ nessa seção. Tal valor situa-se dentro da faixa do limite crítico de desempenho estabelecido para os tubos flexíveis, entre 20 e 30\%. O dano sofrido pelo conduto pode ser classificado como uma ruptura, uma vez que sua habilidade de transferir adequadamente a carga recebida para o solo adjacente foi completamente comprometida. O dano no tubo na região externa do alçapão se estendeu até uma distância $\mathrm{y}_{\mathrm{i}}$ igual a aproximadamente $0,5 \mathrm{D}$, medida a partir da aresta do alçapão.

Como delineado no item anterior, provavelmente o formato preliminar assumido pelo duto no solo fofo seja o elíptico. Sob tal configuração, a concentração de tensões no tubo é maior na região abrangendo a linha d'água e o assento. Uma maior resistência passiva do solo é então mobilizada nessa região, decorrente do 
decréscimo do raio de curvatura. Uma maneira preliminar de quantificar o aumento da tensão horizontal na linha d'água no tubo é dada a seguir.

Desconsiderando-se a aderência entre as paredes do duto e o solo circundante e supondo-se que o estado plano de deformação prevalece, a força circunferencial em qualquer ponto da seção transversal do tubo será igual ao produto da tensão que atua radialmente na parede pelo raio de curvatura. Considerando-se que o tubo adquire uma seção transversal perfeitamente elíptica após o carregamento, a reação horizontal do solo mobilizada na linha d'água $\left(\sigma_{\mathrm{h}, \mathrm{la}}\right)$ pode ser quantificada através da expressão (7.1) (Watkins e Anderson 1999), uma vez conhecida a deflexão total vertical do tubo (d). Sabendo-se que $d$ medida na seção $\mathrm{S} 1$, imediatamente antes da movimentação do alçapão, foi de aproximadamente $2 \%$, obtém-se a um aumento em $\sigma_{\mathrm{h}, \mathrm{la}}$ em torno de $13 \%$.

É provável que a grande extensão do dano na região topo-ombro tenha sido reflexo direto do formato preliminar assumido antes da perda de apoio, que gera tensões elevadas nessa localidade. Inclusive, tal configuração torna o duto bastante susceptível a sofrer reversão de curvatura na base, como de fato aconteceu.

$\sigma_{\mathrm{h}, \mathrm{la}}=\sigma_{\mathrm{v}, \mathrm{t}} \frac{(1+\mathrm{d})^{3}}{(1-\mathrm{d})^{3}}$

onde: $\sigma_{\mathrm{v}, \mathrm{t}}=$ tensão vertical no topo do tubo; $\mathrm{d}=$ deflexão total vertical.

A perda de apoio no maciço compacto (modelo B2) resultou em conseqüências muito menos prejudiciais para o duto, com deformações plásticas praticamente imperceptíveis visualmente (Figura 7.7). O desempenho do duto no maciço compacto é superior principalmente porque a região da linha d'água e do assento experimenta níveis de tensão consideravelmente menores, o que atenua as conseqüências da perda do suporte lateral. Somam-se a isso as menores deformações sofridas pelo solo após a descida do alçapão, quando no estado compacto, o que confere maior suporte ao tubo nessa fase.

Estes resultados alertam sobre a importância do controle da qualidade da compactação do aterro. Quanto melhor a compactação do solo de aterro, menor será 
o potencial de avaria ao duto mediante uma eventual perda de apoio localizada. Nesse caso, o conduto apresentará grandes chances de permanecer operacional.

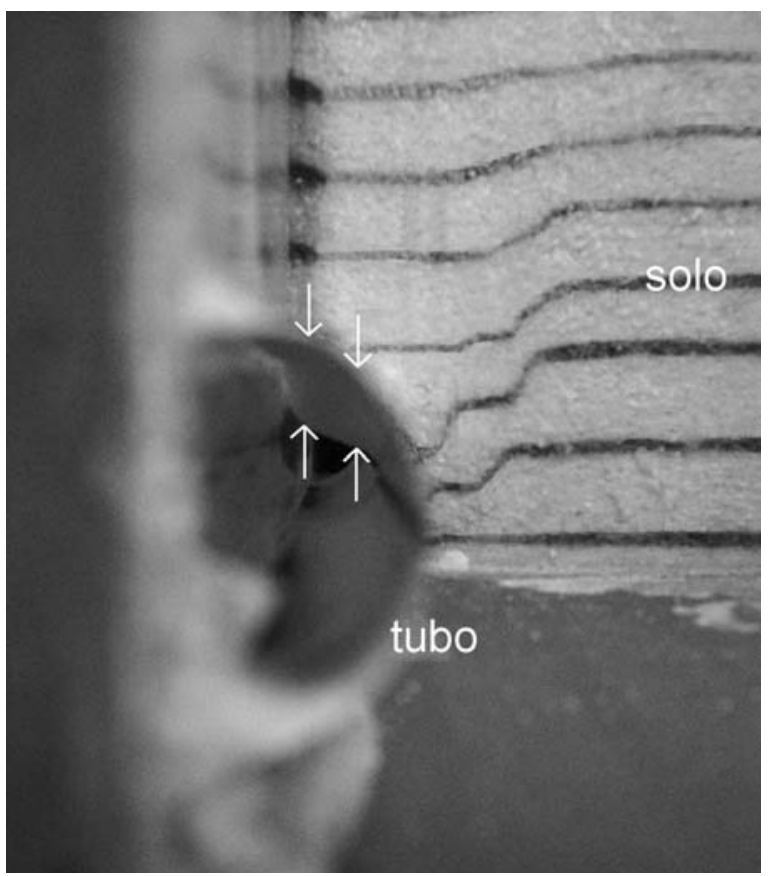

Figura 7.8. Dano sofrido pelo tubo flexível no maciço fofo.

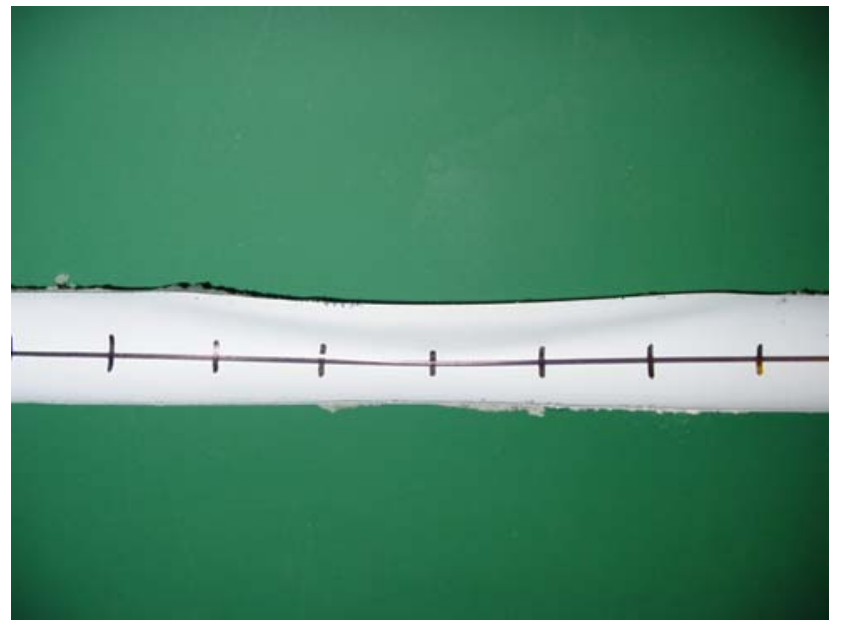

Figura 7.9. Detalhe do dano apresentado pelo tubo flexível após perda de apoio no maciço fofo. 


\section{CAPÍTULO VIII \\ Sistema Solo-Duto-Alçapão: \\ Deflexões e Deformações do Conduto e \\ Tensões no Maciço, na Perda de Apoio ou Elevação Localizada}

\subsection{CONSIDERAÇÕES INICIAIS}

Neste Capítulo são apresentados e discutidos os resultados dos ensaios das séries D, E e F, executados no Depto. de Geotecnia da EESC/USP. Os modelos tiveram por finalidade avaliar as deflexões e deformações experimentadas por condutos imersos em material granular, antes e após a perda de apoio ou elevação localizada. As variações das tensões despertadas no topo e na linha d'água do duto, bem como em diversos pontos da caixa de testes, foram também avaliadas. A elevação ou a perda de apoio era provocada pela movimentação ascendente ou descendente de um alçapão com dimensões de 300 x $100 \mathrm{~mm}$, com o maciço submetido a uma sobrecarga fixa, aplicada à superfície. Os procedimentos de construção e execução dos modelos, bem como o programa de ensaios, encontram-se detalhados no Capítulo 4.

As análises são agrupadas em três itens principais, iniciando com a investigação do comportamento do sistema solo-conduto durante a fase de aplicação da sobrecarga superficial. Nesta fase, destaque é dado à determinação do módulo de reação horizontal do solo (E') a partir dos resultados experimentais. O segundo e o terceiro item abordam, respectivamente, a interação do sistema perante a perda de 
suporte e a elevação. Os resultados experimentais são apresentados, discutidos e comparados a soluções analíticas disponíveis na literatura. A influência da densidade do solo e da sobrecarga aplicada nas variáveis medidas nos modelos físicos é avaliada.

\subsection{ANÁLISES PRELIMINARES}

\subsubsection{Avaliação das Deflexões do Duto e Comparações com Métodos Teóricos}

Os condutos testados apresentaram deflexões $\left(\mathrm{d}^{*}\right)$ bastante semelhantes ao longo do comprimento após a aplicação da sobrecarga superficial. De forma a exemplificar essa constatação, a Figura 8.1 exibe os perfis obtidos ao longo da longitudinal do duto repousando no maciço fofo $\left(\mathrm{D}_{\mathrm{r}}=50 \%\right)$ e sob uma sobrecarga (q) de $100 \mathrm{kPa}$ (ensaio D7). A deflexão foi medida em oito pontos da seção transversal. Vale lembrar que $\mathrm{d}^{*}$ corresponde ao deslocamento do ponto medido dividido pelo diâmetro médio do tubo. Um deslocamento positivo significa que o ponto moveu-se para o centro do tubo.

As Figuras 8.2a e b mostram as deflexões registradas na seção S1, no centro do conduto, para o maciço fofo $\left(D_{r}=50 \%\right)$ e o maciço compacto $\left(D_{r}=100 \%\right)$, respectivamente, ambos com q $=100 \mathrm{kPa}$. Os números externos ao círculo indicam o valor da deflexão sofrida, em percentagem, majorada por um fator igual a 7. Os algarismos interiores marcam as posições dos pontos de leitura (1 e 5). Os dois diagramas são aproximadamente simétricos em relação ao eixo vertical, com uma concentração maior de deflexões no topo do tubo. Uma configuração aproximadamente elíptica foi obtida, caracterizada por achatamento do topo e aumento do diâmetro horizontal. Em ambos os casos, o aumento do diâmetro horizontal ultrapassou o decréscimo do diâmetro vertical. Por conta do recalque da base, a deflexão no assento foi muito pequena. No topo, no ombro e na linha d'água, as deflexões foram maiores no solo fofo, ao passo que no assento e na base foram praticamente independentes da densidade utilizada. Fosse a sobrecarga levada 
adiante, provavelmente a ruptura desses tubos ocorreria por causa da reversão excessiva da curvatura do topo.

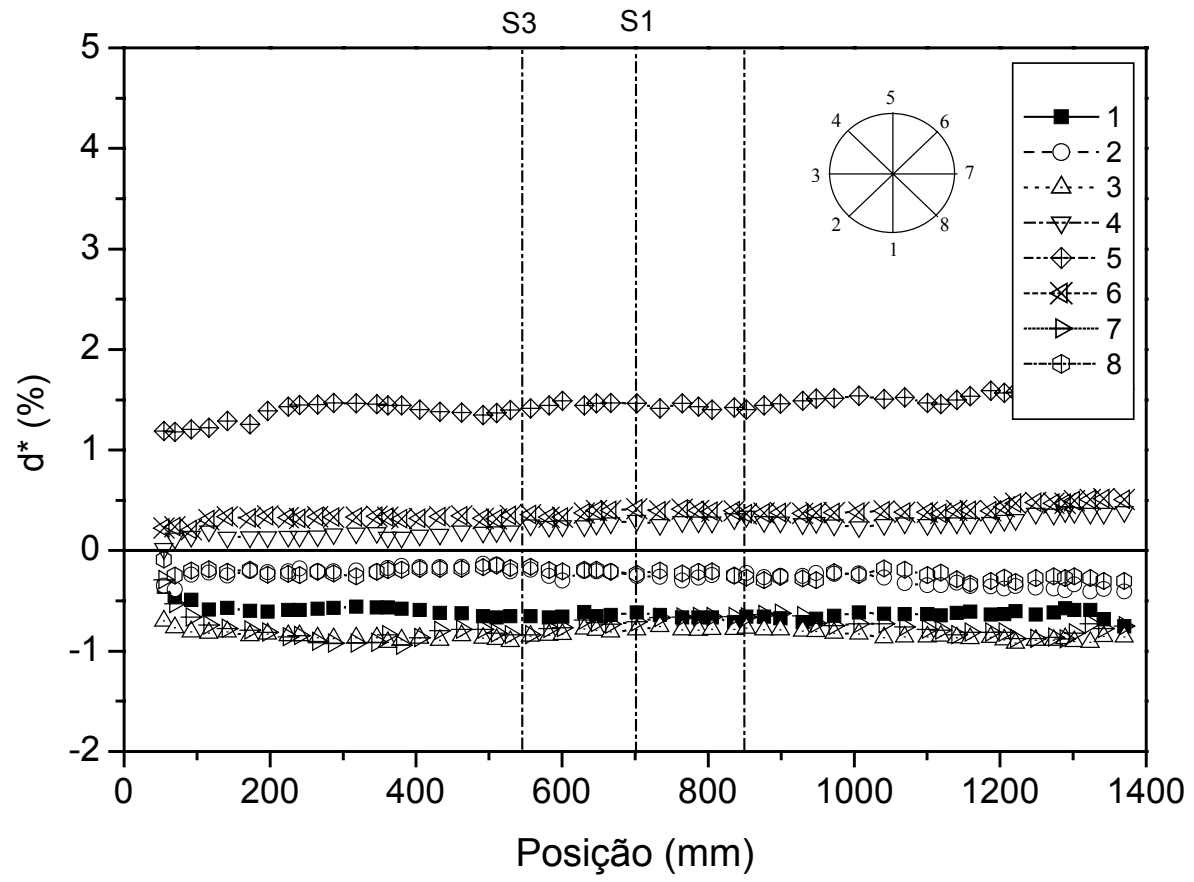

Figura 8.1. Perfis de deflexão d* ao longo do conduto após sobrecarga de $100 \mathrm{kPa}$. Ensaio D7.

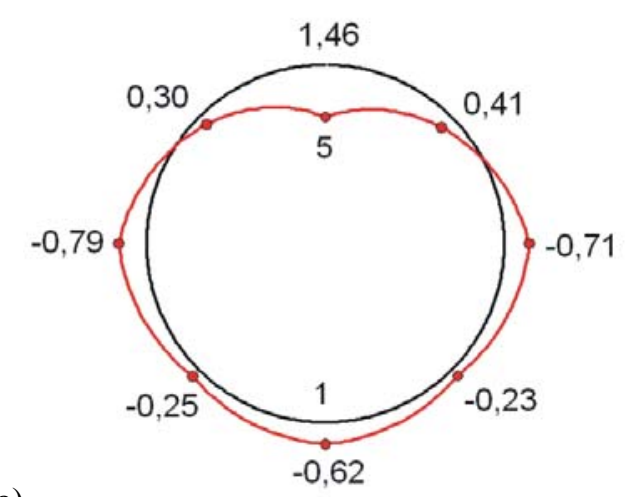

a)

Figura 8.2. Deformada da seção central S1 após aplicação de sobrecarga superficial de $100 \mathrm{kPa}$ no a) maciço fofo $\left(\mathrm{D}_{\mathrm{r}}=50 \%\right)$; b) maciço compacto $\left(\mathrm{D}_{\mathrm{r}}=100 \%\right)$.

A Figura 8.3 mostra a variação da deflexão total (d) da linha d'água do conduto imerso no maciço fofo com o aumento da sobrecarga (q) até $100 \mathrm{kPa}$. A deflexão $\mathrm{d}$ é igual à soma dos valores de $\mathrm{d}^{*}$ diametralmente opostos. $\mathrm{O}$ experimento 
revelou um comportamento crescente e aproximadamente linear da deflexão para a faixa de $\mathrm{q}$ investigada. A Figura 8.3 traz ainda previsões dos resultados experimentais, realizadas com a Fórmula de Iowa e a solução de Burns e Richards (1964).

A Fórmula de Iowa, desenvolvida por Spangler (1941), é o método mais empregado para a estimativa de deflexões em condutos flexíveis. A expressão resultante para a obtenção do aumento do diâmetro horizontal é dada em (8.1). Por sua vez, a solução de Burns e Richard (1964) baseia-se na Teoria da Elasticidade. Trata-se da interação de uma casca cilíndrica em um meio elástico, isotrópico e semiinfinito. Apesar do método ter sido publicado há mais de quarenta anos, somente ganhou maior aceitação a partir do início da década de 1990, basicamente por causa da maior facilidade de implementação em programas computacionais.

$$
\mathrm{d}=\frac{\mathrm{f}_{\mathrm{b}} \cdot \mathrm{f}_{\mathrm{f}} \cdot \mathrm{F}_{\mathrm{a}}}{\frac{\mathrm{E} \cdot \mathrm{t}^{3}}{12 \mathrm{R}^{3}}+0,061 \cdot \mathrm{E}^{\prime}}
$$

onde: $\mathrm{f}_{\mathrm{b}}=$ fator de berço $=0,1($ Goddard 1994$) ; \mathrm{f}_{\mathrm{f}}=$ fator de fluência $=1$ (Goddard 1994); $\mathrm{E}=$ módulo de elasticidade do material do tubo; $\mathrm{t}=$ espessura do tubo; $\mathrm{F}_{\mathrm{a}}=$ carga que chega ao topo do tubo por unidade de comprimento, obtida experimentalmente na seção $\mathrm{S} 1$; E' = módulo de reação horizontal; $\mathrm{R}=$ raio do tubo.

A determinação da deflexão de condutos enterrados esbarra na dificuldade de se eleger um valor adequado para o módulo de reação horizontal do solo (E'), parâmetro que tem sido alvo de muitas discussões no meio técnico. Classicamente, valores para E' são obtidos das tabelas propostas por Howard (1977) e Hartley e Duncan (1987), confeccionadas a partir de resultados de ensaios de campo. Contudo, atualmente há uma tendência em se considerar E' igual ao módulo de compressão confinada do solo, $\mathrm{M}_{\mathrm{s}}$ (AWWA 1989, Goddard 1994, McGrath et al. 1990).

As previsões da Figura 8.3 foram realizadas de duas maneiras distintas: utilizando-se valores de E' calculados com base nos resultados dos modelos físicos (Figura 8.5) e considerando $\mathrm{E}^{\prime}=\mathrm{M}_{\mathrm{s}}$. No primeiro caso, empregou-se a média dos resultados de $E^{\prime}$ para $q=50$ e $100 \mathrm{kPa}$, obtidos para $\mathrm{D}_{\mathrm{r}}=50 \%$. Na segunda abordagem, $\mathrm{M}_{\mathrm{s}}$ foi determinado a partir da seguinte expressão: 
$M_{s}=\frac{E \cdot(1-v)}{(1+v) \cdot(1-2 v)}$

E e $v$ foram obtidos da Tabela 4.4. Os valores empregados nas previsões foram os seguintes: no intervalo $0 \leq \mathrm{q} \leq 50 \mathrm{kPa}$ foram utilizados $\mathrm{E}$ e $v$ obtidos com $\sigma_{3}=50$ $\mathrm{kPa}$; entre $50 \mathrm{kPa}<\mathrm{q} \leq 100 \mathrm{kPa}$, foram adotados $\mathrm{E}$ e $v$ referentes a $\sigma^{\prime}{ }_{3}=100 \mathrm{kPa}$.

A primeira abordagem proporcionou uma excelente previsão com o método de Burns e Richard (1964) e resultados ligeiramente acima dos experimentais com a Fórmula de Iowa. Resultados muito aquém dos laboratoriais (ou seja, contra a segurança) foram obtidos com o uso de $\mathrm{E}^{\prime}=\mathrm{M}_{\mathrm{s}}$, em ambos os métodos. Nesse caso, a divergência dos pontos experimentais aumenta com o aumento de $\mathrm{q}$.

Os valores de E' obtidos experimentalmente são muito inferiores aos de $\mathrm{M}_{\mathrm{s}}$. De fato, a proposição de se substituir E' por $\mathrm{M}_{\mathrm{s}}$ não aparenta ser válida porque a condição do solo na lateral de um duto enterrado não guarda nenhuma relação com a condição de contorno do ensaio oedométrico. A complexa variação das tensões na linha d'água por conta da interação do sistema solo-tubo demanda a obtenção de E' apenas sob condições que promovam tal interação.

Por outro lado, vale lembrar que $\mathrm{M}_{\mathrm{s}}$ não foi determinado diretamente de um ensaio oedométrico, mas a partir de uma simples relação elástico-linear entre parâmetros de deformação obtidos de ensaios triaxiais. Assim, há uma possibilidade de que tal estimativa possa ter fornecido resultados sobreestimados de $\mathrm{M}_{\mathrm{s}}$, resultando em valores comparativamente baixos de $\mathrm{d}^{*}$.

\subsubsection{Avaliação das Tensões no Solo Circundante e Determinação do Módulo de Reação do Solo a Partir dos Experimentos}

A determinação da distribuição de tensões no solo que circunda um conduto flexível enterrado constitui um problema de alta complexidade por causa da interação entre esses dois componentes do sistema. As principais variáveis que influem na distribuição das tensões são o tipo de solo, a rigidez relativa e a qualidade da compactação do aterro. A literatura dispõe de uma quantidade muito pequena de relatos sobre as tensões ao redor de tubos enterrados, tanto em escala laboratorial, 
quanto in situ. Adicionalmente, métodos de projeto, como o de Spangler (1941), contam com distribuições arbitrárias, as quais, muitas vezes, não representam adequadamente a realidade.

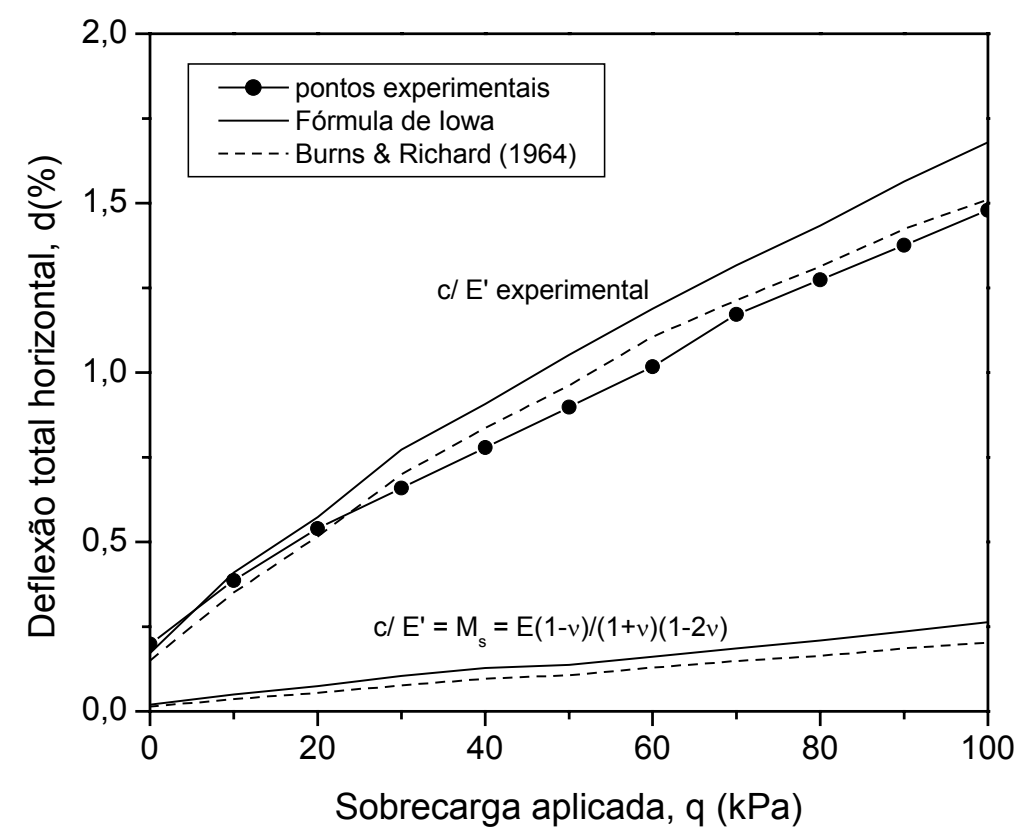

Figura 8.3. Variação da deflexão total horizontal do duto com a sobrecarga aplicada e previsões teóricas.

A Figura 8.4 exibe a variação da tensão no solo $(\sigma)$ com o carregamento aplicado (q), medida no topo, na linha d'água e sob a base do conduto. Recorda-se que a tensão nessa última posição foi medida $30 \mathrm{~mm}$ abaixo da base do conduto. A Figura 8.4a traz os resultados de um ensaio realizado com o maciço fofo e a $8.4 \mathrm{~b}$, de um teste com o maciço compacto. Observa-se uma variação aproximadamente linear de $\sigma$ com q, com a maior concentração de tensão ocorrendo no topo. Devido ao arqueamento do solo, a tensão medida no topo do tubo representa uma parcela da sobrecarga aplicada somada ao peso próprio do solo, de aproximadamente $7 \sim 8 \mathrm{kPa}$. Nota-se que o efeito do arqueamento é muito maior no maciço compacto, de sorte que as tensões em todas as posições medidas apresentaram-se substancialmente inferiores aos respectivos valores obtidos com o maciço fofo. O benefício de uma compactação adequada do solo da envoltória é evidente com esses resultados. 
No maciço compacto, sob uma tensão vertical no topo tão baixa, poder-se-ia cogitar, intuitivamente, que o tubo poderia sofrer uma ovalização vertical, mediante o estabelecimento de uma condição ativa no solo lateral, como fizeram Krizek et al. (1971). Isso de fato não ocorre porque a redução de tensão provocada pelo arqueamento não se restringe ao topo do tubo, mas se estende além dos limites da estrutura (vide Capítulo 6). Dessa forma, como se pôde constatar nas Figuras 8.4a e b, o nível de tensões na lateral do conduto também é atenuado, permitindo ao mesmo defletir por conta da carga no topo e aumentar ligeiramente o diâmetro horizontal.

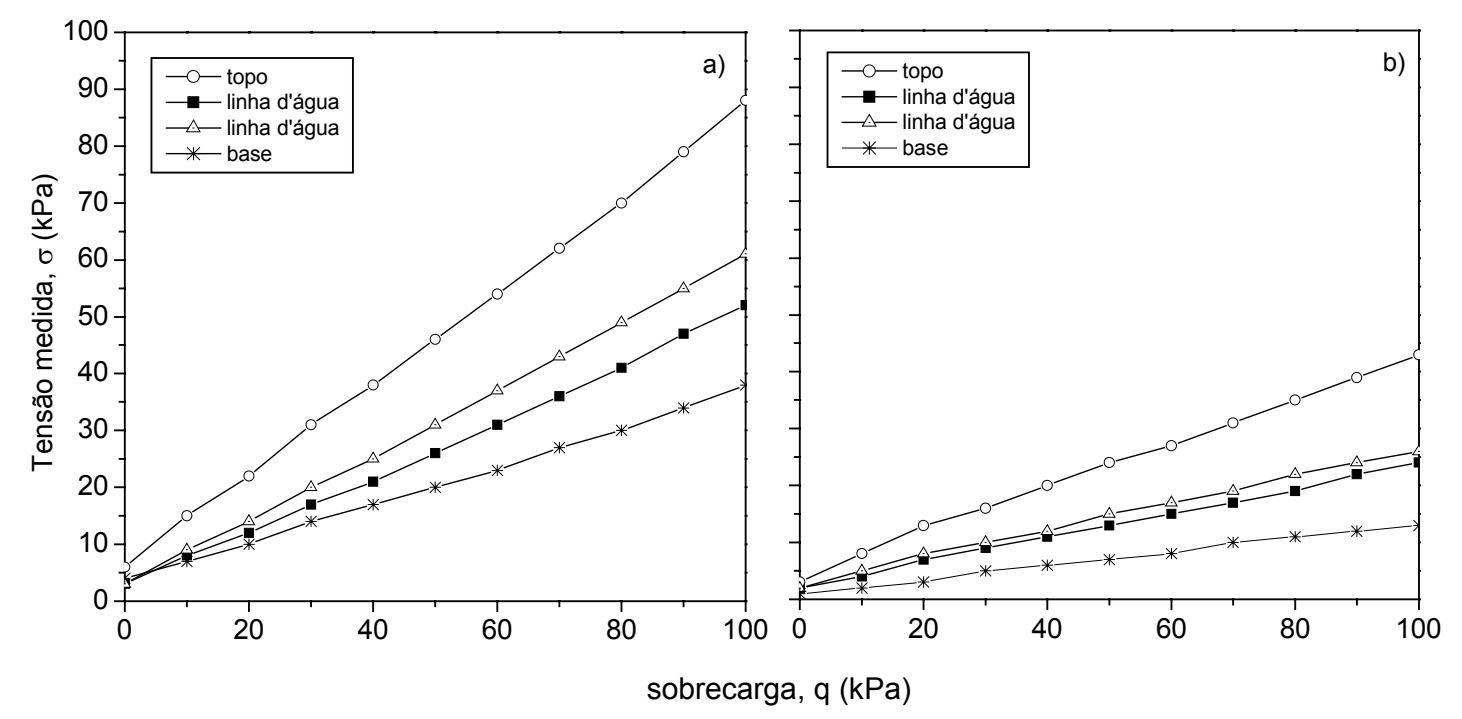

Figura 8.4. Variação das tensões no solo circundante com a aplicação da sobrecarga; a) maciço fofo, b) maciço compacto.

Uma vez conhecida a tensão e a deflexão na linha d'água, foi possível estimar o módulo de reação horizontal do solo (E') nos ensaios (já utilizado nas previsões do item anterior). Para tanto, calculou-se o coeficiente de reação do solo, $\mathrm{k}_{\mathrm{v}}$, definido como a razão entre a tensão e o deslocamento medidos nos pontos 3 e 7 da seção central S1 nos modelos. E' é dado como o produto de $\mathrm{k}_{\mathrm{v}}$ com o diâmetro do tubo (D). A Figura 8.5 mostra a variação de E' em função da densidade relativa do solo $\left(D_{r}\right)$ e da sobrecarga superficial (q). Observa-se que E' aumenta com o aumento de $D_{r}$, tornando-se tal tendência mais evidente com o aumento de q.

A variação de E' com a profundidade foi tema de muitas discussões até a publicação do trabalho de Hartley e Duncan (1987). A partir da análise de dados de 
diversas fontes da literatura, os autores constataram uma influência nítida da profundidade sobre E'. O aumento dessa variável com q na Figura 8.4 também pode ser visto como um aumento com a profundidade. Os dados mostram que a influência da profundidade sobre E' é tão maior quanto maior a densidade do solo. Os resultados obtidos nessa análise são da mesma ordem de grandeza dos valores publicados por Howard (1977) e Hartley e Duncan (1987).

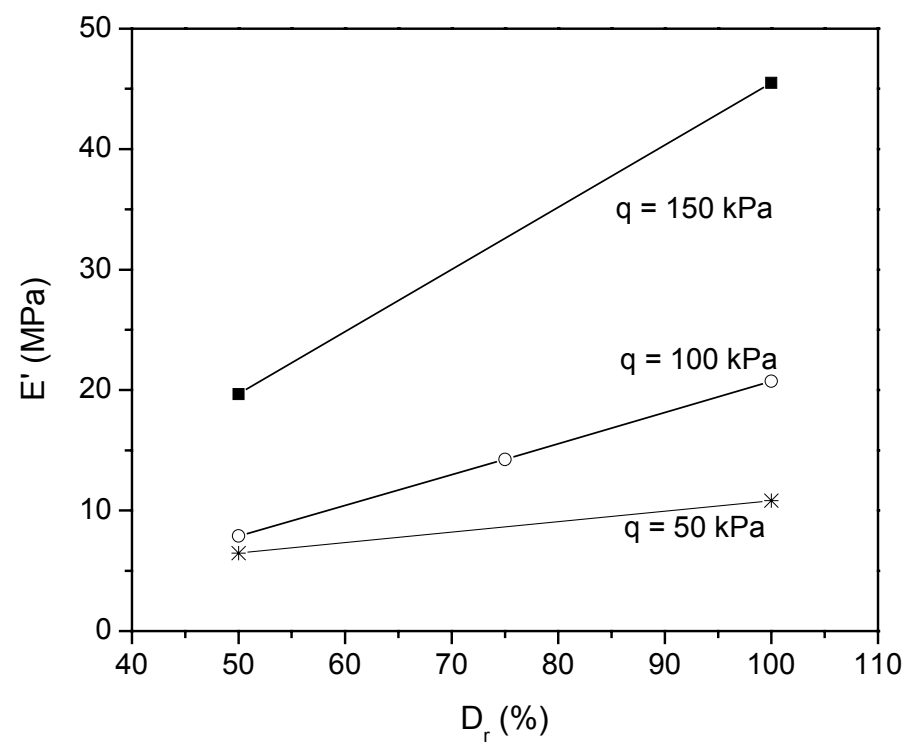

Figura 8.5. Variação do módulo E' com a densidade do solo e com a sobrecarga.

\subsection{DUTO SUBMETIDO A PERDA DE APOIO LOCALIZADA}

\subsubsection{Avaliação das Deflexões do Duto e da Deformada da Seção Central}

Os perfis longitudinais de deflexão do conduto apresentaram-se aproximadamente simétricos em relação ao eixo vertical também após a descida do alçapão. As maiores variações na deflexão ocorreram na seção $\mathrm{S} 1$, sendo gradualmente atenuadas até a seção S3. As variações não se restringiram à região sobre o alçapão: as deflexões do duto induzidas pela perda de apoio alcançaram uma distância $y_{i}$ fora do alçapão de até aproximadamente $5 \mathrm{D}$ (medida a partir da seção S3). Assim como nos modelos 
em centrífuga, em alguns casos houve elevação da base do duto e afundamento na região topo-ombro.

De maneira a exemplificar o comportamento observado, as Figuras 8.6 a 8.8 apresentam os perfis de deflexão ( $\left.\mathrm{d}^{*}\right)$ ao longo do comprimento do duto, registrados no ensaio $\mathrm{D} 7$, com $\mathrm{D}_{\mathrm{r}}=50 \%$ e q $=100 \mathrm{kPa}$. As deflexões são referentes aos deslocamentos relativos $(\delta / \mathrm{B})$ de 1,15 e $50 \%$, respectivamente, os quais foram selecionados de modo a representar condições iniciais, intermediárias e finais do comportamento do sistema. De maneira a fornecer uma noção do dano sofrido pelo tubo por conta da perda de apoio, cada uma das figuras é acompanhada pela respectiva deformada da seção transversal S1. Os números externos ao círculo indicam o valor da deflexão sofrida, em percentagem, majorada por um fator igual a 5. Os algarismos interiores marcam as posições dos pontos de leitura (1 e 5).

Nas figuras, pode-se constatar que a perturbação sofrida no topo e na base do tubo, devida à perda de suporte, atingiu uma distância $y_{i}$ máxima aproximadamente igual a 2,5 D. Porém, as deflexões observadas nas demais posições de medida atingiram distâncias ainda maiores, de até 4,5 D. Em $\delta / B=15 \%$ (Figura 8.7a), a base do tubo é caracterizada pela elevação já mencionada e também por duas regiões onde ocorrem recalques acentuados, num comportamento inverso ao registrado na região sobre o alçapão. Nessas regiões, os recalques máximos aconteceram nas posições 450 e 900 mm. Uma comparação das Figuras 8.7a e 8.8a mostra a ocorrência de uma considerável variação de $\mathrm{d}^{*}$ no topo, na base e na linha d'água na região do tubo sobre o alçapão entre os estágios $\delta / \mathrm{B}=15$ e $50 \%$. Por exemplo, o pico no perfil do topo em $\delta / \mathrm{B}=15 \%$ cedeu espaço a um perfil aproximadamente plano em $\delta / \mathrm{B}=50 \%$, com deflexões praticamente constantes. No entanto, as deflexões no exterior do alçapão variaram muito pouco com o aumento de $\delta / B$.

A evolução da deformação da seção $\mathrm{S} 1$ pode ser observada através das Figuras $8.6 \mathrm{~b}$ a $8.8 \mathrm{~b}$. Já no início do deslocamento do alçapão, em $\delta / \mathrm{B}=1 \%$ (Figura 8.6b), é possível detectar no duto o efeito da perda de suporte. A base e o assento acompanham o sentido descendente do deslocamento do alçapão, juntamente com o topo e o ombro. O diâmetro horizontal do duto sofre encurtamento até um valor próximo do original. Entretanto, a pior situação ocorreu em $\delta / B=15 \%$. Nesse patamar, a deformação é caracterizada pela reversão da curvatura do topo e pela 
elevação da base. Um severo aumento no diâmetro horizontal também é experimentado concomitantemente. O formato de "coração" é o que melhor descreve a aparência de $\mathrm{S} 1$ nesse estágio.

Quando o deslocamento relativo alcançou 50\%, a base voltou a apresentar recalque e o topo, elevação. A deflexão no ombro permaneceu praticamente estável e o diâmetro horizontal retornou a um valor próximo daquele registrado no início do deslocamento do alçapão. De maneira geral, a seção adquiriu um formato parecido com o observado em $\delta / \mathrm{B}=1 \%$.

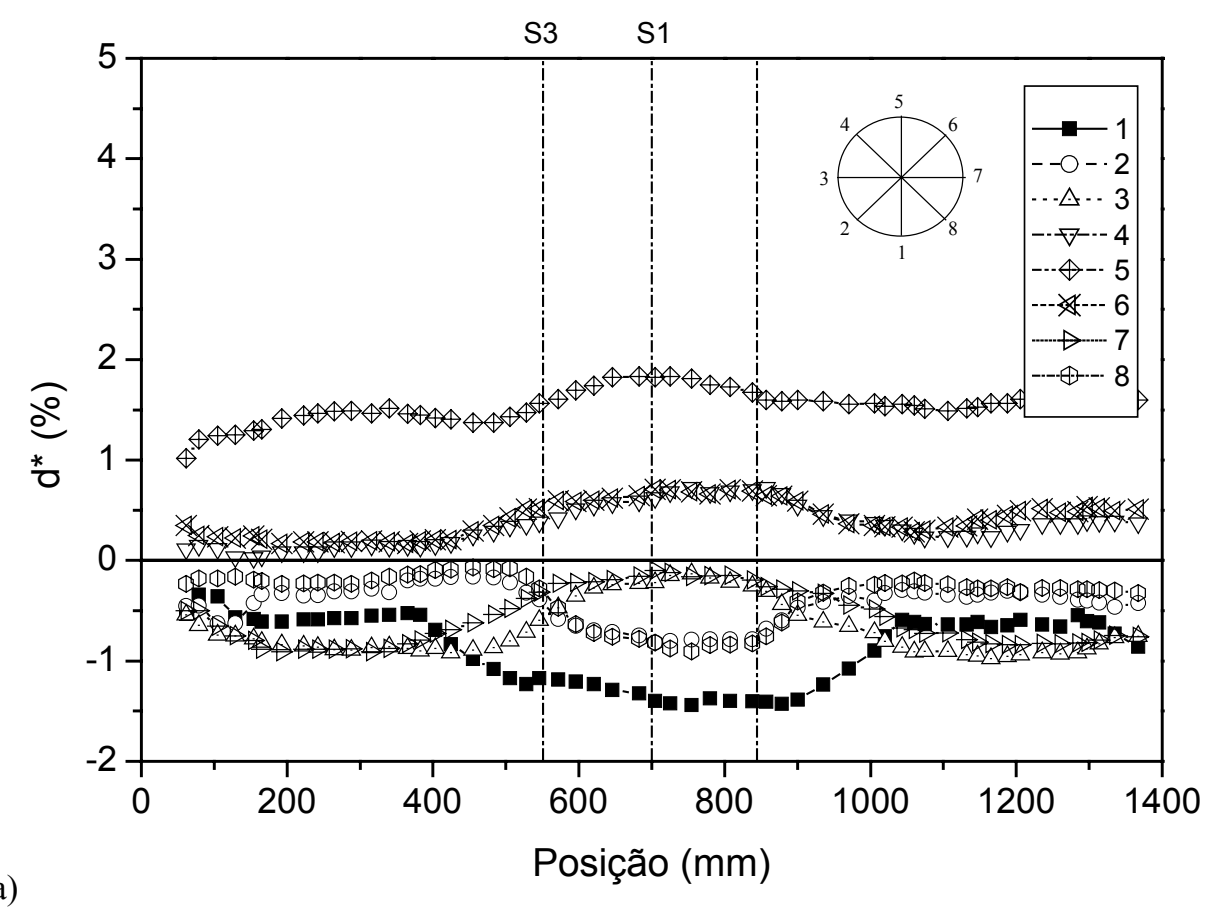

a)

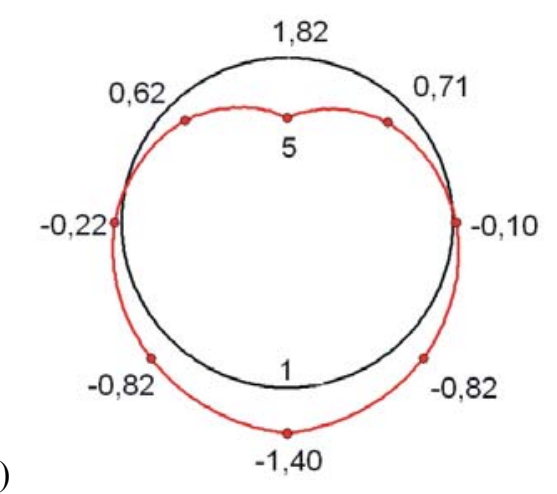

Figura 8.6. a) Perfil de deflexões ao longo do conduto e b) deformada da seção transversal $\mathrm{S} 1 \mathrm{em} \delta / \mathrm{B}=1 \%$ (ensaio D7). 


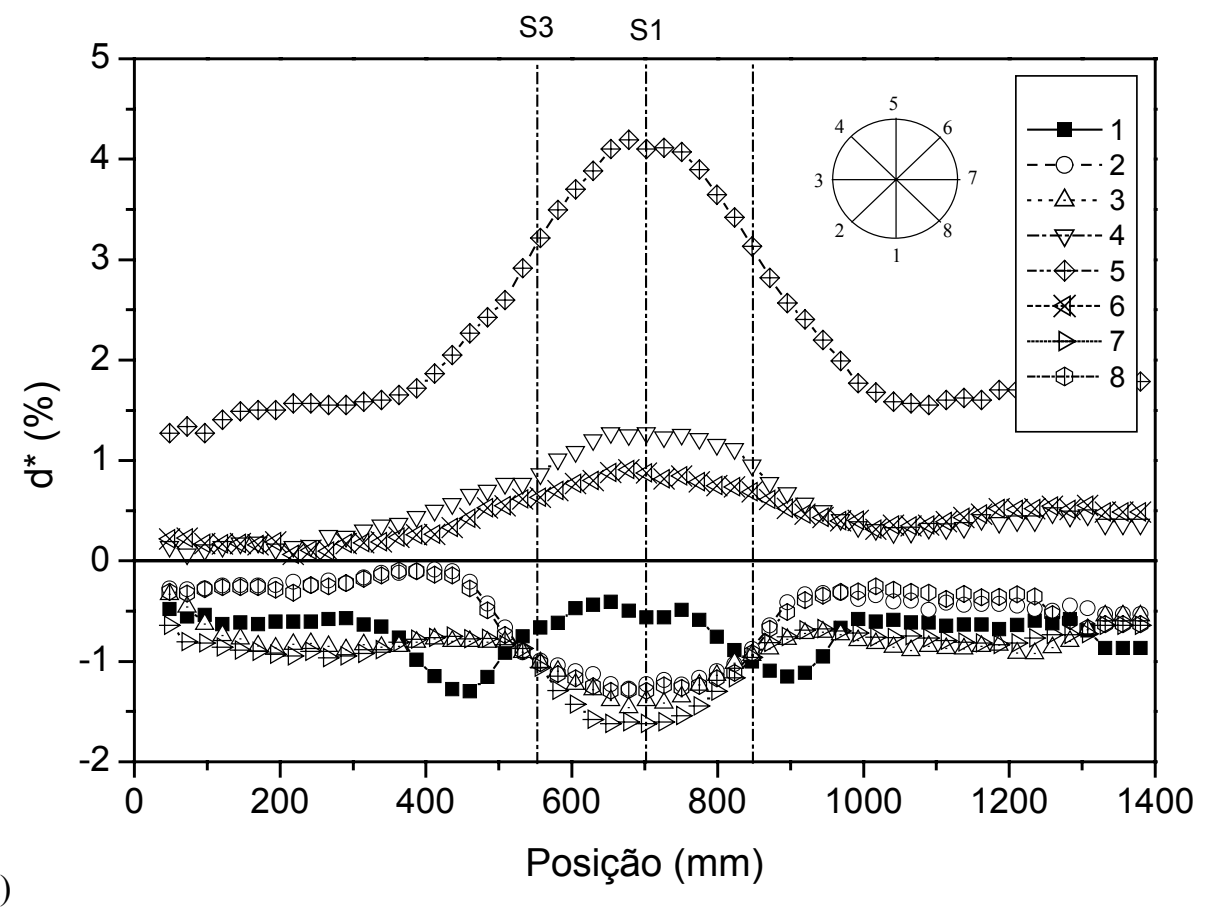

a)

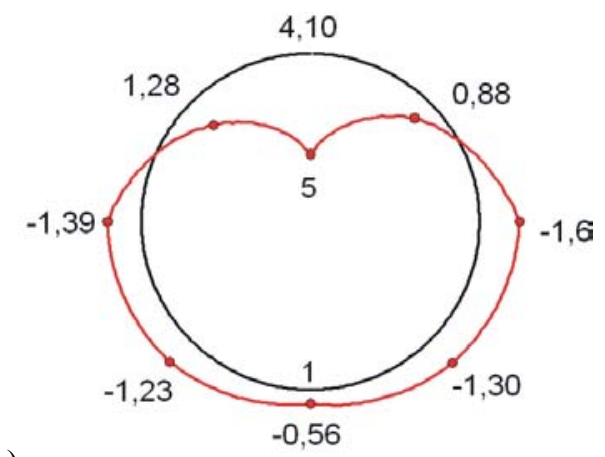

b)

Figura 8.7. a) Perfil de deflexões ao longo do conduto e b) deformada da seção transversal $\mathrm{S} 1 \mathrm{em} \delta / \mathrm{B}=15 \%$ (ensaio D7). 

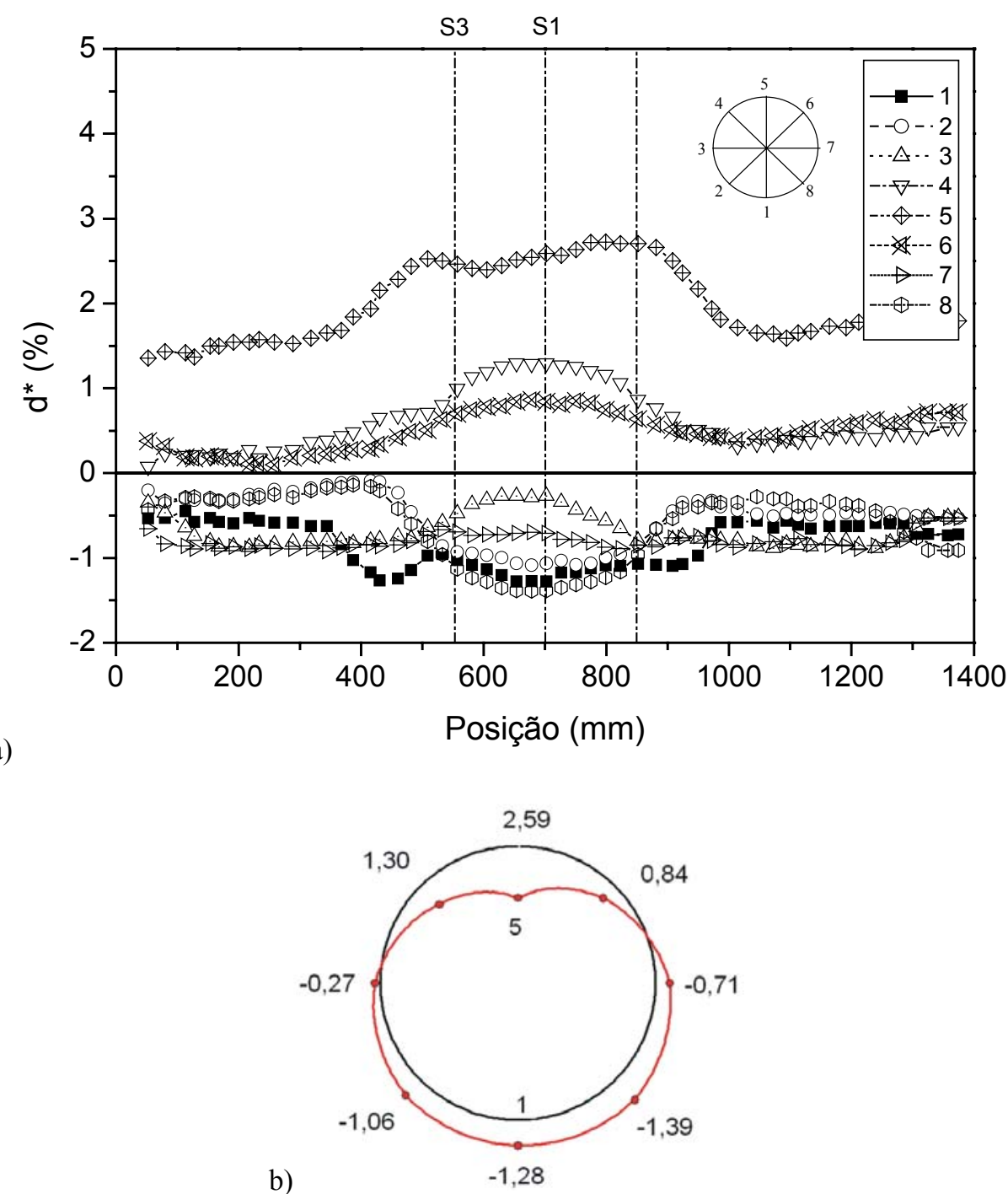

Figura 8.8. a) Perfil de deflexões ao longo do conduto e b) deformada da seção transversal $\mathrm{S} 1 \mathrm{em} \delta / \mathrm{B}=50 \%$ (ensaio D7).

O comportamento da deflexão $\left(\mathrm{d}^{*}\right)$ do conduto ao longo de todo o deslocamento do alçapão, nos oito pontos na seção S1, é dado na Figura 8.9. O desconfinamento lateral promovido pela descida do alçapão promoveu o recalque do topo (ponto 5) até $\delta / \mathrm{B}=15 \%$. Em seguida, o topo passa a apresentar elevação até o final do deslocamento do alçapão, recuperando parte da deflexão positiva sofrida. Tendência semelhante, porém consideravelmente menos pronunciada, foi observada no ombro (pontos 4 e 6), com um suave pico em $\delta / B=8 \%$, seguido de estabilização até o final do ensaio. 
A base do duto (ponto 1) apresentou um comportamento muito singular, com etapas sucessivas de recalque e elevação. Recalques iniciais abruptos ocorreram até $\delta / \mathrm{B}=1 \%$, seguidos de elevação entre $\delta / \mathrm{B}=1$ e $15 \%$. Em seguida, recalques tornaram a ocorrer novamente até o final do teste. O comportamento da linha d'água assemelhou-se ao da base, no sentido de que o diâmetro horizontal sofre encurtamentos e alongamentos sucessivos. As curvas dos pontos 3 e 7 possuem basicamente a mesma forma da curva da base, porém invertida. A variação de $\mathrm{d}^{*}$ no assento (pontos 2 e 8) foi comparativamente pequena durante todo o ensaio, ocorrendo praticamente até $\delta / \mathrm{B}=5 \%$. De maneira geral, a influência da translação do alçapão sobre a deflexão do tubo tornou-se muito pequena a partir de $\delta / B=30 \%$.

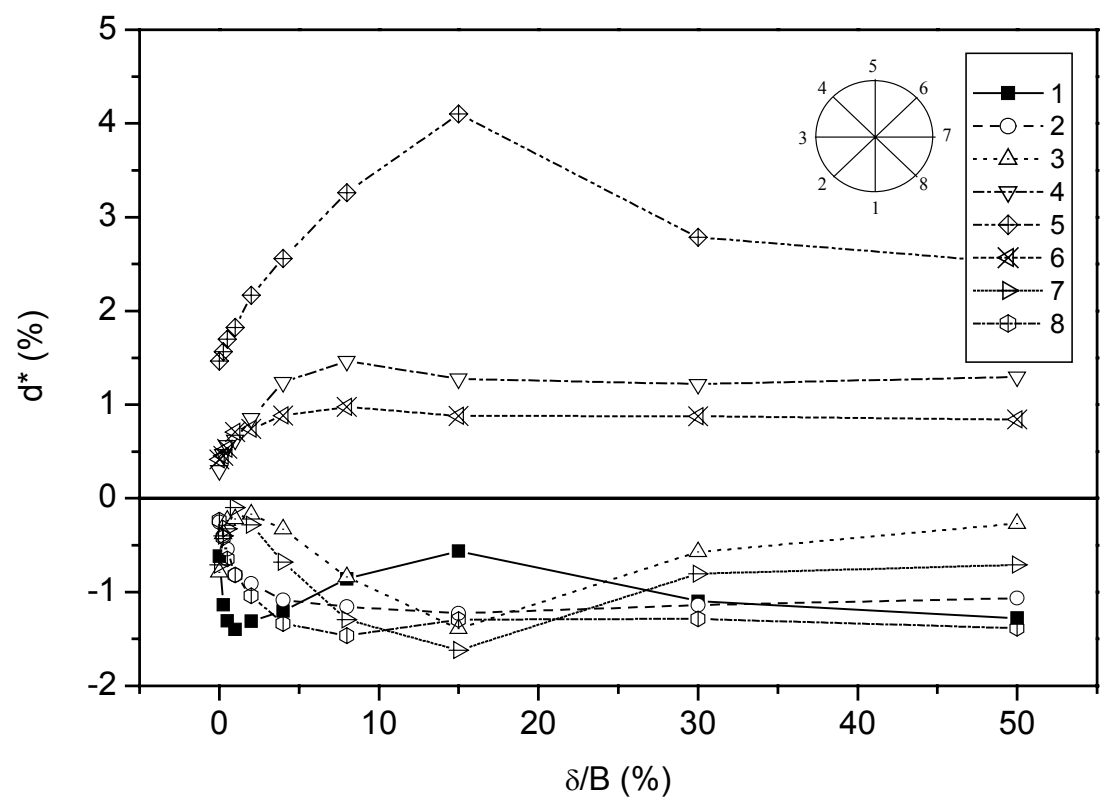

Figura 8.9. Variação da deflexão do duto com o deslocamento do alçapão na seção $\mathrm{S} 1$, com $\mathrm{D}_{\mathrm{r}}=50 \%$ e $\mathrm{q}=100 \mathrm{kPa}$ (ensaio D7).

\subsubsection{Influência da Densidade do Solo e da Sobrecarga Aplicada}

A Figura 8.10 compara as deflexões da seção $\mathrm{S} 1$, em deslocamentos relativos selecionados, obtidas nos maciços compacto $\left(D_{r}=100 \%\right)$, intermediário $\left(D_{r}=75 \%\right)$ e fofo $\left(D_{r}=50 \%\right)$. Os dados são provenientes de ensaios com sobrecarga de $100 \mathrm{kPa}$ e são referentes a $\delta / B=1,5,15$ e 50\%. Observa-se que as deflexões são significativamente maiores no solo de menor densidade, com destaque às variações registradas no topo e na linha d'água do duto. Com efeito, os maciços compacto e 
intermediário apresentaram valores de $\mathrm{d}^{*}$ comparativamente próximos em todos os pontos medidos ao longo da seção.

Particularmente, a influência de $\mathrm{D}_{\mathrm{r}}$ sobre o comportamento do tubo tornou-se bastante evidente quando o alçapão atingiu $\delta / B=15 \%$. Com efeito, o deslocamento relativo de $\delta / \mathrm{B}=15 \%$ reuniu as condições mais críticas de deflexão não somente nos ensaios cujos resultados são apresentado na Figura 8.10, mas em todos os modelos executados. Os maiores recalques do topo, os maiores aumentos do diâmetro horizontal e as maiores elevações da base foram registrados nesse patamar. As deflexões medidas nas densidades de 75 e 100\% após $\delta / B=15 \%$ se aproximaram mais das deflexões obtidas nesse nível crítico de deslocamento em comparação com o solo no estado mais fofo.

O recalque do topo do tubo durante a fase inicial da translação do alçapão foi notado em todas as condições ensaiadas, independentemente do nível de q imposto e da densidade do solo. A base praticamente não sofreu elevação no maciço compacto, o que concorda com os resultados dos ensaios dos modelos da série B.
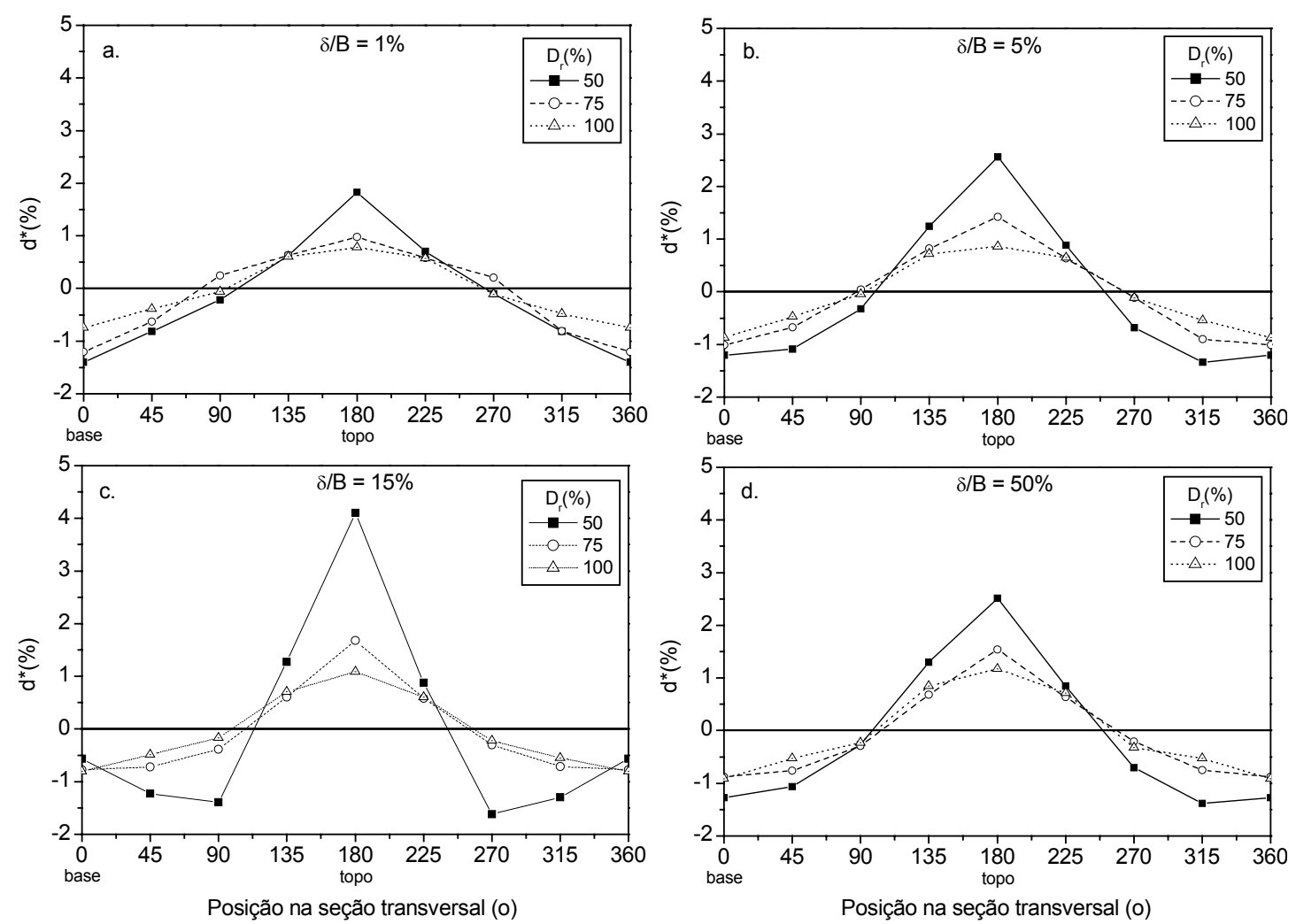

Figura 8.10. Deflexões na seção $\mathrm{S} 1$ com $\mathrm{D}_{\mathrm{r}}=50,75$ e $100 \%$ e sobrecarga de $100 \mathrm{kPa}$ para deslocamentos relativos selecionados. 
A Figura 8.11 mostra a variação de $\mathrm{d}^{*}$ ao longo do duto em $\delta / \mathrm{B}=15 \%$, para $\mathrm{D}_{\mathrm{r}}=50$ e $100 \%$. São exibidos apenas os resultados do topo, da base e de um dos pontos da linha d'água. Destaque é dado à diferença entre os perfis do topo e da base do conduto. O perfil do topo no maciço compacto apresentou um pico muito suave, limitando-se praticamente à região sobre o alçapão. Por outro lado, o perfil de deflexões na base é praticamente plano sobre o alçapão, não apresentando concavidades. A extensão das deflexões na região do duto exterior ao alçapão $\left(\mathrm{y}_{\mathrm{i}}\right)$ foi menor com o maciço compacto. No entanto, $y_{i}$ não aparentou sofrer influência da densidade do solo na linha d'água e na base.

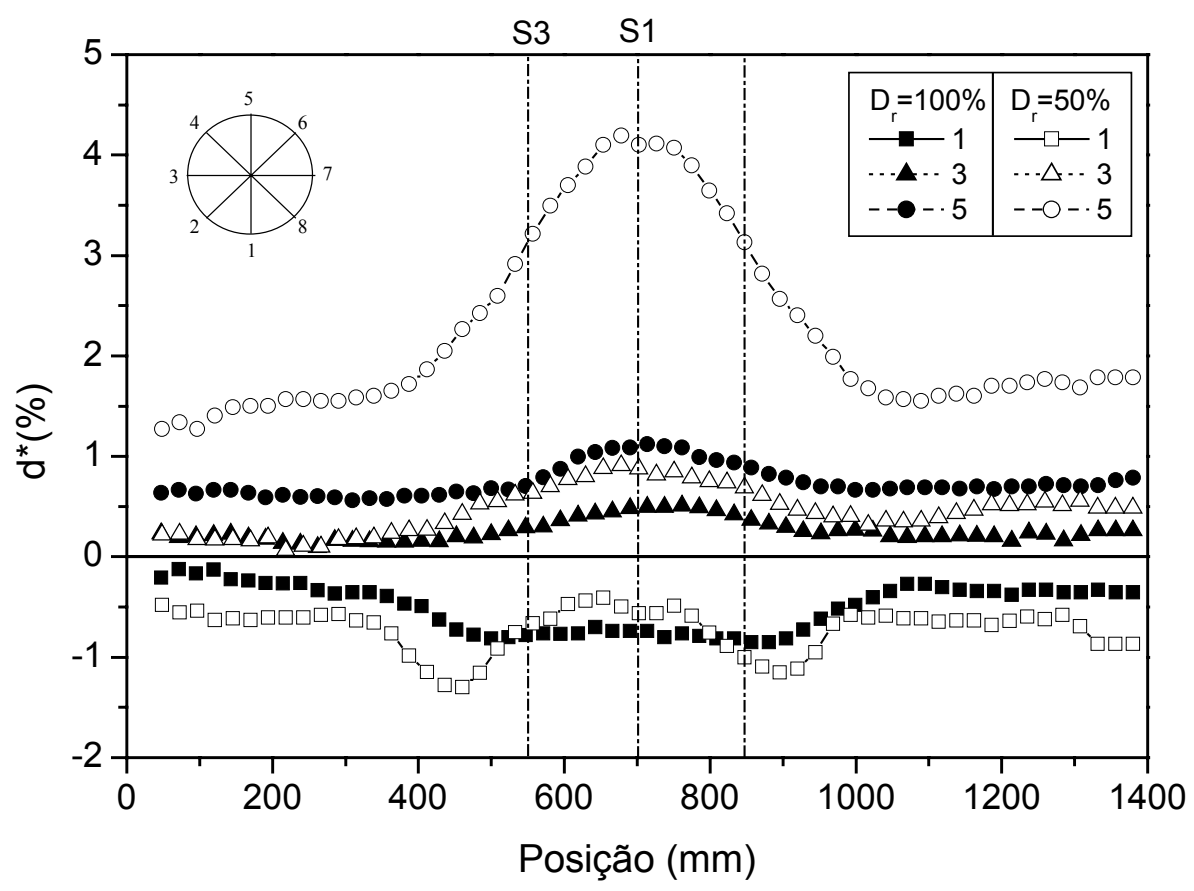

Figura 8.11. Perfis de deflexão em $\delta / B=15 \%$ para $D_{r}=50$ e $100 \%(q=100 \mathrm{kPa})$.

O grau de deformação do tubo pode ser avaliado de forma mais objetiva, face à influência das variáveis em estudo, através do um coeficiente de deflexão global (CDG), dado pela somatória dos módulos dos valores de deflexão dos pontos de medida de uma seção do duto (expressão 8.3). Quanto maior o CDG, maior é o dano associado à seção de interesse. A Figura 8.12 apresenta o comportamento do CDG na seção S1 para as três densidades relativas avaliadas, juntamente com linhas de 
tendência aos pontos experimentais. Apesar de só haver um ponto correspondente a $\mathrm{D}_{\mathrm{r}}=75 \%$, a respectiva reta foi disposta com base nas posições das outras duas.

Observa-se uma relação crescente e basicamente linear do CGD com a sobrecarga aplicada. Como esperado, a deformação do duto aumenta significativamente com a redução da densidade relativa do material, e as deformações sofridas nas densidades de 75 e 100\% são comparativamente mais próximas entre si.

$\mathrm{CDG}=\sum_{\mathrm{i}=1}^{8}|\mathrm{~d} *|$

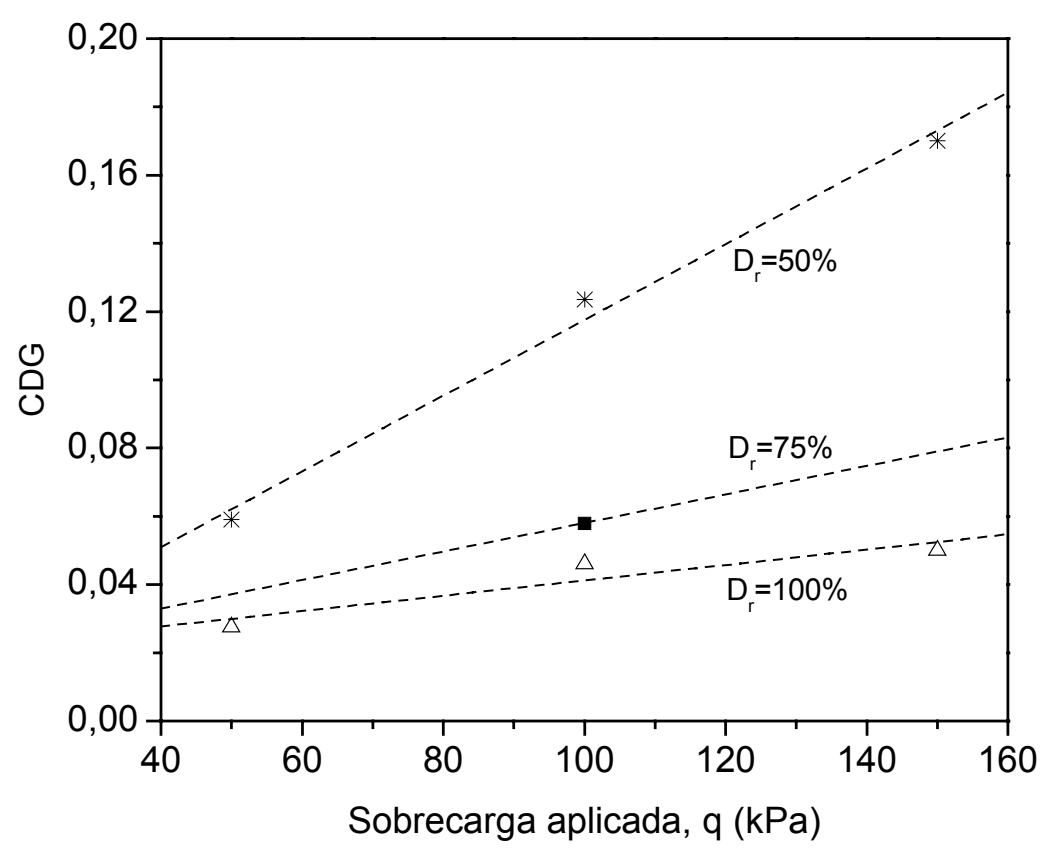

Figura 8.12. Coeficiente de deflexão global em função da sobrecarga e da densidade relativa do material na seção $\mathrm{S} 1$.

\subsubsection{Previsões dos Deslocamentos do Duto}

Como visto no Capítulo 2, a literatura conta com muito poucos métodos analíticos para a previsão do recalque de tubos enterrados. Em uma abordagem simplificada, um grupo de métodos assume o conduto como uma viga simplesmente apoiada ou engastada (Pearson 1977, AWWA 1989, Moser 2001). O recalque é então calculado 
através da equação da linha elástica. Entretanto, o conduto está em contato direto com o meio portante, de modo a despertar forças de reação contínuas após a deflexão. Uma outra classe de soluções (Hetényi 1946, Crofts et al. 1977, Rajani e Morgenstern 1993) leva esse aspecto em consideração através da Hipótese de Winkler (expressão 2.29). Dois dos métodos apresentados no Capítulo 2, pertencente a este último grupo de soluções, foram selecionados para as previsões a serem realizadas neste item, por representarem mais adequadamente o problema investigado. O Caso A considera que o conduto não experimenta nenhuma reação do solo após a perda de apoio. Já o Caso B assume que uma parcela da reação inicial disponível permanece após a descida do alçapão.

\section{Caso A}

Nesta abordagem (Figura 2.33b), o recalque do conduto no centro do alçapão (ponto E) é determinado calculando-se o momento fletor (M) e o esforço cortante (Q) nas extremidades do alçapão (pontos A e B), dados por:

$$
\mathrm{M}_{\mathrm{A}}=\mathrm{M}_{\mathrm{B}}=\frac{\mathrm{qL}_{\mathrm{v}} \alpha}{2 \lambda}
$$

$\mathrm{Q}_{\mathrm{A}}=-\mathrm{Q}_{\mathrm{B}}=\mathrm{qL}_{\mathrm{v}} / 2$

onde: $\lambda=\sqrt[4]{\frac{\mathrm{K}}{4 \mathrm{EI}}} ; \alpha=\frac{6-\lambda^{2} \cdot \mathrm{L}_{\mathrm{v}}^{2}}{6\left(2+\lambda \cdot \mathrm{L}_{\mathrm{v}}\right)} ; \mathrm{q}=$ sobrecarga no topo do duto por unidade de comprimento; $\mathrm{L}_{\mathrm{v}}=$ comprimento do alçapão.

K foi estimado nas análises utilizando a proposição de Vesic (1961) (expressão 8.6), recomendada por diversos autores (ex.: Selvadurai 1985, Rajani e Morgenstern 1993, Bowles 1996, Velloso e Lopes 1996). Os valores de $\mathrm{E}_{\mathrm{s}}$ e $v_{\mathrm{s}}$ foram obtidos da Tabela 4.4 .

$$
\mathrm{K}=0,65 \cdot \sqrt[12]{\frac{\mathrm{E}_{\mathrm{s}} \mathrm{D}^{4}}{\mathrm{EI}}} \frac{\mathrm{E}_{\mathrm{s}}}{1-\mathrm{v}_{\mathrm{s}}^{2}}
$$


Conhecendo-se o momento fletor e o esforço cortante nos pontos A e B (Figura $2.33 b$ ), o recalque no centro foi então estimado através da resolução da seguinte equação diferencial:

$E I \frac{d^{2} u}{d z^{2}}=M_{A}-Q_{A} y+\frac{q \cdot y^{2}}{2}$

Dispondo-se os eixos de referência no ponto A, a resolução de (8.7) é obtida segundo as seguintes condições de contorno:

a) $\mathrm{du} / \mathrm{dz}=0$ em $\mathrm{y}=\mathrm{L}_{\mathrm{v}} / 2$

b) $\mathrm{u}_{\mathrm{A}}=\mathrm{u}_{\mathrm{B}}=\frac{\mathrm{q} \lambda \mathrm{L}}{\mathrm{K}}(1-\alpha)$ em $\mathrm{y}=0$.

Caso B

Neste, a areia que preenche o espaço deixado pelo alçapão confere algum suporte ao duto. A perda parcial de suporte foi simulada utilizando valores de $\mathrm{K}$ iguais a $10 \%$ do valor calculado através de (8.6). O percentual foi selecionado com base no comportamento típico da tensão vertical medida na posição I1, no centro do alçapão, a qual decresce de maneira abrupta e se estabiliza em um valor em torno de $10 \%$ do inicial até $\delta / B=1 \%$. O recalque do duto na seção $\mathrm{S} 1$ foi obtido através da expressão (8.8).

$\mathrm{u}=\frac{\mathrm{q}}{\mathrm{K}}\left[1-\frac{2\left(\operatorname{senh} \frac{\lambda \mathrm{L}_{\mathrm{v}}}{2} \cdot \cos \frac{\lambda \mathrm{L}_{\mathrm{v}}}{2}+\cosh \frac{\lambda \mathrm{L}_{\mathrm{v}}}{2} \cdot \operatorname{sen} \frac{\lambda \mathrm{L}_{\mathrm{v}}}{2}\right)}{\operatorname{senh} \lambda \mathrm{L}_{\mathrm{v}}+\operatorname{sen} \lambda \mathrm{L}_{\mathrm{v}}}\right]$

As Figuras 8.13 e 8.14 apresentam o deslocamento previsto para o duto em função da sobrecarga aplicada (q), obtido com os modelos teóricos dos Casos A e B. As previsões são comparadas às deflexões experimentais devidas apenas à movimentação do alçapão $\left(\Delta \mathrm{d}^{*}\right)$, descontadas das deflexões iniciais por conta do carregamento, medidas no topo e na base do conduto para $\delta / B=15 \%$. Os dados referentes ao maciço fofo são agrupados na Figura 8.13 e os relativos ao maciço compacto, na Figura 8.14. 
No solo fofo, o modelo analítico do Caso B mostrou valores adequados para o recalque da base nas duas sobrecargas iniciais, porém muito aquém do experimental na sobrecarga de $150 \mathrm{kPa}$. O modelo do Caso A forneceu resultados mais próximos das deflexões experimentais medidas no topo.

No maciço compacto, o modelo do Caso A revelou-se muito conservador, prevendo valores muito maiores que os experimentais. Em contrapartida, o modelo do Caso B gerou resultados bem mais adequados, apresentando-se como um limite inferior dos resultados experimentais.

Essa avaliação mostra claramente a principal limitação dos modelos analíticos disponíveis para o cálculo de deslocamentos em condutos enterrados: que o deslocamento computado representa apenas o deslocamento da superfície neutra da tubulação. No entanto, cada parte do conduto apresenta perfis de deflexão com características particulares, o que não é contemplado nos métodos. A situação que melhor exemplifica tal falha é retratada na Figura 8.13, a qual mostra que a previsão fornecida pelo modelo do Caso A é ao mesmo tempo conservadora para a base do conduto e arrojada para o topo. Outra limitação dos métodos utilizados reside no fato de que os mesmos não são capazes de prever o deslocamento do duto em função do recalque do solo abaixo.

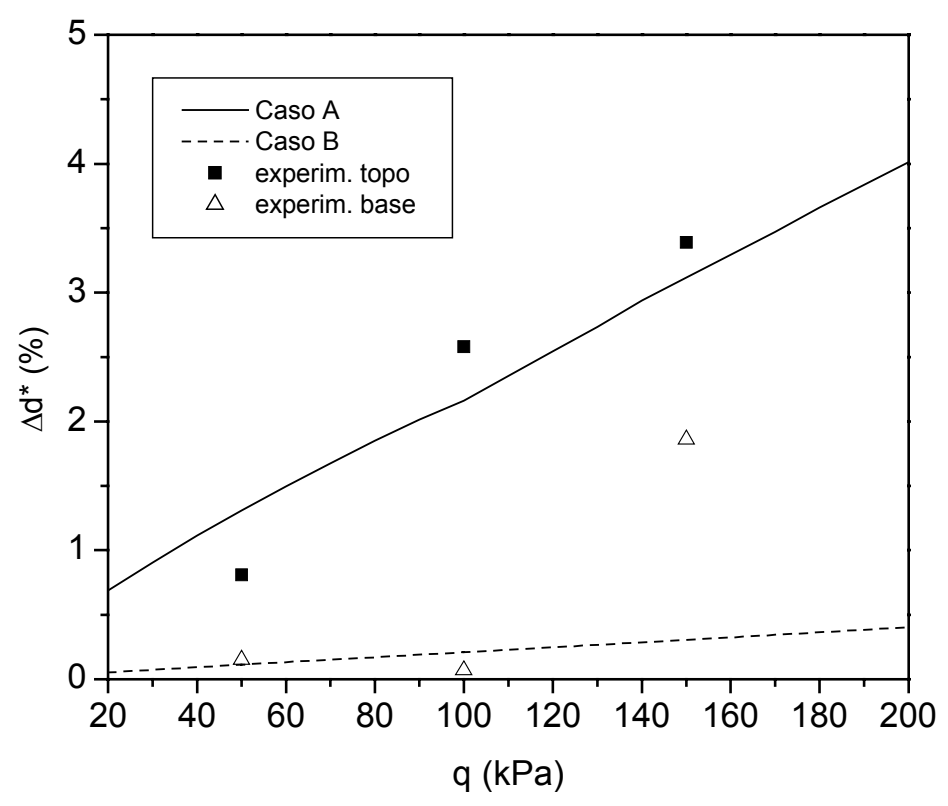

Figura 8.13. Previsões do deslocamento do conduto em maciço fofo. 


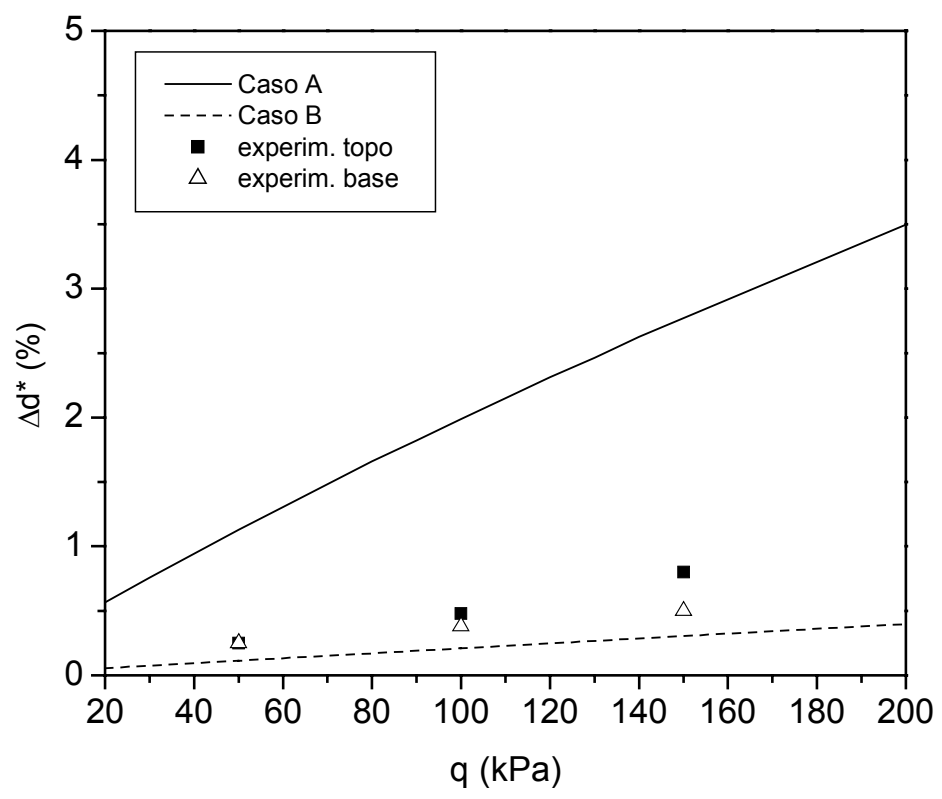

Figura 8.14. Previsões do deslocamento do conduto em maciço compacto.

\subsubsection{Avaliação das Tensões no Solo ao Redor do Duto}

A Figura 8.15 apresenta a variação da tensão total em torno do duto, na seção S1, com o deslocamento relativo $(\delta / \mathrm{B})$. Os dados são pertencentes ao modelo D7, executado com maciço fofo $\left(\mathrm{D}_{\mathrm{r}}=50 \%\right)$ e sobrecarga $(\mathrm{q})$ de $100 \mathrm{kPa}$. Nas posições M1 e M3 mediu-se a tensão horizontal $\left(\sigma_{h}\right)$ atuante próximo à linha d'água, ao passo que nas posições M2 e M4, mediu-se a tensão vertical $\left(\sigma_{v}\right)$ atuante sobre o topo do tubo. M4 encontra-se a aproximadamente 1,5D de distância do topo. Os valores encontram-se normalizados pela tensão inicial $\left(\sigma_{\mathrm{i}}\right)$.

A curva de M2 mostra que a condição inicial de arqueamento ativo que se instalou no topo do duto após a aplicação do carregamento (Figura 8.4) continuou durante a fase de movimentação do alçapão. A deflexão positiva sofrida pelo topo (Figura 8.9) foi acompanhada por uma redução abrupta da tensão após o início do deslocamento do alçapão. Entretanto, uma perda momentânea do efeito do arqueamento ocorreu a partir de $\delta / \mathrm{B}=8 \%$, com a tensão apresentando aumento até $\delta / \mathrm{B}=15 \%$. A Figura 8.9 mostra a ocorrência de recalque do topo entre $\delta / \mathrm{B}=0$ e $15 \%$. No entanto, a redução da tensão entre $\delta / B=0$ e $8 \%$ pode ser explicada assumindo-se que o recalque do topo do duto foi maior que o recalque da massa 
adjacente. Já entre $\delta / B=8$ e $15 \%$, o contrario teria ocorrido, tendo como conseqüência o aumento da tensão. Com efeito, é verificado na Figura 8.9 que a taxa de crescimento de $d^{*}$ sofre redução paulatina ate $\delta / B=8 \%$. Por outro lado, a redução da tensão na massa adjacente deve ter incluído o topo do tubo nos deslocamentos mais adiantados do alçapão, contribuindo para a diminuição da tensão vertical no local. Isso pode explicar porque a tensão volta a diminuir após $\delta / \mathrm{B}=15 \%$ mesmo com a subida do topo. Na posição M4 apenas é observada a redução de $\sigma$ com a translação do alçapão.

Os resultados dos demais ensaios mostraram que o deslocamento relativo necessário para a ocorrência da máxima tensão de recuperação no topo do duto foi ligeiramente maior para maiores sobrecargas aplicadas. Nenhuma variação com $D_{r}$ foi observada a esse respeito.

A redução inicial de $d^{*}$ na linha d'água até $\delta / B=1 \%$, como mostra a Figura 8.9, foi acompanhada pela diminuição de tensão (pontos M1 e M3 na Figura 8.15). A tensão nessa localidade atingiu o valor mínimo em $\delta / B=15 \%$ e praticamente permaneceu neste mesmo patamar até o fimm da translação do alçapão. O aumento da deflexão na linha d'água entre $\delta / B=1$ e 15\% (Figura 8.9) não foi acompanhado por aumento da tensão, uma vez que o tubo não mais podia contar com nenhuma resistência do solo lateral.

A variação da tensão na linha d'água apresentou um comportamento singular no maciço compacto $\left(D_{r}=100 \%\right)$, também caracterizado por um pico, porém bastante acentuado, superior à tensão inicial. A Figura 8.16 mostra a variação de $\sigma$ e $\mathrm{d}^{*}$ para $\mathrm{q}=100 \mathrm{kPa}$. O aumento da deflexão a partir de $\delta / \mathrm{B}=2 \%$ foi acompanhado por um aumento considerável da tensão até $\delta / B=8 \%$, a qual decaiu novamente em seguida até se tornar praticamente nula em $\delta / \mathrm{B}=15 \%$. Ao contrário do estado fofo, $\mathrm{o}$ solo compacto nas laterais do tubo foi capaz de conferir alguma reação ao aumento do diâmetro horizontal. Com a continuidade dos deslocamentos, a diminuição do diâmetro horizontal, juntamente com o efeito do arqueamento do solo na região, provocou a redução da tensão na linha d'água a valores próximos de zero. O pico de tensão na linha d'água não apresentou nenhuma variação com a sobrecarga aplicada. 


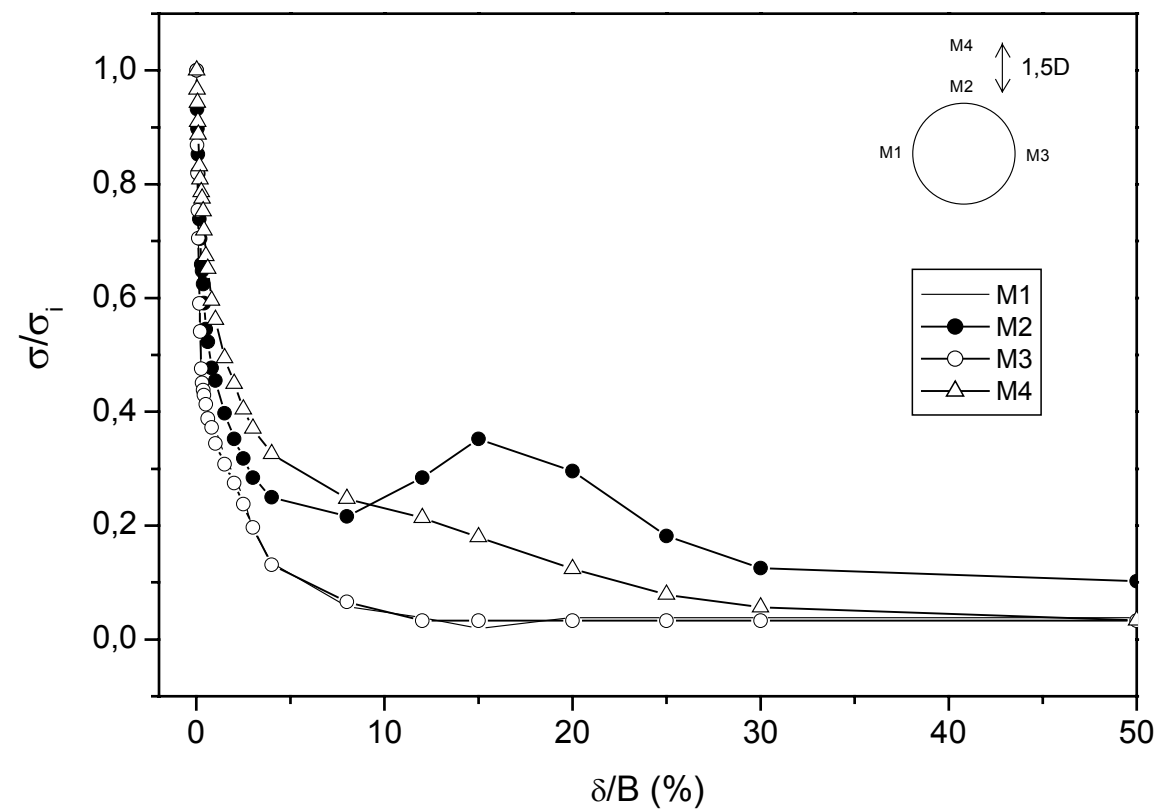

Figura 8.15. Variação da tensão no solo em torno da seção S1 no ensaio D7.

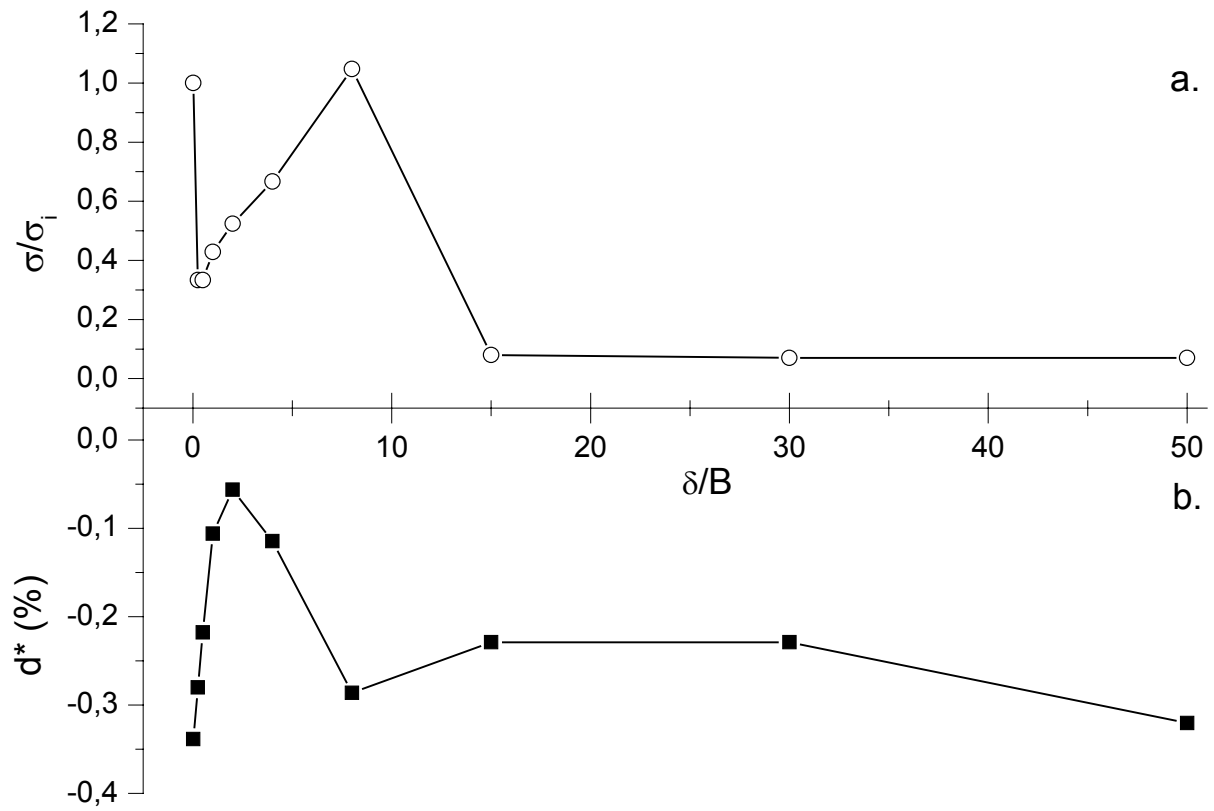

Figura 8.16. a) Variação da tensão e b) variação da deflexão alçapão em ensaio realizado com $\mathrm{D}_{\mathrm{r}}=100 \%$ e $\mathrm{q}=100 \mathrm{kPa}$. 
O comportamento de $\sigma$ em S3 assemelhou-se ao observado em S1 (Figura 8.17). Entretanto, a variação da tensão no solo foi comparativamente menor em S3 para um determinado deslocamento relativo, principalmente no topo do duto (posição M6). Por exemplo, em $\delta / \mathrm{B}=8 \% \sigma$ decaiu a $0,2 \sigma_{\mathrm{i}}$ em S1 e a $0,5 \sigma_{\mathrm{i}}$ em S3. Além disso, a recuperação temporária da tensão no topo do duto foi menos acentuada em S3. Os resultados na linha d'água seguiram a mesma tendência. Valores mais tênues das variáveis medidas junto à aresta do alçapão podem ser explicados pelo efeito de borda que ocorre nesse local, comportamento discutido nos Capítulos 5 e 6 .

Os resultados obtidos por Hachiya et al. (2002), Figura 2.24, revelaram aumento da tensão medida no topo do duto, na região sobre o alçapão, após sua movimentação. Esse comportamento aparenta ser coerente, uma vez que o problema estudado pelos autores envolvia o recalque de uma região extensa do maciço (perda de apoio generalizada), com $\mathrm{B} / \mathrm{D}=5$, contra $\mathrm{B} / \mathrm{D}=1,3$ nos testes do presente trabalho. Dessa forma, o efeito resultante do arqueamento mobilizado após a translação do alçapão é bastante inferior (ou até mesmo nulo) comparativamente àquele obtido nos modelos que simulam a perda de apoio localizada. Como resultado, houve aumento da tensão no topo do tubo sobre o alçapão, em virtude do peso do solo deslocado.

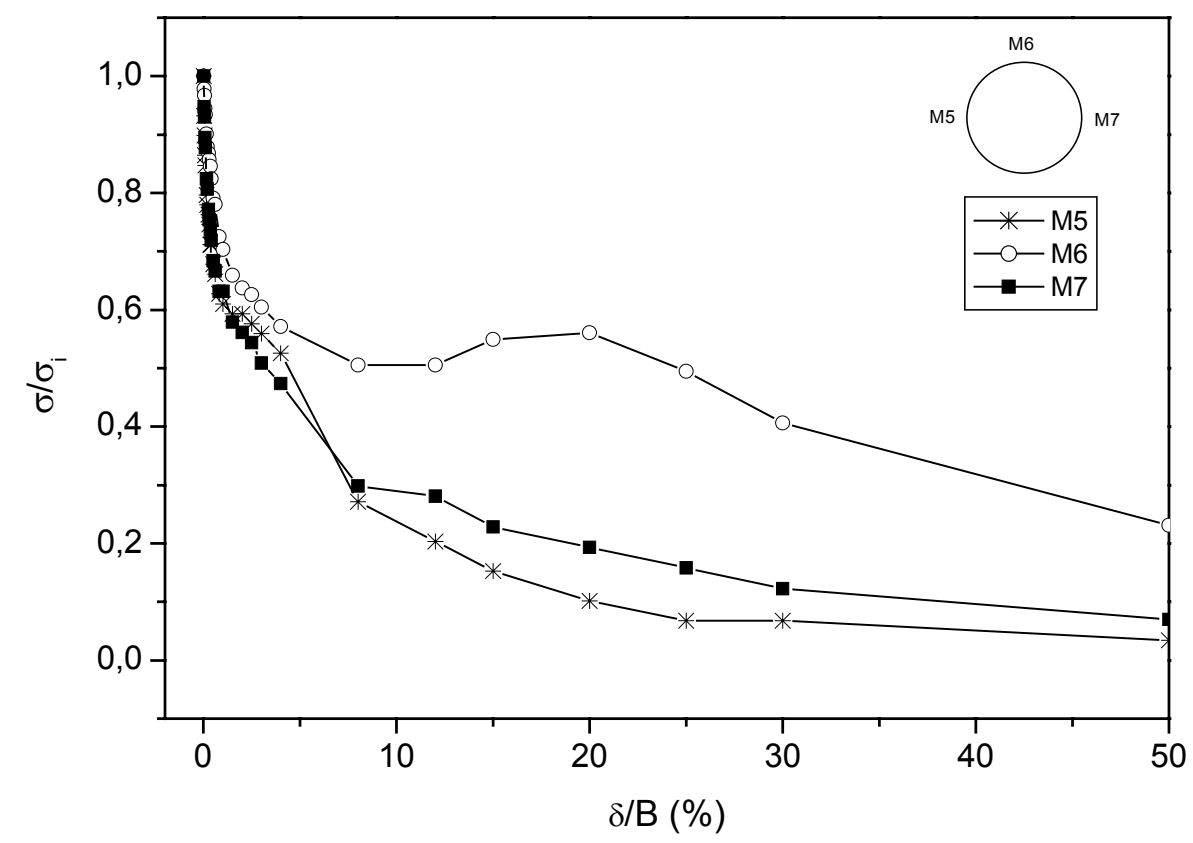

Figura 8.17. Variação da tensão no solo em torno da seção S3 no ensaio D7. 
A influência da densidade do solo e da sobrecarga sobre a transferência de tensão no solo circundante durante a movimentação do alçapão é investigada a seguir. A Figura 8.18 mostra a mínima tensão vertical $\left(\sigma_{\mathrm{va}}\right)$ em função da sobrecarga (q), registrada no topo da seção S1 dos modelos. O solo compacto é capaz de transferir mais a carga do topo do conduto para outras regiões em virtude de sua maior resistência ao cisalhamento, porém o efeito da densidade é relativamente pequeno. $\mathrm{O}$ efeito da sobrecarga sobre $\sigma_{\mathrm{va}}$ aparenta ser mais pronunciado.

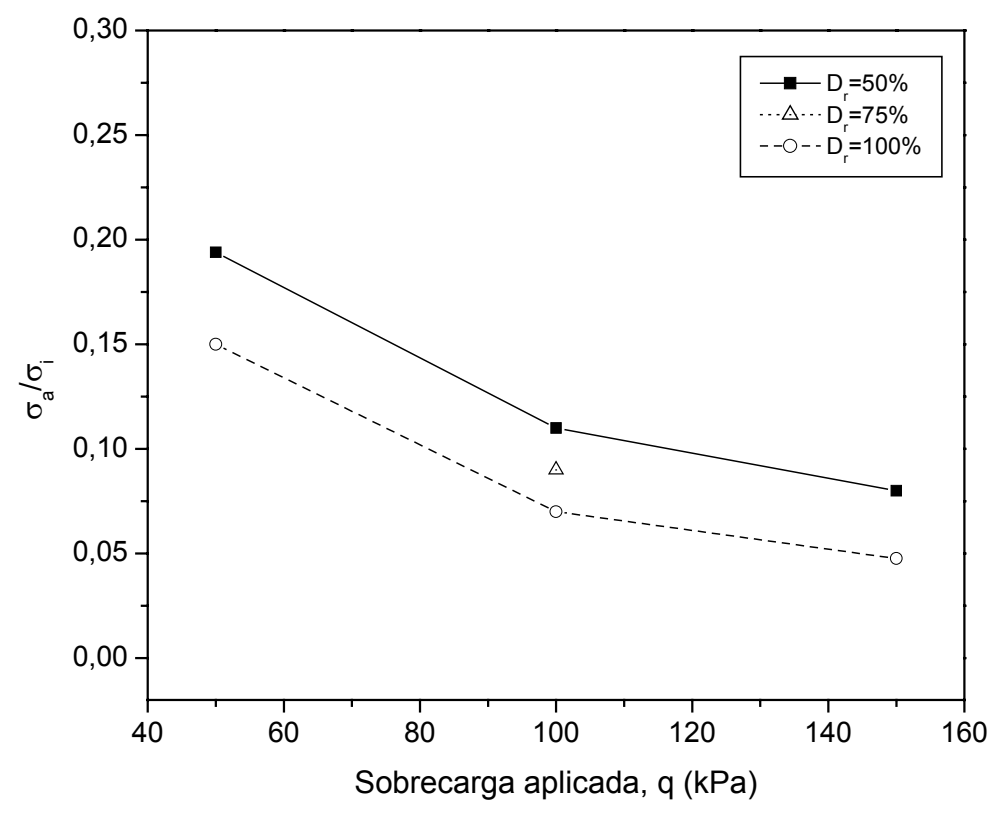

Figura 8.18. Variação da mínima tensão sobre o topo do duto após a perda de apoio.

A Figura 8.19 apresenta a variação da tensão vertical $\left(\sigma_{v}\right)$ com a movimentação do alçapão, medida em diversos pontos na base da caixa de testes $\left(\mathrm{H}_{\mathrm{e}} / \mathrm{B}=0\right)$, de acordo com a disposição ilustrada na Figura 4.9. Os resultados são referentes aos modelos executados com $\mathrm{D}_{\mathrm{r}}=50,75$ e $100 \%$ e sobrecarga $\mathrm{q}=100$ $\mathrm{kPa}$. Imediatamente após o início dos deslocamentos do alçapão, um ligeiro aumento na tensão vertical foi registrado em $\mathrm{x}_{\mathrm{i}} / \mathrm{B}=0,2$ (I4), como mostra a Figura 8.19a. Com o avanço de $\delta, \sigma_{\mathrm{v}}$ sofreu uma redução abrupta até próximo de zero, estabilizando-se em seguida. O efeito do arqueamento nessa região foi superior ao observado no topo e na linha d'água do tubo. Como exibe a Figura 8.19 b, o alívio de tensão também foi proeminente em $\mathrm{x}_{\mathrm{i}} / \mathrm{B}=0,8$ (I5), porém menor que em $\mathrm{x}_{\mathrm{i}} / \mathrm{B}=0,2$. A redução da 
tensão nessa posição foi ainda maior que a ocorrida nos ensaios correspondentes sem o tubo.

O fato da tensão vertical diminuir mais na presença do duto, após a movimentação do alçapão, concorda com as análises do item 7.2.1.2 (Capítulo 7), em que se verificou que a extensão $x_{i}$ das localizações exteriores aumenta na presença do conduto e a inclinação com a horizontal $\left(\theta_{\mathrm{e}}\right)$, diminui. Localizações mais inclinadas para a horizontal aumentam a zona de alívio no solo (ver Figura 6.11).

Sob o tubo, em $\mathrm{y}_{\mathrm{i}} / \mathrm{B}=0,2$ (I6), a tensão apresentou um comportamento semelhante ao verificado em I4 e I5, sofrendo um ligeiro aumento no início da translação e decréscimo em seguida (Figura 8.19c). Em y $\mathrm{i} / \mathrm{B}=0,8$ e 2,7 (posições I7 e I8, respectivamente) a tensão aumentou gradualmente até o final do deslocamento do alçapão, em decorrência da transferência de parte da carga das regiões mais próximas.

A influência da densidade do solo sobre a variação da tensão foi relativamente pequena, tendo se manifestado mais em $\mathrm{x}_{\mathrm{i}} / \mathrm{B}=0,8$ (Figura 8.19b). Nas posições I4, I5 e I6, para um mesmo deslocamento $\delta / B$, a magnitude da tensão vertical foi inversamente proporcional à densidade relativa do material, por conta da maior abrangência da zona cisalhante, a qual é tão maior quanto menor a dilatação do solo. Nas posições I7 e I8 (Figuras 8.19d e 8.19e), o efeito da densidade do solo foi menos evidente, não demonstrando uma tendência clara.

\subsubsection{Avaliação das Deformações na Parede do Duto}

O comportamento da deformação específica $(\varepsilon)$ da parede externa do duto, com o deslocamento do alçapão, é mostrado nas Figuras 8.20 a 8.22. As deformações foram medidas em oito pontos distintos distribuídos em torno da seção S1 (ver Figura 4.11), nos sentidos transversal e longitudinal. Os dados são pertencentes aos testes F1 e F2, realizados com maciço nos estados fofo $\left(D_{r}=50 \%\right)$ e compacto $\left(D_{r}=\right.$ $100 \%$ ), ambos com sobrecarga de $100 \mathrm{kPa}$. Convencionou-se deformação negativa representando compressão da parede. 

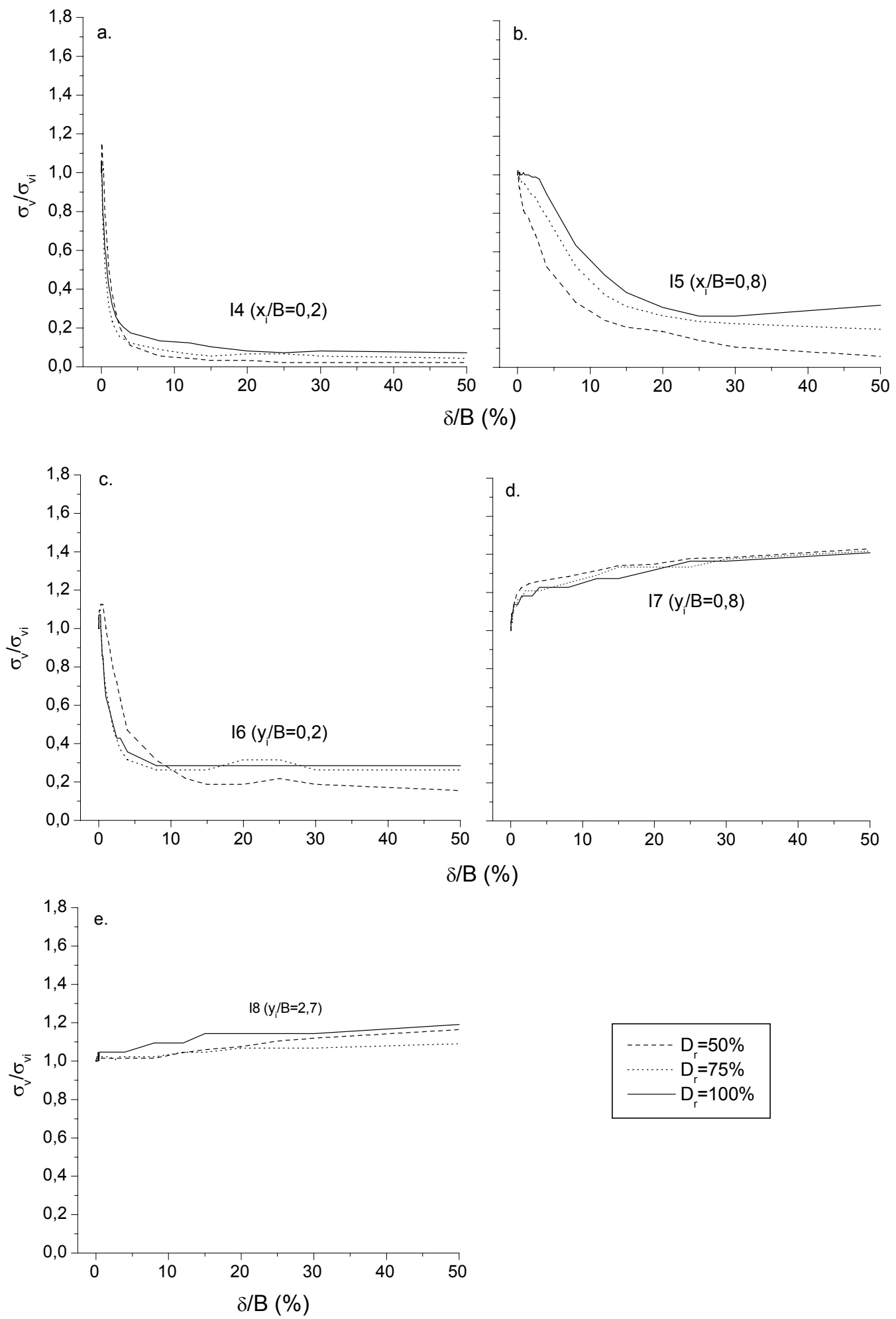

Figura 8.19. Variação da tensão vertical em $\mathrm{H}_{\mathrm{e}} / \mathrm{B}=0$ para tubos sofrendo perda de apoio em maciços com densidades relativas de 50, 75 e $100 \%$ e sobrecarga de 100 $\mathrm{kPa}$. 
No topo do conduto, sentido transversal (Figura 8.20a), houve uma extensão inicial da parede em deslocamentos $\delta / B$ inferiores a 5\%. Em seguida, registrou-se compressão até $\delta / \mathrm{B}=12 \%$, e novamente extensão até o término da translação do alçapão. No sentido longitudinal (Figura 8.20b) as medidas revelaram compressão seguida de extensão, sendo a magnitude das deformações comparativamente elevada. Esses dados indicam a formação de uma depressão no topo do tubo, após o deslocamento do alçapão (ver Figuras 8.7 e 8.8 ).
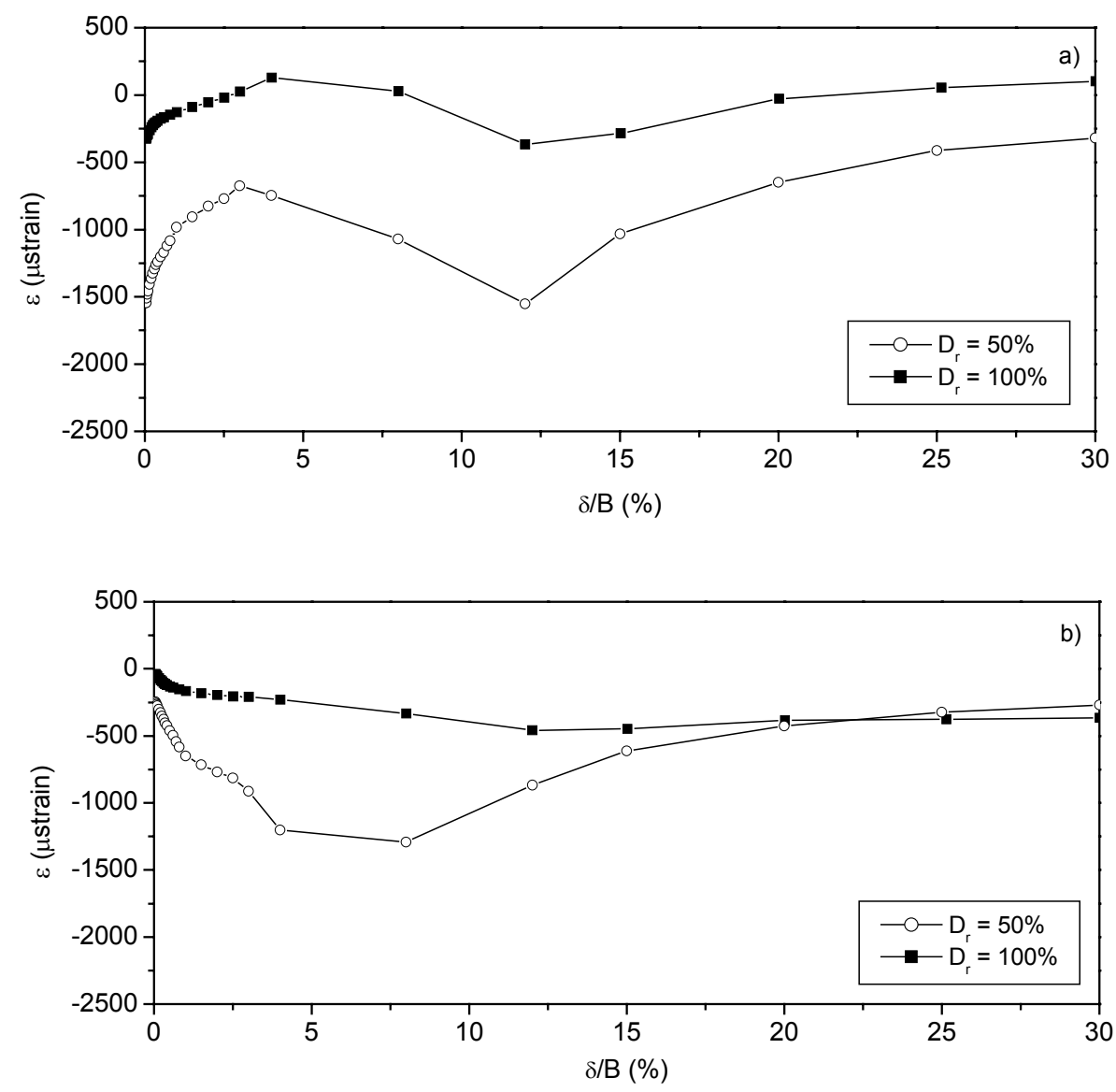

Figura 8.20. Variação da deformação da parede do conduto com o deslocamento do alçapão (topo), com $100 \mathrm{kPa}$ de sobrecarga. a) deformação transversal; b) deformação longitudinal.

A deformação longitudinal na base e na linha d'água do conduto foi muito inferior à medida no topo, exercendo, portanto, um papel muito menor nas deformações transversais, pelo efeito de Poisson. Como conseqüência, houve uma 
relação bastante próxima com respeito ao significado das deformações transversais medidas e as deflexões registradas nas respectivas posições.

Na base do conduto, a deformação inicial de 750 e $1000 \mu$ strain no sentido transversal (Figura 8.21a) é decorrente do recalque sofrido durante a fase de carregamento (Figura $8.2 \mathrm{~b}$ ). A compressão que se sucede até $\delta / B=1 \%$ não foi compatível com a descida da base nesse intervalo, mostrada na curva $n^{0} 1$ da Figura 8.9. Na verdade, tal compressão ocorreu em virtude da extensão registrada no sentido longitudinal até aproximadamente $\delta / \mathrm{B}=1,5 \%$ (Figura $8.21 \mathrm{~b}$ ). Não obstante, a extensão ao final dos deslocamentos do alçapão (para a curva correspondente a $D_{r}=$ $50 \%$ ) concorda com a descida subseqüente da base a partir de $\delta / \mathrm{B}=15 \%$, como indica a Figura 8.9. O efeito de Poisson é muito desprezível nesse estágio, por $\varepsilon$ ser constante com $\delta /$ B (Figura 8.21b).
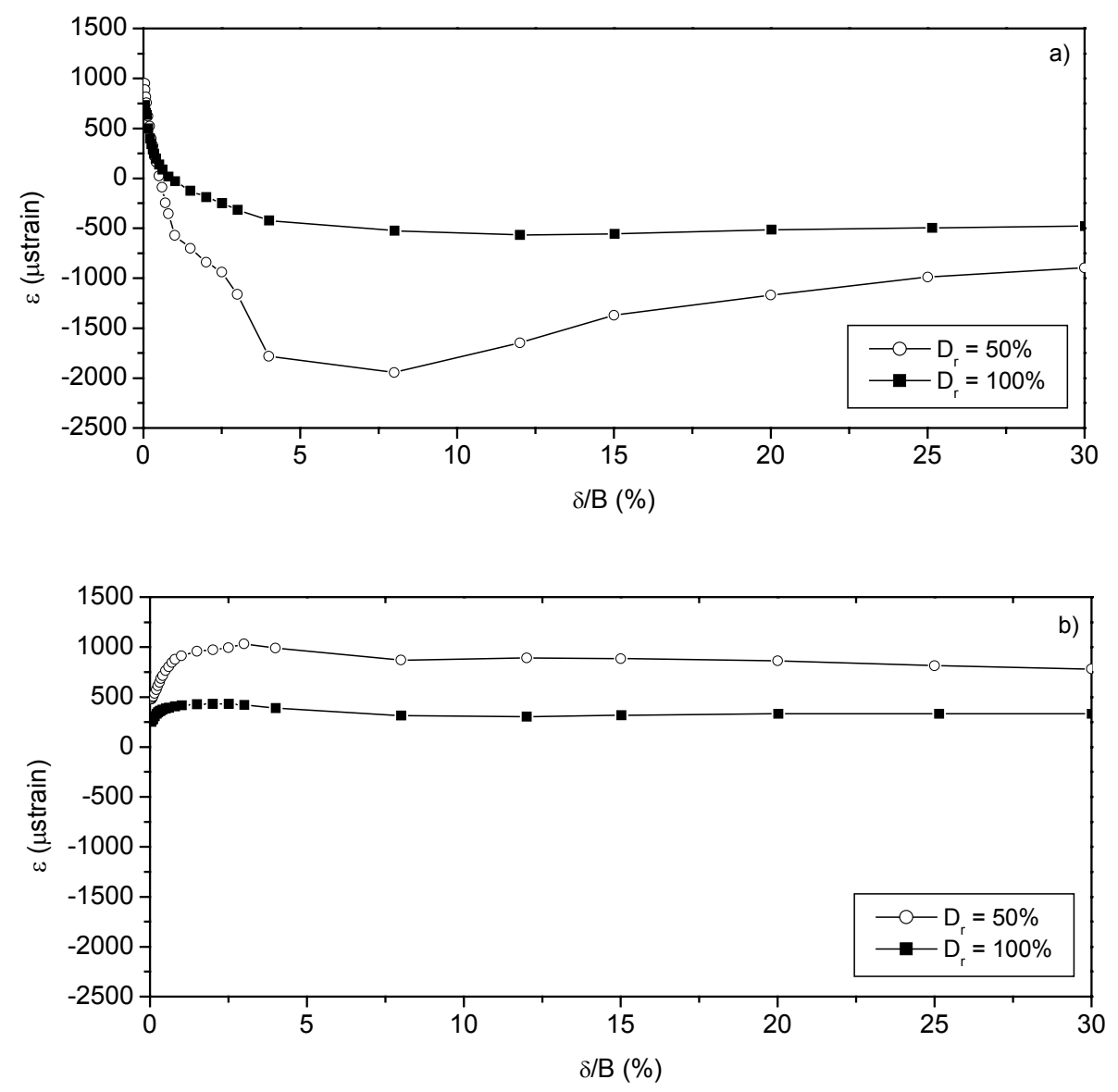

Figura 8.21. Variação da deformação da parede do conduto com o deslocamento do alçapão (base), com $100 \mathrm{kPa}$ de sobrecarga. a) deformação transversal; b) deformação longitudinal. 
A deformação transversal na linha d'água (Figura 8.22a) iniciou-se em valores positivos em virtude do aumento do diâmetro horizontal sofrido durante a fase de carregamento (Figura 8.2). Em seguida, observa-se uma breve compressão até aproximadamente $\delta / \mathrm{B}=1 \%$, seguida de extensão até $\delta / \mathrm{B}=8 \%$ e novamente de compressão até o término dos deslocamentos. Esse comportamento concorda com a variação das deflexões registradas no local (curvas $n^{0} 3$ e 7 da Figura 8.9): retração, extensão e novamente retração do diâmetro horizontal. Com efeito, as deformações longitudinais na linha d'água foram muito pequenas, permanecendo abaixo de \pm 500 ustrain, como exibe a Figura 8.22b, o que manteve o efeito de Poisson em nível muito reduzido.

Por fim, é importante ressaltar que o tubo imerso no maciço compacto apresentou deformações específicas de magnitudes muito inferiores às referentes ao conduto no maciço fofo em todas as posições medidas, para um mesmo deslocamento $\delta / B$.
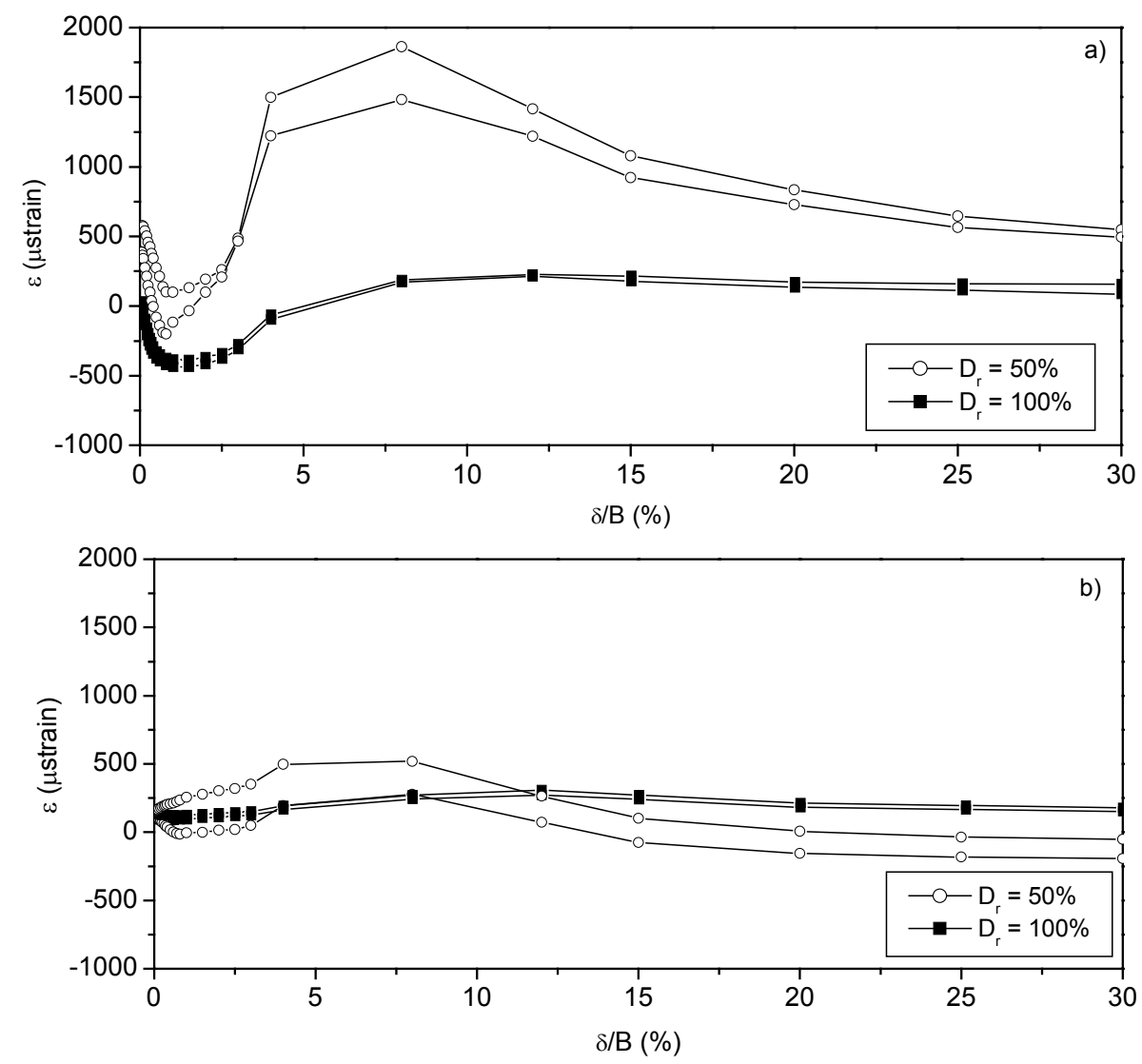

Figura 8.22. Variação da deformação da parede do conduto com o deslocamento do alçapão (linha d'água), com $100 \mathrm{kPa}$ de sobrecarga. a) deformação transversal; b) deformação longitudinal. 


\subsection{DUTO SUBMETIDO A ELEVAÇÃO LOCALIZADA}

\subsubsection{Avaliação das Deflexões do Duto e da Deformada da Seção Central}

Assim como constatado nos modelos de perda de suporte, os perfis longitudinais de deflexão do conduto apresentaram-se aproximadamente simétricos em relação ao eixo vertical. As maiores variações na deflexão $\left(d^{*}\right)$ ocorreram na seção $\mathrm{S} 1$, sendo gradualmente atenuadas em direção às extremidades do tubo. As deflexões do duto induzidas pela elevação alcançaram uma distância $y_{i}$ fora do alçapão, medida a partir de S3, entre 3 e 7 D, dependendo da sobrecarga aplicada e da densidade do solo. Em linhas gerais, os perfis revelaram uma forte ascensão da base e do assento do duto, além de aumento do diâmetro horizontal.

As Figuras 8.23 e 8.24 apresentam perfis de deflexão $\left(\mathrm{d}^{*}\right)$ do duto para $\delta / \mathrm{B}=$ 2 e $4 \%$, respectivamente, registrados no ensaio E6, conduzido com $D_{r}=50 \%$ e q $=$ $100 \mathrm{kPa}$. Os deslocamentos relativos selecionados representam a metade e o final do curso do alçapão no ensaio correspondente. Cada figura é acompanhada pela respectiva deformada da seção central $\mathrm{S} 1$. Em $\delta / \mathrm{B}=2 \%$ (Figura 8.23a) as deflexões decorrentes da elevação já assumiram magnitudes perceptíveis sobre a região do alçapão, especialmente na base e no topo. Quando o deslocamento relativo do alçapão atingiu 4\% (Figura 8.24a), o topo apresentou um perfil com concavidade voltada para cima, indicando a formação de uma depressão nessa região, cujo ponto mínimo ocorre exatamente em S1. Esse comportamento se repetiu apenas nos ensaios $\mathrm{E} 3$, com $\mathrm{D}_{\mathrm{r}}=100 \%$ e $\mathrm{q}=50 \mathrm{kPa}$, e $\mathrm{E} 4$, com $\mathrm{D}_{\mathrm{r}}=100 \%$ e q $=25 \mathrm{kPa}$. As deflexões decorrentes do deslocamento do alçapão atingiram uma distância $\mathrm{y}_{\mathrm{i}} / \mathrm{D}$ superior a 3 na base. Por outro lado, as regiões do ombro e assento praticamente não sofreram deflexões além dos limites do alçapão.

As deformadas da seção $\mathrm{S} 1$ em $\delta / \mathrm{B}=2$ e $4 \%$ são apresentadas, respectivamente, nas Figuras $8.23 \mathrm{~b}$ e $8.24 \mathrm{~b}$. Os valores exteriores ao círculo correspondem à deflexão sofrida no ponto de medida, em percentagem e encontramse majorados por um fator igual a 7. A resistência passiva do solo à movimentação ascendente do conduto resultou na flambagem do topo e em um forte aumento do diâmetro horizontal. O ombro foi a região que menos sofreu deflexão. S1 assume um 
formato aproximado de coração, com o terço inferior achatado por conta da elevação imposta pelo alçapão. Em $\delta / B=2 \%$, observa-se que a elevação no terço inferior anulou o recalque sofrido durante a fase de aplicação da sobrecarga.

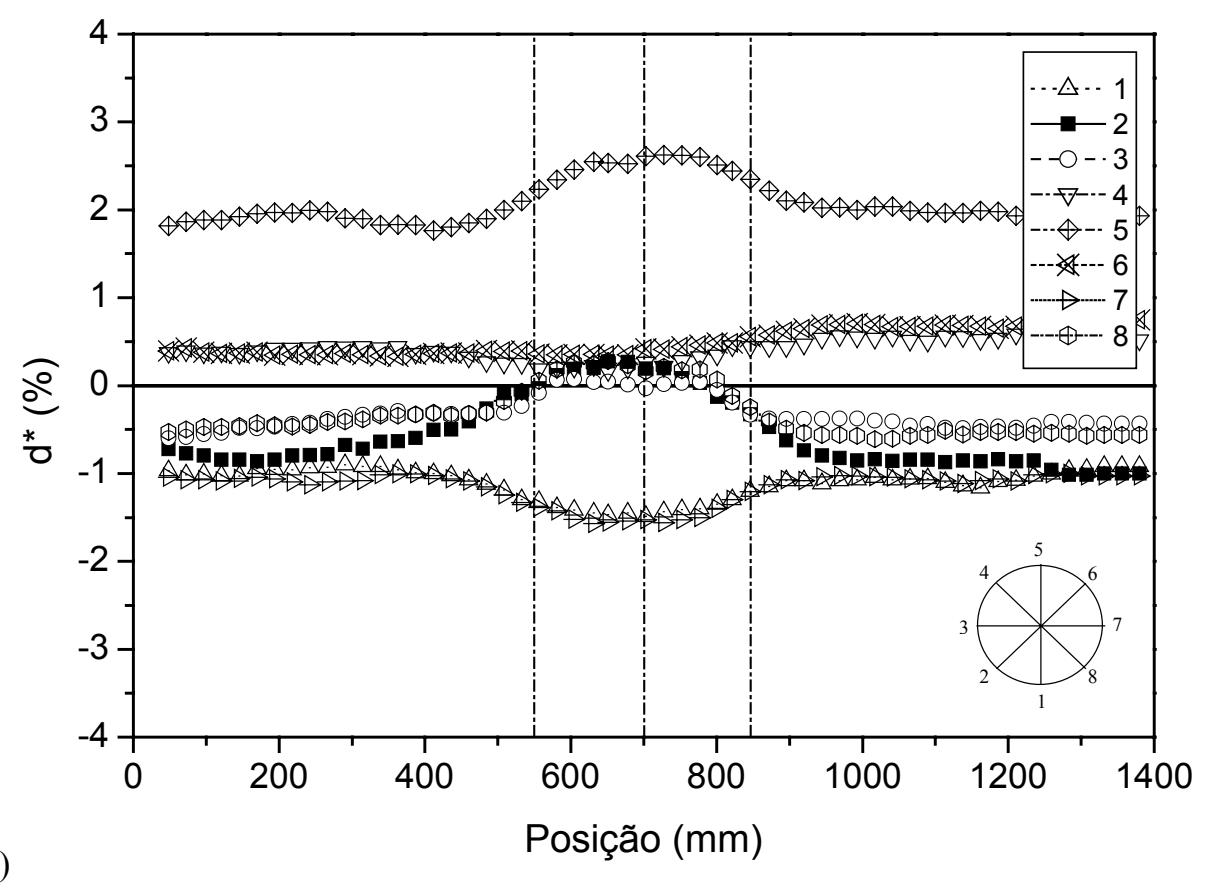

a)

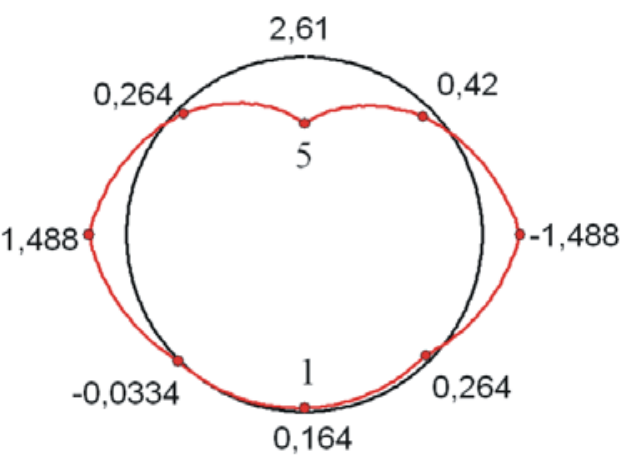

Figura 8.23. a) Perfil de deflexões ao longo do conduto e b) deformada da seção transversal S1 em $\delta / B=2 \%$ (ensaio E6). $D_{\mathrm{r}}=50 \% ; \mathrm{q}=100 \mathrm{kPa}$. 

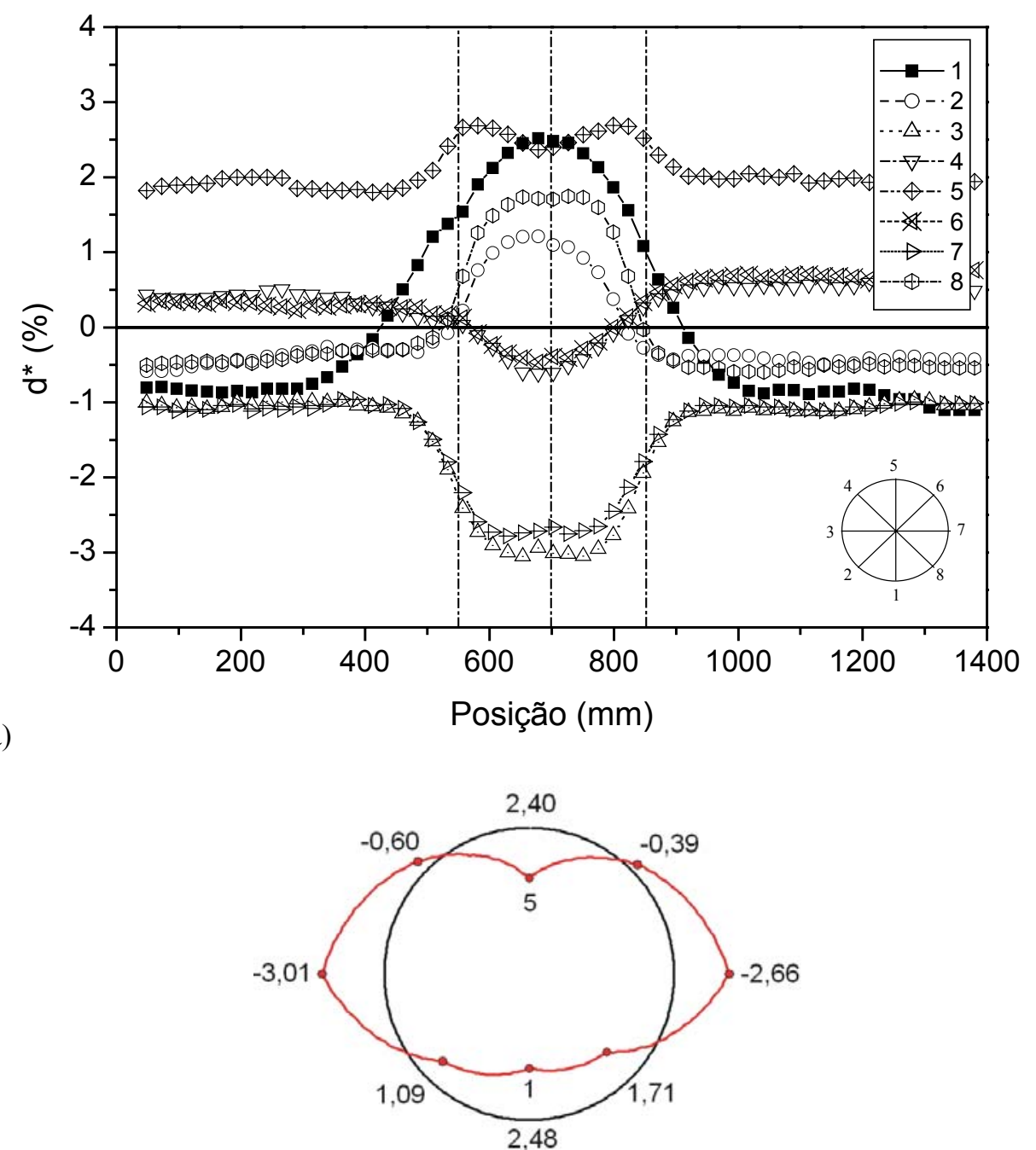

b)

Figura 8.24. a) Perfil de deflexões ao longo do conduto e b) deformada da seção transversal $\mathrm{S} 1 \mathrm{em} \delta / \mathrm{B}=4 \%$ (ensaio E6). $\mathrm{D}_{\mathrm{r}}=50 \% ; \mathrm{q}=100 \mathrm{kPa}$.

A Figura 8.25 traz a variação das deflexões $\left(\mathrm{d}^{*}\right)$ do tubo com o deslocamento relativo do alçapão $(\delta / B)$, em torno da seção $\mathrm{S} 1$. O topo do duto (ponto 5) sofreu recalque até $\delta / \mathrm{B}=2 \%$, passando a apresentar uma ligeira elevação em $\delta / \mathrm{B}=2 \%$ até o deslocamento terminal de 4\%. O terço inferior da seção (pontos 1,2 e 8 ) praticamente não sofreu variação de deflexão até $\delta / B=0,5 \%$. Em seguida essa região experimentou elevação até o final da translação, com a taxa de variação de $d^{*}$ crescendo continuamente com o aumento de $\delta / \mathrm{B}$. O duto só começou a sofrer efetivamente deflexão no ombro (pontos 4 e 6 ) a partir de $\delta / \mathrm{B}=2 \%$, traduzida por 
uma discreta elevação. O diâmetro horizontal do duto cresceu de forma basicamente linear até $\delta / B=2 \%$ e de forma ligeiramente mais acentuada a partir de então (pontos 3 e 7$)$.

Na seção S3, o ombro e o assento sofreram deflexões de magnitudes muito reduzidas durante a movimentação do alçapão. Nas demais posições, o formato das curvas correspondentes assemelhou-se ao observado em S1, porém com valores de $d^{*}$ menores para um dado deslocamento relativo.

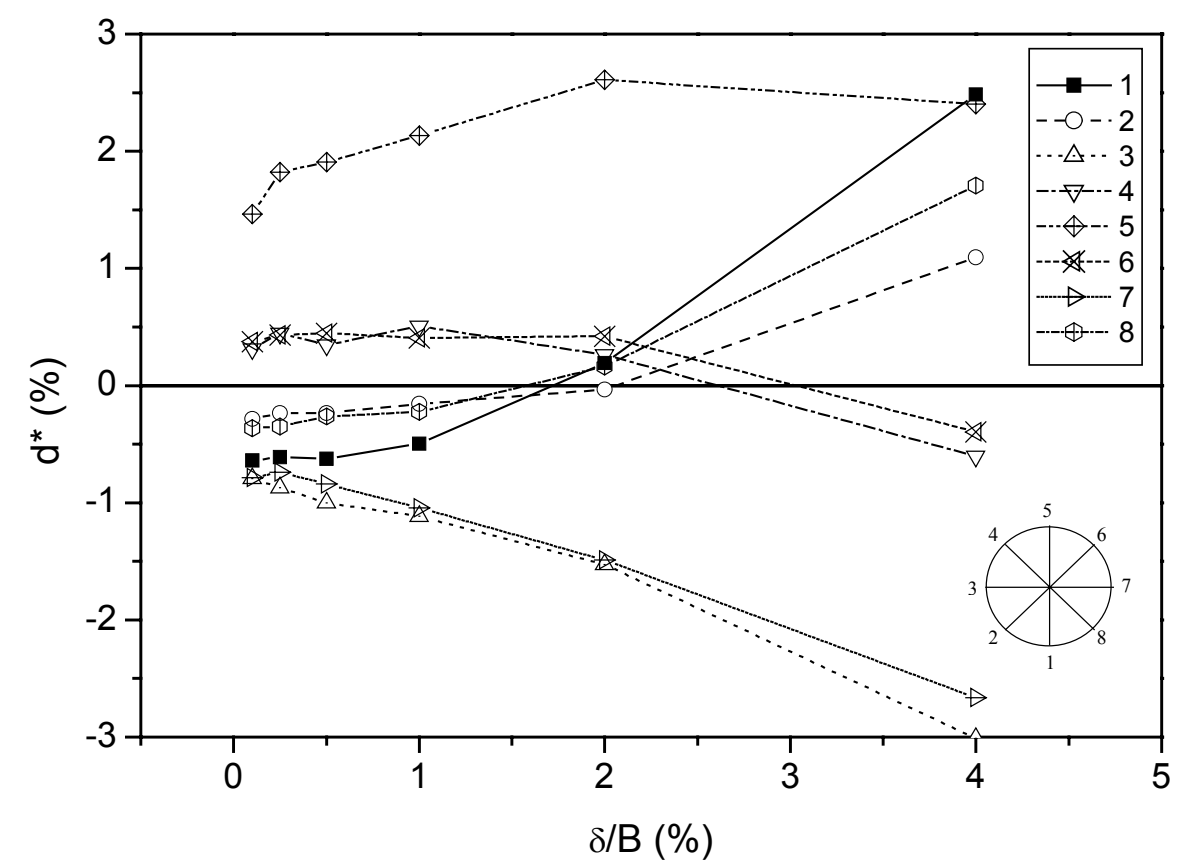

Figura 8.25. Variação da deflexão do duto com o deslocamento do alçapão, com $\mathrm{D}_{\mathrm{r}}=$ $50 \%$ e q $=100 \mathrm{kPa}$ (ensaio E6).

\subsubsection{Influência da Densidade do Solo e da Sobrecarga Aplicada}

A Figura 8.26 ilustra a variação da deflexão com $\mathrm{D}_{\mathrm{r}}$ na seção transversal $\mathrm{S} 1$ para $\delta / \mathrm{B}$ $=1$ e $4 \%$ e q $=50 \mathrm{kPa}$. Inicialmente, a maior diferença entre a deflexão medida no maciço fofo e no compacto ocorreu no topo do conduto (Figura 8.26a). Com o aumento de $\delta / B$, as deflexões sofreram aumento significativo também na linha d'água e na base (Figura 8.26b). Particularmente, a deflexão na base do tubo no maciço fofo aumentou cerca de três vezes mais em relação ao conduto contido no 
solo denso. Já a deflexão no topo do tubo no solo compacto não apresentou variação aparente.
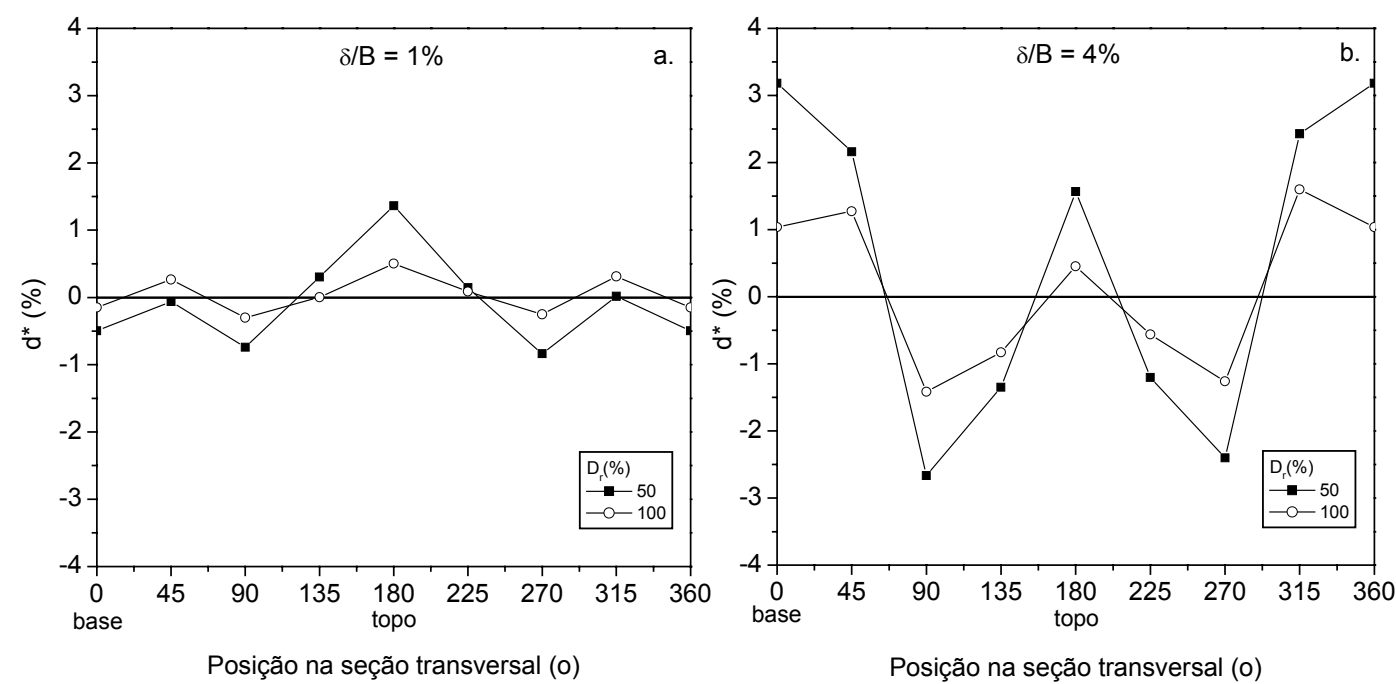

Figura 8.26. Deflexões do duto na elevação localizada, na seção $\mathrm{S} 1$, com $\mathrm{D}_{\mathrm{r}}=50 \mathrm{e}$ $100 \%$ e q $=50 \mathrm{kPa}$ para deslocamentos relativos selecionados.

As Figuras 8.27a e b apresentam a variação da deflexão na seção S1 com a sobrecarga aplicada, para o solo compacto $\left(D_{r}=100 \%\right)$ e o fofo $\left(D_{r}=50 \%\right)$, respectivamente. A deflexão apresentada nas figuras $\left(\Delta \mathrm{d}^{*}\right)$ encontra-se subtraída da deflexão decorrente da aplicação da sobrecarga. São exibidos dados do topo, da base e da linha d'água, correspondentes a $\delta / B=4 \%$, exceto os pontos com $D_{r}=100 \%$ e q $=50 \mathrm{kPa}$, os quais são pertencentes a $\delta / \mathrm{B}=3,5 \%$. Esse foi o deslocamento máximo permitido do alçapão no respectivo ensaio. Linhas de tendência acompanham os dados experimentais. Com os dados do topo e da base, o sinal negativo significa elevação do ponto medido. Com os dados da linha d'água, o sinal negativo denota aumento do diâmetro horizontal.

No maciço compacto, o topo do duto apresentou elevação quando sob sobrecargas mais baixas. À medida que a sobrecarga aplicada aumenta, a elevação sofrida decresce, por conta do crescimento da resistência do solo à movimentação ascendente do duto. A partir de $50 \mathrm{kPa}$ a tendência do topo é aparentemente de apresentar recalque com o aumento de q. Comportamento semelhante foi verificado 
no maciço fofo, porém a variação de $\Delta \mathrm{d}^{*}$ com q é comparativamente menor, uma vez que a influência da sobrecarga aplicada na resistência passiva é menor nesse caso.

No solo compacto, a linha d'água do tubo sofreu um suave aumento com q, reflexo do crescimento da restrição à movimentação ascendente da estrutura. Já no solo fofo, a variação da deflexão foi praticamente nula. A base do tubo seguiu o mesmo comportamento observado no topo com o solo compacto, e apresentou variação praticamente nula no solo fofo.

No maciço compacto, o CGD decresceu com a sobrecarga na seção S1, variando entre 0,14 e 0,08 , o que demonstra que a deformação da seção diminuiu com o aumento do nível de tensão do solo. No maciço fofo, o CGD se situou entre 0,11 e 0,16 , porém não apresentou uma tendência nítida com q.

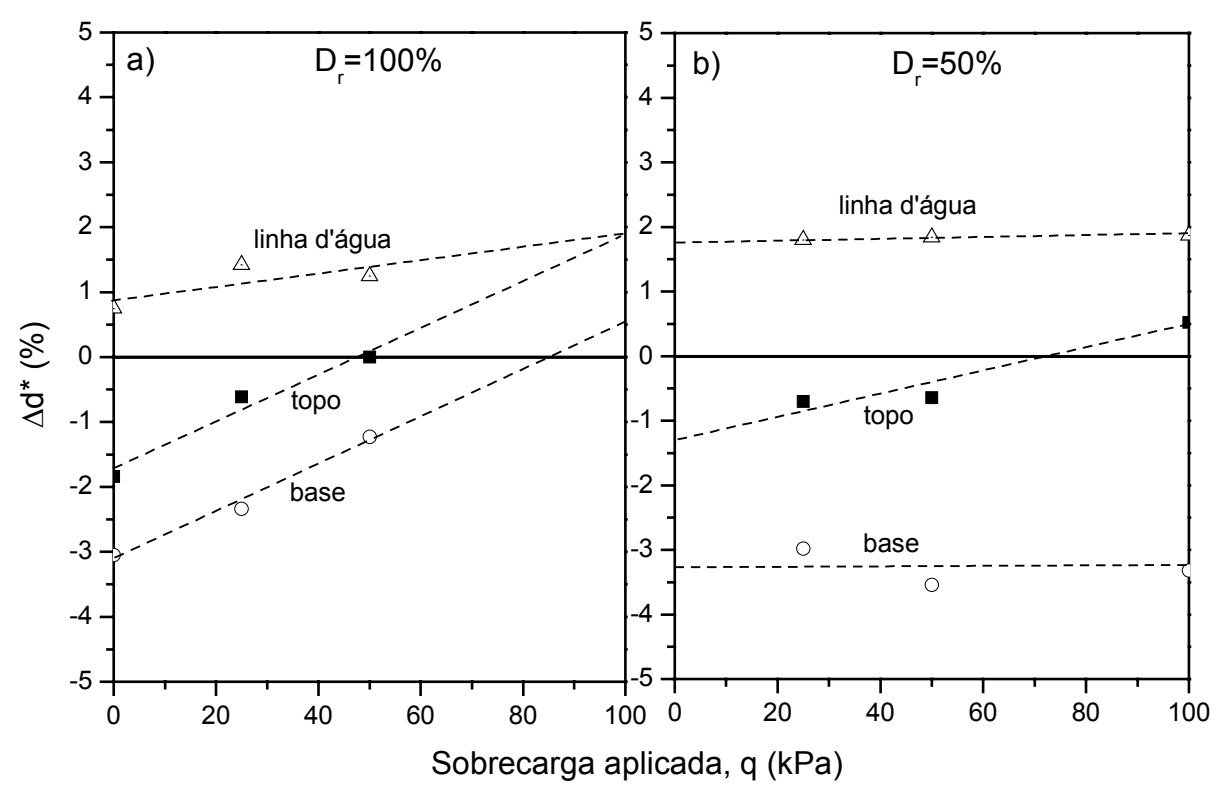

Figura 8.27. Variação da deflexão com a sobrecarga aplicada, a) para solo compacto e b) para solo fofo.

\subsubsection{Previsões dos Deslocamentos do Duto}

Neste item uma previsão do deslocamento do conduto submetido à elevação é realizada através de uma modificação do modelo analítico de Rajani e Morgenstern (1993), descrito no item 2.4.3. Utilizando a hipótese de Winkler, o método se destaca 
dos demais por utilizar um componente descritivo do comportamento elasto-plástico do solo. Para tanto, os autores propõem a utilização de ábacos de Rowe e Davis (1982 a, b) para a determinação da resistência passiva do solo. No entanto, os resultados de Rowe e Davis (1982 a, b) foram obtidos com ancoragens retangulares rígidas. De modo a representar adequadamente o comportamento dos condutos flexíveis, a resistência passiva utilizada nas análises a seguir foi obtida experimentalmente a partir da tensão medida no topo do duto.

A Figura 8.28 esquematiza as considerações adotadas para o modelo. Quando em movimento ascendente, assume-se que o tubo adquire uma dupla curvatura, com inflexão no ponto $O$. Uma carga vertical concentrada $\mathrm{P}$, resultante do contato da aresta do alçapão com o duto, é aplicada na seção S3, sendo obtida a partir da tensão medida em I3 assumindo uma área útil de contato do tubo com o alçapão igual a $15 \mathrm{x}$ $100 \mathrm{~mm}$.

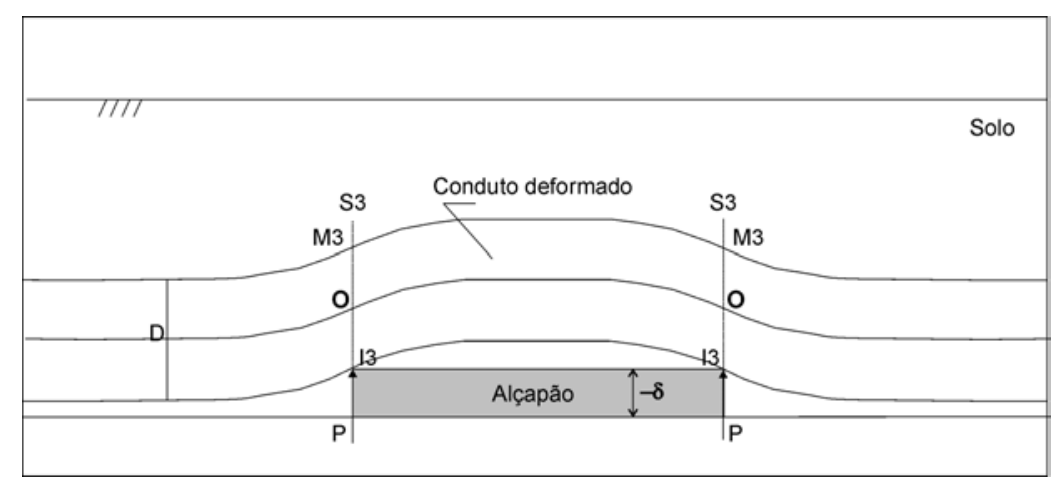

Figura 8.28. Esquema do conduto sofrendo elevação localizada.

A resistência passiva adimensional $\left(\mathrm{N}_{\mathrm{p}}\right)$ foi determinada como a razão $\sigma / \sigma_{\mathrm{i}}$, medida no topo do conduto na posição M6, seção S3. A Figura 8.29 apresenta as curvas tensão versus deslocamento do alçapão em M6. Nos testes realizados com sobrecargas mais baixas, as curvas apresentaram estabilização em deslocamentos superiores a $10 \%$. Nesses casos, a determinação de $\mathrm{N}_{\mathrm{p}}$ é direta. No entanto, nos ensaios executados com sobrecargas mais elevadas, o alçapão não pôde ser transladado além de $\delta / \mathrm{B}=4 \%$ por limitação dos equipamentos de medida, e as curvas apenas exibem um trecho aproximadamente retilíneo. Assim, de forma a 
atender a todos os ensaios, a resistência passiva adimensional foi convencionada como a razão $\sigma / \sigma_{\mathrm{i}}$ equivalente ao deslocamento relativo do alçapão de $4 \%$.

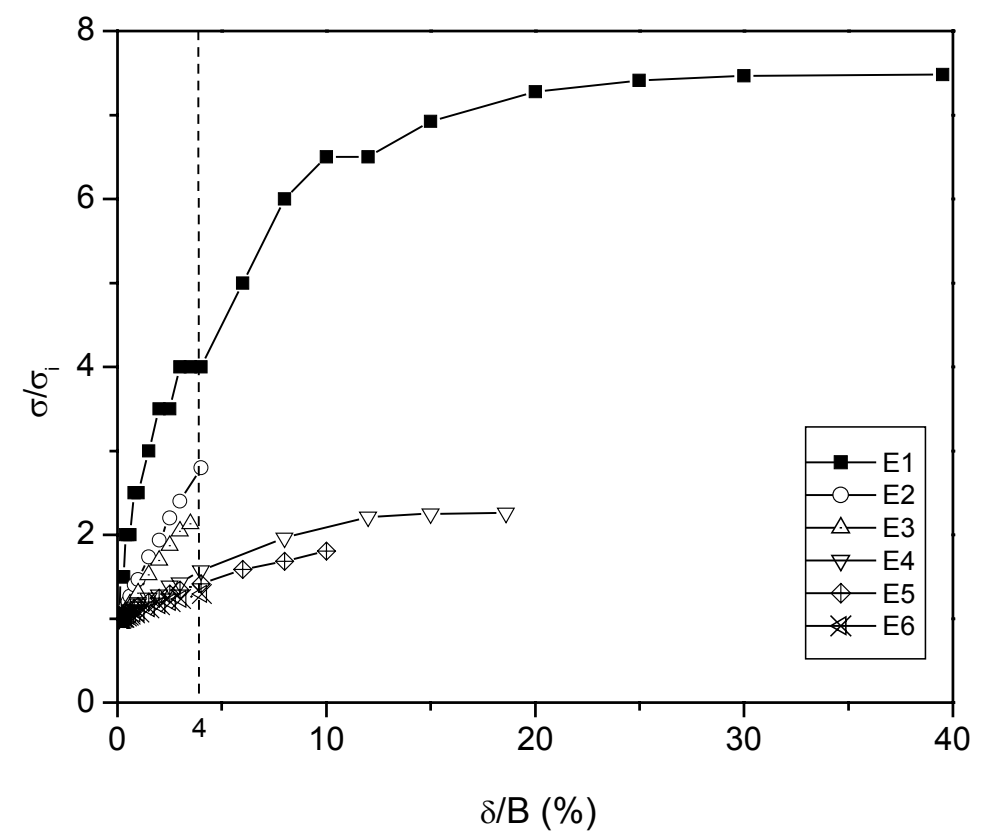

Figura 8.29. Curvas tensão versus deslocamento do alçapão em M6, utilizadas para a obtenção de $\mathrm{N}_{\mathrm{p}}$.

O deslocamento do duto em S3 foi determinado através da expressão (8.9), com $\overline{\mathrm{F}}$ expresso por (8.10) e $\mathrm{K}$ calculado a partir da expressão (8.6), segundo sugestão dos autores.

$\mathrm{u}=\frac{\sigma_{\mathrm{p}} \mathrm{D}}{\mathrm{K}}\left(\frac{1}{2}+\frac{2}{3} \frac{\overline{\mathrm{F}}}{\mathrm{N}_{\mathrm{p}}}+\frac{8}{3} \frac{\overline{\mathrm{F}}^{4}}{\mathrm{~N}_{\mathrm{p}}^{4}}\right)$

$\overline{\mathrm{F}}=\frac{\sigma}{\sigma_{\mathrm{i}}} \frac{\lambda \mathrm{A}}{\mathrm{D}}$

onde: $\sigma / \sigma_{\mathrm{i}}=$ razão de tensão medida na posição I3; $\mathrm{A}=$ área de contato do alçapão $=$ $0,0015 \mathrm{~m}^{2} ; \lambda=$ característica do sistema $=(\mathrm{K} / 4 \mathrm{EI})^{0,25} ; \mathrm{D}=$ diâmetro do conduto; $\sigma_{\mathrm{p}}=$ tensão passiva máxima no topo do tubo, na posição M6. 
A Figura 8.30 apresenta a variação da deflexão com $\delta / B$ na seção $\mathrm{S} 3$, prevista com o modelo teórico para o ensaio E6, realizado com $D_{\mathrm{r}}=50 \%$ e q $=100 \mathrm{kPa}$. Valores experimentais da deflexão do topo e da base do duto $\left(\Delta \mathrm{d}^{*}\right)$, devidamente subtraídos das medidas anteriores à subida do alçapão, são apresentados na mesma figura. Valores negativos de $\Delta \mathrm{d}^{*}$ denotam elevação do ponto medido. Comparado aos dados da base do conduto, o método analítico forneceu resultados com variação durante a translação do alçapão muito pequena, tornando-se contra a segurança a partir de $\delta / \mathrm{B}=1,5 \%$. Da mesma forma como destacado na previsão do deslocamento do duto submetido à perda de apoio (item 8.3.3), o modelo teórico utilizado trata o duto como um elemento linear, fornecendo um valor de deslocamento único em uma determinada posição, representativo de toda a seção transversal. Desconsidera-se completamente o fato de que as diferentes partes do conduto se comportam de forma bastante distinta. Por exemplo, nesse ensaio específico cujos resultados são mostrados na Figura 8.30 o topo não sofreu elevação junto com a base, mas recalque ao longo de todo o deslocamento do alçapão, porém o modelo analítico não pode prever tal fato.

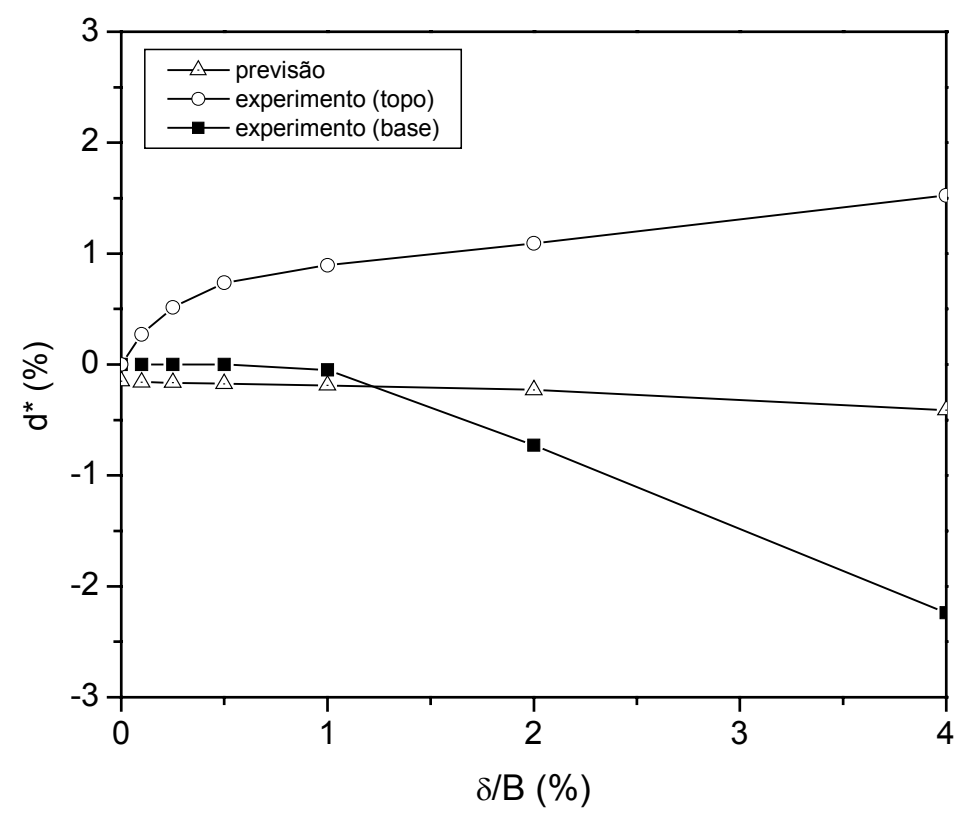

Figura 8.30. Previsão da deflexão do duto submetido a elevação através do modelo de Rajani e Morgenstern (1993) e comparação com resultados experimentais. 
A Tabela 8.1 expõe as previsões correspondentes a cada ensaio realizado, quando $\delta / \mathrm{B}$ atinge $4 \%$, juntamente com os valores experimentais para a base e o topo do duto. A elevação diminui com o aumento de $\mathrm{q}$, tanto na base quanto no topo em $D_{r}=100 \%$, e no topo em $D_{r}=50 \%$ (ver também Figura 8.27). No entanto, o modelo teórico previu uma tendência oposta, com $\Delta \mathrm{d}^{*}$ crescendo com $\mathrm{q}$, sendo sua magnitude excessiva para a condição com $\mathrm{D}_{\mathrm{r}}=100 \%$ e sobrecargas de 25 e $50 \mathrm{kPa}$. $\mathrm{Na}$ formulação analítica, quanto maior q, maior é a força $\mathrm{F}$ na base do tubo necessária para se atingir o deslocamento relativo pré-definido de 4\%. Tal comportamento é muito mais incisivo para a maior densidade relativa. Sendo F diretamente proporcional ao deslocamento calculado $u$, seu aumento com q resulta em previsões de $d^{*}$ também crescentes com q.

Tabela 8.1. Deslocamentos do conduto na seção $\mathrm{S} 3$ para $\delta / \mathrm{B}=4 \%$

\begin{tabular}{cccccc}
\cline { 3 - 6 } & & & \multicolumn{3}{c}{$\Delta \mathrm{d}^{*}(\%)$} \\
\hline Ensaio & $\mathrm{D}_{\mathrm{r}}(\%)$ & $\mathrm{q}(\mathrm{kPa})$ & topo & base & previsão \\
\hline E1 & 100 & 0 & $-1,84$ & $-3,05$ & $-0,10$ \\
E2 & 100 & 25 & $-0,61$ & $-2,34$ & $-28,1$ \\
E3 & 100 & 50 & 0,00 & $-1,23$ & $-37,7$ \\
E4 & 50 & 25 & $-0,70$ & $-2,98$ & $-0,43$ \\
E5 & 50 & 50 & $-0,64$ & $-3,54$ & $-0,48$ \\
E6 & 50 & 100 & 0,52 & $-3,32$ & $-0,55$ \\
\hline
\end{tabular}

\subsubsection{Avaliação das Tensões no Solo ao Redor do Duto}

A tensão total no solo em torno do duto foi avaliada na linha d'água e no topo das seções S1 e S3. A Figura 4.10 esquematiza a posição das seções de interesse e dos pontos de medida nas mesmas. A Tabela 8.2 apresenta as tensões iniciais $\left(\sigma_{i}\right)$ e finais $\left(\sigma_{f}\right)$ medidas nas posições investigadas, juntamente com o deslocamento máximo do alçapão $\left(\delta / \mathrm{B}_{\max }\right)$. No maciço compacto, o arqueamento positivo inicial manteve as tensões iniciais em níveis bastante reduzidos. No topo do duto, as tensões finais são comparativamente menores na seção $\mathrm{S} 1$, seguindo a mesma tendência dos resultados 
observados no interior do alçapão nos ensaios sem tubo. Já na linha d'água, o oposto ocorre. Particularmente, a tensão que atingiu o topo do duto em S1 (posição M6) no ensaio E1, conduzido com $\mathrm{D}_{\mathrm{r}}=100 \mathrm{e} \mathrm{q}=0 \mathrm{kPa}$, sofreu uma ligeira redução após a translação do alçapão, decaindo a zero.

Tabela 8.2. Tensões ao redor do duto em elevação

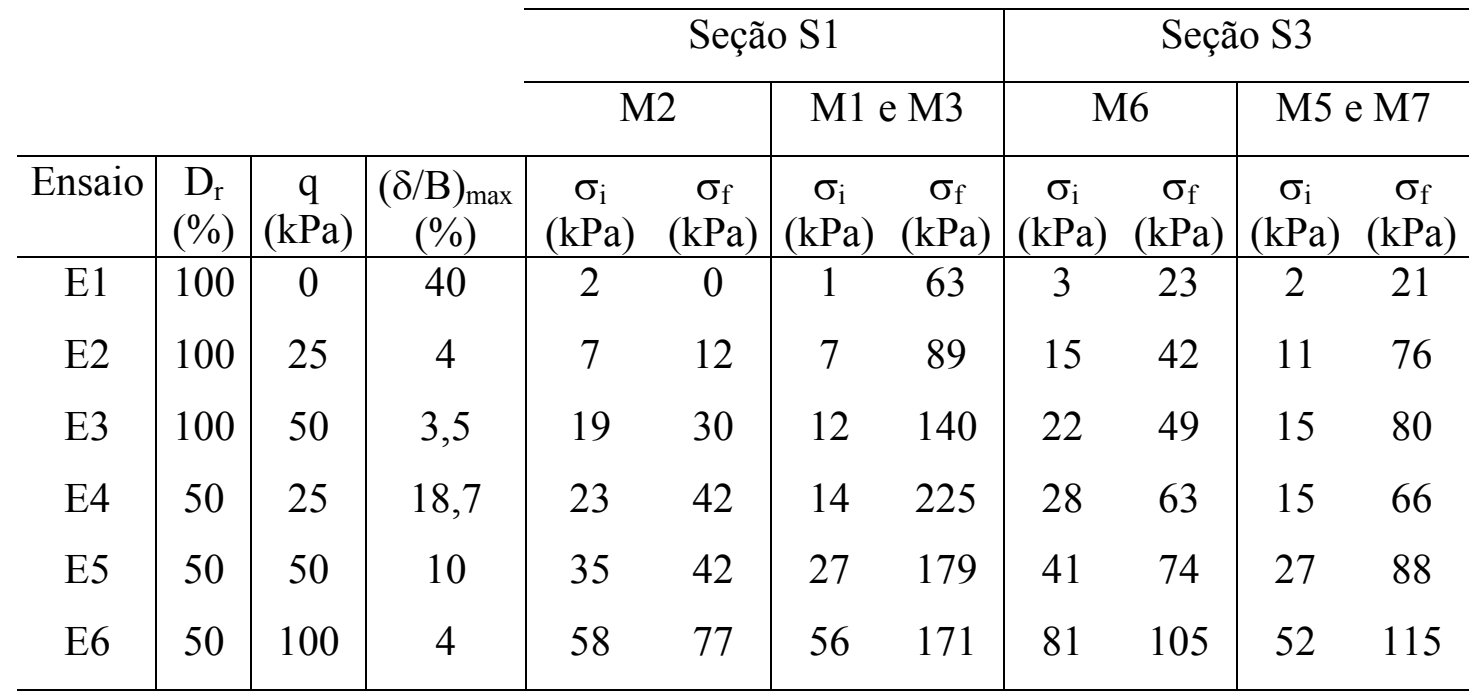

A variação da tensão na posição M6 é dada na Figura 8.29. Observa-se que a variação é inversamente proporcional à sobrecarga aplicada e diretamente proporcional à densidade do solo. Quanto menor a sobrecarga aplicada, maior a elevação do topo (ver Figura 8.27), o que resulta em maior variação da tensão. $O$ duto imerso no solo mais compacto apresenta elevação comparativamente menor. Com exceção de E1, o mesmo comportamento foi observado em M2.

Todas as curvas tensão-deslocamento correspondentes à linha d'água, tanto em S1 quanto em S2 apresentaram formato aproximadamente linear, sem tendência à estabilização da tensão aplicada. A Figura 8.31 apresenta a variação da tensão total com $\delta / B$, na seção S1, para o modelo E6. Nas posições no topo (M2 e M4), a razão $\sigma / \sigma_{i}$ não superou 1,3 ao final da translação do alçapão. Como se observa na Tabela 8.2, a tensão no topo do duto na seção central S1 sofreu variações muito pequenas em todos os ensaios. No ensaio E6, no qual o topo sofreu recalque, o menor recalque do ombro em relação ao topo contribuiu ainda mais com a redução do efeito do arqueamento passivo na região. Esses resultados mostram nitidamente o benefício da 
rigidez baixa do tubo na diminuição da concentração de carga no topo em um caso crítico de elevação localizada.

O valor da tensão medida na posição M4 foi maior que na posição M2, decorrente do menor efeito do arqueamento passivo do solo em maiores distâncias verticais do duto. Sua variação também foi comparativamente maior em relação ao registrado em M2 (Figura 8.31). A investigação na linha d'água revelou uma forte mobilização da resistência passiva do solo, decorrente do crescimento do diâmetro horizontal. A tensão horizontal aumentou em torno de três vezes o valor inicial no final da translação do alçapão (posições M1 e M3).

A tendência geral da variação de $\sigma$ acompanhada na seção S3 assemelhou-se à de S1. Entretanto, no topo do duto as tensões foram comparativamente maiores na seção S3, seguindo a mesma tendência dos resultados observados no interior do alçapão nos ensaios sem tubo. Já na linha d'água, o oposto ocorreu. A Figura 8.32 mostra a variação de $\sigma / \sigma_{i}$ na seção $\mathrm{S} 3$ no ensaio E6.

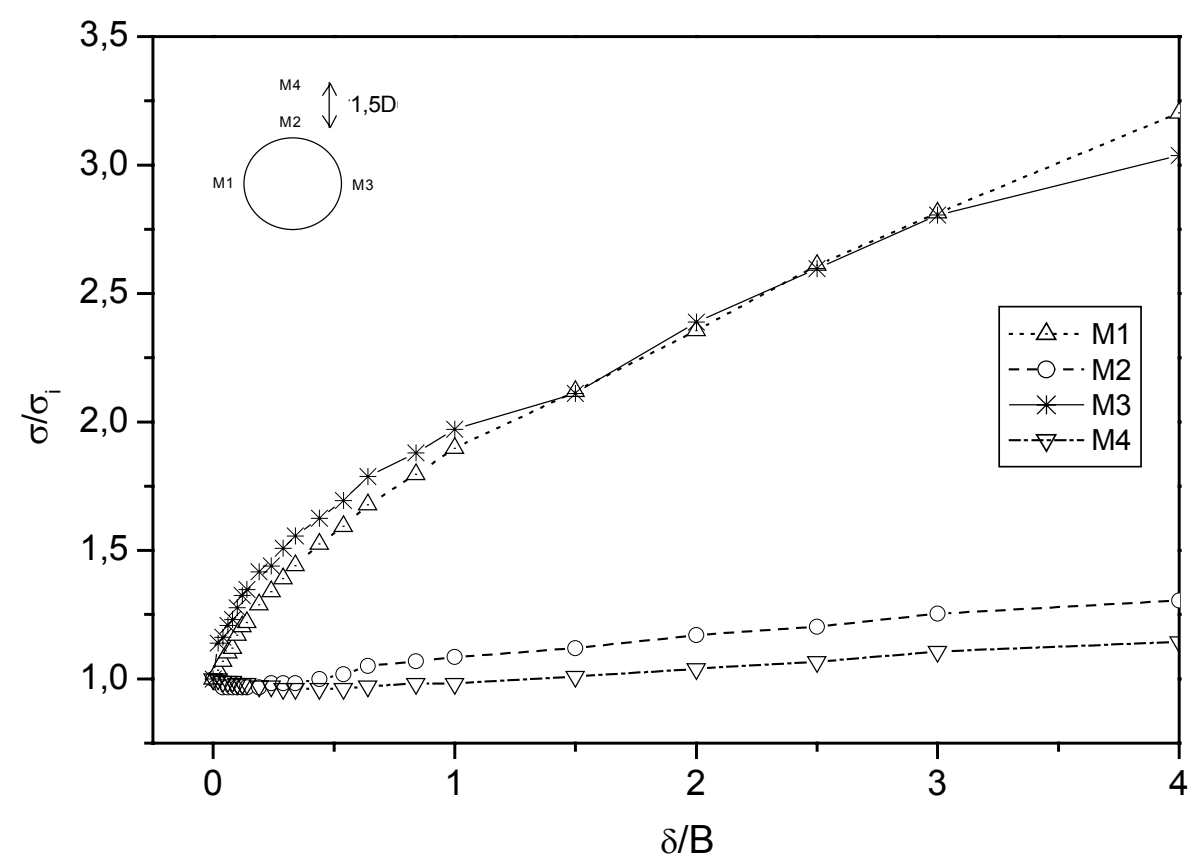

Figura 8.31. Variação da tensão no solo em torno da seção S1 no ensaio E6.

A Figura 8.33 exibe a variação da tensão medida na linha d'água em S1 em função da sobrecarga (q), para o deslocamento $\delta / B=4 \%$. Os valores apresentados correspondem à média das dos valores registrados em M1 e M3. O maciço compacto 
permite o desenvolvimento de uma maior resistência passiva na lateral do duto, crescente com o aumento da sobrecarga aplicada. Já no maciço fofo, nenhuma variação da tensão mobilizada com a sobrecarga foi observada, e $\sigma$ permanece em torno de $2,5 \sigma_{\mathrm{i}}$.

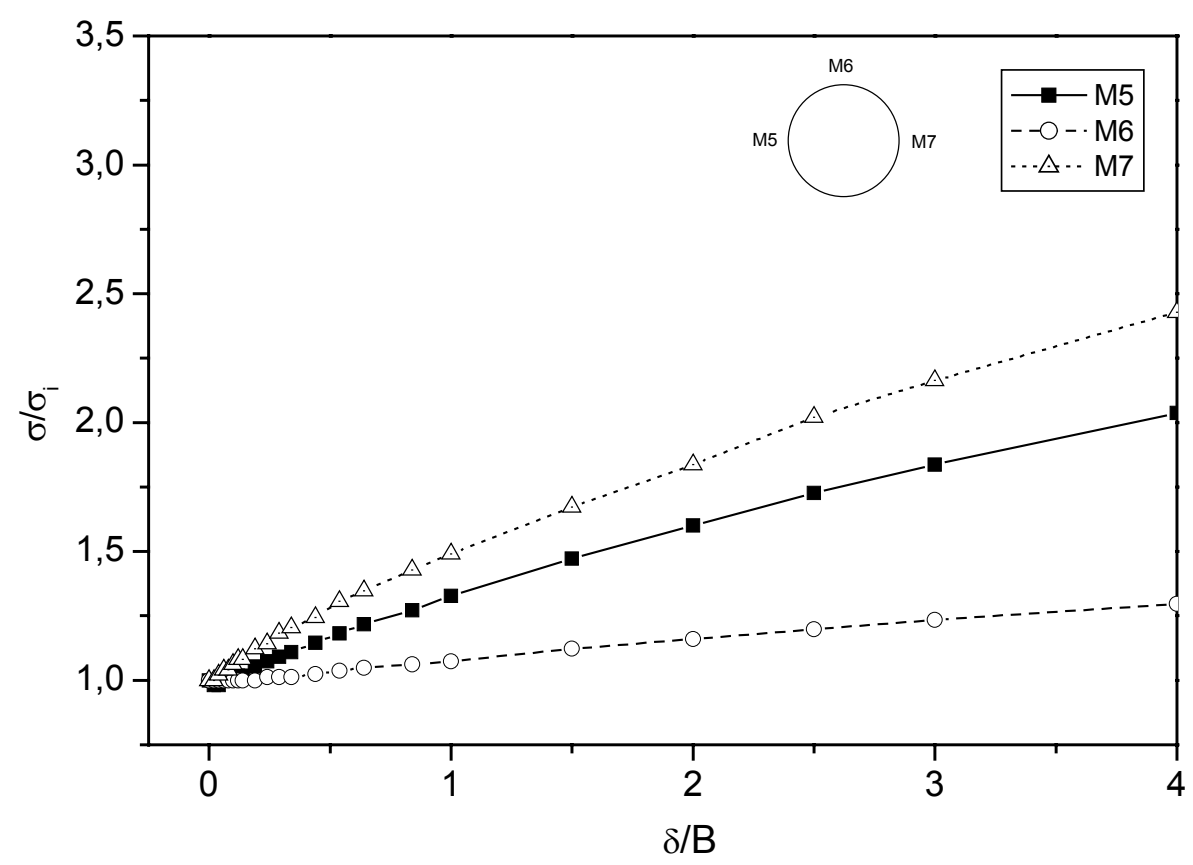

Figura 8.32. Variação da tensão no solo em torno da seção S3 no ensaio E6.

Em linhas gerais, os resultados mostraram que, em se tratando de condutos flexíveis submetidos a elevação, o foco da atenção deve ser a linha d'água, visto que o aumento da concentração de tensão no topo permanece baixa.

A Figura 8.34 apresenta o comportamento da tensão vertical $\left(\sigma_{\mathrm{v}}\right)$ com a movimentação do alçapão, medida em diversos pontos na base da caixa de testes $\left(\mathrm{H}_{\mathrm{e}} / \mathrm{B}=0\right)$. A disposição dos locais de medida das tensões na base da caixa de testes é ilustrada através da Figura 4.9. Os resultados são referentes aos modelos executados com maciço fofo e compacto, ambos com q $=50 \mathrm{kPa}$.

$\mathrm{Em} \mathrm{x}_{\mathrm{i}} / \mathrm{B}=0,2$ (posição I4), observa-se um alívio marcante da tensão vertical (Figura 8.34a), em função da transferência de carga inicial nas adjacências para a região do alçapão, a qual ocorre após a elevação. A estabilização da tensão dá-se abaixo de $\sigma_{\mathrm{v}} / \sigma_{\mathrm{vi}}=0,1$. A influência exercida pela movimentação da estrutura em $\mathrm{x}_{\mathrm{i}} / \mathrm{B}$ $=0,8$ (posição I5, Figura 8.34b) é comparativamente menor para o maciço fofo, com 
a tensão vertical reduzindo a aproximadamente metade de $\sigma_{\mathrm{vi}}$, e aumentando ligeiramente até o final da translação. No maciço compacto, a redução é quase tão intensa quanto a 0,2B de distância, ocorrendo em virtude da maior capacidade do material mais compacto de transferir as tensões.

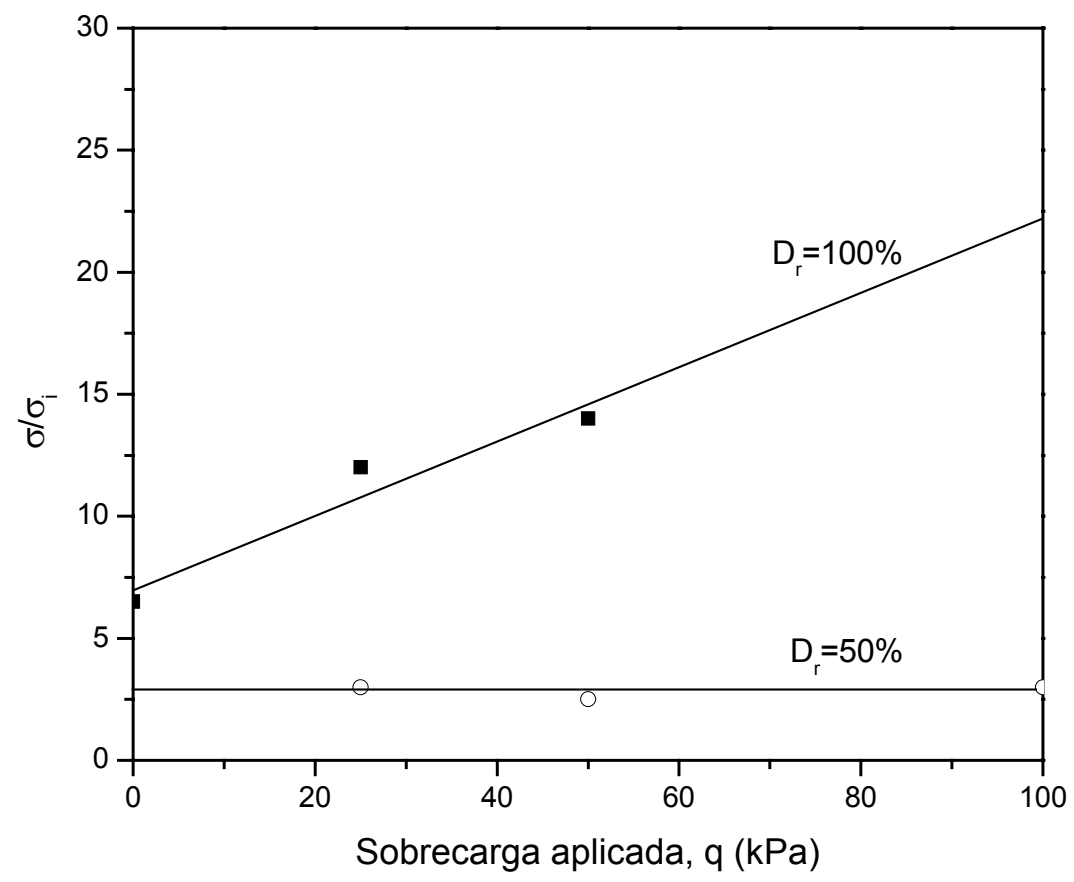

Figura 8.33. Efeito da sobrecarga e da densidade do solo na tensão no solo na linha d'água do conduto em $\delta / B=4 \%$.

Sob o conduto, em $\mathrm{y}_{\mathrm{i}} / \mathrm{B}=0,2$ e 0,8 (posições I6 e I7, respectivamente), também foi registrado alívio de tensão com a movimentação do alçapão. No entanto, ao contrário do observado na lateral do duto, o maior alívio de tensão acontece no solo fofo. A maior elevação da base para um deslocamento $\delta$ fixo quando o solo se encontra no estado fofo pode ser apontada como responsável por esse comportamento inverso (ver Figura 8.27).

$\mathrm{Em} \mathrm{y}_{\mathrm{i}} / \mathrm{B}=2,7$ (posição I8, Figura 8.34e), os dados referentes ao maciço fofo revelaram um aumento de $16 \%$ em $\sigma_{\mathrm{vi}}$ até aproximadamente $\delta / \mathrm{B}=2,5 \%$, seguido de redução contínua e relativamente acentuada até o término do ensaio. Já no maciço compacto, praticamente não houve aumento de $\sigma_{\mathrm{v}}$, mas apenas redução, também em torno de $\delta / B=2,5 \%$. Evidentemente, a elevação do duto com a continuidade do deslocamento do alçapão foi responsável pelo decréscimo posterior da tensão. Com 
efeito, nos ensaios sem a presença do duto, apenas foi constatado aumento de $\sigma_{v}$ (Figura 6.29).
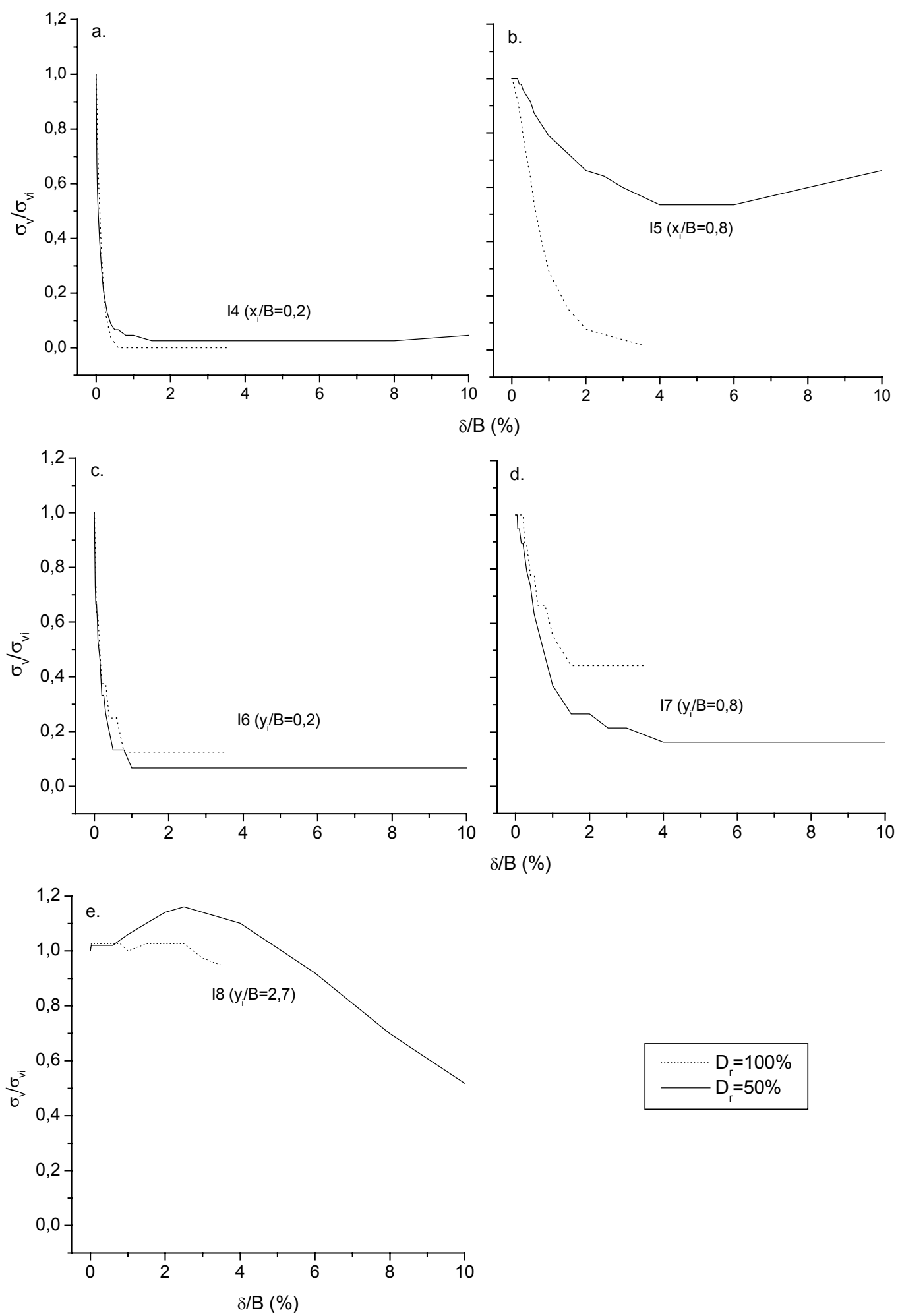

Figura 8.34. Variação da tensão vertical em $\mathrm{H}_{\mathrm{e}} / \mathrm{B}=0$ para tubo sofrendo elevação em maciços com densidades relativas de 50 e $100 \%$ e sobrecarga de $50 \mathrm{kPa}$. 


\subsubsection{Avaliação das Deformações na Parede do Duto}

O comportamento da deformação específica $(\varepsilon)$ da parede externa do duto, com o deslocamento do alçapão, é mostrado nas Figuras 8.35 a 8.37. As deformações foram medidas em oito pontos distintos distribuídos em torno da seção S1 (ver Figura 4.11), nos sentidos transversal e longitudinal. Os dados são pertencentes aos testes F3 e F4, realizados com maciço nos estados fofo $\left(D_{r}=50 \%\right)$ e compacto $\left(D_{r}=\right.$ $100 \%$ ), ambos com sobrecarga de $50 \mathrm{kPa}$. Convencionou-se deformação negativa representando compressão da parede.

No topo do conduto, sentido transversal (Figura 8.35a), registrou-se compressão contínua até o término da translação do alçapão. No sentido longitudinal, o oposto ocorreu (Figura 8.35b). As variações em $\varepsilon$ por efeito da densidade do material foram praticamente nulas.
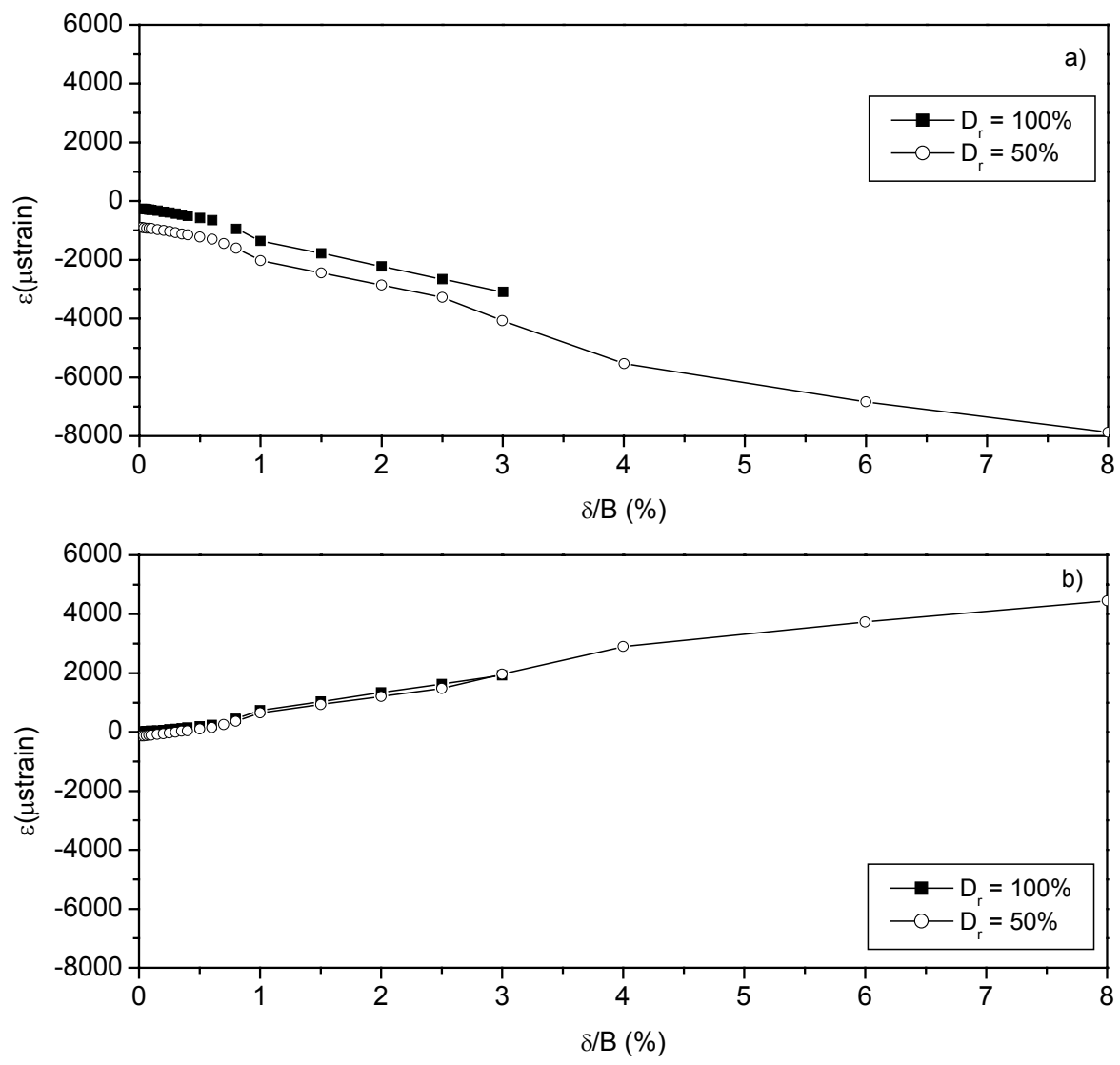

Figura 8.35. Variação da deformação da parede do conduto com o deslocamento do alçapão (topo), com $50 \mathrm{kPa}$ de sobrecarga. a) deformação transversal; b) deformação longitudinal. 
A base apresentou uma extensão muito discreta no sentido transversal e uma compressão relativamente acentuada no sentido longitudinal até o término dos deslocamentos (Figuras $8.36 \mathrm{a} \mathrm{e} \mathrm{b).}$

A linha d'água experimentou deformações de extensão de magnitudes muito elevadas na transversal (Figura 8.37a), aproximando-se de $10000 \mu$ strain. $\mathrm{Na}$ longitudinal, as deformações permaneceram em patamares muito reduzidos (Figura 8.37b). A influência da densidade do material nos resultados obtidos revelou-se muito pequena também na base e na linha d'água do duto em elevação.
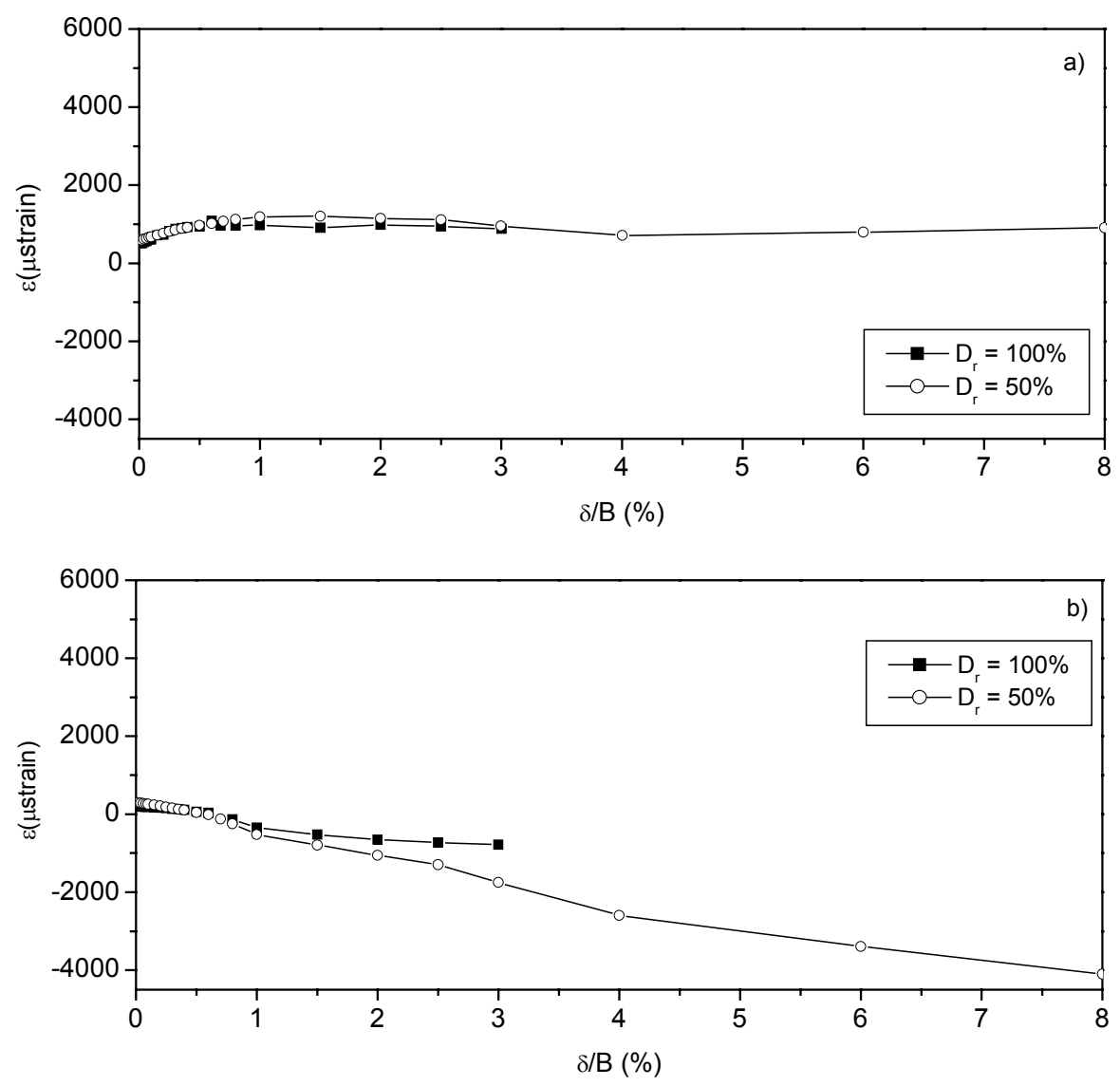

Figura 8.36. Variação da deformação da parede do conduto com o deslocamento do alçapão (base), com $50 \mathrm{kPa}$ de sobrecarga. a) deformação transversal; b) deformação longitudinal. 

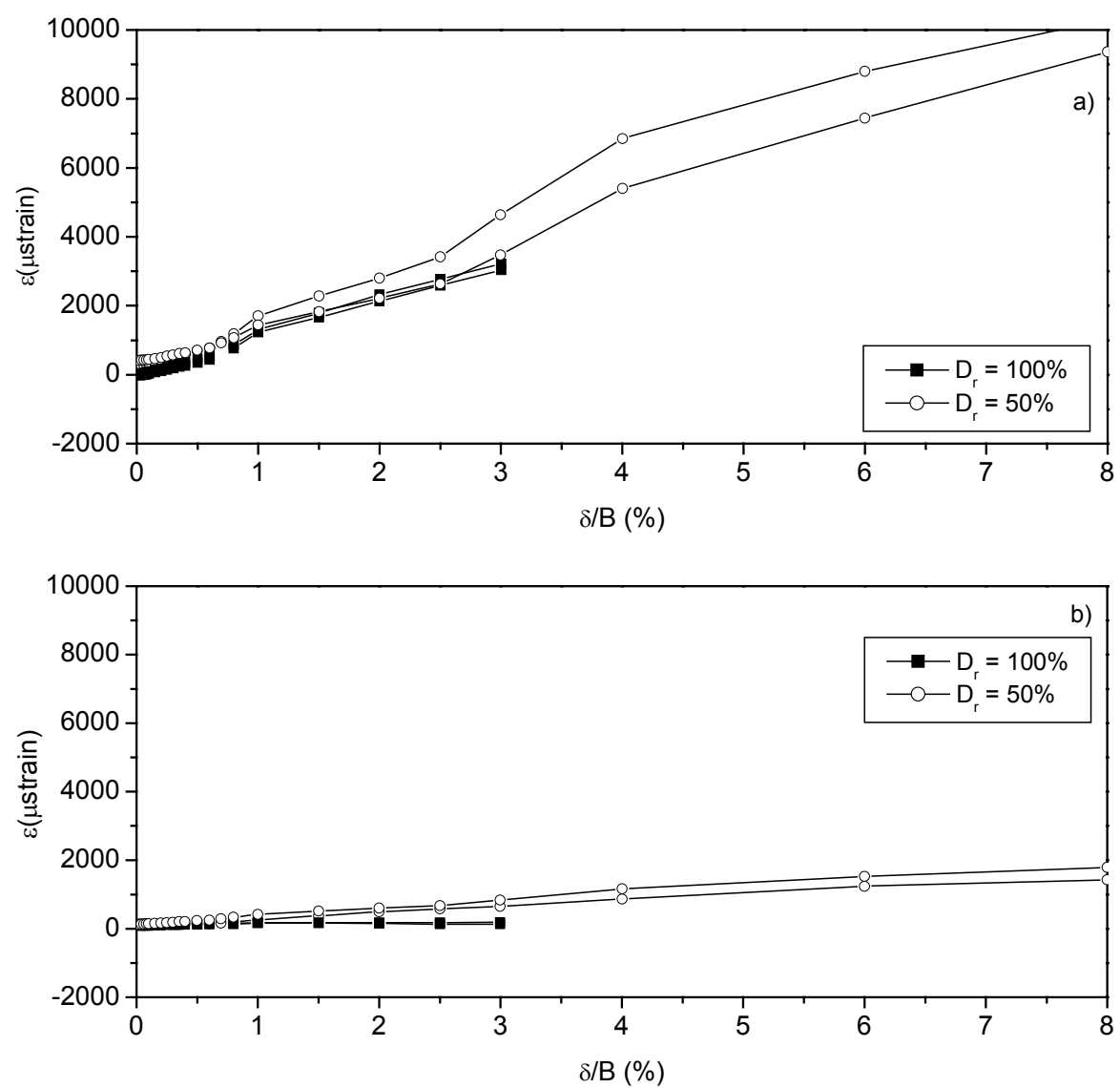

Figura 8.37. Variação da deformação da parede do conduto com o deslocamento do alçapão (linha d'água), com $50 \mathrm{kPa}$ de sobrecarga. a) deformação transversal; b) deformação longitudinal. 


\section{Conclusões}

\subsection{CONSIDERAÇÕES INICIAIS}

A presente tese descreve uma investigação experimental sobre o comportamento de dutos enterrados submetidos a perda de apoio ou elevação em uma determinada localidade ao longo de seu comprimento, compreendendo um total de 37 ensaios realizados. A geometria do alçapão, a rigidez do duto, a densidade relativa do solo e o nível de tensão foram as principais variáveis investigadas. As principais conclusões obtidas na pesquisa são destacadas a seguir.

\subsection{SISTEMA SOLO-ALÇAPÃO}

Para dar suporte às análises dos resultados dos modelos com os tubos, a pesquisa também contou com testes com modelos sem tubo, denominados ao longo do texto de ensaios de arqueamento, nos quais foram medidas as variações das tensões verticais no maciço (sistema solo-alçapão). No que diz respeito a essa parte do trabalho, as seguintes observações devem ser ressaltadas:

(i) $\mathrm{O}$ mecanismo de ruptura em condição profunda, em arqueamento ativo, difere bastante daquele comumente descrito para a condição rasa. Em profundidade, o solo acima do alçapão sofre grandes deformações na direção da movimentação da estrutura, interagindo diretamente no processo de formação das localizações. Registrou-se a propagação de um único par de localizações sobre o alçapão. 
(ii) A propagação da localização em arqueamento ativo envolve um processo contínuo de cisalhamento com aumento longitudinal e também lateral da localização, excluindo a formação de "blocos rígidos" de solo, característicos da condição rasa.

(iii) Para um determinado deslocamento do alçapão em arqueamento ativo, as seções transversais apresentaram padrões mais desenvolvidos em comparação com a seção longitudinal investigada, incluindo a formação de localizações se propagando em direção ao maciço de solo exterior ao alçapão.

(iv) $\mathrm{O}$ mecanismo de formação das localizações externas em arqueamento ativo é basicamente governado pela instabilidade da massa de solo adjacente ao alçapão, despertada pela migração contínua do material central para o vazio criado.

(v) A maior extensão horizontal das localizações externas foi observada no maciço fofo, correspondendo a $0,6 \mathrm{~B}$ independentemente do nível de aceleração imposto. Esse valor é o triplo do obtido no maciço compacto na aceleração unitária. As localizações atingiram uma altura de aproximadamente 2 B no maciço compacto, independentemente da aceleração. A mesma altura foi alcançada no maciço fofo a $1 \mathrm{~g}$.

(vi) A dilatação do solo exerce uma forte influência sobre o mecanismo de ruptura do sistema em profundidade, definindo o aspecto e o número das localizações. Uma maior dilatação contribui para a formação de localizações mais bem definidas e de menor espessura. Em contraste, uma menor dilatação é associada a localizações mais largas, com espessura aumentando gradualmente da base ao topo. Na maioria das situações investigadas, as localizações apresentaram espessura acima da faixa típica reportada, principalmente quando propagadas no maciço fofo.

(vii) O comportamento da tensão vertical no interior do alçapão em arqueamento ativo mostrou-se muito pouco dependente da densidade do solo, da sobrecarga aplicada e da geometria da estrutura. A redução da carga acima do centro do alçapão atingiu uma altura de influência estimada em 4,5 B.

(viii) A redistribuição de tensões verticais no maciço de solo abrange uma área de considerável extensão em torno do alçapão em arqueamento ativo. A 
tendência geral observada foi de um ligeiro aumento da tensão vertical, seguido de redução brusca logo no início da translação do alçapão. As regiões mais remotas do maciço experimentaram apenas aumento de tensão.

(ix) O alívio da carga estendeu-se a uma parte da massa de solo exterior adjacente igual a, no mínimo, 0,8 B na região do maior lado e entre 0,2 e 0,7 B nas proximidades do menor lado do alçapão retangular em arqueamento ativo. A partir desses limites, o solo experimentou aumento de carga, o qual foi registrado até uma distância de quase $5 \mathrm{~B}$.

(x) Na região do maior lado do alçapão retangular em arqueamento ativo, a densidade do solo e o nível de sobrecarga aplicada exerceram uma influência pequena na transferência de tensão. O efeito dessas variáveis foi mais significativo na região do menor lado.

(xi) Os resultados dos ensaios de arqueamento passivo revelaram um forte aumento das tensões sobre a estrutura, sendo tal crescimento ainda mais pronunciado nas extremidades do alçapão, efeito decorrente da maior proximidade da zona cisalhante formada na massa de solo.

(xii) A influência da movimentação ascendente do alçapão sobre a redistribuição das tensões na massa de solo sobre a estrutura atingiu alturas em torno de 4 B.

(xiii) A movimentação passiva da estrutura modificou o campo de tensões de uma grande área do maciço em seu entorno. A massa de solo externa adjacente experimentou uma redução marcante da tensão a $0,2 \mathrm{~B}$ de distância dos limites do alçapão, em ambos os lados. Reduções de tensão foram observadas até 2,7 B do menor lado do alçapão retangular.

(xiv) $\mathrm{O}$ alçapão de formato quadrado $\left(\mathrm{L}_{\mathrm{v}} / \mathrm{B}=1\right)$ forneceu tensões ligeiramente superiores às do alçapão de formato retangular $\left(\mathrm{L}_{\mathrm{v}} / \mathrm{B}=3\right)$. Diferenças significativas na redistribuição das tensões externas entre ambos os alçapões não foram observadas.

(xv) A mobilização total do estado passivo requer deslocamentos de magnitude bastante superior à mobilização total do estado ativo. Quanto maior a razão geométrica $\mathrm{H} / \mathrm{B}$, maior é o deslocamento necessário para a mobilização da tensão máxima do estado ativo. Já o deslocamento para a mobilização da 
tensão mínima no estado ativo aparenta guardar relação com a profundidade somente para H/B inferior a aproximadamente 2.

\subsection{SISTEMA SOLO-DUTO-ALÇAPÃO}

Com respeito à parte do trabalho envolvendo os modelos com tubos sofrendo perda de apoio localizada, as seguintes observações são enumeradas:

(i) Após a perda de apoio, o padrão de ruptura no solo foi caracterizado pela formação de três localizações de deformação propagando-se a partir da região próxima à aresta do alçapão. As localizações se estenderam até o maciço de solo exterior até uma distância horizontal igual a quase $1 \mathrm{~B}$ e uma altura de aproximadamente $2 \mathrm{~B}$.

(ii) No maciço compacto, zonas de ruptura maiores foram observadas com os tubos de maior rigidez. Tal tendência foi menos evidente no maciço fofo.

(iii) A magnitude do recalque superficial apresentou-se independente da rigidez do duto, guardando relação apenas com a densidade do solo.

(iv) Após a perda de apoio, o duto flexível imerso no maciço fofo apresentou um padrão caracterizado pela ascensão da base e por uma flambagem acentuada na região compreendida entre o ombro e o topo. O dano sofrido pode ser classificado como uma ruptura, uma vez que sua habilidade de transferir adequadamente a carga recebida para o solo adjacente foi completamente comprometida.

(v) Os resultados evidenciaram que o potencial de avaria ao duto mediante uma eventual perda de apoio localizada é intimamente relacionado à compactação do solo de aterro. Se o aterro é adequadamente compactado, o conduto apresentará grandes chances de permanecer operacional após a ocorrência.

(vi) Após a perda de apoio, cada parte do conduto assumiu um perfil de deflexão distinto ao longo do comprimento. As deflexões induzidas pela perda de apoio atingiram uma distância de até $5 \mathrm{D}$ na região do duto fora do alçapão.

(vii) As condições mais críticas com respeito à deflexão do duto em todas as situações investigadas ocorreram no deslocamento relativo do alçapão $(\delta / B)$ de $15 \%$. 
(viii) De forma geral, a deformação da seção transversal central do duto aumentou significativamente com a redução da densidade relativa do solo e com o aumento da sobrecarga superficial.

(ix) Soluções analíticas para a estimativa de deslocamentos vertical em dutos sujeitos a perda de apoio localizada podem fornecer resultados inconsistentes, uma vez que as deflexões das diferentes partes do conduto não são consideradas de forma separada pelos métodos. Um modelo analítico baseado na hipótese de Winkler, ao qual foi implementada uma perda parcial de suporte, gerou previsões adequadas do comportamento do duto registrado nos modelos construídos com o maciço compacto.

(x) Para a geometria do alçapão investigada, observou-se que o topo do duto e as laterais experimentaram uma forte redução de tensão após a perda de apoio. No entanto, houve a recuperação momentânea de uma parcela da tensão no topo quando o alçapão atingiu um determinado nível de deslocamento, a qual foi ligeiramente maior para maiores sobrecargas, tanto no maciço fofo quanto no compacto. A tensão na linha d'água também aumentou expressivamente após o alçapão ter atingido um determinado deslocamento, porém apenas no maciço compacto. Em seguida houve novo decréscimo da tensão.

(xi) A redução da tensão no solo na lateral do alçapão foi ainda mais expressiva que a obtida nos ensaios sem o duto. $\mathrm{O}$ efeito do arqueamento nessa região também foi superior ao verificado no topo e na linha d'água. A influência da densidade do solo sobre as tensões na base da caixa de testes foi relativamente pequena.

(xii) As deformações específicas medidas na parede externa do tubo foram mais proeminentes no topo, em comparação com o ocorrido na base e, principalmente, na linha d'água. Exceto no topo, as deformações longitudinais foram inferiores às transversais. As deformações no tubo no maciço compacto foram muito inferiores às registradas no maciço fofo.

Com relação à parte da pesquisa sobre os modelos com tubos submetidos a elevação localizada, os seguintes aspectos são destacados: 
(i) As deflexões do duto induzidas pela elevação alcançaram uma distância fora do alçapão entre 4 e 7 D. Em linhas gerais, os perfís revelaram uma forte ascensão da base e do assento do duto, além de aumento do diâmetro horizontal. O ombro foi a região que menos sofreu deflexão.

(ii) No maciço compacto, o topo do duto apresentou elevação quando sob sobrecargas mais baixas. À medida que a sobrecarga aplicada aumentou, a elevação sofrida decresceu, por conta do crescimento da resistência do solo à movimentação ascendente do duto. A partir de certo patamar de sobrecarga, o duto apresentou uma tendência de afundamento do topo. Comportamento semelhante foi verificado no maciço fofo, porém a variação da deflexão com a sobrecarga foi comparativamente menor.

(iii) No solo compacto, a linha d'água do tubo sofreu um suave aumento com o aumento da sobrecarga aplicada, reflexo do crescimento da restrição à movimentação ascendente da estrutura. Já no solo fofo, a variação da deflexão foi praticamente nula.

(iv) A modificação do método analítico de Rajani e Morgenstern (1993) proposta, com a resistência passiva obtida experimentalmente a partir da tensão medida no topo do duto, previu uma tendência oposta à observada com os modelos físicos, com a deflexão crescendo com a sobrecarga aplicada. Em adição, a solução analítica gerou resultados com magnitudes excessivas para o solo compacto.

(v) Uma forte mobilização da resistência passiva do solo, decorrente do crescimento do diâmetro horizontal do duto foi observada na seção central. O maciço compacto permitiu o desenvolvimento de uma maior resistência passiva na lateral do duto, crescente com o aumento da sobrecarga aplicada. Já no maciço fofo, a tensão mobilizada lateralmente não variou com o aumento da sobrecarga.

(vi) Em linhas gerais, os resultados mostraram que, em se tratando de condutos flexíveis submetidos a elevação, o foco da atenção deve ser a linha d'água, visto que o aumento da concentração de tensão no topo permanece baixo. 
(vii) Um alívio marcante da tensão foi observado na região do maciço adjacente ao alçapão ao lado do duto. Sob o conduto, também foi registrado alívio de tensão com a movimentação do alçapão.

(viii) As deformações específicas medidas na parede do duto sujeito à elevação não sofreram influência da densidade do material em nenhuma das posições medidas. A linha d'água experimentou deformações de magnitudes muito elevadas na transversal, permanecendo, no entanto, em patamares muito reduzidos na longitudinal. 


\section{REFERÊNCIAS BIBLIOGRÁFICAS}

Allgood, J. R. (1964). The behavior of shallow-buried cylinders. In: Symposium on Soil-structure Interaction. Proceedings. Tucson, Arizona. 1964. p.189-210.

Allgood, J. R. (1971). Structures in soil under high loads. Journal of the Soil Mechanics and Foundation Division. v. 97, n. SM3, p. 565-579.

Allison, C. J. (1967). An experimental study of the strength of circular tubes in a confined medium, Military Experiment Establishment, Res. Rep. 47.5/8. (após Bulson 1985).

Altaee, A.; Fellenius, B. F.; Salem, H. (1996). Finite element modeling of lateral pipeline-soil interaction. In: Pipeline Technology Proceedings of the International Conference on Offshore Mechanics and Arctic Engineering OMAE, v.5, ASME, New York, p. 333-341.

American Society for Testing and Materials (2002). D 2412-2. Standard Test Method for Determination of External Loading Characteristics of Plastic Pipe by Parallel-Plate Loading. ASTM.

ARMCO (1958). Handbook of Drainage and Construction Products.

Arriaga, F. (2003). Response of geosynthetic-reinforced structures under working stress and failure conditions. Ph.D. thesis, University of Colorado at Boulder. $261 \mathrm{p}$.

Associação Brasileira de Normas Técnicas (1984). NBR 7181 - Solo - Análise Granulométrica. Rio de Janeiro.

Associação Brasileira de Normas Técnicas (1990). NBR 12004/MB 3324 - Solo Determinação do índice de vazios máximo de solos não coesivos. Rio de Janeiro.

Associação Brasileira de Normas Técnicas (1991). NBR 12051/MB 3388 - Solo Determinação do índice de vazios mínimo de solos não coesivos. Rio de Janeiro.

Atkinson, J. (1993). Na introduction to the mechanics of soils and Foundations. McGraw-Hill.

Audibert, J. M. E; Nyman, K. J. (1977). Soil restraint against horizontal motion of pipes. Journal of the Geotechnical Engineering Division, v.103, n.GT10.

AWWA (1989). Steel pipe - a guide for design and installation, $3^{\text {rd }}$ ed. Denver, CO. 
Batiste, S. N. (1998). Mechanics of granular materials at low confining stress. M.Sc. Thesis, University of Colorado at Boulder.166p.

Benmansour, A.; Abdallah, A.; Masrouri, F.; Auvinet, G. (1997). Analyse fiabiliste du comportement axial des conduits d'assainissement. Canadian Geotechnical Journal, v.34, n.329-343.

Bierbaumer, A. (1913). Die Dimensionerung des Tunnelmauerwerks, Engelmann, Leipzig (após Iglesias 1999).

Bolton, M. D. (1986). The strenght and dilatancy of sands. Géotechnique, v.36, n.1, 65-78.

Bowles, J. E. (1996). Foundation analysis and design. $5^{\text {a }}$ ed. McGraw-Hill.

Brachman, R. W. I; Moore, I. D.; Rowe, R. K. (2000). The design of a laboratory facility for evaluating the structural response of small-diameter buried pipes. Canadian Geotechnical Journal, v.37, p.281-295.

Bransby, M. F.; Newson, T. A.; Davies, M. C.; Brunning, P. (2002). Physical modeling of the upheaval resistance of buried offshore pipelines. In: Physical Modeling in Geotechnics; ICPMG '02. Phillips, Guo, Popescu (eds.). Swets \& Zeitling Lisse, p. 899-904.

Bueno, B. S. (1987). The behaviour of thin walled pipes in trenches. Tese (Ph.D.) University of Leeds, U.K., 337p.

Bueno, B. S. (2005). Dimensionamento geotécnico de tubulações enterradas. /no prelo/

Bulson, P. S. (1985). Buried structures - static and dinamic strength. Chapman and Hall.

Burns, J. Q.; Richard, R. M. (1964). Attenuation of stresses for buried cylinders. In: Symposium on soil-structure interaction, proceedings, Tucson, Arizona, p. 378-392.

Buttlerfield, R., Harkness, R. M., Andrews, K. Z. (1970). A stereo-photogrametric method for measuring displacement fields. Geotechnique, v.20, n.3, p. 308314.

Chelapati, C. V. (1964). Arching in soil due to the deflection of a rigid horizontal strip. Proc. Symposium on Soil-Structure Interaction. Tucson. Arizona. p. 356377.

Chelapati, C. V.; Allgood, J. R. (1972). Buckling of cylinders in a confining medium. Highway Research Record, n. 413, Highway Research Board. p.77-88. 
Conrad, B. E.; Lohnes, R. A.; Klaiber, F. W.; Wipf, T. J. (1998). Boundary effects on response of polyethylene pipe under simulated live load. Transportation Research Record 1624, p. 196-205.

Coyle, H. M.; Reese, L. C. (1966). Load transfer for axially loaded piles in clay. Journal of the Soil Mechanics and Foundations Division, v.92, n.SM2, p.1-26.

Craig, R. F. (1996). Soil Mechanics. $6^{\text {a }}$ ed.. E \& FN Spoon.

Crofts, J. E.; Menzies, B. K.; Tarzi, A. I. (1977). Lateral displacement of shallow buried pipelines due to adjacent deep trench excavations. Géotechnique, v. 27, n. 2, p. 161-179.

Davies, M. C. R., and Jones, A. M. (1998). "Image acquisition using an on-board film camera". Proc. of the Intl. Conf. Centrifuge '98, Kimura, Kusakabe, and Takemura (eds), Japan, p. 67-71.

Davis, E. H. (1968). Theories of plasticity and the failure of soil masses. Soil Mechanics Selected Topics. Lee, K. (ed.). p.341-380.

De Beer, E. E. (1948). Computation of beams resting on soil. In: International Conference on Soil Mechanics and Foundation Engineering, $2^{\text {nd }}$, Rotterdam, v.1, p.119-121.

Desrues, J., Lanier, J., Stutz, P. (1985). Localization of the deformation in tests on sand sample. Engineering Fracture Mechanics, vol. 21, n. 4, p/.909-921.

Dickin, E. A. (1988). Stress displacement of buried plates and pipes. In: Centrifuge '88. Corté (ed.), A. A. Balkema. p. 205-214.

Dickin, E. A. (1994). Uplift resistance of buried pipelines in sand. Soils and Foundations, v. 34, n. 2, p. 41-48.

Dickin, E.; Leung, C. F. (1985). Evaluation of design methods for vertical anchor plates. Journal of Geotechnical Engineering, v.111, n.4, p500-520.

Engesser, F. (1882). Ueber den Erdduck gegen innere Stützwande (Tunnelwande). Deutsche Bauzeitung, n.16, p.91-93 (após Iglesias 1999).

Evans, C. H. (1983). An examination of arching in granular soils. M.Sc. Thesis, Department of Civil Engineering, MIT.

Fernando, N. S.; Carter, J. P. (1998). Elastic analysis of buried pipes under surface patch loadings. Journal of Geotechnical and Geoenviromental Engineering, v. 124 , n. 8 , p. $720-728$.

Finn, W. D. (1963). Boundary value problems of soil mechanics Journal of the Soil Mechanics and Foundation Division. v.89, n.SM5. 
Foriero, A.; Landanyi, B. (1994). Pipe uplift resístanse in frozen soil and comparison with measurements. Journal of Cold Regions Engineering, v.8, n.3, p.93-111.

Forrestal, M. J.; Herrmann, G. (1965). Buckling of a long cylindrical shell surrounded by an elastic medium. International Journal of Solids Struct., v.1, p.297-310.

Frydman, S; Shaham, I. (1989). Pullout capacity of slab anchors in sand. Canadian Geotechnical Journal, v. 26, pp. 385-400.

Garnier, J., Chambon, P., Ranaivoson, D., Charrier, J., and Mathurin, R. (1991). "Computer image for displacement measurements". Proc. of the Intl. Conf. Centrifuge '91, Ko and McLean (eds), Boulder, p. 543-550.

Getzler, Z.; Korormik, A.; Mazurik, A. (1968). Model study in arching above buried structures. Journal of the Soil Mechanics and Foundation Division. n. SM5. p. 1123-1141.

Gill, H. L. (1967). Active arching of sand during dynamic loading. US Naval civil Engineering Laboratory, Report TR541. (após Bulson 1985).

Goddard, J. B. (1994). Plastic pipe design - technical note 4103. http://adspipe.com/techsup/tech4103.html (28/07/00).

Gumbel, J. E.; O’Reilly, M. P.; Lake, L. M.; Carder, D. R. (1982). The development of a new design method for buried flexible pipes. In: Europipe '82. Proceedings. Basel, 1982. p. 87-98.

Hachiya, M.; Inoue Y.; Tohda, J.; Takatsuka, Y.; Takagi, R.(2002). Response of buried pipelines subjected to differential ground settlement. In: Physical Modeling in Geotechnics; ICPMG '02. Phillips, Guo, Popescu (eds.). Swets \& Zeitling Lisse, p. 911-916.

Han, C. (1991). Localization of deformation in sand. Ph.D. Thesis, Department of Civil and Mineral Engineering, University of Minnesota.

Handy, R. L. (1985). The arch in soil arching. Journal of Geotechnical Engineering. V.111, n.3, p. 302-318.

Hartley, J. D.; Duncan, J. M. (1987). E' and its variation with depth. Journal of Transportation Engineering, v.113, n.5, p.538-553.

Hearn, E. J. (1985). Mechanics of materials, $2^{\text {nd }}$ ed. Pergamon Press Ltd, Oxford.

Hetényi, M. (1946). Beams on elastic foundation. Ann Arbor: the University of Michigan Press.

Howard, A. K. (1968). Laboratory load tests on buried flexible pipe, Progress Report No. 1, US Bureau of Reclamation. Rep. EM-763 (após Bulson 1985). 
Howard, A. K. (1972). Laboratory Load Tests on buried flexible pipe. Journal of the American Water Works Association, v. 64, p. 655-662.

Howard, A. K. (1977). Modulus of soil reaction values for buried flexible pipeline. Journal of Geotechnical Engineering Division, v.103 n.GT1, jan, p. 33-43.

Hsu, T. (1993). Rate effect on lateral soil restraint of pipelines. Soils and Foundations, v. 33, n. 4, p. 159-169.

Hsu, T. (1996). Soil restraint against oblique motion of pipelines in sand. Canadian Geotechnical Journal, v. 33, n. 1, p. 180-188.

Hsu, T.; Chen, Y.; Wu, C. (2001). Soil friction restraint of oblique pipeline in loose sand. Journal of Transportation Engineering, v. 127, n. 1, p. 82-87.

Hunt, R. E. (1986). Geotechnical engineering analysis and evaluation. McGraw-Hill.

Iglesia, G. R. (1991). Trapdoor experiments on the centrifuge: a study of arching in geomaterials and similitude in geotechnical models. Tese (Doutorado) Massachusetts Institute of Technology.

Iglesia, G. R.; Einstein, H. H.; Whitman, R. V. (1999). Determination of vertical loading on underground structures based on arching evolution concept. Geotechnical Special Publication $n^{0}$ 90, p. 495-506.

Janssen, H. A. (1895). Versuche über Getreidedruck in Silozellen. Z. D. Vereins deutscher Ingenieure, v.39, p.1045 (após Iglesias 1999).

Kassif, G.; Zeitlen, J. G. (1962). Behavior of pipes buried in expansive clays. Journal of the soil Mechanics and Foundations Division, v.88, n. SM2, p133-148.

Katona, M. G. (1988). Allowable fill height for corrugated polyethlene pipe. TRB 1191, Transportation Research Board, National Research Council. Washington, DC.

Kim, H-, S.; Kim, W-, S.; Bang, I-,W.; Oh, K. (1998). Analysis of stresses on buried natural gas pipeline subjected to ground subsidence. In: International Pipeline Conference, ASME. vol.2, p. 749-756.

Ko, H. Y. (1988a). Summary of the state-of-the-art in centrifuge modeling testing. In: Centrifuges in Soil Mechanics. Proceedings. James and Schofield, eds., p. $11-18$.

Ko, H. Y. (1988b). The Colorado centrifuge facility. In: Centrifuge 88. Proceedings. Paris, p. 73-75.

Koutsabeloulis, N. C.; Griffiths, D. V. (1989). Numerical modelling of the trap door problem. Géotechnique v. 39, n.1. p.77-89. 
Krizek, R. J.; Parmelee, R. A.; Kay, J.; Elnagger, H. (1971). Structural analysis and design of pipe culverts. National Cooperative Highway Research Program Report 116, HRB.

Krynine, D. P. (1945). Stability and stiffness of cellular cofferdams (discussion). Transactions, ASCE, v.110, p.1175-1178.

Kulhawy, F. H.; Trautmann, C. H.; Nicolaides, C. N. (1987). Spread foundations in uplift: experimental study. Session on Foundations for Transmission Line Towers, Proceedings, ASCE, p. 96-109.

Ladanyi, B,; Hoyaux, B. (1969). A study of the trap-door problem in a granular mass. Canadian Geotechnical Journal, v.6, n.1. p. 1-15.

Ladd, C.; Foott, R.; Ishihara, K.; Scholosser, F.; Poulos, H. (1977). Stressdeformation and strength characteristics. Proceedings. International Conference on Soil Mechanics and Foundation Engineering, 9. A. A. Balkema, Rotterdam, The Netherlands, 421-494.

Levinton, Z. (1947). Elastic foundation analyzed by the method of redundant reactions. Transactions of the ASCE, v.114, n.40-52.

Lins Costa, C. M. (2004). Deformações dependentes do tempo em muros de solo reforçado com geotêxteis. Tese (Doutorado) - EESC/USP.

Luscher, U. (1966). Buckling of soil-surrounded tubes. Journal of the Soil Mechanics and Foundations Division, v.88, n.SM6, p. 211-228.

Masad, E., Taha, R., Ho, C., Papagiannakis, T. (1996). Engineering properties of tire/soil mixtures as lightweight fill material. Geotechnical Testing Journal, vol. 19 , n. 3, p. 297-304.

Matyas, E.; Davis, J. B. (1983). Prediction of vertical earth loads on rigid pipes. Journal of Geotechnical Engineering, v.109, n.2, p. 190-209.

McGrath, T. J.; Chambers, R. E.; Sharff, P. A. (1990). Recent trends in installation standards for plastic pipe. Buried Plastic Pipe Technology. ASTM STP 1093, Buczala, G. S.; Cassady, M. J., eds., ASTM. p.281-293.

McNulty, J. W. (1965). An experimental study of arching on sand. US Waterways Experimental Station, Vicksburg, Tech. Report. 674p.

Meyerhof, G. G. (1973). Uplift resistance of inclined anchors and piles. In: Proc. $8^{\text {th }}$ International Conference on Soil Mechanics and Foundation Engineering. Moscow.

Meyerhof, G. G.; Adams, J. I. (1968). The ultimate uplift capacity of foundations. Canadian Geotechnical Journal, v.5, n.4, p. 225-244. 
Miura, S.; Toki, S. (1982). A sample preparation method and its effects on static and cyclic deformation-strength properties of sand. Soils and Foundation,v. 22, n. 1, p. 61-77.

Moore, I. D. (1989). Elastic buckling of buried flexible tubes - a review of theory and experiment. Journal of Geotechnical Engineering. v.115, n.3, p. 340-358.

Moser, A. P. S. (2001). Buried pipe analysis and design. McGrall-Hill.

Murray, E. J.; Geddes, J. D. (1987). Uplift of anchors plates in sand. Journal of Geotechnical Engineering, v.113, n.3, p202-215.

Murray, E. J.; Geddes, J. D. (1989). Resistance of passive inclined anchors in cohesionless medium. Géotecnique, v.39, n.3, p.417-431.

Nath, B. (1977). Finite element analysis of a large diameter buried steel pipeline. Transport and Road Research Laboratory, Crowthorne, Rep. LR 778. 26p (após Bueno 1987).

Nelson, J. D.; Miller, D. J. (1992). Expansive soils. John Wiley \& Sons, New York, $295 \mathrm{p}$.

Ng, C.; Springman S. (1994). Uplift resistance of buried pipelines in granular materials. In: Centrifuge 94. Leung, Lee \& Tan (eds.). A. A. Balkema, Rotterdam. p. 753-758.

Nielson, F. D.; Koo, H. P. (1968). Determination of settlement ratio for conduits in homogeneous backfill. Comm. on Culverts and Culvert Pipes, $47^{\text {th }}$ Annual Meeting HRB.

O'Rourke, M. J.; El Hmadi, K. (1988). Analysis of continuous buried pipelines for seismic wave effects. Earthquake Engineering Struct. Dynamics. v.16, n.6, p.917-929.

O’Rourke, M. J.; Liu, X.; Flores-Berrones, R. (1995). Steel pipe wrinkling due to longitudinal permanent ground deformation. Journal of Transportation Engineering, v. 121, n. 5, p. 443-451.

O'Rourke, T. D.; Ahmed, S. M. (1985). Effect of shallow trench construction on cast iron pipelines. In: International Conference on Advances in Underground Pipeline Engineering, ed. JEYAPALAN, J. K., Proceedings, ASCE.

Ohde, J. (1942). Die berechnung der sohldruckverteilung unter grundungskorpern, Bauingenieur, 23 Jahrgang, Helf 14/16, Helf 17/18. Apud VELLOSO \& LOPES (1996).

Ono, K; Yamada, M. (1993). Analysis of the arching action in granular mass. Geotechnique, 43 n1 105-120. 
Palmer, A. C.; Williams, P. J. (2003). Frost heave and pipeline upheaval buckling. Canadian Geotechnical Journal, v.40, p.1033-1038.

Paulin, M.; Phillips, R.; Boivin, R. (1995). Centrifuge modeling of lateral pipeline/soil interaction. In: Pipeline Technology Proceedings of the International Conference on Offshore Mechanics and Arctic Engineering OMAE, v.5, ASME, New York, p. 107-123.

Pearson, F. H. (1977). Journal of the environmental engineering division, v. 103, n. EE5, p. 767-783.

Peck, R. B. (1958). A study of the comparative behavior of friction piles. Highway Research Board, Special Report 36.

Peck, R. B. (1969). State-of-the-Art Report: Deep excavations and tunneling in soft ground. In: $7^{\text {th }}$ International Conference in Soil Mechanics and Foundation Engineering, Proceedings, Mexico City, v.1, p. 225-290.

Peng, S. S.; Luo, Y. (1988). Determination of stress field in buried thin pipelines resulting from ground subsidence due to longwall mining. Mining Science and Technology, v.6, n.2, p.205-216.

Phares, B. M.; Wipf, T. J.; Klaiber, F. W.; Lohnes, R. A. (1998). Behavior of highdensity polyethylene pipe with shallow cover. Transportation Research Record 1624, p.214-224.

Poulos, H. G. (1974). Analysis of longitudinal behavior of buried pipes. In: Conf. on analysis and design in Geotechnical engineering, proceedings. V.1, Austin, Texas, p.199-223.

Powrie, W. (1997). Soil mechanics: concepts and applications, $1^{\text {st }}$ ed. E \& FN Spon. $420 \mathrm{p}$.

Prevost, R.C.; Kienow, K. K. (1994). Basics of flexible pipe structural design. Journal of Transportation Engineering, v.120, p.652-671.

Rad, N. S.; Tumay, M. T. (1987). Factors affecting sand specimen preparation by raining. Geotechnical Testing Journal. v. 10, n. 1, p. 31-37.

Rajani, B. B.; Morgenstern, N. (1993). Pipelines and laterally loaded piles in elastoplastic medium. Journal of Geotechnical Engineering, v. 119, n. 9, p. 1431-1448.

Rajani, B. B.; Robertson, P. K.; Morgenstern, N. R. (1995). Simplified design methods for pipelines subject to transverse and longitudinal soil movements. Canadian Geotechnical Journal, v. 32, p. 309-323.

Rajani, B.; Zhan, C.; Kuraoka, S. (1996). Pipe-soil interaction analysis of jointed water mains. Canadian Geotechnical Journal, v. 33, p. 393-404. 
Ramberg, W.; Osgood, W. (1943). Description of stress-strain curves by three parameters. Technical note no. 902, National Advisory Comitee for Aeronautics, 28. Após O'ROURKE et al. (1995).

Razaqpur, A. G.; Wang, D. (1996). Frost-induced deformations and stresses in pipelines. International Journal of Pressure Vessels and Pipping, v.69, p. 105118.

Rogers, C. D. F. (1987) The influence of surrounding soil on flexible pipe performance. Transportation Research Record 1129, p. 1-11.

Rogers, C. D. F. (1988). Some observations on flexible pipe response to load. Transportation Research Record 1191, p. 1-11.

Roscoe, K. H. (1970). The influence of strains in soil mechanics. Tenth Rankine Lecture. Géotechnique, v.20, n.2, 129-170.

Rowe, R. K.; Davis, E. H. (1982a). The behaviour of anchor plates in sand. Géotechnique, v.32, n.1, p.25-41.

Rowe, R. K.; Davis, E. H. (1982b). The behaviour of anchor plates in clay. Géotechnique, v.32, n.1, p.9-23.

Santichaianaint, K. (2002). Centrifuge modeling and analysis of active trapdoor in sand. Ph.D. Thesis. Department of Civil, Environmental and Architectural Engineering, University of Colorado at Boulder.

Schamineé, P. E. L.; Zorn, N. F. (1990). Soil response for pipeline upheaval buckling analysis: full-scale laboratory tests and modeling. In: Annual Offshore Technology Conference, 22. Houston, TX, p. 563-572.

Schofield, A. N. (1980). Cambridge geotechnical centrifuge operations. Geotechnique, v. 20, p. 227-268.

Scott, R. F. (1981). Foundation Analysis. Prentice Hall, New Jersey, NY.

Selvadurai, A. P. S. (1985). Soil-pipe interaction during ground movement. Civil Engineering in the Artic Offshore. BENNETT, F. L.; MACHEMEHL, J. L. eds. ASCE Specialty Conference, San Francisco.

Selvadurai, A. P. S.; Pang, S. (1988). Non-linear effects in soil-pipeline interaction in a ground subsidence zone. Numerical Methods in Geomechanics. SWOBODA, ed. A. A. Balkema. Rotterdam.

Selvadurai, A. P. S.; Shinde, S. B. (1993). Frost heave induced mechanics of buried pipelines. Journal of Geotechnical Engineering, v.119, p. 1929-1952.

Shibli, K. A. A.- (1995). Localized deformations in granular material. Ph.D. Thesis. Department of Civil, Environmental and Architectural Engineering, University of Colorado at Boulder. 
Sladen, J. A. (1992). The adhesion factor: applications and limitations. Canadian Geotechnical Journal, v. 29, p. 322-326.

Small, J. C.; Ngu, J. T. M. (1991). Longitudinal bending in pipelines subjected to embankment loading. Computer Methods and Advances in Geomechanics. BEER; BOOKER; CARTER, eds. A. A. Balkema, Rotterdam, p. 1233-1239.

Spangler, M. G. (1941). The structural design of flexible pipe culverts, Bul. 153. Iowa Eng. Expt. Station.

Spangler, M. G. (1948). Underground conduits - an appraisal of modern research. ASCE, New York, v.113.

Spangler, M. G. (1950). Theory of loads on negative projecting conduits. Proc. HRB, v.30. p.153-161.

Stone, K. J. L.; Muir Wood, D. (1992). Effects of dilatancy and particle size observed in model tests on sand. Soils and Foundations. V.32, n.4, p. 43-57.

Tanaka, T.; Sakai, T. (1993). Progressive failure and scale effect of trap-door problems with granular materials. Soils and Foundations, vol. 33, n. 1, p. 1122.

Taylor, R. N. (1995). Centifuges in modeling: principles and scale effects. In: Taylor, R. N., ed., Geotechnical Centrifuge Technology. Blackie Academic \& Professional.

Terzaghi, K. (1943). Theoretical soil mechanics. John Wiley \& Sons, New York.

Terzaghi, K. (1936). Stress distribution in dry and saturated sand above a yielding trap-door. $1^{\text {st }}$ International Conference on Soil Mechanics and Foundation Engineering, Proceedings. Cambridge, 1936, v.1, p. 35-39.

Terzaghi, K.; Peck, R. Mesri, G. (1996). Soil mechanics in engineering practice. 3a. ed., Wiley-Interscience.

Timoshenko, P. S.; Gere, J. M. (1961). Theory of elastic stability. McGraw-Hill, New York, 541p.

Tohda, J. et al. (1991). Centrifuge model tests on several problems of buried pipes. In: Centrifuge '91, Boulder, Co. Proceedings. Ko, H-Y; McLean, F. G., eds., Rotterdam, A. A. Balkema, p. 83-90.

Trautmann, C. H.; O'Rourke, D.(1985). Lateral force-displacement response of buried pipe. Journal of Geotechnical Engineering, v. 111, n.9, p.1077-1092.

Trautmann, C. H.; O’Rourke, D.; Kulhawy, F. H. (1985). Uplift force-displacement response of buried pipe. Journal of Geotechnical Engineering, v. 111, n.9, p.1061-1076. 
Trott, J. J.; Taylor, R. N.; Symons, I. F. (1984). Tests to validate centrifuge modelling of flexible pipes. Ground Engineering, sept.,. p. 17-28.

Ueno, K. (1998). Methods for preparation of sand samples. Centrifuge 98. A. A. Balkema. p.1047-1055.

UNIBELL (1997). Deflection: the pipe-soil mechanism. Uni-TR-1-97, Unibell PVC Pipe Association.

Valsangkar, A. J.; Britto, A. M. (1979). Centrifuge tests of flexible circular pipes subjected to surface loading. Supplementary Report 530, Transport and Road Research Laboratory, Crowthorne.

Vardoulakis, I. (1988). Theoretical and experimental bounds for shear band bifurcation strain in biaxial tests on dry sand. Res Mechanica, Vol. 23, p. 239259.

Vardoularkis, I.; Graf, B. (1985). Calibration of constitutive models for granular materials using data from biaxial experiments.Geotechnique, v 35, n. 3, p. 299317.

Vardoularkis, I.; Graf, B.; Gudehus, G. (1981). Trap-door problem with dry sand: a statical approach based upon model kinematics. International Journal for Numerical and Analytical Methods in Geomechanics. V.5. p. 57-78.

Velloso, D. A.; Lopes, F. R. (1996). Fundações. $1^{\text {a }}$ ed., Coppe-UFRJ.

Vermeer, P. A.; Sutjiadi, W. (1985). The uplift resistance of shallow embedded anchors. In: International Conference on Soil Mechanics and Foundation Engineering, 11, San Francisco. V.4; p.1635-1638.

Viana, P. M. F. (2003). Geovala: um novo processo construtivo para dutos enterrados. Tese (Doutorado). Escola de Engenharia de São Carlos Universidade de São Paulo. 238p.

Villard, P.; Gourc, J. P.; Giraud, H. (2000). A geosynthetic reinforcement solution to prevent the formation of localized sinkholes. Canadian Geotechnical Journal, v. 37, p. 987-999.

Walters, J. V.; Thomas, J. N. (1982). Shear zone development in granular materials. Proc. $4^{\text {th }}$ Internationa Conference on Numerical Methods in Geomechanics. Edmonton, v.1, p. 263-274.

Watkins, R. K.; Spangler, M. G. (1958). Some characteristics of the modulus of passive resistance of soil: a study in similitude. Annual meeting, Highway Research Board, 37. p.576-583.

Watkins, R.. K.; Anderson, L. R. (1999). Structural mechanics of buried pipes. 1 ed. CRC Press. 
White, H. L.; Layer, J. P (1960). The corrugated metal conduit as a compression ring. Highway Research Record, HRB, n.39, p. 389-397.

Wood, D. M. (1990). Soil Behaviour and Critical State Soil Mechanics. Cambridge University Press.

Woodruff, R. (2004). The performance of MSE shoring composite walls. Dissertação (Mestrado) - University of Colorado at Boulder.

Ymsiri, S.; Soga, K.; Yoshizaki, K.; Dasari, G.; O’Rourke, T. (2004). Lateral and upward soil-pipeline interactions in sand for deep embedment conditions. Journal of Geotechnical and Geoenvironmental Engineering, ASCE, v.130, no. 8. p. $830-842$.

Young, O. C.; Trott, J. J. (1984). Buried rigid pipes - structural design of pipelines. Elsevier.

Zhan, C.; Rajani, B. (1997). Load transfer analysis of buried pipe in different backfills. Journal of Transportation Engineering, v.123, n.6, nov/dec, p.447453.

Zornberg, J. G. (1994). Performance of geotextile-reinforced soil structures. Tese (Doutorado) - University of California, Berkley.

Zornberg, J. G.; Sitar, N.; Mitchell, J. (1998). Limit equilibrium as basis for design of geosynthetic reinforced slopes. Journal of Geotechnical and Geoenvironment Engineering. v.124, n.8, p. 684-698. 


\section{ANEXO A: Rotinas para o cálculo das deformações do solo}

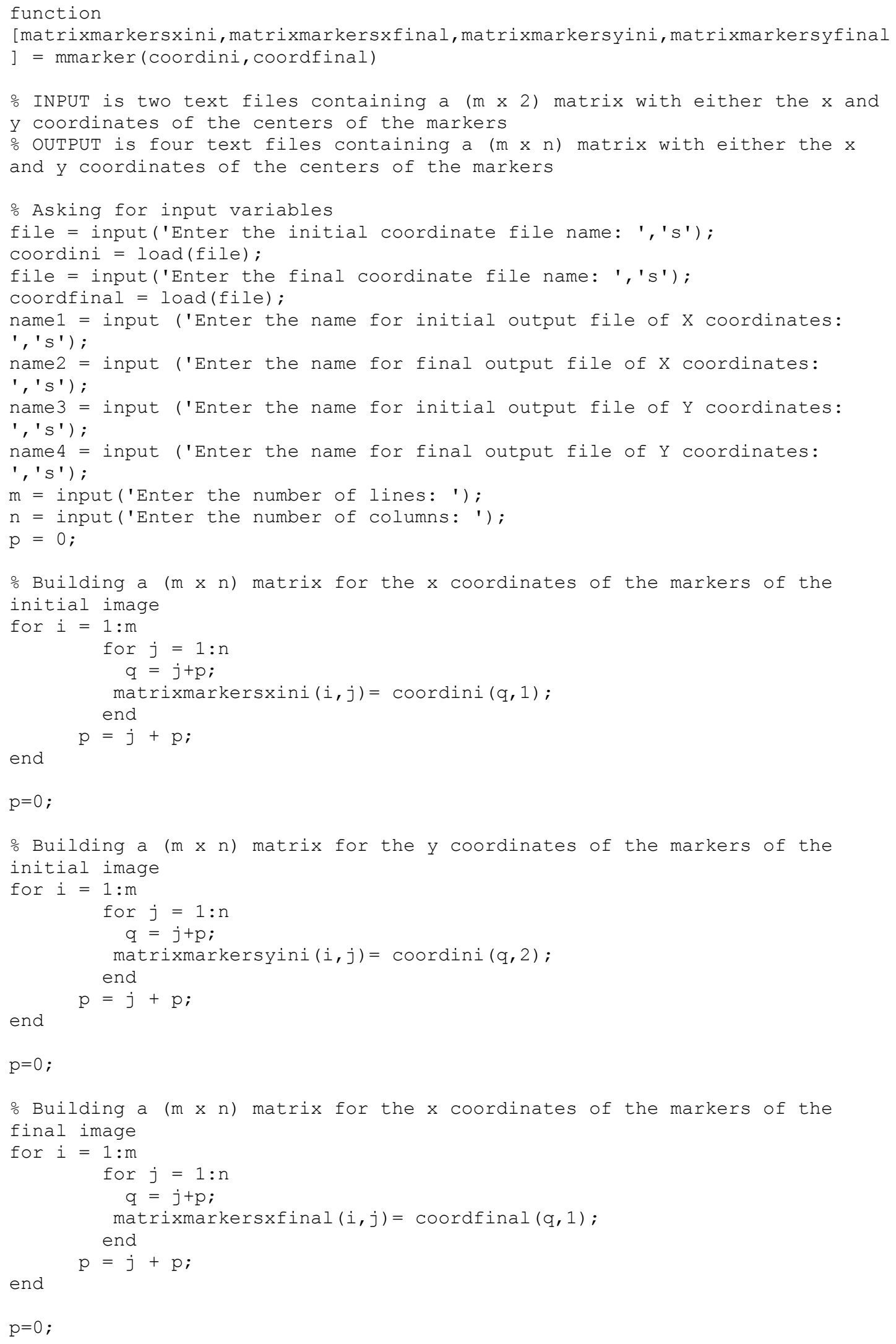




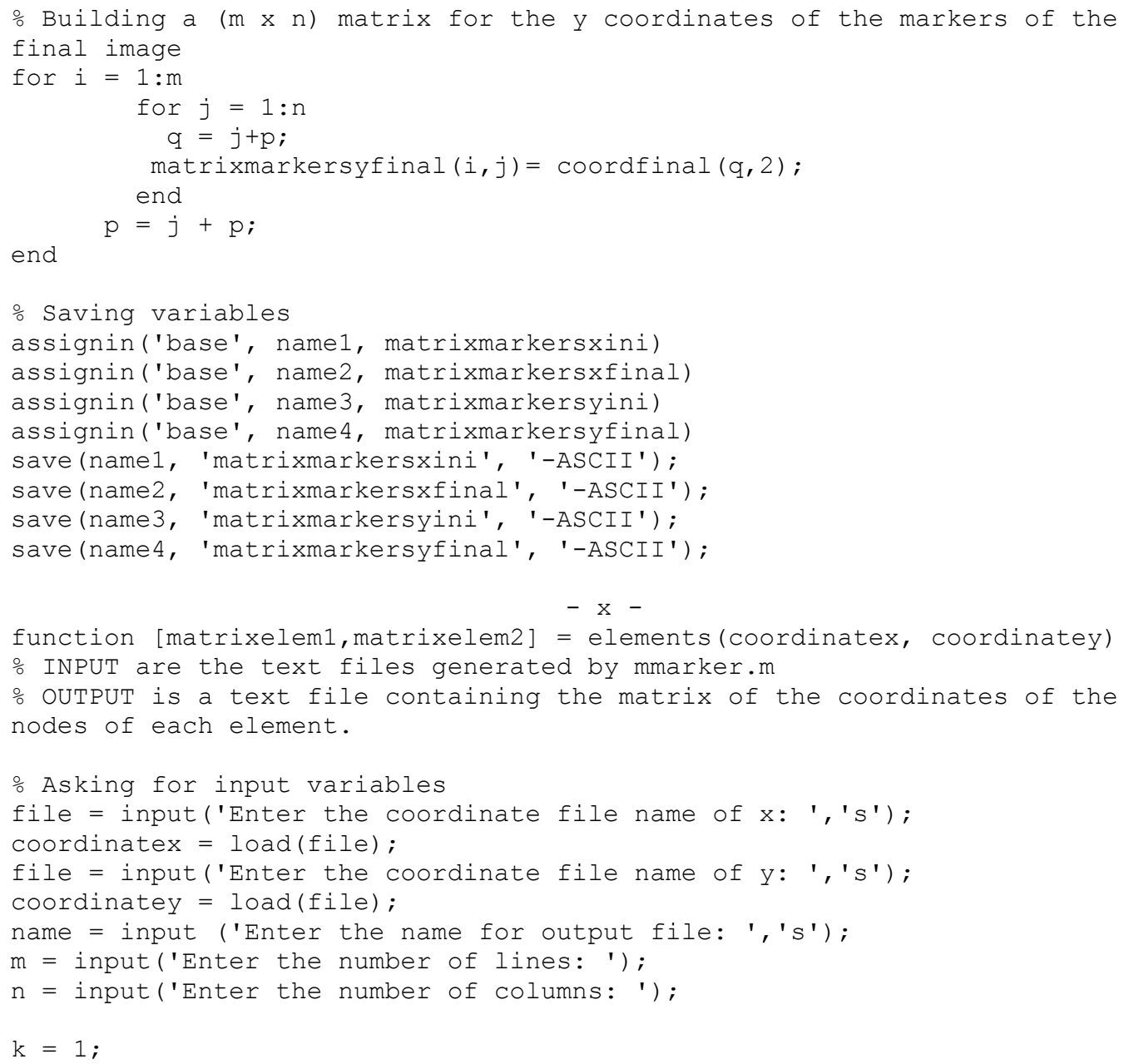

\% Generating the part of the matrix containing the $\mathrm{x}$ coordinates of the nodes of the upper elements.

for $i=1: m-1$ for $j=1: n-1$

end

$\mathrm{k}=1$;

- Generating the part of the matrix containing the y coordinates of the nodes of the upper elements.

for $i=1: m-1$

for $j=1: n-1$

matrixeleml $(k, 2)=\operatorname{coordinatey}(i, j) ;$

matrixelem $(k+1,2)=\operatorname{coordinatey}(i, j+1)$;

matrixelem $1(k+2,2)=\operatorname{coordinatey}(i+1, j)$;

$\mathrm{k}=\mathrm{k}+3$;

end

end

$k=1$;

\% Generating the part of the matrix containing the $\mathrm{x}$ coordinates of the nodes of the lower elements. 


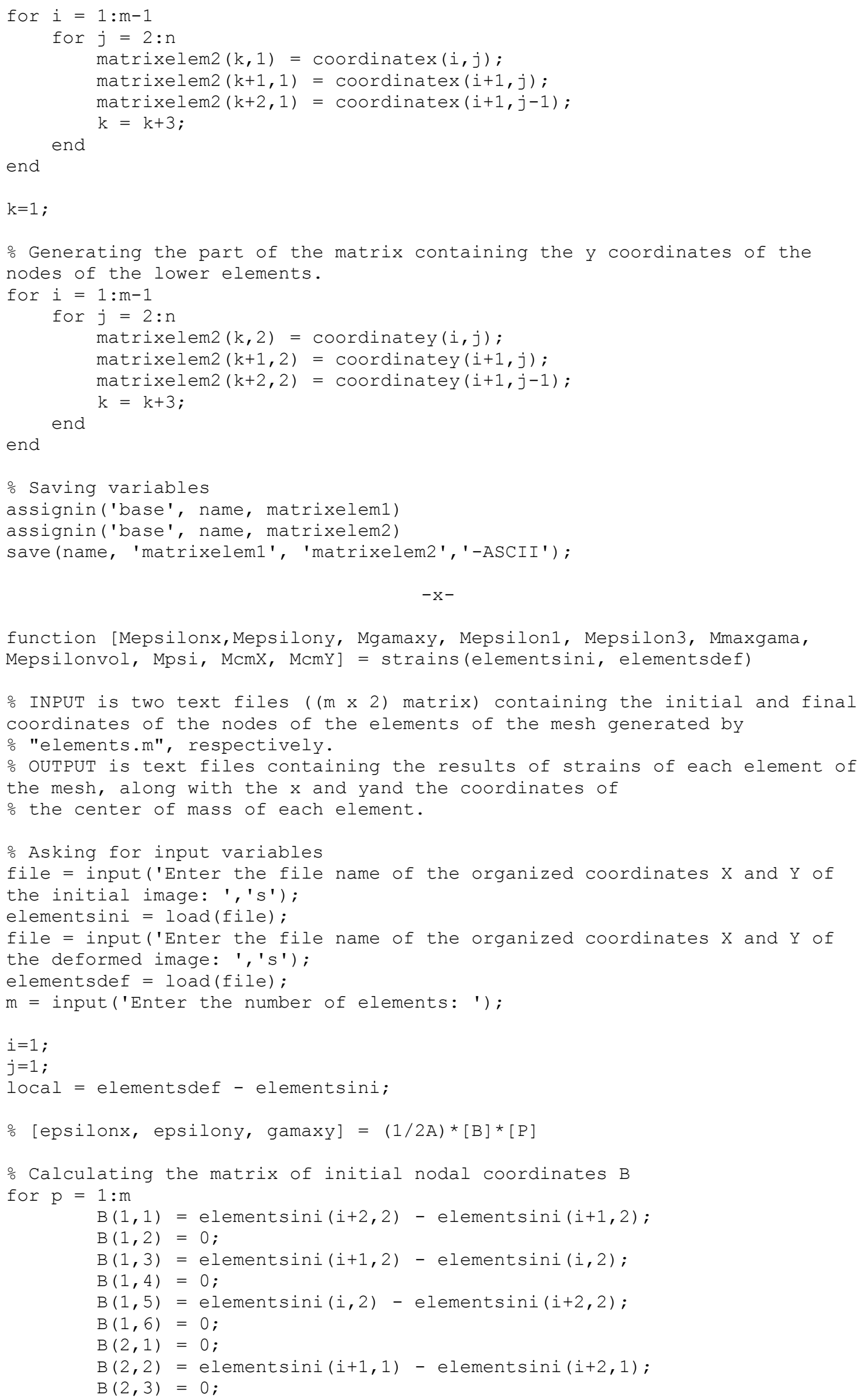




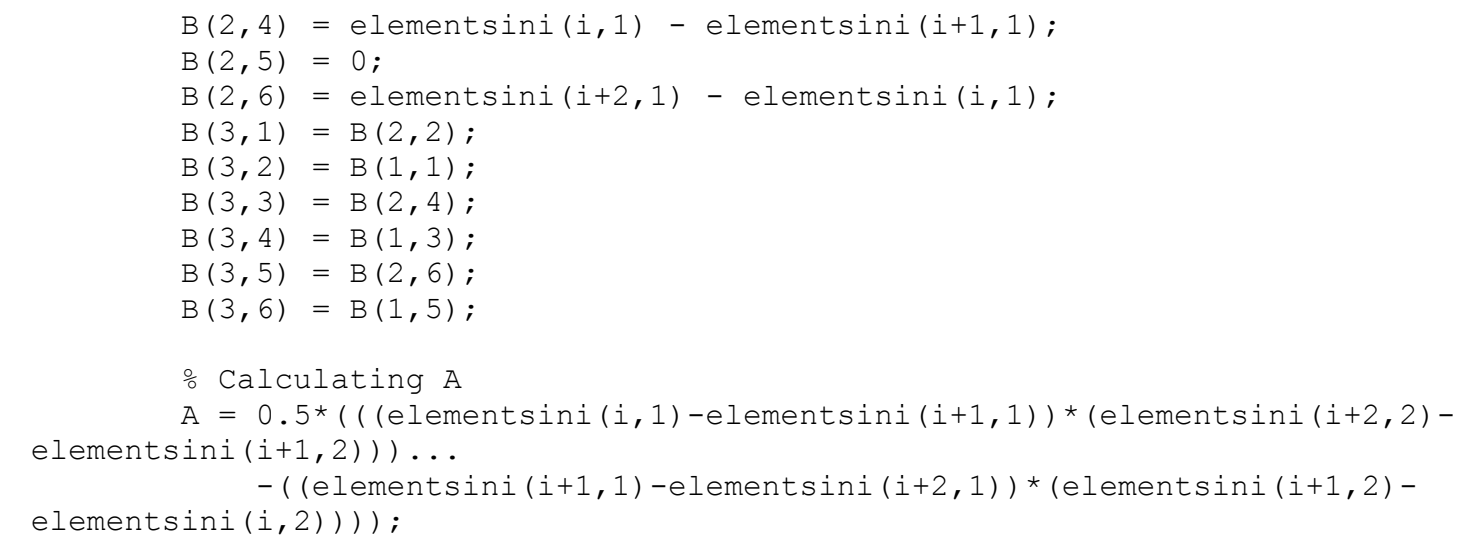

o Calculating the matrix of local nodal coordinates $P$

$P(1,1)=$ local $(i, 1)$;

$P(2,1)=\operatorname{local}(i, 2)$;

$P(3,1)=$ local $(i+2,1)$;

$P(4,1)=$ local $(i+2,2)$;

$P(5,1)=$ local $(i+1,1)$;

$P(6,1)=\operatorname{local}(i+1,2)$;

o Calculating the matrix of strains

strains $=(1 /(2 * A)) *(B * P)$;

\% Calculating the derived parameters

epsilonx $(j, 1)=\operatorname{strains}(1,1)$;

epsilony $(j, 1)=\operatorname{strains}(2,1)$;

gamaxy $(j, 1)=\operatorname{strains}(3,1)$;

epsilon $1(j, 1)=((\operatorname{strains}(1,1)+\operatorname{strains}(2,1)) / 2)+(((\operatorname{strains}(1,1)$

$\left.-\operatorname{strains}(2,1)) / 2)^{\wedge} 2+(\operatorname{strains}(3,1) / 2)^{\wedge} 2\right)^{\wedge} 0.5$

$\operatorname{epsilon} 3(j, 1)=((\operatorname{strains}(1,1)+\operatorname{strains}(2,1)) / 2)-(((\operatorname{strains}(1,1)$

- $\left.\operatorname{strains}(2,1)) / 2)^{\wedge} 2+(\operatorname{strains}(3,1) / 2)^{\wedge} 2\right)^{\wedge} 0.5 ;$

$\operatorname{maxgama}(j, 1)=\operatorname{epsilon} 1(j, 1)-\operatorname{epsilon} 3(j, 1) ;$

epsilonvol $(j, 1)=\operatorname{epsilon} 1(j, 1)+\operatorname{epsilon} 3(j, 1) ;$

$\operatorname{psi}(j, 1)=(\operatorname{asin}(-\operatorname{epsilonvol}(j, 1) / \operatorname{maxgama}(j, 1))) *(180 / 3.1416) ;$

o Calculating the center of mass of each triangular element $\operatorname{cmX}(j, 1)=$

(elementsdef $(i, 1)+$ elementsdef $(i+1,1)+$ elementsdef $(i+2,1)) / 3$; $\operatorname{cmY}(j, 1)=$

$($ elementsdef $(i, 2)+$ elementsdef $(i+1,2)+$ elementsdef $(i+2,2)) / 3$;

$j=j+1$;

$i=i+3$;

end

Mepsilon $x=[\operatorname{epsilonx}(1: m)]$;

Mepsilony=[epsilony $(1: \mathrm{m})]$;

$\operatorname{Mgamaxy}=[\operatorname{gamaxy}(1: \mathrm{m})]$;

Mepsilon $1=[\operatorname{epsilon} 1(1: \mathrm{m})]$;

Mepsilon3=[epsilon3 $(1: \mathrm{m})]$;

Mmaxgama $=[\operatorname{maxgama}(1: \mathrm{m})]$;

Mepsilonvol=[epsilonvol $(1: \mathrm{m})]$;

$\operatorname{Mpsi}=[\operatorname{psi}(1: \mathrm{m})]$;

$\mathrm{McmX}=[\mathrm{cmX}(1: \mathrm{m})]$;

$\mathrm{McmY}=[\mathrm{cmY}(1: \mathrm{m})]$;

\% Saving variables

save epsilonx.dat Mepsilonx -ASCII; 


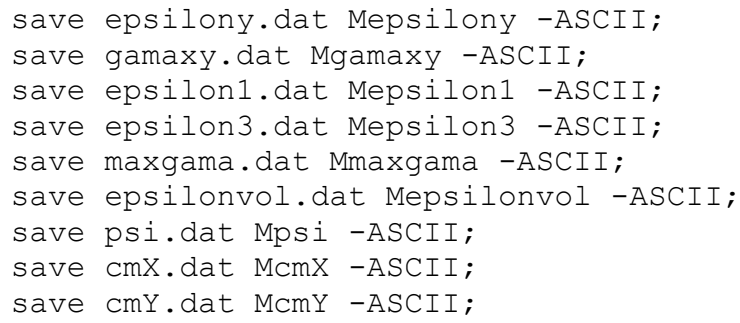

function out $=$ contorno2 $(\mathrm{x}, \mathrm{y}, \mathrm{z})$

$\mathrm{x}=$ load ('cmX.dat') ;

$\mathrm{y}=$ load ('cmY.dat') ;

file3=input('Enter the file name for the variable to be ploted:','s'); $\mathrm{z}=$ load (file3);

\% The linspace function generates linearly spaced vectors. It is similar to the colon

\% operator ":", but gives direct control over the number of points. $1000=$ n. of points.

xlin=linspace (min (x), $\max (x), 2000)$;

ylin=linspace $(\min (y), \max (y), 2000)$;

$\%[X, Y]=$ meshgrid $(x, y)$ transforms the domain specified by vectors $x$ and $y$ into arrays

$\% \mathrm{X}$ and $\mathrm{Y}$, which can be used to evaluate functions of two variables and three-

odimensional mesh/surface plots. The rows of the output array $\mathrm{x}$ are copies of the

ovector $\mathrm{x}$; columns of the output array $\mathrm{Y}$ are copies of the vector $\mathrm{y}$. $[X I, Y I]=$ meshgrid (xlin, ylin);

oZI $=$ griddata $(x, y, z, X I, Y I)$ fits a surface of the form $z=f(x, y)$ to the data in the

o (usually) nonuniformly spaced vectors $(x, y, z)$. griddata interpolates this surface

oat the points specified by (XI,YI) to produce ZI. The surface always passes through

othe data points. XI and YI usually form a uniform grid (as produced by meshgrid).

ooptions: linear, cubic, nearest, v4.

$\mathrm{ZI}=\operatorname{griddata}\left(\mathrm{x}, \mathrm{y}, \mathrm{z}, \mathrm{XI}, \mathrm{YI}, \mathrm{CcubiC}^{\prime}\right)$;

ofunction contour: 10 - \#of contours, k - color (black).

$[\mathrm{C}, \mathrm{h}]=$ contour $\left(\mathrm{XI}, \mathrm{YI}, \mathrm{ZI}, 5, \mathrm{k}^{\prime}\right)$;

clabel (C,h, 'manual') 


\section{ANEXO B: Caixa de Testes dos Ensaios da EESC/USP}
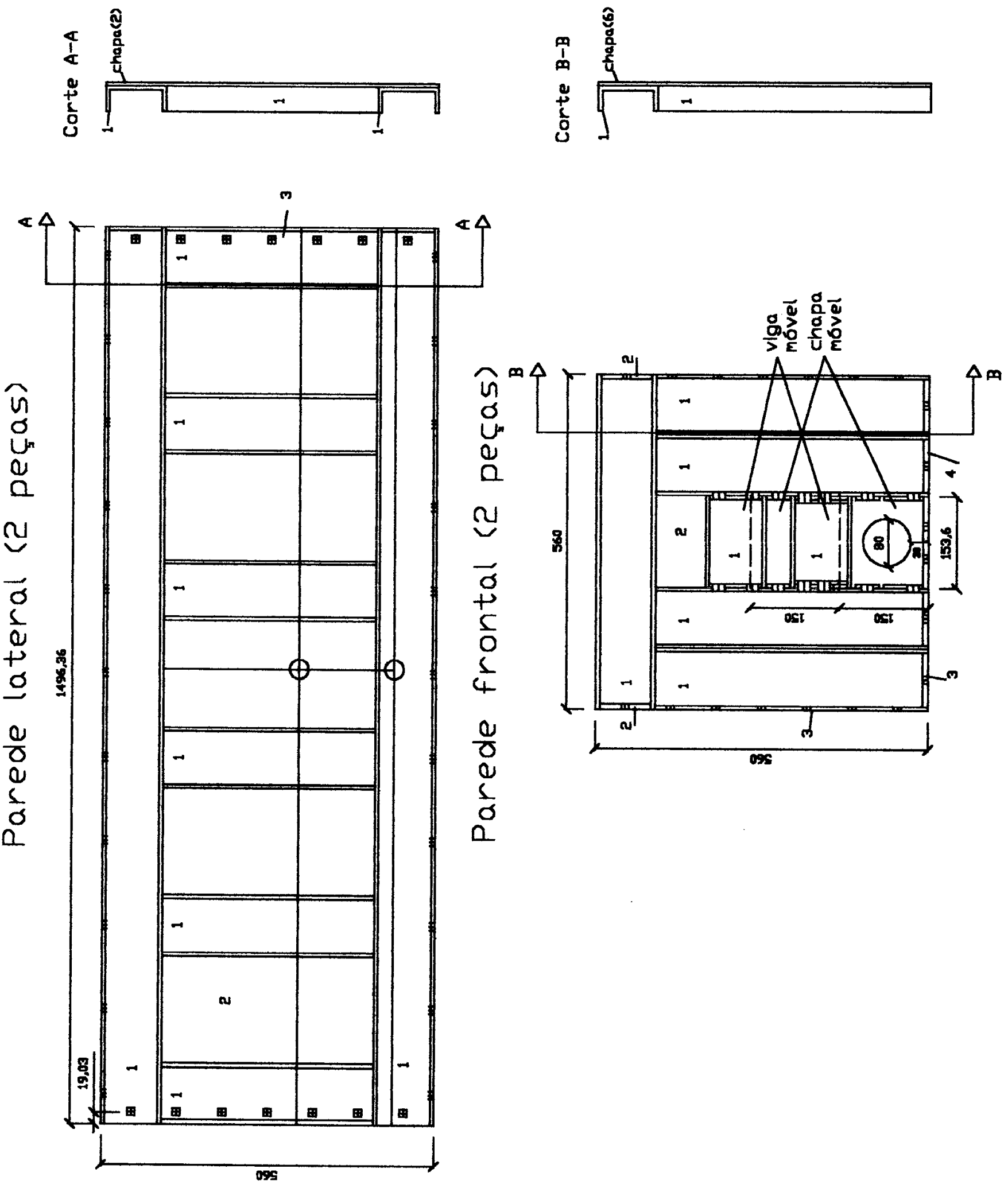

Figura B1. Paredes laterais e frontais da caixa de testes (Escala 1:10). 

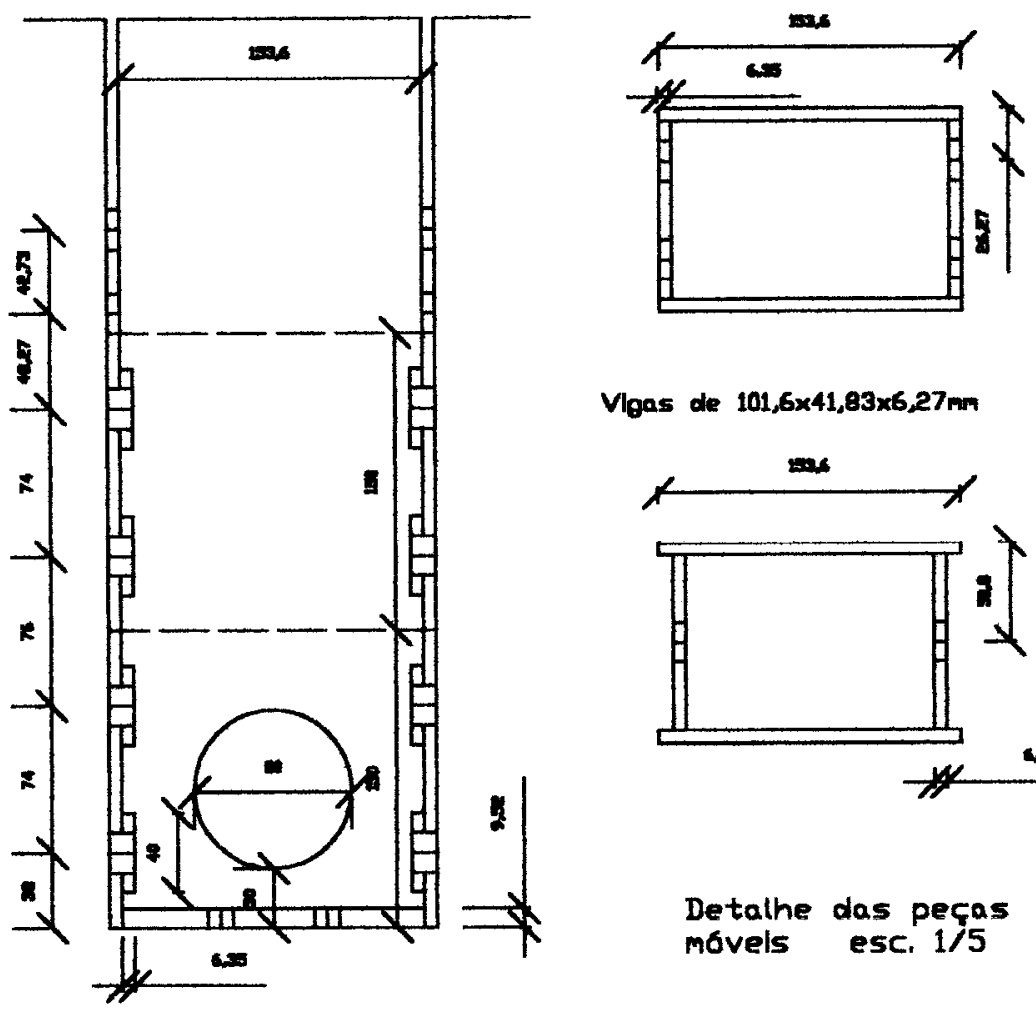

Vigas de $101,6 \times 41,83 \times 6,27 \mathrm{~mm}$

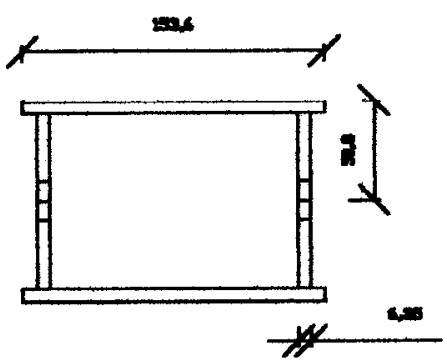

Detalhe das peças movels esc. $1 / 5$

\section{Legenda:}

$1-v \operatorname{lga} \cup 101,6 \times 43,69 \times 8,13 \mathrm{~mm}$

2-chapa 5/16"

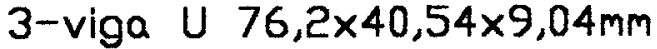

4-ferro chato $3 / 8^{\prime \prime} \times 1$ 1/2"

$5-v i g a$ U $152 \times 57,89 \times 14,20 \mathrm{~mm}$

6-chapa 7/32"

7-cantonelra $1 / 4^{\prime \prime} \times 21 / 2^{\prime \prime}$

8-parafuso 1/2"

(dimensôes das cotas em mm)

Figura B2. Detalhe das chapas móveis na parede frontal (Escala 1:5) e legenda com dimensões das peças utilizadas. 


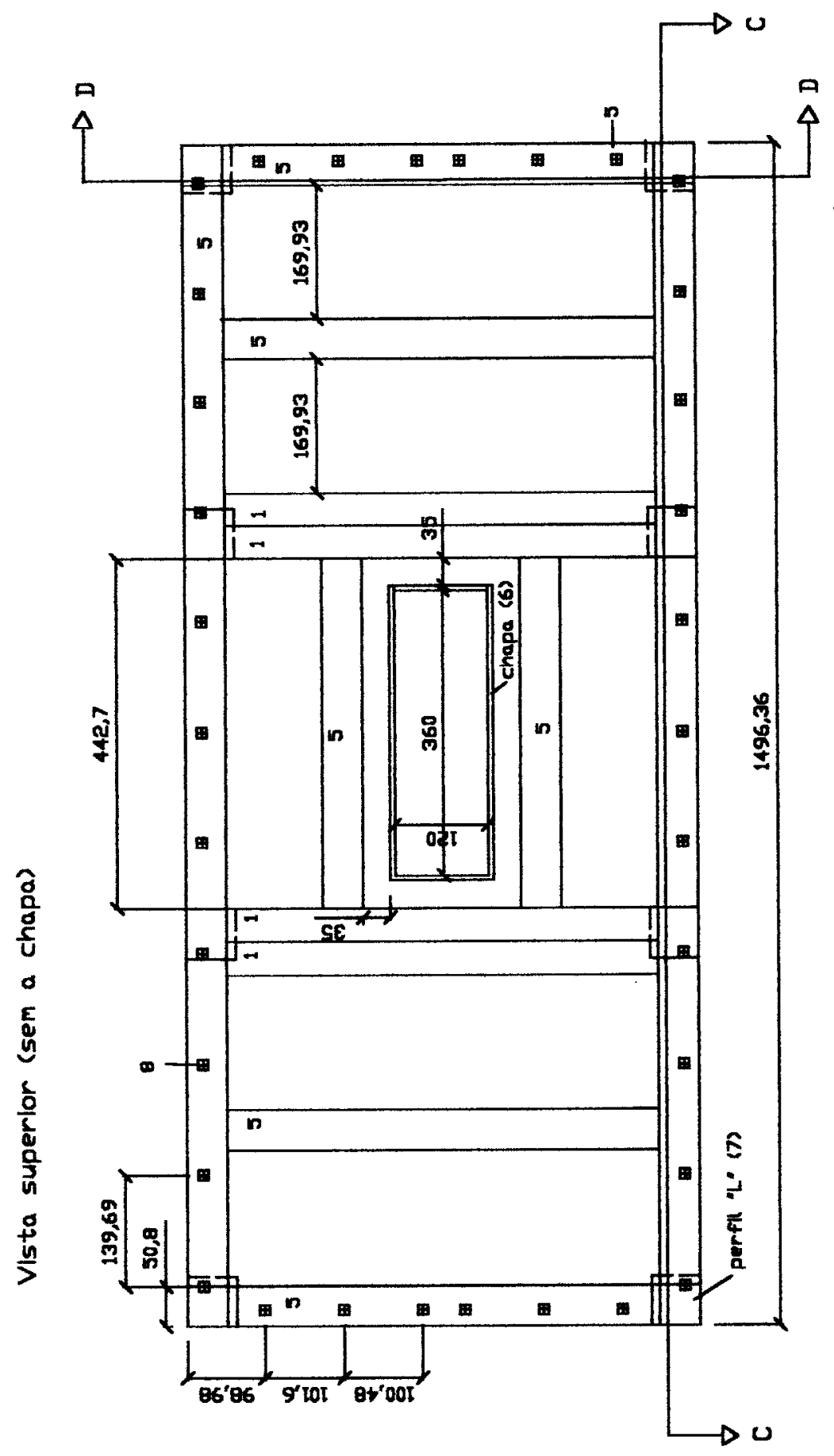

Figura B3. Base da caixa de testes (Escala 1:10). 


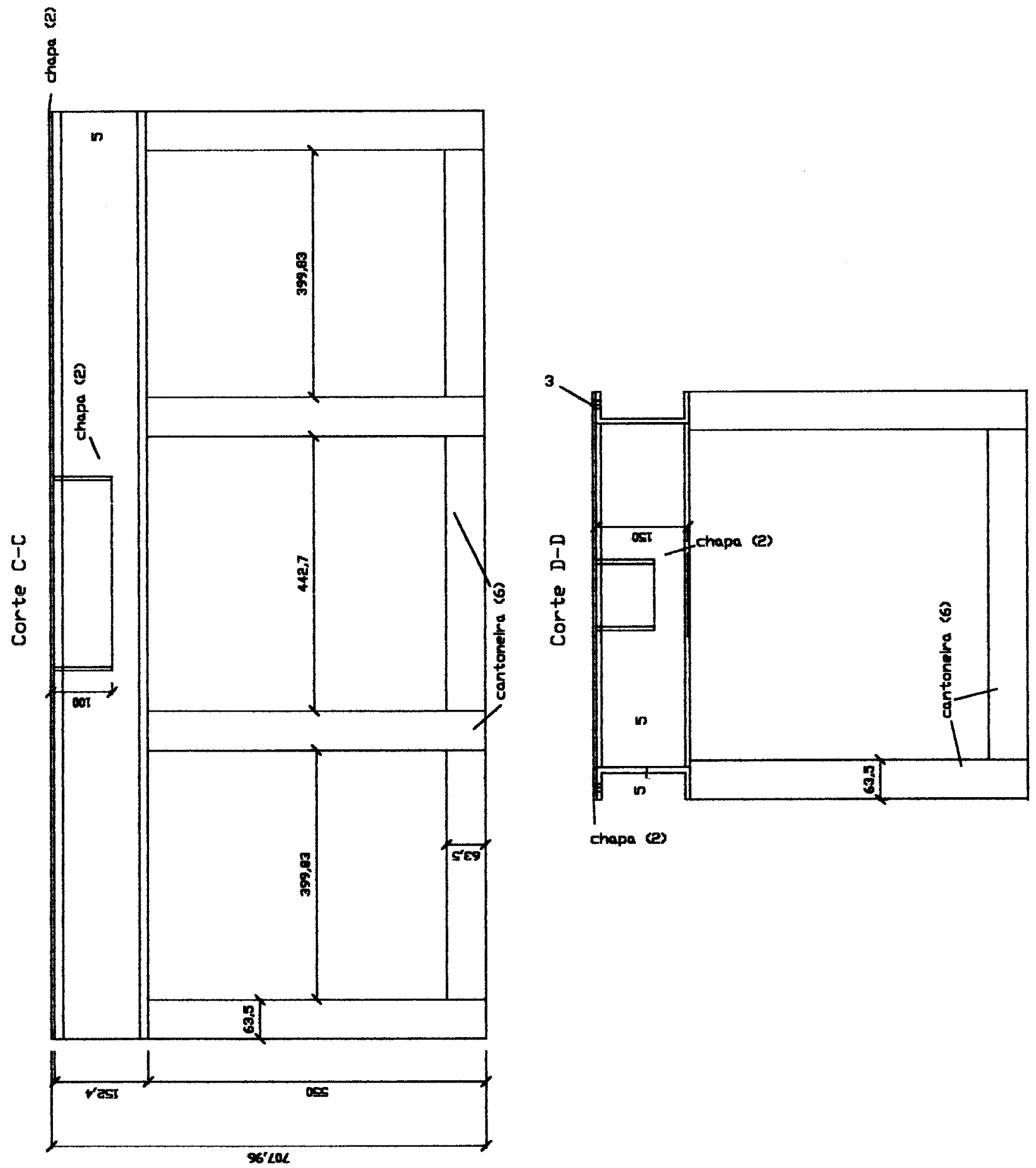

Figura B3 (continuação). Base da caixa de testes (Escala 1:10). 


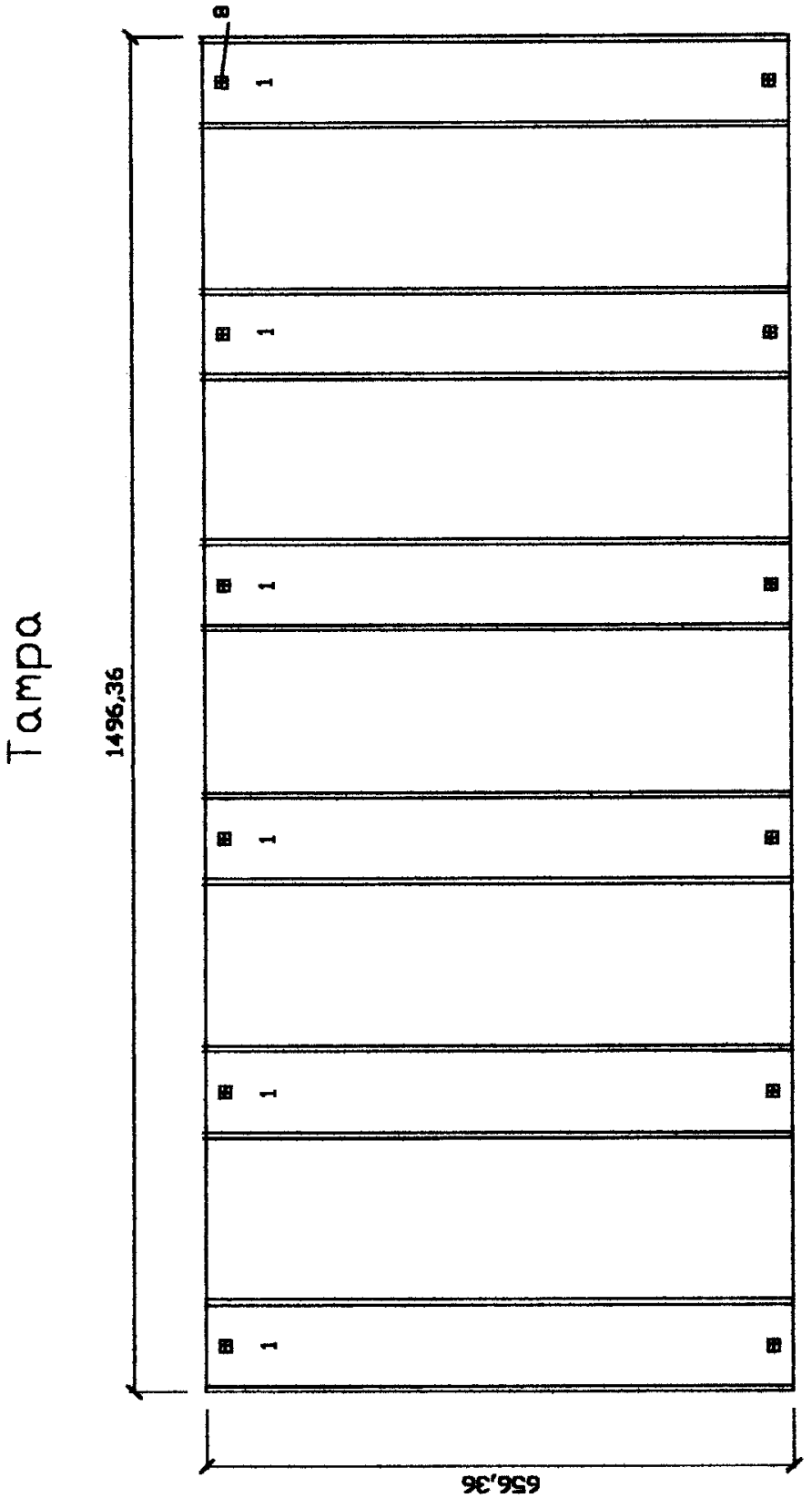

Figura B4. Tampa de reação (Escala 1:10). 


\section{ANEXO C: VARIAÇÃO DE TENSÃO TOTAL NOS ENSAIOS}

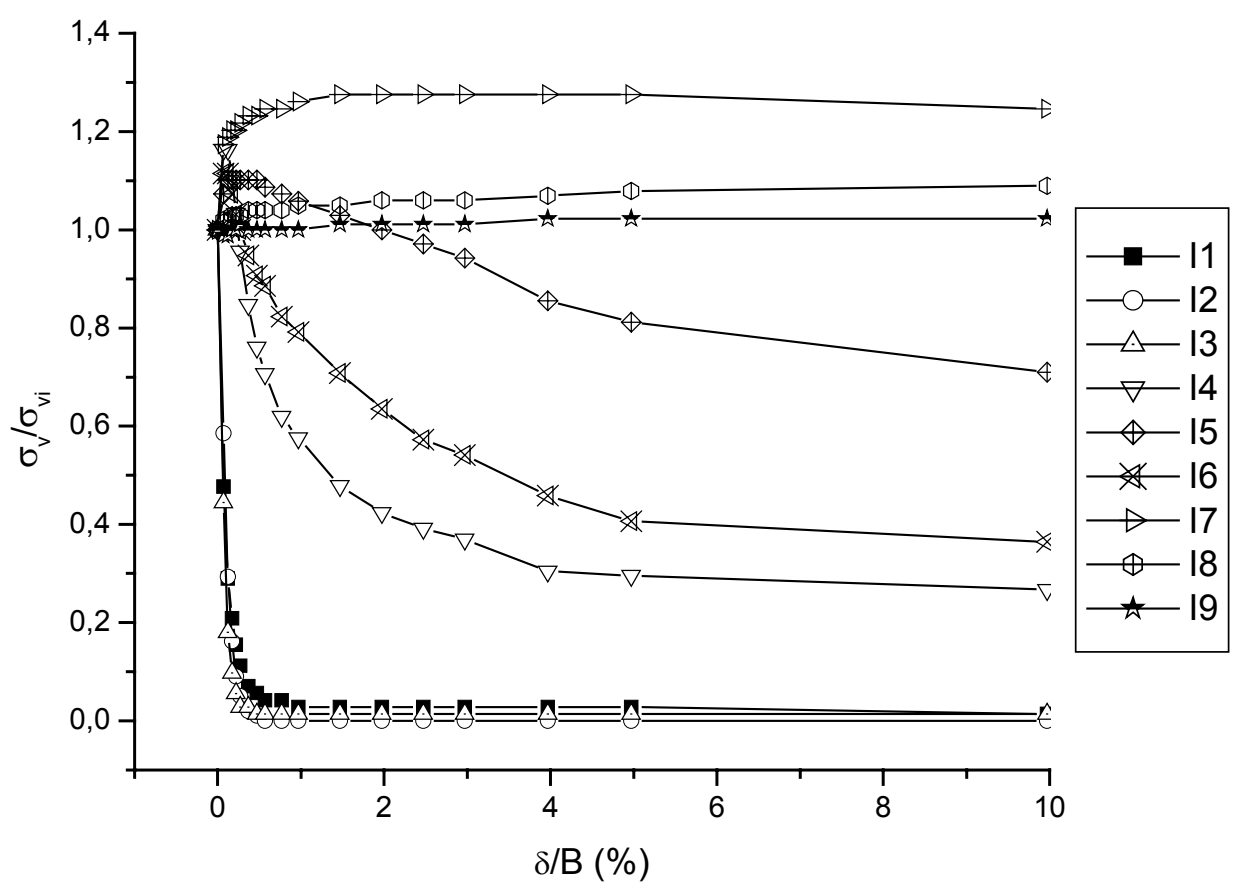

Figura C1. Resultados do ensaio C1, células I.

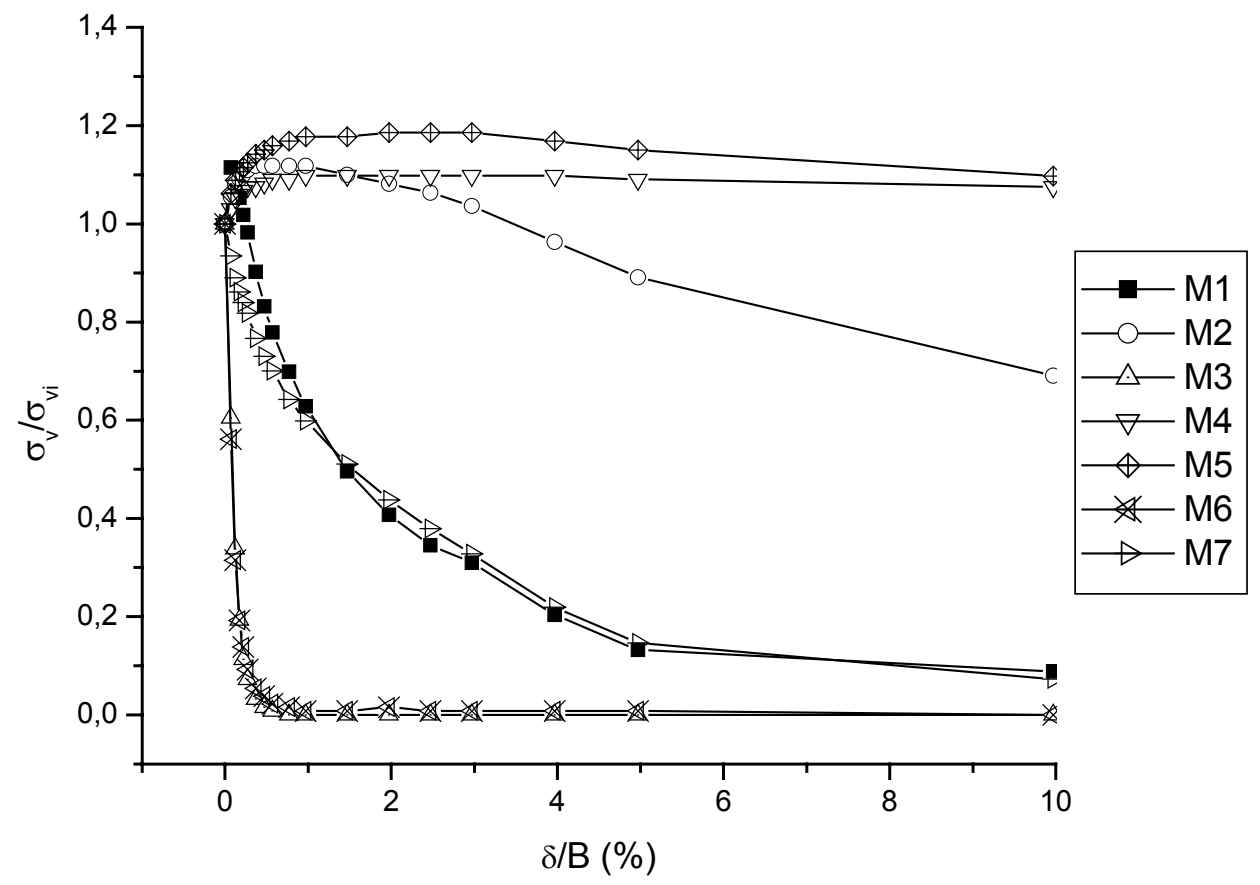

Figura C2. Resultados do ensaio C1, células M. 


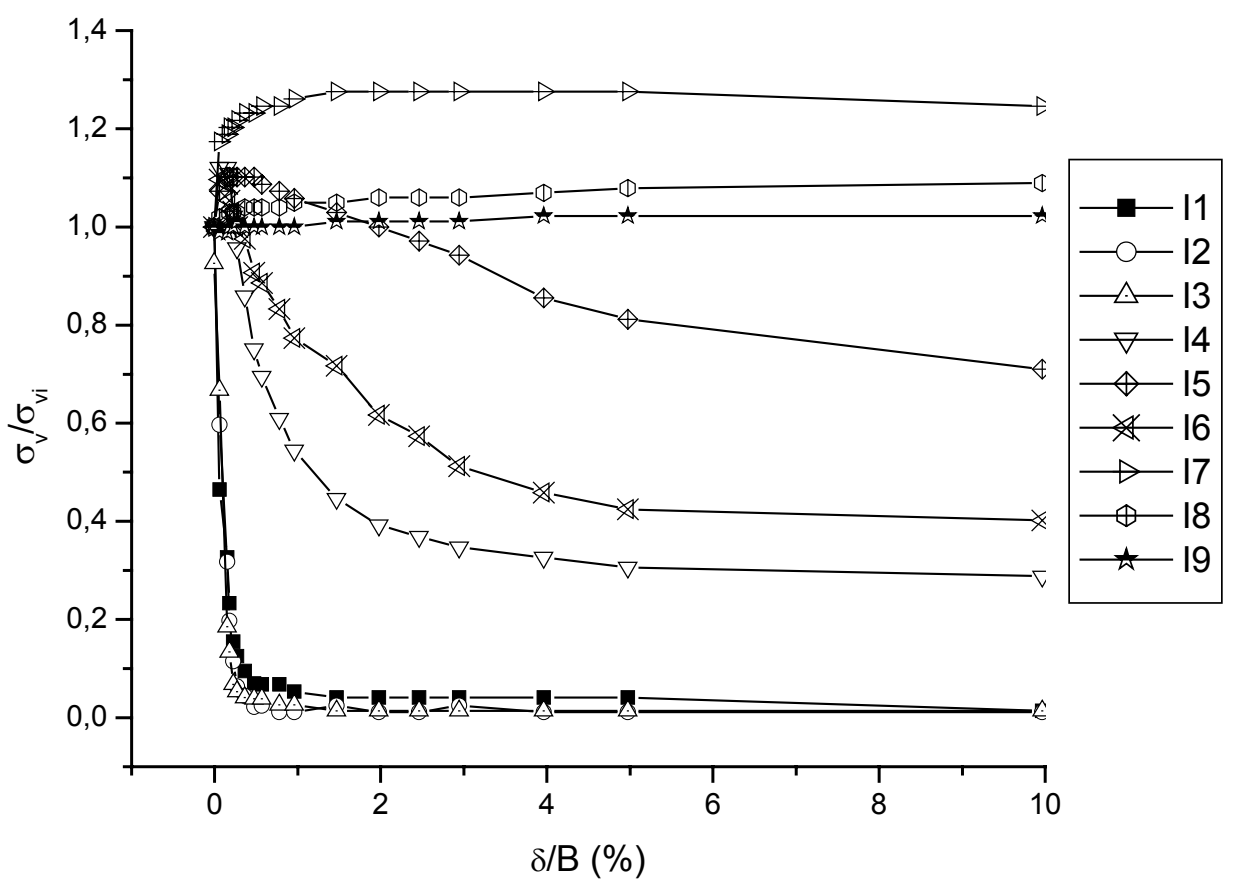

Figura C3. Resultados do ensaio C2, células I.

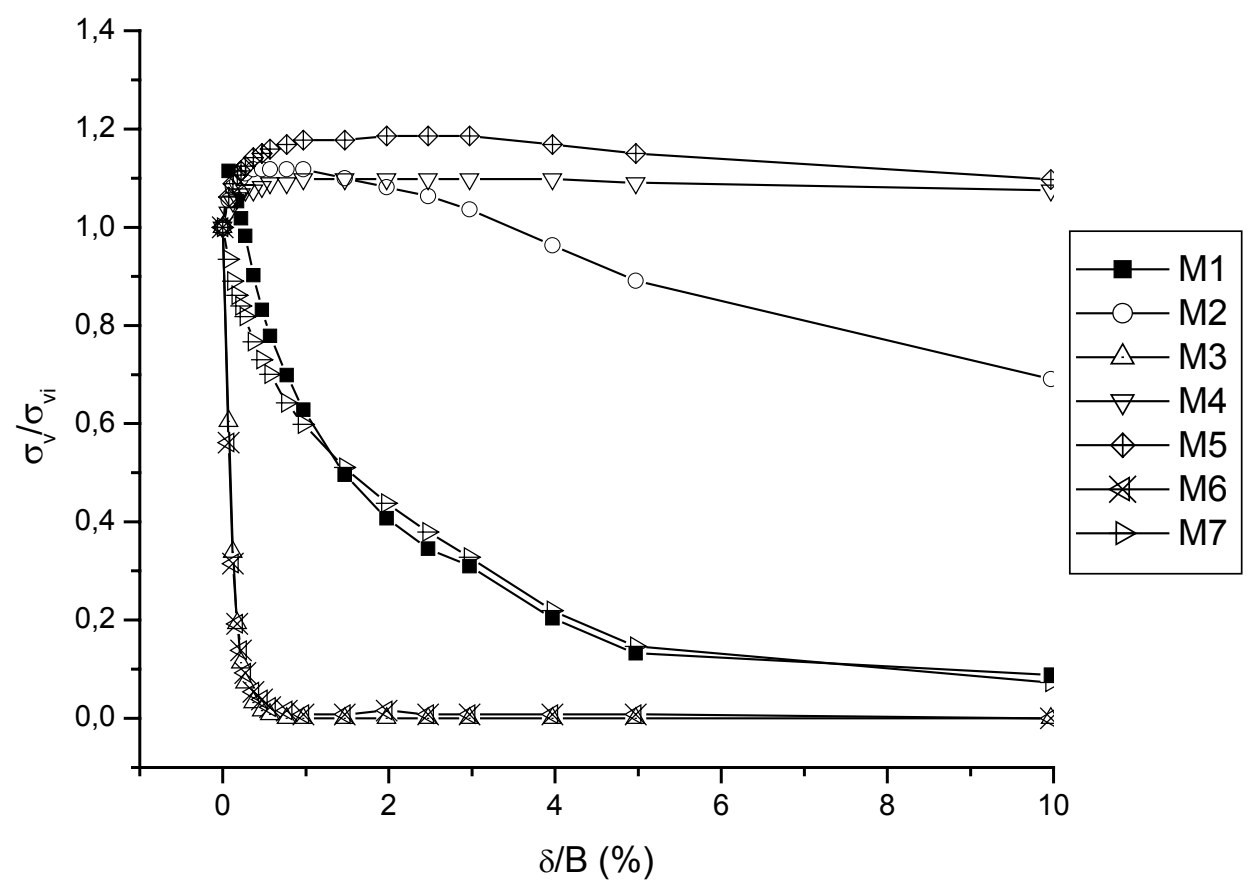

Figura C4. Resultados do ensaio C2, células M. 


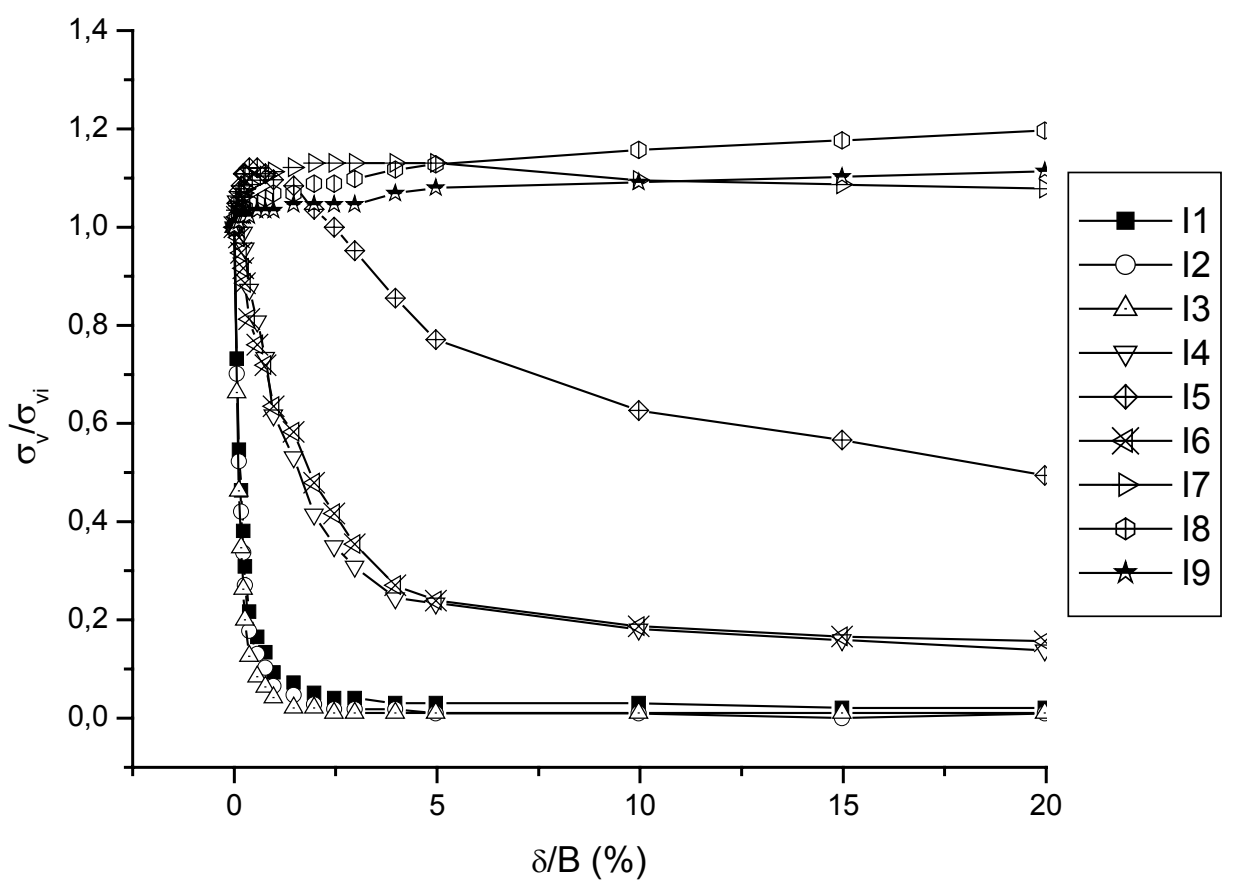

Figura C5. Resultados do ensaio C3, células I.

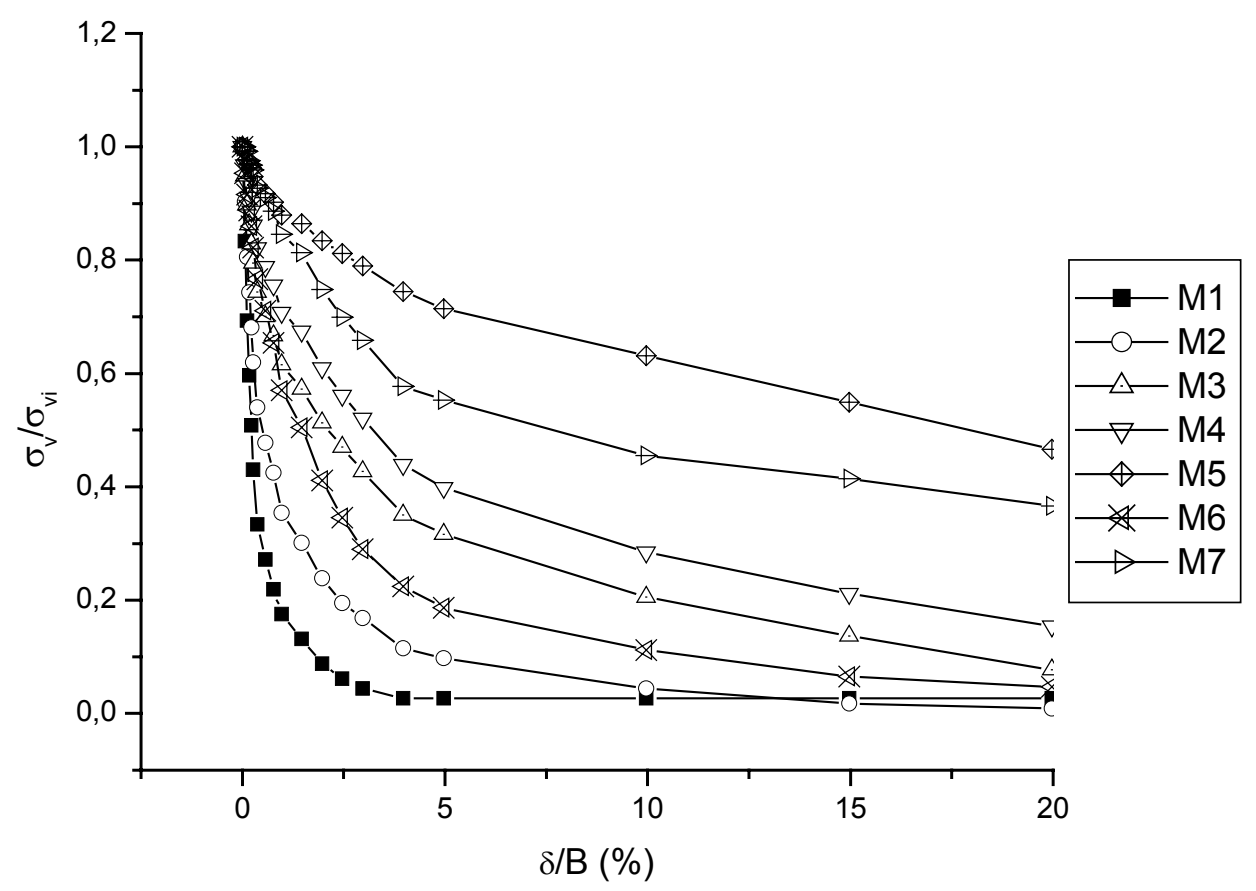

Figura C6. Resultados do ensaio C3, células M. 


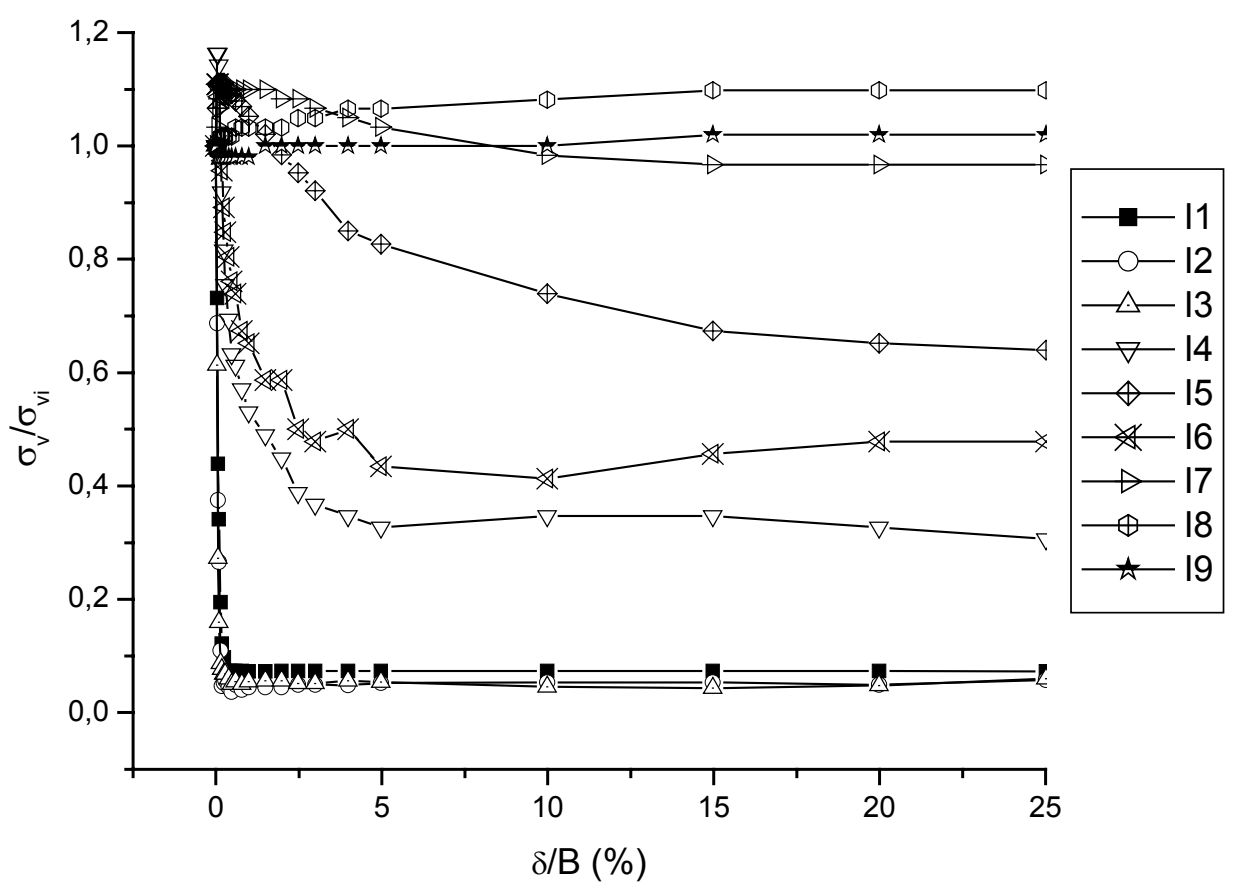

Figura C7. Resultados do ensaio C4, células I.

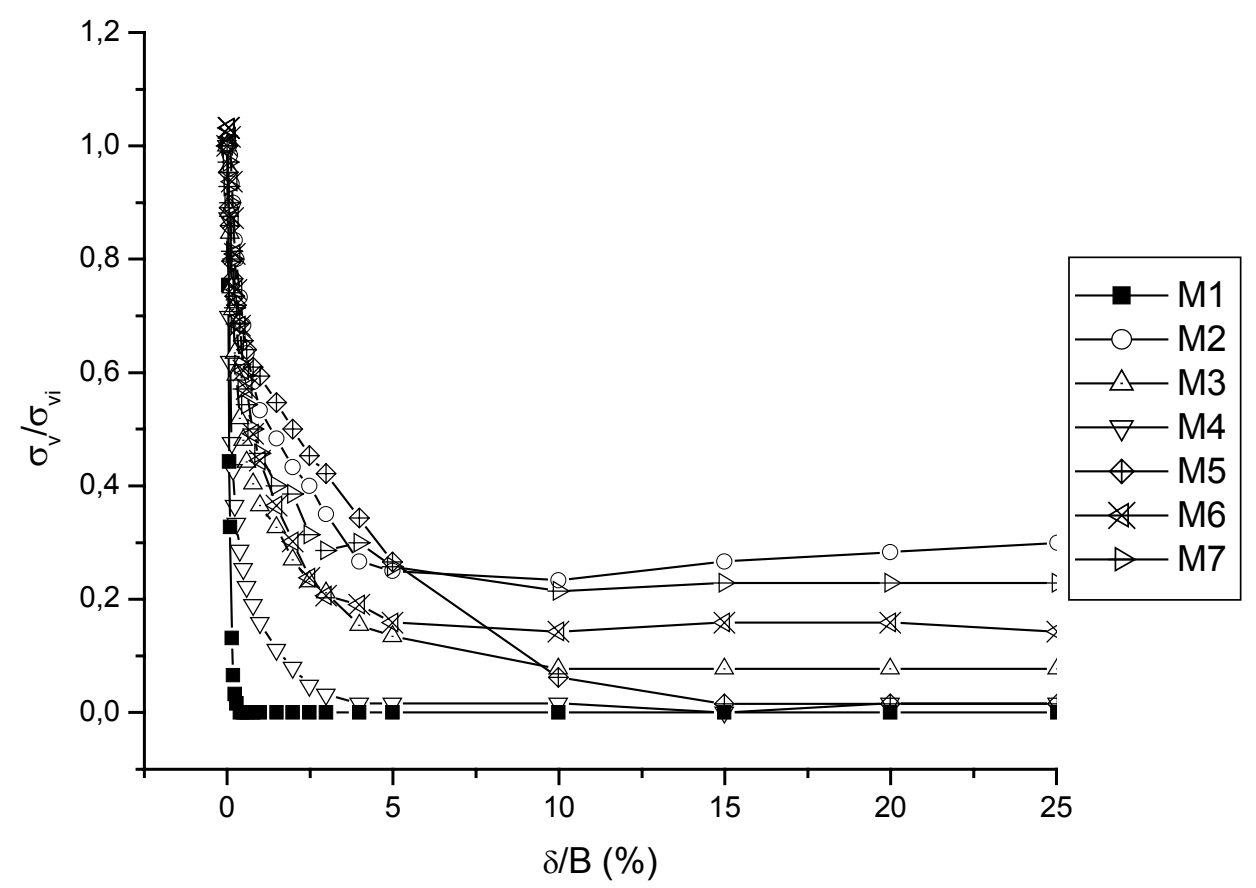

Figura C8. Resultados do ensaio C4, células M. 


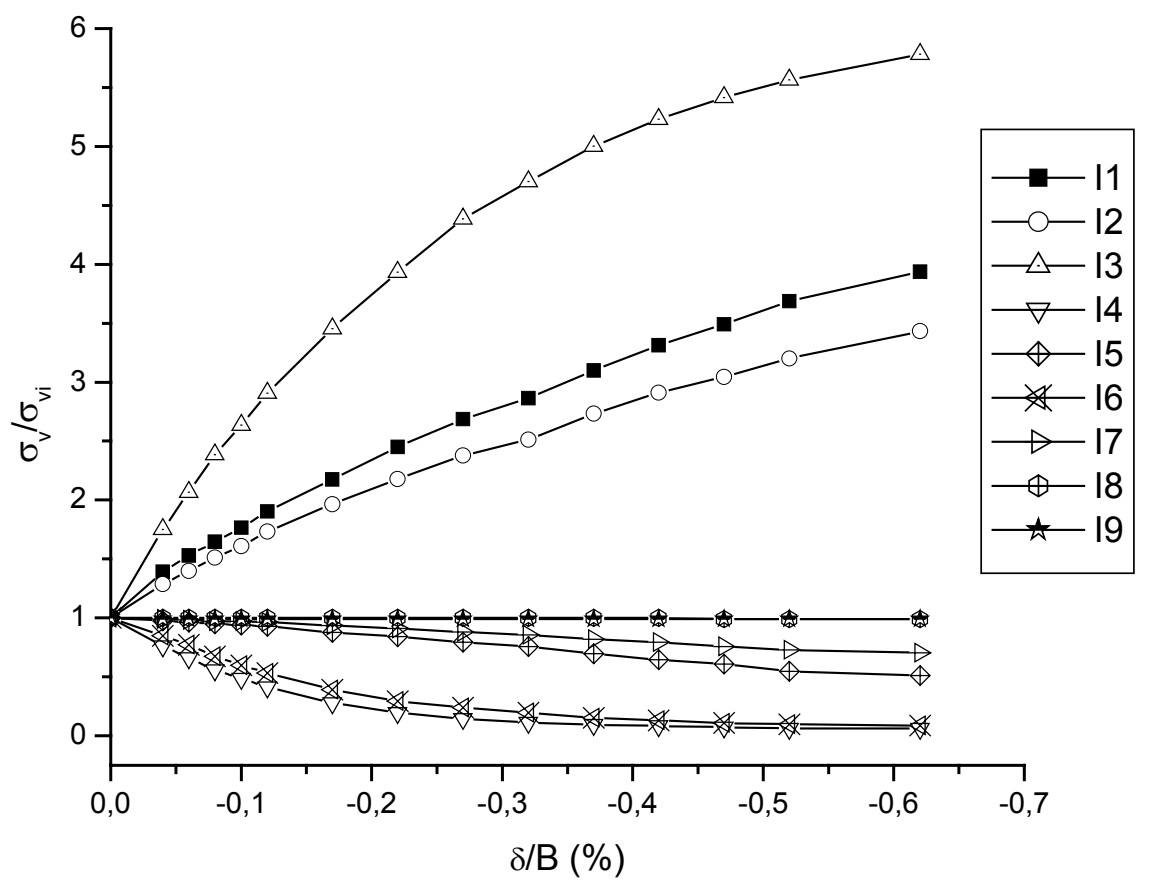

Figura C9. Resultados do ensaio C5, células I.

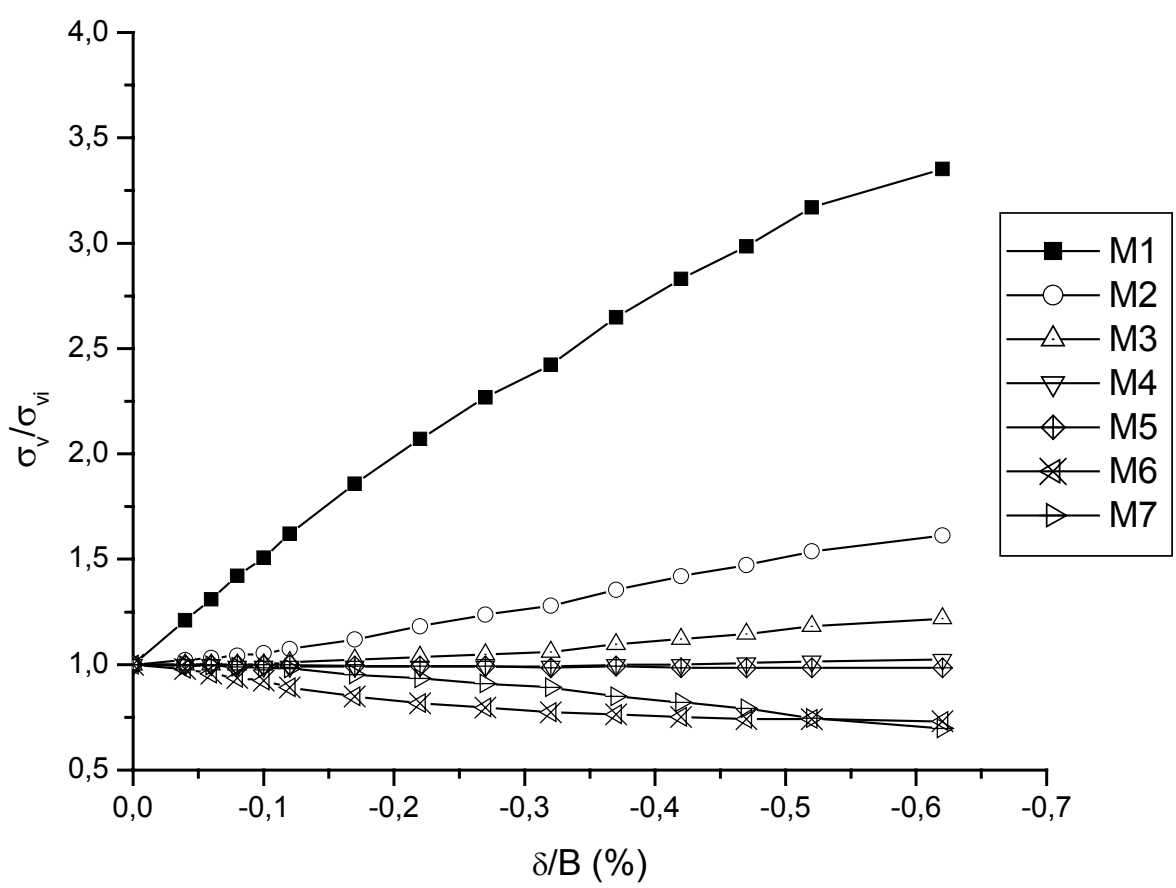

Figura C10. Resultados do ensaio C5, células M. 


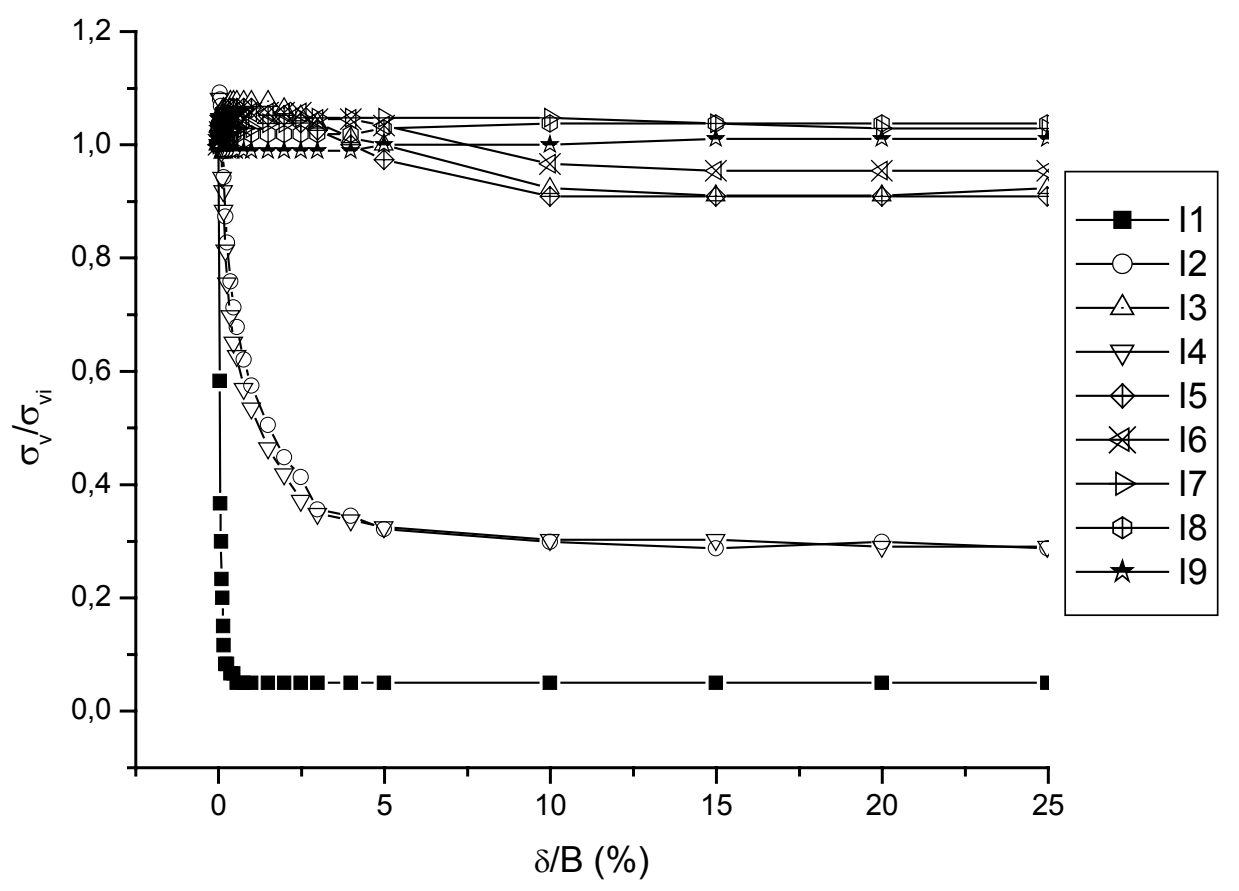

Figura C11. Resultados do ensaio C6, células I.

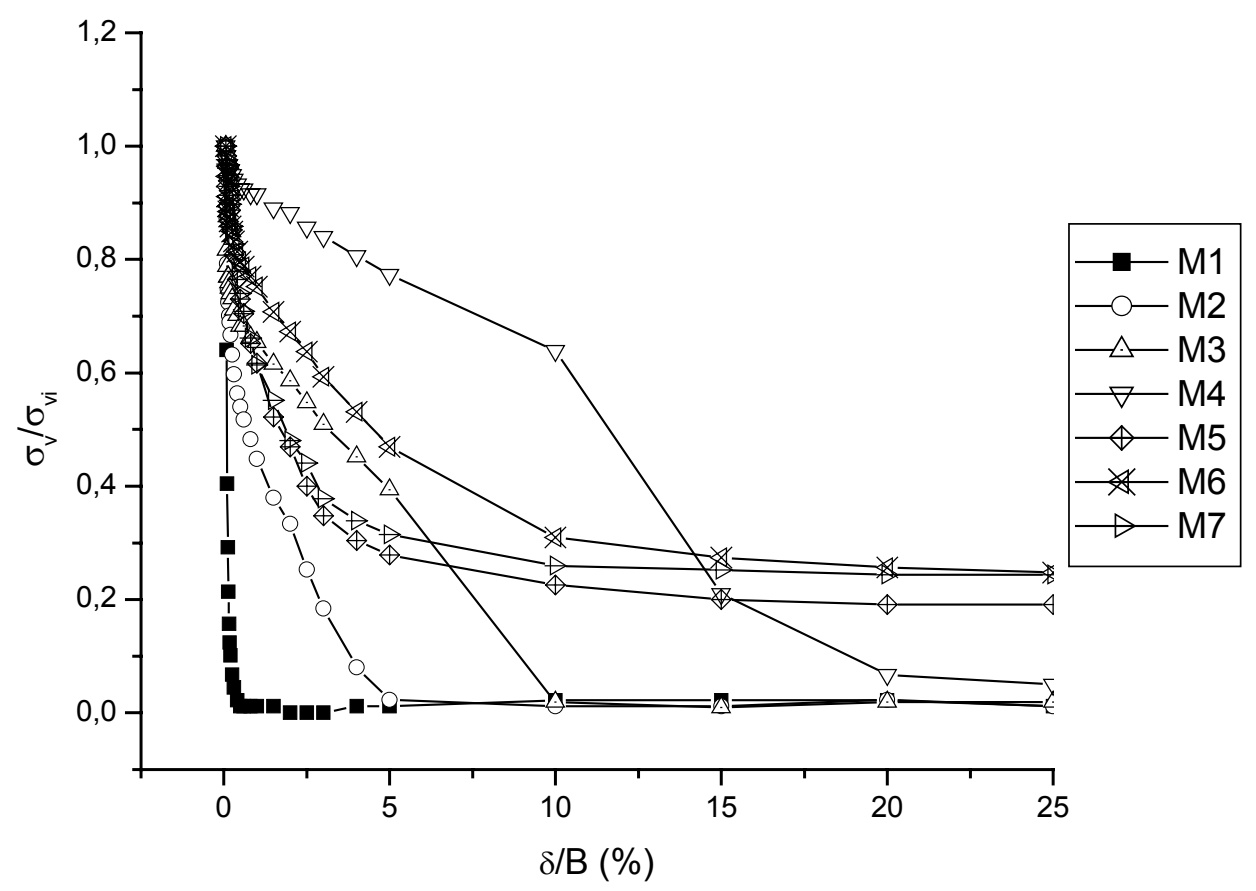

Figura C12. Resultados do modelo C6, células M. 


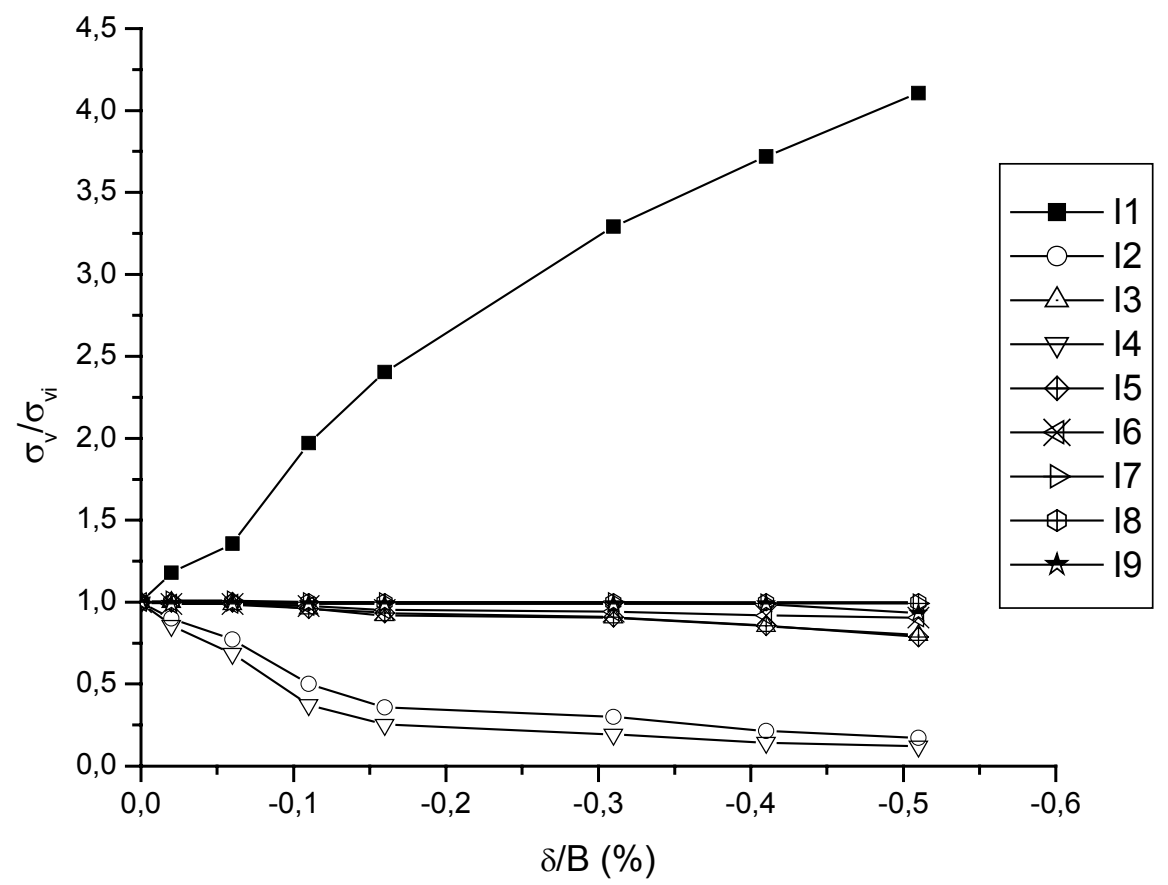

Figura C13. Resultados do ensaio C7, células I.

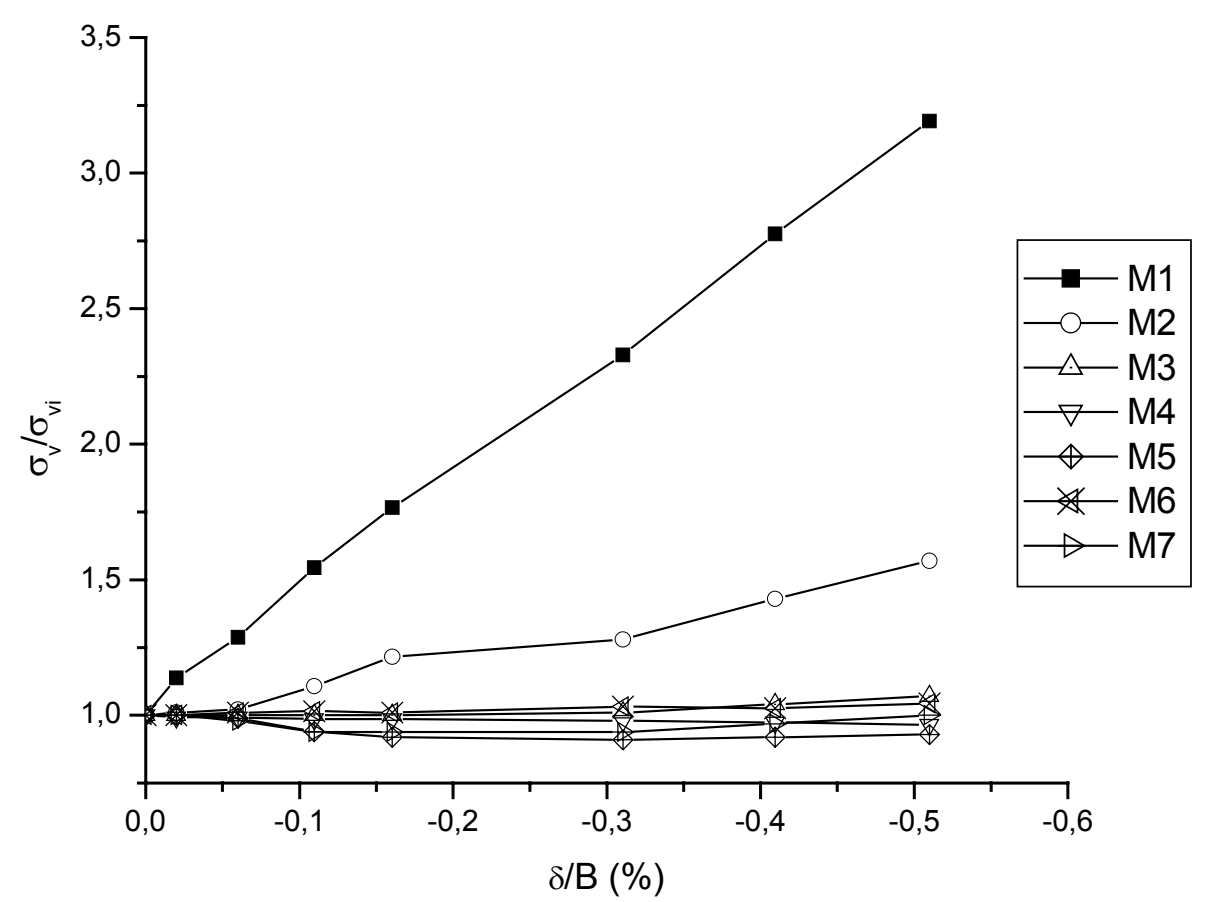

Figura C14. Resultados do ensaio C7, células M. 


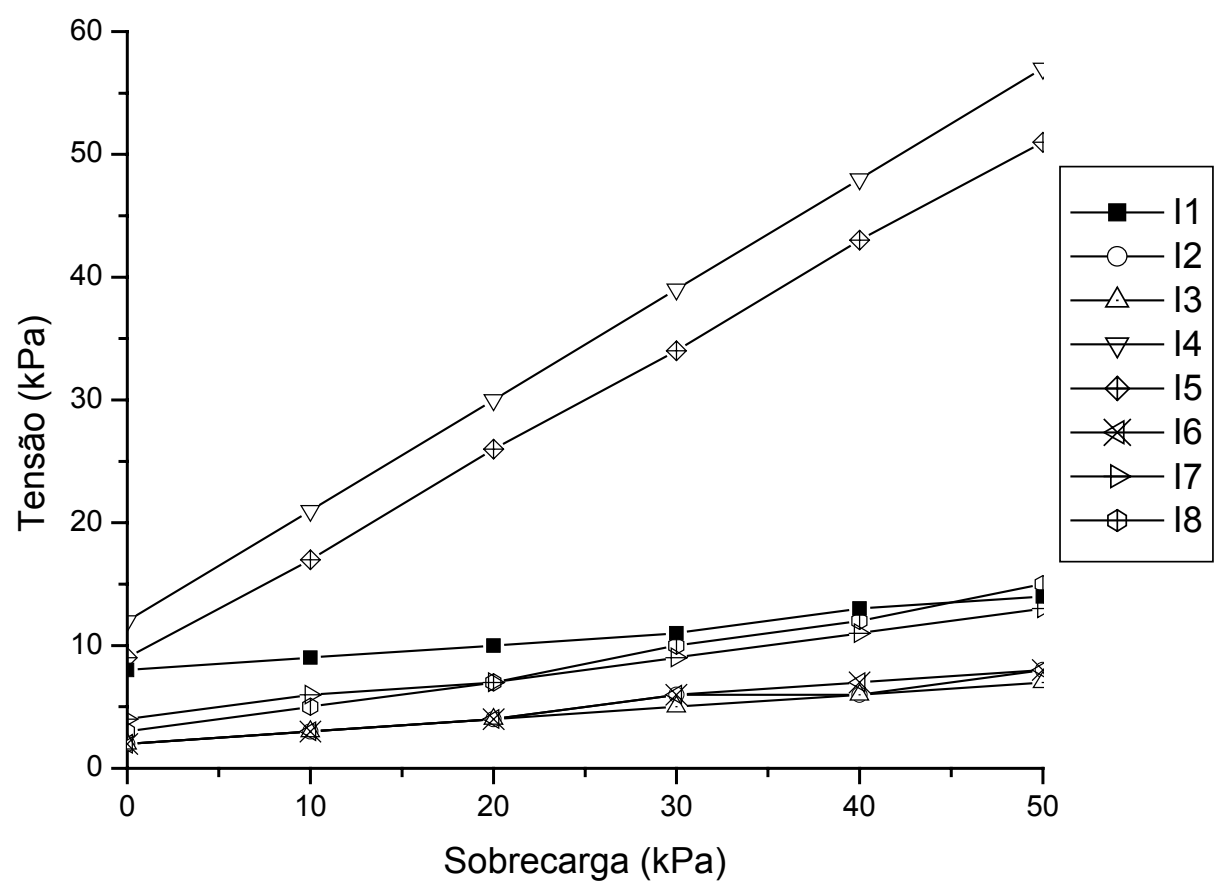

Figura C15. Sobrecarga aplicada x tensão medida no modelo D1, células I.

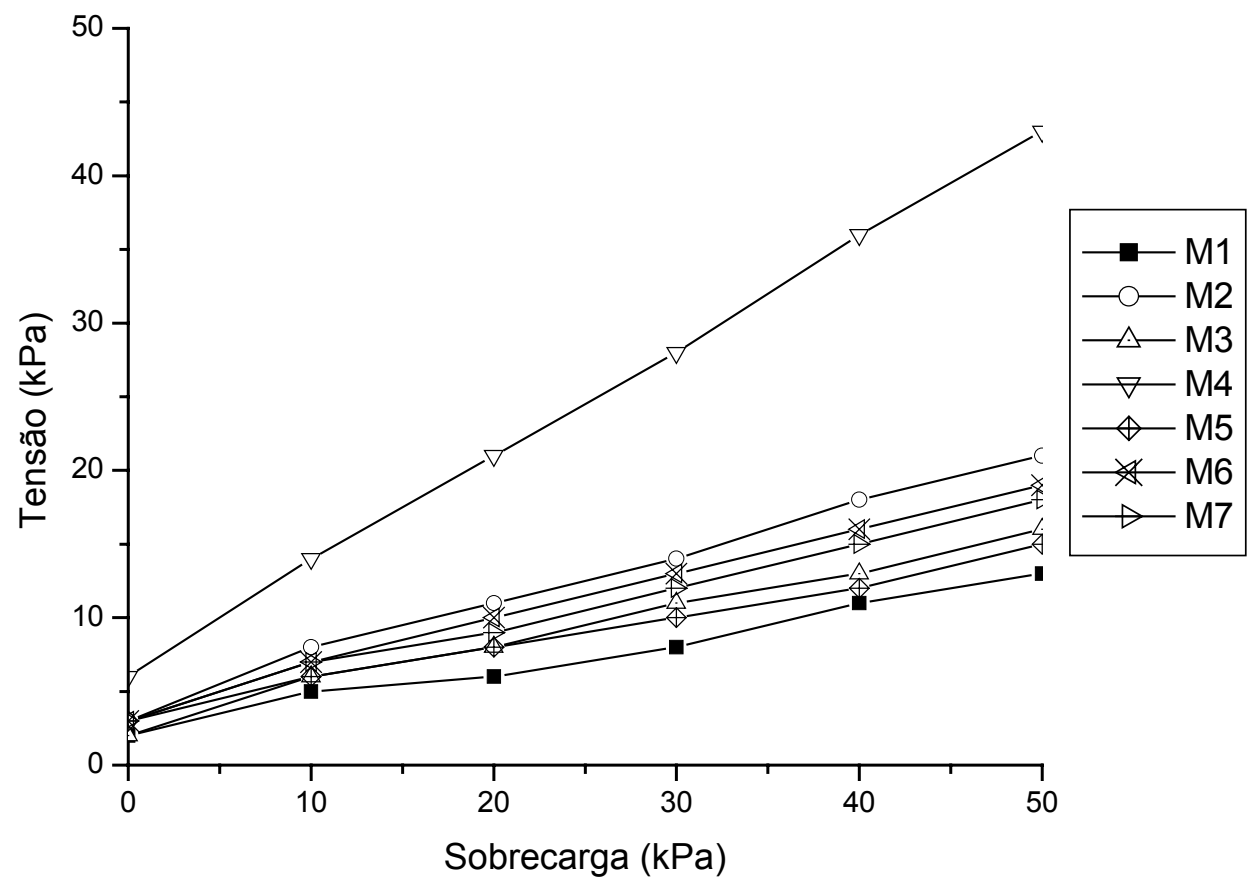

Figura C16. Sobrecarga aplicada x tensão medida no modelo D1, células M. 


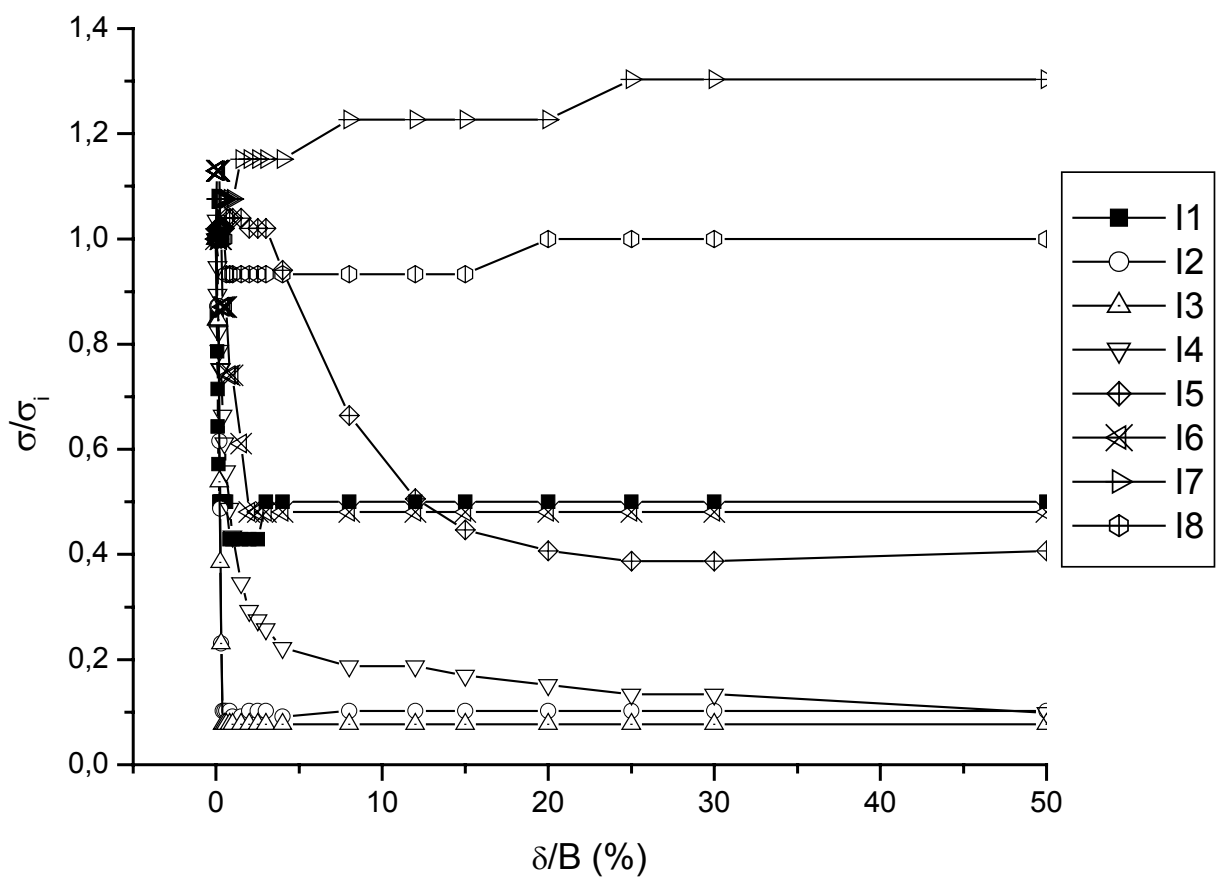

Figura C17. Resultados do ensaio D1, células I.

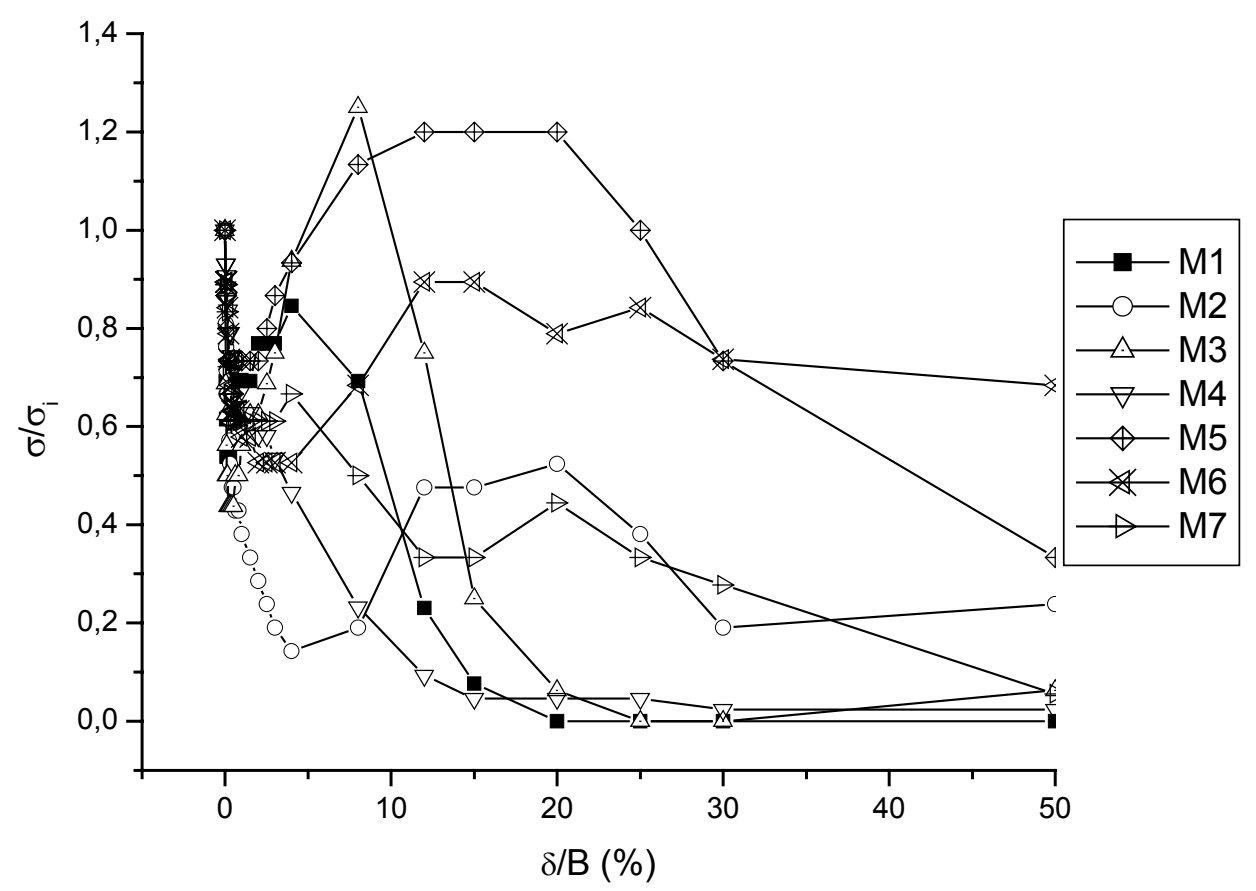

Figura C18. Resultados do ensaio D1, células M. 


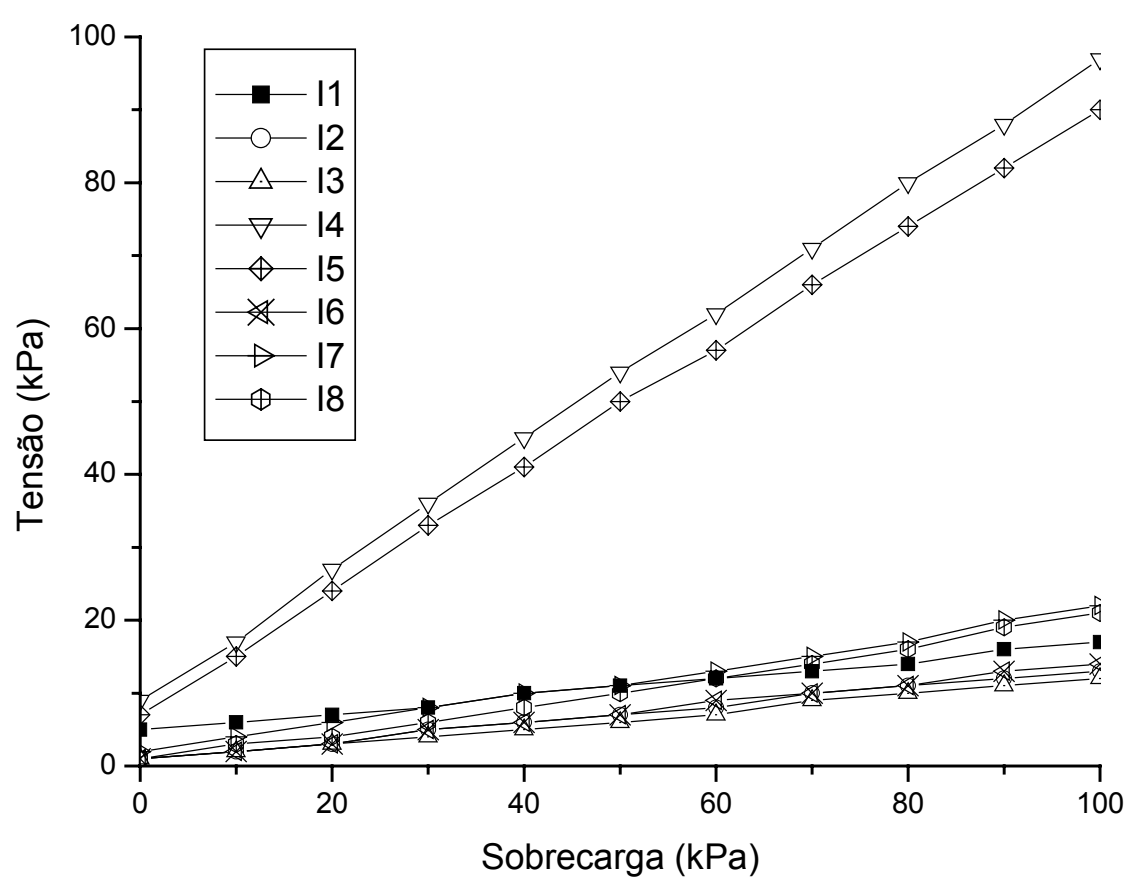

Figura C19. Sobrecarga aplicada x tensão medida no modelo D2, células I.

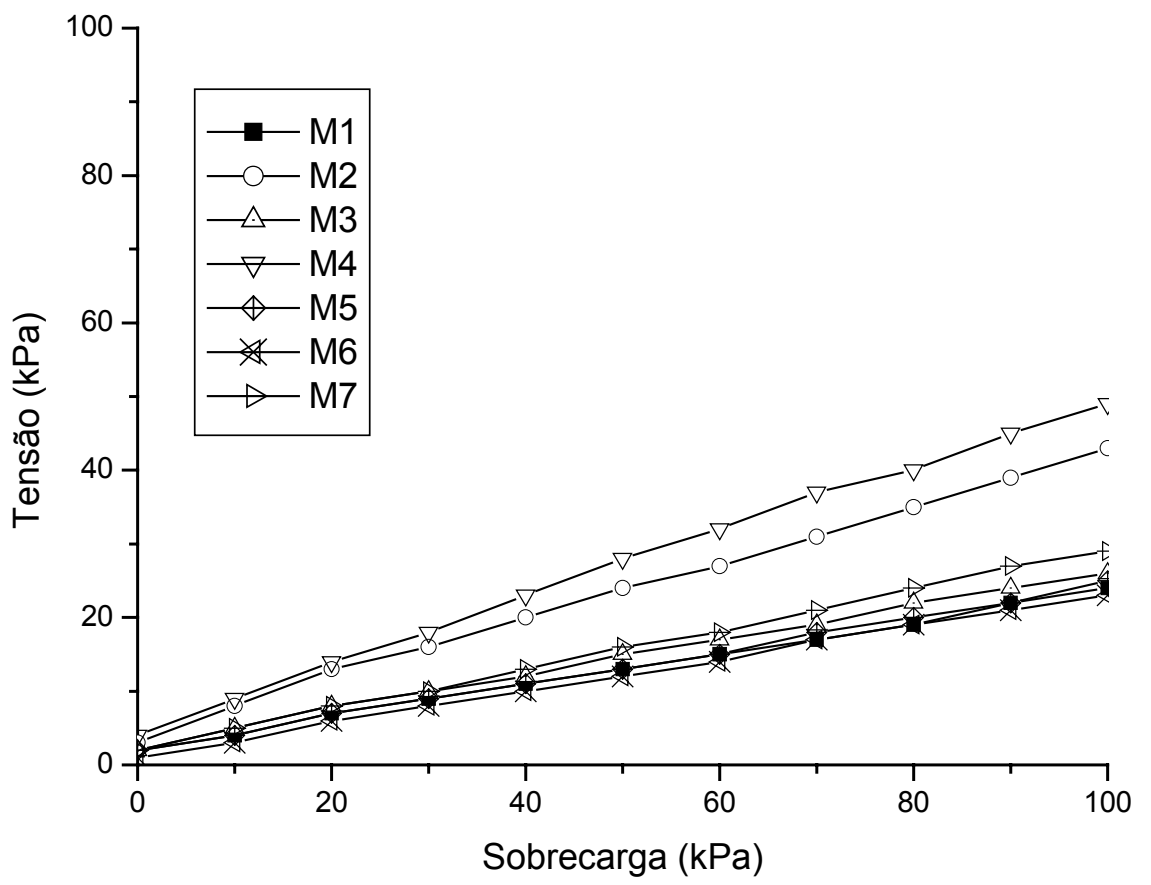

Figura C20. Sobrecarga aplicada x tensão medida no modelo D2, células M. 


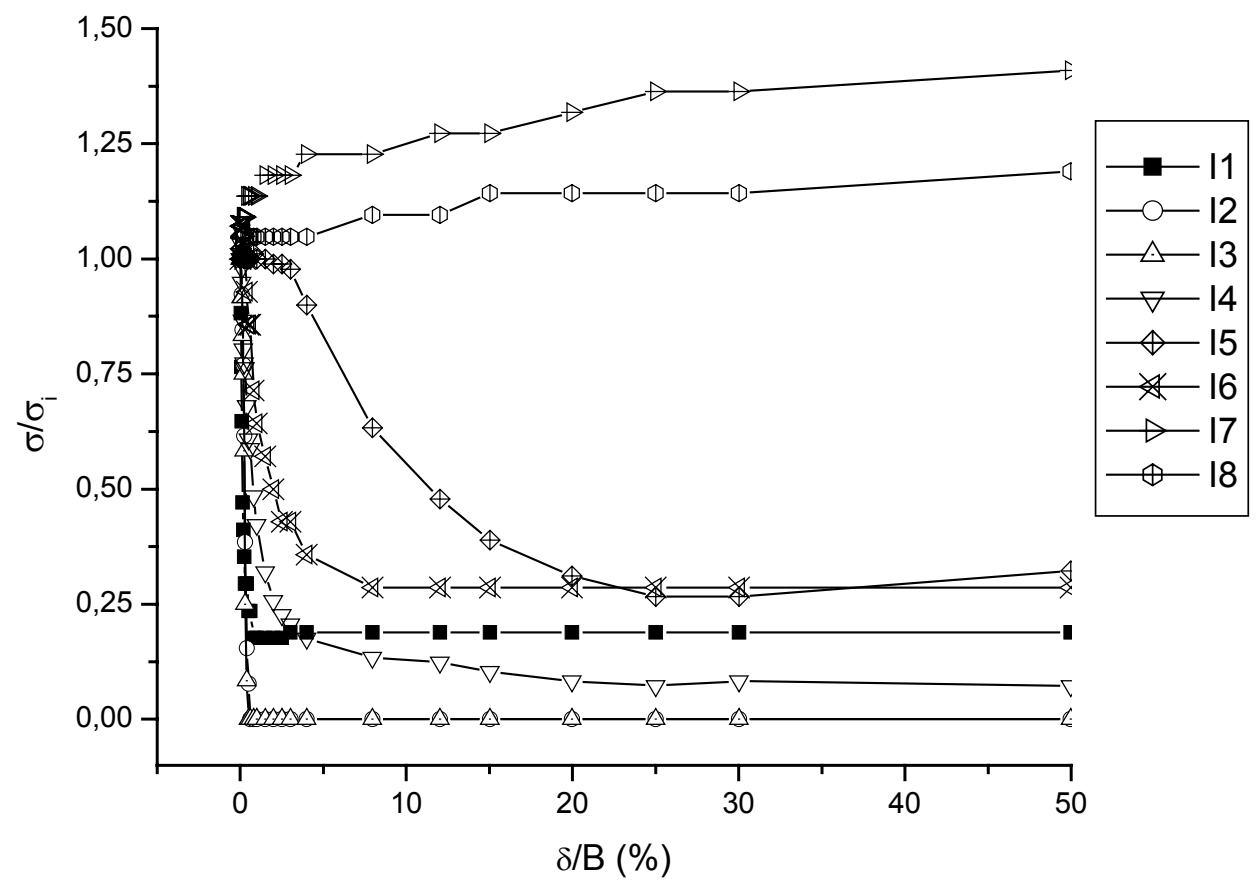

Figura C21. Resultados do ensaio D2, células I.

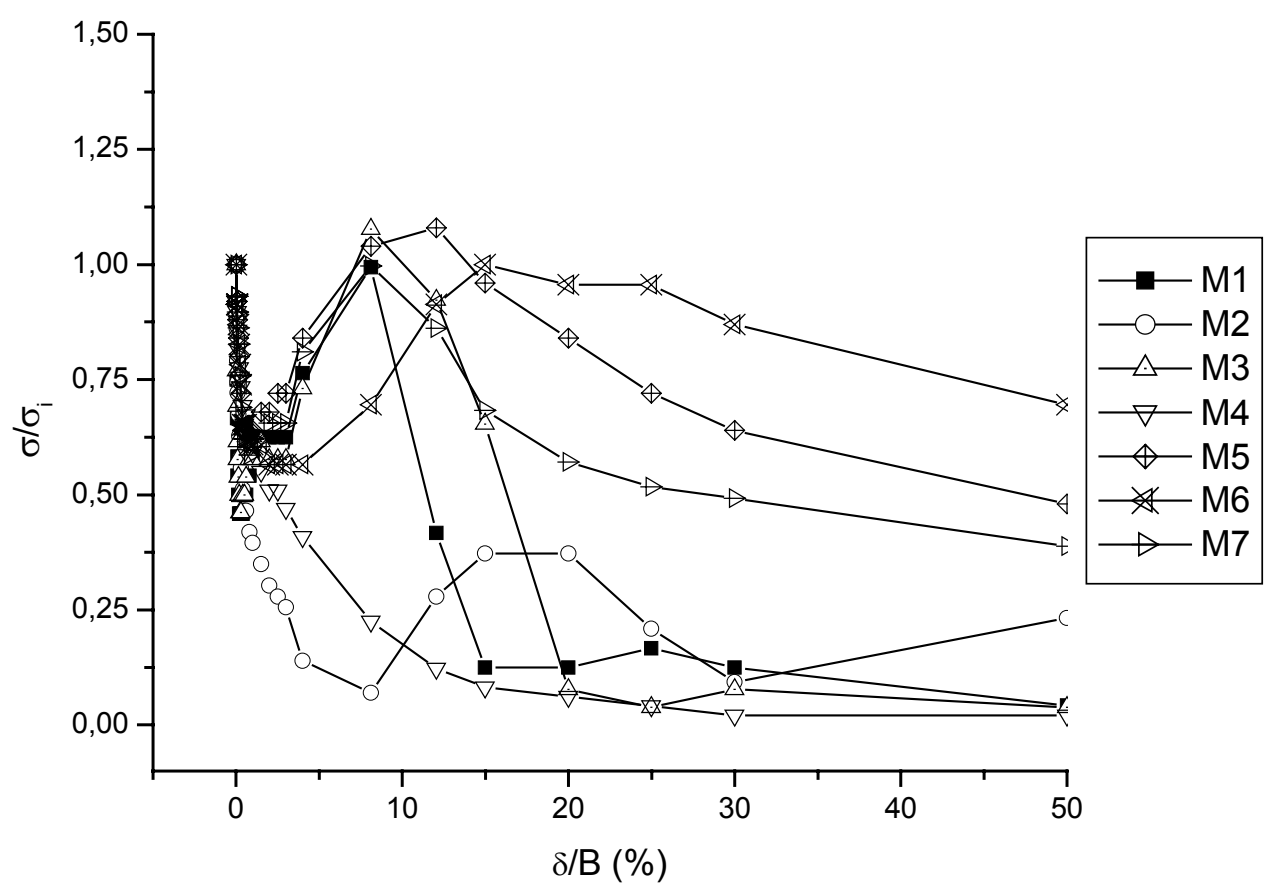

Figura C22. Resultados do ensaio D2, células M. 


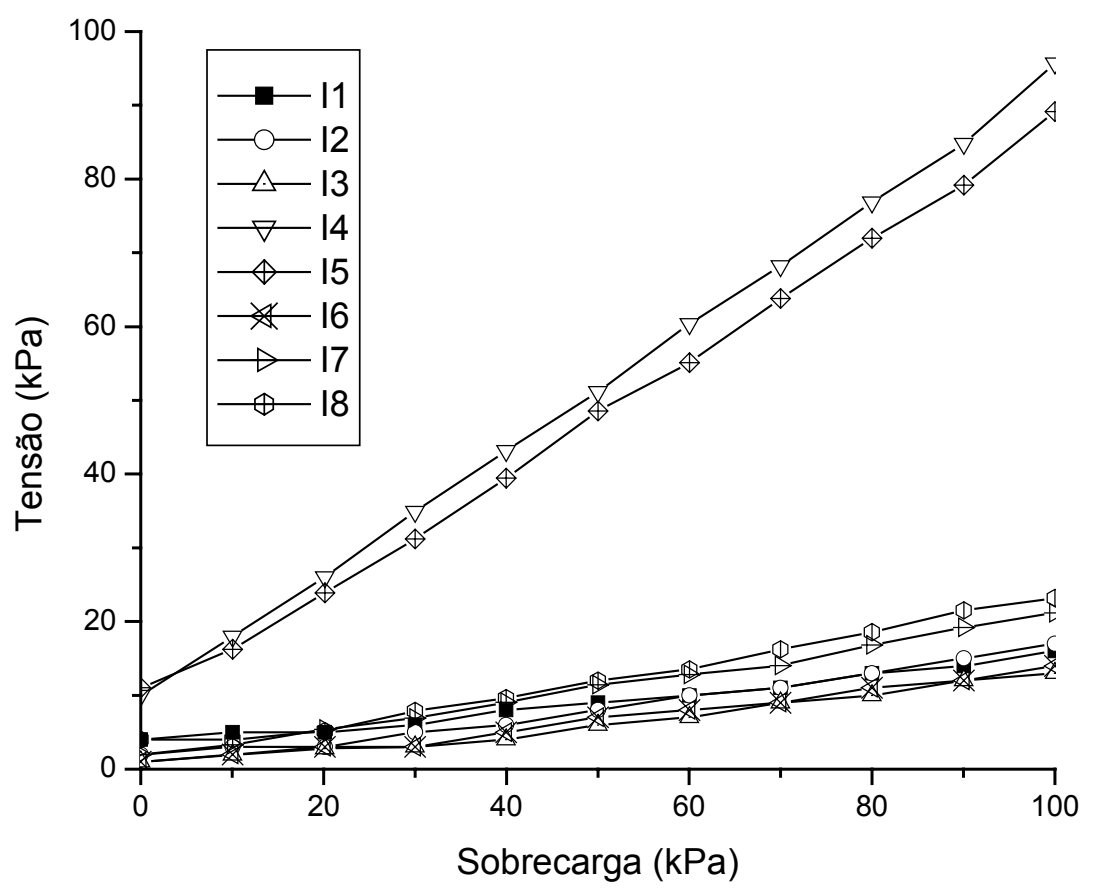

Figura C23. Sobrecarga aplicada x tensão medida no modelo D3, células I.

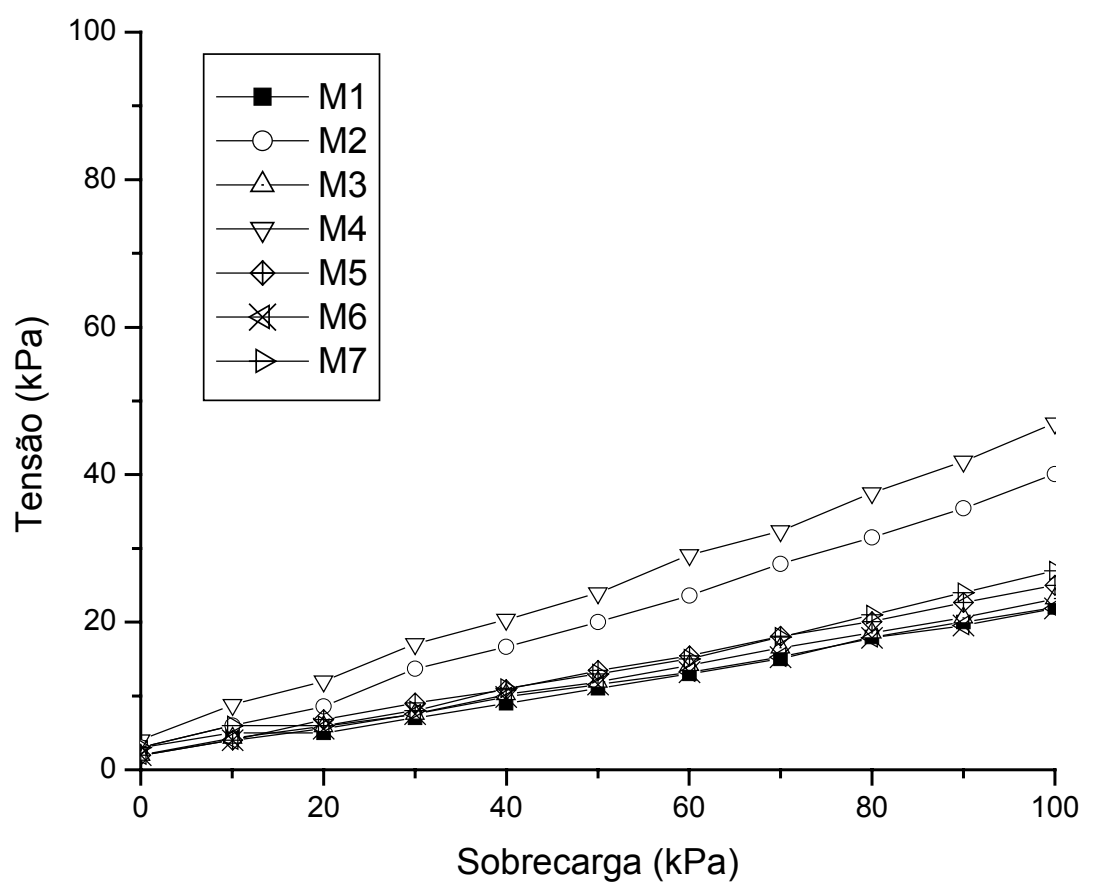

Figura C24. Sobrecarga aplicada x tensão medida no modelo D3, células M. 


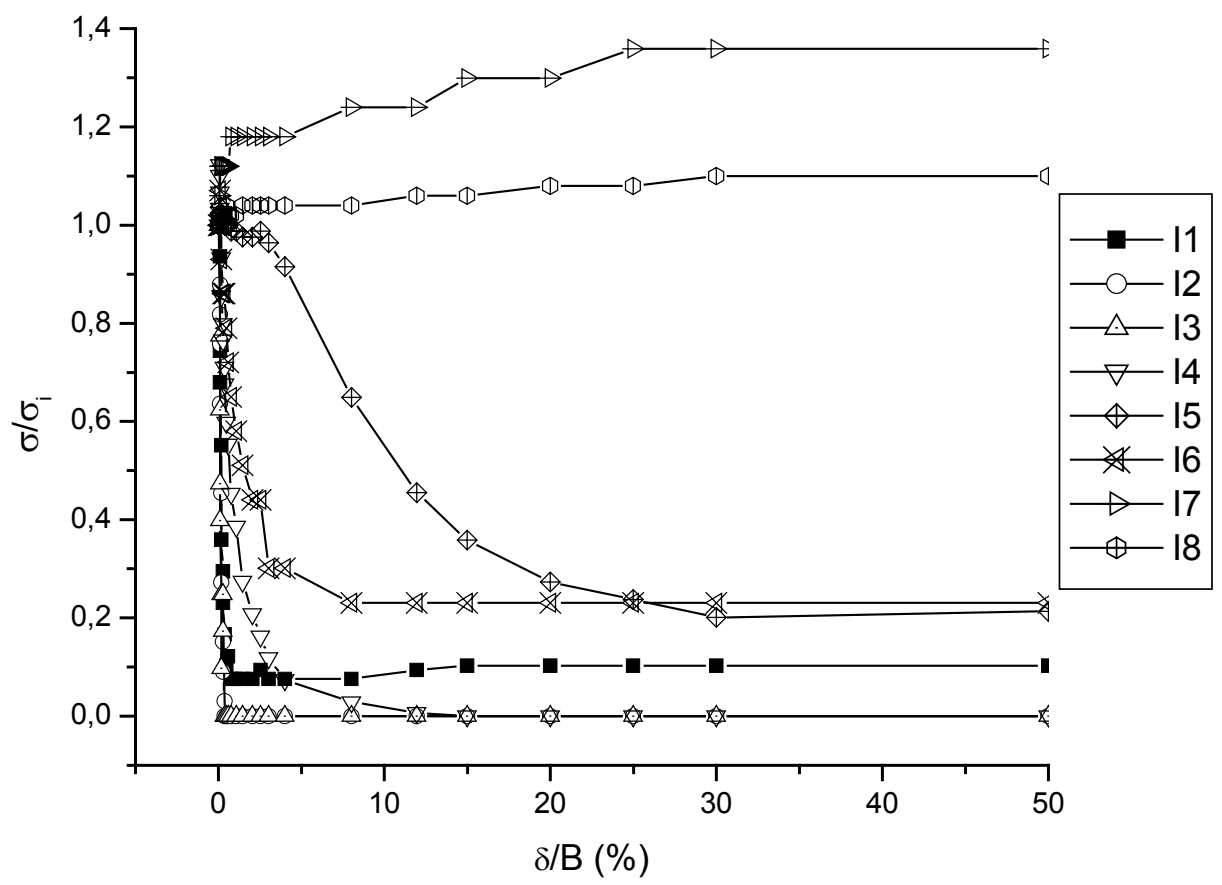

Figura C25. Resultados do ensaio D3, células I.

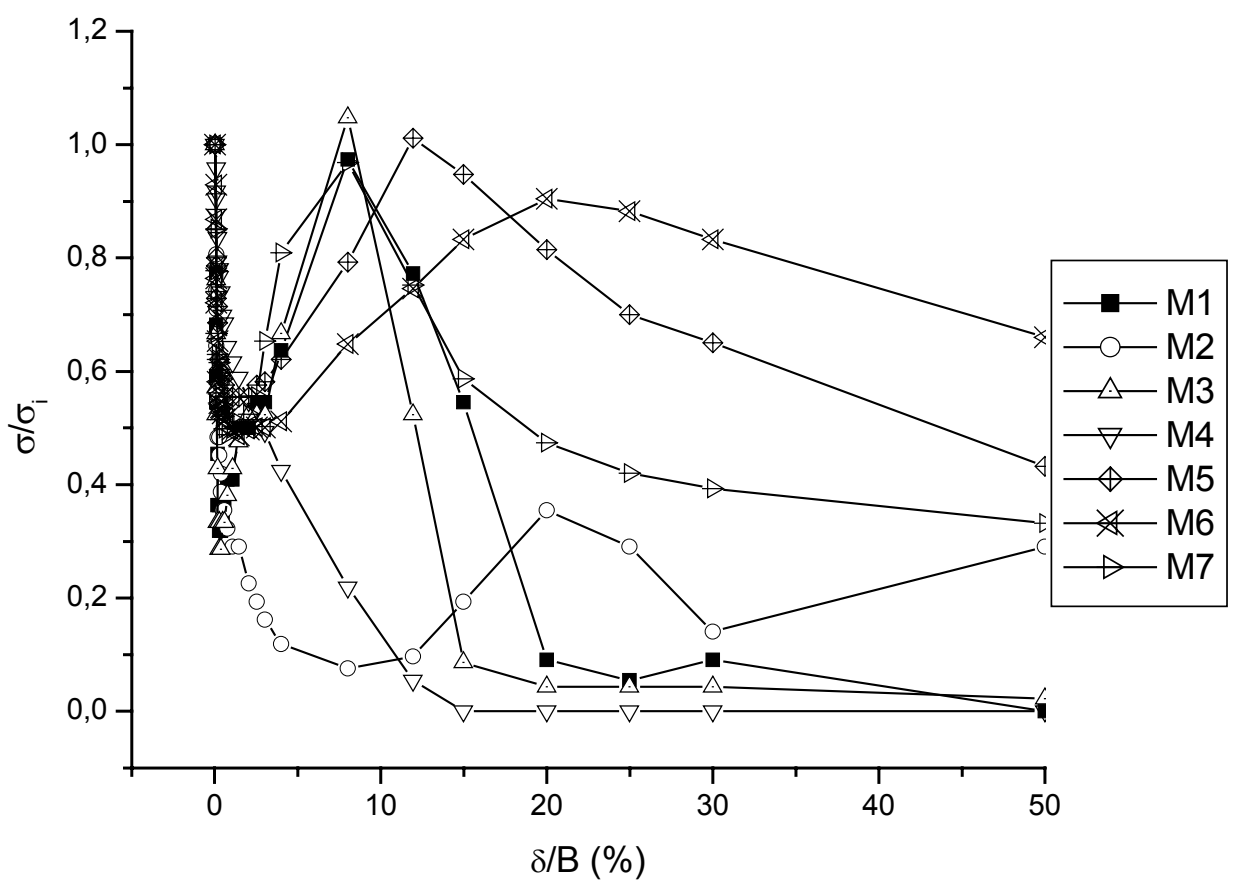

Figura C26. Resultados do ensaio D3, células M. 


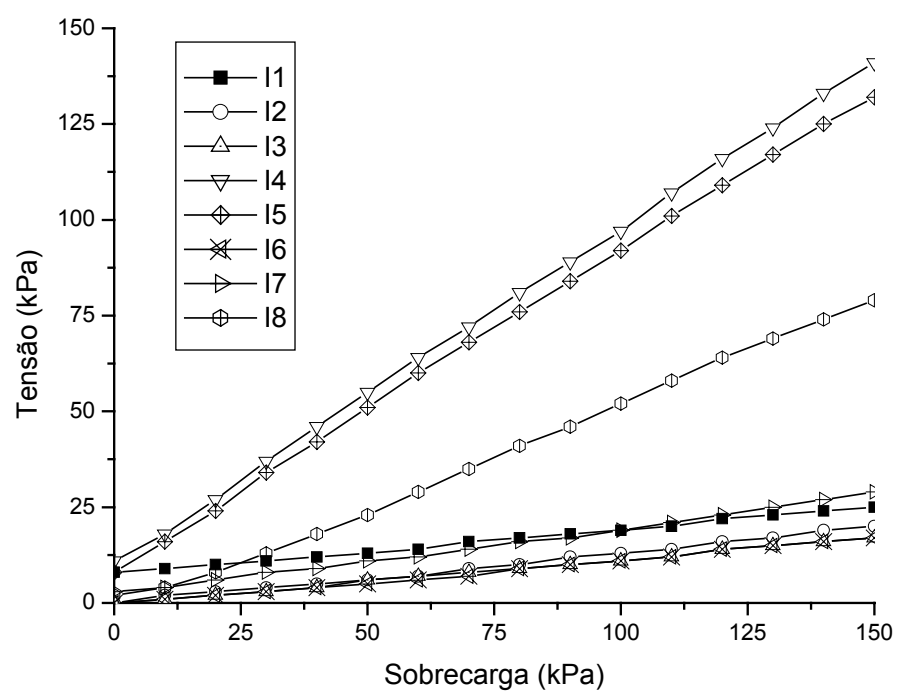

Figura C27. Sobrecarga aplicada x tensão medida no modelo D4, células I.

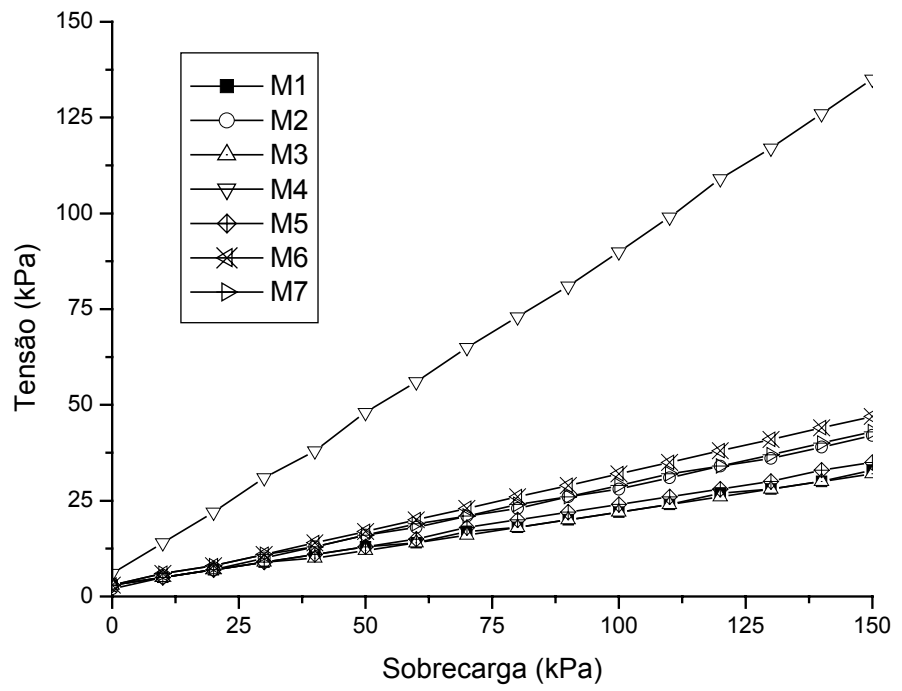

Figura C28. Sobrecarga aplicada x tensão medida no modelo D4, células M. 


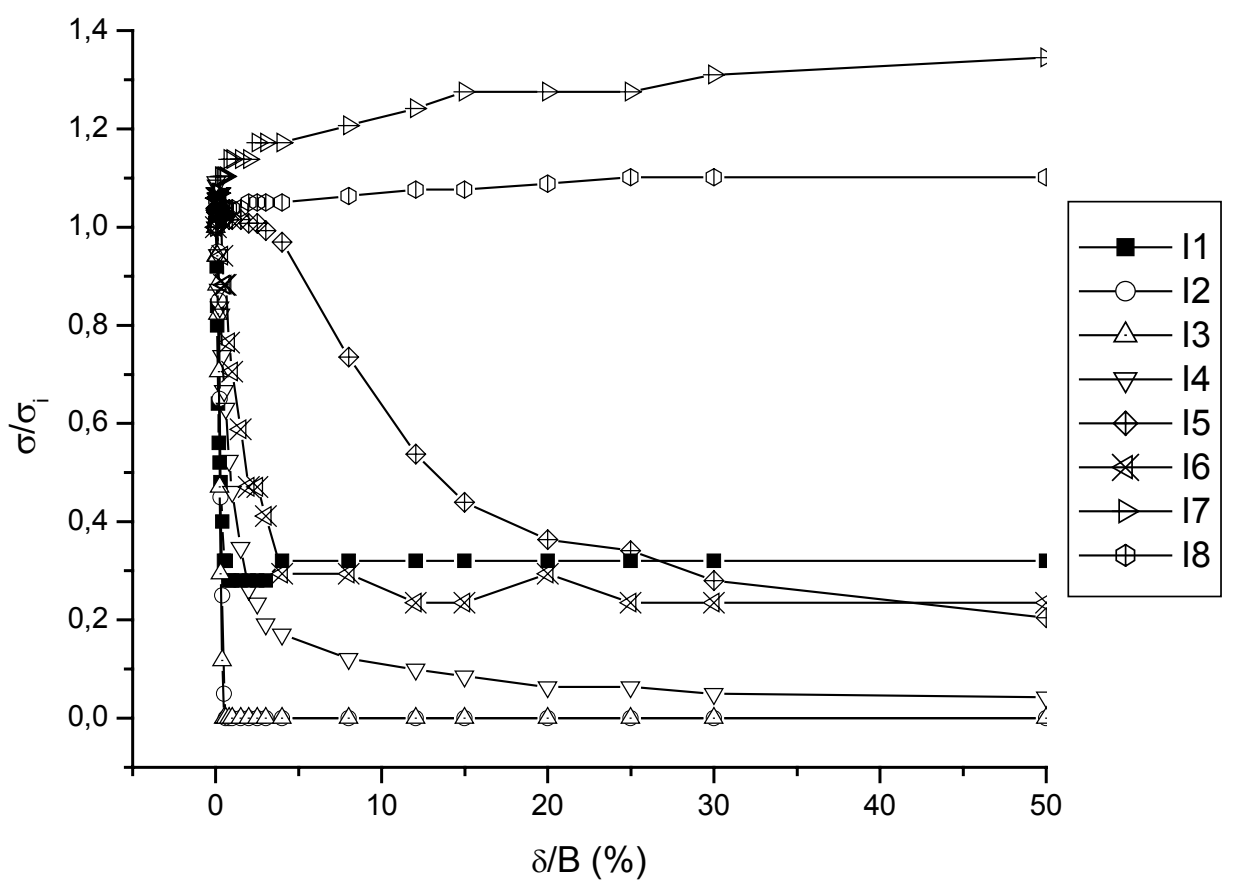

Figura C29. Resultados do ensaio D4, células I.

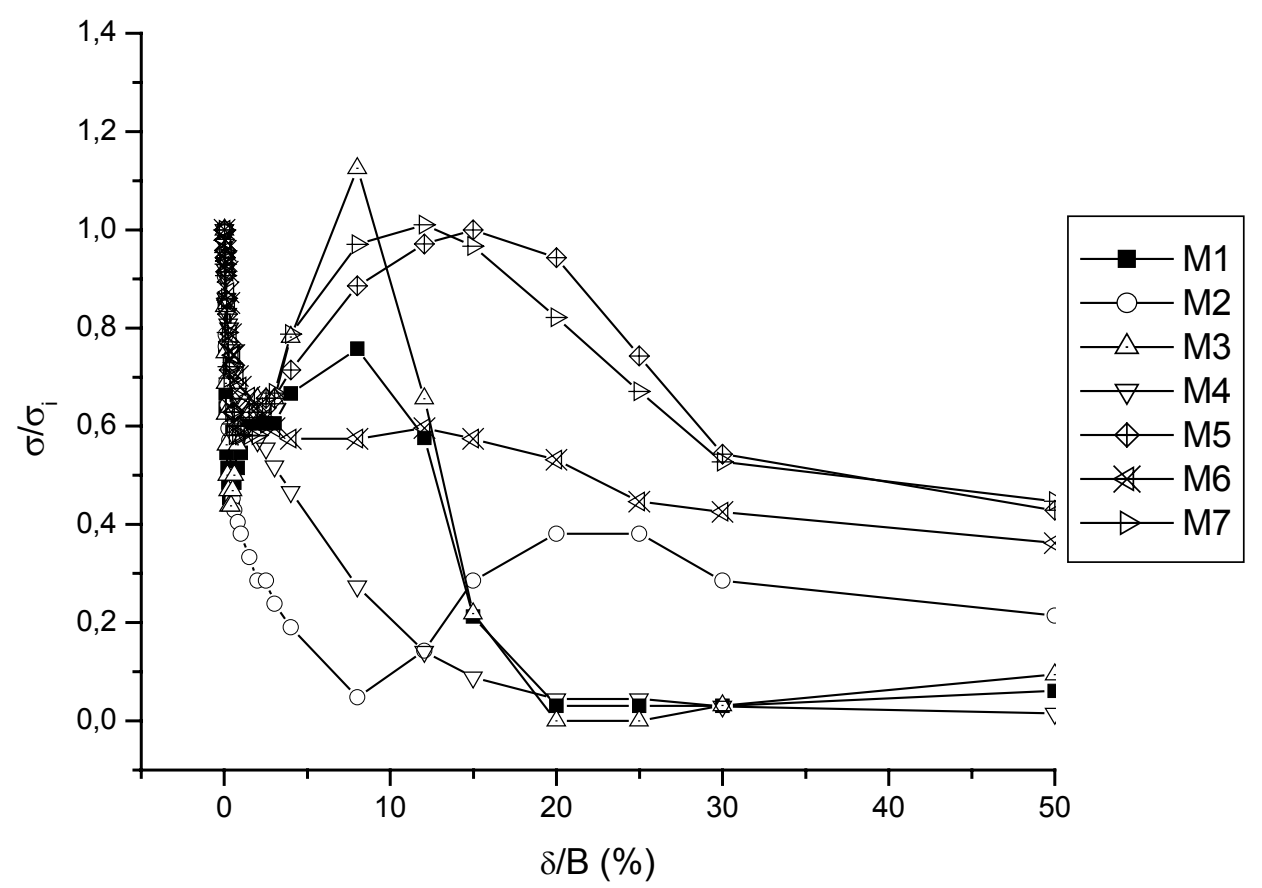

Figura C30. Resultados do ensaio D4, células M. 


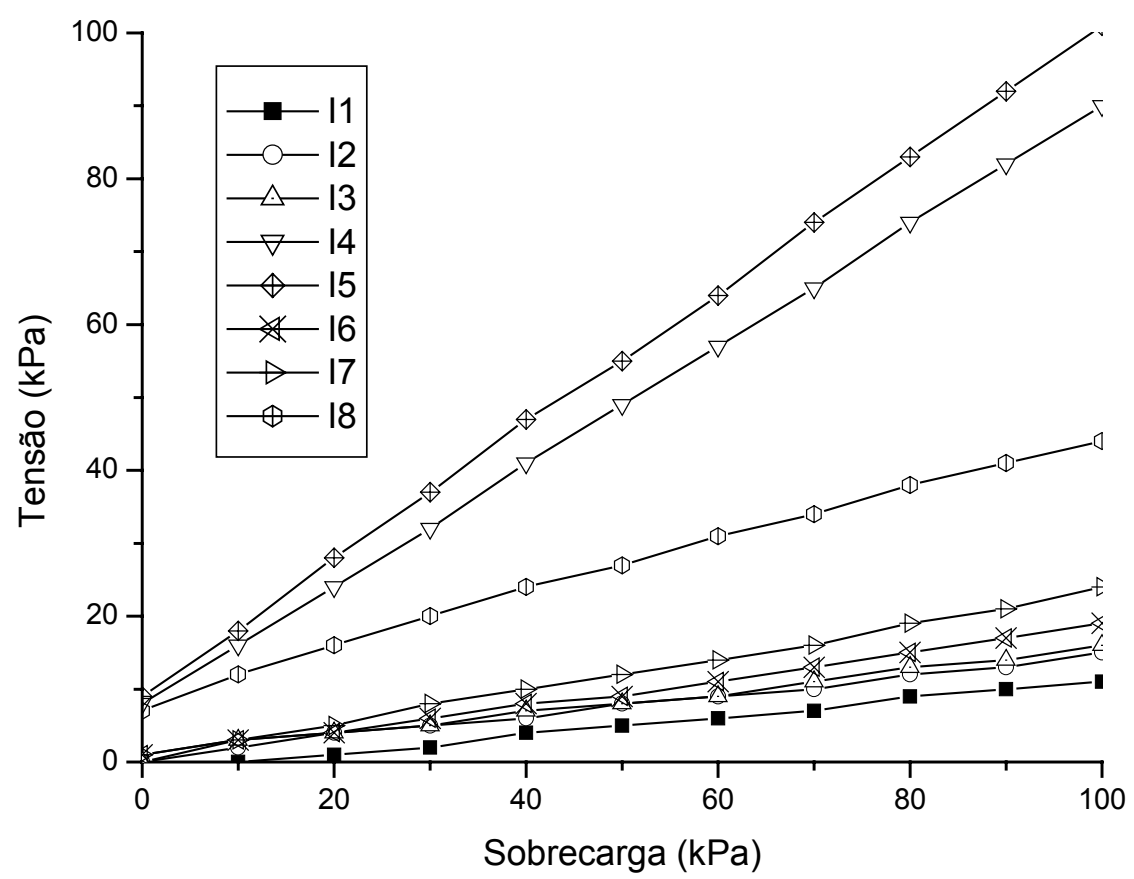

Figura C31. Sobrecarga aplicada x tensão medida no modelo D5, células I.

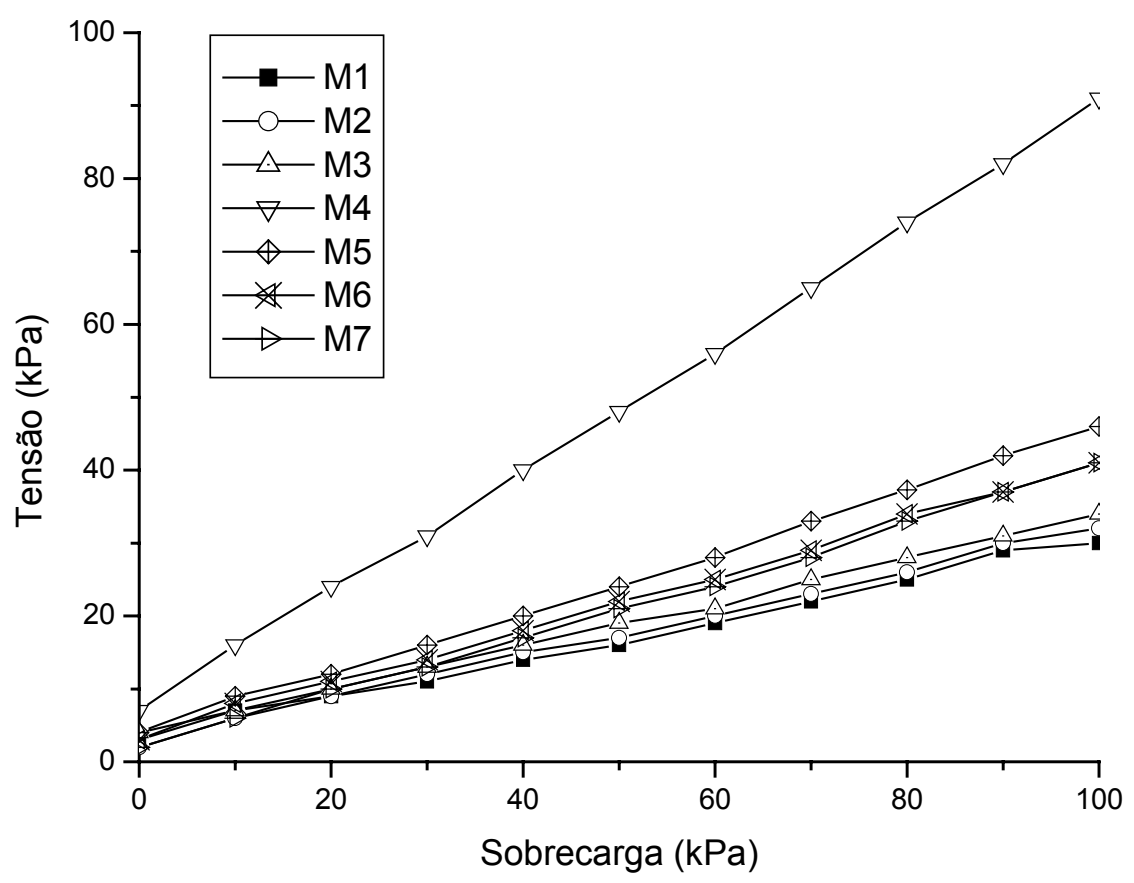

Figura C32. Sobrecarga aplicada x tensão medida no modelo D5, células M. 


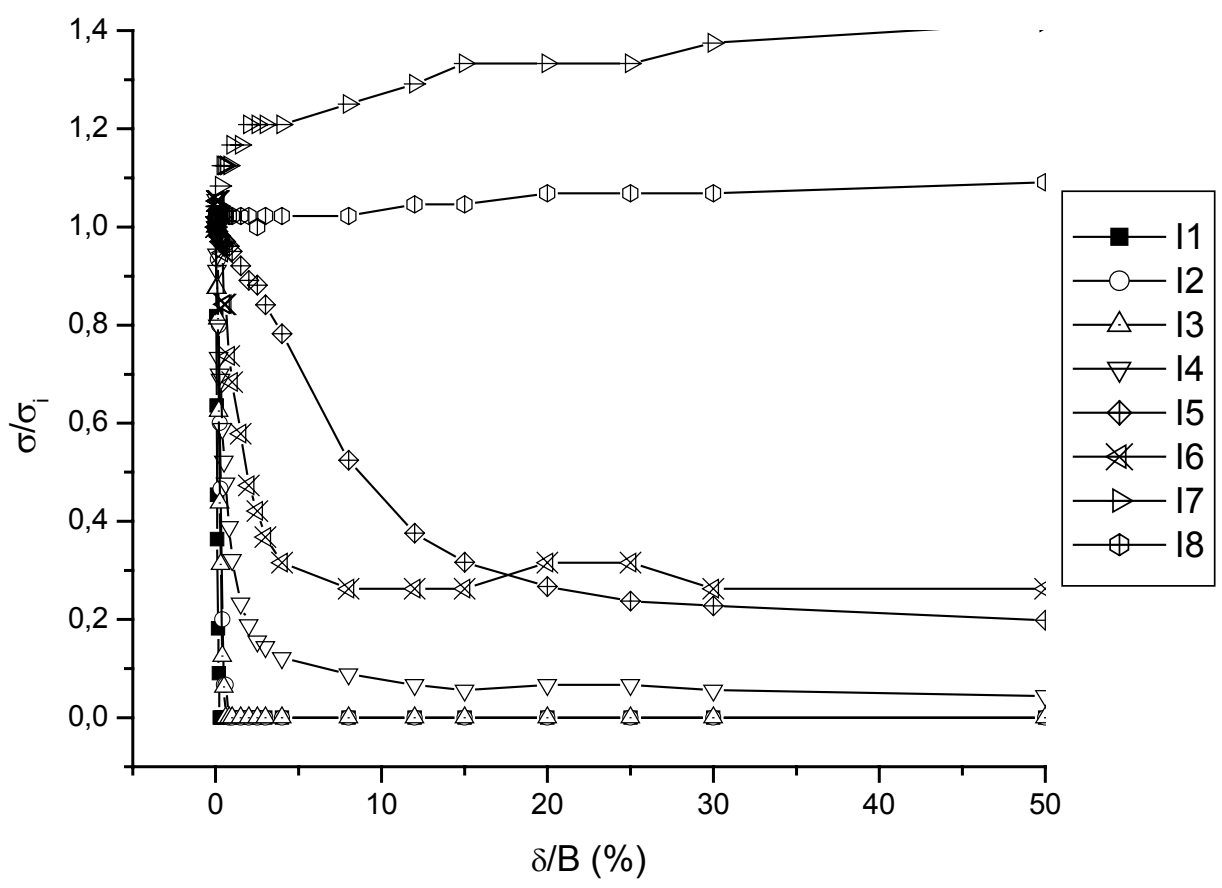

Figura C33. Resultados do ensaio D5, células I.

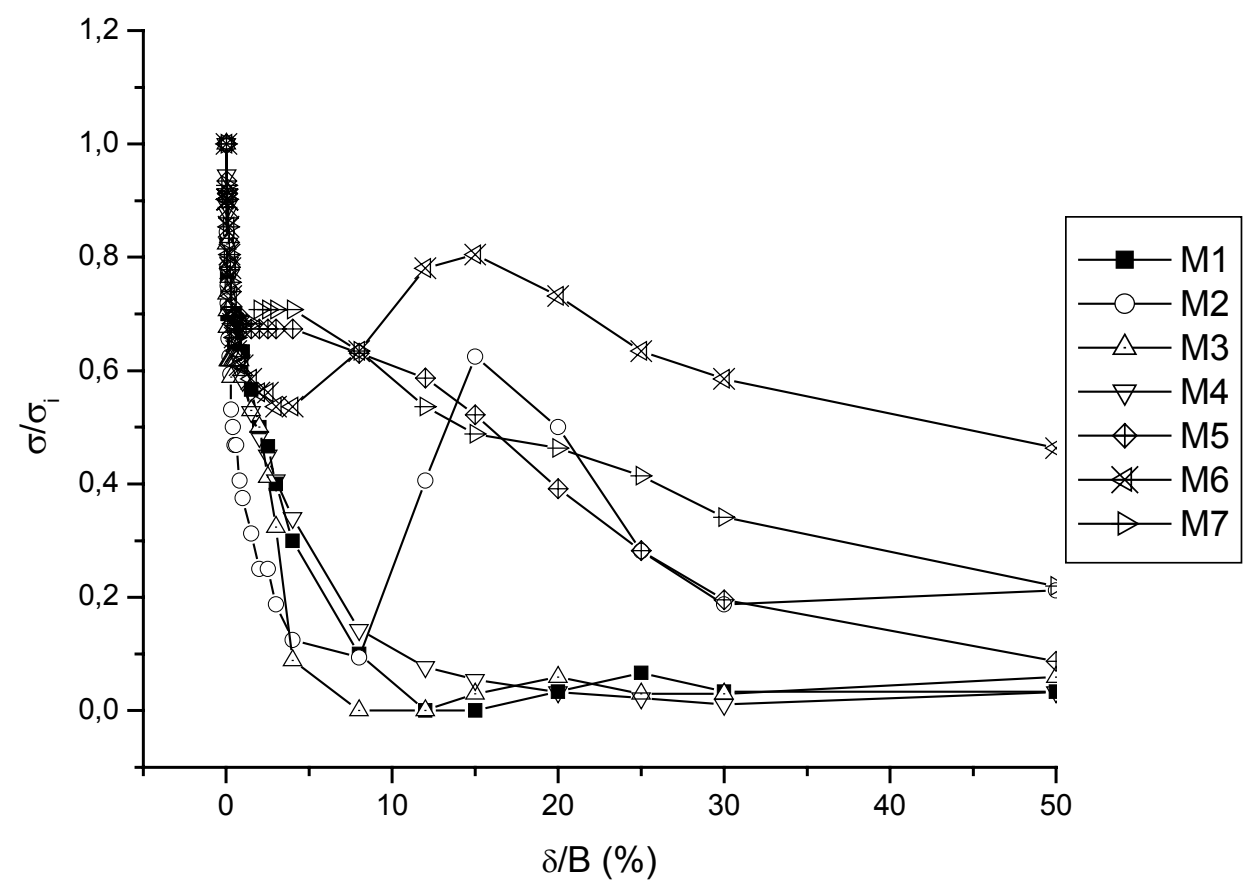

Figura C34. Resultados do ensaio D5, células M. 


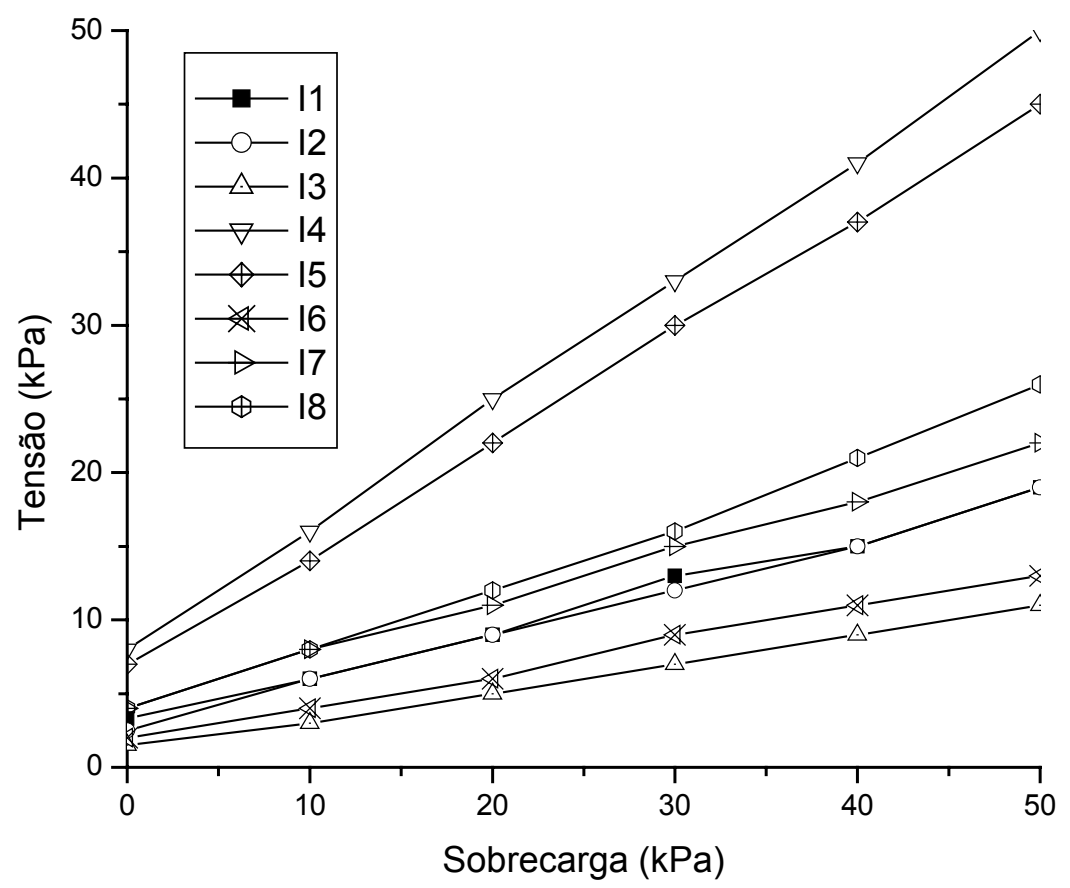

Figura C35. Sobrecarga aplicada x tensão medida no modelo D6, células I.

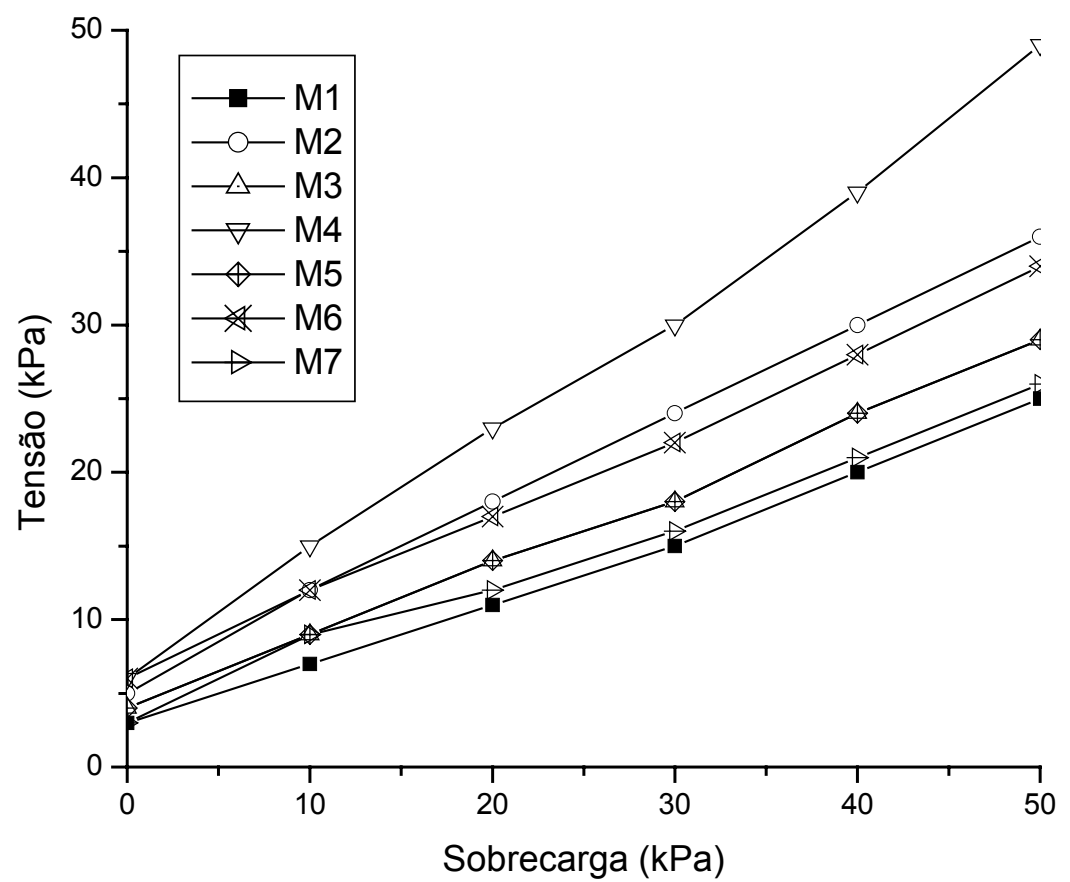

Figura C36. Sobrecarga aplicada x tensão medida no modelo D6, células M. 


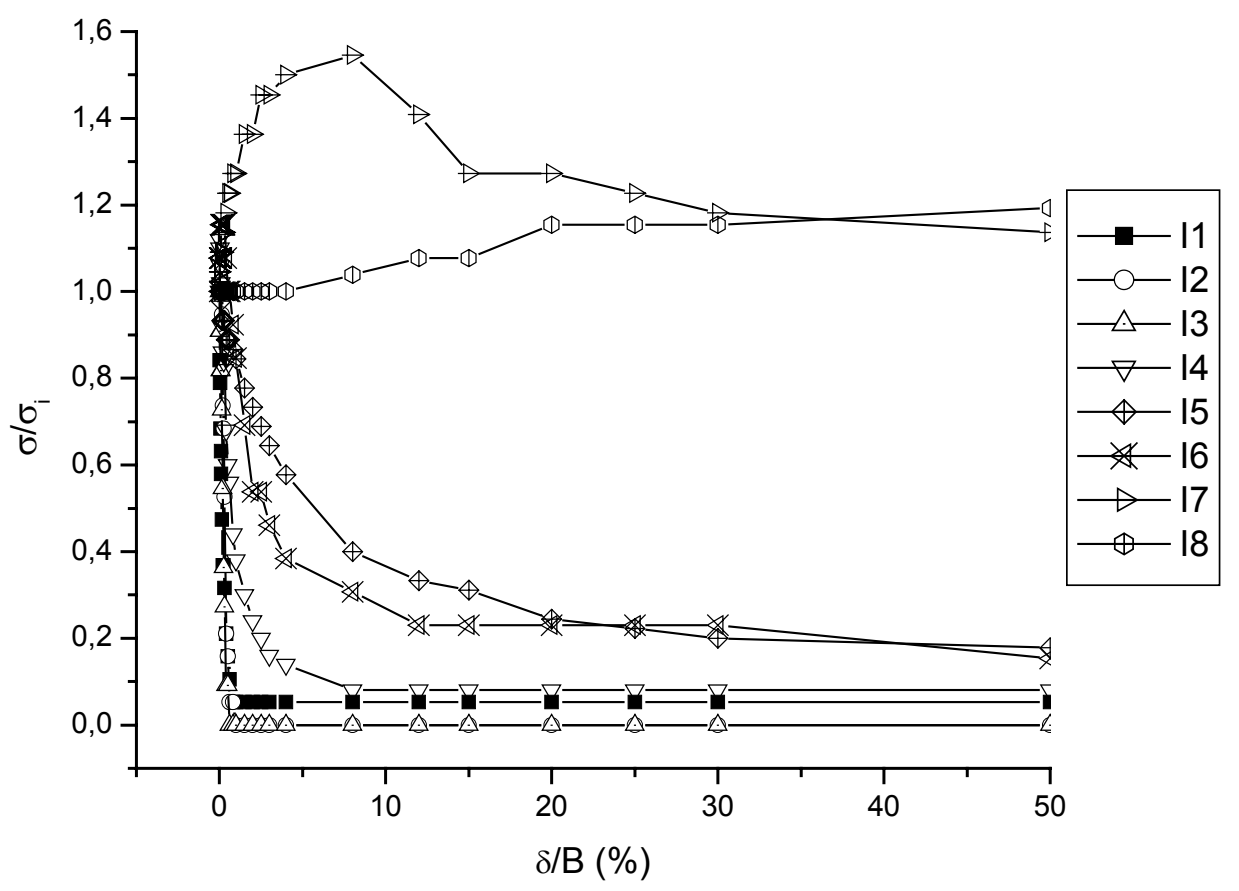

Figura C37. Resultados do ensaio D6, células I.

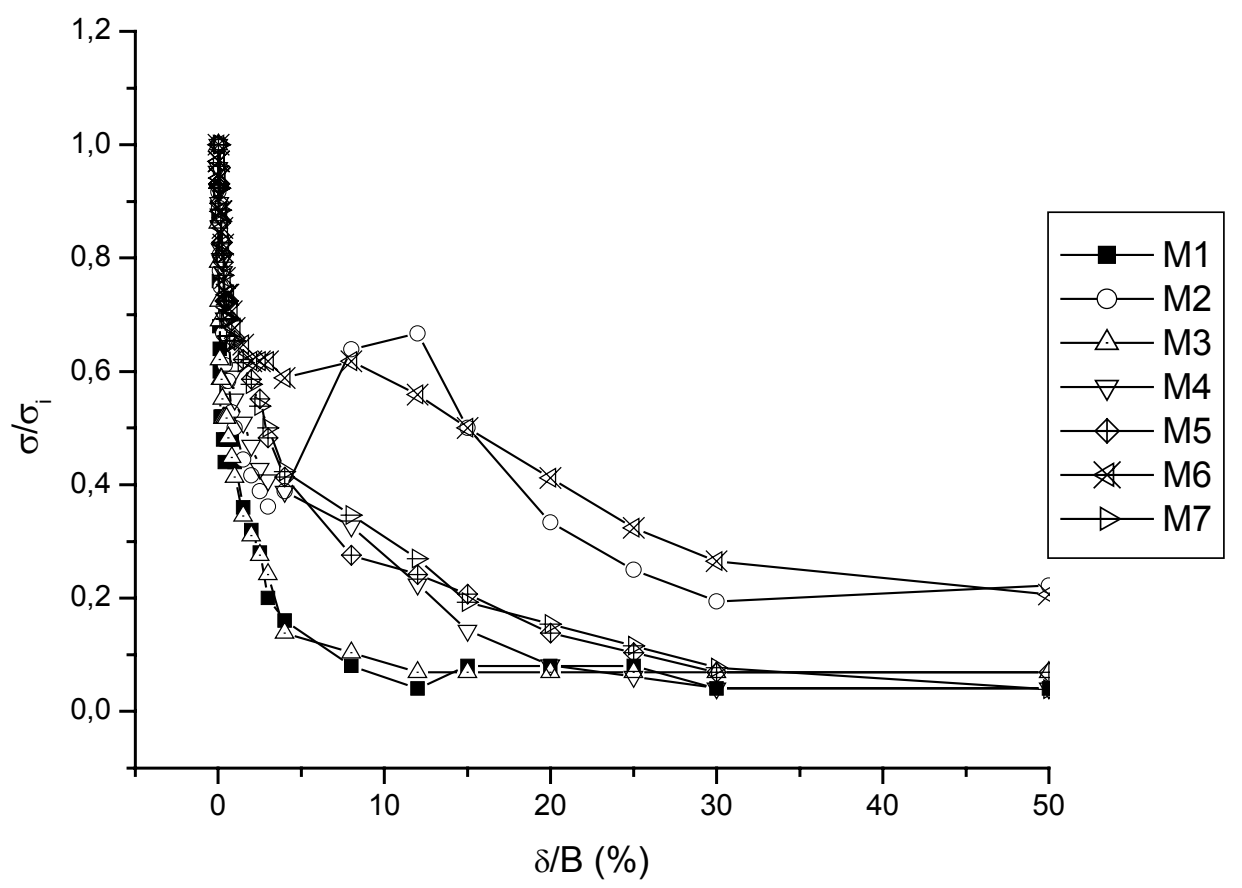

Figura C38. Resultados do ensaio D6, células M. 


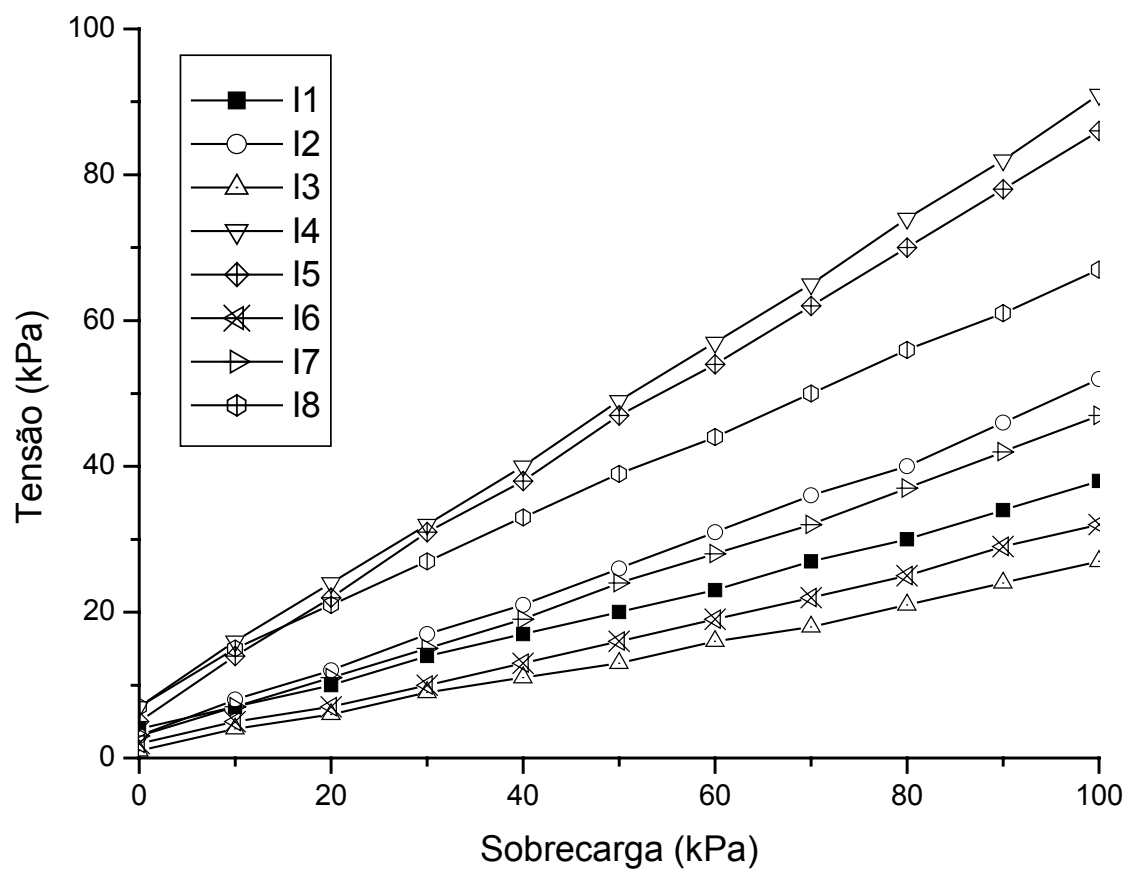

Figura C39. Sobrecarga aplicada x tensão medida no modelo D7, células I.

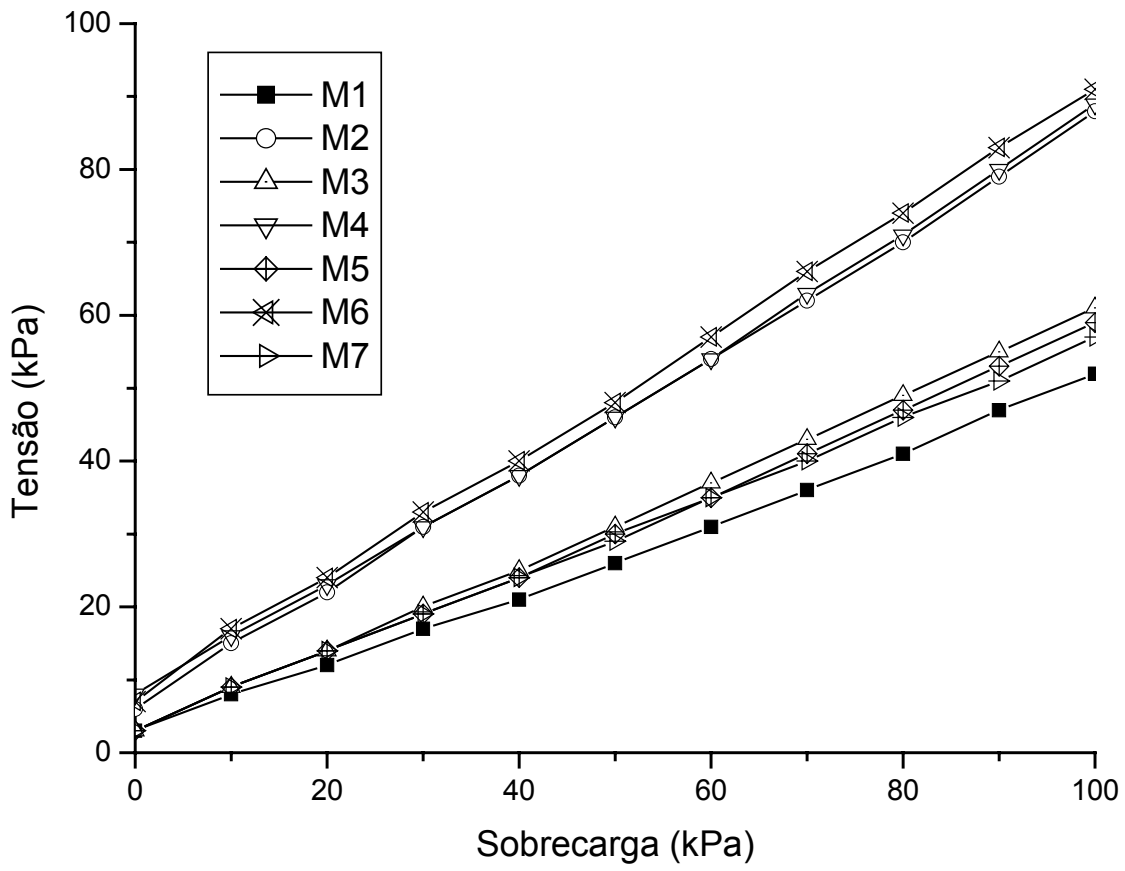

Figura C40. Sobrecarga aplicada x tensão medida no modelo D7, células M. 


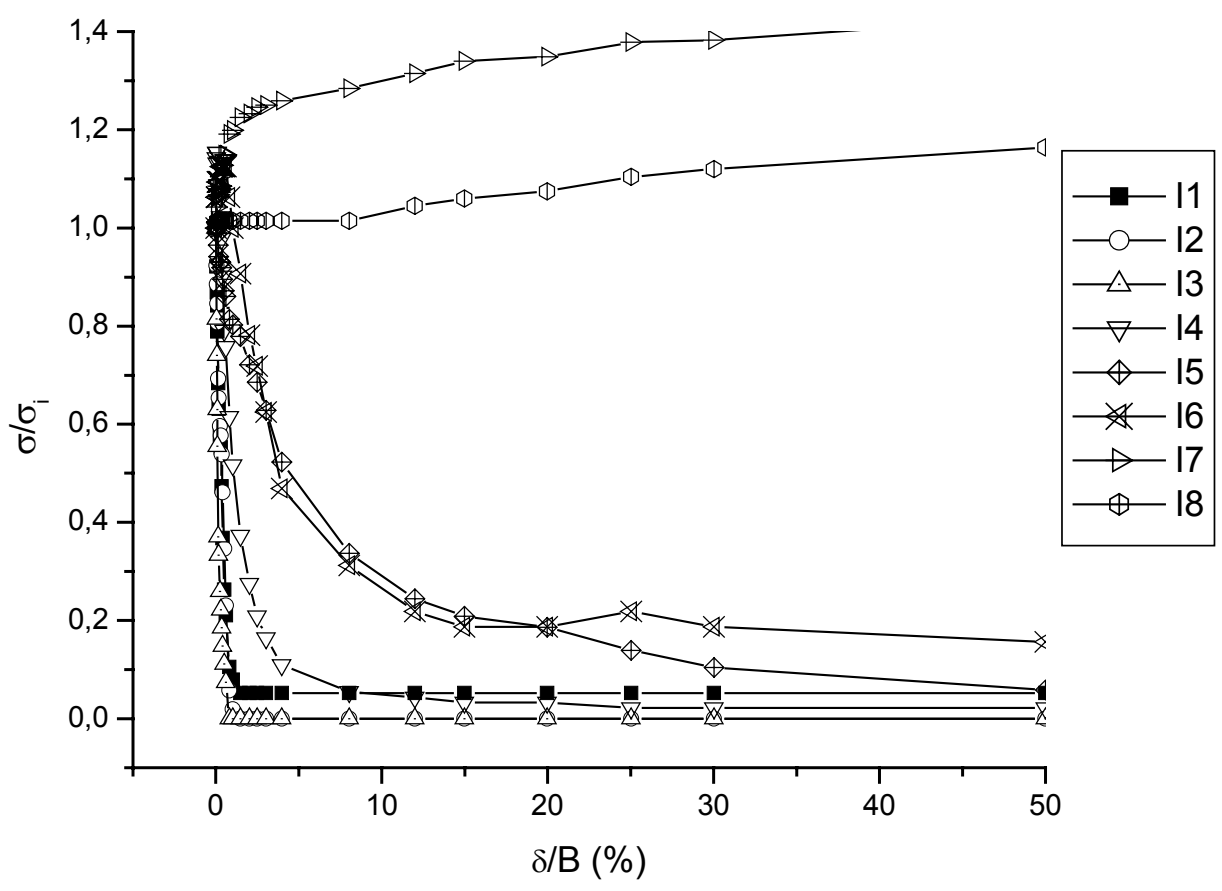

Figura C41. Resultados do ensaio D7, células I.

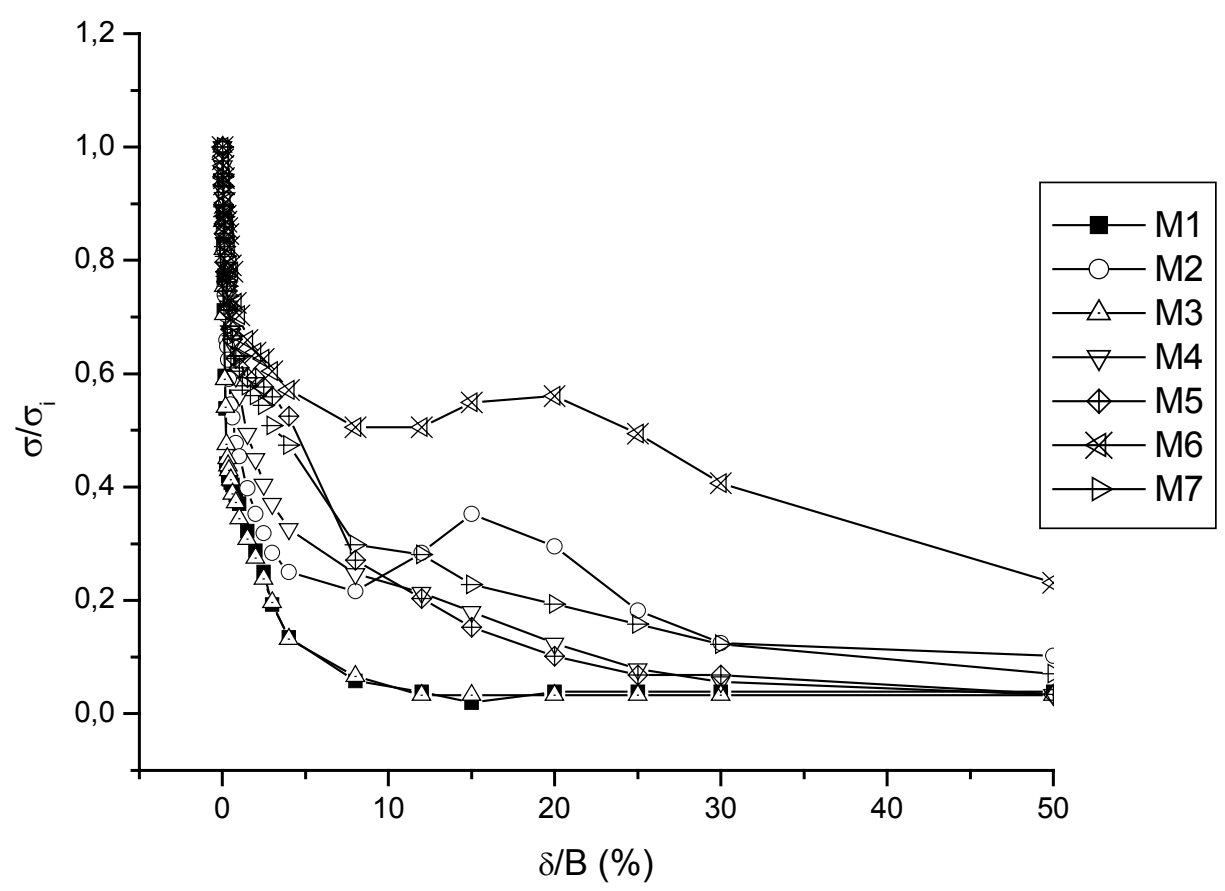

Figura C42. Resultados do ensaio D7, células M. 


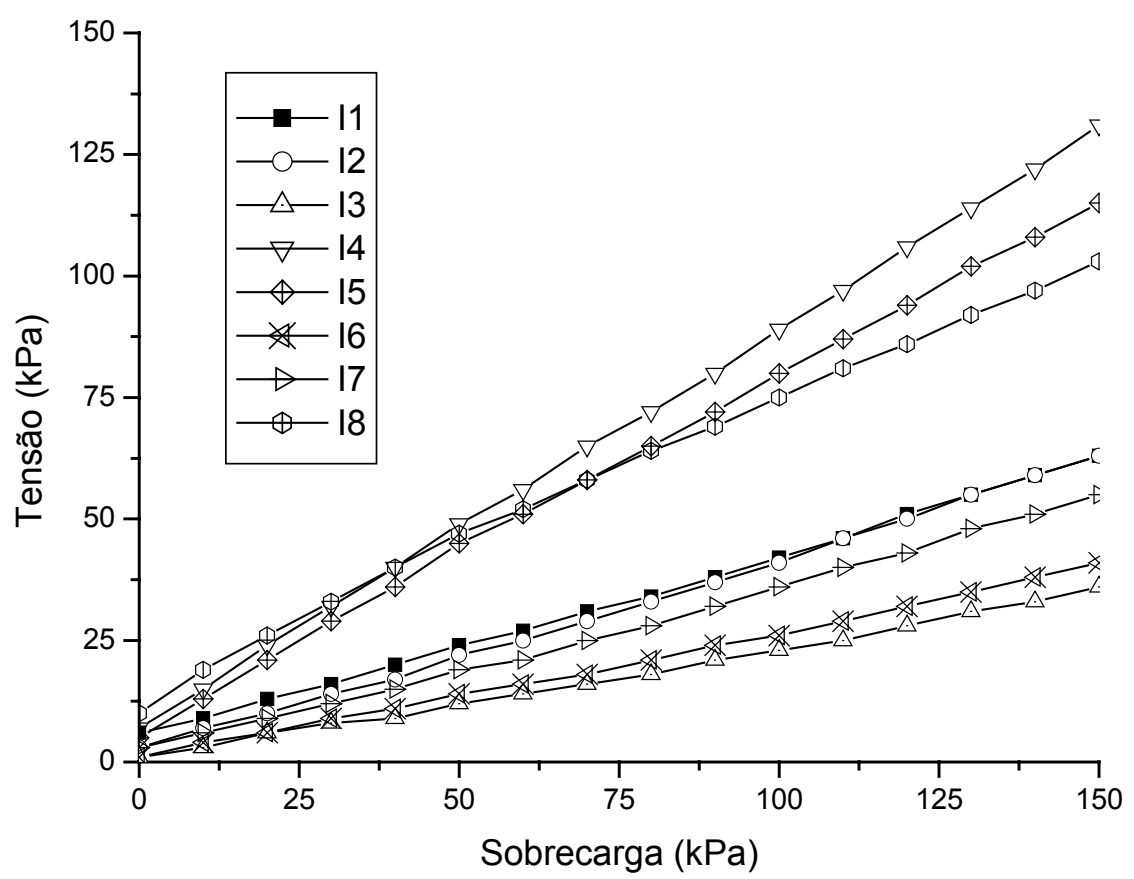

Figura C43. Sobrecarga aplicada x tensão medida no modelo D8, células I.

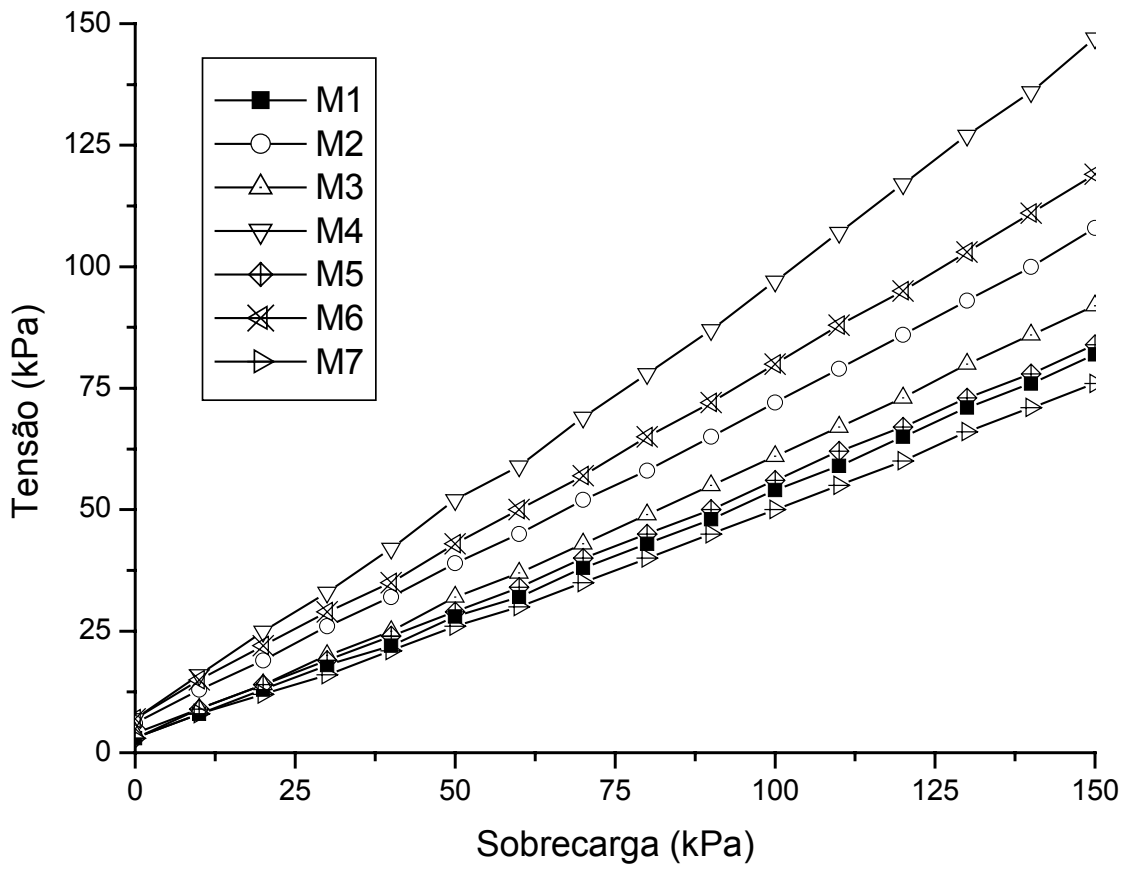

Figura C44. Sobrecarga aplicada x tensão medida no modelo D8, células M. 


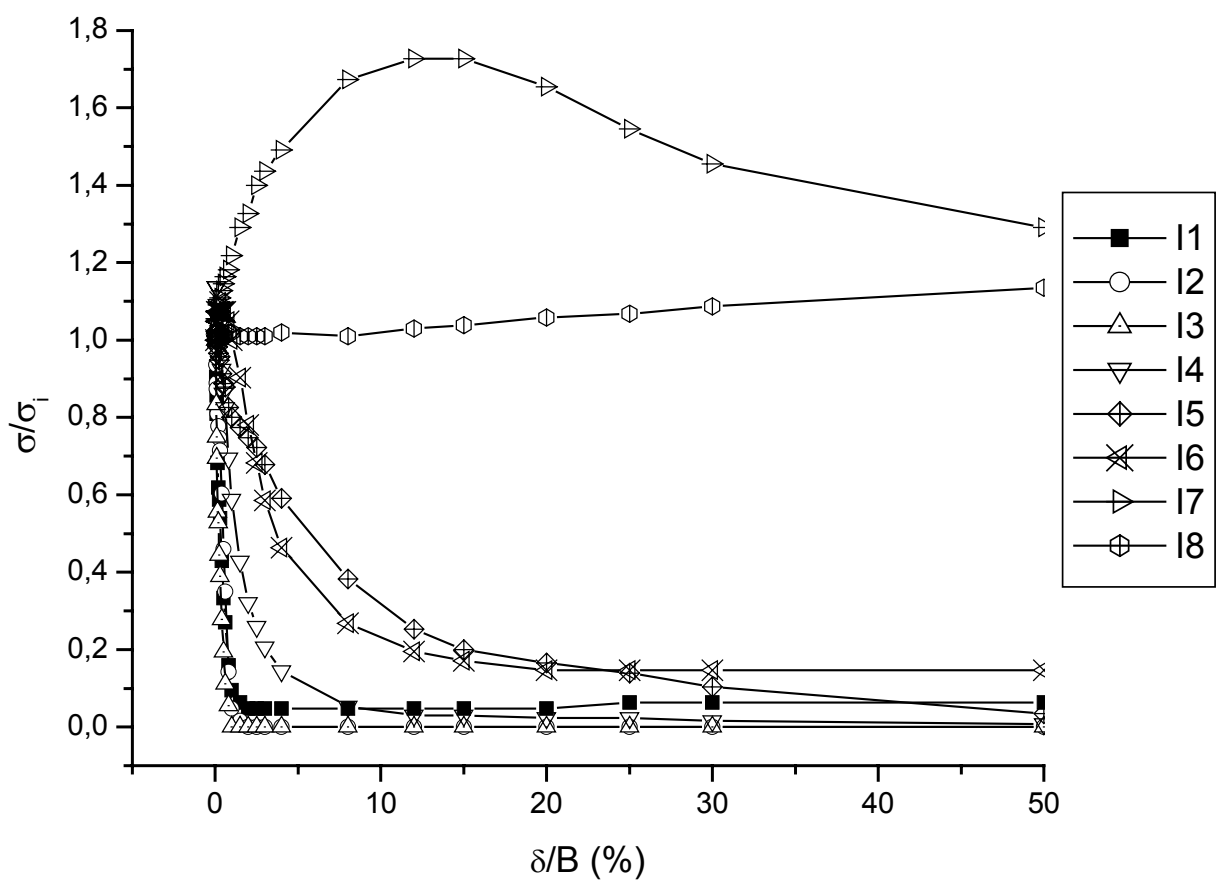

Figura C45. Resultados do ensaio D8, células I.

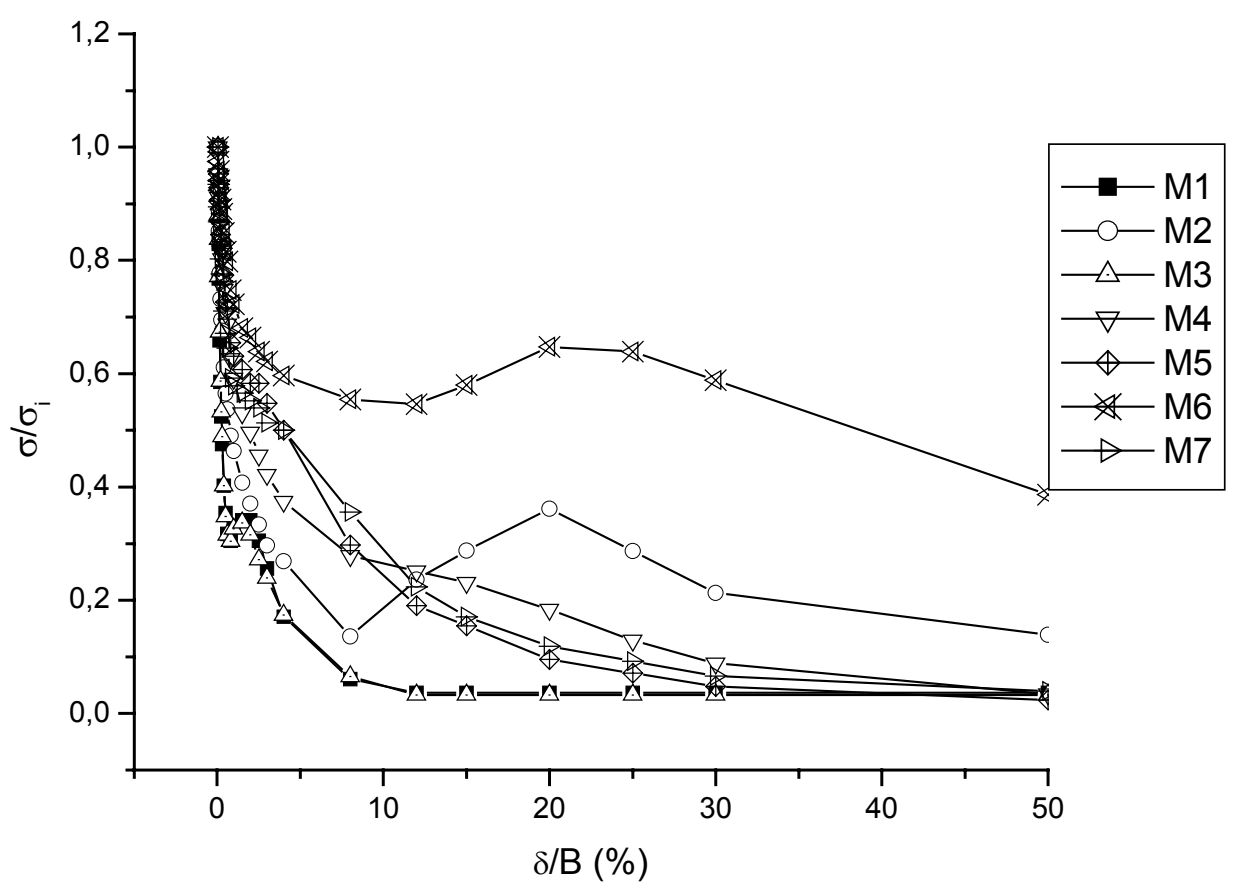

Figura C46. Resultados do ensaio D8, células M. 


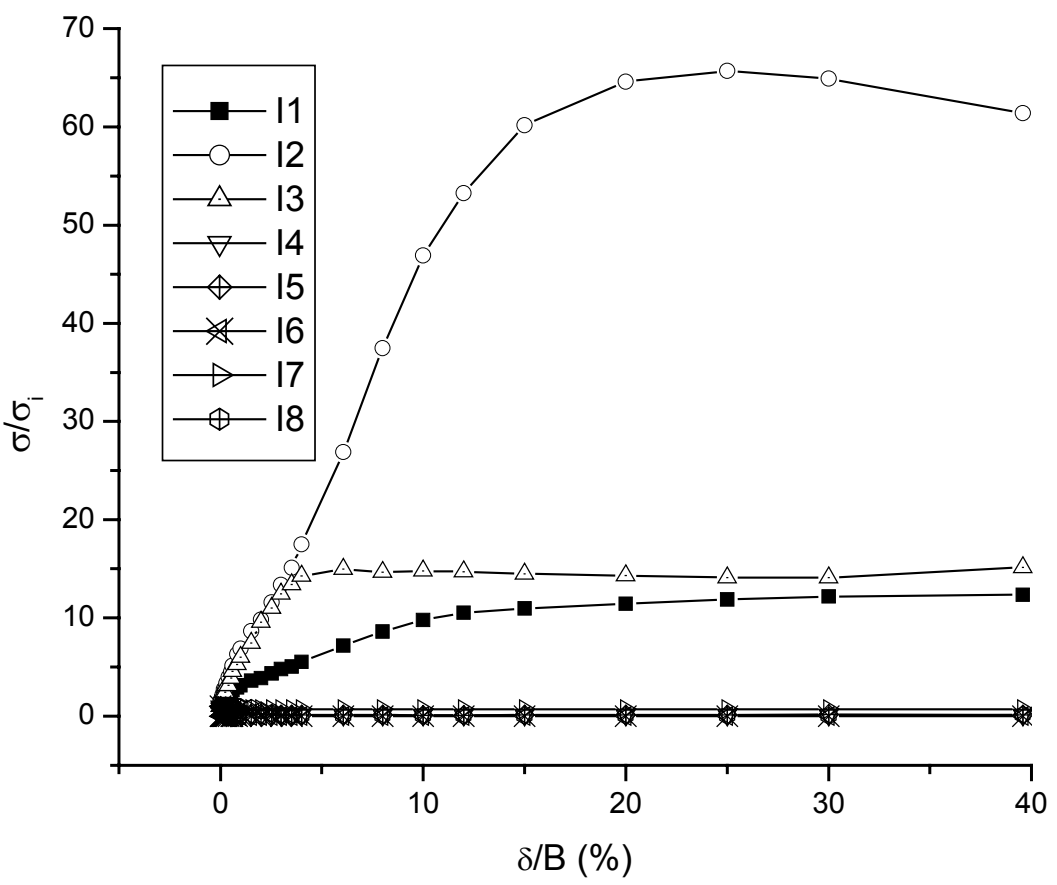

Figura C47. Resultados do ensaio E1, células I.

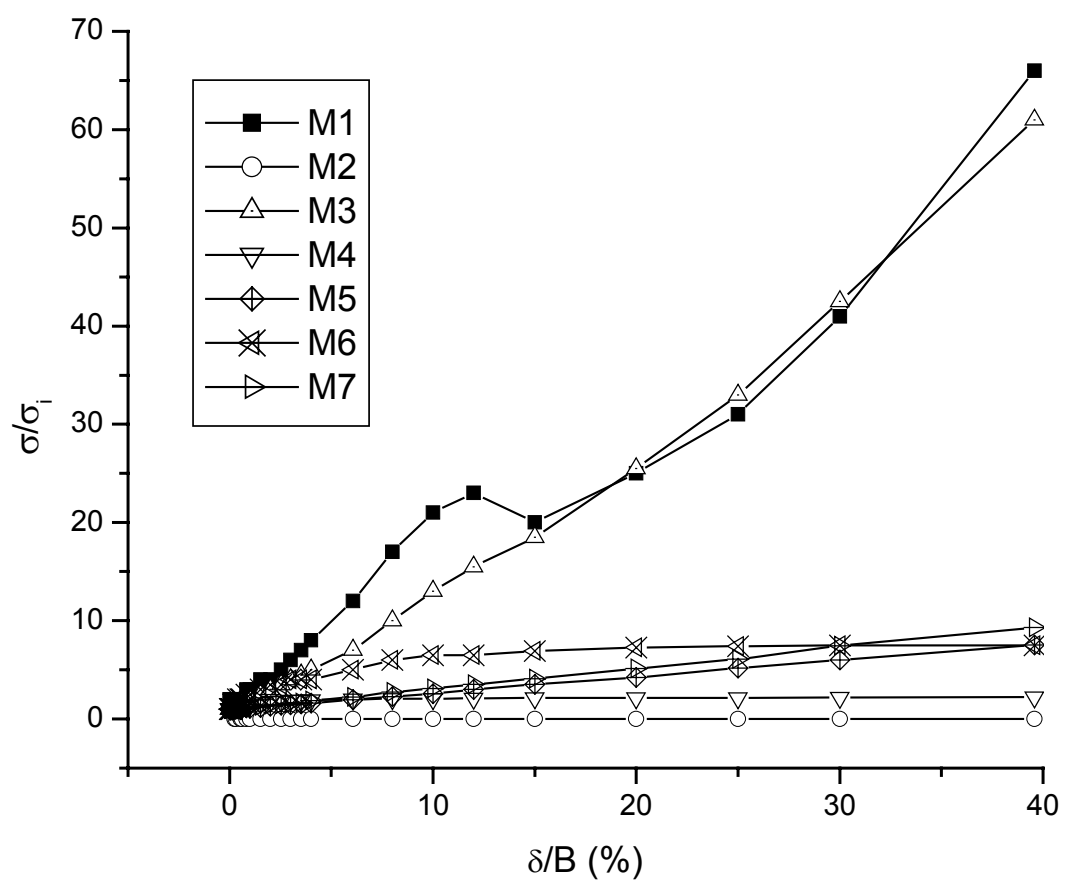

Figura C48. Resultados do ensaio E1, células M. 


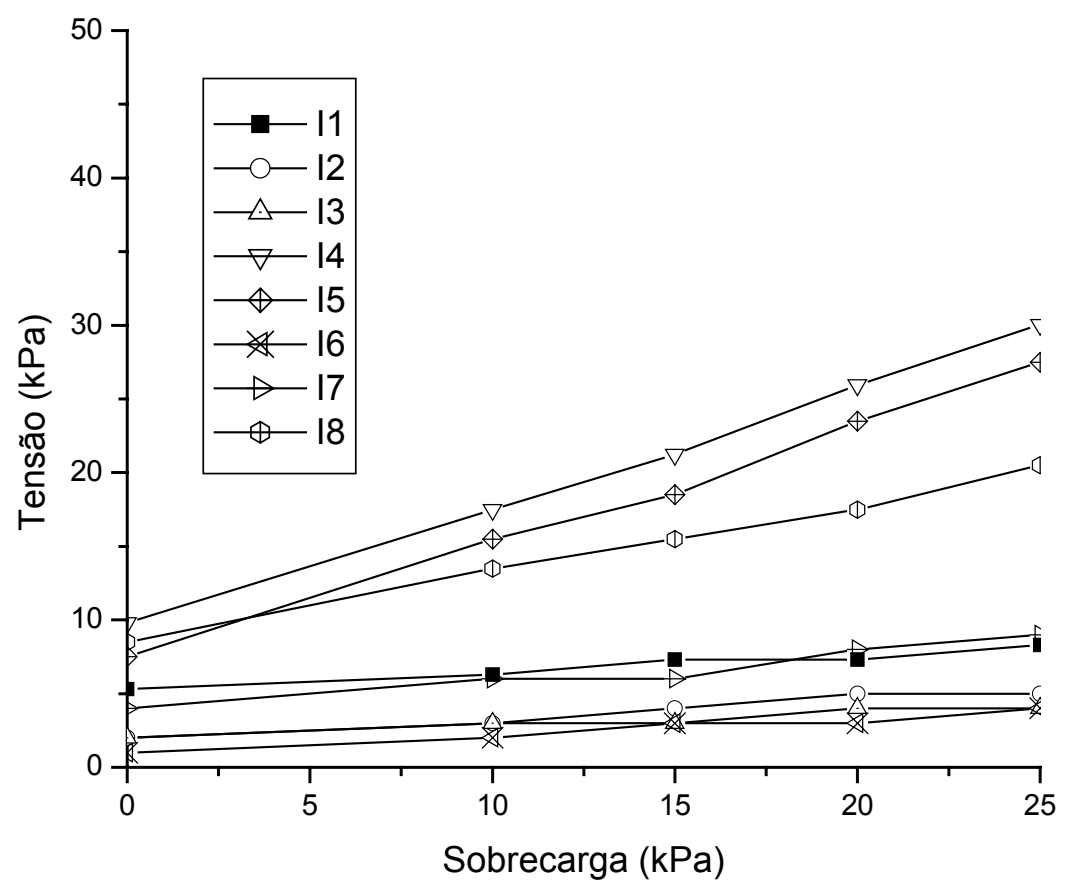

Figura C49. Sobrecarga aplicada x tensão medida no modelo E2, células I.

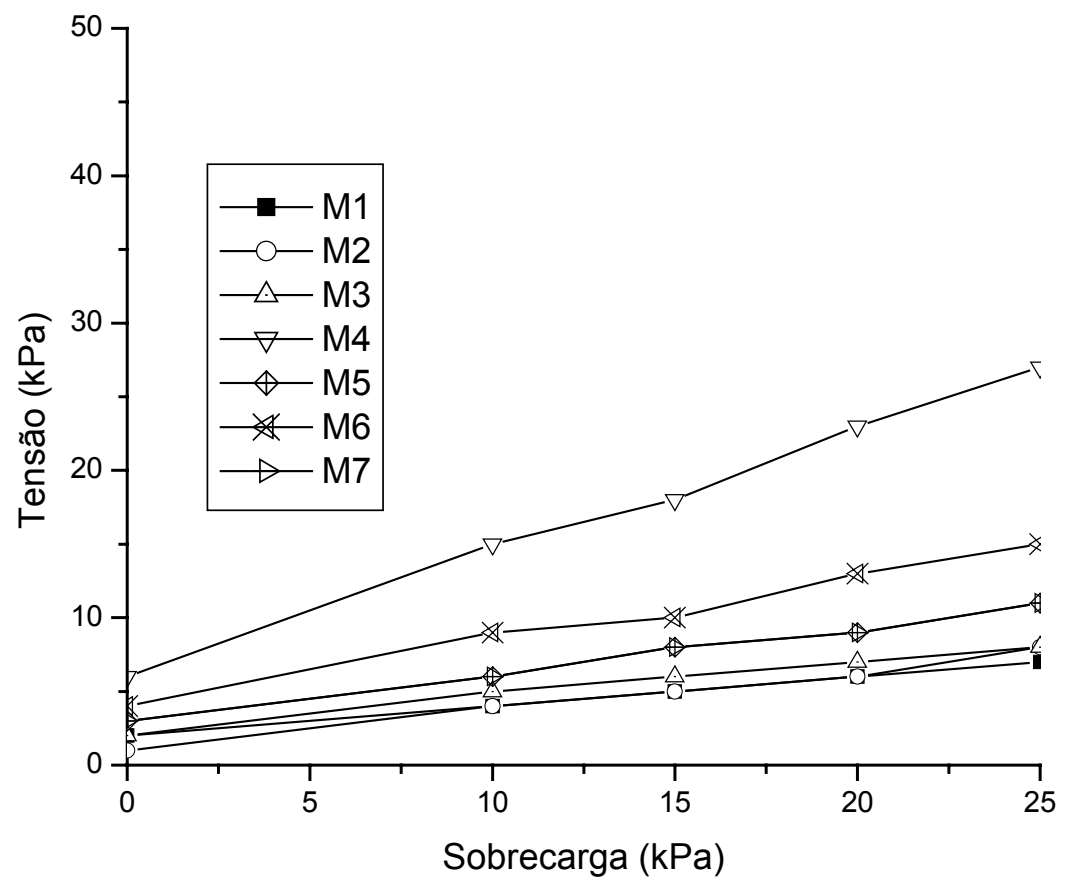

Figura C50. Sobrecarga aplicada x tensão medida no modelo E2, células M. 


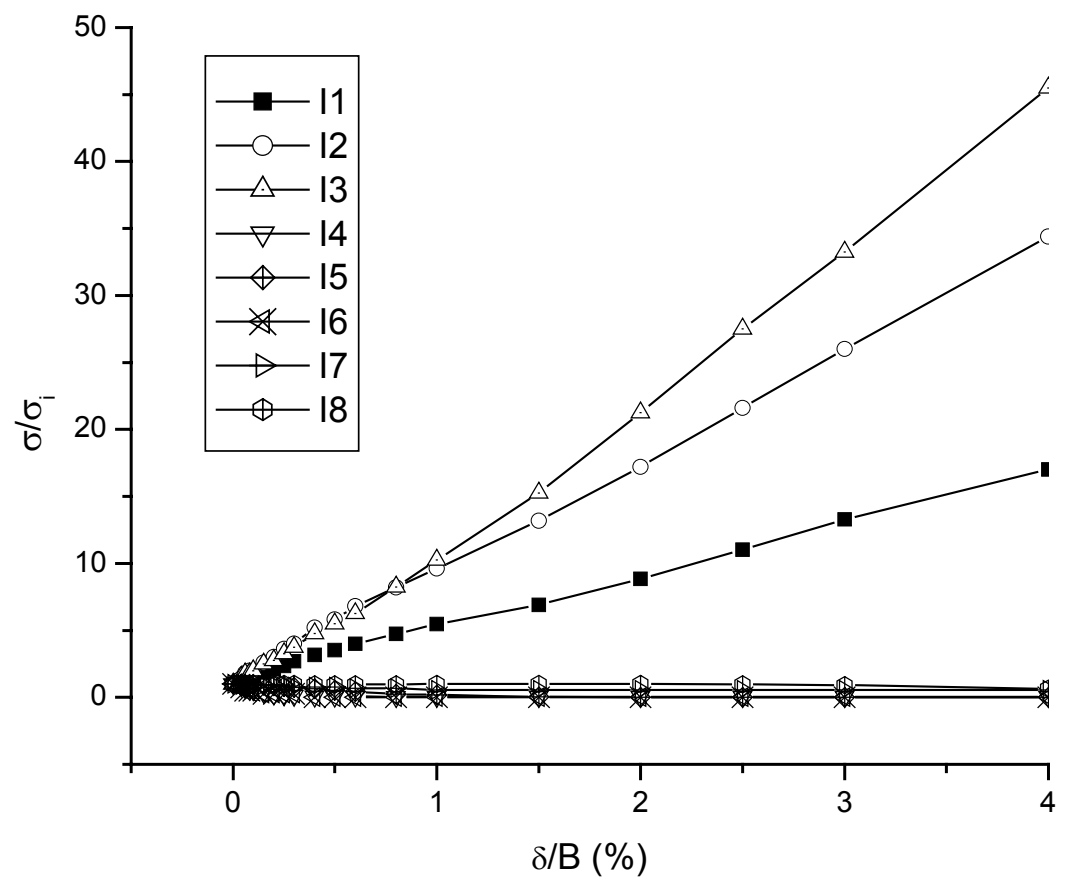

Figura C51. Resultados do ensaio E2, células I.

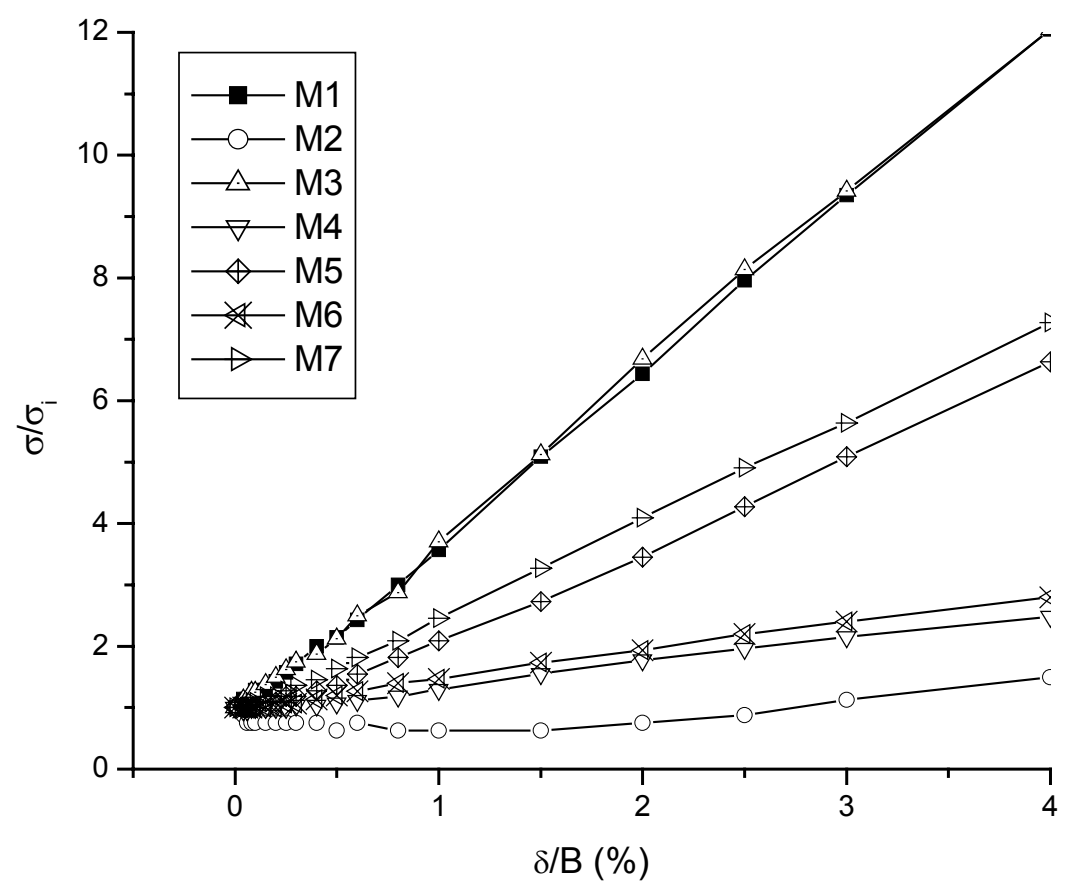

Figura C52. Resultados do ensaio E2, células M. 


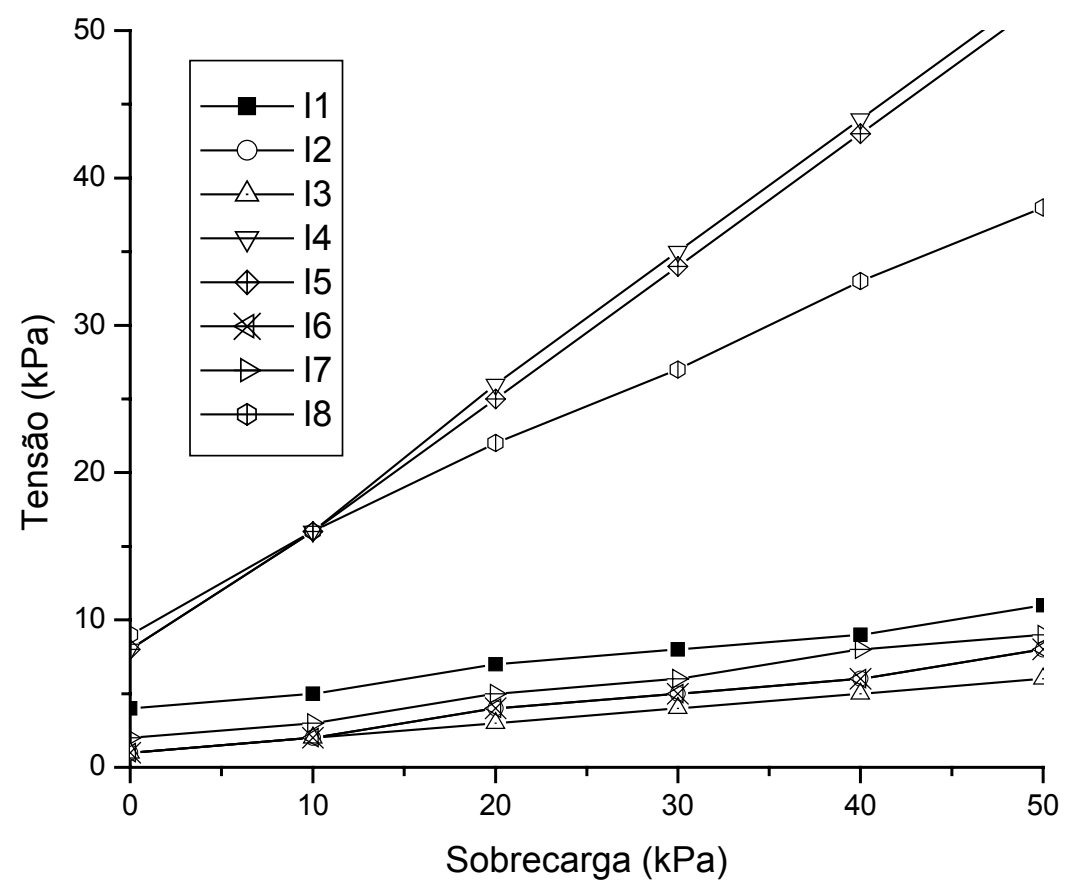

Figura C53. Sobrecarga aplicada x tensão medida no modelo E3, células I.

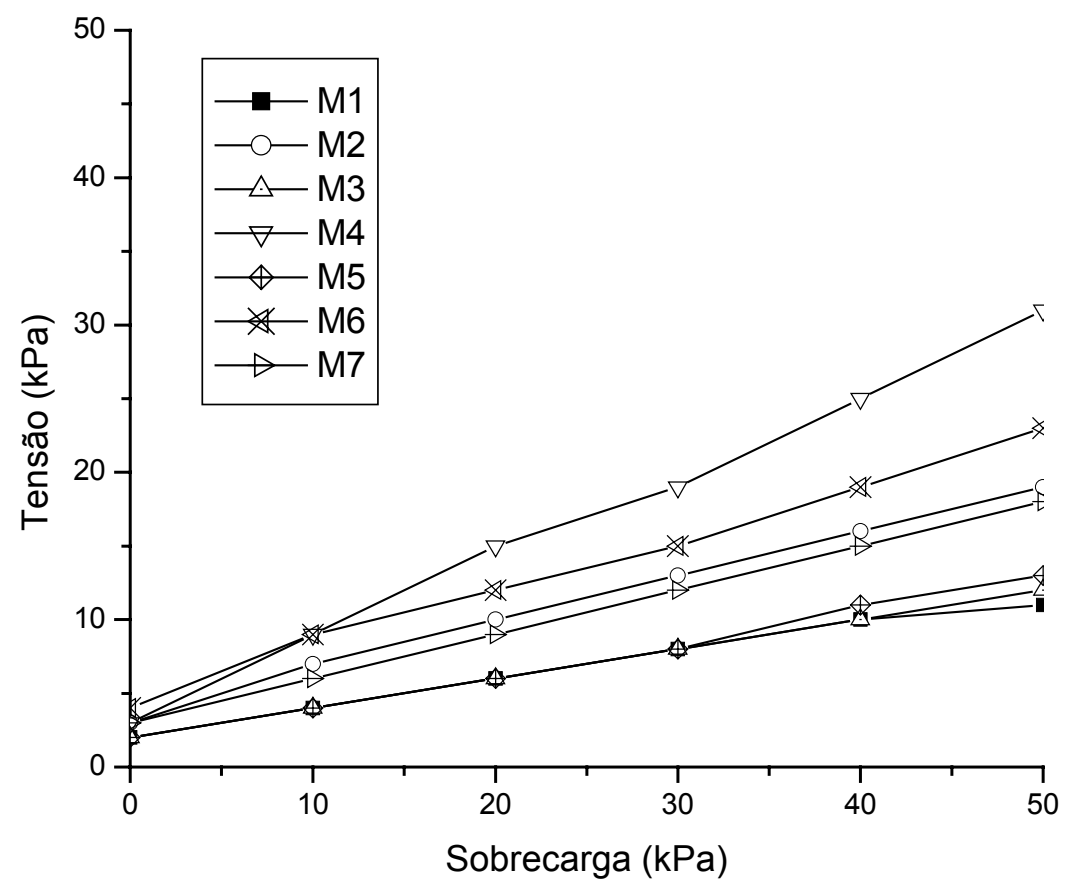

Figura C54. Sobrecarga aplicada x tensão medida no modelo E3, células M. 


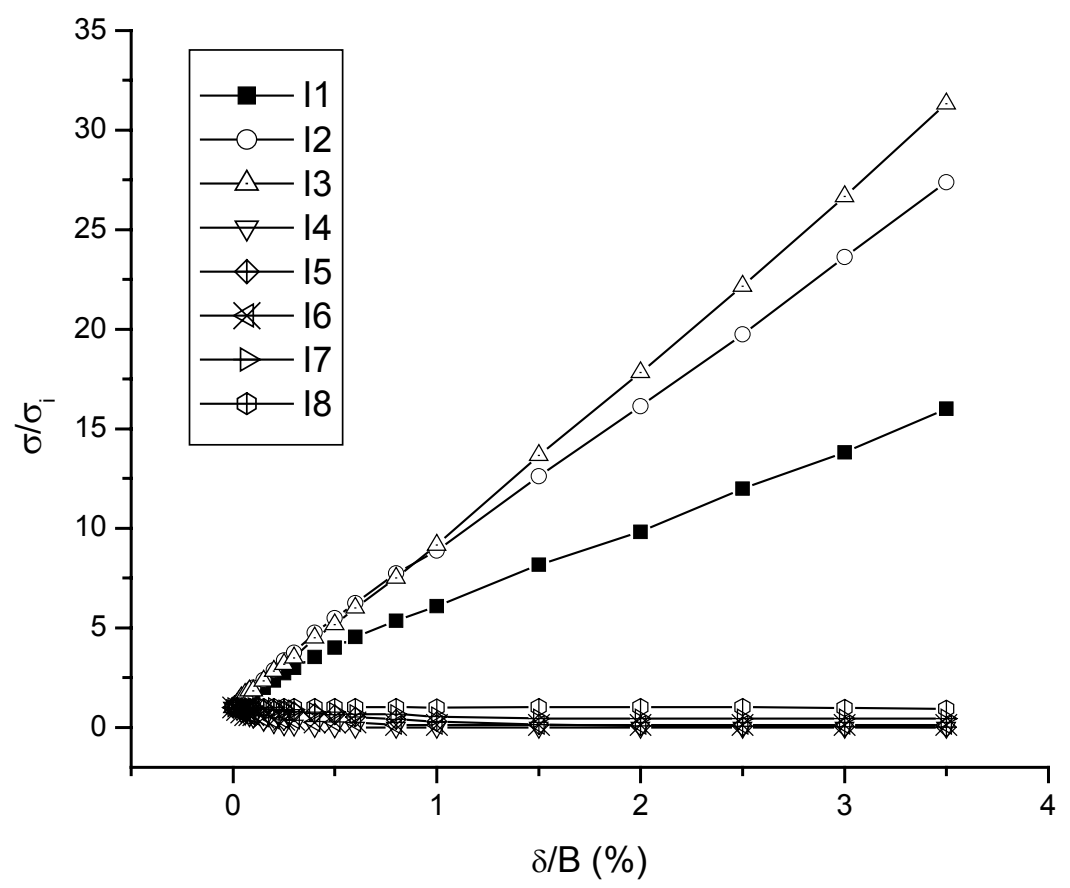

Figura C55. Resultados do ensaio E3, células I.

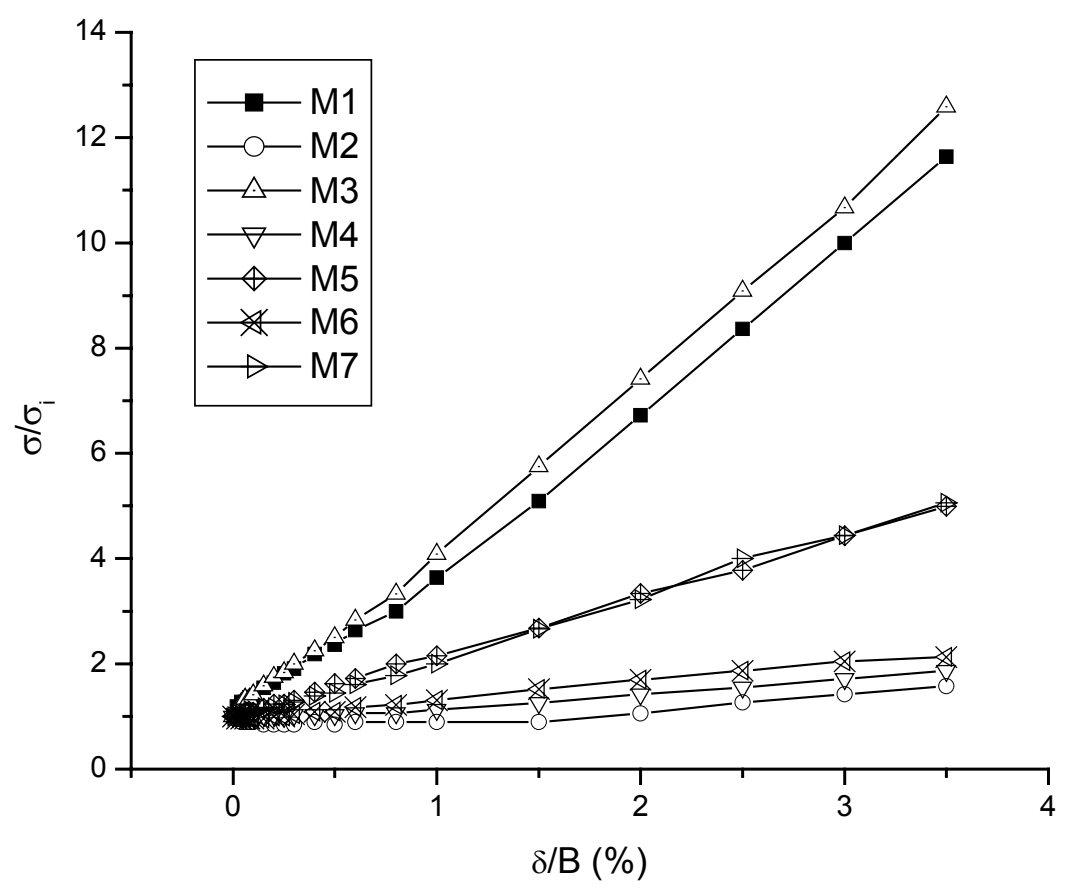

Figura C56. Resultados do ensaio E3, células M. 


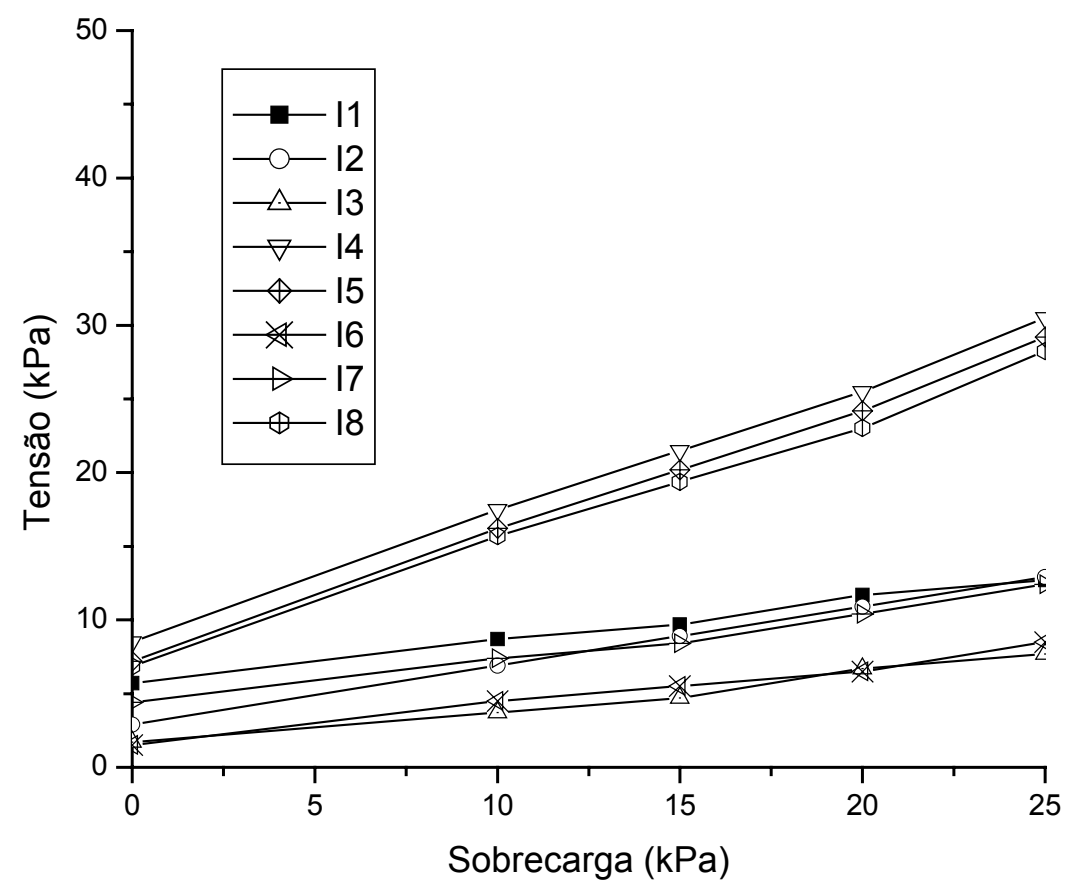

Figura C57. Sobrecarga aplicada x tensão medida no modelo E4, células I.

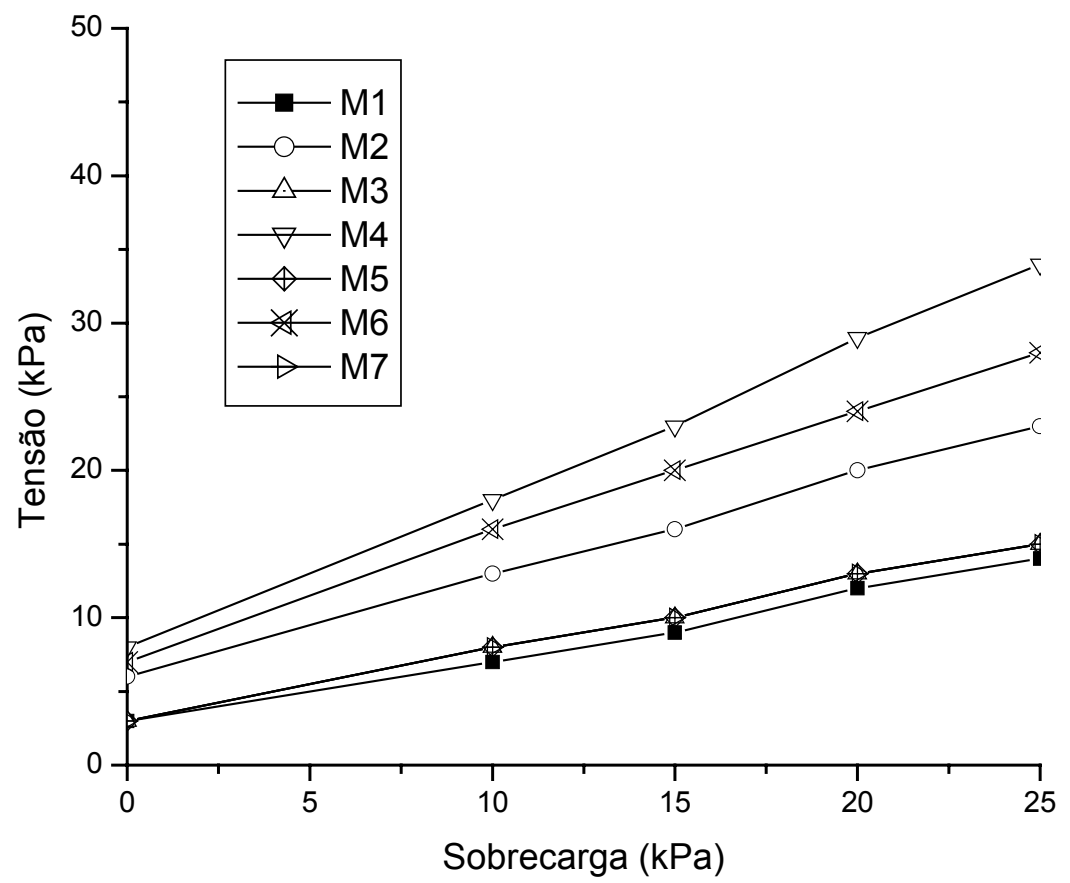

Figura C58. Sobrecarga aplicada x tensão medida no modelo E4, células M. 


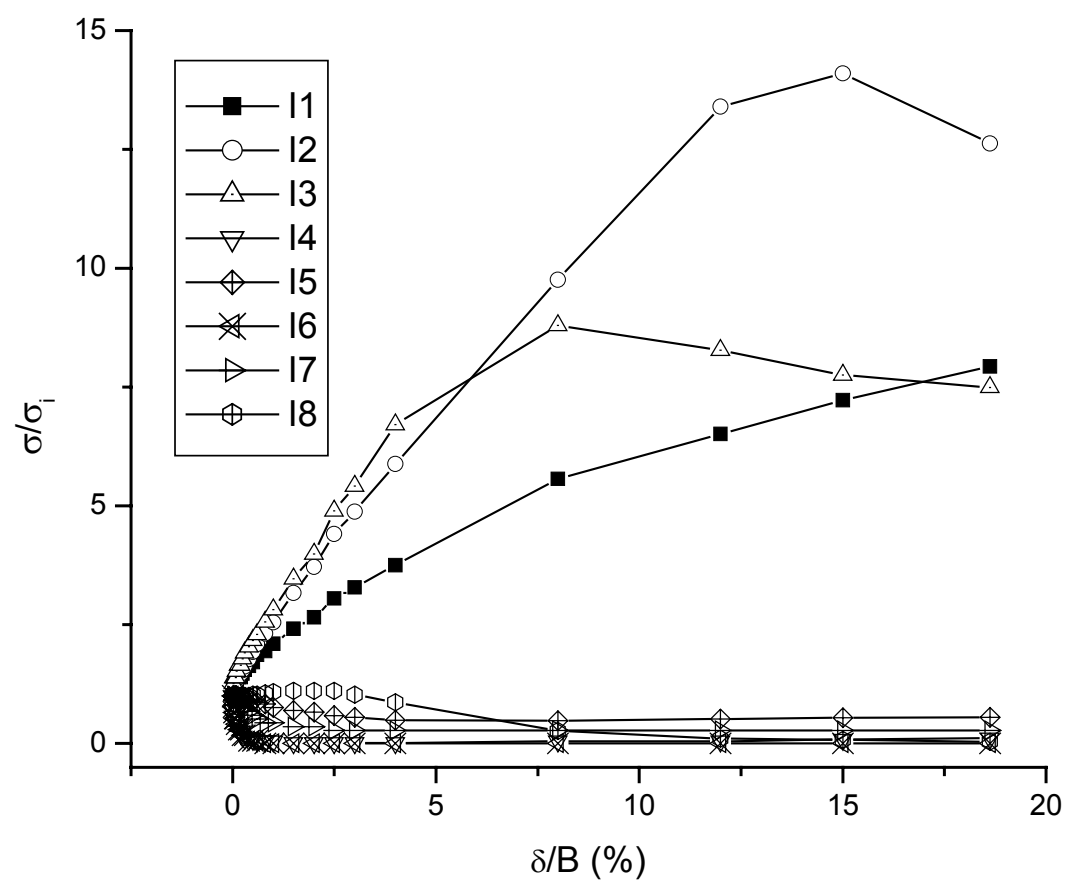

Figura C59. Resultados do ensaio E4, células I.

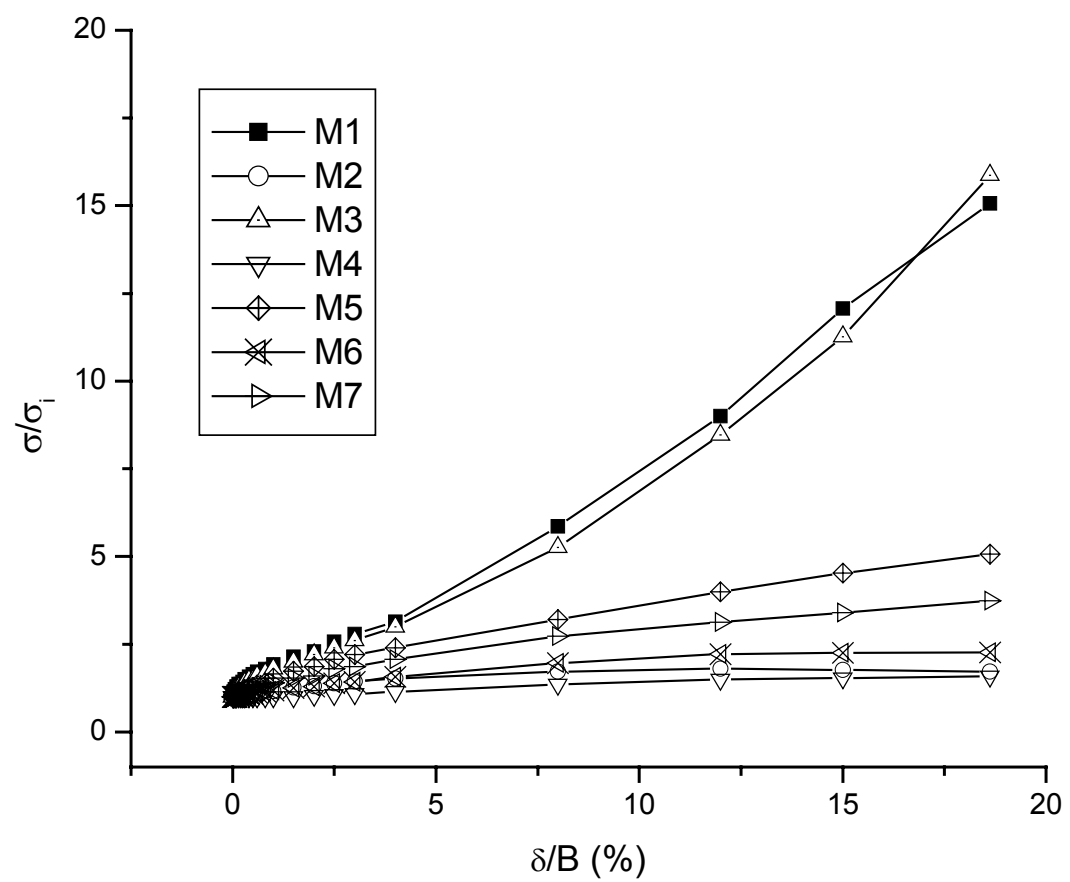

Figura C60. Resultados do ensaio E4, células M. 


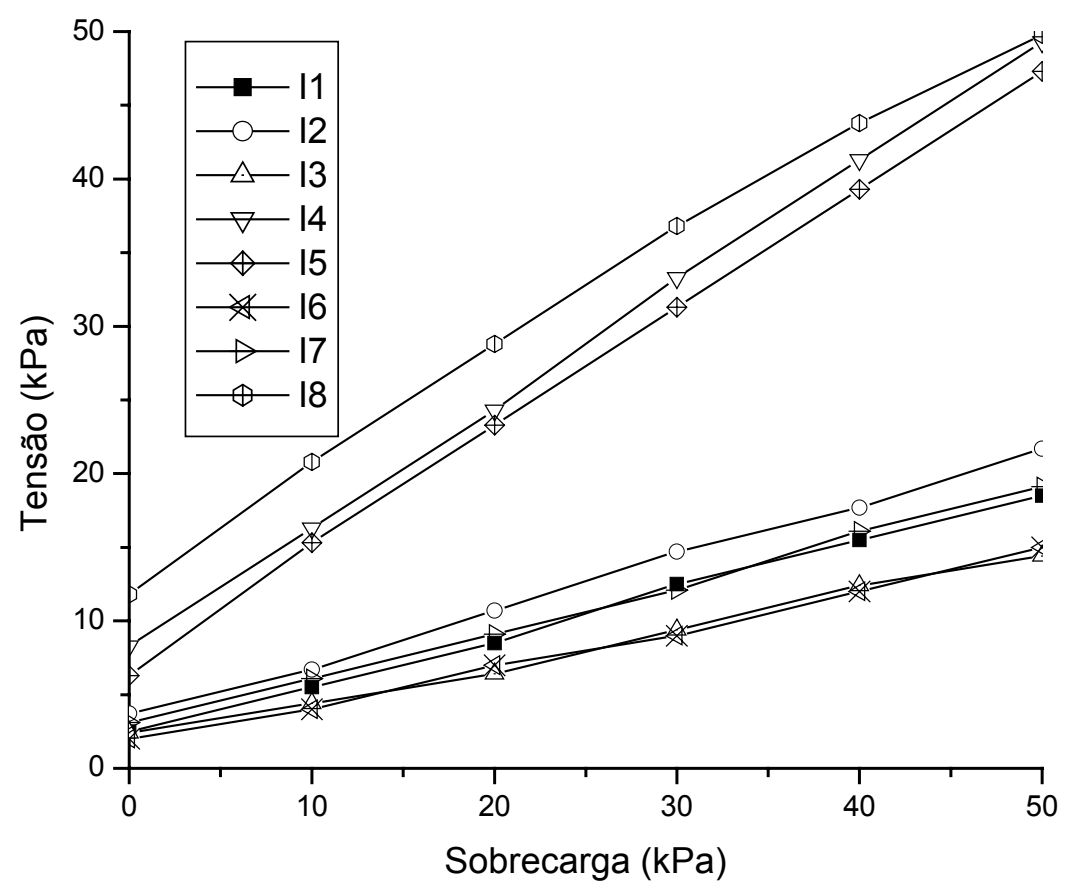

Figura C61. Sobrecarga aplicada x tensão medida no modelo E5, células I.

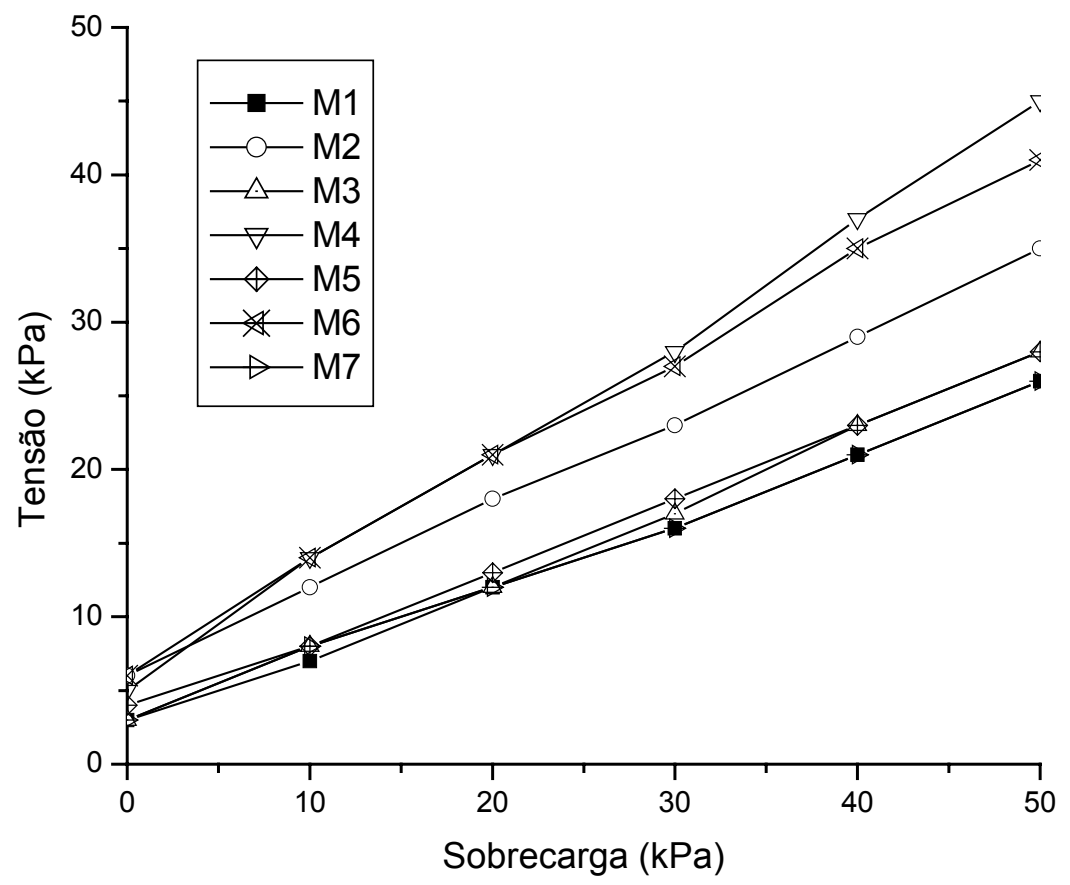

Figura C62. Sobrecarga aplicada x tensão medida no modelo E5, células M. 


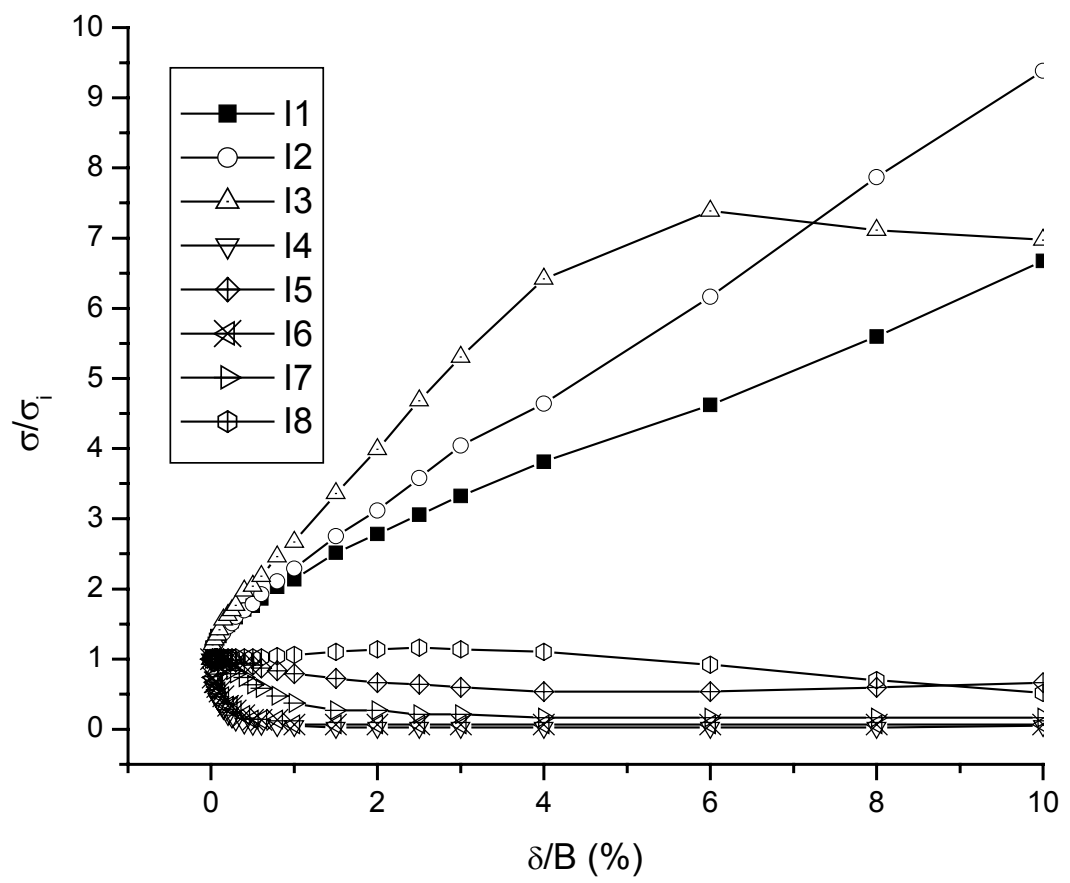

Figura C63. Resultados do ensaio E5, células I.

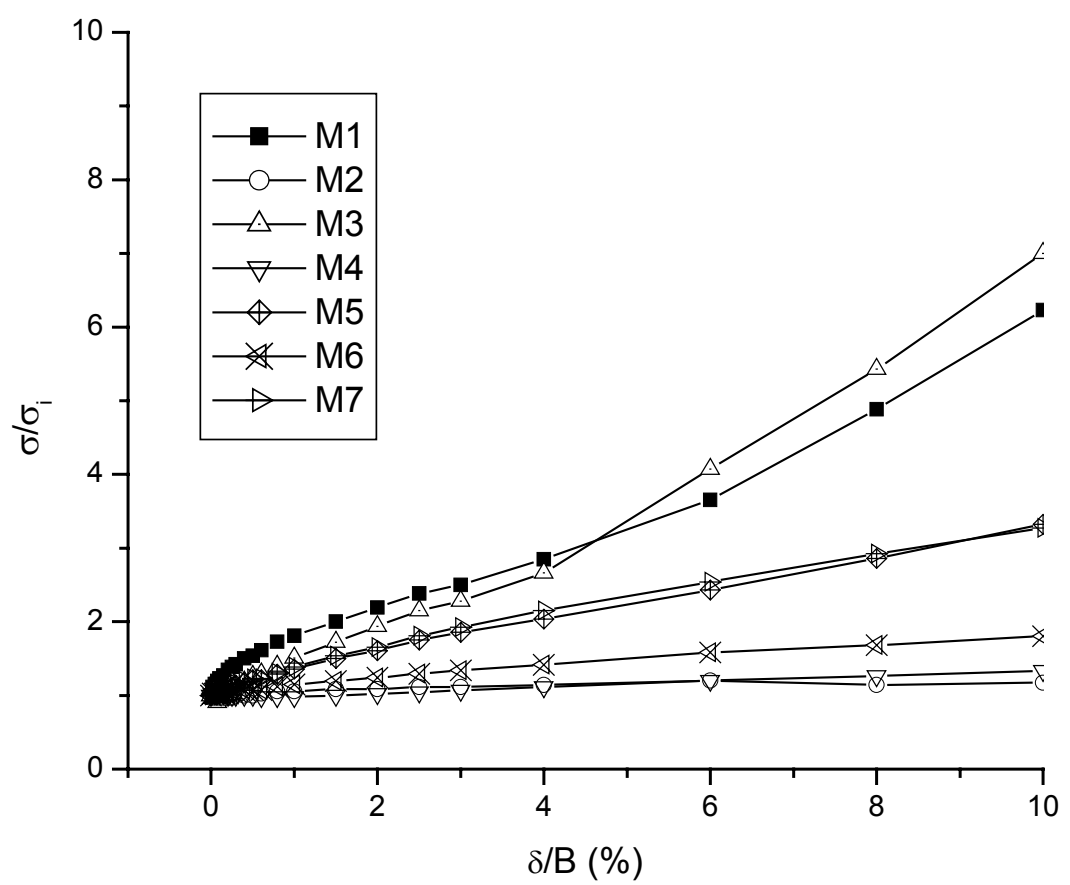

Figura C64. Resultados do ensaio E5, células M. 


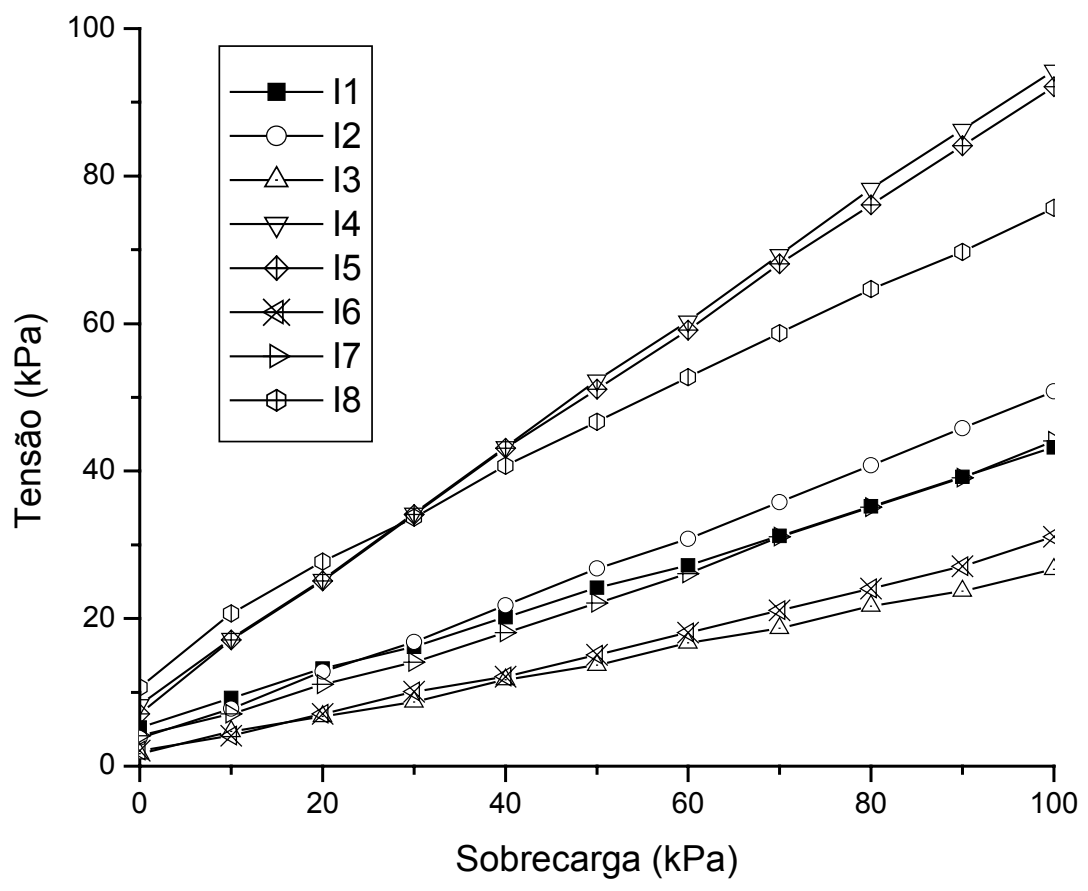

Figura C65. Sobrecarga aplicada x tensão medida no modelo E6, células I.

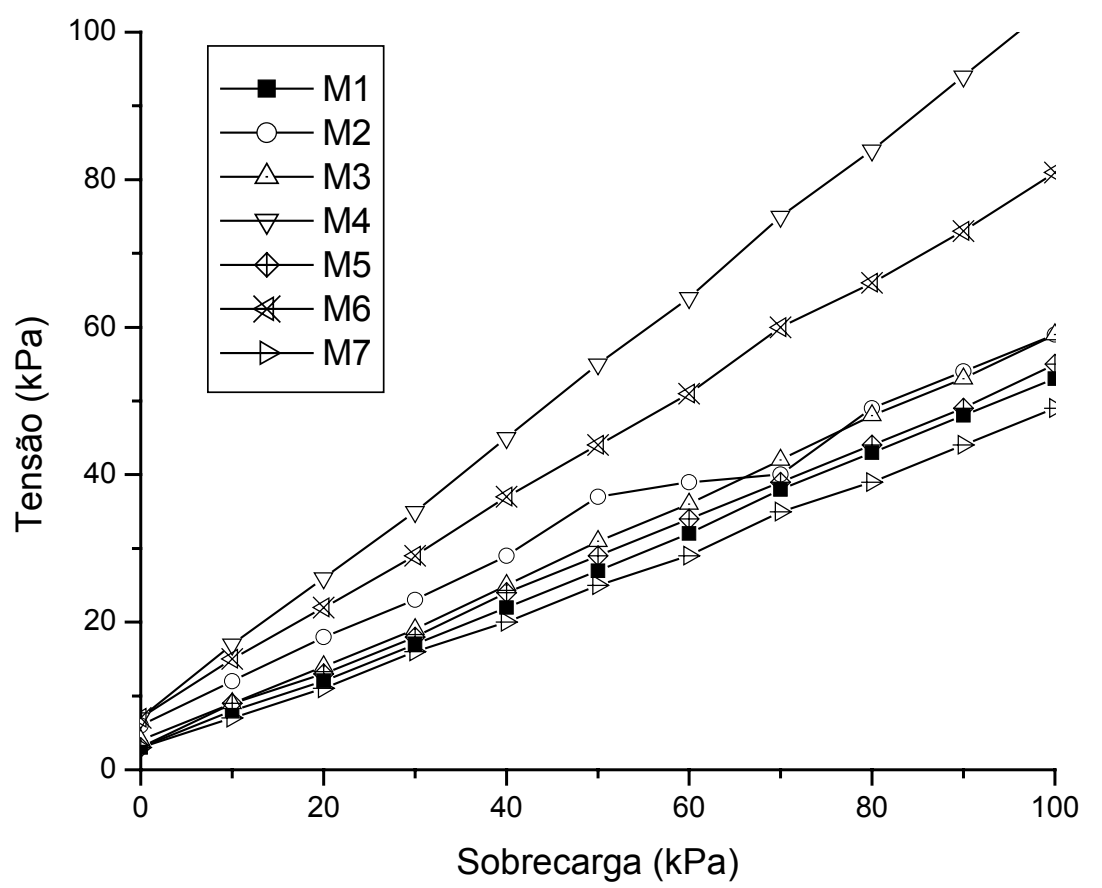

Figura C66. Sobrecarga aplicada x tensão medida no modelo E6, células M. 


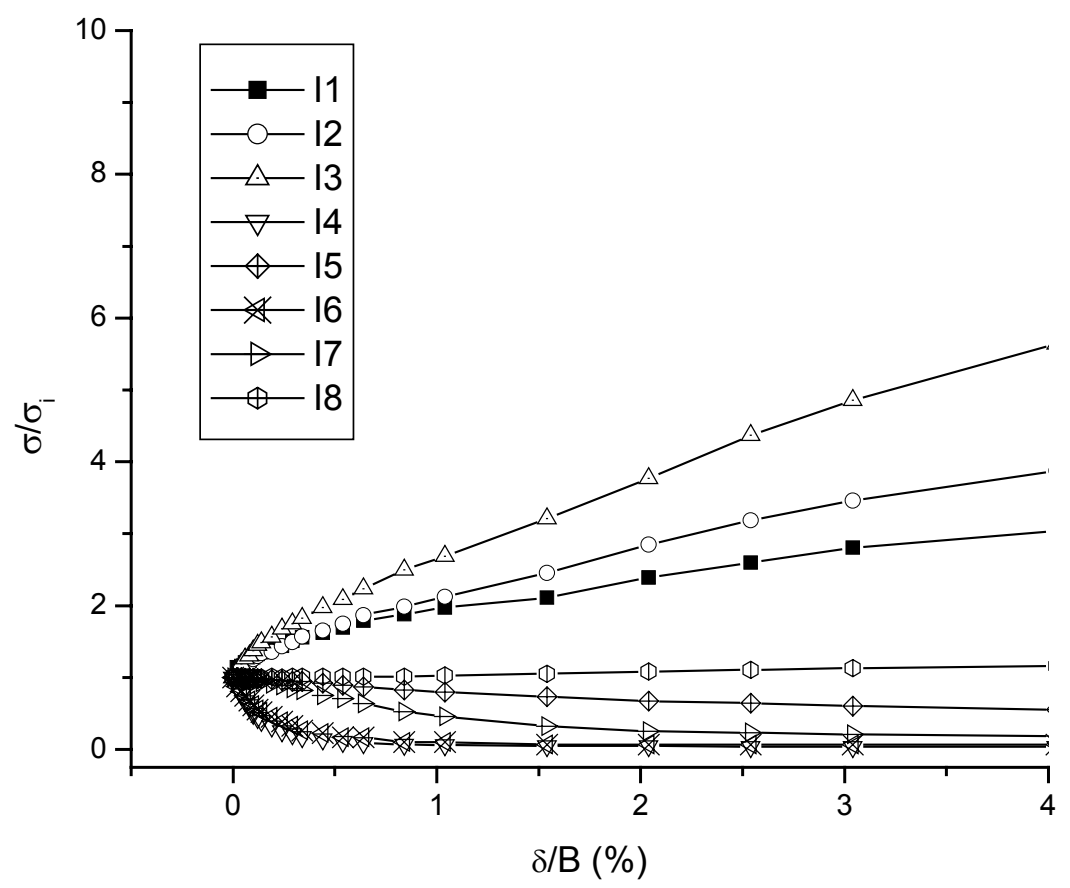

Figura C67. Resultados do ensaio E6, células I.

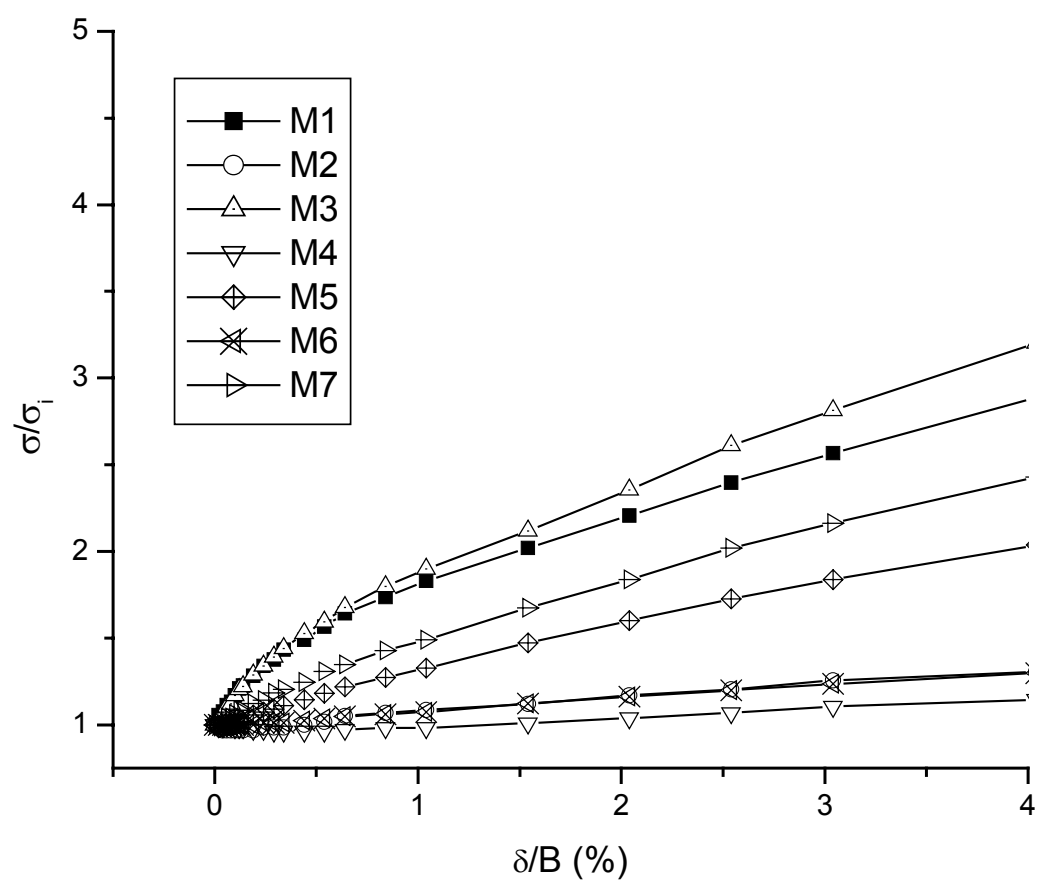

Figura C68. Resultados do ensaio E6, células M. 